\title{
Low-Rank Coal Research
}

Final Report

Volume II. Advanced Research and Technology Development
M.D. Mann
D.P. McCollor
M.L. Swanson
D. Kleesattel
S.A. Benson
D. Grow
L. Radonovich
S.K. Falcone
E.N. Steadman
S.J. Miller
P.G. Sweeny
D.L. Laudal

April 1987

Work Performed Under Cooperative Agreement No.: DE-FC21-86MC10637

For

U.S. Department of Energy

Office of Fossil Energy

Morgantown Energy Technology Center

Morgantown, West Virginia

By

University of North Dakota Energy Research Center

Grand Forks, North Dakota 


\section{DISCLAIMER}

This report was prepared as an account of work sponsored by an agency of the United States Government. Neither the United States Government nor any agency Thereof, nor any of their employees, makes any warranty, express or implied, or assumes any legal liability or responsibility for the accuracy, completeness, or usefulness of any information, apparatus, product, or process disclosed, or represents that its use would not infringe privately owned rights. Reference herein to any specific commercial product, process, or service by trade name, trademark, manufacturer, or otherwise does not necessarily constitute or imply its endorsement, recommendation, or favoring by the United States Government or any agency thereof. The views and opinions of authors expressed herein do not necessarily state or reflect those of the United States Government or any agency thereof. 


\section{DISCLAIMER}

Portions of this document may be illegible in electronic image products. Images are produced from the best available original document. 


\section{DISCLAIMER}

This report was prepared as an account of work sponsored by an agency of the United States Government. Neither the United States Government nor any agency thereof, nor any of their employees, makes any warranty, express or implied, or assumes any legal liability or responsibility for the accuracy, completeness, or usefulness of any information, apparatus, product, or process disclosed, or represents that its use would not infringe privately owned rights. Reference herein to any specific commercial product, process, or service by trade name, trademark, manufacturer, or otherwise does not necessarily constitute or imply its endorsement, recommendation, or favoring by the United States Government or any agency thereof. The views and opinions of authors expressed herein do not necessarily state or reflect those of the United States Government or any agency thereof.

This report has been reproduced directly from the best available copy.

Available from the National Technical Information Service, U. S. Department of Commerce, Springfield, Virginia 22161.

\section{Price: Printed Copy A21 \\ Microfiche A01}

Codes are used for pricing all publications. The code is determined by the number of pages in the publication. Information pertaining to the pricing codes can be found in the current issues of the following publications, which are generally available in most libraries: Energy Research Abstracts (ERA); Government Reports Announcements and Index (GRA and 1); Scientific and Technical Abstract Reports (STAR); and publication NTIS-PR-360 available from NTIS at the above address. 


\title{
Low-Rank Coal Research
}

\author{
Final Report
}

Volume II. Advanced Research and Technology Development
M.D. Mann
D.P. McCollor
M.L. Swanson
D. Kleesattel
S.A. Benson
D. Grow
L. Radonovich
S.K. Falcone
E.N. Steadman
S.J. Miller
P.G. Sweeny
D.L. Laudal

Work Performed Under Cooperative Agreement No.: DE-FC21-86MC10637

\section{For}

U.S. Department of Energy

Office of Fussil Energy

Morgantown Energy Technology Center

P.O. Box 880

Murganlluwn, West Virginia 26b07-0880

j By

University of Nurth Dakota Encrgy Research Center

P.O. Box 8213, University Station

Grand Forks, North Dakota 58202 
TABLE OF CONTENTS

VOLUME I. CONTROL TECHNOLOGY, LIQUEFACTION, AND GASIFICATION

$\mathrm{SO}_{\mathrm{x}} / \mathrm{NO}_{\mathrm{x}}$ Control

Waste Management

Low-Rank Direct Liquefaction

Hydrogen Production from Low-Rank Coals

Advanced Wastewater Treatiment

VOLUME II. ADVANCED RESEARCH AND TECHNOLOGY DEVELOPMENT -

Advanced Combustion Phenomena

Combustion Inorganin Transformation

Coal/Char Reactivity

Liquefaction Reactivity of Low-Rank Coals

Gasification Ash and Slag Characterization

Fine Particulate Emissions

VOLUME III. COMBUSTION RESEARCH

Fluidized Bed Combustion

Advanced Processes for Low-Rank Coal Slurry Production Low-Rank Coal Slurry Combustion

Heat Engine Utilization of Low-Rank Coals

Great Plains Gasification Plant 


\title{
ADVANCED COMBUSTION PHENOMENA
}

First-Year Technical Report for the Period April 1, 1986 - March 31, 1987 including the Quarterly Technical Progress Report

for the Period January through March, 1987

by

M.D. Mann and M.L. Swanson

University of North Dakota Energy Research Center

ن.0. Bux 8213 , University Stakion

Grand Forks, North Dakota 58202

April 1987

Cullbating Of ficer's Terhnical Representative: Dr. H. Fred Bauer

\author{
Prepared for \\ United States Department of Energy \\ of fice of trossil Eutigy \\ Morgantown Energy Technology Center
}

Under Cooperative Agreement No. DE-FC21-86MC10637-T3 


\section{TABLE OF CONTENTS}

Page

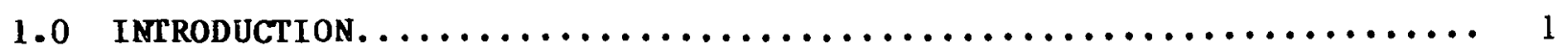

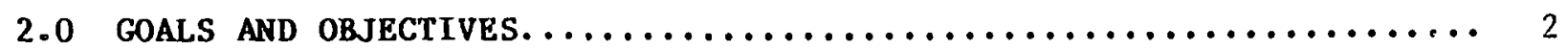

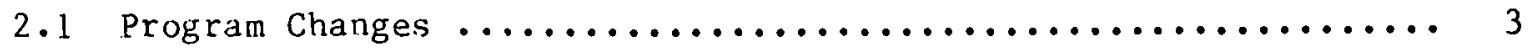

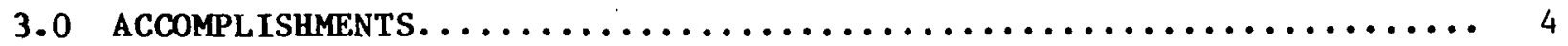

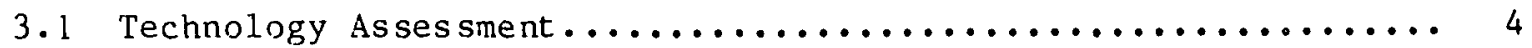

3.2 Reactivity of Fuel in Pressurized Systems................ 9

3.3 Characterization of LRC Combustion Behavior in Diese1 Engines.. 12

3.4 Characterization of LRC Slurry Combustion in a Gas Turbine.... 14

3.5 Erosion/Abrasion in Advanced Combustion Systems............. 21

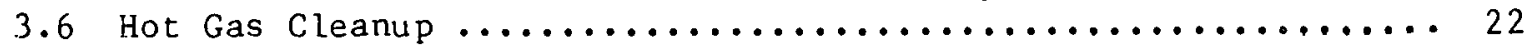

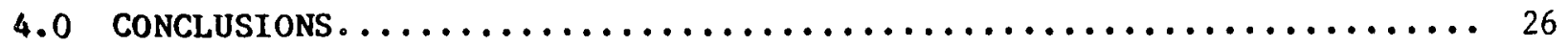

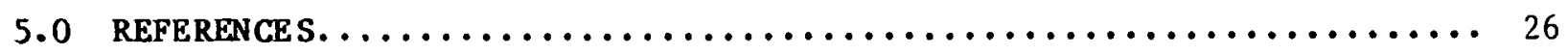




\subsection{INTRODUCTION}

A coal-water slurry fuel has the potential of being injected and burned directly in gas turbine and low-medium speed diesel engines utilizing injection and fuel handling methods similar to those employed with heavy petroleum fuels. Traditionally, gas turbine fuels have been limited to clean Euels, such as natural gas or distillate fuels to minimize the interrelated degradation processes of deposition, erosion and corrosion (DEC) caused by Euel impurities. Even with these fuels, traces of mineral components present problems of erosion and alkali deposition on turbine blades and slag accumulations in burners and nozzles.

Burning coal in a gas turbine combustor is not a new idea, but commercial success has not been achieved. The major technical problems inhibiting commercialization are: 1) deposits on the pressure and suction sides of the turbine blade reducing the gas flow area and turbine efficiency, 2) coal burnout during the short residence times inherent with gas turbine combustors, 3) corrosion of turbine blades by condensation of alkali sulfates, 4) erosion of turbine blades and other components by ash particulates entrained in the products of combustion, and 5) emissions control of $\mathrm{NO}_{x}, \mathrm{SO}_{2}$ and particulates. It is known that during combustion, release of certain mineral matter species can lead to deposition of mineral matter on surfaces, regardless of the ash content and composition of the fuel. This deposition can lead to blocking and corrosion of the turbine vanes and blades and ultimately to derating or unavailability of the power generating system. The presence of alkali metals and sulfur, which exist as impurities in the coal, have been identified as key components in the initiation of deposition and the onset of corrosion. To take advantage of low-cost coal fuels, the coal will have to be beneficiated to reduce the ash content substantially and modify the form of the ash in the coal. In addition, modifications of the turbine system itself may be required to allow for the higher ash levels in the fuel.

The utilization of coal slurry fuels in medium speed diesel engines of fers the opportunity to replace premium petroleum derived distillate fuels with more economical and abundant coal. Two major problem areas associated with the use of coal fuels in diesel engines are: 1) material wear and 2) slurry injection, ignitim? and combustion. The primary constraint on the practical use of coal slurries is their abrasiveness, due nainly to the presence of mineral components which are harder than the carbonaceous component of the coa1. Research to date has denonstraced encouraging short-term engine performance using bituninous coals with ash levels under $0.5 \%$ on a dry weight basis, however, long-term operation has not been successful due to the erosion and abrasion of various diesel components.

Coal-water slurries are now considered to be candidates as fuel for gas turbine and diesel engines. Until recently, low-rank coals were not considered for preparation of a coal-water slurry because of their high intrinsic moisture level which may exceed $35 \%$. It is extremely difficult therefore, to prepare a pumpable slurry of as-mined lignite with a dry solid loading of over 35 percent. With the development of UNDERC's hot-water-drying (HWD) process, lignite and other low-rank coal slurries have been produced with solids loadings up to $62 \%$ and a heating value of $6800 \mathrm{Btu} / \mathrm{lb}$ of slurry. Subbituminous coals respond very well to hydrothermal treatment and produce high-quality slurries. With the availability of a slurry with a high enough 
energy density, it is now possible to take advantage of the higher reactivity exhibited by the non-volatile carbonaceous component of low-rank coals as comparcd to bituminous coal chars. Consequently, a low-rank coal slurry should require less residence time in the gas turbine combustor or in the cylinder of an engine to achieve complate combustion. Another advantage of low-rank slurries is their non-caking properties, thus they are not expected to agglomerate to the extent of bituminous coals during evaporation, devolatilization and combustion. Thus, the effectiveness of atomization by micronization to extremely fine particle sizes will be less critical than for bi tuminous slurries.

\subsection{GOALS AND OBJECTIVES}

The overall objective of these projects has been to expand the data base on the fundamental reactions of low-rank coals in pressurized combustion systems such as those found in heat engine applications. The low cost and higher reactivity of low-rank coal (LRC) and LRC slurries together with its non-agglomerating propetties chance LRS's potential as a fuel for the short residence times available in heat engines such as gas turbines and diesel engines. This researah will devalop data that will (1) quant ify the potential advantages of LRC slurries mentioned above; (2) contribute to establishment of fuel specifications for LRC slurry fuels; and (3) indicate needed design changes in the heat engines themselves. This program evaluates LRC fuel. characteristics as produced from existing and advanced beneficiation processes in relation to their combustion behavior and formation of products of combustion ( $P O C$ ) including alkali metals, particulates, and other ash constituents; formation of nitrogen and sulfur oxides; and studies on the deposition, erosion and corrosion behavior of these fuels.

The goals for the project have been divided into seven separate tasks. These tasks and their purpose are listed:

Task 1 Technology As ses sment

This assessment will develop an understanding of the concerins and areas where major research is needed in the use of LRC derived fuels for heat engine applications. This literature search will familiarize UNDERC's personnel with the current state-of-the-art technology in the heat engines area and limit duplication of other researchers efforts.

Task 2 Reactivity of Fuel in Pressurized Systems

The objective of this task is to develop a East, simple, and inexpensive method of generating reactivity data on a variety of fuels under pressurized combustion conditions. This will be accomplished using a bomb calorimeter modified to monitor the pressure changes obtained with combustion of injected fuels. 
Task 3 Fundamental Combustion Characteristics of LRC in a Diesel Simulator

During this task, the fundamental combustion characteristics of LRC slurries will be studied under operating conditions typical of a diesel engine. A test device will be constructed for use in this task that simulates the conditions in a diesel engine.

Task 4 Fundamental Combustion Characteristics of LRC in a Gas Turbine Simulator

The goal of this task is to determine the impact of various fuels and their properties on the performance and the deterioration of metal components of a combustor in a simulated gas turbine. This information will lead to the development of fuel specifications required for the successful utilization of LRC in gas turbine applications.

Task 5 Combustion System Abrasion/Erosion

This task will measure the relative abrasiveness of various fuels both in their original form and as their post combustion residual ash. This testing will help understand the erosive forces on components such as the injector and other internal or moving parts of the heat engines.

Task 6 Feasibility of Using LRC in a Diesel Engine

During this task, three LRC slurries possessing the best fuel properties as determined in previous tasks will be tested in a small test diesel engine. The performance characteristics, deposition, erosion, emissions, and ease of fuel handling and injection will be evaluated. No work on this task will be performed during the first year of this project.

Task 7 Hot Gas Cleanup

This task will evaluate current hot gas cleanup technology for its use in adranced pressulized combustion systems utilizing LRC as a primary fuel source. It is anticipated that only a paper study will be conducted $i$ near 1 with testing of selected devices occurring in year 2.

\subsection{PROGRAM CHANGES}

Due to a decrease in Funding from the FY 87 appropriations, two major changes in the program were implemented. First, the overall scope of work was changed from studying the fundamental characteristics of both diesel engines and direct fired turbines to focus the project such that a comprehensive study of at least one of the heat engine systems could be completed within the new budget constraints. The work planned on the diesel simulator fnr the duration of this year and the second year of the Cooperative Agreement was eliminated from this project but will be performed as a part of a parallel project entitled "Heat Engine Utilization of Low-Rank Coals." The study of 
fundamental combustion characteristics of low-rank coal in this project will be confined to the turbine simulator and hot yas cleanup devices. A second change made was the deletion of Task 5 System Abrasion and Erosion from the program plan.

\subsection{ACCOMPLISHMENTS}

This project was initiated with an assessment of the current technology of coal-fired heat engines. Results of this assessment were used to determine program needs and further develop the scope of work for the project. To facilitate the investigation of LRC combustion properties under pressure, a constant volume combustion bomb, a single combustion cycle diescl simulator and a two stage gas turbine simulator have been designed and constructed. Work in the areas of erosion/abrasion and hot gas cleanup have focused mainly on literature assessments and development of test plans.

\subsection{TECHNOI.MGY ASSESSMENT}

Information on coal-fired gas turbines has been reviewed to provide a fundamental linderstanding of the current problem areas and research needs. Numerous technical problellis assoeiatod with the design of a coal-fired gas turbine were identified. These problems can be divided into four najor areas which deal with the fuel, the combustor, the turbine, and the environment.

While the relations between fuel quality and power plant characteristics (i.e. combustor performance and ef ficiency, emissions, turbine life, etc.) are not well understood, small particle size, low ash and alkali concentration and a low viscosity are known to improve a fuel's performance in a gas turbine. A small particle size reduces the residence time constraints needed to achieve good combustion and maintain a high efficicncy by limiting carbon carryover into the turbine. In general, ash particles tend to have a size distribution smaller than the original coal size distribution, thus small coal particles will result in small ash particles thereby reducing the amount of erosion callsed by larger ash particles. Fui particle diamerers greater than a few microns, inertial impaction on turbine surfaces increises rapidly (1). Various chemical and physical cleaning processes such as the AMAX and De isca processes offer potential for the reduction of ash and alkali levels in the $\operatorname{coa} 1(2,3)$.

One of the preliminary findings reported by Berman (4) was that CWS muet be burned in an external combustor because of the low volumetri.r. heat releasc ratc obtainable with the current combustor technology. Heat release rates of $1.5-2.3 \mathrm{MBtu} / \mathrm{hr}-\mathrm{ft}^{3}$-atm have been reported for conventional fuels in cur rent internal somhustors while preliminary results for bjtuminous CWS tests had heat release rates between $0.065-U . b \mathrm{MBCu} / \mathrm{hI}_{\mathrm{L}} \mathrm{f}^{3}$ atm. Tho adifitional combustor volume which can be available with the "off-board" combustor is necessary to give the bituminous CWS adequate residence time to complete combustion. An added advantage of the external combustor is its flexibility in allowing pre-expander clean-up devices to be inserted.

Achieving a high level of atomization is. a key requirement for attaining high combustion efficiencies for CWS fired combustors. While atomization i.s not a parameter specifically being investigated under this contract, fine atomization should improve flame stability, turndown and burnout by liniting 
the agglomeration of the coal particles in a droplet as the carrier fluid is evaporated. The principal objective of very high fuel atomization is to achieve as high a ratio of fuel surface to mass as possible, which produces very high evaporation rates and keeps the number of coal particles per droplet to a minimum. Several researchers have shown that carbon conversion decreases and the mass mean ash particle diameter increases with increasing mass mean droplet diameter $(5,6)$. It has been hypothesized that low-rank coals noncaking properties should result in less agglomeration during the evaporation, devolitalization and char combustion stages of coal-water combustion. DunnRankin, Hoornstra, and Holve. (7) have reported on tests using coal-water slurries of different rank in a laboratory-scale laminar flow combustor with particle size evolution being monitored using a in-situ laser-based particlecounter-sizer-velocimeter (PCSV). In these tests, they conclude that the agglomerates from the non-caking subbituminous and lignite coal slurries appeared to remain intact after evaporation and devolitalization. However, another explanation would be that the evaporation and devolitalization stages were not completed at the point measured. This possibility conforms with the larger decrease in the number density of larger particles and high number density of smaller particles seen for the low-rank coals, which would indicate that the agglomerates are fracturing back down to their original particle size. The large difference in the ash content for these coals confounds these observations. In addition, testing here at UNDERC with a Insitec PCSV system on a $75 \mathrm{lb} / \mathrm{hr}$ pulverized coal fired combustor has a given large deviations Erom particle size distributions measured using the PCSV and those obtained using SEM, EPA method 5 with Anderson multicyclone's and coulter counter analysis. This indicates that this in-situ method might not be developed to the point where it can accurately differentiate between these slurry atomization tests. Atomization performance is sensitive to small changes in water content and to chemical and physical effects of additives. Atomized slurry droplet size has been found to decrease with increasing air-to-fuel ratio (8). Atomization performance is also affected significantly by the atomizer design itself.

Three types of atomizers typically used are plain orifice pressure atonizers, pressure swirl atomizers, and jet airblast atomizers. These have been described in detail elsewhere (9).

The major technical problems associated with a direct coal-fired gas turbine itself is deposition, erosion and corrosion (DEC) of the expander vanes, and turbine blades. As discussed previously, unless fuel treatment, combustur deslyn, or hot gas cleanup devices can reduce the ash particle sizes to smaller than a few microns, high inertial impaction rates on turbine airfoil pressure surfaces will result. Erosion rate reductions of 66 to 75 percent are expected just by modification of existing utility turbine designs to allow for more even power extraction in each expander stage (i.e. b; reducing the flow turning angle) (10). This decreases the gas velocities and turbulence levels experienced by the first two erosion sensitive stages thus reducing the rates of inertial impact and turbulent eddy particle delivery. In addition, the trailing edge thicknesses should be increased by 35 to 45 percent and fewer blades and air foils per row should be used to increase ininimum flow areas to account for higher airflow blockage due to deposition and decrease reblading maintenance intervals. 
Preliminary data from turbine uperating experience using residual oil and from Pressurized Fluidized Bed Combustion ( $P F B C$ ) experinents indicate that temperature plays a large role in deposition and corrosion (10). At temperatures above $1800^{\circ} \mathrm{F}$ heavy tenacious deposits occurced on vane and blade pressure surfaces while much thinner and less dense deposits occurred on the suction surfaces. In relatively low temperature experiments $\left(1600^{\circ} \mathrm{F}\right)$ the vane pressure surfaces experienced some erosion but were relatively free of deposition and loosely bonded, fragile deposits were formed on the suction surfaces.

Deposition, which is a function of the fraction of the ash in the molten state, results if the surface temperature is above or close to the melting point of the molten species. However, if the surface temperature is significantly below the melting point, deposition can decrease due to the [reezing of molten particle as it approaches the colder surface. Surface temperatures between $1420^{\circ}$ and $1520^{\circ} \mathrm{F}$ are expected to significantly reduce turbine corrosion since it is below the usual temperature range $\left(1520^{\circ}-1740^{\circ} \mathrm{F}\right)$ of Type $I$. hot corrosion alld lelow the nominal $1540^{\circ} \mathrm{F}$ melting point of the $\mathrm{Na}_{2} \mathrm{SO}_{4}-\mathrm{Fe}_{2} \mathrm{SO}_{4}$ eutectic (10) yet above the temperature range $\left(1290^{\circ}-1420^{\circ} \mathrm{F}\right)$ of Type II currosion.

Interactions between erosion/corrosion and deposition/corrosion have synergistic effects on the rate of surface metal recision while with the deposition/erosion interaction one tends to occur at the expense of the other. If a significant fraction of the ash particles are molten (perhaps only one percent or less) deposits build up which protect the surface from erosion. If the ash particles are almost all hard, then the impact particles tend to sweep the surface clean of any deposits. Therefore, if some erosion is desired to remove deposiced material, stronger materials of construction are ueted.

Deposition/erosion/corrosion (DEC) interactions are not the only degradations affecting reblading illervalg. Vane and hlade lifetimes are limited even for turbines operacing with clean fucls. Their service lives are restricted by stress-related liclus sueh ac srarp life or stress rupture life. Experience with baseload utility turbines using clean fuels has demonstrated typical lifetimes on the order of 40,000 hours for cooled airfolls, which experience the highest gas temperatures and 60,000 to 100,000 hours for uncooled airfoils, which experience lower gas temperatures. Airfoil reblading is determined by Lle shorter of the strog related lifetimes or the DEC related lifetimes. Table 1 summarizes the turbine modifications which can be used to improve the turbines tolerance of DEC.

Visits were made to several of the organlzatluns with ongoing research in the area of coal-fired heat engines co help UNDERC become more aware of the current research in heat engines. Observations of the various test equipment currently being used by these organizations were made to help in the design of. UNDERC's diesel and turbine simulators. The facilities visited include Westinghouse Combustion Turbine Development Center, United Technologies Research Center, General Electric Company Turbine Technology Department and Corporate R\&D, Allison Turbine Division of General Motors, Solar Turbines, Inc. and the Morgantown Energy Technology Center, National Institute for Petroleum and Fnergy Research, and Southwest Research Institute. 
TABLE 1

TURBINE MODIFICATIONS TO IMPROVE D/E/C/ TOLERANCES

Turbine

Design Modification
Turbine

Tole rance Impröovement

\begin{tabular}{|c|c|c|}
\hline \multirow[t]{4}{*}{ Erosion } & $\begin{array}{l}\text { Modify blade contours } \\
\text { Redistribute work between } \\
\text { stages }\end{array}$ & $\begin{array}{l}\text { - reduce particle lmpact frequency and } \\
\text { impact angles to less damaging values } \\
\text { - provide more uniform erosion for all } \\
\text { stages by providing more evenly } \\
\text { distributed turning }\end{array}$ \\
\hline & Coatings of armoring & $\begin{array}{l}\text { - more erosion/corrosion resistant } \\
\text { materials }\end{array}$ \\
\hline & $\begin{array}{l}\text { Boundary layer fences } \\
\text { or grooves }\end{array}$ & $\begin{array}{l}\text { - inhibit high particle concentrations } \\
\text { at roots and tips }\end{array}$ \\
\hline & Deflector rings & $\begin{array}{l}\text { - decrease high particle concentrations } \\
\text { at roots and tips; Increases } T . E \text {. } \\
\text { erosion life }\end{array}$ \\
\hline \multirow{3}{*}{$\begin{array}{l}\text { Deposition } \\
\text { Control }\end{array}$} & $\begin{array}{l}\text { Decrease vane and blade } \\
\text { surface temperatures }\end{array}$ & $\begin{array}{l}\text { - freeze molten particles having at } \\
\text { surface to decrease sticking } \\
\text { fractions and deposit bonding }\end{array}$ \\
\hline & Design for nutshelling & $\begin{array}{l}\text { - removal of pressure sides deposits } \\
\text { without shutdown }\end{array}$ \\
\hline & Reduce blade solidarity & $\begin{array}{l}\text { - larger passage throats less af fected } \\
\text { for given deposit thickness }\end{array}$ \\
\hline & $\begin{array}{l}\text { Dccrease value and blade } \\
\text { surface temperatures }\end{array}$ & $\begin{array}{l}\text { - freeze molten species and inhibit } \\
\text { corrosion reactions }\end{array}$ \\
\hline Corrosion & $\begin{array}{l}\text { Corrosion resistant } \\
\text { alloys/coatings }\end{array}$ & $\begin{array}{l}\text { - much greater selection of protective } \\
\text { materials is provided by lower } \\
\text { surface temperatures }\end{array}$ \\
\hline
\end{tabular}


The visit to United Technology Research Center (UTRC) proved to be the most beneficial in that the information collected was used to make several major design decisions on UNDERC's proposed turbine simulator. Items that were discussed included results from their atomization tests using four different nozzles, probe designs and techniques for collecting particulate and gaseous samples from their combustor, the selection criteria of a control valve for back pressuring the turbine simulator and the effects of various swirlers on flame stability and combustion efficiency. Other items discussed included the evaluation of various ceramic liners in the rich zone chamber, results from their flow pattern testing in the rich zone and the effects of residence time on $\mathrm{NO}_{\mathrm{x}}$ emissions.

At GE's Corporate R\&D (CRD) Division, items discussed included CRD's current project directed at measuring the rates of deposition and chemical transformations of alkali metal species which occur with the combustion of CWS in gas turbines. Analytical results from extended X-ray absorption fine structure (EXAFS) on the collected deposits from both otisca and AMAX CWs's indicate that potassium was present in alumfuusilicatco. This lead to the hypothesis rhe aluminosilicates in the ash are acting as "getters" for the alkali vapors (both $\mathrm{K}$ and $\mathrm{Na}$ ), thus preveuling the format inn uf corrosive alkali sulfates. This information could possibly be useful in developing UNDERC's strategy for investigating the effects of burning low-rank coals which have ashes typically high in alkali.

GE's diesel test facilities were also inspected. One item discussed was GE's combustion bomb. This device is designed to model a large locomotive engine at top dead center and is being used to evaluate the reactivity of CWS in a diesel engine environment as well as for evaluating various fuel injectors.

At the Allison Turbine Division of General Motors, Allison's coal-fired gas turbine and coal-flred diesel system research programs were discussed. of particular interest were results from testing on Allison's rich-quench-lean (RQL) combistor. Also of interest was the deposicton, erosion and corrosion research that is currently being performed by GH.

A visit to the Morgantown Energy Technology Center's (METC) diesel laboratory proved useful by providing insight into the design of the UNDERC combustion bomb and fuel injection systems. The main feature of METC's diesel lab is a research engine by Ricardo Ltd. (UK). This engine should prove beneficial in developing data on the firing of coal in a diesel engine.

Test site visits were also made to the National Institute for Petroleum and Energy Research (NIPFR) and Southwest Research Institute (SWRI). Niper uses a heavily instrumented Caterpillar 1473 diesel cnglue for tecting a variety of bituminous coals, slurried in water, methanol or diesel fuel. All tests sprayed a pilot fuel on a glow plug to provide enough energy to evaporate the water or methanol (amounting to as little as $5 \%$ of the total energy 1npul). Fucl injectinn pressures between 5,000 to 10,000 psi were necessary to obtain good atomization for injections directly into the cylinder, however, lower injection pressures were possible when fuel was injected into a prechamber due to turbulence enhanced atomization. Niper also 
noticed that plugging or clotting problems occurred whenever diesel fuel came in contact with water or methanol coal slurries. SWRI has several heavily instrumented single cylinder engines which have burned a variety of slurries. After experimenting with other types of injectors, Tom Ryan at SWRI felt that satisfactory atomization is possible with more-or-less conventional injectors and good turbulence in the cylinder. Another area of long-term interest at SWRI has been the adlabatic engine concept where the ceramic-lined cylinders are in thermal equilibrium with the combustion process reducing heat rejection to a cooling water system.

\section{MARKET ASSESSMENT - GAS TURBINE}

Various studies have been reported on the production costs of various beneficiated coal water slurries $(11,12)$. These production costs were estimated at about $\$ 4.35$ to $\$ 4.49 / \mathrm{MMBtu}$ for a coal slurry produced by the AMAX caustic and acid leaching process while a slurry can be produced for $\$ 3.96 / M M B t u$ using the UCC heavy media beneficiation process. This is consistent with economic evaluation which use a base cost of $\$ 4 / \mathrm{MMBtu}$ for their CWM (13). This study indicated that $1000 \mathrm{MW}$ baseloaded CWS cycle system was estimated to have a $17 \%$ higher cost of electricity (COE) than a pulverized coal (PC) fired steam plant. This was mainly due to the much higher capital costs (43\%) and the higher operating and maintenance costs (170\%) for the CWS system as compared to steam system. In order for the baseloaded CWS combined cycle to be competitive with PC fired steam plants the CWS capital costs would have to be reduced $30 \%$ and the cost for additives would have to be eliminated almost completely. For smaller-sized utilities (300 and $100 \mathrm{MW}$ ) the CWS combined cycle is much more competitive. The $\mathrm{COE}$ estimates for a baseline peaking gas turbine engine indicates that above a $10 \%$ capacity factor a CWS fired gas turbine with a $1600^{\circ} \mathrm{F}$ firing temperature was competitive with a distillate fired gas turbine at $2000^{\circ} \mathrm{F}$. As soon as technology advances to where a CWS fired gas turbine could be operated at $2000^{\circ} \mathrm{F}$ over long terms, it will compete across the entire capacity range.

Industrial applications of CWS fueled gas turbines are particularly attractive since most industrial applications typically burn premium grade fuels and generally run at a high capacity factor (13). Environmental controls were also found to have a significant impact on the economics of industrial CWS cogeneration systems. If flue gas emissions controls are not required (either becausc the coal has beth betlellciated enough to meet standards or enough pollutants are removed during the combustion process) the cost differential between the distillate and the CWS need only be $\$ 0.50 / \mathrm{MMB}$ tu to be economical. If flue gas emission control is needed the cost differential jumps to $\$ 1.50 /$ MMBtu for CWS to be competitive.

\subsection{REACTIVITY OF FUEL IN PRESSURIZED SYSTEMS}

The reactivities of dry and slurried low-rank coals are higher than those of bituminous coals, but the magnitude of these differences is not welldocumented. The reactivity of the fuel can also be improved by the use of additives to the slurry, such as methanol. To quantify the reactivities of the LRC fuels in pressurized systems, a $f$ ast, simple, inexpensive experimental techniques in a modified combustion bomb was developed to provide very basic information about the pressurized combustion behavior of coals and coal slurries. This reactivity data obtained from the combustion bomb experiments 
consists of temperature and pressure traces from which the pressure and temperature deficit and recovery ignition delay times as defined by Seibers and Dyer (14) can be measured. The deficit ignition delay time has been defined as the time from initial injection of the test fuel to the time the lowest temperature or pressure is obtained before starting to increase again due to the fuel combustion. The recovery ignition delay has been defined (14) as the time from initial test fuel injection to point where the temperature or pressure returns to the temperature or pressure it would have had with a constant rate of heat loss. Another measure of reactivity will be obtained by comparison of the combustion efficiency of different fuels at similar injection conditions. This information will be critical in determining the fuel specifications of slurries for use in heat engine applications. Data collected during these tests will include the heat of combustion (calorimetry) of the sample, the sample burning time/reactivity (from temperature and pressure profiles), and the analysis of subsequent combustion products to determine combustion efficiency and overall reactivity as a result of combusting the fuel under various conditions. Parameters to be varied include coal type, particle size distribution, gas composition (percent oxygen), and system pressure. This testing will provide semi-quantitative information in a fast and inexpenslve malute 1 . During tho first year, a system has been designed and constructed. Details are presented here.

The constant volume combustion bomb to be used in this study is a modified Parr oxygen combustion bomb. This $342 \mathrm{ml}$ pressure vessel has an easily removable head that seals internally when the bomb is pressurized. Figure 1 shows a cross-sectional view of the: head and sealing rings in the combustion bomb. Also shown in this figure are the electrodes and nickel alloy fuse used for igniting the lean mixture of $\mathrm{H}_{2} / \mathrm{O}_{2} / \mathrm{N}_{2}$ in the bomb. The

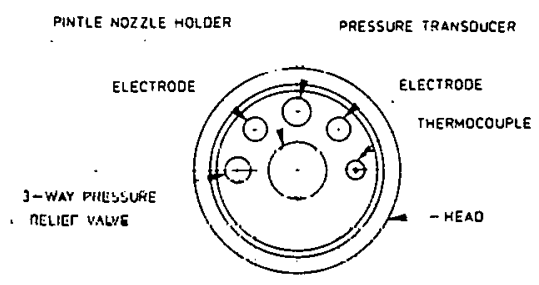

Figure 1. Cross-sectional view of constant volume combustion bomb.

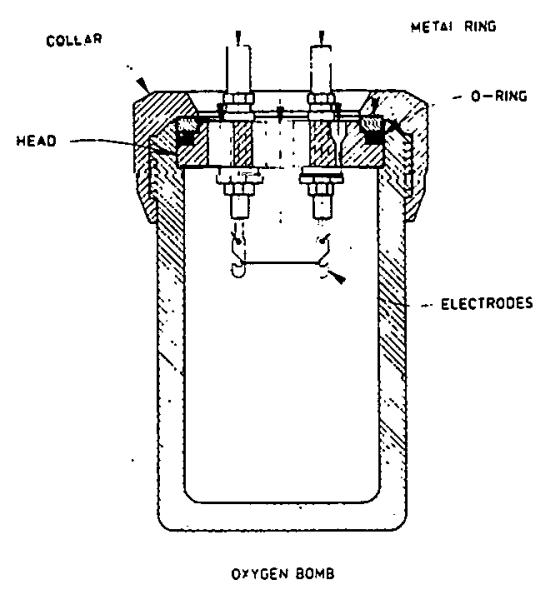


pressure and heat developed by igniting the gas mixture provides the conditions necessary to simulate diesel compression conditions. In addition, openings for a pressure transducer and thermocouple were machined in the head of combustion bomb for monitoring the combustion behavior of the fuel. Another opening was machined in the head for feeding the $\mathrm{H}_{2} / \mathrm{O}_{2} / \mathrm{N}_{2}$ mixture into the combustion bomb and For venting the combustion gas through the pres sure reljef valve if the bomb should over-pressurize. Combustion bomb and fuel. injection pressures will be obtained using Kistler Piezotron pressure transducers while the combustion temperature will be measured using a microminiature thermocouple.

A gas mixing system which allows various concentrations of gases to be accurately mixed and fed to the combustion bomb has also been constructed. Several combustion tests firing the lean hydrogen-oxygen-nitrogen mixtures in the combustion bomb to obtain pressure and temperature traces we re completed with reasonable results.

Figure 2 displays a cross-sectional view of the Bocsh KCA 18548 nozzle holder and DK $0 \mathrm{~S} 225$ pintle nozzle which will be used on the combustion bomb. This fuel injector has a screw-in type seal and is capable of injecting fuels at pressures up to 8700 psia while the fuel pump is capable of pumping approximately $0.2 \mathrm{gm}$ of fuel at pressures up to $7250 \mathrm{psia}$. This fuel injection equipment was sclected because of its relatively large fuel passages and its fuel delivery characteristics while still retaining a size capable of fitting in the calorimeter. A cut away view of the adiabatic calorimeter is shown in Figure 3. The combustion homb will be immersed in a bucket of deionized water during the combustion event. The calorimeter maintains adiabatic conditions by keeping the temperature of the water flowing in the jacket surrounding the bucket at the same temperature as the water surrounding the combustion bomb. Thus external heat loss effects can be neglected and the quantity of heat released can be determined by the thermal mass of the closed system and the final temperature rise. This heat release is dependent on the initial pressure and composition of the $\mathrm{H}_{2} / \mathrm{O}_{2} / \mathrm{N}_{2}$ mixture, the quantity of fuel irjected and its heating value, and the percentage of the fuel which actually burns. Since all the parameters except the last are known or can be controlled, the combustion efficiency of a particular fuel can be calculated Eroin the calorinetric data. In addition, a second measure of the combustion efficiency is determined from product gas analyses and "loss on ignition" (LOI) analysis of the remaining residue.

The data acquisition and control system is capable of sampling its 8 input channels at 25,000 conversions per second. This board also has 4 digital inputs and outputs for triggering events. The software which has been written for the analog/digital board will allow various timing sequences to be tested.

Test plans have been developed for the combustion bomb which will compare the reactivity of low-rank coals against that of conmercially available bituminous slurries. The test plan for the constant volume combustion bomb will evaluate the effects of particle size distribution, fuel injection temperature and fuel injection pressure on combustion delay and efficiency 


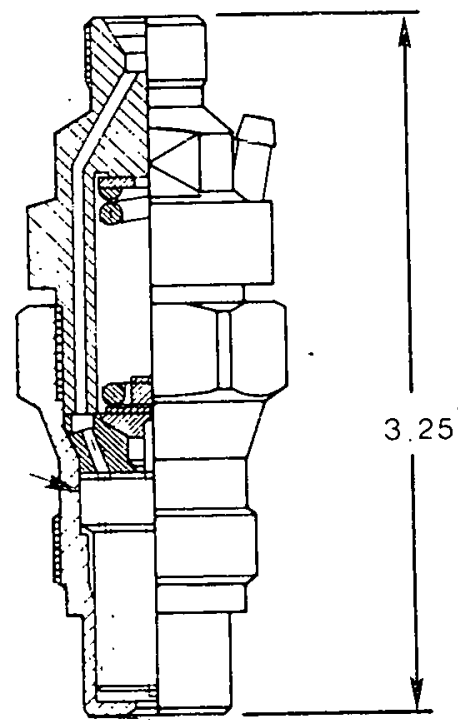

Figure 2. Cross-sectional. view of Bosch nozzle holder and pintle nozzle.

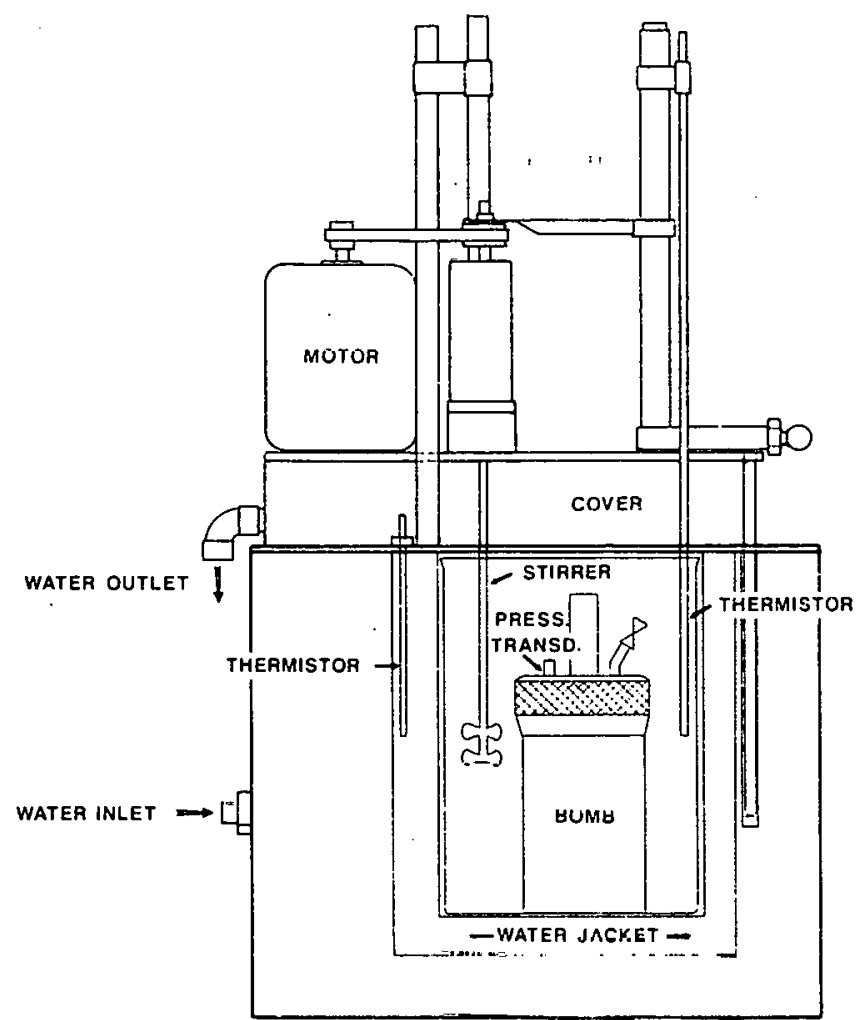

Figure 3. Schematic of the combustion bomb inside adiabatic calorimeter.

for a wide range of dif Eerent low ash coal-vater slurries. The potential lowaeh, low-rank rnals that will be tested in the combustion bomb include velva and Beulah Iignites and Fagle Butte, Black Thunder and Kemmerer subbicumlıuus coals along with yet-to-be selected bituminous coal slurries.

\subsection{CHARACIEKIZATION OF LRC COMBUSTION BEHAVIOR IN ULESFC, FNGINES}

A single-stroke diesel simulator 1 s used to investigate the combustinn behavior or various coal-derived fuels during a single cycle of a diesel engine. A user Cooper-Ajax AE-15 diesel engine has been acquired to provide the frame, flywheel, clutch, cross-head cylinder, crank and connecting rod for this single cycle diesel engine. Flguce 4 shows the dotailad design nf the hase engine, flywheel and rigid supporting frame on which the test cylinder wi11. he mounted. The original piston is mounted to the suppurting freme and provides a second cross-head for the smaller piston in the cest cyllnder. The $\mathrm{AE}-15$ diesel engine uses a five horsepower electrle vali-diuve motor to bring the system up to speed betore injecting the siagle shot of Eucl.

Figure 5 shows the ported two-cycle test cylinder and the instrumentation that is used to obtain the desired data from the single combustion event in the cylinder. The bore of the test cylinder is $2.375^{\prime \prime}$ with an $8^{\prime \prime}$ stroke. The cylinder is lined with lengths of standard hydraulic cylinder tubing with a 


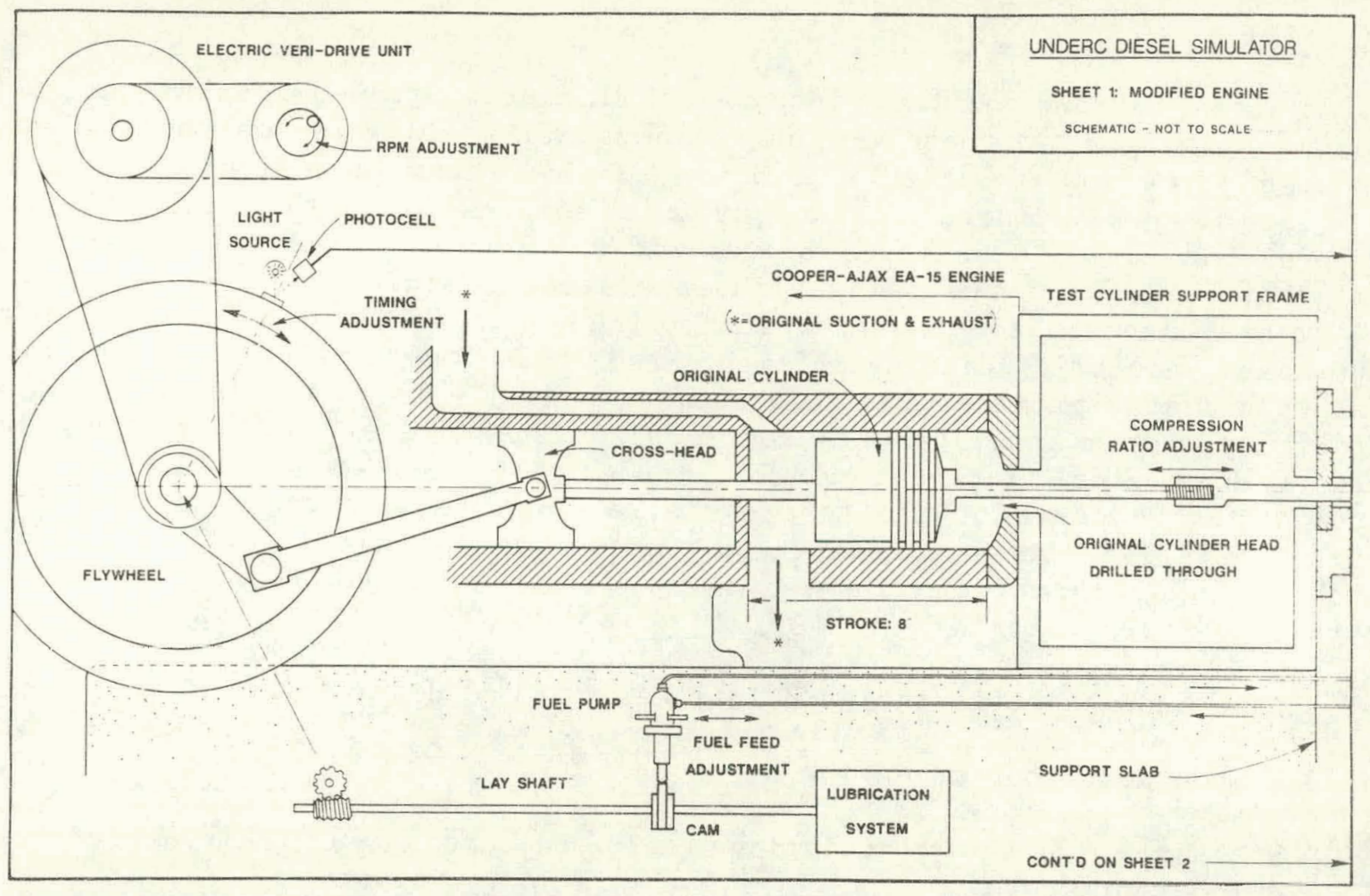

Figure 4. Schematic of diesel simulator base engine.

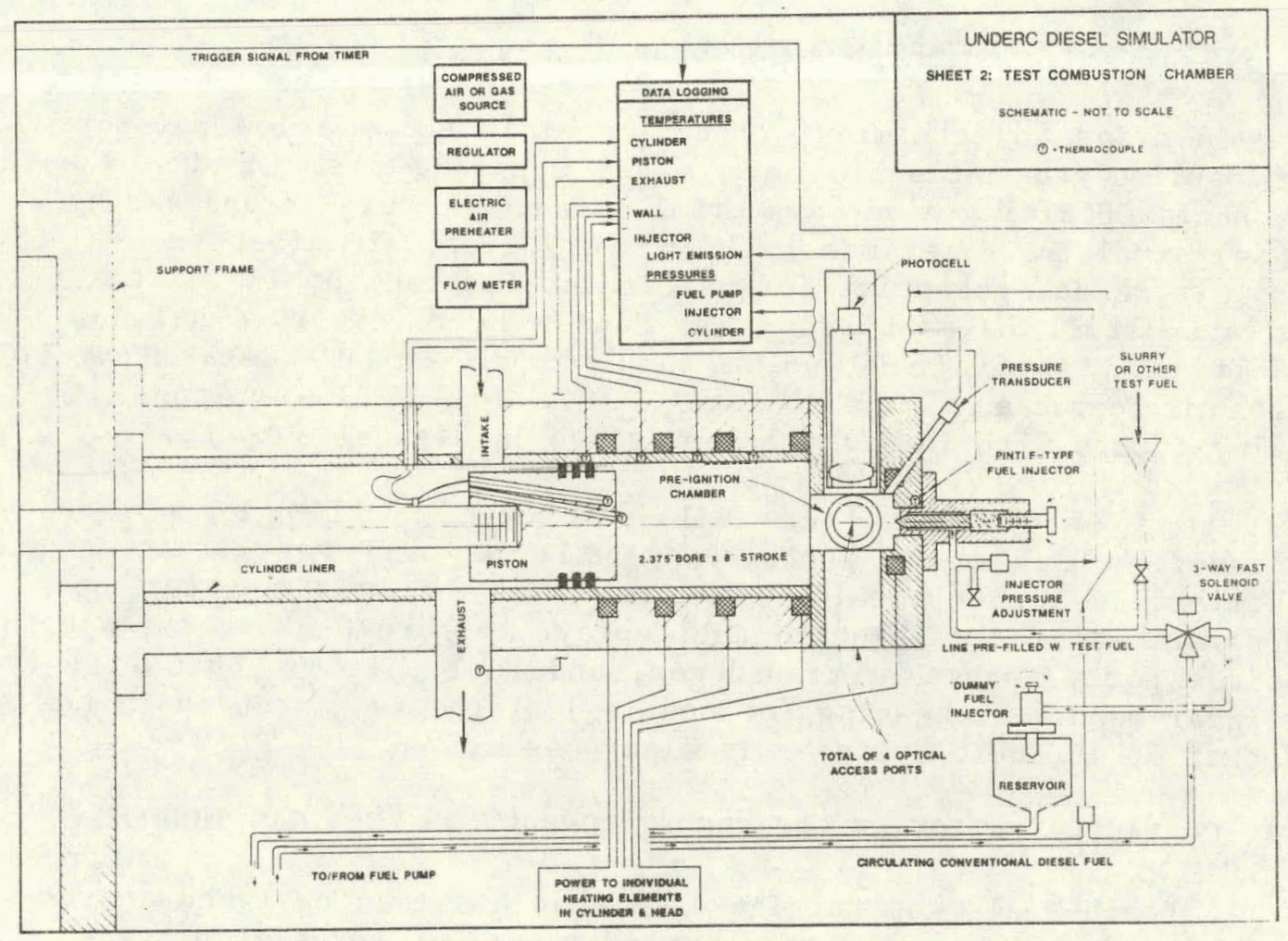

Figure 5. Schematic of diesel simulator ported test cylinder. 
2.375 inch ID and a 0.25 inch wall thickness which requires no further honing. The use of these cylinder liners allows location of the suction and exhaust ports to be varied. A major consideration in designing this diesel simulator was the need for a variable compression ratio. This variable compression ratio is achieved by varying the length of the rod connecting the original piston and the test cylinder piston. Machined in the test cylinder block are channels for the flow of cooling water or the placement of flexible Chromalox electric heating elements so that the cylinder walls can be maintained at typical engine temperatures. As displayed in Figure 5, the fuel injection system consists of a semi-conventional diesel fuel jerk pump system and a dummy fuel injector which is used to circulate conventional diesel fue1. At the start of the test cycle, a 3-way fast-acting solenoid valve is used to displace the test fuel from the pre-filled fuel line. The ability to preheat and compress the intake air provides the capability of studying the effects of turbocharging.

Instrumentation is included in the system to determine:

$\circ$

Piston position and engine speed,

- Pressures of the ctrculaling fucl, injected test fuel and combustion chamber pressure,

o Temperatures of the intake and exhaust gases, cylinder wall temperatires, piston surface temperatures and combustion chamber temperature.

Gas flow rate on the intake air and exhaust gas.

o Light emission, high speed photo'graphy and optical pyrometry.

In order to determine combustion efficiency, a low pressure drop filter for particulate collection and a gas sampling port in the exhaust line are planned. Obtaining a good material balance closure around a single cycle of a diesel simulator experiment will be very difficult given the relatively small sample size and potential for particulate entrapment inside the test cylinder but will still be measured. Tlie data will be rennried using a programmable 12-bit high speed (5000 point samples per second) data acquisition system which is capable of 16 voltage ( $\pm 10 \mathrm{~V}$ ) and 12 low voltage (thermocouples) analog inputs with 16 digital inputs and 16 digital outputs.

Multiple cylinder heads will be bullt lo allow optical access to the cylinder. High speed photography will be used for obtaining droplet size distribution and optical pyrometers will be utilized for obtaining flame temperatures of the injected fuel spray. Figure 6 shows the openings for the optical ports, pressure transducer, and fuel injector that will fit the test cylinder head. Preheating (or cooling) of the hed section in the same manner as that of the test cylinder is also posible.

\subsection{CHARACTERIZATION OF LRC SLURRY COMBUSTION IN A GAS TURBINE}

A bench-scale gas turbine simulator has been desigiled and constructed to measure the pressure, temperature, carbon conversion, gas composition, deposition of inorganics on simulated turbine blades and other components of 


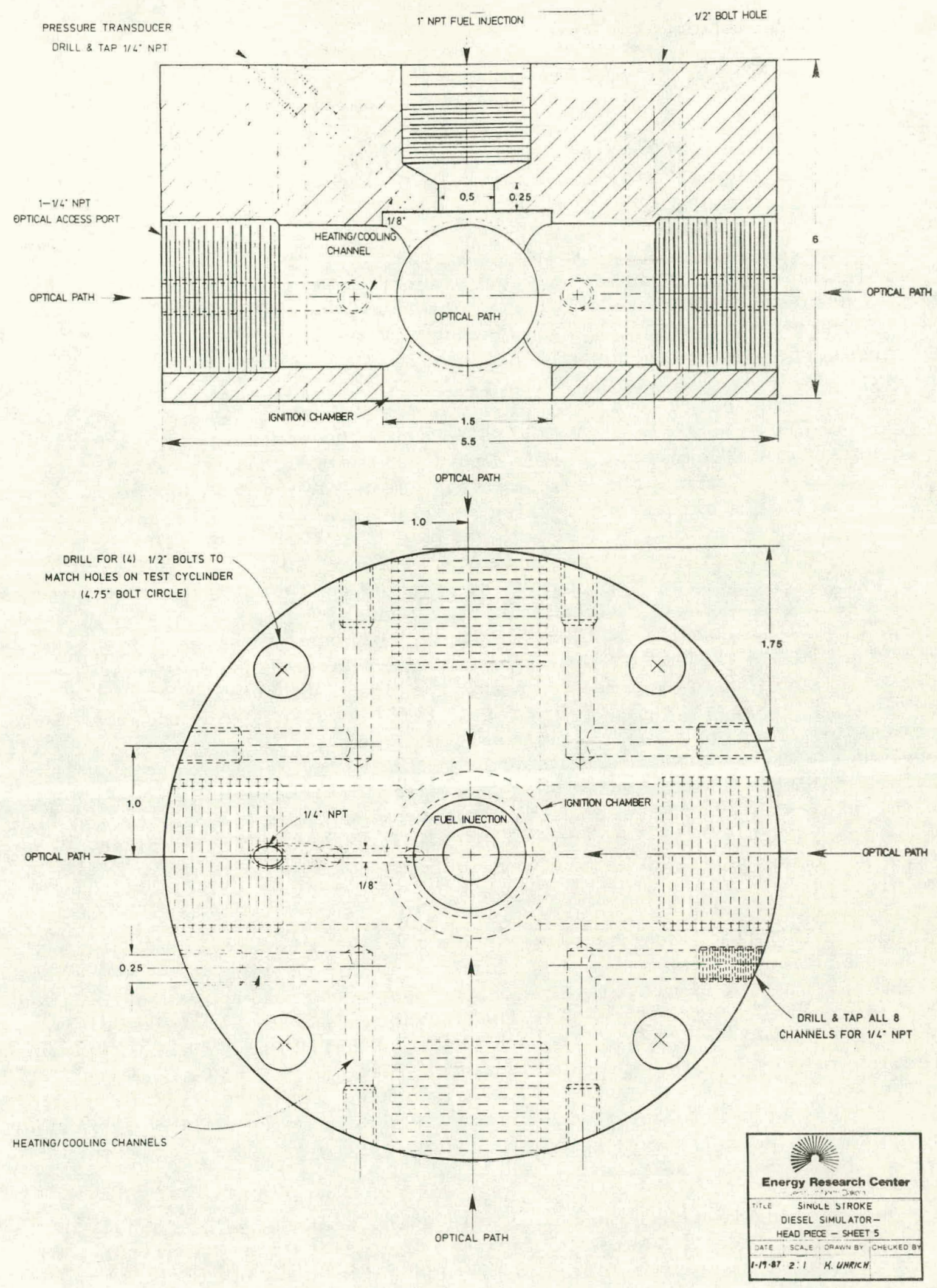

Figure 6. Schematic of diesel simulator test cylinder head. 
the system, fuel reactivity, and ash particle size and distribution resulting Erom pressurized combustion of low-rank coal slurries. These fundamental studies will demonstrate the impact of the various fuels and fuel properties on the combustor and turbine blade, and lead to the development of fuel specifications required for successful operation of low-rank coal slurries in a turbine application.

Figure 7 shows the detailed design of the combustion vessel and deposition sections. This design has incorporated several improvements and ideas obtained from test site visits made previously (15). The head section of the turbine consists. of an 8-inch 300-1b blind flange which has a horizontal $45^{\circ}$ air swirler and a Delavan Swirl-Air nozzle with either $50^{\circ}$ or $75^{\circ}$ spray angles. The combustion vessel itself is made from sections (Figure 8) of 8-inch schedule $40304 \mathrm{SS}$ pipe while the deposition section (Figure 9) is fabricated from sections of $304 \mathrm{SS} 4$-inch schedule 40 pipe. The rich zone in the combustion vessel is lined with 1 inch of castable alumina refractory (rated to $3400^{\circ} \mathrm{F}$ ) while the rest of the combustor and the deposicton section will be lined with a refractory rated to $3000^{\circ} \mathrm{F}$.

The quench section of the simulator (Figure b0) will he a 3.0 inch ID metal walled section with a concentric air passage encircling the inner wall with sixteen $0.4 " \times 0.15^{\prime \prime}$ slots machined through the wall. This allows rapid mixing of the secondary air to minimize the occurrence of localized "hot spots" and the formation of thermal NOx. A reduced flow area in the deposition section is used to increase the gas velocities to those typically seen in the expander section of a gas turbine. This reduced area will be obtained by lining the deposition section with retractory to form a 1-1/4" square duct with exposed square probes which are machined from 9/16" high pressure tubing. These probes are intended to simulate the leading edge of turbine blades. A water quench zone is located after the deposition section to cool the flue gas to less than $750^{\circ} \mathrm{F}$ by spraying water in to the flue gas before it passes through the rotary control valve used to back pressure the similator.

Gas and particulate sampling probes will be made from progressively smaller concentric tubes so that air or water-cooling of the probes is possible. In the particulate sampling probe, an extra tube is used in addition to the cooling jacket so that an inert gas can be injected into the particulate sampling stream to quench the sample preventing the further oxidation of unconverted char particles. These particulale samples will bc transported through heat-traced line to a high pressure filter holder and 0.3 micron borosilicate glass filters. Gas samples will be transported through heat-traced lines to a sample conditioner where the sample moisture is removed before being analyzed.

The existing UNDERC slurry feed skid used in atmospheric combustion tests will be used to feed the selected fuels to the gas turbine simulator. Another rotary control valve and a high temperature guided-seat control valve will be used to control the amount of air entering the air preheater and the distribution of the air between the rich and lean zones, respectively. A natural gas fired fluidized bed will be used to preheat the combustion air up to $1000^{\circ} \mathrm{F}$. 

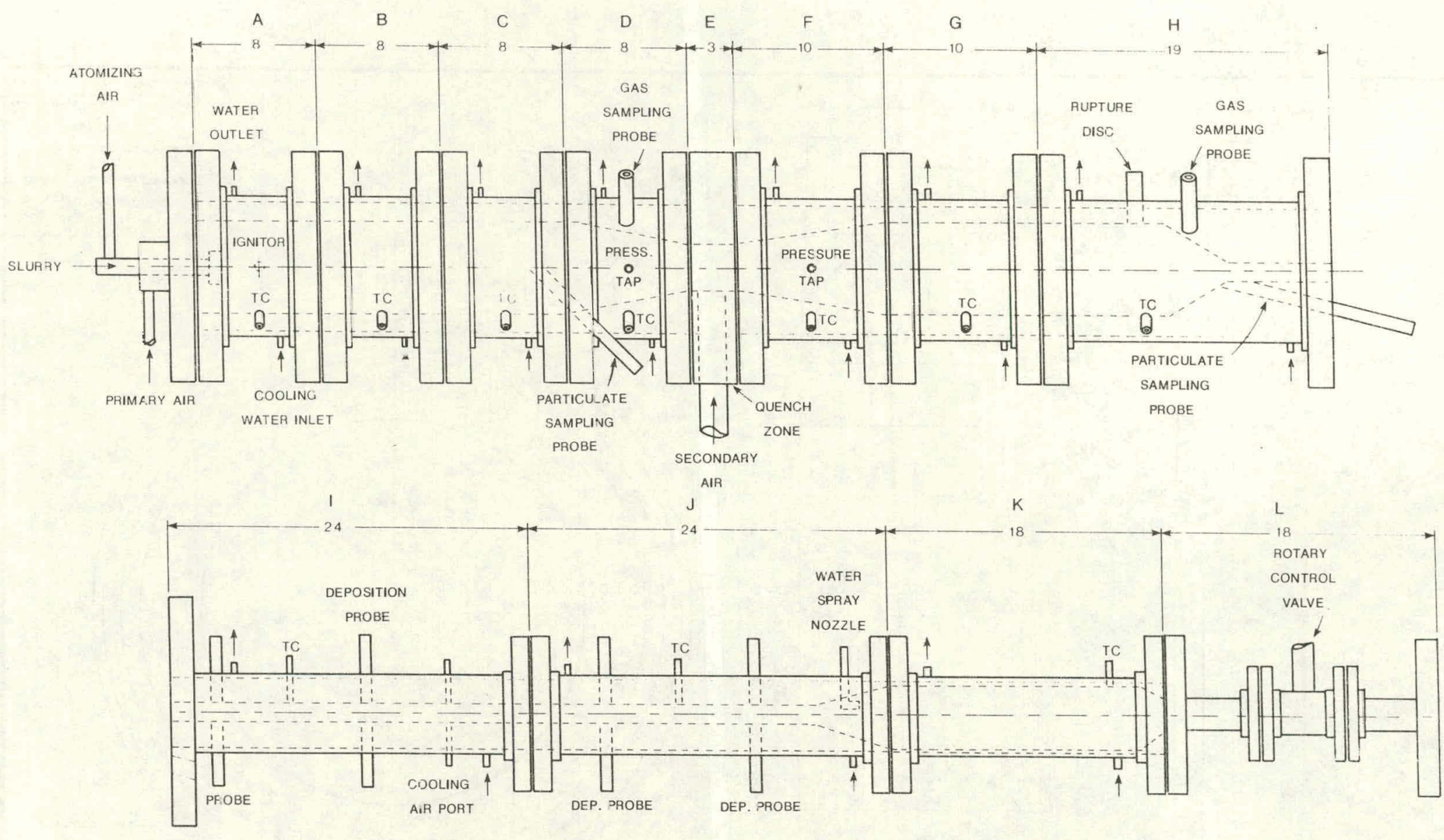

1 Million Btu/hr Two Stage Gas Turbine Simulator

Figure 7. Detailed design of $1 \mathrm{MBtu} / \mathrm{lb}$ gas turbine simulator. 


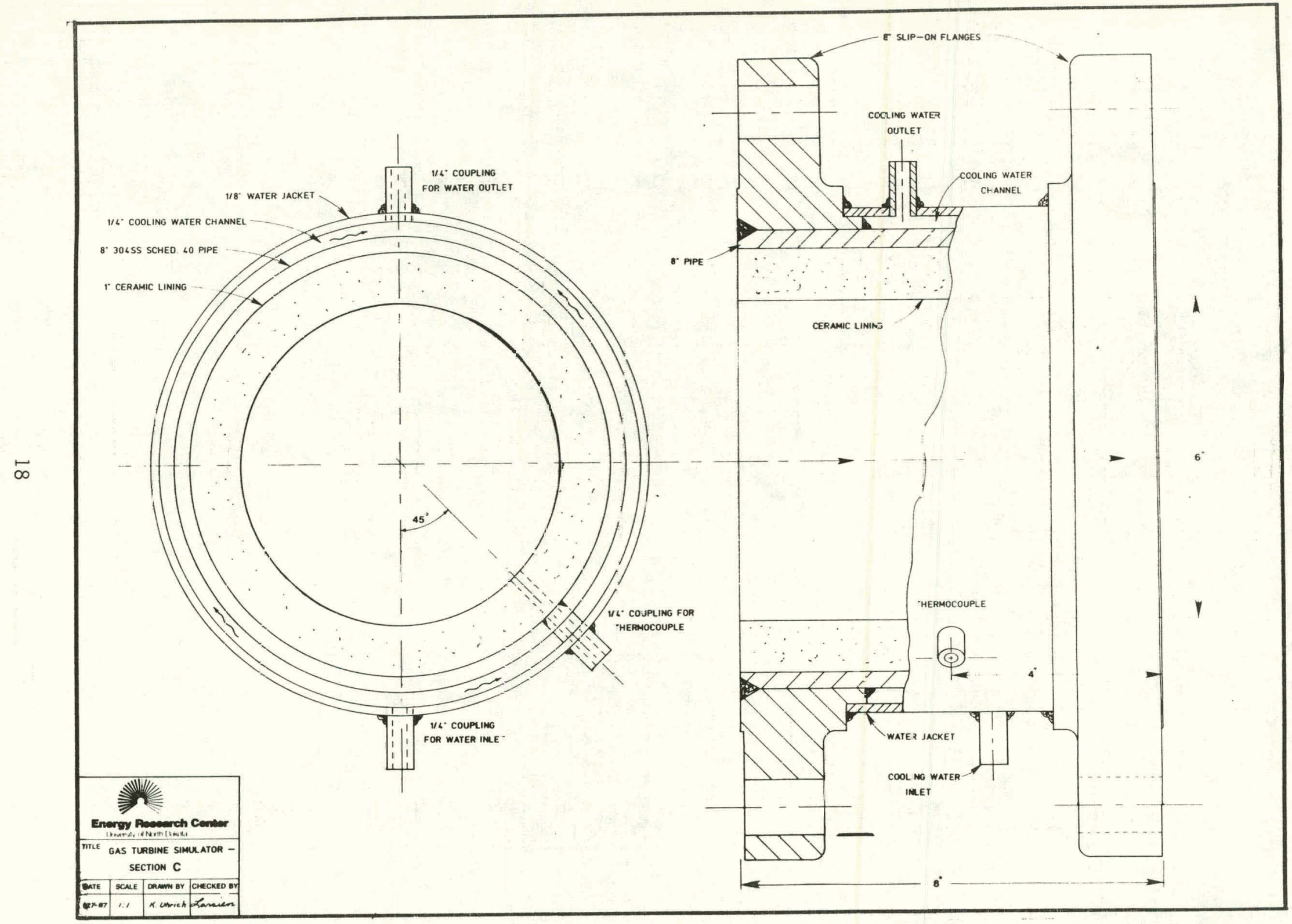

Figure 8. Schematic of turbine combustor module. 


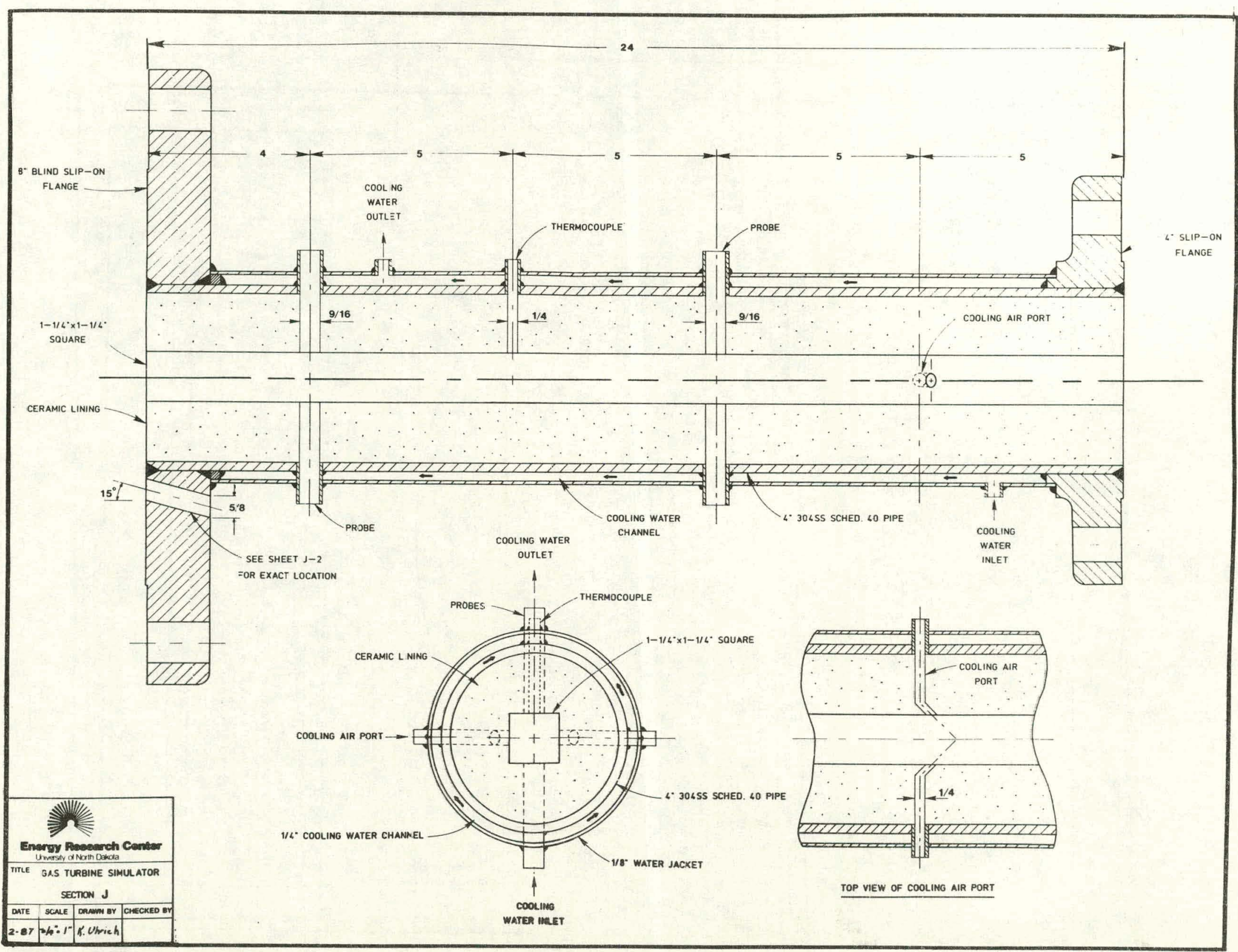

Figure 9. Schematic of turbine simulator deposition section. 


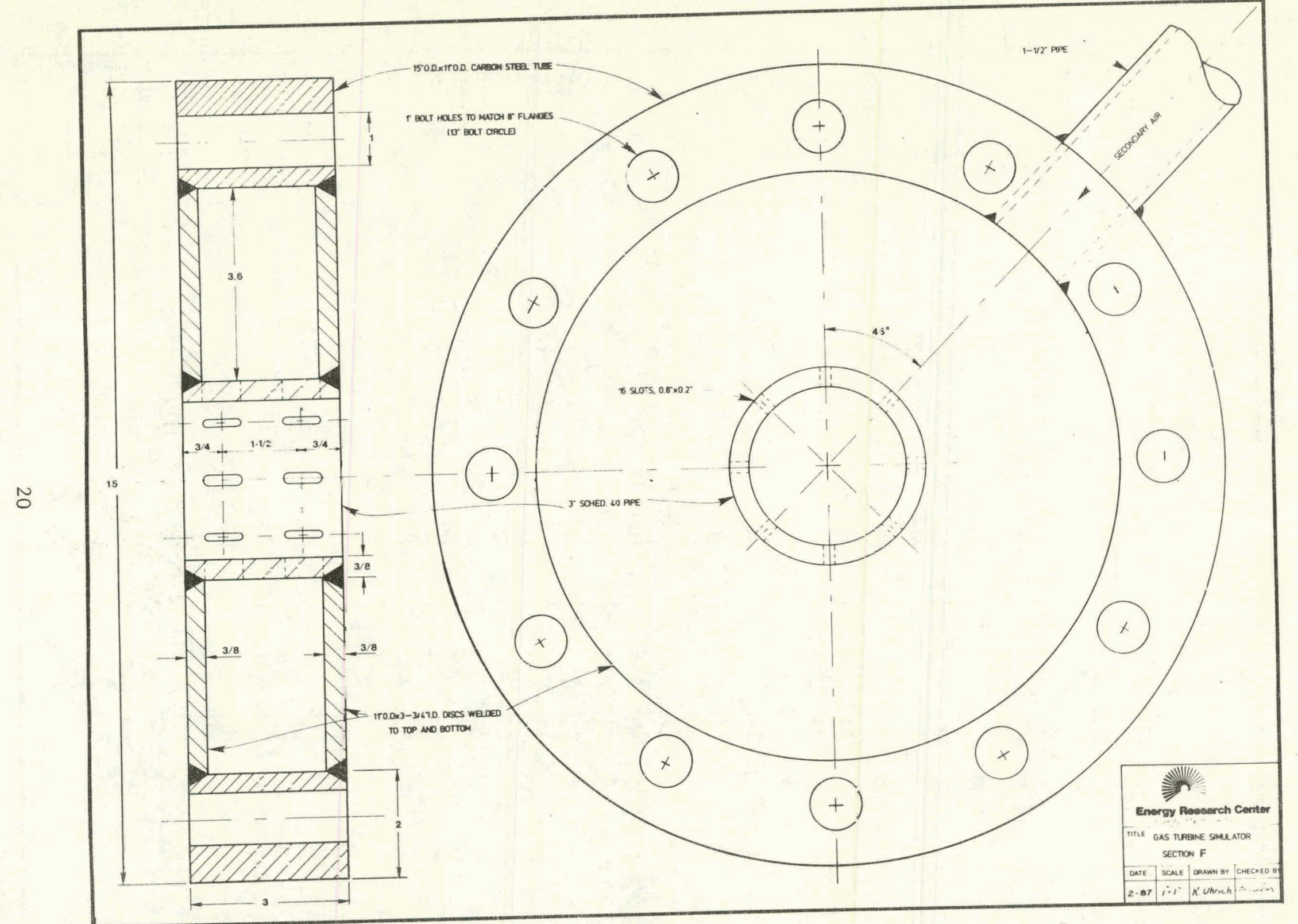

Figure 10. Eetailed design of turbine simulator quench section. 
Temperatures in the rich zone will be measured with alumina-sheathed type $B$ thermocouples while the lean zone temperatures will be measured with mulite-sheathed type $K$ thermocouples. Combustion air and flue gas temperatures in the deposition section will be measured using standard stainless steel sheathed type $K$ thermocouples. Combustion zone, preheated air, fuel injection and atomizing air pressures will be measured using pressure transducers with $0-300,0-500$ and $0-1000$ psig ranges, respectively. The gas analyzers from the $2.25 \mathrm{ft}^{2}$ fluidized bed combustor (FBC) at UNDERC have been mounted in to a mobile panel to enable these analyzers to be shared by both the FBC and the gas turbine simulator projects. Flow and pressure control will be accomplished using pneumatic and electric controllers. A data acquisition system currently used on the FBC also will be used to monitor process conditions on the turbine and has the following I/O capabilities:

64 thermocouples/low level inputs

28 high level inputs

2 analog outputs

16 digital inputs

16 digital outputs

2 serial $I / 0$

The test plan for the turbine simulator will consist of a fractional factorial design which investigates the effects of fuel type, particle size distribution, combustion air temperature, equivalence ratios, combustor pressure, temperature and residence time on combustion efficiency and deposition and erosion of air cooled probes located in the turbine exit.

\subsection{EROSION/ABRASION IN ADVANCED COMBUSTION SYSTEMS}

In general, deposition of ash contaminants on the turbine vanes and plugging of the vane area is the most significant problem facing coal-water slurry use in direct-fired gas turbines. Deposition and erosion are usually mutually exclusive phenomena (i.e. turbine components can experience deposition without erosion or erosion without deposition, however, these components will not experience both deposition and erosion at the same time). Despite the greater problems presented by deposition; erosion of turbinc vanes aud blades is still an important factor in determining the effective lifetime of the turbine surfaces.

Abrasiveness of coal-water slurry fuels on components such as injectors, turbine blades, and other internal or moving parts is a major technical concern in the utilization of these fuels in heat engines. Turbine blade erosion and wear on reciprocating surfaces can be a problem even when burning cuals and slurries with low ash contents. Several potential methods of minimizing erosion/abrasion in heat engines include removing virtually all of the ash from the coal during preparation, micronization of the coal to reduce the particle size of the coal and ash formed during the combustion process, the selective removal of the more erosive species in coal mineral matter and the selection and/or development of component materials which are more resistant to erosion/abrasion. 
Abrasiveness of coal-ash particles depends on many factors, the majority of which can be grouped into the following four general categories: 1) particulate flow stream variables, 2) particle properties, 3) material properties, and 4) environmental ef fects. These factors include: particle size, particle shape (whether angular or spherical), particle hardness, particle density, particle brittleness, particle velocity, particle quartz content, properties of material being abraded, angle of impact, temperature, gaseous environment, concentration of particles and extent to which the geometry allows removal of the wear debris. In coal-fired boilers, ash characteristics such as particle size and "abrasiveness" and the angle of impact, all influence erosion, but velocity of the particles is the most important factor (16). According to Raask, for a given loading of ash particles, the rate of boiler tube metal loss is proportional to particle velocity to the 2.5 power (17). It appears that particles less than approximately 4 microns diameter will have little erosive effect; for particles larger than 20 microns or so, the erosion damage, in terms of weight of metal removed per unit weight of erodent striking the surface, is independent of particle stze. The abrasivcnees of soal-ash particles depends on factors such as quartz content, shape and hardness. There is no widely accepted measure of eruslun in boilcro nor any generally used test method. Boiler designers apparently set an arbitrarily established upper velocity limit for particles passing erosion-prone surfaces.

Results from the technology assessment performed indicate clial significant work has been done investigating the factors which affect erosion/abrasion $(16-24)$. Additional work looking at the coal particle properties (size, composition, etc.), both in their original form and as residual ash following combustion, is needed to fully understand the underlying mechanisms of erosion. Work at UNDERC was planned to measure the relative erosiveness/abraslveness of low-rank coal-water mixtures as compared to high-rank coal-water mixtures and conventional fuels. However, due to changes in FY 87 funding levels, this ef fort has been climinated from the work plan.

\subsection{HOT GAS CLEANUP}

Four major categories of impurities are recognized as important in turbine applications: $\mathrm{NO}_{x}, \mathrm{SO}_{2}$, particulate matter, and alkali constituent. The first three impurities are regulated by the 1979 New Source Performance Standards (NSPS) for fossil fuel-fired statloutey sourccs which are rated at. 73 MWe or greater. In addition to particulate matter, turbine perfornance and longevity are affected by alkali vapor concentration in the flue gas. For effective turbine operation to occur, these impurities should be controlled to the levels below the NSPS.

Nitrogen oxides produced in combustion processes originate from molecular nitrogen in the combustion air and from heterocyclic nitrogeneous compounds present in the fuel. Coal typically contains 1-2 wt\% organic nitrogen. In the case of coal-water mixture combustion, the fuel bound nitrogen (FBN) contributes to generally unacceptably high NO emlssions. The use of richlean two stage combustion has been shown to greatly reduce the $\mathrm{NO}_{\mathrm{x}}$ emissions resulting from the $\mathrm{FBN}(25,26,27)$. Several researchers have shown that a minimum in $\mathrm{NO}_{x}$ emissions is achieved at primary fuel-rich zone fuel equivalence ratio between 1.3 and 1.5 with the sharpest decline in $\mathrm{NO}_{x}$ 
formation occurring at equivalence ratios between 0.9 and 1.2 . The effectiveness of staged combustion was also significantly affected by atomization quality. This effect is a direct consequence of the carryover of nitrogen in unburnt fuel caused by the poor fuel burnout experienced with coarser atomization. This suggests that a sufficient residence time in the fuel-rich zone is needed to decompose the heterocyclic nitrogen compounds in their cyanogens which are then oxidized to oxycyanogens (25). These oxycyanogens are either oxidized further to $\mathrm{NO}_{x}$ or are converted in a reducing atmosphere to ammonia and amines which undergo two competing reactions; one with NO to form $\mathrm{N}_{2}$ and the other with $\mathrm{O}$ or $\mathrm{OH}$ to form NO. Nitrogen oxides emissions have also been shown to decrease with increasing system pressure.

For non-regenerable sorbents, the use of calcium-based materials for $\mathrm{SO}_{2}$ emission control currently bears the most hope of being able to satisfy the requirements of high $\mathrm{SO}_{2}$ removal at high pressure and temperature. The most desirable approach would be to eliminate sulfur species in the exhaust gas using an all-dry process prior to the turbine inlet. Unfortunately, the reaction kinetics for these sorbent minerals are relatively slow, and there is a limited temperature range at which the kinetics are rapid enough to al low for significant removal of $\mathrm{SO}_{2}$ (greater than $50 \%$ ) within residence times of less than 2 seconds. Optimal sulfur removal occurs at temperatures of $1832^{\circ} \mathrm{F}$ to $2192^{\circ} \mathrm{F}$.

The direct injection of calcium-based sorbents into combustion furnaces and duct work has been under investigation at UNDERC (formerly the Grand Forks Energy Technology Center (GFETC) of the U.S. DOE) since 1978. Initial sorbents used were limestone and calcined lime (quick lime) with sorbentut 1 lization values of $16 \%$ and $25 \%$, respectively (28). This low utilization was due to poor development of sorbent surface area by a non-optimal time/ temperature profile in the combustion system. Recent research has centered around the use of a pressure hydrated high calcium lime which provides a finely sized $(<1 \mu \mathrm{m})$ sorbent material with high specific surface area $(15-20$ $\left.\mathrm{m}^{2} / \mathrm{g}\right)$. In their tests, optimal control of $\mathrm{SO}_{2}$ occurred near $1900^{\circ} \mathrm{F}$ resulting in a $50 \%$ reduction in $\mathrm{SO}_{2}$ emissions at a $\mathrm{Ca} / \mathrm{S}$ ratio of 1.0 and $80 \%$ reduction at a $\mathrm{Ca} / \mathrm{S}$ ratio of 2.0 (28). Forty to sixty percent utilization was readily obtained at these conditions.

Physical Sciences Incorporated (PSI) has performed some recent research in injecting ralcium-based corbents directly into a pressurized combustor for in situ sulfur capture and developed a kinetic model based on some of these results $(29,30)$. Results indlcated that sulfur capture increased with increasing pressure, residence time, and $\mathrm{Ca} / \mathrm{S}$ ratio. A $30 \%$ reduction in $\mathrm{SO}_{2}$ was reportedly obtained for the injection of a Longview slaked lime at a $\mathrm{Ca} / \mathrm{S}$ ratio of $3,1830^{\circ} \mathrm{F}$ and a residence time of $0.5 \mathrm{sec}$ onds. These results have been extrapolated to indicate that a $10 \%$ reduction in $\mathrm{SO}_{2}$ could achieved at residence times of 0.1 seconds. Fur heat engine applications where residence times are short, the objective is to capture as much sulfur as possible in the short residence time available. Other results have suggested that sulfation reactions occur very rapidly until the sorbent pores fill with product and block a large fraction of the surface area available for reaction. This indicates that smaller sorbent particles sizes would have a higher utilization due to a higher external surface area to total surface area ratio. Thus, a sorbent with a high surface area and small diameter is needed to achieve the rapid sulfur conversion (via $\mathrm{Can}+\mathrm{SO}_{2}+1 / 2 \mathrm{O}_{2} \cdots-\mathrm{CaSO}_{4}$ ) typical of a 
kinetically limited reaction versus the slower diffusion controlled reaction. Optimal sulfur capture using precalcined limestone occurred between $1800^{\circ}$ and $2200^{\circ} \mathrm{F}$. Sorbent utilization was adversely affected by the presence of $\mathrm{CO}_{2}$ in the flue gas especially at a temperature below $1650^{\circ} \mathrm{F}$ due to the reaction of $\mathrm{CO}_{2}$ with the sorbent to reform calcium carbonate. This results in a reduced sorbent surface area and porosity and deactivation of the sorbent. Sorbent reactivities were also enhanced by the presence of promoters such as those found in coal ash (i.e., sodium and potassium). The Coal Tech Co. has reported (31) a $99 \%$ sulfur removal for the injection of limestone at a $\mathrm{Ca} / \mathrm{S}$ ratio of 4.4 into $2170^{\circ} \mathrm{F}$ with a $100 \mathrm{millisec}$ residence time. This contrasts with data reported by $\mathrm{PSI}$ indicating only a $10 \% \quad \mathrm{SO}_{2}$ reduction with a $\mathrm{Ca} / \mathrm{S}$ ratio of 3.3 at $2200^{\circ} \mathrm{F}$ and a 1 second residence time. Clearly more data is needed to clarify the sorbent $-\mathrm{SO}_{2}$ reactions at high temperatures, especially at high pressures.

Ninery percent removal is theoretically possible at a ca/s of 4, using pressure hydraced dulinitic lime and pressures of $10 \mathrm{~atm}$. The addition of sorbents at that level w111 reyuire advanced hor gas eleanup devicus if particulate matter emissions are to be in compliance with the NSPS prior to the turbine inlet. ocher techniques for controlling the impact of fuel contaminants on the turbine and the environment include the use of various hot gas cleaning devices such as cyclones, porous ceramic crossflow filters and other filter barriers, and ESP's.

Advanced HGCU devices have been reviewed (25-51). Table 2 summarizes the results of testing on ten devices which have been evaluated for PFBC and HTHP gasifiers (44). As the table shows, there is a wide range of conditions and levels of development represented among the various contractors, and a baseline comparison is difficult to perform. Based on a survey of contractors, consultants, and DOE personnel, Rubow et a1. (44) reported that three devices would have the highest probability of success with respect to PFBC particulate control: the CES ESP, the CPC GBF, and the Westinghouse cross-flow ceramic filter. For HTHP gasification conditinns, Case et al. (45) reported that the devices which would be most suitable for particulate control would be the CPC GBF, the Westinghouse croso-flow ceramic filter, and cyclone collectors used with acoustic agglomeration. Another perspective is of fered by First (49), who recommends the development of Nextel ceramic fabric filters, and rules out development of ceramic cross-flow filters, electrostatic precipitators, and granular bed filters.

Renoval of alkalis hy use of injected sorbents or gas flow through a fluidized bed of sorbents have also been proposed $(1,10,48)$. Due to the high predicted capture rates, the direct injection of alumina silicate additives into the combustor should also be very effective (51), however the alkali saturated sorbent tends to be sticky. This sickiness probably will present problems for hot gas cleanup devices such as ceramic crossflow filters and cyclones. Physical Science Inc. (PSI) has reported (30) on tests using Longview slaked lime, quartz, bauxite and diatomaceous earth as sorbents for sodium vapor in which they found that slaked lime was approximately 3 times more efficient in capturing sodium than the other surbents. They felt that their data indicated that the rate of alkali capture is still slow by at least a order of magnitude to be useful in entrained flow applications. However, the use of aluminosilicate or calcium-based sorbents in a fixed bed may be a viable option. 
- TABLE 2

SUMMARY OF HOT GAS PARTICULATE REMOVAL TECHNOLOGY (40)

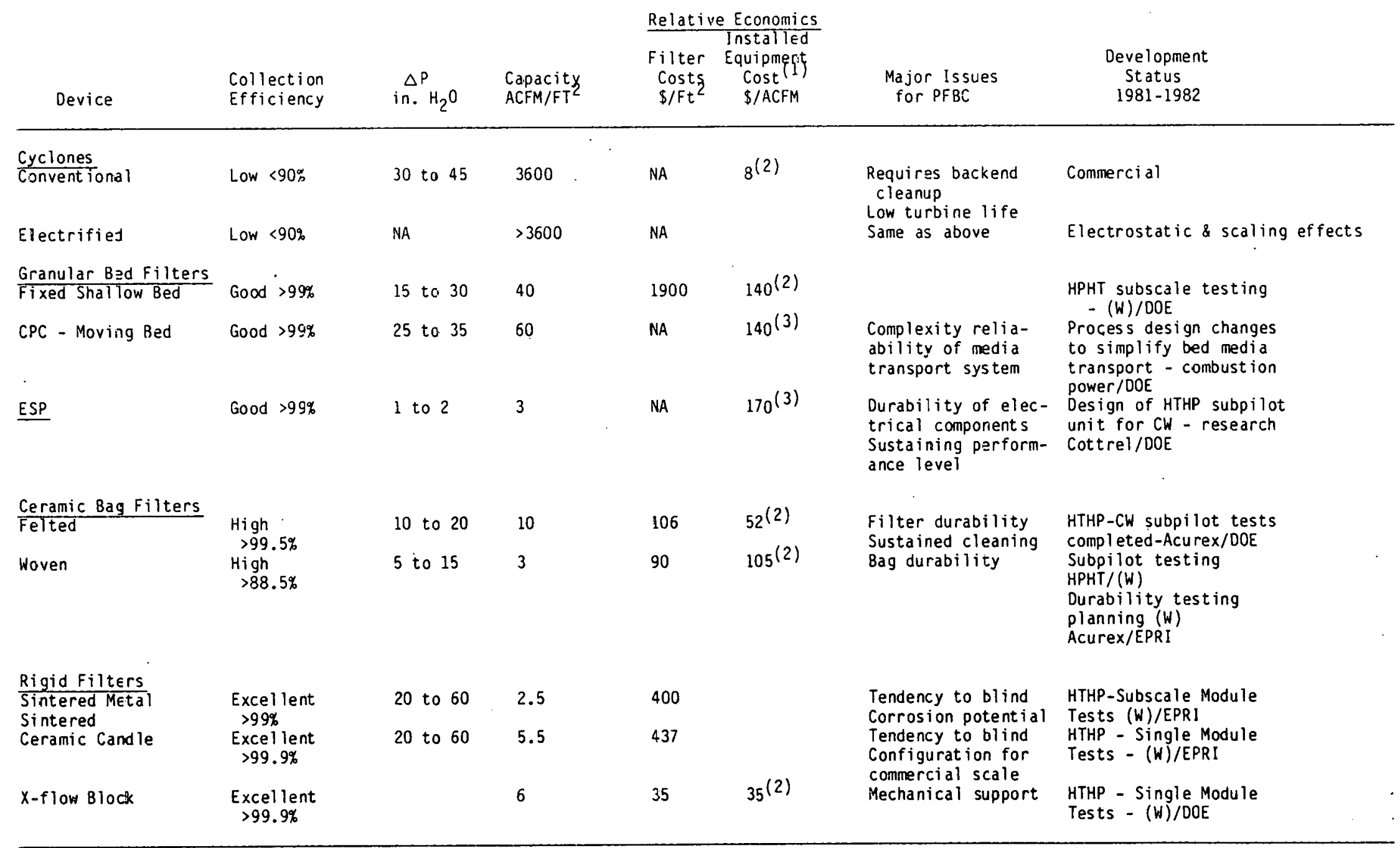

$\frac{1}{2}=$ Omits Hot Gas Piping Costs Tota: Plant Cost Approx. $=1250 \$ / \mathrm{ACFM}$.

$3=$ West inghouse Studies.

$3=$ Gi ibert Associates Studies
$\star H T H P=H i g h$ Temperature High Pressure

$N A=$ Not Applicable or given. 
Future work wili involve testing of hot gas cleanup methods for $\mathrm{SO}_{2}$ control. This work will include an evaluation of chemically-enhanced pres sure hydrated lime for the removal of sulfur and nitrogen oxides at high temperature/pressure. UNDERC has investigated the use of pressure hydrated high-calcium lime for $\mathrm{SO}_{2}$ control in atmospheric combustors, and an extensive data base has been developed with respect to bench-and pilot-scale results with various sorbent additives but control of $\mathrm{SO}_{2}$ emissions at high pressures (up to $17 \mathrm{~atm}$ ) and the effects of additives, interactions with ash, and removal of $\mathrm{NO}_{x}$ have not been addressed in detail. The effect of fuel properties and $\mathrm{SO}_{2}$ cleanup methods on particulate control methods will also be evaluated. A more detailed review of various hot gas cleanup techniques and devices are given in previous quarterly reports $(52,15)$.

\subsection{SUMMARY OF RESULTS/ACOOMPLISHMENTS}

o Performed technology reviews and assessments of coal-fired heat engine applications, hot gas cleanup, dud depusition, corrosion, and ernsinn phe nnmena.

- Designed and constructed a constant volume combustion bomb/adiabatic calorimeter for testing the reactivity of various coal derived fuels.

- Designed and initlated construction of a diesel simulator which moniters the combustion behavior of various coal derived fuels over the course of a single diesel engine cycle.

- Designed and initiated construction of a gas turbine simulator which is capable of combusting up to approximately 1 million Btu/hr of coal derived fuel while measuring the effect of air-staging, fuel type and particle size, residence time and air temperature on combustion efficiency, the products of combustion and depusition-erosion-corrosion interactions.

- Developed a computer program to determine the effect of various parameters on the mass and heat balances in the turbine simulator.

\subsection{REFERENCES}

1. Giramonti, A.J. and W.A. Blecher, "Gas Turbine Systems Research and Development Second Topical Report," September 1984.

2. Bhasin, A.K., F.J. Smit, K.R. Anast, R.E. Doane, "Development Testing and Manufacture of Ultra-Clean Coal-Water Mixture for Gas-Turbine Firing Tests," Proceedings of the F1rst Alumal lleat Engince Cuulidutors Merting, Morgantown, West Virginia, November 1984, p. 108-120.

3. Walia, D.S. and C.J. Im, "The Development, Testing, and Manufacture of an IItra-clean Coal/Water Mixture," First Annual Heat Engines Contractors Meeting, Morgantown, West Virginia, November 1984, p. yi-107.

4. Berman, P.A., "A Competitive Coal-Fired Gas Turbine Combined Cycle," Proceedings of the First Annual Heat Engines Contractors Meeting, November 1984 , p. 56-65. 
5. Winters, P.J., R.T. Bailey, and K.R. Olen, "The Éffect of Fuel Formulation on the Atomization Characteristics of Coal-Water Mixtures," Proceedings of the Seventh International Symposium on Coal Slurry Fuels Preparation and Utilization, New Orleans, Louisiana, May 21-24, 1985, p. 430-439.

6. Cook, D.A., J.D. Kearns, D.A. Smith, M.J. Rini, and R.C. LaFlesh, "C-E Canada CWM Nozzle Development and Firing Experience," Proceedings of the Sixth International Symposium on Coal Slurry Combustion and Technology, Orlando, Florida, June 25-27, 1984, p. 993-1011.

7. Dunn-Rankin, D.; Hoornstra, J. and Holve, P.J.; "Combustion Rese arch for Advanced Heat Engine Power Systems"; Proceedings of the Third Annual Heat Engines Contractors Meeting, Morgantown, West Virginia, May 1986, p. 163175.

8. Allen, J.W., A.G. Rennie, and M.C. Welbourne, "Atomization of Coal Water Mixtures," Proceedings of the Seventh International Symposium on Coal Slurry Fuels Preparation and Utilities, New Orleans, Loulsiana, May 2124,1985, p. $392-401$.

9. Lefebure, A.M., P.E. Sojkg, and C.F. Smith, "Investigation of Spray Characteristics of Coal Water Slurry Fuels," Proceedings of the First Annual Heat Engine Contractors Meeting, Morgantown, West Virginia, November 1984 , p. 206-213.

10. Horazak, D.A., P.W. Pillsbury, P.R. Mulik, E.J. Vidt, and R.A. Wenglarz, "Gas Turbine Systems Research and Development Program Topical Report for the Period June 6, 1983 - October 19, 1984," Date Issued - March 1985.

11. Smit, F.J., M.H. Berggren, A.K. Bhasin, and N.J. Ronzia; "Chemical Coal Cleaning Process and Costs Refinement for Coal-Water Slurry Manufacture," Proceedings of the Second Annual Heat Engines Contractors Meeting, Morgantown, West Virginia, May 1985, p. 87-93.

12. Im, J.C., "Physical Beneficiation Process and Cost Refinement for CoalWater Slurry Manufacture," Proceedings of the Second Annual Heat Engines Contractors Mesting, Morgantown, Wect Virginia, May 1985, p. 79-86.

13. Giramonti, A.J., "Coal-Fueled Gas Turbine Industrial Systems Applications," Proceedings of the Second Annual Heat Engines Contractors Meeting, Morgantown, West Virginia, May 1985, p. 67-78.

14. Seibers, D.L. and T.M., Dyer; "The Autoignition and Combustion of CoalWater Slurry Under Simulated Diesel Engine Conditions"; Journal of Engineering for Gas Turbines and Power, 108, October. 1986, pp. 654-660.

15. Mann, M.D. et al., University of North Dakota Energy Research Center Quarterly Technical Progress Report, July-September 1986.

16. Reid, W.T., "The Relation of Mineral Composition to Slagging, Fouling and Erosion During and After Combustion," Prog. Energy Combust. Sci,. Vol. 10, 1984, pp. 159-175. 
17. Raask, E., Wear, Vo1. 13, 1969, p. 301.

18. Stringer, J., "Erosion, Corrosion, and Deposition in Coal-Fired Gas Turbines: The Experience Derived During the Past Decade," Workshop Proceedings: Direct Coal-Fired Combustion Turbines, EPRI AP-39390SR, April 1985, pp. 6-1 through 6-38.

19. Glitz, R.W., "Solid Particle Erosion - A Literature Review," High Temperature Technology Program, Reference Turbine Subsystems (Primary and Backeys Concepts) Topical Report, DOE/FE/1806-27, July 1977, pp. A2-1 through A2-36.

20. Rabinowicz, E., "The Wear of Hard Surfaces by Soft Abrasives," Wear of Materials, ASME, New York, 1983.

21. Rabinowicz, E., "Abrasive Wear Resistance as a Materials Test," Lubrication Engineering, Vol. 33, 1977, pp. 378-381.

22. Hauserman, W.B., "Hardness of Fine Ground Coals and Mineral Residues to Predict Slurry Erosion," DOE/FE/60181-66, April, 1984.

23. Shida, Y., N. Ohtsuka, and H. Fujikawa, "Influence of Particle Properties on the Solid Particle Erusion Behavior at High Temperature," High Temperature Corrosion in Energy Systems, 1986, pp. 769.770 .

24. Tabakoff, W., "Erosion Study of High Temperature Metals Used in Turbomachinery," High Temperature Corrosion in Energy Systems, 1985, pp. 809-823.

25. Farmayan, W.F., S. Srinivasachar, L. Monroe, F. Ditaranto, J.D. Teare, and J.M. Beer, "NO$x$ and Carbon Emission Control in Coal-Water Slur ry Combustion," Sixth International Symposium on Cnal Siurry Combustion and Technology, Orlando, Florida, June 25-27, 1984, p. 165-184.

26. Clark, D.W., "Allison Low Emissions Combustor Technology Program," Proceedings of the First Annual Heat Engines Contractors Meeting, Morgantown, West Virginia, November 1984, p. 171-176.

27. Rosfjord, T.J., "Staged Combust in of CWM Fuel," ASME Paper 85-JPGC-GT-6, Presented at the Joint ASME/IEEE Power Generation Conference, Milwaukee, Wisconsin, October 20-24, 1985.

28. Dorchak, T.P., H.M. Ness, G.F. Weber, and V. Menze, " $\mathrm{SO}_{2}$ Removal Using Pressure Hydrated Lime," Thirteenth Bionnial Lignite Syuposiun: l'echnology and Utilization of Low-Rank Coal Proceedings, Vol. 1, Grand Forks, North Dakota, May 20-23, 1985, p. 229-241.

29. Boni, A.A., A.R. Garman, S.A. Johnson, and G.A. Simons, "Mineral Matter Deposition and Sorption of Fuel-Bound Contaminants," Proceedings of the Second Annual Heat Engine Contractors Meeting, Morgantown, West Virginia, May 1985, p. 124-148. 
30. Garman, A.R., Simons, G.A., Parker, T.E. and Johnson, S.A.; "Sorption of Fuel-Bound Contaminants for Coal and CWM-Fired Gas Turbine Systems", Proceedings of the Third Annual Heat Contractors Meeting, Morgantown, West Virginia, May 1986, p. 189-204.

31. Zauderer, B., Fleming, E. and Swift, B.; "Combustion and Fuel Bound Contaminant Control with a Staged Cyclone Contractor for Gas Turbines"; Proceedings of the Third Annual Heat Engines Contractor's Meeting, Morgantown, West Virginia, May 1986, p. 152-162.

32. McCarthy, J.M.; S.L. Chen, J.C. Kramlich, W.R. Seeker, and D.W. Pershing, "Reactivity of Atmospheric and Pressure Hydrated Sorbents for $\mathrm{SO}_{2}$ and Simultaneous $\mathrm{SO}_{2} / \mathrm{NO}_{\mathrm{x}}$ Control Technologies, Raleigh, North Carolina, June $2-6,1986$.

33. Bortz, S.J., V.P. Roman, R.J. Yang, P. Flament, and G.R. Offen, "Precalcination and its Effect on Sorbent Utilization during Upper Furnace Injection," EPA/EPRI Joint Symposium on Dry $\mathrm{SO}_{2}$ and Simulateous $\mathrm{SO}_{2} / \mathrm{NO}_{\mathrm{x}}$ Control Technologies, Raleigh, North Carolina, June 2-6, 1986.

34. Borgwardt, R.H. and K.R. Bruce, AIChE Journal, 32(2), p. $239,1986$.

35. Cole, J.A., J.C. Kramlich, W.R. Seeker, G.D. Silcox, G.H. Newton, D.J. Harrison, and D.W. Pershing, "Fundamental Studies of Sorbent Reactivity in Isothermal Reactors," EPA/EPRI Joint Symposium on Dry $\mathrm{SO}_{2}$ and Simultaneous $\mathrm{SO}_{2} / \mathrm{NO}_{\mathrm{x}}$ Control Technologies, Raleigh, North Carolina, June $2-6,1986$.

36. Lee, D.C. and C. Georgakis, Am. Inst. Chem. Eng. J., 27(3), p. 472, 1981.

37. Borgwardt, R.H. and K.R. Bruce, "EPA Study of Hydroxide Reactivity in a Differential Reactor," EPA/EPRI Joint Symposium on Dry $\mathrm{SO}_{2}$ and Simultaneous $\mathrm{SO}_{2} / \mathrm{NO} \times$ Control Technologies, Raleigh, North Carolina, June $2-6,1986$.

38. Stansel, J., J. Kuenzly, D. Sheppard, and S. Ubhayakar, "TRW's Slagging Combustor System Progress," Seventh International Coal and Lignite Utilization Exhibition and Conference, Houston, Texas, November 1984.

39. Borgwardt, R.H., K.R. Bruce, and J. Blake, "EPA Experimental Studies of the Mechanisms of Sulfur Capture by Limestone," First Joint Symposium on Dry $\mathrm{SO}_{2}$ and Simultaneous $\mathrm{SO}_{2} / \mathrm{NO}_{x}$ Control Technologies, San Diego, California, November 13-16, $198 \%$.

40. Borgwardt, R.H., N.F. Roach, and K.R. Bruce, "Surface Area of Calcium Oxide and Kinetics of Calcium Sulfide Formation," Environmental Progress, $3(2), p .129,1984$.

41. Kramlich, J.C., P.C. Malte, and W.L. Grosshandler, "The Reaction of FuelSulfur in Hydrocarbon Combustion," Eighteenth International Symposium on Combustion, The Combustion Institute, Pittsburgh, Pennsylvania, 1981 .

42. DeYoung, D., "Sulfur Solubility in Slags for Cyclone Coal Combustors," ACS Division of tuel Chemistry, 29(4), p. 117, 1984 . 
43. LaFond, J.F., T.R. Johnson, R. Payne, and J.A. McSorley, "Evaluation of Fundamental Phenomena Associated with $\mathrm{NO}_{\mathrm{x}}$ Control and Sulfur Capture in Slagging Precombustors," Thirteenth Energy Technology Conference, Washington, D.C., March 1986.

44. Rubow, L.N. et al., "Technical and Economic Evaluation of Ten High Temperature, High Pressure Particulate Cleanup Systems for Pressurized Fluidized Bed Combustion," DOE/MC/19196-1654, Morgantown, West Virginia, July 1984.

45. Case, G.D. et al., "Evaluation of Particulate Collection Devices Developed for Pressurized Fluidized-Bed Combustors as Applied to Coal Gasification Processes," DOE/MC/20035-1702, Morgantown, West Virginia, October 1984.

46. Rinard, G., D. Rugg, M. Durham, and J. Armstrong, "High Pres sure, High Temperature Electrostatic Precipitation Technology in the U.S.A.," Proceedings of the Second International Confercnce on Elcctrostatic Precipitation, Air Pollution Control Association, Pittsburgh, Penns y livania, 1985.

47. Wilson, K.B., "Granular Bed Filter Evaluation in a Pressurized Fluid Bed System," Proceedings of the Fifth Annual Contractors Meeting on Contaminant Control in Coal-Derived Gas. Streams, DOE/METC-85/6025, Morgantown, West Virginia, May 1985.

48. Reijnen, K. and J. Van Brakel, "Gas Cleaning at High Temperatures and .High Pressures: A Review," Powder Technology, 40, 81-111, 1980.

49. First, M.W., "High Temperature Gas Filtration Research Needs," $\mathrm{DOE} / \mathrm{FE} / 60365-\mathrm{Tl}$, Boston, Massachusetts, April 1984.

50. Faeser, R.J. and G. Reethof, "Development of Acoustic Agglomerator," Proc. 4th Annual Contractors Meeting on Containment Control in Hot CoalDerived Gas Streams. DOE/METC-85/3, December 1983.

51. Zauderer, B., C.H. Marsten, E. Fleming, K.M. Myles, T. Johnson, and E.B. Smyk, "Combustion and Fuel-Bound Contamination Control with a StagedCyclone Coal Combustor for Gas Turbines," Proceedings of the Second Annual Heat Engines Contractors Meeting, May 1985, p. 110-123.

52. Mann, M.D. et al., University of North Dakota Energy Research Center Quarterly Technical Progress Report, Apri1-June, 1986. 


\begin{tabular}{|c|c|c|}
\hline 1. Program/Projecl Identilication No. & $\begin{array}{l}\text { 2. Program:Project Title } \\
\text { Adyanced Combust ion Phenomenon }\end{array}$ & 3. Reporligo perigh $03 / 31 / 87$ \\
\hline $\begin{array}{l}\text { 4. Name and Address } \\
\text { University of }\end{array}$ & Energy Research & $\begin{array}{l}\text { 5. Programuproiect Starl Date } \\
04 / 01 / 86\end{array}$ \\
\hline
\end{tabular}
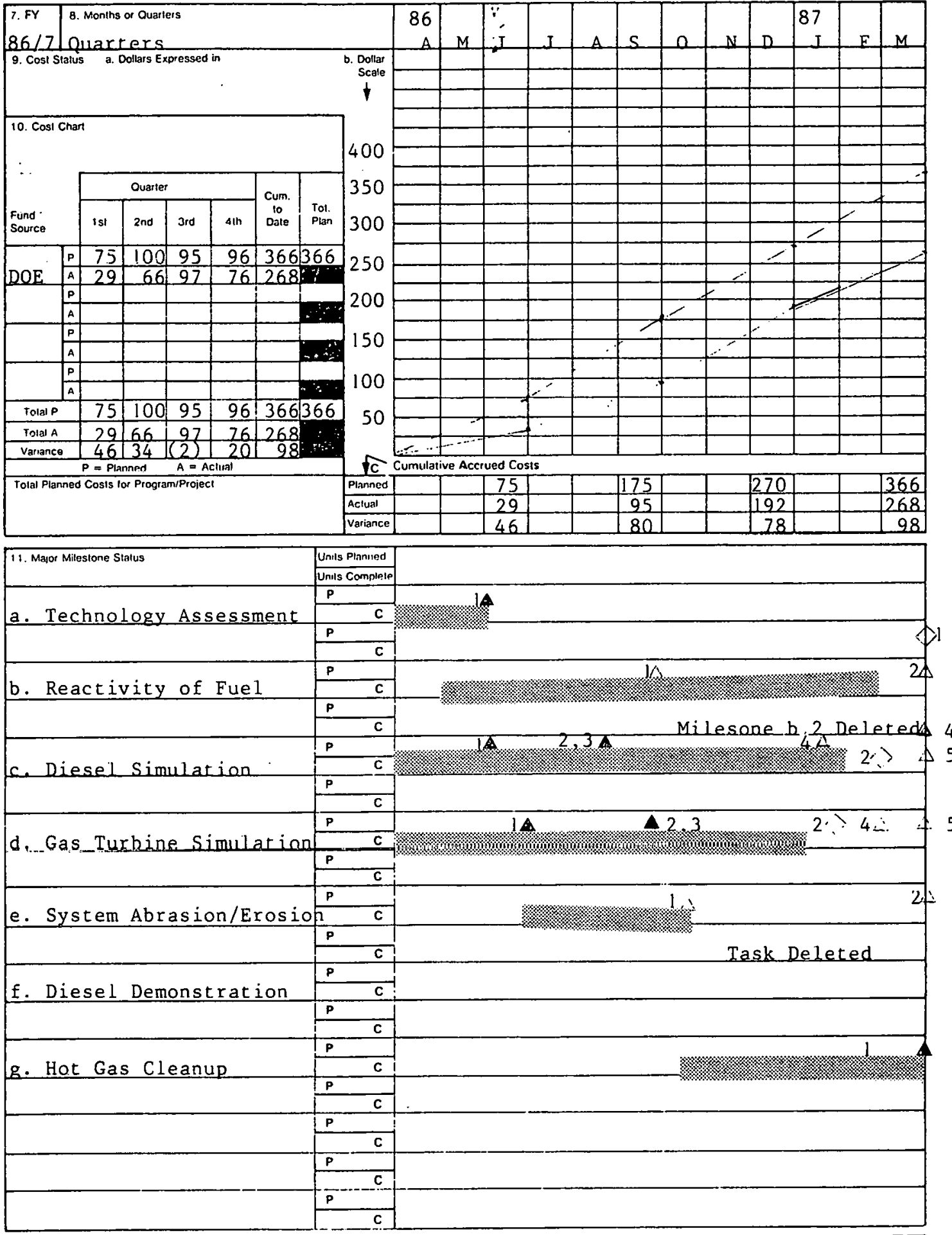

12. Remarks 


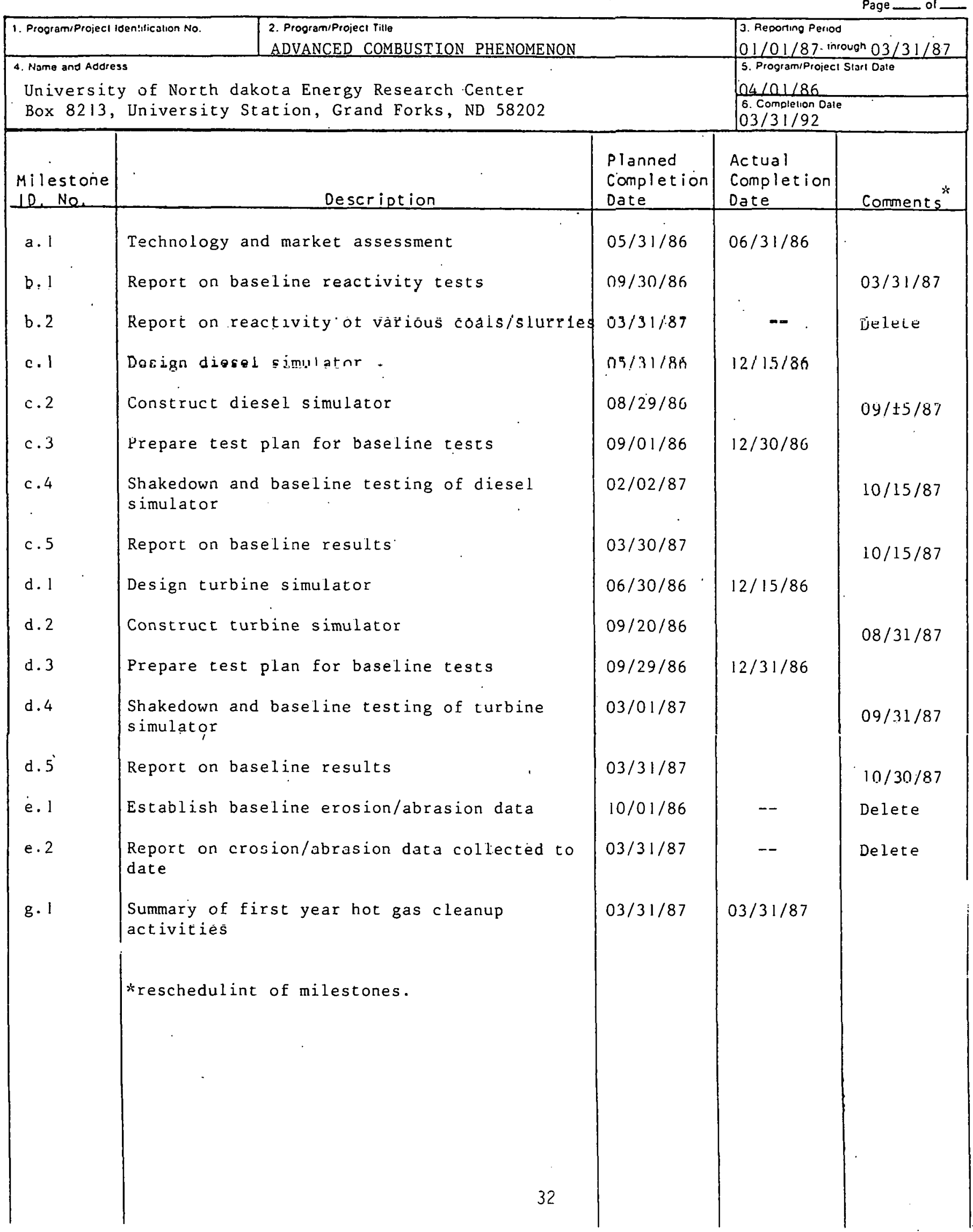




\title{
COMBUSTION INORGANIC TRANSFORMATIONS
}

\author{
Final Technical Report for the Period April 1, 1986 - March 31, 1987 \\ Including the Quarterly Technical Progress Report for the Period \\ January through March, 1987 \\ by \\ Steven A. Benson, Lewis Radonovich, \\ Edward N. Steadman, and Philip G. Sweeny \\ University of North Dakota Energy Research Center \\ P.0. Box 8213, University Station \\ Grand Forks, ND 58202 \\ Aprì 1987
}

Contracting Officer's Technical Representative: James Hickerson

Prepared for

United States Department of Energy Office of Fossil Energy

Morgantown Energy Technology Center

Morgantown, West Virginia

Under Cooperative Agreement No. DE-FC21-86MC 10637-T3 
THIS PAGE

\section{WAS INTENTIONALLY LEFT BLANK}


ABSTRACT

$\frac{\text { Page }}{1}$

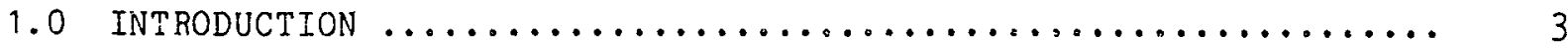

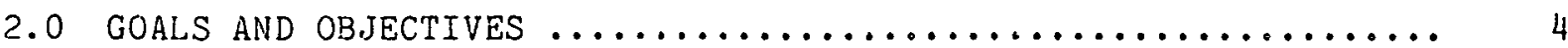

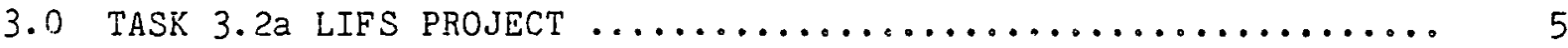

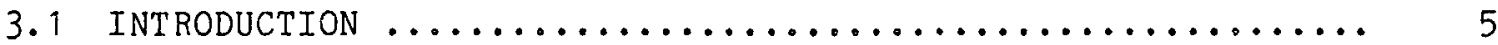

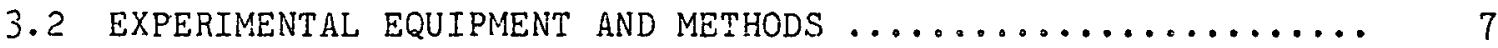

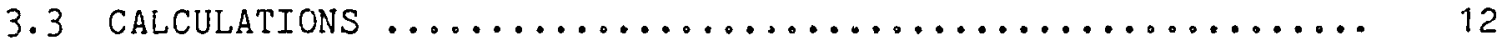

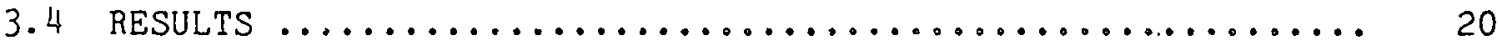

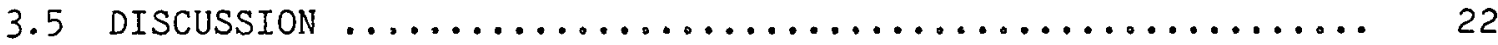

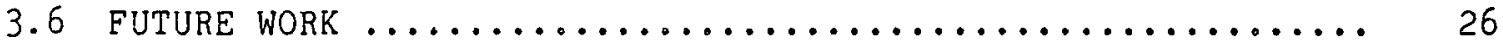

4.0 TASK 3.2 b DROP TUBE FURNACE PROJECT $\ldots \ldots \ldots \ldots \ldots \ldots \ldots \ldots \ldots \ldots$

4.1 INTRODUCTION $\ldots \ldots \ldots \ldots \ldots \ldots \ldots \ldots \ldots \ldots \ldots \ldots \ldots \ldots \ldots \ldots \ldots$

4.2 CONSTRUCTION AND TESTING OF DROP TUBE FURNACE $\ldots \ldots \ldots \ldots \ldots \ldots . \ldots \ldots$

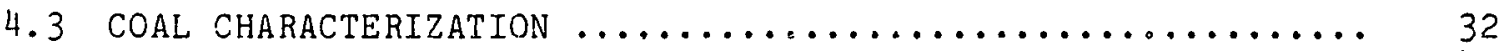

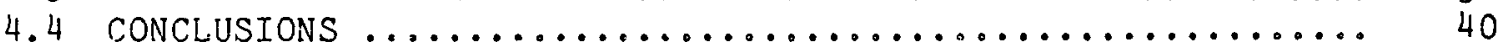

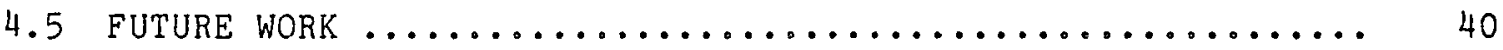

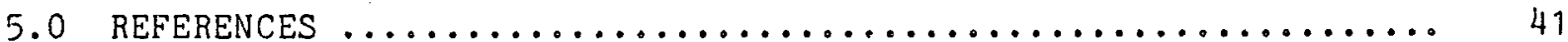


THIS PAGE

\section{WAS INTENTIONALLY LEFT BLANK}




\section{ABSTRACT}

\section{TASK 1 LIFS PROJECT}

The primary goal of Task 1 consisted of building a laser induced fluorescence spectrometer (LIFS) that is capable of measuring sodium atom fluorescence at appropriate concentrations and under conditions similar to those in coal burning flames. These conditions have been met and LIFS has been successfully used to measure the atomic sodium produced from $\mathrm{NaCl}$ solutions aspirated into methane-oxygen flame. In addition, preliminary measurements of sodium release from a North Dakota lignite have been made.

Both horizontal and vertical temperature profiles were measured in order to study the temperature at various positions in the flame. The effects of sheath gas were also studied. The presence of sheath gas was observed to decrease the temperature of the flame and to narrow the flame width. Horizontal and vertical fluorescence signal profiles were also measured in order to correlate flurescence signal with temperature and flame position.; These results indicate that the fluorescence signal is proportional to the temperature at a given position in the flame when the sheath gas flow is held constant. The effect of sheath gas, however, is to increase the fluorescence signal even though the temperature at that position is reduced.

Experiments were also carried out to determine if the UND laser had sufficient power to achieve sturaltion. This condition is highly desirable because at saturation the observed signal would be independent of pulse to pulse fluctuations in laser power. Our results indicate that the laser power is at least twice that necessary to achieve saturation for aspirated $\mathrm{NaCl}$ solutions.

A concentration curve was obtained for NaCl solutions under a set of conditions that were experimentally optimized. This curve remained linear over a concentration range of some three orders of magnitude, indicating that the technique is indeed quantitative. The detection limit was established as 9.8 parts per milizion sodium to water. Preliminary calculations indicate that the minimum amoint of coal containing 0.7 wt $\%$ sodium required to reach the specified detection limit is approximately $0.027 \mathrm{mg} / \mathrm{min}$. This delivery rate should easily be exceeded with the designed solid introduction device as it has been designed.

The source of sodium and the gas stream composition are expected to be very important when coal is combusted. The effects of these two parameters were tested by injecting homogeneous sodium solutions into the flame. The results of injecting several different sodium salt solutions revealed that the source of sodium had no effect on the fluoresence signal. This is consistent with the complete conversion of sodium to the atomic form in the analytical region of the flame.

A technique was developed to subtract the scatter and reflection from the fluorescence signal. This technique involved tuning the laser to a wavelength where sodium does not fluoresce and measuring the intensity due to scatter and reflection. The background measured at the alternative wavelength was

subtracted from the sodium fluorescence signal. 


\section{TASK 2 DROP-TUBE FURHACE PROJECT}

The drop-tube furnace project has been undertaken as a means of studying the inorganic transformation mechanisms of fly ash formation that occur during coal combustion. The drop-tube furnace is a laboratory-scale, laminar-flow, tube furnace which has the ability to simulate the conditions of commercial combustors without the high costs associated with pilot-scale combustion. In addition, furnace parameters including initial hot zone temperature, residence times, and gas cooling rates can be closely controlled.

A drop-tube furnace system has been construced. It consists of a series of electrically heated tube furnaces that are vertically oriented. The system is modular in design so that the residence times can easily be change by inserting and remaining furnaces. The temperature controllers for each heated zone are interfaced with a personal computer for complete automation of the heat-up and cool-down procedures. A preheat/coal injection assembly was designed and constructed. It is capable of preheating the secondary air up to $1000^{\circ} \mathrm{C}$ and injecting coal plus primary air into the furnace hot zone. Several coal feed systems were tested and a plunger type f'eed system appears to provide the best feed rates. The fly ash quenching and collection systems have been tested.

The coals for combustion testing have been characterized using chemical fractionation and computer-controlled scanning electron microscopy. 


\subsection{INTRODUCTION}

The problems caused by the inorganic constituents in coals can have significant technological impact. For example, inorganic constituents can, in some instances, cause severe operational problems in utility boilers $(1,2)$. The problems include: deposition on heat transfer surfaces; formation of fine particulates that are difficult to collect; and erosion and corrosion of boiler parts. Because of the importance of these problems there is voluminous literature on the subject. A precise and quantitative knowledge of the distribution of inorganic constituents and their chemical and physical transformations may provide insights leading to solutions to these problems.

The extent of these problems depends upon the abundance and distribution of inorganic constituents. The inorganic constituents in low-rank coals are distributed within the coal matrix as cations associated with organic acid groups and clays, organically coordinated species, and discrete mineral grains. The mineral grains in pulverized coal are associated as either inherent (within a coal article) or extraneous (not associated with coal). The characteristics of the fly ash formed during combustion are dependent upon the chemical and physical transformations of the inorganic material.

The physical transformations of the inorganic constituents during the combustion process include: (1) coalescence of individual mineral grains, (2) formation of cenospheres, and (3) evaporation and condensation of flame volatilized species. The factors that influence the behavior of the inorganic constituents include combustion conditions and the form of the inorganic constituents in the coal. In the past the composition of the coal ash produced under ASTM ashing conditions has been used to provide a crude guide as to the behavior of a specific coal during combustion. However, examination of the fly ash shows that many different types of particles are present, each having its own composition and probably its own melting behavior ( 3 ). Therefore, in order to understand and ultimately predict the behavior of the inorganic constituents during pulverized coal combustion fundamental knowledge of the mechanism of fly ash formation must be elucidated.

The emphasis of tnis project is to determine and measure some of the critical inorganic transformations that occur during combustion. There are several critical issues that need to be addressed in order to better understand the behavior of inorganic constituents during combustion. These include the following:

1. The abundance and distribution of inorganic constituents in pulverized coal must be accurately determined for low-rank coals. This will include a combination of the following techniques: A) chemical fractionation which involves selectively extracting inorganic elements based on their association in the coal, B) computer controlled scanning electron microscopy which will be used to quantify and size the mineral phases in the coal, and $C$ ) scanning transmission electron microscopy to examine the submicron mineral matter. In addition, coals will be altered by extracting and adding various cations. A synthetic coal needs to be formulated that contains a precisely sized mineral distribution. 
2. Sodium volatilization in the coal-fired flame followed by subsequent condensation in the convective pass is a major problem associated with the use of low-rank coals in utility boilers. The volatility of sodium needs to be determined as a function of the association of sodium in the coal and of combustion conditions.

3. The interaction of organically-bound cations and mineral phases during the combustion of a coal particle is not well understood. The interaction of these phases results in the formation of low-melting-point particles that can play a significant role in the formation of tenacious deposits in boilers. The interaction of these species needs to be determined as a function of combustion conditions, gas cooling rates and association inorganic constituents.

\subsection{GOALS AND OBJECTIVES}

The primary objective of the combustion inorganic transformation projont is the development of a unified picture of the physical and chemical mechanisms that take place in inorganic matter during coal combustion. Thus research goals respond to the need to understand both the characteristics of the inorganic constituents present in the coals, and their behavior under simulated combustion conditions. This project is divided into two tasks.

TASK 3.2a-- Sodium Release. This task involves studying the release of atomic sodium during combustion using laser-induced fluorescence spectrometry (LIFS). The objectives include: (1) building a LIFS spectrometer that is capable of detecting atomic sodium above $10 \mathrm{ppm}$ concentrations for solutions, (2) assessing the feasibility of this technique for detecting the release of sodium when solids are introduced directly into a flame, (3) using tinis spectrometer to study the release of atomic sodium during coal oombustion and (4) developing a detailed knowledge of how a variety of faotors including flame temperature/position, source of sodium and gas stream composjtion affect. the release of sodium under typical combustion conditions.

TASK 3.2b--Drop Tube Furnace. This task involves the study of fly ash formation during pulverized coal combustion using a drop tube type furnace that simulates the time-temperature profile of a utility-ocals furnace. The objectives include: (1) determine the sequence of inorganic transformations that occur during the char burn out for selected coals, (2) determine the size distribution of $f l y$ ash particles produced from size fractionated coal, and (3) determine the interaction of organically bound cations and minerals during the formation of fly ash.

Objectives for the first year:

Task 1. Sodium Release - LIFS Project

1. Asscmbly and optimization of the laser-induced fluorescence spectrometer (LIFS). 
2. Measurement of sodium-release from model compounds in aqueous solution with the LIFS system.

3. Preliminary measurements on sodium release from coal during combustion in a flame.

Task 2. Drop Tube Furnace

1. Construction of a drop-tube furnace system.

2. Characterize two low-rank coals to be combusted in the drop-tube furnace.

\subsection{TASK 3.2a - LIFS PROJECT}

\subsection{INTRODUCTION}

Many western low-rank coals contain significant quantities of alkali, primarily sodium, that is associated as salts of organic acid groups (4-5). Upon combustion these alkali constituents will readily volatilize in the flame and condense downstream in the combustion system. The condensed alkali components can cause serious operational problems in combustion systems such as convective pass fouling $(1,2)$. The flame volatilized alkali can condense on surfaces of entrained fly ash particles forming low-melting point surface layers which can aid in the sticking of ash particles on heat transfer surfaces $(6,7)$. These alkali containing phases can aid in forming a liquid that is responsible for the development of deposit strength due to viscous flow sintering and for the capture of impacting fly ash particles (8). In addition, the flame volatilized alkali can condense homogeneously to form very small particles that can be very difficult to collect. These small particles have also been found on the inner layers of deposits $(9,10,11)$.

Because organic alkalis (carboxylates) are relatively volatile, it is generally expected that these alkali will vaporize in coal-fired combustors. Laboratory experiments have demonstrated that vaporization occurs in an oxygen environment (12) and several studies on their volatilization have been carried out. Stewart et al. (13) have recently reported that vaporization is highly dependent upon the chemical reactions of the alkali with the other components of the gas stream. For example, they report that under an atmosphere rich in carbon dioxide and sulfur dioxide at temperatures of $700-900^{\circ} \mathrm{C}$ the alkali carboxylates do not vaporized because only carbon monoxide and solid alkali carbonate are produced. Many of the past studies have been concerned with the analysis of the reactants and products. This does not provide adequate information on the release of alkali during combustion. What is needed is a probe that would perform in situ measurement of the concentration of shortlived atomic alkali. 
Laser irduced fluorescence spectroscopy (LIFS) is well suited for probing various locations of flames to examine alkali release. The high powers and narrow bandwidths available from modern lasers allow their use as excitation sources in analytical techniques that have very low detection limits and very high selectivities for particular analytes. The fluorescent emission of sodium atoms excited by lasers has been studied over the past decade including the detection of sodium in flames. As well as establishing the range and sensitivity of the technique, these studies have also probed the nature of the kinetic and optical processes taking place. The usual experimental arrangement includes a hydrogen/oxygen or hydrocarbon/oxygen flame with inert gas diluent, and aqueous sodium solutions aspirated into the flame, as for classical atomic absorption spectroscopy. The most common excitation source is a pulsed or $\mathrm{c.w}$. dye laser operating at the wavelength of the sodium $D$ line. A detection limit of less than 10 sodium atoms/mL in a flame at one atmosphere pressure has been achieved using saturated optioal nonresonant emission spectroscopy for atomic detection (14). This corresponds to ahnut. one part in $10^{14}$ of the flame species. Nonresonant operation means that one excites the $D_{1}$ line of the sodium $(589.6 \mathrm{~nm})$ and detects emissions at the $D_{2}$ line ( $589.0 \mathrm{~mm}$ ) ul the reverse. Ihis technique is feasible because the two excited states responsible for the emissions $\left({ }^{2} \mathrm{P}_{1 / 2}\right.$ and $\left.{ }^{2} \mathrm{P}_{3 / 2}\right)$ are equilibrated by collisional energy transfer under the relatively high density conditions present in the flame.

This nonresonant detection is very useful because a large amount of scattered light is generated by solids and unvolatilized aerosols (15). However, resonant atomic fluorescence can be and has been useful. In this case the excitation and emission are both at the same wavelength. With resonant fluorescence techniques, a low detection limit can be achieved by a reduction of the scattered light (14). The principal way to accomplish this is by polarizing the excitation laser in the plane parallel to the observation direction (horizontal polarization). This polarized light is scattered much less efficiently by the flame than vertically polarized excitiation (16). By placing another horizontal polarizer in the output beam, the scattered light is rejected, and only fluorescence is passed. The use of polarization techniques in this way reduces the amount of emitted light available for detection by approximately $50 \%$ and reduces the interfering scattered light to a much larger extent. Both Rayleigh scattering (from ambient molecules) and Mie scattering (from nonvolatilized aerosols and other particles) are reduced by this strategem $(17,18)$.

There are a number of advantages to operating under saturated conditions, that is, where the maximum number of atoms is excited (14). One advantage of saturated operation is that the signal level is relatively insensitive to fluctuations in the power of the exciting laser. In addition, the rate of atomic emission from the system is at a maximum and is not noticeable affected by normal quenchers present in the flame. Operation at saturated conditions also means that the range of linearity of the technique is extended and that the laser beam is only attenuated minimally as it passes through the sample. 
It is apparent that there is a significant need to develop advanced diagnostic methods to probe various locations in the flame as a means of measuring, in situ, the release of alkali during low-rank coal combustion. Developing detailed knowledge of how different forms of sodium are released under various conditions should help in elucidating how to control the release. The results would then be directly applicable to the development of techniques to reduce fouling and allow operation of efficient and clean coalfired combustors.

\subsection{EXPERIMENTAL EQUIPMENT AND METHODS}

The configuration of the laser induced fluorescence spectrometer (LIFS) is shown in Figure 1. The configuration of the system was modified based on experimental findings during the past year and Figure 1 represents the latest modification. The outputs from the photo multiplier tubes (PMTS) and the photodiode are relayed to a dual channel boxcar averager and subsequently to an IBM PC/XT. The monchromator was rotated $90^{\circ}$ about the optical axis so the slit height is aligned horizontally and the slit width opens vertically. The final optical layout is shown in Figure 2 .

The burner head which was designed and used in the solution studies is shown in Figure 3. This burner is slightly different from that originally planned (19). In the new design which is similar to that used by Daily and Chan (16), the sheath gas is passed through 0.031 inches diameter holes drilled into the base instead of through capillary tubes. The redesigned burner head is mounted on a stainless steel Perkin Elmer burner body. The burner head and body were used for the preliminary coal combustion study as well as the solution experiments.

A spouting bed feeder shown in Figure 4 was selected to introduce coal into the oxidant gas stream. This technique was chosen over the initially diagrammed rotating drum design (20) due to the readily available technology for constructing the spouting bed feeder; this is the same type of feeder originally used in the drop tube furnace project. The coal selected for the initial tests was a Beula' lignite from North Dakota. A sized fraction between 200 and 325 mesh was dried at $50^{\circ} \mathrm{C}$ and 1 tor and added to the feeder. The moisture free elemental $\mathrm{Na}$ content of this coal is $0.74 \mathrm{wt} \%$.

Flame temperatures were measured with a Pt/Pt-10\% Rh thermocouple. The temperatures reported are those read directly from the thermocouple; no adjustments for phenomena such as radiative heat loss from the thermocouple were incorporated.

The LIFS was used to measure the sodium atom densities produced from the aspiration of solutions and solids into a methane/argon/oxygen flame. This LIFS has been previously described (20). The following conditions were used in the present study. The front slit height of the monchromator was $1 \mathrm{~mm}$ and the back slit height was $12 \mathrm{~mm}$. The slit widths were varied between 25 and 800 $4 \mathrm{~m}$ producing bandpasses between 0.4 and $4.2 \mathrm{~nm}$. Usually $200 \mu \mathrm{m}$ slit widths were chosen producing a bandpass of $1.2 \mathrm{~nm}$. The diameter of the focused laser 


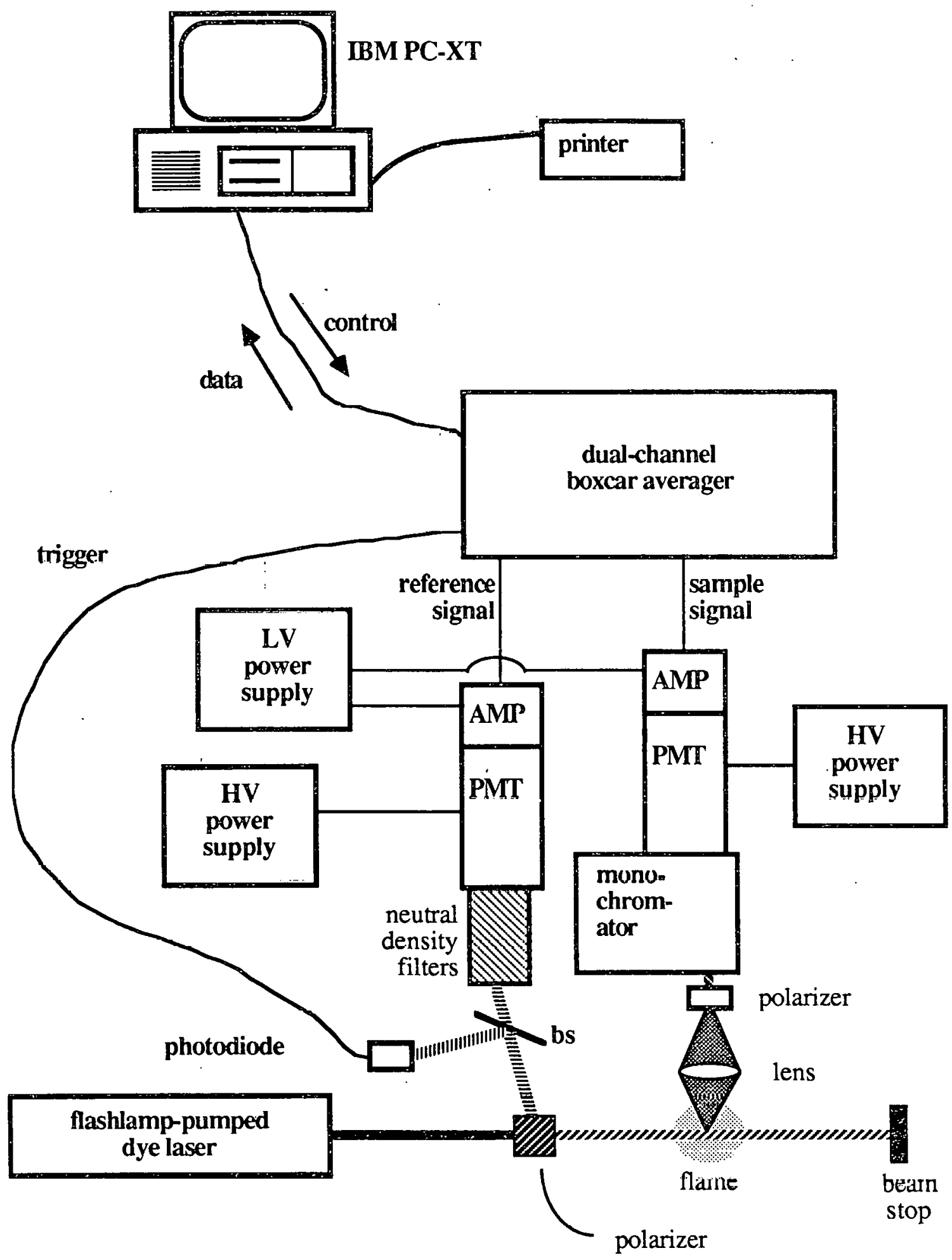

Figure 1. Sodium Analysis System.

Heavy line is optical path, light lines are electrical connections.

$\mathrm{PMT}=$ photomultiplier, AMP = amplifier/socket assembly, bs = beamsplitter. 


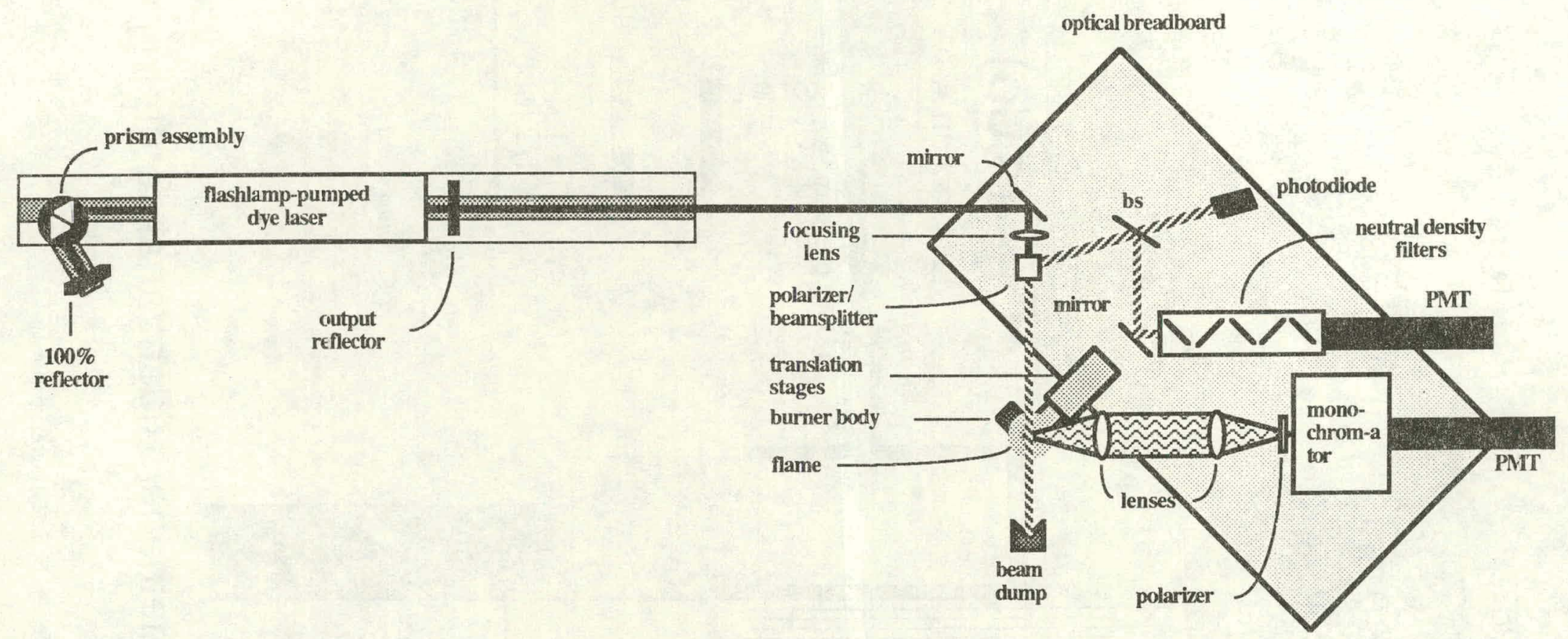

Figure 2. The laser-induced fluorescence spectrometer (LIFS) optical layout. Heavy line is optical path. PMT = Photomultiplier tube in amplifier/socket assembly. BS = Beamsplitter. 


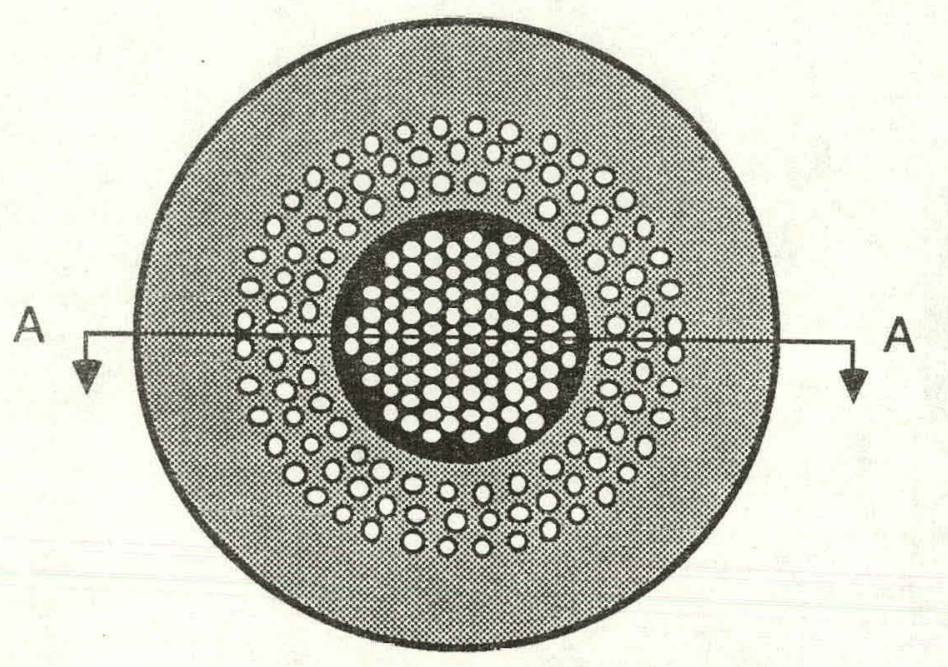

\section{(top)}

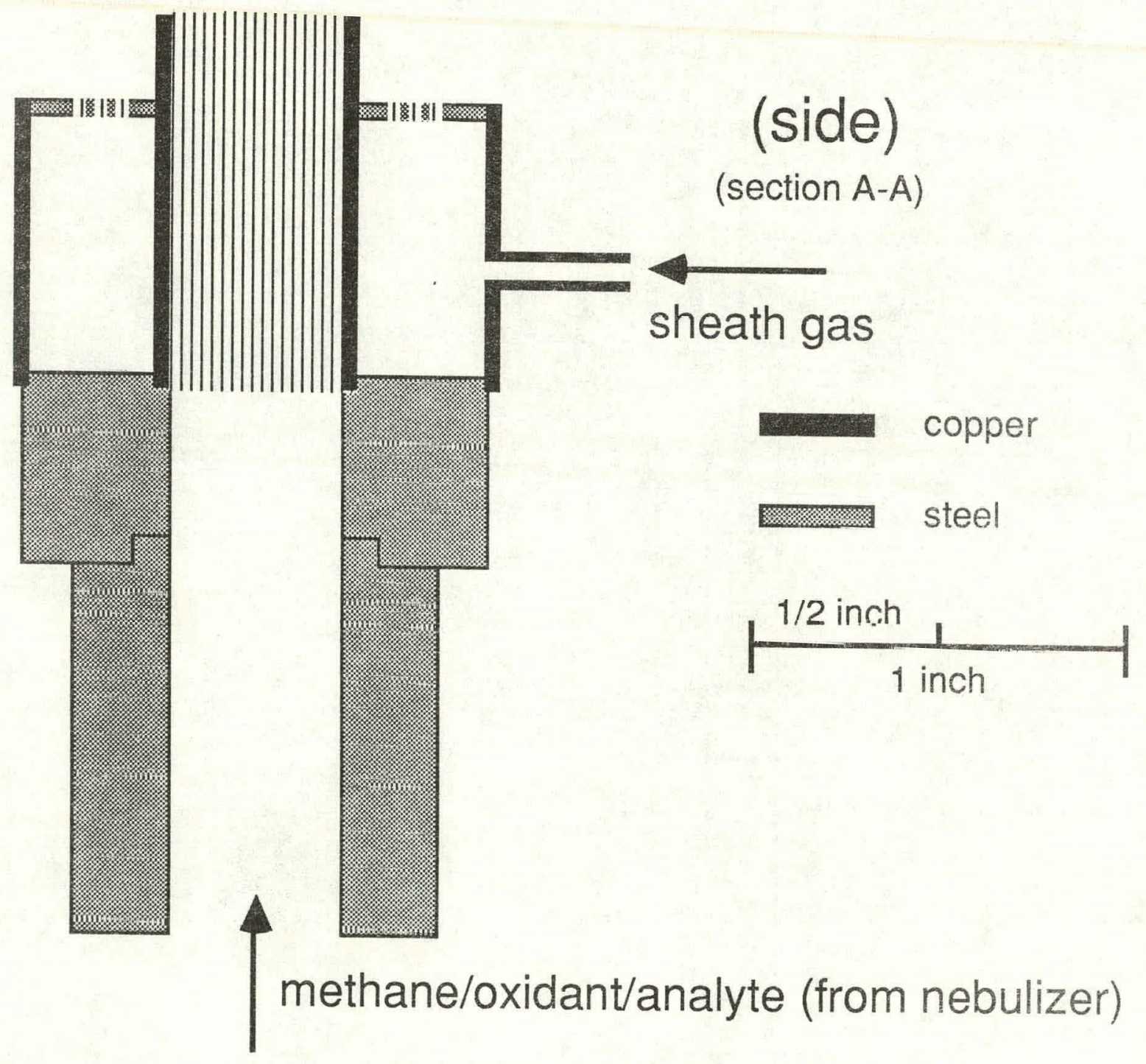

Figure 3. Solution burner design. 


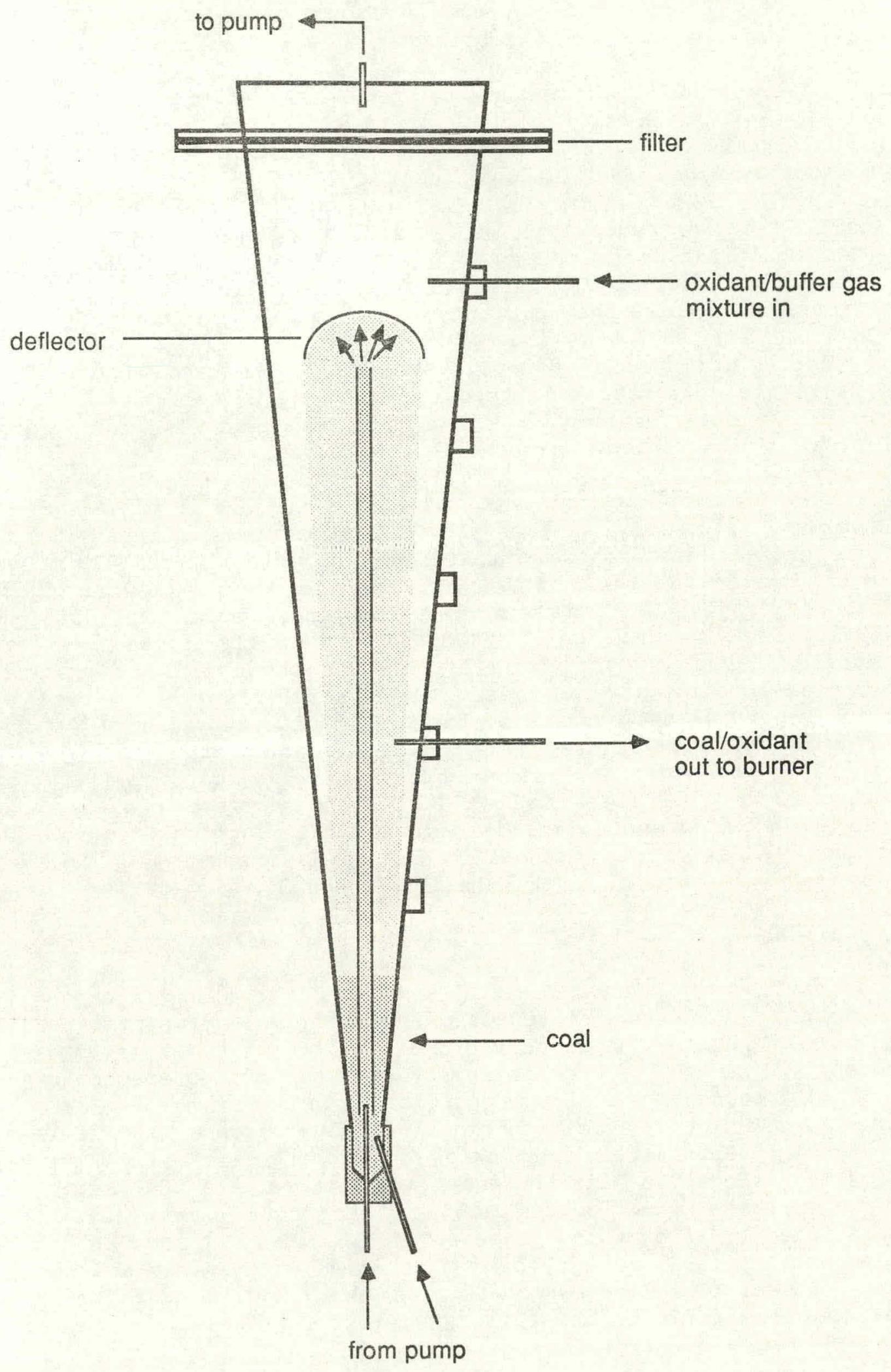

Figure 1. Spoutiug bed feeder. 
beam was approximately $2 \mathrm{~nm}$. Thus the sample volume varied from $0.05 \mathrm{~mm}^{3}$ to $1.6 \mathrm{~mm}^{3}$ as dictated by the slit width settings.

The flow rates of the gases used to generate the flame were those previously listed as flame condition 非 1 (21): methane $2.9 \mathrm{~L} / \mathrm{min}$, oxygen 3.2 $\mathrm{L} / \mathrm{min}$, argon $3.2 \mathrm{~L} / \mathrm{min}$ and argon sheath gas $3.9 \mathrm{~L} / \mathrm{min}$. The Perkin Elmer nebulizer was used to introduce solutions into the flame at a rate of $0.0034 \pm$ $0.0001 \mathrm{~mL} / \mathrm{sec}(0.012 \mathrm{~mL} / \mathrm{sec}$ at a $28 \%$ efficiency). The spouting bed coal feeder (1) was used to introduce coal into the flame at a rate of $38.6 \pm 2.6$ $\mathrm{mg} / \mathrm{min}$. Slight modifications were made to the burner body to improve the mechanism of solids introduction. These modifications, depicted in Figure 5, were made in order to minimize the settling of solids in the burner body.

The coal selected for initial solids tests was Beulah lignite from North Dakota. The proximate, ultimate and mineral matter analyses of this coal are shown in Table 1. A sized fraction between 200 and 325 mesh was dried at $50^{\circ} \mathrm{C}$ and 1 torr for $2 h$. This fraction was used in all studies.

The horizontal Clame posisions reported are distinces from the flames center of symmetry. Positive values indicate positions closest to the detector. The vertical distances are distances above the burner head. All data points reported in Figures 6 through 8 are the average values from 5 individual data points with the standard deviations indicated. Two additional methods of evaluating the data were attempted due to the tendency of the solids introduction device to produce pulsations in the coal delivery rate. Method. 1 consisted of taking seven data points, excluding the highest and lowest value and reporting the average of the five remaining values. Method 2 consisted of taking ten data points, averaging them, calculating the standard deviation, excluding those original points outside the standard deviation and averaging the six to nine remaining values to obtain the reported data point. The data refinement method used to obtain the reported figures were: Figure 9 (method 2), k'igure 10 (method 2), Figure 11 (methnd 1), Figure 12 (method 1), Figure 13 (method 2) and Figure 14 (mothod 2).

\subsection{CALCULATIONS}

One of the benefits of using LIFS as an analytical tool is the capability of correlating the fluorescence intensities to the atom densities in the sample volume. This calculation is possible due to the high intensity of the excitation source. This high source intensity produces a fluorescence signal independent of the source intensity a condition known as saturation. At saturation the calculation of atom densities from fluorescence intensities is possible due to the elimination of unknown quenching constants from the calculation $(19,17)$. Equation 1 is the equation which results when saturation is achieved and a three level system such as sodium is considered. This equation was modified to allow calculation of the atom density from the sum of the intensities of the 589.0 and $589.6 \mathrm{~nm}$ fluorescence lines rather than the individual intensities. The Einstein coefficient for spontaneous emission was assumed to be the same for both the $2 \mathrm{P}_{1 / 2}$ and $2 \mathrm{Y}_{3 / 2}$ energy levels (22). The results in Equation 2 were used to calculate atom densities reported herein. 

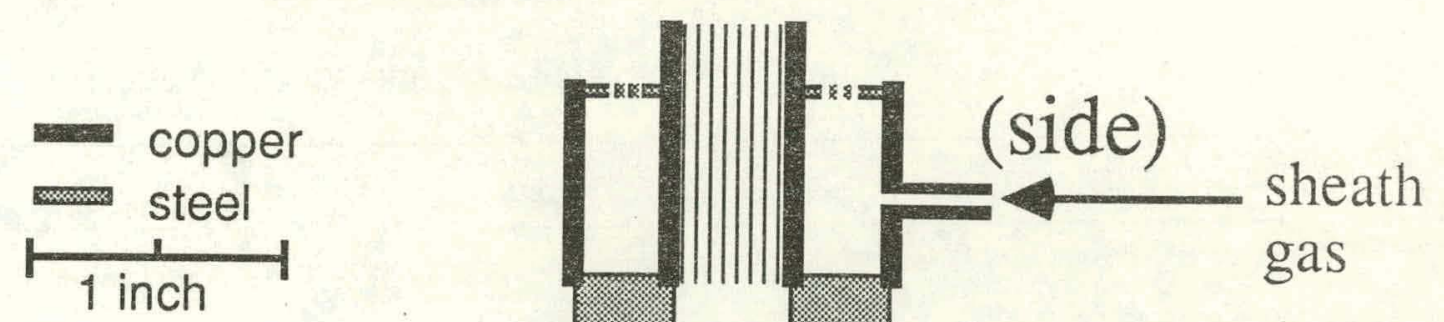

methane/oxidant

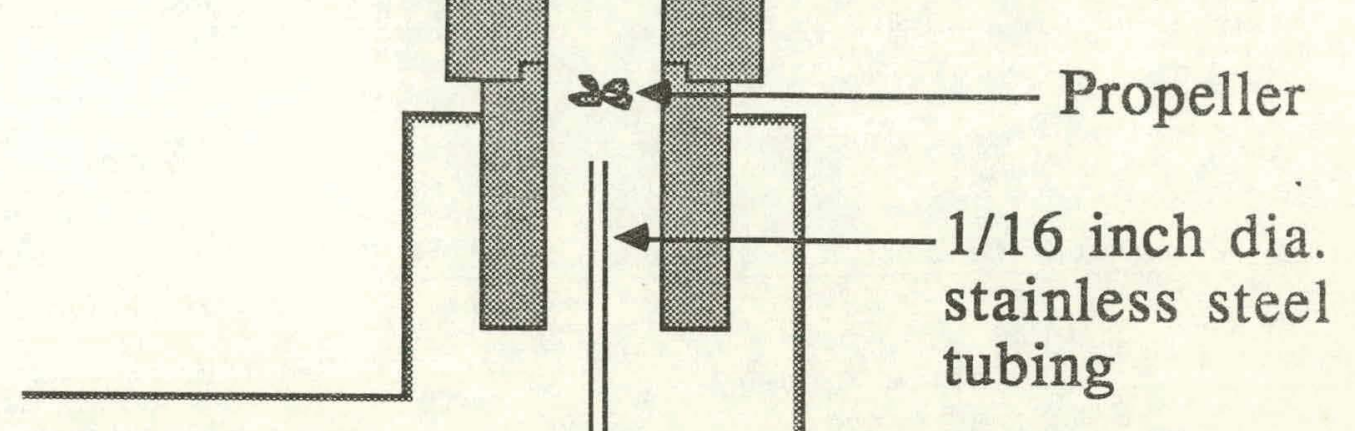

from spouting hed coal feeder

Burner Body

Figure 5. Modified burner body for solids introduction. 
TABLE 1

ANALYSIS OF BEULAH HIGH SODIUM LIGNITE

Ultimate Analysis (wt \% moisture free)

$\begin{array}{lc}\mathrm{C} & 62.8 \\ \mathrm{H} & 3.9 \\ \mathrm{~N} & 1.5 \\ \mathrm{~S} & 1.7 \\ \mathrm{O} & 16.8 \\ \text { Ash } & 13.3\end{array}$

Proximate Analysis (wt \% as received)

$\mathrm{H}_{2} \mathrm{O}$

Volatile Matter

Fixed Carbon

Ash
28.3

38.3

46.5

12.7
Ash Analysis (wt \% ASTM)

$\begin{array}{cc}\mathrm{SiO}_{2} & 20.4 \\ \mathrm{Al}_{2} \mathrm{O}_{3} & 12.6 \\ \mathrm{Fe}_{2} \mathrm{O}_{3} & 10.8 \\ \mathrm{TiO}_{2} & 1.2 \\ \mathrm{P}_{2} \mathrm{O}_{5} & 0.9 \\ \mathrm{CaO} & 18.9 \\ \mathrm{MgO} & 5.9 \\ \mathrm{Na}_{2} \mathrm{O} & 6.3 \\ \mathrm{~K}_{2} \mathrm{O} & 0.0 \\ \mathrm{SO}_{3} & 2.8 \\ \mathrm{O}_{3} & \end{array}$

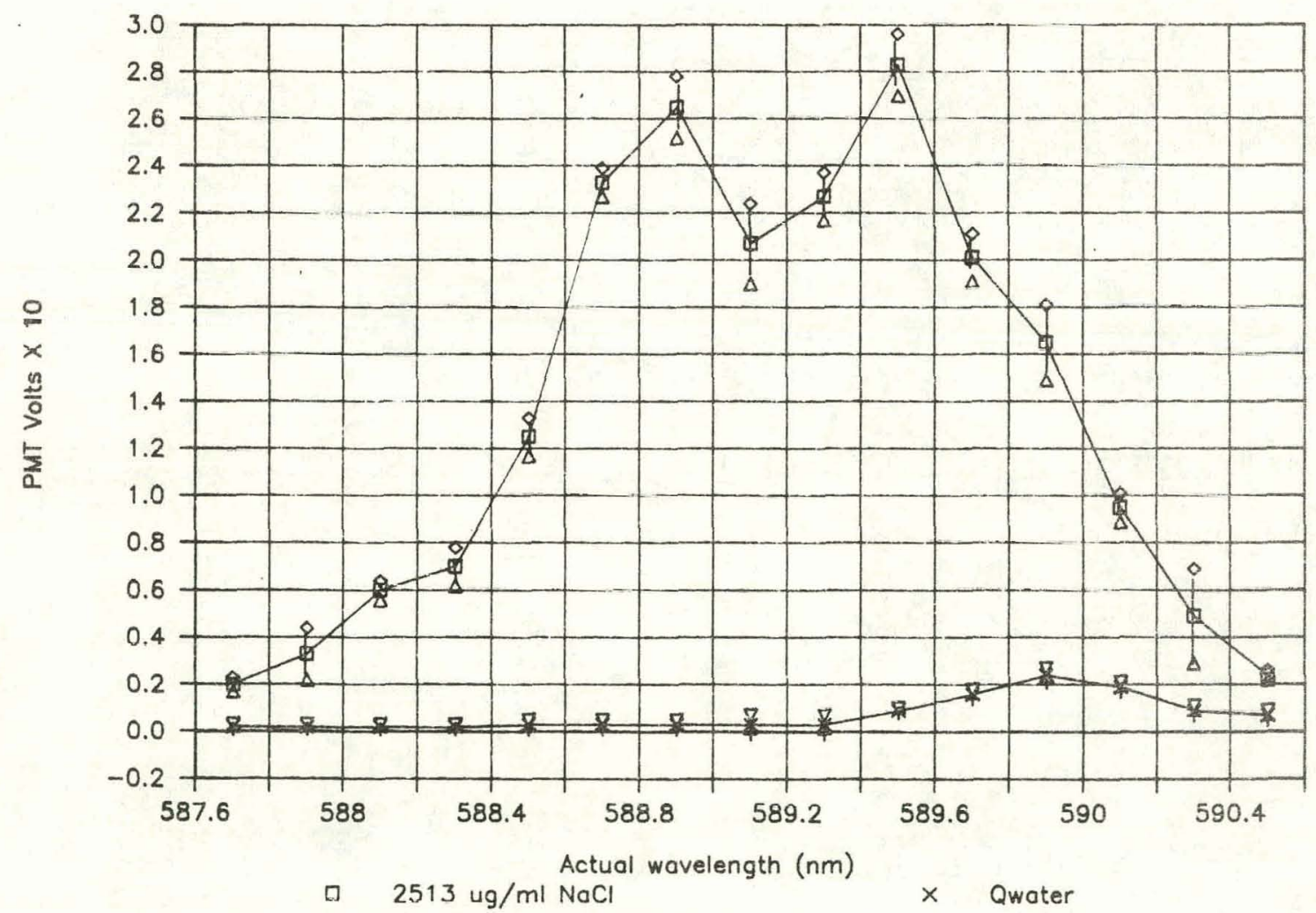

Figure 6. Nonresonant study using a $\mathrm{NaCl}$ solution. 


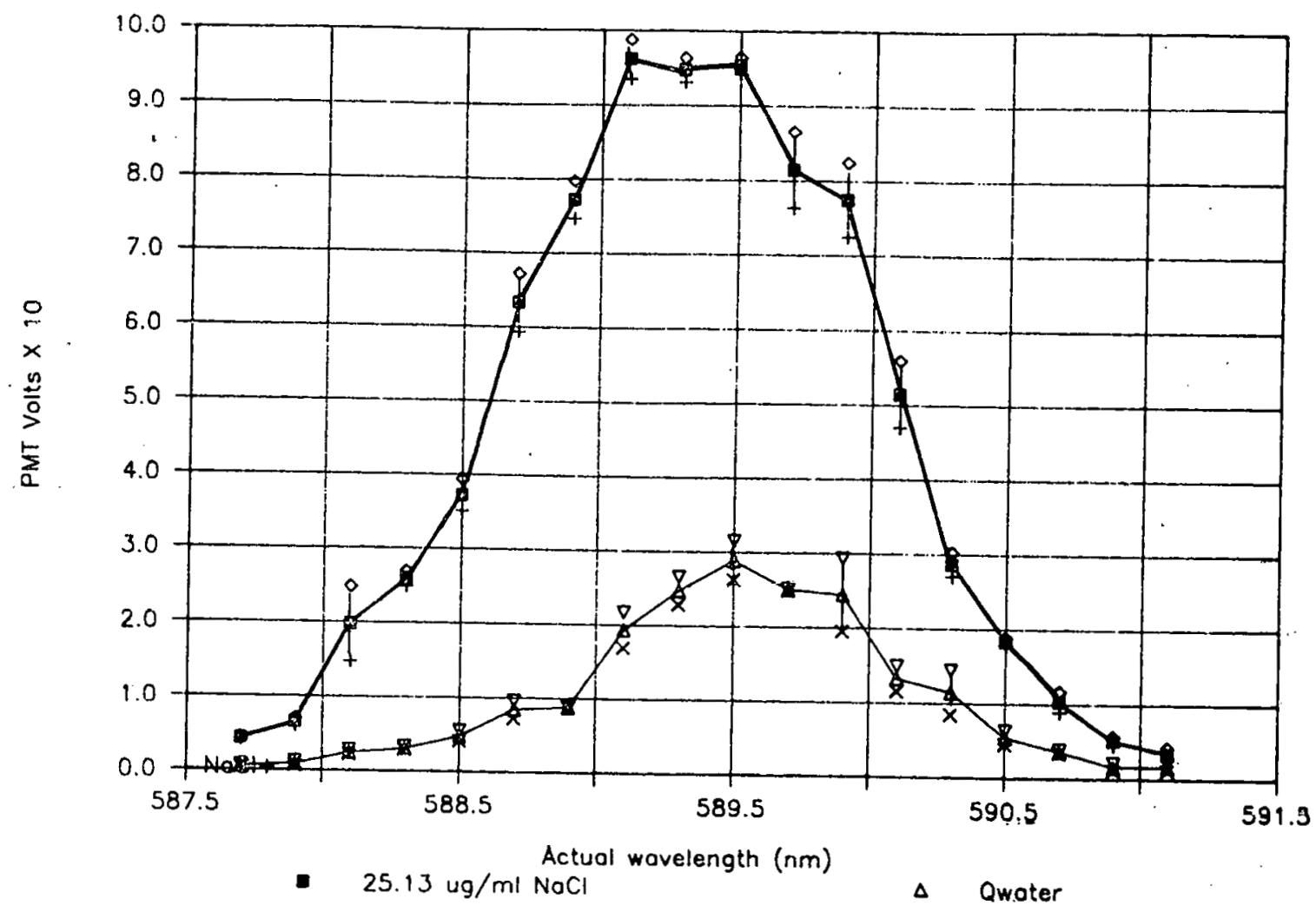

Figure 7. A wavelength proflle of a dilute NaCl solution and deionized water.

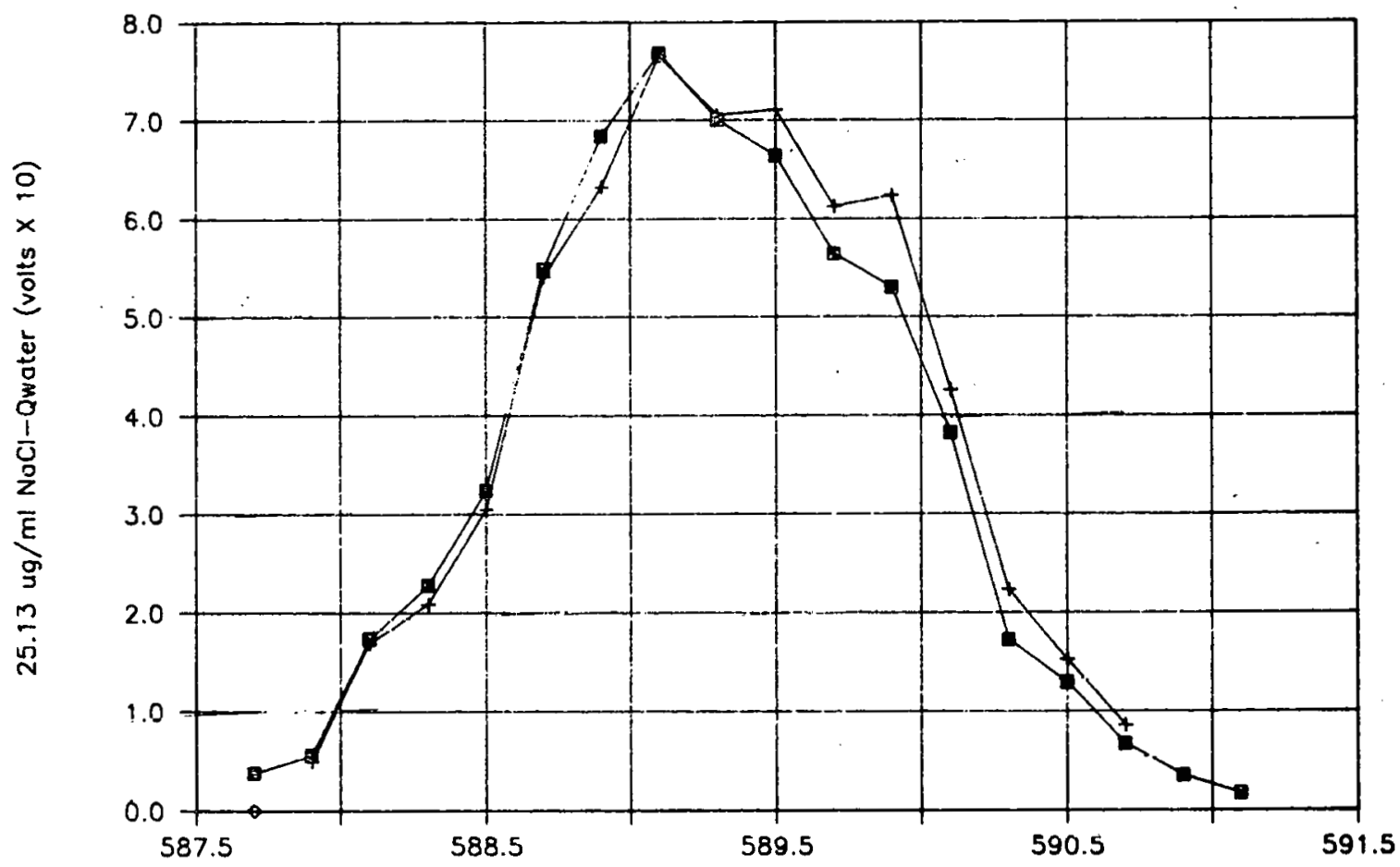

- Bockground $589.5 \mathrm{~nm}$

Actual wovelength of $\mathrm{NaCl}$ meosurement

$+\quad$ Bockground $586.7 \mathrm{~nm}$

Figure 8. A comparison of the results produced by using the background measured at $589.5 \mathrm{~nm}$ and $586.7 \mathrm{~nm}$. 


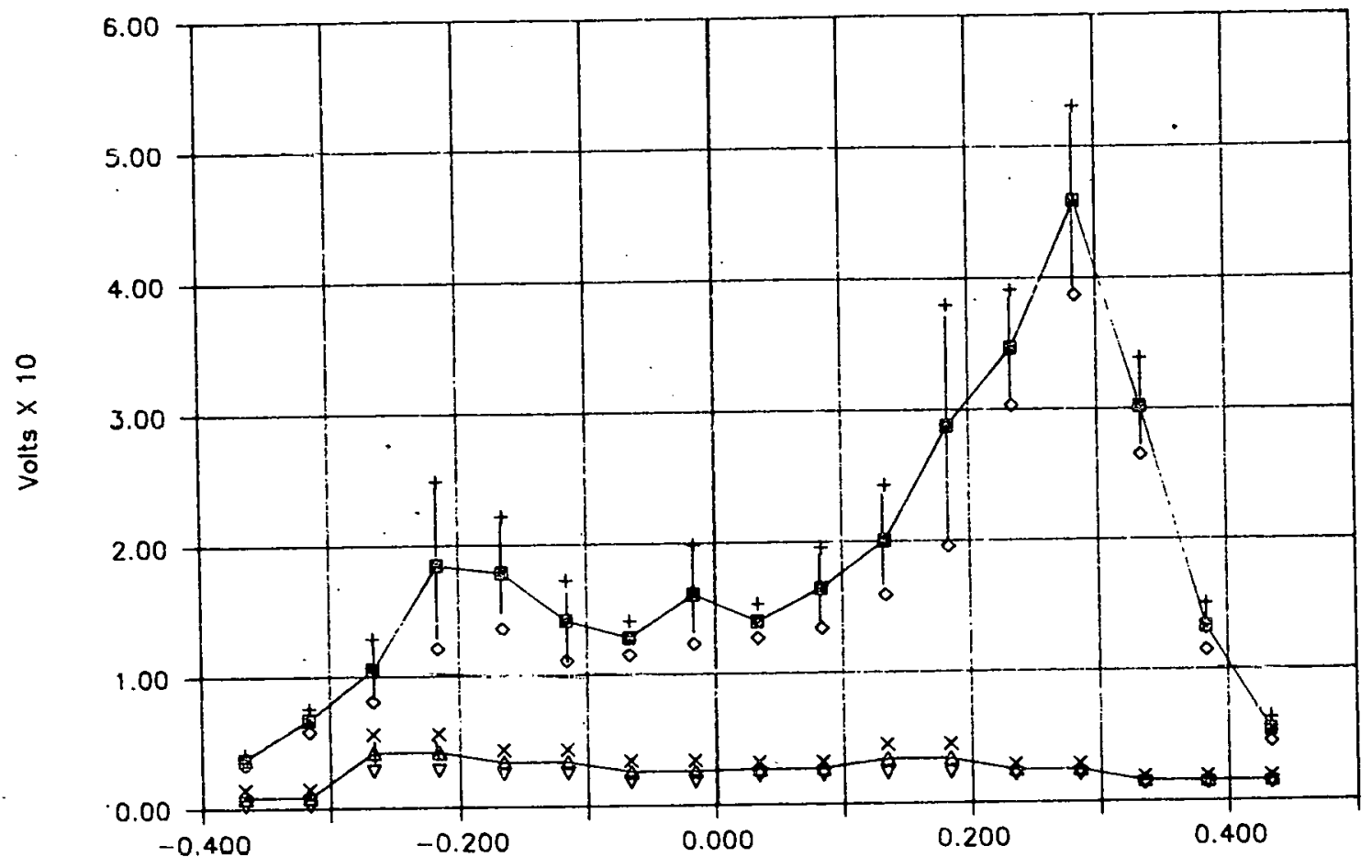

Distance from symmetry center (in.)

* Loser $5891 \mathrm{~nm} \quad \Delta \quad$ Loser $586.7 \mathrm{~nm}$

Figure 9. A horizontal profile of Beulah lignite taken at 0.415 in above the flame.

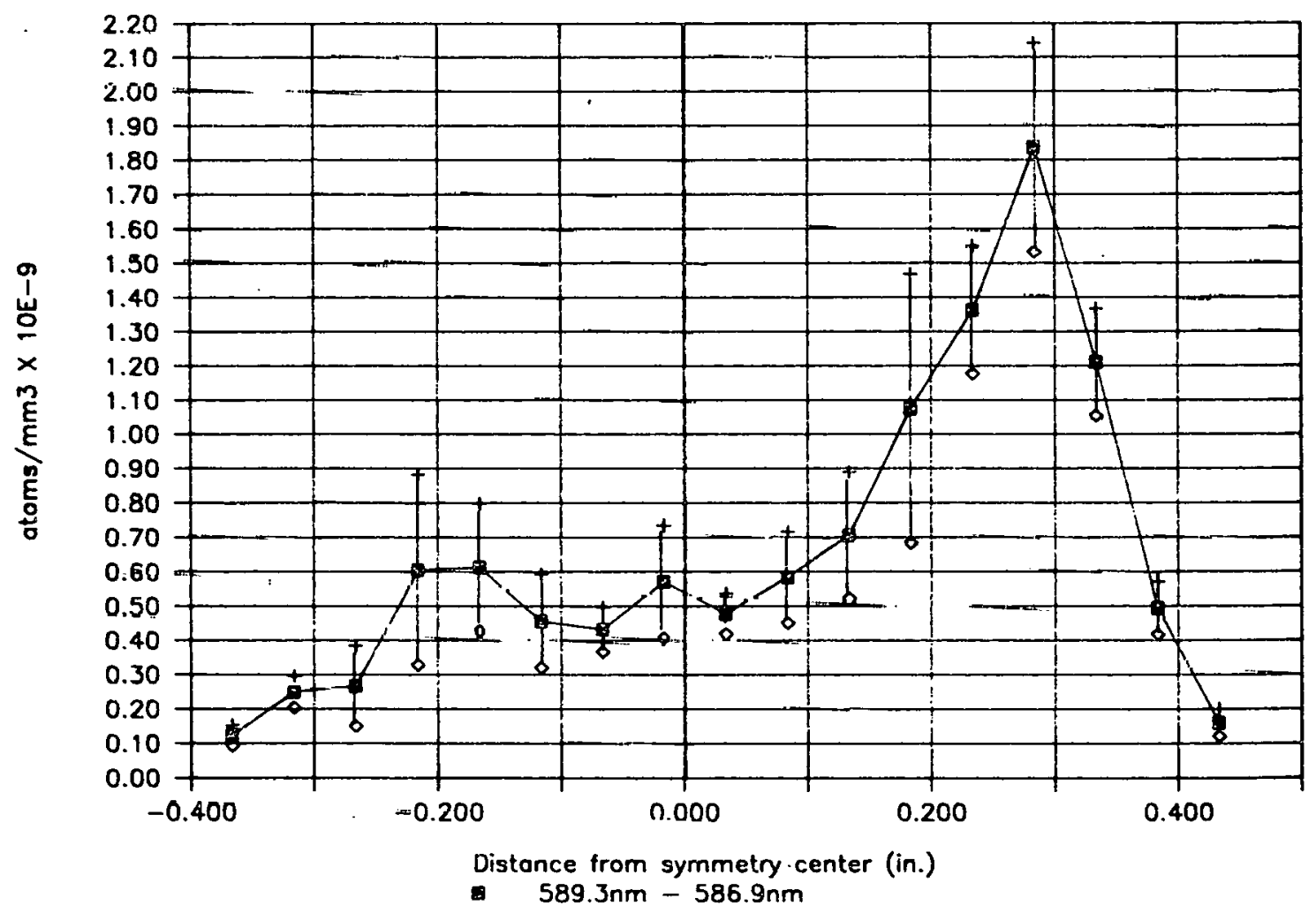

Figure 10. A horizontal profile of the sodium atom density produced from Beulah lignite taken at 0.145 in above the flame. 


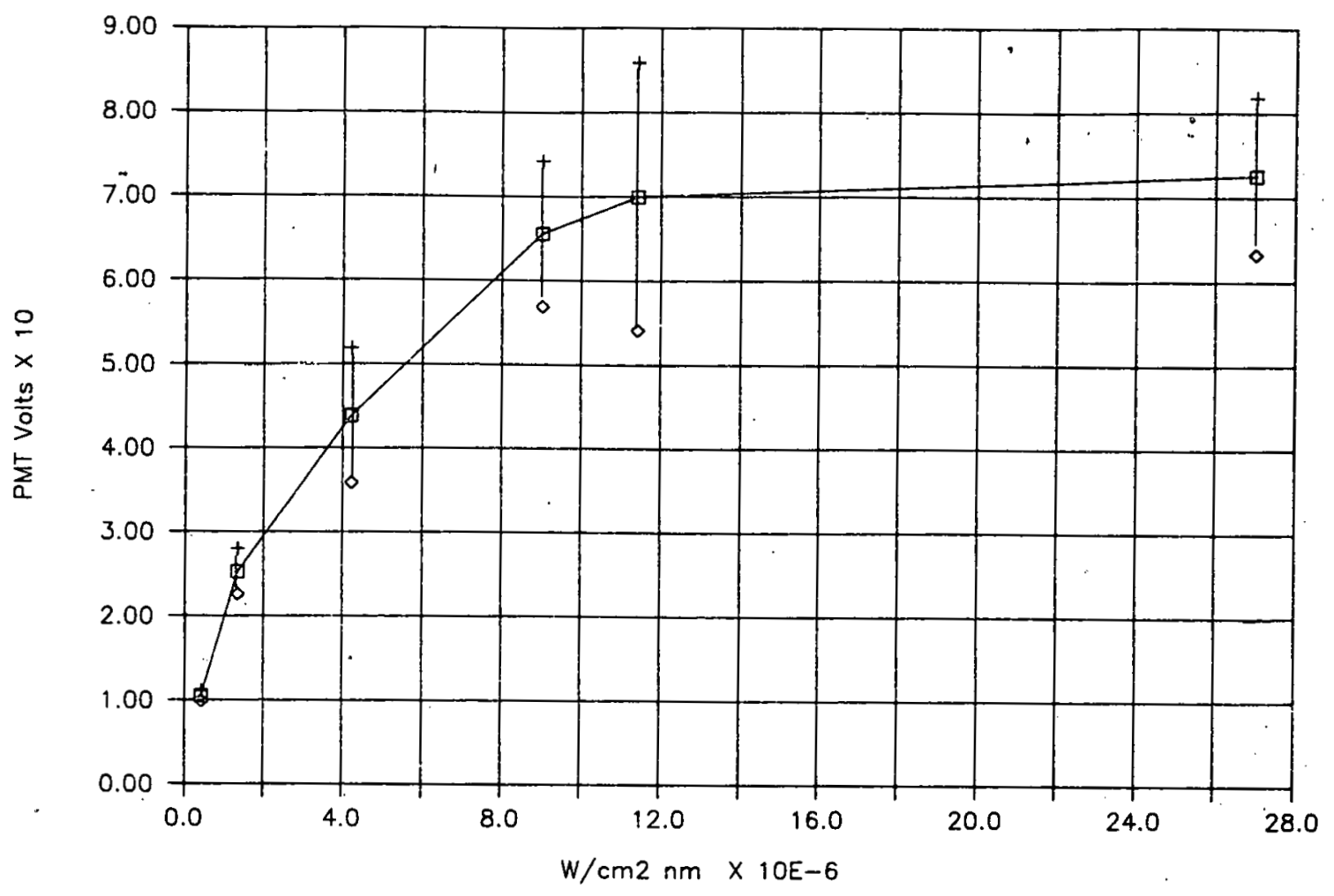

Figure 11. The effect of laser intensity on fluorescence.

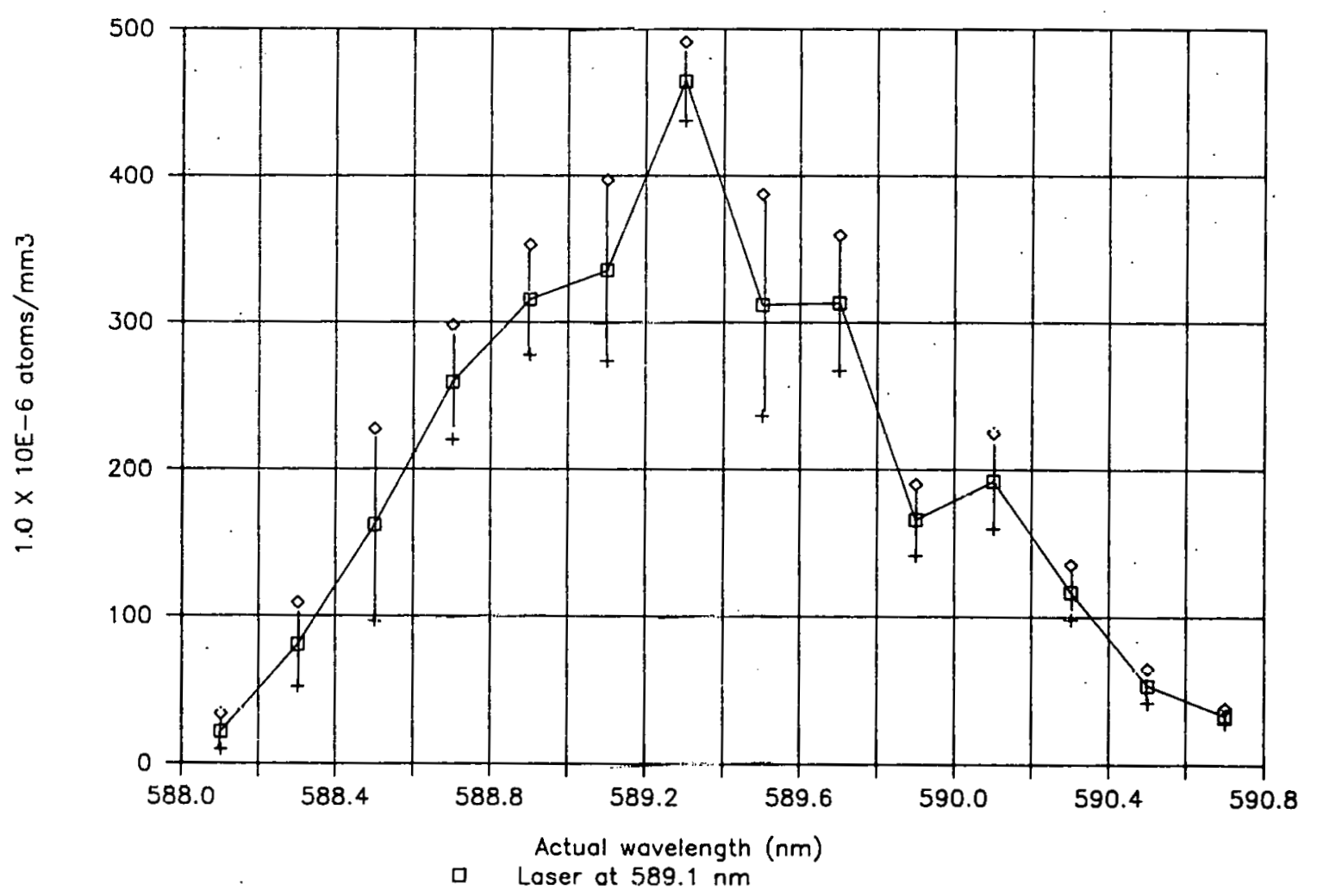

Figure 12. Fluorescence intensity as a function of wavclength. 


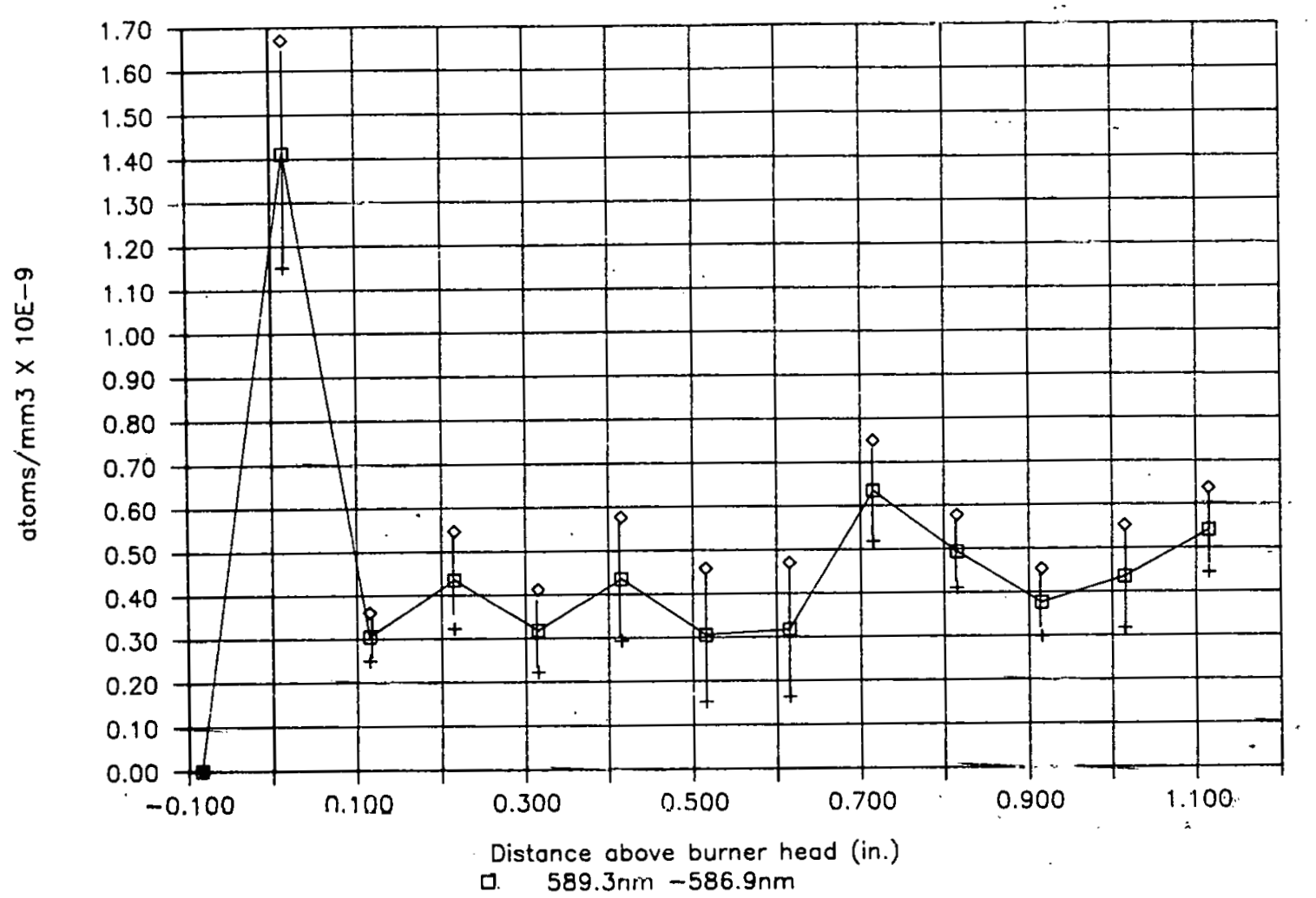

Figure 13. A vertical profile of the sodium atom density at the flame center.

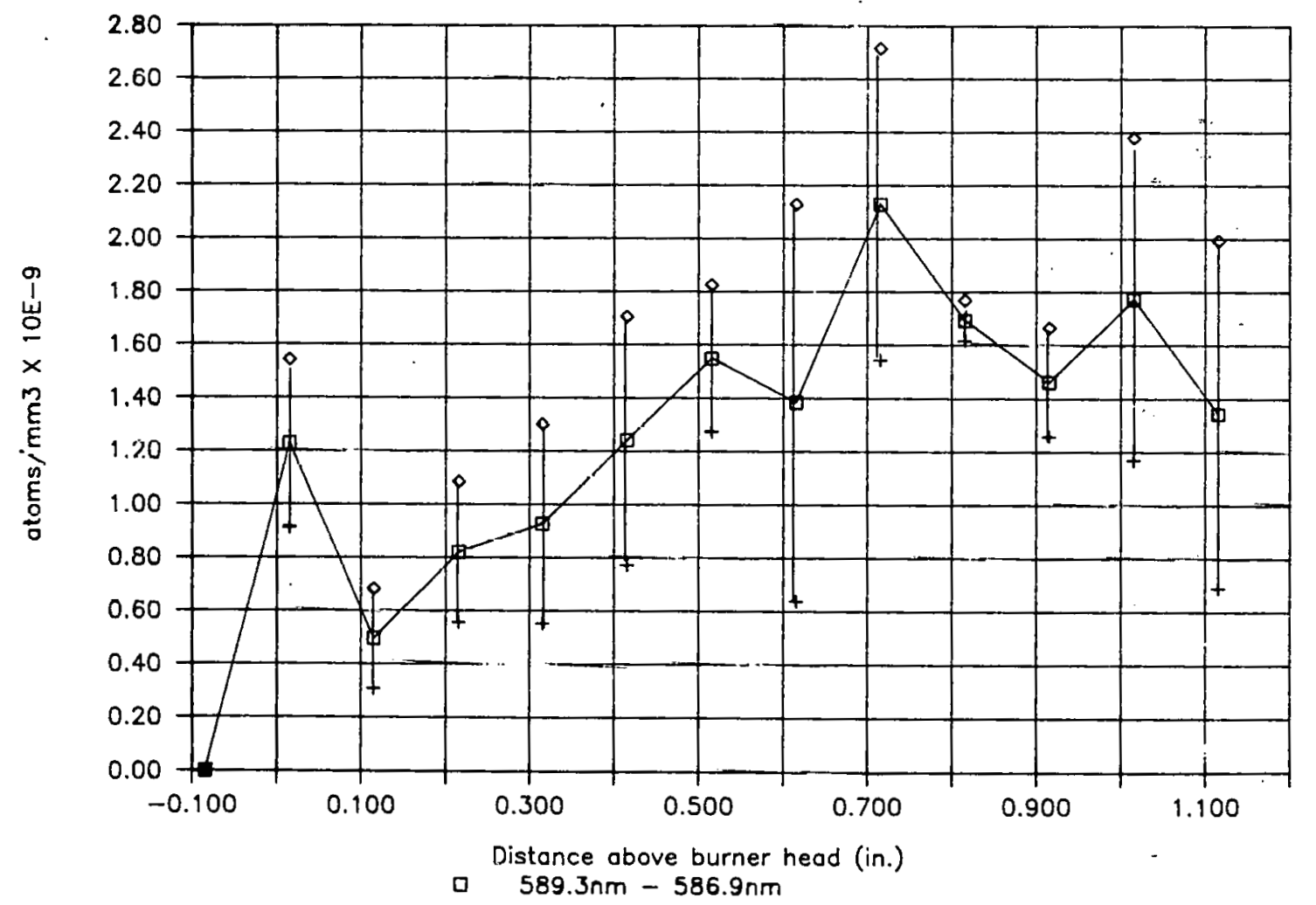

Figure 14. A vertical profile of the sodium atom density taken at a horizontal position of 0.348 inches. 
$W_{t f}=\left(1+g_{1} / g_{3}\right) \cdot \frac{I_{3}}{h_{v}\left(A_{3} / 4 \pi\right) \Omega_{c} V_{c}}+\frac{I_{2}}{h v\left(A_{2} / 4 \pi\right) \Omega_{c} V_{c}}$

$\mathrm{N}_{\mathrm{tf}}=\left(1+g_{1} / \mathrm{g}_{3}\right) \quad \frac{0.67 \mathrm{I}_{\mathrm{t}}}{\mathrm{h}_{v}\left(\mathrm{~A}_{3} / 4 \pi\right) \Omega_{c} V_{c}}+\frac{0.33 I_{t}}{h v\left(A_{2} / 4 \pi\right) \Omega_{c} V_{c}}$

Equation symbols and employed values are listed below.

$\mathrm{g}_{1}=$ degeneracy of the ${ }^{2} \mathrm{~S}_{1 / 2}$ level $=2$

$8_{2}=$ degeneracy of the ${ }_{2}^{2} p_{1 / 2}$ level $=2$

$\mathrm{g}_{3}=$ degeneracy of the ${ }^{2} \mathrm{P}_{3 / 2}$ leyel $=4$

$\mathrm{I}_{3}=$ fluorescence intensity of ${ }^{2} \mathrm{P}_{3 / 2}$ level

$I_{2}^{3}=$ fluorescence intensity of ${ }^{2} P_{1 / 2}^{3 / 2}$ level

$I_{t}=I_{2}+I_{3}$
$h^{2}=$ Planks constant $=6.63 \times 10^{-34} \mathrm{Js}$

$v=$ Frequency $=5.09 \times 10^{14} \mathrm{~s}^{-1}$

$A_{3}=A_{2}=$ Einstein coefficient for spontaneous emission $=6.28 \times 10^{7} \mathrm{~s}^{-1}$

$\Omega_{c}=$ Solid angle cut by the collection optics $=0.14 \mathrm{sr}$

$V_{c}=$ Sample volume

$N_{t f}=$ atom density calculated from fluorescence

Atom densities in the sample volume were also calculated from aspiration rates for comparison purposes. Equation 3 was used for this calculation when solutions were aspirated. This equation was reported by Winefordner and Vickers (23) and employed by Smith et al. (24). The values employed were derived from flame condition $\|_{1} 1$.

$$
\mathrm{N}_{\mathrm{ta}}=\frac{C \mathrm{n}_{298} \phi \varepsilon B}{\mathrm{TQ} 3.3 \times 10^{-22} \mathrm{n}_{\mathrm{T}}}
$$

Equation symbols and values employed are listed below.

$\mathrm{N}_{\text {ta }}=$ atom density in the flame

$\mathrm{C} \stackrel{\text { Concentration }(M)}{\mathrm{M}}$ of $\mathrm{Na}$ in aspirated solution

$\phi=$ aspiration rate of solution $=2.0 \times 10^{-1} \mathrm{ml} / \mathrm{min}$

$Q=$ flow rate of unburnt gases at introduction temperature $25^{\circ} \mathrm{c}=1.55 \mathrm{ml} / \mathrm{sec}$

$\varepsilon=$ sample introduction efficiency $=1.0$

$B=$ reactivity and ionization coefficient $=1.0$

$\mathrm{n}_{298}=$ moles of flame components at introduction temperature $=0.38 \mathrm{moles} / \mathrm{min}$

$\mathrm{n}_{\mathrm{T}}=$ moles of combustion products at $\mathrm{T}=0.39 \mathrm{moles} / \mathrm{min}$

$\mathrm{T}^{\mathrm{T}}=$ flame temperature $=2073^{\circ} \mathrm{K}$

The sample introduction efficiency is a measurement of the efficiency of drop desolvation in the f'lame. This was assumed to equal $1.0(100 \%$ efficiency) based on the results of Winefordner et al. (25) which showed 100\% efficiencies for all aspiration rates at or below $0.15 \mathrm{~mL} / \mathrm{min}$. Decreased efficiencies were not reported until the aspiration rate was increased to 5.0 $\mathrm{mL} / \mathrm{min}$. 
The reactivity and ionization coefficient is a measurement of the amount of sodium not present in the atomic form due to ionization and/or reactions of the atomic sodium with other flame species. Muller et al. (26) reported that the ionization of sodium atoms is not fast enough to significantly decrease atomic fluorescence in a hydrogen/oxygen/nitrogen flame. They also reported ihat reactions of sodium atoms with $\mathrm{H}_{2} \mathrm{O}$ may be significant. In the present study unity was assumed for the reactivity and ionization coefficient.

The sodium atom density calculated from the introduction rate of Beulah lignite into the flame was also calculated from Equation 3 with the following modifications. The sodium concentration in solution was replaced by its elemental wt\% in the lignite. The aspiration rate was calculated in mg/min. The aspiration rate of the coal was insignificant in comparison with the combustion gases and $n_{T}$ was set equal with $n_{298}$ and the constant was modified according to the units employed. The sample introduction efficiency and the reactivity and ionization coefficient were left as unity.

\subsection{RESULTS}

A wavelength profile of the response produced from the aspiration of a $2512 \mathrm{ug} / \mathrm{ml} \mathrm{NaCl}$ solution and a deionized water sample (Qwater) is shown in Figure 6 . The laser was tuned to $589.9 \mathrm{~nm}$. The bandpass of the monochromator used for this study was $0.5 \mathrm{~nm}$. When the $\mathrm{NaCl}$ solution was aspirated two distinct peaks of equal intensity were observed one centered at $588.9 \mathrm{~nm}$ and one centered at $589.5 \mathrm{~nm}$. Only a single peak centered at $589.9 \mathrm{~nm}$ was. observed when the deionized water was introduced.

The possibility was evaluated of measuring the intensity of scattered and reflected light at a wavelength differing from that at which fluorescence was measured. The laser was tuned to $589.5 \mathrm{~nm}$ and a $25.13 \mathrm{ug} / \mathrm{mI} \mathrm{NaCl}$ solution and pure deionized water were aspirated into the flame. The sample intensity was measured as a function of wavelength by scanning the monochromator. The bandpass of the monochromator was $0.9 \mathrm{~nm}$ for this study and the results are shown in Figure 7. The $\mathrm{NaCl}$ solution produced only a single peak centered at $589.3 \mathrm{~nm}$ due to the wide monochromator bandpass employed. The deionized water produced $\exists$ peak at $589.5 \mathrm{~nm}$ with an intensity of 0.28 volts and a bandwidth of $1.1 \mathrm{~nm}$.

The signal produced from a $251.3 \mathrm{ug} / \mathrm{ml} \mathrm{NaCl}$ solution and a deionized water sample were measured with the laser tuned to $586.7 \mathrm{~nm}$. Both peak intensities of these signals were 0.24 volts with bandwidths at half heights of $1.1-1.2 \mathrm{~nm}$. The two signals were centered around $586.7 \mathrm{~nm}$. l'he peak intensities and bandwidths were almost identical to the those measured when the laser was tuned to $589.5 \mathrm{~nm}$ and deionized water was aspirated. Figure 8 compares the results of subtracting the deionized water response obtained with the laser tuned to $586.7 \mathrm{~nm}$ from the $\mathrm{NaCl}$ response obtained with the laser tuned to $589.5 \mathrm{~nm}$. The background signal obtained with the laser tuned to $586.7 \mathrm{~nm}$ was correlated to the $\mathrm{NaCl}$ results obtained with the laser tuned to $589.5 \mathrm{~nm}$ by adding $2.8 \mathrm{~nm}$ to the lower wavelength monochromator settings. Figure 8 shows that the two techniques produce the same results within experimental error. 
A horizontal profile of the sodium fluorescence response observed from the aspiration of Beulah lignite into the analytical flame is shown in Figure 9. The vertical position of this profile was 0.415 in. The monochromator bandpass was $1.2 \mathrm{~nm}$. The monochromator was tuned to $589.3 \mathrm{~nm}$ when the laser was tuned to $589.1 \mathrm{~nm}$. To evaluate the background intensity the monochromator was set at $586.0 \mathrm{~nm}$ and the laser was tuned to $586.7 \mathrm{~nm}$. The resuits show that at 0.415 in. above the burner the amount of reflection and scatter is small relative to the total signal. The sodium atom density is shown to be the largest at the flame edge closest to the detector. Subtraction of the background from the $589.3 \mathrm{~nm}$ signal followed by application of Equation 2 produced the results shown in Figure 10. The sodium atom densities in the flame can be seen to vary from $1.8 \times 10^{9}$ atoms $/ \mathrm{mm}^{3}$ at the flame edge to $0.5 \mathrm{x}$ $10^{9}$ atoms $/ \mathrm{mm}^{3}$ at the flame center.

The laser power necessary to produce saturation was determined from the data shown in Figure 11. This data was obtained by subtracting the background signal measured at $586.5 \mathrm{~nm}$ with the laser tuned to $586.7 \mathrm{~nm}$ from the total signal measured at $588.9 \mathrm{~nm}$ with the laser tuned to $589.1 \mathrm{~nm}$. The bandpass of the monochromator was $0.9 \mathrm{~nm}$. The horizontal position of the flame was 0.380 in. and the vertical position was $0.415 \mathrm{in}$. The results show that saturation was achieved when the laser intensity was $1.2 \times 10^{17} \mathrm{~W} / \mathrm{cm}^{2} \mathrm{~nm}$ or greater.

A wavelength profile of the signal produced by Beulah lignite at a vertical flame position of $0.415 \mathrm{in}$. and a horizontal position of 0.380 in. is shown in Figure 12. The reported signal intensity is again the difference between the signals measured with the laser tuned to $589.1 \mathrm{~nm}$ and $586.7 \mathrm{~nm}$. The wavelengths reported are those through which the monochromator was scanned when the laser was tuned to $589.1 \mathrm{~nm}$. The background signal was obtained by scanning the monochromator through a similar range $2.4 \mathrm{~nm}$ lower in wavelength. A single peak centered at $589.3 \mathrm{~nm}$ was obtained. This result is consistent with the large size of the monochromator bandpass employed.

A vertical profile of the sodium atom density measured at the center of the flame is shown in Figure 13. The fluorescence including intensity was measured by setting the monochromator at $589.3 \mathrm{~nm}$, expanding the bandpass to $1.2 \mathrm{~nm}$ and tuning the laser to $589.1 \mathrm{~nm}$. The background was measured at 586.9 $\mathrm{nm}$ with the laser tuned to $586.7 \mathrm{~nm}$. The background signal was subtracted from the fluorescence including measurement. Equation 2 was used to calculate the sodium atom densities. This study showed a maximum sodium atom concentration of $1.4 \times 10^{9}$ atoms $/ \mathrm{mm}^{3}$ at 0.015 in, above the burner head. The concentration decreased to $4.0 \times 10^{8}$ atoms $/ \mathrm{mm}^{3}$ at 0.115 in. and remained constant up to 1.115 inches above the burner head.

A vertical profile of the sodium atom density at a horizontal position of 0.348 in. is shown in Figure 14. The laser and monochromator settings employed were identical to those used to obtain in Figure 13. Figure 14 shows that the sodium atom density initially decreased with increased height above the burner head and then increased with further jncreases in the burner height. The largest sodium atom density was $2.1 \times 10^{9}$ atoms $/ \mathrm{mm}^{3}$ at a position of 0.715 in. above the burner head. 
A vertical temperature profile at a horizontal position of 0.348 in. is shown in Figure 15. This flame position is outside the radius of the burner head and therefore this profile reflects the effect of moving into the flame which has expanded beyond the burner head. The temperature increased rapidly and then leveled with increased vertical position.

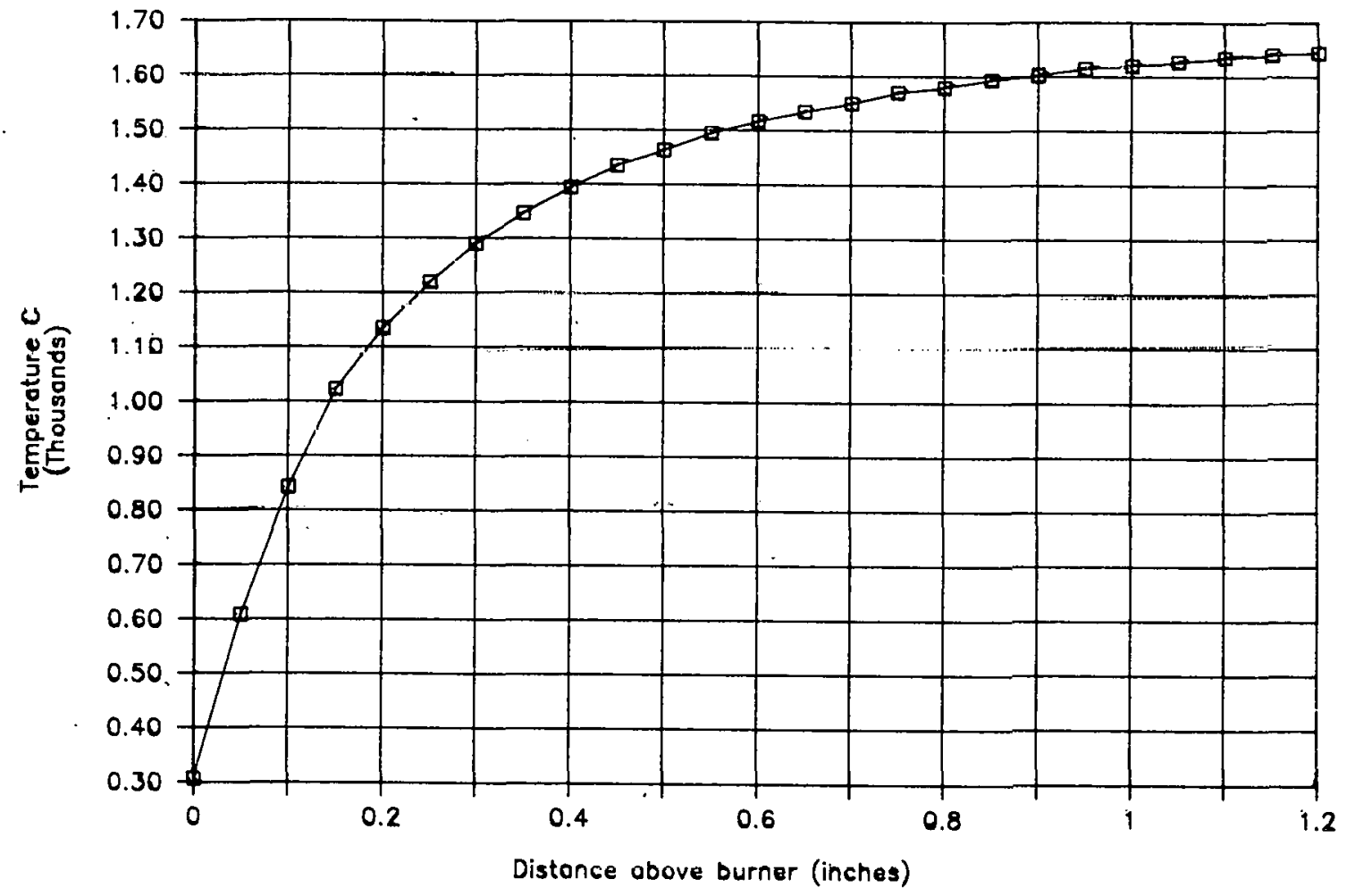

Figure 15. A vertical temperature profile taken at a horizontal position of 0.348 inches.

\subsection{DISCUSSION}

To determine sodium atom densities from the LIFS measurements in the coal-containing flames it is necessary to know the intensity of the fluorescence produced from the atomized sodium. If the sample intensity is measured at the same wavelength used for excitation (resonance spectroscopy) then the observed intensity will contain reflected and scattered light in addition to that f'luoresced. This technique is viable as long as an appropriate standard is available from which the intensity of the reflected and scattered light can be determined and subtracted from the fluorescence containing measurement. The solution studies demonstrate an example where resonance spectroscopy is viable since the background measured from pure deionized water can be subtracted from the solution measurements. 
When coals are the analyte of interest the use of resonance spectroscopy is not practical unless an appropriate standard is available. Recently steps have been taken towards the production of synthetic chars designed to imitate coal particles (27). Although this technology is directly applicable to our investigations the use of synthetic coal particles as a standard would necessitate strict characterization of the original and the synthetic coal in order to determine whether critical properties such as combustion rate and ash content were comparable.

To eliminate the need for standards the decision was made to measure the sodium fluorescence at a wavelength $(589.0 \mathrm{~nm})$ different from that at which the sodium was excited $(589.6 \mathrm{~nm})$. This technique is termed nonresonance spectroscopy and is based on the fact that energy levels close in energy establish thermal equilibration in short time periods. The equilibration of the sodium doublet has been investigated and confirmed (28). The population ratios of the ${ }^{2} \mathrm{P}_{1 / 2}(589.6 \mathrm{~nm})$ and ${ }^{2} \mathrm{P}_{3 / 2}(589.0 \mathrm{~nm})$ levels were shown to be nearly equal to the ratio of their degeneracies when the populations were measured using the alternate excitation wavelength. The slight deviations from the degeneracy ratios were correlated to differences in quenching rates and mixing constants.

The results from the nonresonance study are shown in Figure 6 . The pure deionized water signal is due to reflection and scatter of the excitation laser pulse and is therefore proportional to the laser power. Since the deionized water produced no significant response at $589.0 \mathrm{~nm}$ it was expected that the intensity measured at $589.0 \mathrm{~nm}$ when $\mathrm{NaCl}$ solutions were aspirated would be due purely to sodium fluorescence. Two peaks of equal intensity were obtained from the aspiration of $a_{2} 2513 \mathrm{ug} / \mathrm{ml} \mathrm{NaCl}$ sample into the flame. These two peaks correspond to the ${ }^{2} \mathrm{P}_{3 / 2}(589.0 \mathrm{~nm})$ and the ${ }^{2} \mathrm{P}_{1 / 2}(589.6 \mathrm{~nm})$ energy levels. In order to quantitatively employ the nonresonant technique these two peaks must be distinct. The fact that they are of equal intensity instead of in a ratio of their degeneracies $(2: 1)$ demonstrates that the two peaks are not resolved sufficiently for quantitative use.

Since the nonresonance procedure could not produce a fluorescence signal free from reflection and scatter a technique was devised to measure the intensity of this background signal so that it could be eventually subtracted from the fluorescence containing signal. This technique involved tuning the laser to a wavelength where sodium does not fluoresce and measuring the intensity of the reflection and scatter. The background measured at the alternative wavelength was compared to the background measured at the excitation wavelengths to determine the feasibility of using this technique quantitatively. Figure 8 shows the results of comparing the background observed at $589.5 \mathrm{~nm}$ to the background measured with the laser tuned to 586.7 nm. The fact that the same results are obtained whether the background is measured at $589.5 \mathrm{~nm}$ or $586.7 \mathrm{~nm}$ demonstrates that the sodium fluorescence intensity can be measured by subtracting the background signal obtained at $586.7 \mathrm{~nm}$ from the total intensities measured at the fluorescence wavelengths. Furthermore the fact that the background signal measured at $586.7 \mathrm{~nm}$ is independent of the sodium concentration demonstrates that a standard is not necessary when this procedure is employed. 
The investigations on solids were begun once a procedure for calculating fluorescence intensities without the need of a standard was established. A horizontal profile of the response produced when Beulah lignite was introducted into the flame is shown in Figure 10. The sodium atom density was highest on the outside edge of flame closest to the detector. This observation is probably a result of self absorption and/or optical density of the flame rather than an actual fluctuation of the sodium atom density. Daily and Chan (16) reported a horizontal profile similar to that seen in Figure 10. This profile was produced by the aspiration of high concentrations of $\mathrm{NaCl}$ into a $\mathrm{CH}_{4}$ /air flame. Daily and Chan attributed their results to self absorption. The large self absorption precludes correlating the flame temperature (20) to sodium atom densities through the use of the horizontal profiles.

The laser intensity necessary to produce saturation was determined from the results shown in figure \%. The use of a source intensity capable of producing saturation is necessary in order to calculate sodium atom densities via Equation 2. Figure 11 show3 that saturation is achieved when the laser intensity is of $1.2 \times 10^{7} \mathrm{~W} / \mathrm{cm}^{2} \mathrm{~nm}$ or greater. Smith et al. (24) reported $2 \mathrm{x}$ $10^{6} \mathrm{~W} / \mathrm{cm}^{2} \mathrm{~nm}$ as the saturation threshold. Daily (17) reports an estimate of $3.5 \times 10^{7} \mathrm{~W} / \mathrm{cm}^{2} \mathrm{~nm}$ for this value. Saturation is achieved in our system and the threshold intensity is within the range of values previously reported.

A measurement of the fluorescence intensity produced by Beulah lignite as a function of wavelength is shown in Figure 12. A single peak which centered at $589.3 \mathrm{~nm}$ was observed. This result was expected due to the $0.9 \mathrm{~nm}$ monochromator bandpass employed. The monochromator bandpass necessary to collect the total light fluoresced from the 589.0 and $589.6 \mathrm{~nm}$ levels was calculated from this profile. These calculations indicated that centering the monochromator on $589.3 \mathrm{~nm}$ and using a bandpass of $1.7 \mathrm{~nm}$ will result in the measurement of the total fluorescence signal intensity.

A vertical sodium atom density profile at the flame edge $(0.348$ in. horizontal position) was obtained as illustrated in Figure 14. Figure 14 shows that the sodium atom density increased slightly with vertical position. The vertical temperature profile of the flame at the $0.348 \mathrm{in}$. horizontal position (Figure 15) increased rapidly with initial increases in the vertical position and then leveled. Comparison of this result with the vertical sodium atom density profile shows increased sodium atom density with increased flame temperatures. Comparing these two vertical profiles also shows that the high fluorescence reading at the vertical position closest to the burner head is most likely due to reflection of the laser beam off the burner head since at this elevation the sample zone was below the flame.

A vertical profile of the sodium atom density at the flame center produced from the introduction of Beulah lignite is shown in Figure 13. The average sodium density is smaller in this profile than in the previous vertical profile. This is consistent with the results of the horizontal profile as shown in Figure 6 . The sodium atom concentration is independent of vertical position between 0.115 and 1.115 in. Immediately above the burner 
head $(0.015 \mathrm{in.})$ the calculated sodium atom density is $1.4 \mathrm{x} 10^{9}$ atoms $/ \mathrm{mm}^{3}$ a significantly higher value than in the rest of the flame. This high value for the sodium atom density closest to the burner head is probably an experimental artifact as discussed previously.

In order to calculate the percent of the total sodium in the atomic state it is necessary to calculate the concentration of all forms of sodium in the flame. The total sodium concentration $\left(\mathrm{N}_{\mathrm{ta}}\right)$ is proportional to the rate of sample introduction. Equation 3 was used to calculate the $\mathrm{N}_{\text {ta }}$ values. Since the sample introductory efficiency and the reactivity and ionization coefficient were assumed to be unity, the $\mathrm{N}_{\text {ta }}$ values reflect the total density of sodium in the flame regardless of its state.

The fact that for the solution cases the assumed value of unity for the sample introductory efficiency and the reactivity and ionization coefficient can be justified means that for the solution studies $\mathrm{N}_{\text {ta }}$ should be equal to $\mathrm{N}_{t f}$. The $\mathrm{N}_{\text {ta }}$ calculated for the aspiration of a $2.5 \mathrm{ug} / \mathrm{ml} \mathrm{NaCl}$ solution into a $1800^{\circ} \mathrm{C}$ flame is $7.6 \times 10^{7}$ atoms $/ \mathrm{mm}^{3}$. The $\mathrm{N}_{\mathrm{tf}}$ calculated from the fluorescence measurements of this solution (21) is $1.0 \times 10^{7}, \mathrm{~N}_{\mathrm{tf}} / \mathrm{N}_{\mathrm{ta}}=$ 0.14. Assuming that $\mathrm{N}_{t a}$ is an accurate estimate of the total sodium density when unity is used for the atomization efficiency parameters then the $14 \%$ difference between $\mathrm{N}_{t a}$ and $\mathrm{N}_{t f}$ is a measurement of the percent of sodium atoms in the atomic site. Conversely stated our results show that the product of the sample introductory coefficient, the reactivity and the ionization coefficient should equal 0.14 if we want to use $N_{\text {ta }}$ to estimate the sodium atom conceritration rather than total sodium density from the aspiration rates.

Smith et al. (24) used techniques similar to those employed herein to arrive at $\mathrm{N}_{t a}$ and $\mathrm{N}_{t f}$ values for the aspiration of $\mathrm{NaCl}$ solutions into a hydrogen/air flame and reported $\mathrm{N}_{t f}$ to be $10 \%$ of $\mathrm{N}_{t a}$. These workers suggested that the discrepancy between these two values was due to the inaccurate estimation of contributing values in the $\mathrm{N}_{\text {ta }}$ calculation and that the $\mathrm{N}_{\mathrm{tf}}$ values were indeed an accurate measurement of the sodium atom concentration in the flame. If this alternate assumption is applied to the present calculations then the $\mathrm{N}_{t a}$ values cannot be used to directly determine the total amount of sodium in the flame.

Thermodynamic calculations using a modified SOLGASMIX program with the NaSSi data base (29) were performed to predict the equilibrium compcnents of the methane/argon/oxygen flame containing both solutions and Beulah lignite. The calculations were made for $1800^{\circ} \mathrm{C}$ and the composition of the employed flame was used. The results predicted only gas phase species to be present and that $82 \%$ of the sodium would be in the atomic form with the remainder being $\mathrm{NaOH}$. If it is assumed that equilibrium was reached in the solution studies and that the percent of sodium in the atomic form was $82 \%$. The ratio of $\mathrm{N}_{\mathrm{tf}} / \mathrm{N}_{\text {ta }}$ should have been 0.82 instead of 0.14 . Using the thermodynamic values as a basis and assuming $N_{t f}$ to be correct produces the conclusion that $\mathrm{N}_{\text {ta }}$ is 5.9 times higher than the actual value of total sodium atom concentration. The $\mathrm{N}_{\text {ta }}$ value for the Beulah lignite studies is $1.2 \times 10^{11}$ atoms $/ \mathrm{mm}^{3}$. The largest $\mathrm{N}_{\mathrm{tf}}$ value measured in the Beulah lignite studies was $2.1 \times 10^{9}$ atoms $/ \mathrm{mm}^{3}$ (Figure 14) $\mathrm{N}_{t f} / \mathrm{N}_{\text {ta }}=0.018$. Multiplication of $\mathrm{N}_{\text {ta }}$ by 5.9 as Indicated by the solution studies produces a $\mathrm{N}_{t f} / \mathrm{N}_{t a}$ for the Beulah lignite 
studies of 0.106 or $10.6 \%$ of the total sodium concentration is present in the atomic form. The discrepancy between the measured $10.6 \%$ and the thermodynamically calculated $82 \%$ sodium atom percentages for the Beulah lignite studies is due to the finite combustion rate of the coal particles. At a vertical position of 0.715 inches the particles have only been exposed to the flame for 15 milliseconds and only partial combustion has occurred. This fact is substantiated by the physical observation of the flame. In order to directly compare the thermodynamic calculations with the fluorescence measurements the particle pyrolysis rate will need to be estimated. This process is currently being pursued.

The thermodynamic calculations also predict the percentage of volatilized sodium to increase with increased temperatures. This prediction contradicts the results of Neville and Sarofim (30) who reported the percent of volatilized sodium to decrease with increased temperatures. They attributed this result to enhanced reaction rates of sodium with silicates at the higher temperatures. This fact accompanied by our results indicate that the reaction rates of sodium and the combustion rates of the coal particles have a larger influence on the sodium vapor concentration than the thermodynamics of the system.

\subsection{FUTURE WORK}

The second year of this project will focus on the vaporization of atomic sodium from solid sources. Four sodium salts will be included. Two of these will be organic carboxylates and two will be inorganic salts representing the range of sodium containing salts found in coal. Experiments will be carried out starting from the relatively simply substrates to much more complex. Numerous questions should be answered in this segment of the study. Is there a sharp temperature regime where sodium is released in the flame from a given solid-source? What fraction of the sodium is converted to atomic form for a given source? Can saturation be achieved with solid sources as it can be with solutions? How does the fraction of sodium vaporized depend upon the matrix containing the solid? To what extent do these results depend upon gas stream composition?

For each of the four sodium salts a series of experiments will. be run. A study of sodium release as a function of temperature/position in the flame will be obtained for the pure solids. These same results will then be obtained for the solid in a synthetic char (glassy carbon) matrix. Concentration curves for the quantitat,ive determination of atomic sodium will be obtained. Those cases that show the most significant and interesting effects will then be studied in more detail by varying the gas stream composition. Gases to be studied will include $\mathrm{NO}$ and $\mathrm{SO}_{2}$. The effects of $\mathrm{CO}_{2}$ in the gas stream may also be studied if it appears to be important.

After these results are obtained, the complexity of the matrix will then be increased for the most interesting salts. Accordingly, the effects of adding clays and $\mathrm{SiO}_{2}$ to the matrix will be studied. Because both of these are found in coal it is important that their effect be studied before detailed work on coals is carried out. 


\subsection{TASK 3.2b DROP TUBE FURNACE PROJECT}

\section{1 INTRODUCTION}

Low-rank coals contain significant quantities of organically associated cations in addition to mineral matter. The drop tube furnace project seeks to understand the transformations of these inorganic constituents that take place during combustion. These interactions cause low-melting point phases to form that can aggrevate ash deposition problems in utility boilers.

The organically associated cations commonly found in low-rank coals include: sodium, calcium, magnesium, strontjum, barium and small quantities of potassium (4). Portions of these elements can also be associated with mineral particles. The mineral particles in pulverized coal are distributed within coal particles as inherent mineral grains and extraneous mineral grains not associated with coal.

Most of the ash forming species remain with the residual char during the combustion process. A very small portion of the ash is found associated with the volatiles (31). Therefore the mode of char combustion has the most significant influence on the mechanisms of fly ash formation. For example, if a char particle retains its integrity and burns as a shrinking core, it is likely that the ash droplets adhering to the char would coalesce to form a single fly ash particle per coal particle (ignoring the contributions due to flame volatilized species). On the other hand, char disintegration may occur with coal particles that swell during devolatilization forming coke cenospheres.

According to Wibberly and Wall (32) char disintegration is more likely to occur during combustion of the coke cenospheres which burn out on several expanding combustion fronts. In addition, fracture or breakup of the char particle in advanced stages of char combustion can result in the formation of many fly ash particles per coal particle. Sarofim et al. (31) estimated that 3 fly ash particles per coal particle form from a lignite as compared to 5 for a bituminous coal. Lowe (33) estimated that up to $33 \mathrm{fly}$ ash particles per coal particle can form. In a more recent study on a Montana lignite, Quann and Sarofim (34) accounted for the smaller particles less than 5 microns and found a large number of very small partjculate had formed, many more than the number of coal particles. Although on a mass basis most of the ash particles adhered to the surface of the char and coalesced to form larger particles (20 micrometers). Combustion temperature has a marked influence on the particle size distribution of the fly ash particles. Wibberly and Wall (32) found that $2-3$ times as many fines ( 10 micrometers) formed at $1600^{\circ} \mathrm{C}$ as compared to $1400^{\circ} \mathrm{C}$.

The minerals and organically-bound cations present in low-rank coals can combine to form low-melting point particles during combustion and gas cooling that can cause serious ash deposition problems in boilers. The formation of these low-melting point particles depends upon the following: association of mineral and organically-bound phases in coal particles that produces a lowmelting point particles; char particle temperature; and the gaseous environment at the surface and within the burning char particle. The transformations 
of organically-bound cations on the surfaces of char particles and their interaction with other organic phases are not well understood. Quann and Sarofim (34) found that organically-associated calcium and magnesium agglomerate along with quartz and clay minerals to form larger particles. The addition of calcium and magnesium to quartz and clay minerals can result in the formation of particles having low-melting points. In another study, iron silicate particles (which probably form due to the coalescence of pyrite and quartz grains during combustion) were found to have low-roelting points and would readily stick to boiler steel surfaces (29). During gas cooling, volatilized species (as studied in Task 3.2a) can condense on the surfaces on entrained ash particles forming low-melting point surface layers (7). In addition, these volatilized species contribute to the very fine particulate.

\subsection{CONSTRUCTION AND TESTING OF DROP TUBE FIIRNACE}

The orop-tube furnace system consists of four major components: 1) a fluidized bed pulverized coal feeder system, 2) a secondary-air preheater and sample injector system, 3) a series of vertically-oriented tube furnaces, and 4) a sample collection system. Work has been completed on all of these components. The following will describe the work completed on each component.

Construction of the laboratory to house the drop-tube furnace has been completed. The structure consists of three levels, as shown in Figure 16. The vertically oriented tube furnaces are mounted on furnace bars which extend through all three levels. The top of the furnaces is located at approximately the floor of l.evel 3. Level 3 provides easy access and adequate space for housing and operation of the coal feed system. The adjoining control room at Level 3 provides a clean, climate-controlled environment for the electronic equipment associated with the drop-tube apparatus. Level 2 provides easy access to the furnaces and associated thermocouples. This level also houses any analysis equipment and associated optical access ports into the furnaces. Level 1 one houses the sample collection systems, and gas cylinders.

The heated zone consists of a series of thres vertically oriented tube furnaces with five independently controlled zones with a maximum heated length or 48" as illustrated in Figure 17. These furnaces are capable of producing working temperatures of up to $1650^{\circ} \mathrm{C}$. A dual-pivot mounting arrangement was designed for easy access and versatility as it allows the furnaces to be used singly or in series. Electrical connections for the furnaces are side mount to allow for only one inch of insulation between furnaces to minimize the possibility of a cool zone in the system. Temperature controliers for the entire system are now being interfaced with a personal computer to allow precise control and to record temperature profiles during furnace operation.

The preheater/injector system shown in Figure 18 has been completed and is now in operation. The system introduces preheated secondary air and ambient temperature primary air and coal into the furnaces. The secondary air entering the system is heated by Kanthal A-1 wire to a temperature of 


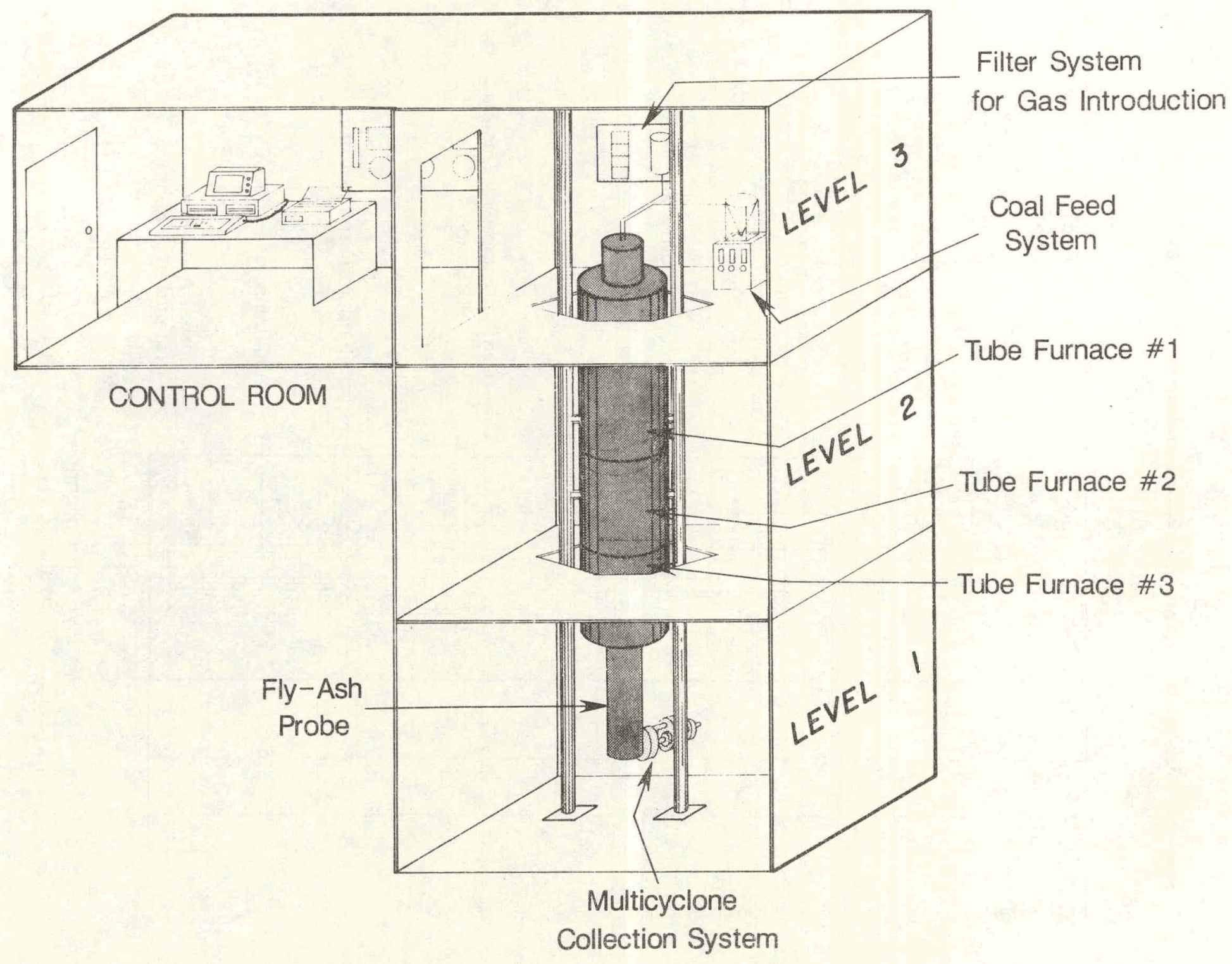

Figure 16. Drop tube furnace laboratory. 


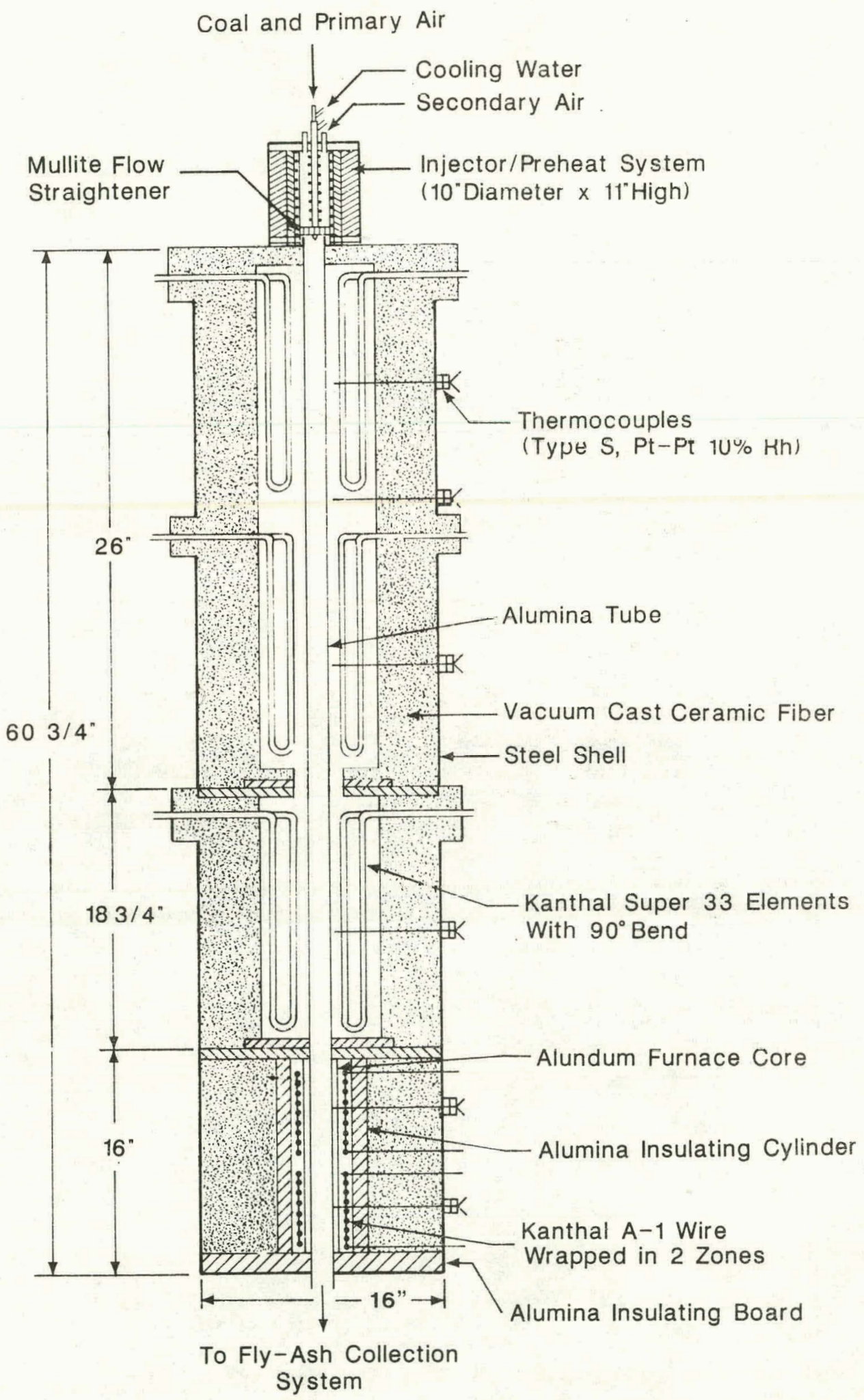

Figure 17. Drop tube furnace assembly. 


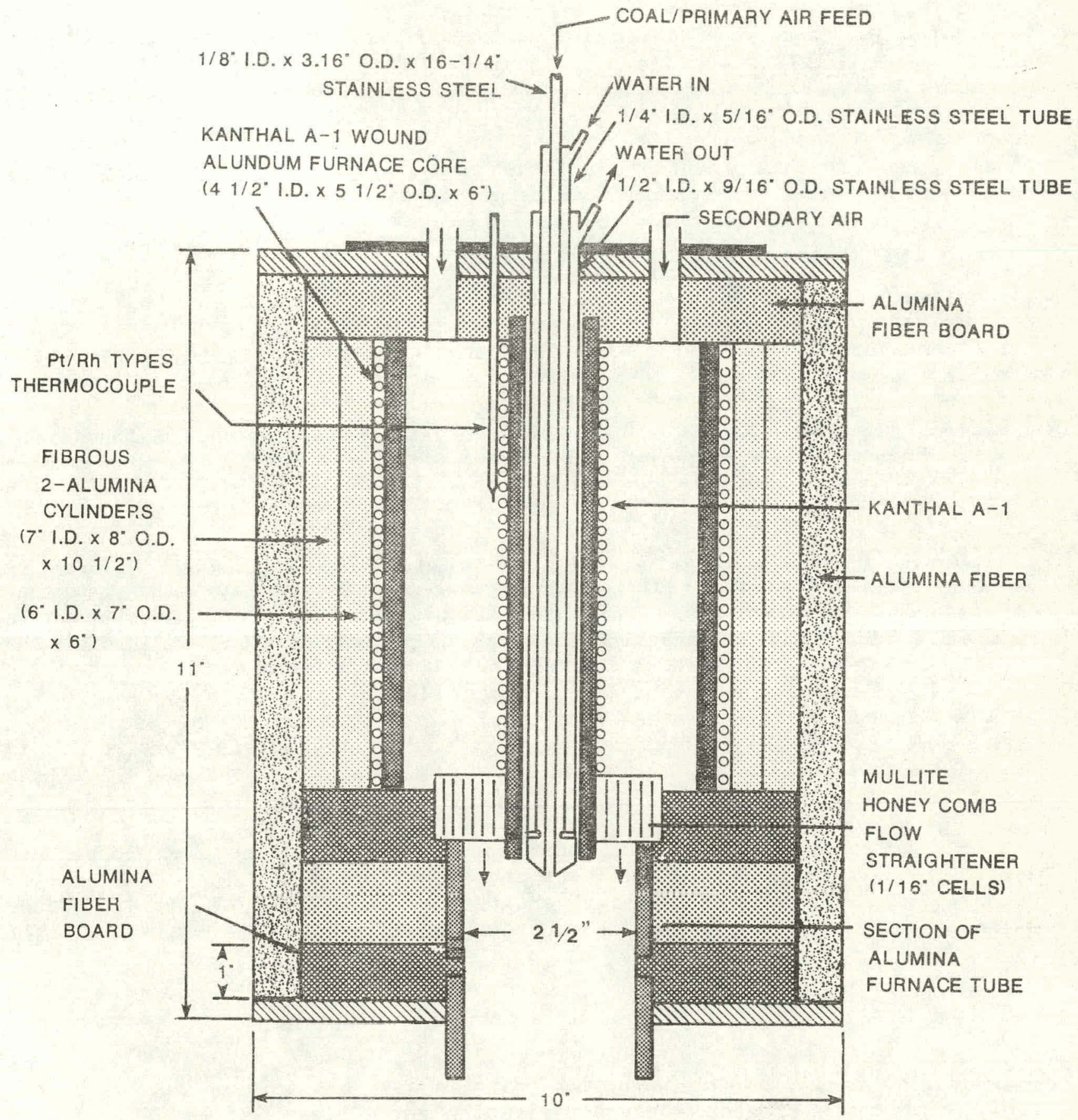

Figure 18. Preheat injector. 
approximately $1000^{\circ} \mathrm{C}$. After heating, the secondary air passes through a mullite honeycomb flow straightener to ensure laminar flow entering the furnace system. This system has been designed to give $30 \%$ excess air in order to provide realistic simulation of combustor conditions. At a coal feed rate of $0.5 \mathrm{~g} / \mathrm{min}$ a flow rate of $3.5 \mathrm{l} / \mathrm{min}$ is necessary to ensure a $30 \%$ excess of secondary air. The system as designed will heat the secondary air sufficiently for flow rates of up to $5 \mathrm{l} / \mathrm{min}$. The coal and primary air is protected from the secondary air preheating system by a water-cooled stainless steel jacket. This ensures that the coal and primary air entering the furnaces will be at, or near ambient temperatures.

The coal feed system has been one of the most challenging design problems encountered in the reporting period. The first coal feed system tested (described in detail in the July-December Quarterly Report) did not provide the consistancy and reliability required for the investigation of inorganic transformations. A series of other feeders were designed and tested, each with some merit, but again the desired consistancy of feed rate and particle size was lacking. During the final quarter of this reporting period a feeder was designed and constructed which appears to fulfill the requirements of the study. Further improvements in the performance of the feed system are likely to be modifications of the current system. The following will describe the feed system now in use.

The coal-feed system presently in use is designed to feed particles of various sizes at rates of 0.1 to 0.5 grams per minute and at primary carrier gas rates of approximately 1 liter per minute. The basic apparatus shown in Figure 19 consists of a pressurized glass cylinder designed to fluidize the sample and feed particles and carriér gas into the preheat injector. The sample level is kept constant with respect to the exit tube by means of a variable-speed vertical translation device. To prevent the sample from channeling, and to aid in fluidization, the entire assembly is vibrated. This system provides a steady, controllable, even rate of sample feed into the Curnace syslem.

One improvement planned for the feed system will allow for continuous monitoring and recording of the rate and amount of sample feed. The entire apparatus will be reduced in weight and rest on an RS-232 computer interfaced balance. Software will allow for recording and controling the f'eed rate tior each run.

\subsection{COAL CHARACTERIZATION}

Much developmental work has been completed in the area of coal characterization. The Robinson Seam coal has been extensively characterized, and through this process a characterization methodology has been developed. The following will discuss the characterization work done to date, the characterization methodology that will be employed through the entire project, and the developmental work yet to be completed. 


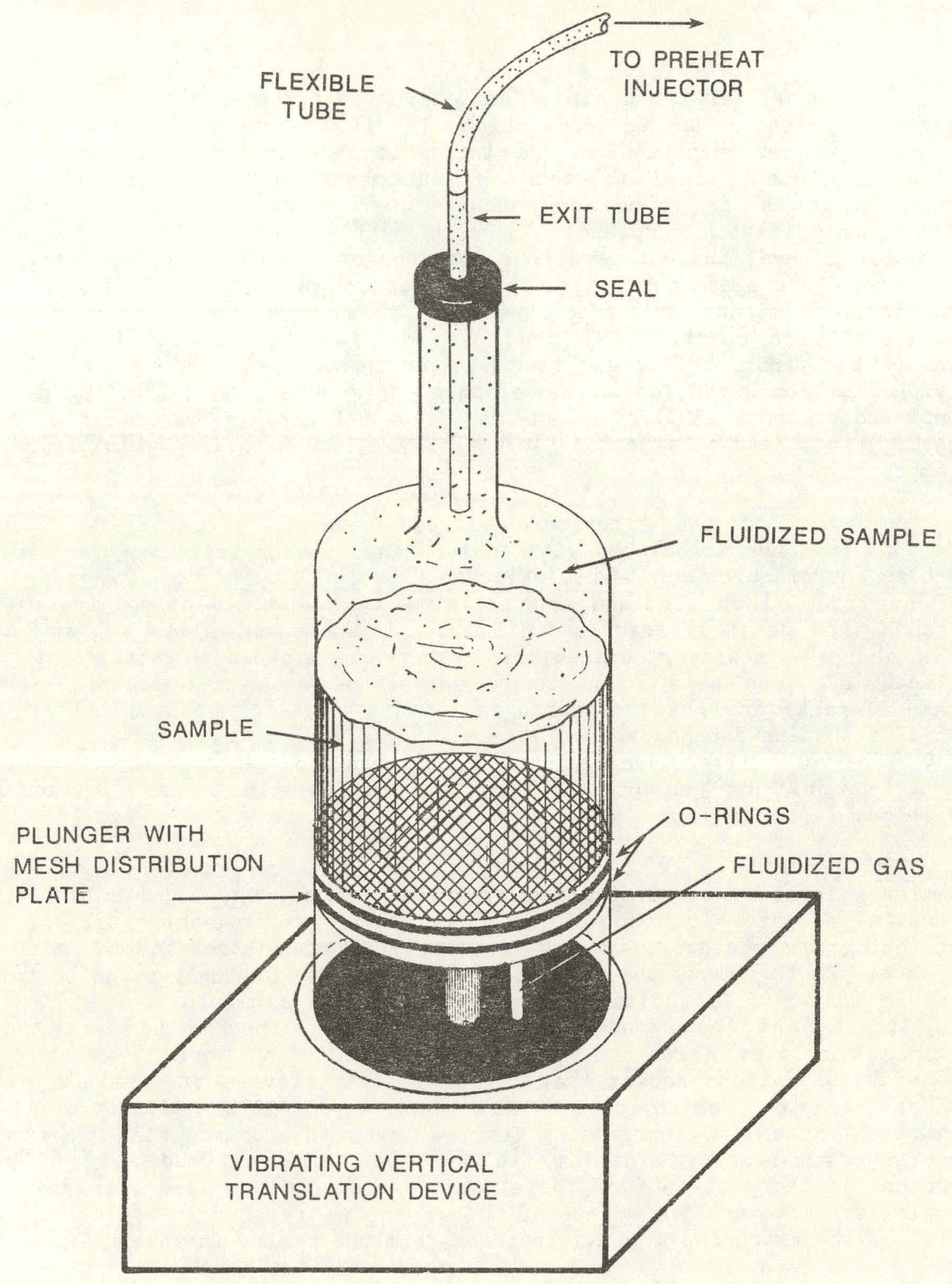

Figure 19. Sample feed system. 
A necessary first step in understanding the reactions that occur in coal inorganic matter during combustion in the drop-tube furnace is the quantitative determination of the inorganic associations in the coal. The inorganic elements in coal occur in four major associations: 1) salts of organic acids that can be ion exchanged with 1 molar ammonium acetate; 2) organic coordination complexes; 3) acid soluble mineral phases; and 4) acid insoluble mineral phases. Previous research at UNDERC under the Distribution of Inorganics project has led to the development of chemical fractionation and quantitative mineralogy. procedures. These procedures have been used successfully to quantify the inorganic constituents associated with coal in each of the first, third, and fourth major phases mentioned above (29), while laying the groundwork for the development of a method to quantify organically complexed elements (30). Substantial additional work was performed as part of the effort to develop a method for quantifying organically complexed inorganic elements.

A review of the literature yielded several references to inorganin elements that are associated with coal organic matter relatively stable forms such as coordination complexes. Float-sink work performed by Miller and Given (5) has shown that aluminum and titanium are sometimes associated with the organic (low density) fraction of coal. In addition, Allen and Vandersande (35) describe scanning transmission electron microscope studies in which silicon and iron were found to be associated with coal organic matrices. These elements are not ion-exchangeable with 1 molar ammonium acetate (29), yet like the ion-exchangeable elements such as sodium, magnesium, and calcium, they are volatilized during coal combustion to react with existing ash particles or form gas phases that may subsequently undergo a variety of reactions (17).

The previous work in quantifying the metals bound in coal organic complexes involved extracting a sample of Gascoyne, ND, lignite with 1 molar ammonium acetate to remove the easily ion-exchangeable cations, then extracting the residue with 0.1 molar ethylenediaminetretracetic acid (EDTA) at three pHs to remove the elements that were more strongly bound to the coal organic matter. In addition, samples of several minerals known to exist in the lignite and that contain elements that are thought to exist in coal organic complexes (aluminum, silicon, titanium, and iron) were extracted. These investigations showed that relatively high levels of aluminum and iron can be extracted from the coal by EDTA whereas very little silicon or titanium can be extracted. By correcting for the level of aluminum that was extracted from aluminum-bearing minerals, it was found that as much as $20 \%$ of the aluminum in the coal ( $98 \%$ of the extracted aluminum) is associated in organic complexes. However, the source of the extracted iron was less clear as a high level of the extracted iron was removed from the pyrite in the coal.

The chemical fractionation procedure was run on samples of Robinson Seam Coal that were tested in the old feed system. The following will report the results of these analyses. 
Two samples of Robinson coal were tested (Table 1 ) in the old feed system for one hour; one sample had previousiy been ground to -325 mesh, and the other sample was ground to -200 mesh. In this time period only a portion of the coal had time to go through the feeder, so samples of the coal that went through the feeder, as well as samples of the coal that remained in the feeder were both collected and analyzed by chemical fractionation (Tables 2, 3, 4, and 5). The initial concentrations of sodium, magnesium, aluminum, potassium, calcium, titanium, iron, and strontium were determined in each of the four raw coal samples by acid digestion. The percentages of elements removed were determined from ICP-AES analyses of the extracts.

TABLE 2

CHEMICAL FRACTIONATION RESULTS FOR -200 MESH ROBINSON COAL STAYED IN FEEDER

\begin{tabular}{|c|c|c|c|c|c|}
\hline & Initial (mg/g $\mathrm{mf}$ coal) & $\begin{array}{c}\% \text { removed } \\
\text { by } \mathrm{H}_{2} \mathrm{O}\end{array}$ & $\begin{array}{l}\% \text { removed } \\
\text { by } \mathrm{NH}_{4} \mathrm{OAC}\end{array}$ & $\begin{array}{c}\text { \% removed } \\
\text { by } \mathrm{HCl}\end{array}$ & $\begin{array}{c}\% \\
\text { remaining }\end{array}$ \\
\hline $\mathrm{Na}$ & 1310 & 35 & 76 & 0 & -11 \\
\hline $\mathrm{Mg}$ & 695 & 0 & 98 & 5 & -3 \\
\hline $\mathrm{AI}$ & 3510 & 0 & 0 & 19 & 81 \\
\hline $\mathrm{K}$ & 0 & 0 & trace & 0 & 0 \\
\hline $\mathrm{Ca}$ & 4980 & 0 & 99 & 19 & -18 \\
\hline $\mathrm{Ti}$ & 110 & 0 & 0 & 20 & 80 \\
\hline $\mathrm{Fe}$ & 3610 & 2 & 0 & 16 & 82 \\
\hline Sr & 170 & 0 & 108 & 16 & -24 \\
\hline
\end{tabular}

Elements renoved by water extraction were probably present in the sample as various inorganic salts or ao the salt of water soluble humic acids. At combustion flame temperatures, these elements would be volatilized to participate in numerous reactions.

Elements removed by ammonium acetate treatments exist predominantly as salts of organic acids in the coal. Some, however, may exist as ammonium acetate soluble minerals such as gypsum, or in association with ion-exchange. sites on clays. These elements are lhe most reactive of the coal inorganics under combustion conditions. They are volatilized and then are free to cool and condense on ash or boiler curfaces. 
TABLE 3

CHEMICAL FRACTIONATION RESULTS FOR -200 MESH ROBINSON COAL, THROUGH FEEDER

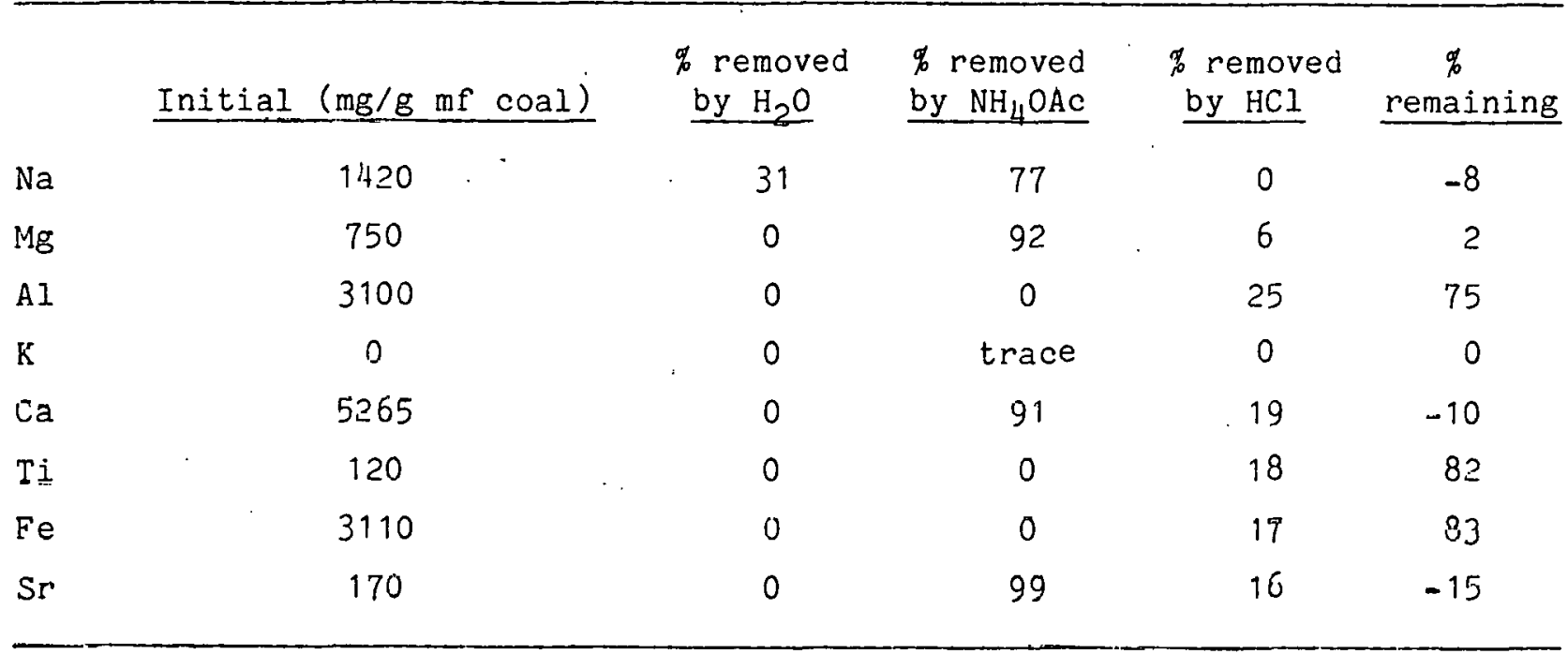

TABLE 4

CHEMICAL FRACTTINNATION RESULTS FOR -325 MESH ROBINSON COAL, STAYED IN FEEDER

\begin{tabular}{|c|c|c|c|c|c|c|}
\hline & Initial & $(\mathrm{mg} / \mathrm{g} \mathrm{mf}$ coal $)$ & $\begin{array}{l}\% \text { removed } \\
\text { by } \mathrm{H}_{2} \mathrm{O}\end{array}$ & $\begin{array}{l}\text { t removed } \\
\text { by } \mathrm{NH}_{4} \mathrm{OAC} \\
\end{array}$ & $\begin{array}{l}\text { \% removed } \\
\text { by } \mathrm{HCl}\end{array}$ & $\stackrel{\%}{\%}$ remaining \\
\hline $\mathrm{Na}$ & & 1365 & 34 & 80 & 0 & -14 \\
\hline$M g$ & & 710 & 0 & 100 & 5 & -5 \\
\hline Al & & 3405 & 0 & 0 & 24 & 76 \\
\hline $\mathrm{K}$ & & 90 & 0 & 21 & 0 & 79 \\
\hline $\mathrm{Ca}$ & & 5040 & 0 & 101 & 18 & -19 \\
\hline $\mathrm{Ti}$ & & 115 & 0 & 0 & 18 & 82 \\
\hline $\mathrm{Fe}$ & & 2840 & 0 & 0 & 19 & 81 \\
\hline $\mathrm{Sr}$ & & 170 & 0 & 101 & 16 & -17 \\
\hline
\end{tabular}


TABLE 5

CHEMICAL FRACTIONATION RESULTS FOR -325 MESH ROBINSON COAL, THROUGH FEEDER

\begin{tabular}{|c|c|c|c|c|c|c|}
\hline & Initial & $(\mathrm{mg} / \mathrm{g} \mathrm{mf}$ coal $)$ & $\begin{array}{l}\text { \% removed } \\
\text { by } \mathrm{H}_{2} \mathrm{O}\end{array}$ & $\begin{array}{l}\text { \% removed } \\
\text { by } \mathrm{NH}_{4} \mathrm{OAc}\end{array}$ & $\begin{array}{c}\% \text { removed } \\
\text { by HCI }\end{array}$ & $\begin{array}{c}\% \\
\text { remaining }\end{array}$ \\
\hline $\mathrm{Na}$ & & 1425 & 33 & 72 & 0 & -5 \\
\hline $\mathrm{Mg}$ & & 740 & 0 & 93 & 5 & 2 \\
\hline $\mathrm{Al}$ & & 3085 & 0 & 0 & 33 & 67 \\
\hline K & & 0 & 0 & trace & 0 & 0 \\
\hline $\mathrm{Ca}$ & & 5235 & 0 & 93 & 16 & -9 \\
\hline $\mathrm{Ti}$ & & 120 & 0 & 0 & 19 & 81 \\
\hline $\mathrm{Fe}$ & & 2830 & 0 & 0 & 22 & 78 \\
\hline $\mathrm{Sr}$ & & 175 & 0 & 99 & 13 & -12 \\
\hline
\end{tabular}

Elements removed by hydrochloric acid originally existed in the coal in organic coordination complexes, as acid soluble minerals, or perhaps as noncrystalline clays. The organically coordinated elements and some of the acid soluble minerals would also volatilize upon combustion. The non-crystalline clays, along with acid insoluble oxides and aluminosilicates, undergo little if any vaporization. These mineral particles may act as surfaces on which the volatilized species may condense.

As the data indicates, there is little difference among the samples tested. The feeder did not seem to greatly partition the coal particles as far as composition of those particles is concerned.

In the future more carefully oized fractions of coals will be characterized using the chemical fractionation technique in conjunction with the SEM/EMPA analysis of minerals present. A detailed description of the characterization methodology will follow the description of the work completed on the SEM/EMPA technique.

The -200 mesh fraction of Robinson seam coal was analyzed for mineralogy by the SEM/EMPA system (see Table 6). The combined Scanning Electron Microscope and Electron Miroprobe has proven to be an effective instrument for the quantitative analysis of minerals in coal (36). The SEM/EMPA system permits observation and chemical analysis of very fine-grained minerals, while preserving both the original chemistry of the minerals and their relationships to the organic constituents. Various procedures and techniques of automated SEM/EMPA analysis have been published which illustrate the benefits of using the SEM for mineralogic analysis $(36,37,38)$. 
TABLE 6

: SEM/EMPA MINERALOGIC ANALYSES

Mineral

Quartz

Kaolinite

Pyrite

Gypsum

Total Minerals $\frac{\text { Weight Percent }}{-200 \text { Mesh }}$

$2.0 \%$

$2.7 \%$

$1.3 \%$

Trace

Ash $70.5 \%$

The UNDERC JEOL JXA-35 microprobe is interfaced with a Tracor Northern TN $5500 \mathrm{x}$-ray analyzer, and was manipulated to perform quantitative analysis of mineral particles in coal. A point-counting method was used to quantify mineral species. Mineral quantities were determined by moving the stage and sample at equal increments and recording the type of material which was encountered under the electron beam spot (i.e. mineral, coal matrix, epoxy). All minerals encountered were analyzed by energy-dispersive $x$-ray spectrometry (EDS) for 50 seconds, and the energy spectra were stored for later analysis. Identification of minerals was accomplished by comparing the ratios of elements as determined by EDS with known elemental ratios determined from the minerals' chemical formulas. For example, kaolinite has an aluminum-silicon ratio of 45:55 (weight percent oxide) and typical EDS percentages for kaolinite are approximately 45:55. Since most low-rank coals typically contain only five or six major constituents, the spectral patterns for the minerals present are fairly consistent and easily identified.

Quantitative analysis of the elemental composition of each mineral was performed using the $\mathrm{ZAF}$ corrected $\mathrm{x}$-ray fluorescence analysis procedure. Each mineral was subsequently identified by examination of the elemental weight percents and the comparison of these data with known elemental compositions of minerals. Five hundred points were recorded for each sample and volume percentages of the major mineral phases and coal matrix were determined. The volume percentages were converted to weight percentages using pub],ished densities of the minerals.

Although the quantitative mineralogy method as employed was effective in determining the morphology, occurrence, and relative abundance of minerals present, further development is needed. Further automation would allow a much larger number of points to be counted and could therefore increase the accuracy of the results. A methodology will be developed to distinguish the minerals inherent to the coal particles and those extraneous to the particles, as this will affect the behavior of the minerals during combustion. 
The coal characterization work completed in this reporting period has resulted in the development of an overall coal characterization and preparation methodology shown in Figure 20. This methodology has been developed to address the objectives of this project.

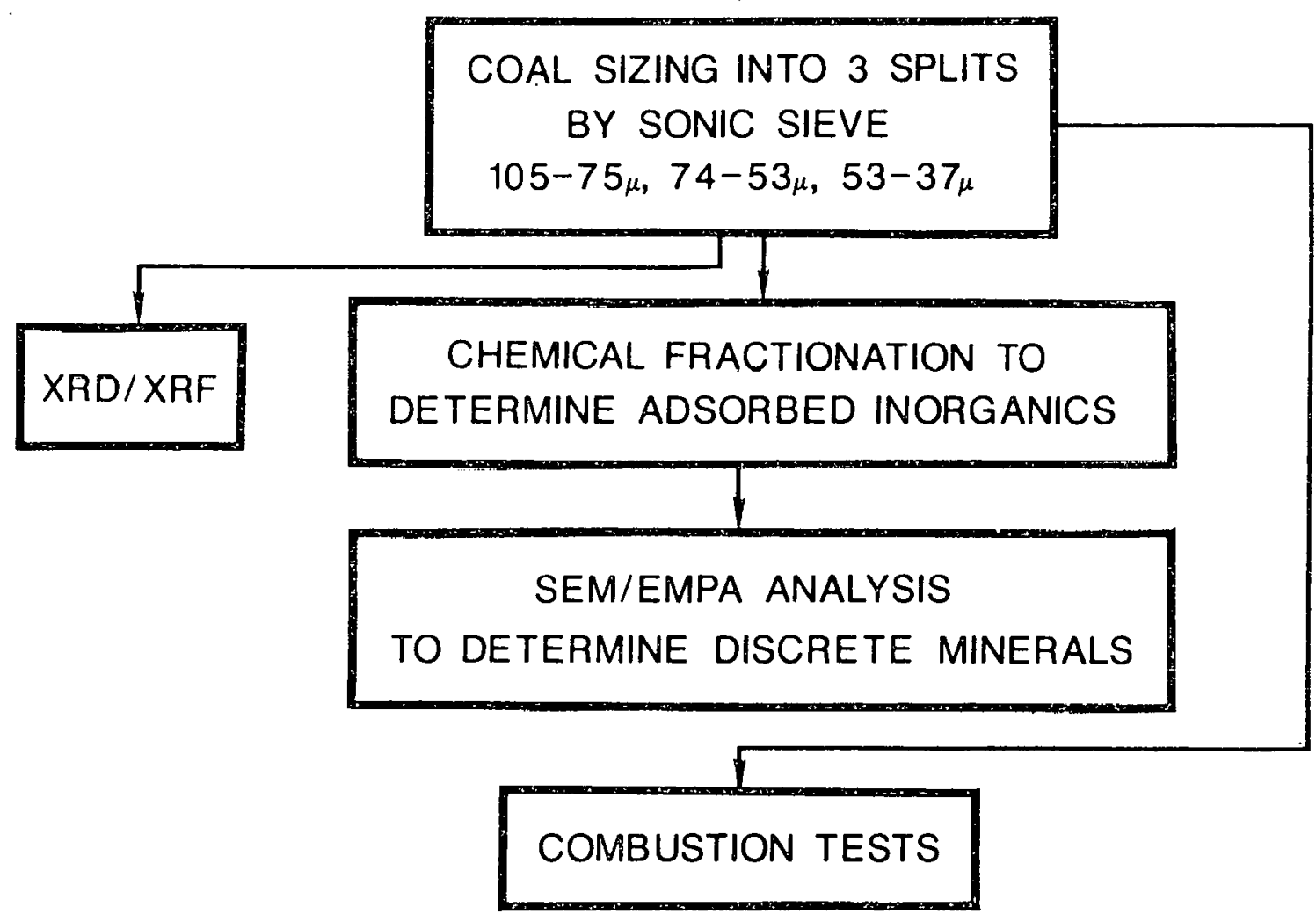

Figure 20. Coal characterization and preparation methodology.

The first step in the characterization methodology is the careful proparation of the coal salnules to be tested. Since many of the mechanisms of particulate formation can be related to the initial size and morphology of the coal particles, great care will be taken in preparation of samples for combustion. Each coal sample will be carefully size-segregated prior to analysis and testing. A sonic sieve will be used to accurately size the coal. This technique has been successfully used to size coals and chars for reactivity studies. Samples will be scanned and photographed with an optical micruscope to ensure proper sizing and document the morphology of the coal particles prior to combustion.

After sample preperation each size fraction will be analyzed using the chemical fractionation and quantitative mineralogy techniques described previously. Since the resultant fly ash will be characterized by similar methods, direct comparisons of the data will be possible. This will allow for conclusions on the mechanisms of fly ash formation. 


\subsection{CONCLUSIONS}

The primary objective of the drop tube furnace project is to determine the mechanisms of inorganic transformations that take place during coal combustion. The goals of the first year included 1) the design and construction of a laboratory scale furnace system, 2) the testing and characterization of that system, and 3) the development of a characterization methodology for the study of inorganic transformations in coal. These major objectives were met and have provided a firm foundation for the work to follow.

\subsection{FUTURE WORK}

The work in year two will address the problems of ash formation mechanisms with a multifaceted approach. The experimental approach addresses the critical variables associated with fly ash formation during coal combustion. These critical variables are:

1. Knowledge of the composition, association, and morphology of the inorganic constituents present in the coal prior to combustion.

2. Strict control of coal particle size prior to combustion.

3. A detailed knowledge of the combustion conditions.

4. Knowledge of the size, morphology, and composition of particulate after combustion.

The experiments will be performed using the extremely flexible laninarflow drop-tube furnace system completed in this reporting period. This system is capable of simulating the time/temperature history of a full scale boiler. The coals will be caretully prepared and characterliced uriur to combustion experiments. The particle size distribution of the inorganic constituents will be measured at various temperatures and residence times. This will be used to determine the degree of fragmentation as a function of temperature and residence time. The composition of the particulates will be determined on a particle by particle basis and correlated with distribution of inorganic constituents, with a primary goal of determining the interaction of organically-bound cations and mineral particles prior to deposition.

Investigations such as those by Quann and Sarofim (34), Wibberly and Wall (32), Neville et al. (30), Sarofim et al. (31) and others have demonstrated ut,ility of using laboratory-scale combustion systems in conjunction with detailed analysis of the coals and resultant particulates. The advantages of this study over past research are several. The investigators have developed unique inorganic coal characterization techniques that are especially well suited for the examination of low-rank coals. Chemical fractionation combined with SEM/EMPA mineralogic analysis of the coals results in a quantitative determination of the modes of occurrence of inorganic species. In addition, the investigations have significant past experience on the ash deposition behvaior of western U.S. coals. 
The use of novel research equipment is an advantage afforded to the investigators of this study. The use of an advanced characterization methodology in conjunction with a flexible, laboratory-scale combustion system will result in the elucidation of the transformations of inorganics during coal, combustion.

\subsection{REFERENCES}

1. Sondreal, E.A., P.H. Tufte, and W. Beckering. Combustion Science and Technology, 1977, 16, 95.

2. Raask, E., "Mineral Impurities in Coal Combustion", Hemisphere Publishing Company, New York, 1985.

3. Benson, S.A., D.K. Rindt, G.G. Montgomery, and D.R. Sears. Ind. Eng. Chem. Prod. Res. Dev., 1984, 23, 252.

4. Benson, S.A. and P.L. Holm. Ind. Eng. Chem. Prod. Res. Dev., 1985, 24, 145.

5. Miller, R.N. and P.H. Given. U.S. Depart. of Eng. Report, FE-2494-TR1, 1978.

6. Wibberley, L.J. and T.F. Wall, Fuel, 1982, 61, 87.

7. Boow, J. Fuel, 1972, 51, 170 .

8. Tangsathitkulchai, M., "Studies of the Initiation, Growth, and Sintering in the Formation of Utility Boiler Deposits", Ph.D. Thesis, The Pennsylvania State University, 1986.

9. Rindt, D.K., S.J. Selle, and W. Beckering, "Investigations of Ash Fouling Mechanisms for Western Coals Using Microscopic and X-Ray Diffraction Techniques", ASME Paper No. 79-WA/CD-5, 1979.

10. Rindt, D.K., M.L. Jones, and H.H. Schobert, "Investigations of the Mechanism of Ash Fouling in Low-Rank Coal Combustion", in Fouling and Slagging From Mineral Impurities in Combustion Gases, R.W. Bryers, Ed., $17-36,1983$.

11. Tufte, P.H. and W. Beckering, ASME J. Eng. for Power, 1975, 407.

12. Mims, C.A., R.J. Neville, and A.F. Sarofim, "Laboratory Studies of Trace Element Transformation During Coal Combustion", presented at the 87 th AIChE Meeting, August 1979, Boston, Massachusetts.

13. Stewart, G.W., C.D. Stinespring, and P. Davidovits. Prepr., Div. Fuel Chem., Am. Chem. Soc., 1982, 27 (1), 38. 
14. Gelbwachs, J.A., C.F. Klein, and J.E. Wessel. Appl: Phys. Lett., 1977, 30, 489 .

15. Denton, M.B. and H.V. Malmstadt, Appl. Phys. Lett., 1971, $18,485$.

16. Daily, J.W. and C. Chan. Combustion and Flame, 1978, 33, 47.

17. Daily, J.W. Applied Optics, 1977, 16, 568.

18. Landau, L.D. and E.M. Lifshitz, "Electrodynamics of Continuous Media:, Pergamon: Oxford, 1960, Sec. 72.

19. Combustion Inorganic Transformations, Quarterly Technical Progress Report, April - June, 1986.

20. Combustion Inorganic Transformations, Quartcrly Technical Prugresij Report, July - September, 1986.

21. Combustion Inorganic Transtorinations, Quarlerly. Technioal Progress Report, October - December, 1986.

22. Van Calcar, R.A., Van De Ven, M.J.M., Van Vitert, B.K., Biewenga, K.J., Hollander, TJ., Alkemade, C.TH.J. J.Q.S.R.T. 1979, $21,11$.

23. Winefordner, J.D., Vickers, T.J. Anal. Chem 1964, 36, 1939.

24. Smith, B., Winefordner, J.D., Omenetto, N. J. of Applied Physics, 1977, $48,2676$.

25. Winefordner, J.D., Mansf.ield, C.T., Vickers, T.J. Anal. Chem. 1963, 35, 1607 .

26. Muller, C.H., Schorield, K., Steinberg, M. J. Chem. Phys. 1980, 72, 6620.

27. Senior, C.L. Flagan, R.C., Symp. (Int.) Combust., (Proc.) 1984, 921.

28. Omenetto, N., Epstein, M.S., Bradshnw, J.D., Bayer, S., Horrath J.J., Winefordner, J.D. J.Q.S.R.T. 1979, 22, ?87.

29. Benson, S.A. Ph.D. Thesis, The Pennsylvania State University, 1987.

30. Neville, M., Sarofim, A.F. Fuel 1985, 64, 384.

31. Sarofim, A.F., Howard, J.B., and A.S. Paodia, Combustion Science and Technology, 1986, $48,177$.

32. Wibberley, L.J. and T.F. Wall, Combustion Science and Technology, 1986, $\underline{48}, 177$. 
33. Lowe, 1979. Ph.D. Thesis, Measurements and Analysis of the Radiative Properties of Fly Ash Particles in Pulverized Coal Flames and Their Effect on Heat Transfer. University of Newcastle, NSW, Australia.

34. Quann, R.J. and A.F. Sarofim, Fuel, 1986, 65, 40.

35. Allen, R.M. and J.B. Vandersande, Fuel, 63 (1), 24.

36. Huggins, F.E., D.A. Kosmack, G.P. Huffman, and R.J. Lee, Scanning Electron Microscopy, 1980, I, 531.

37. Moza, A.K., D.W. Strickler, and L.G. Austin, Scanning Electron Microscopy, IV, 91.

38. Moza, A.K., L.G. Austin, and G.G. Johnson, Jr., Scanning Electron Microscopy, 1980, I, 473. 


\begin{tabular}{|c|c|c|}
\hline 1. Program/Project Identitication No. & $\begin{array}{l}\text { 2. ProgramiProject Tille } \\
\text { COMBUST ION INORGANIC TRANSEORMATION }\end{array}$ & $\begin{array}{l}\text { 3. Reporting Period } \\
4 / 1 / 86 \text { inrough } 3 / 31 / 87\end{array}$ \\
\hline 4. Name and Acdress & Dakota Fneroy Research Center & $\begin{array}{l}\text { 5. Program/Project Start Date } \\
4 / 1 / 86\end{array}$ \\
\hline Box 8213 , University & Station, Grand Forks, ND 58202 & 6. Completjon Oate $31 / 92$ \\
\hline
\end{tabular}

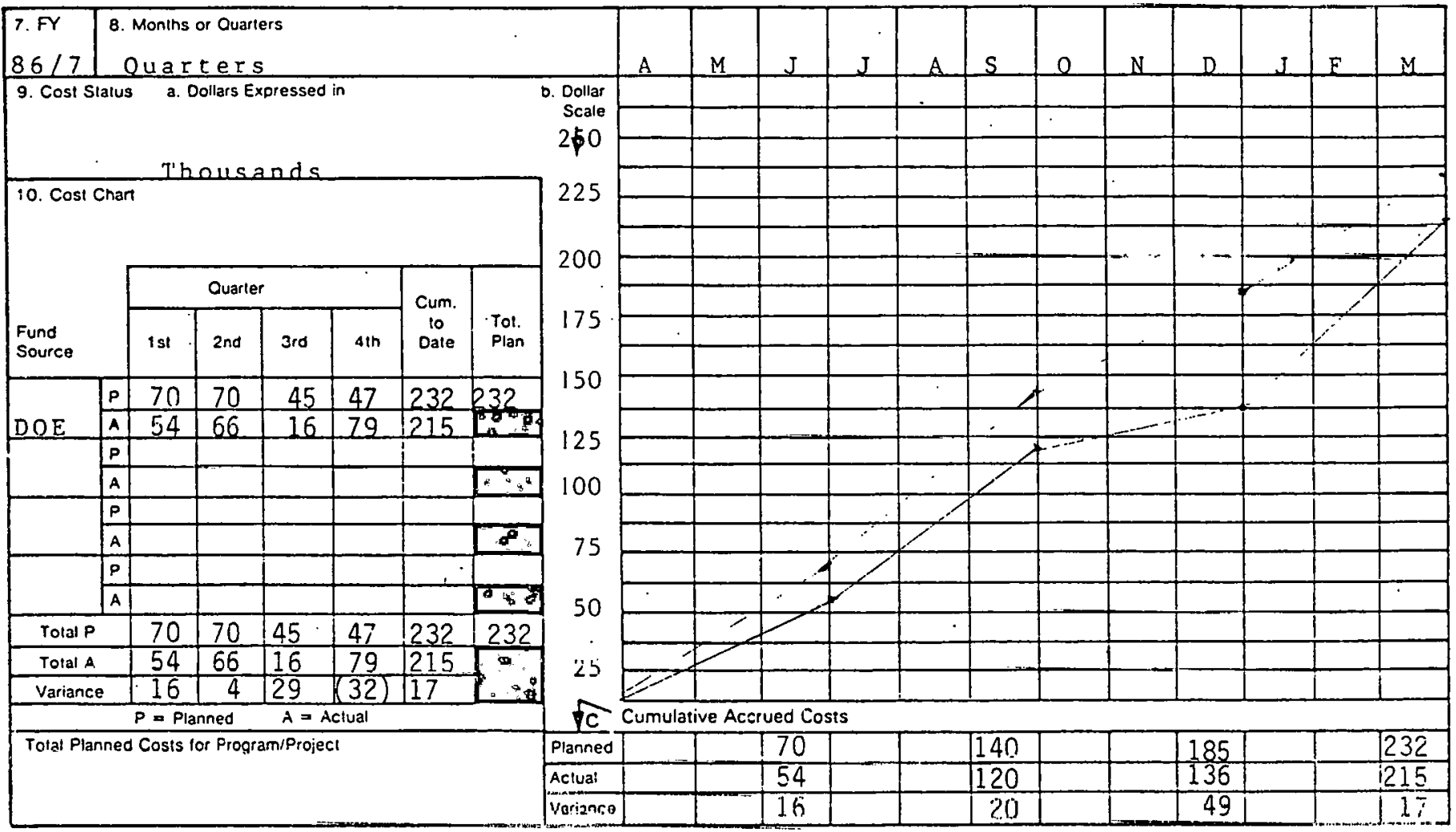

\begin{tabular}{|c|c|c|}
\hline \multirow[t]{2}{*}{ 11. Major Milesione Sinius } & \multirow{2}{*}{ Urills Plannes } & \\
\hline & & \\
\hline & $P$ & \\
\hline & C & \\
\hline \multirow{4}{*}{$\begin{array}{l}\text { a. LIAF System Installation. } \\
\text { and Optimization }\end{array}$} & $\bar{p}$ & $? \nabla$ \\
\hline & c & 3. \\
\hline & $\mathbf{P}$ & \\
\hline & c & \\
\hline \multirow[t]{3}{*}{$\begin{array}{l}\text { b. Measurement of Sodium } \\
\text { Release from Aqueous Sol. }\end{array}$} & c & $\pi_{1}$ \\
\hline & $P$ & \\
\hline & C & \\
\hline \multirow{4}{*}{$\begin{array}{l}\text { C. Drop-tube Furnace } \\
\text { Construction }\end{array}$} & $\mathbf{P}$ & 18 \\
\hline & c & 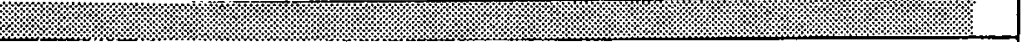 \\
\hline & $P$ & \\
\hline & $C$ & 17 \\
\hline \multirow{8}{*}{$\begin{array}{l}\text { d. Inorganic Characterization } \\
\text { of two LRC }\end{array}$} & E & 17 \\
\hline & $\mathbf{P}$ & \\
\hline & c & \\
\hline & $P$ & \\
\hline & C & \\
\hline & c & \\
\hline & $\mathbf{P}$ & ח \\
\hline & C & 80 \\
\hline
\end{tabular}


Page _ of __

\begin{tabular}{|c|c|c|}
\hline 1. Precramispolect loentilicstion No. & $\begin{array}{l}\text { 2. ProgramiPropect THle } \\
\text { COMBUSTION INORGANIC TRANSFORMATION }\end{array}$ & $\begin{array}{l}\text { 3. Reonninn Perroo } \\
4 / 1 / 86^{-2} \text { inrougi: } 3 / 31787\end{array}$ \\
\hline $\begin{array}{l}\text { 4. Name and todess } \\
\text { University of North }\end{array}$ & kota Energy Research Center & $\begin{array}{l}\text { 5. ProgramiProled Stsi Ode } \\
4 / 1 / 86\end{array}$ \\
\hline Box 8213 , University & ation, Grand Forks, ND 58202 & $\begin{array}{l}\text { 6. Compietion Oale } \\
3 / 31 / 92\end{array}$ \\
\hline
\end{tabular}

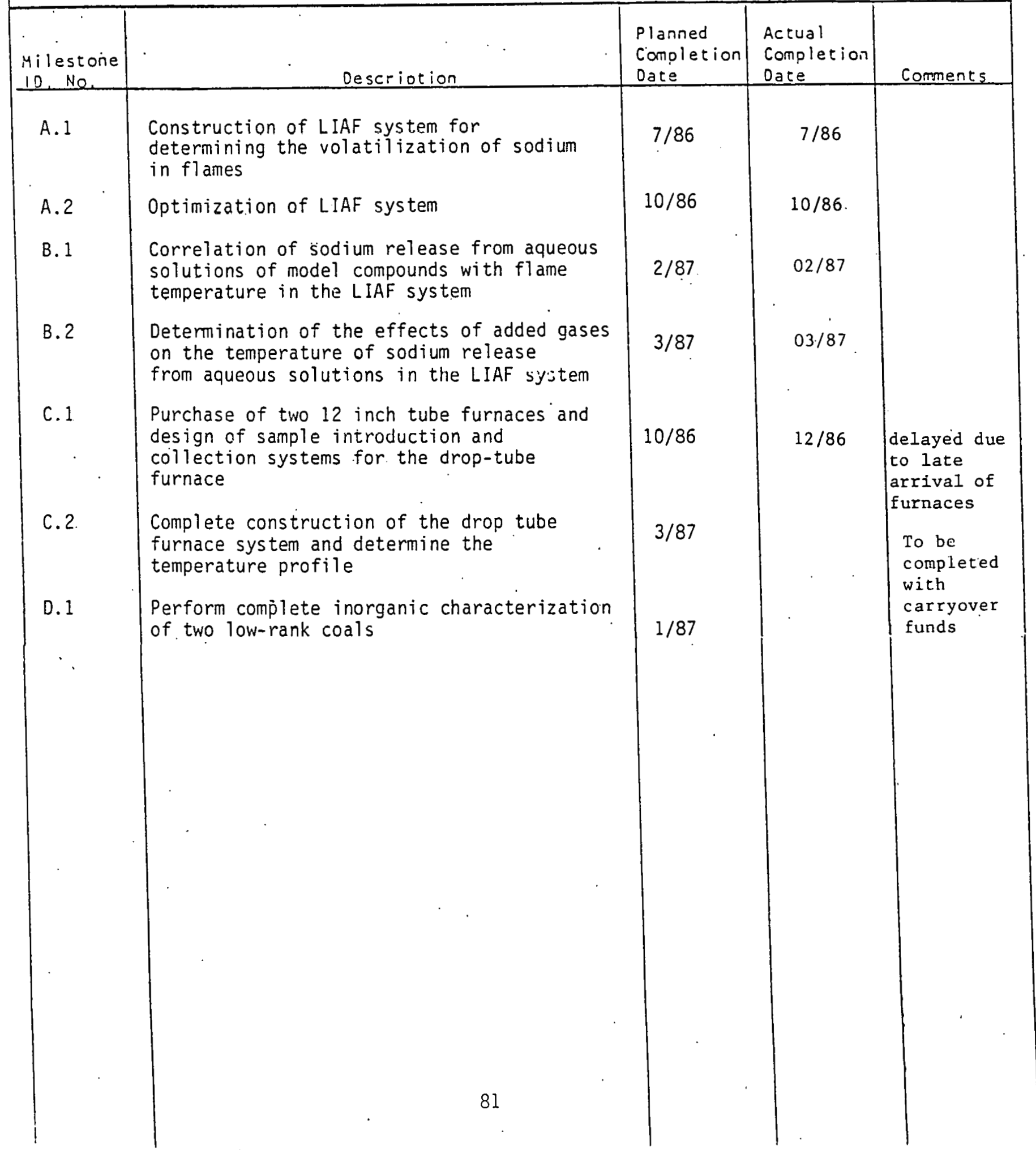


THIS PAGE

\section{WAS INTENTIONALLY \\ LEFT BLANK}




\section{COAL/CBAR REACTIVITY}

Final Technical Report for the Period April 1, 1986 -March 31, 1987 Including the Quarterly Technical Progress Report for the Period January through March, 1987

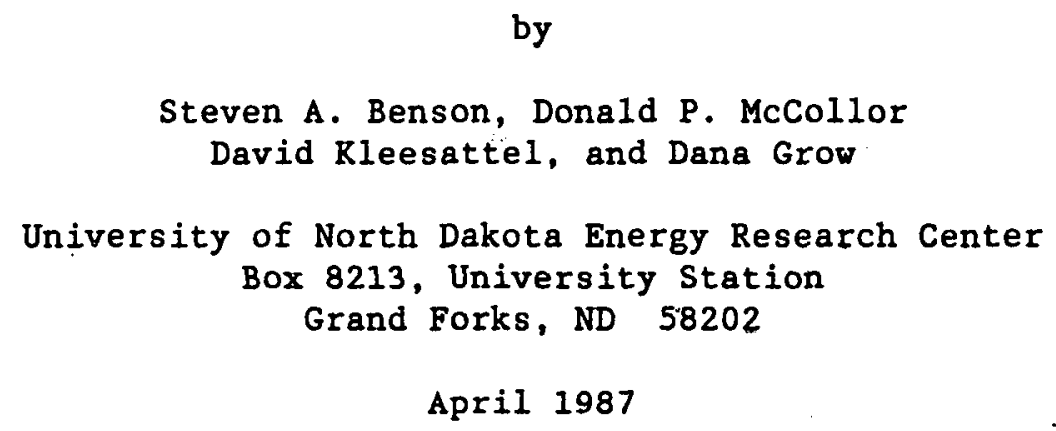

Contracting Officer's Technical Representative: James Hickerson

Prepared For

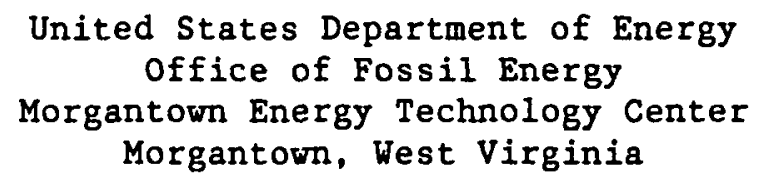

Under Cooperative Agreement No. DE-FC21-86MC10632-T3 
THIS PAGE

\section{WAS INTENTIONALLY LEFT BLANK}




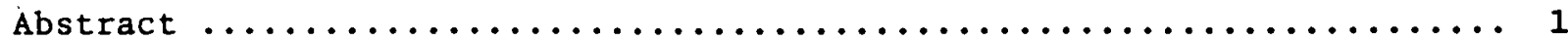

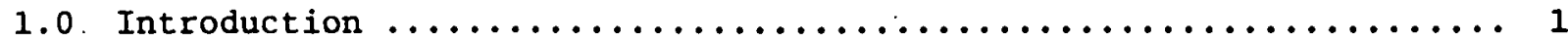

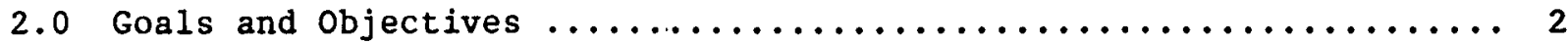

3.0 Assessment of the Influence of Catalytic Mineral Matter Effects and Physical Structure on the Combustion Behaving of Highly

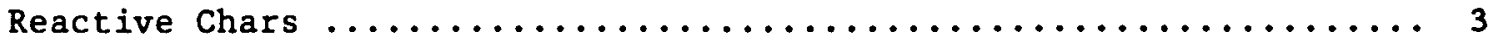

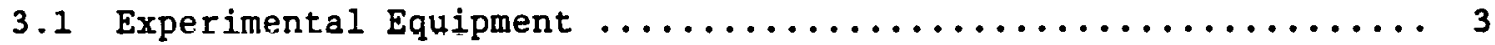

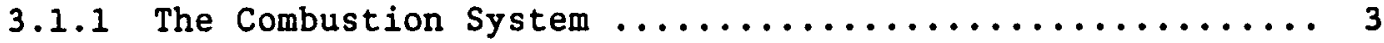

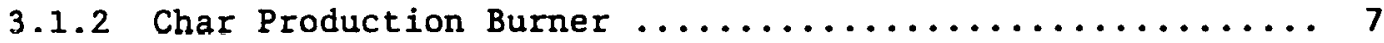

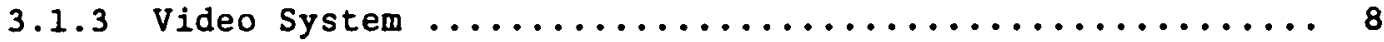

3.2 Preparation and Characterization of Chars $\ldots \ldots \ldots \ldots \ldots \ldots \ldots \ldots$

3.2.1 Coal Characteristics and Preparation $\ldots \ldots \ldots \ldots \ldots \ldots \ldots 10$

3.2 .2 Preparation of Cation Loaded Coals ................ 12

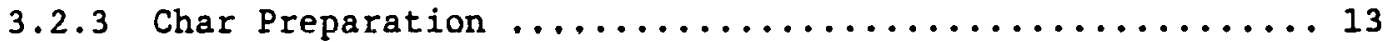

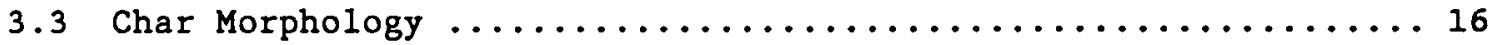

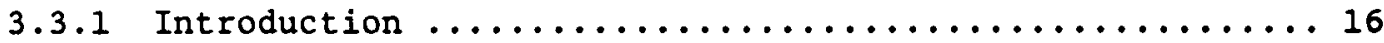

3.3.2 Char Morphotype Terminology .................. 17

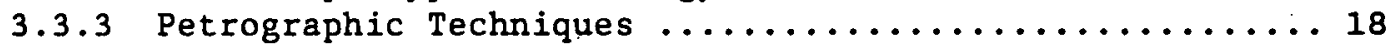

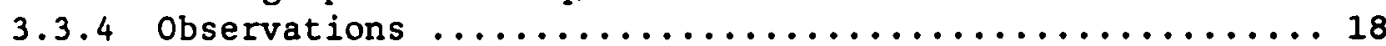

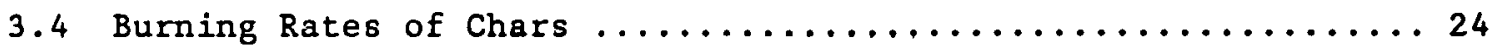

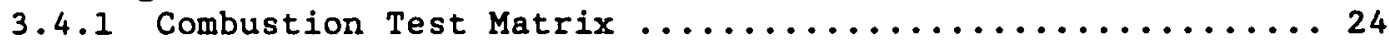

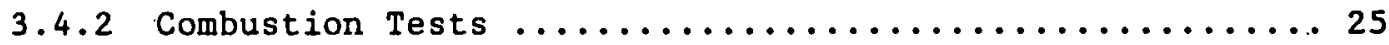

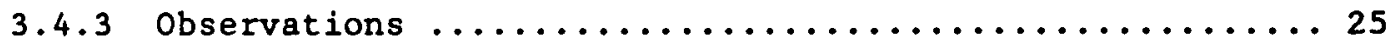

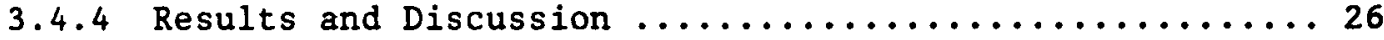

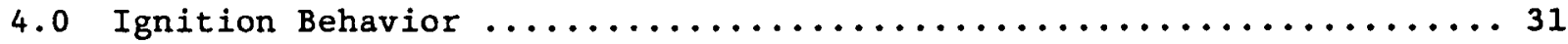

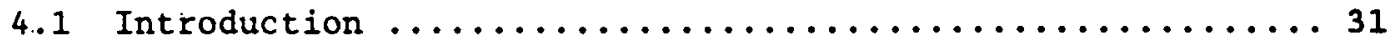

4.2 Calculation of Gas Ignition Temperatures ............ 35

4.3 Experimental Approach ........................... 37

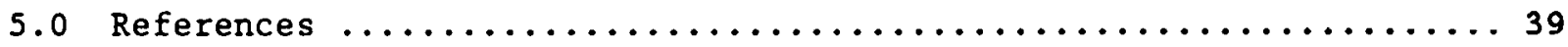


THIS PAGE

\section{WAS INTENTIONALLY LEFT BLANK}




\section{ABSTRACT}

Studies have been conducted to determine the effects of organically-bound cations on the burning rates of char particles. Two coals, Beulah-2ap (ND) and New Mexico Blue, have been studied. The coals were demineralized and loaded with various cations including $\mathrm{R}^{+}, \mathrm{Ca}^{++}$, and $\mathrm{Na}^{+}$. The burning rates for demineralized Beulah-Zap char was greatly reduced as compared to the untreated coal char. The reactivity was increased to that of the untreated chars after reloading with cations. The increased burning rates noted for some of those chars may be attributed to the promotion of $\mathrm{CO}_{2}$ production by the catalytic activity of the organically-bound cations.

Petrographic analysis of the Beulah-Zap chars were conducted to determine the effects of pretreatment (i.e., demineralization and cation loading) on the morphology of the char particles produced during rapid pyrolysis. The most obvious change in particle morphology was found in the char produced from the demineralized coal. The demineralized coal appears to become more plastic during rapid pyrolysis than the untreated coal as indicated by the large increase in the formation of cenospheres. Preliminary morphological studies have been conducted on the char residues collected at various heights from the injection point of the single particle reactor. The results have shown that the unfused and inertosphere morphotypes increase in relative abundance at higher heights in the reactor chimney. This is probably due to their relative low reactivity which inhibits ignition and combustion.

A review of the literature was conducted on ignition phenomena. In addition, some preliminary work was done on the calculation of the conditions necessary for particle ignition. An apparatus was designed to measure. single particle ignition by measuring $\mathrm{CO}_{2}$ and $\mathrm{CO}_{2}$ concentrations and the light generated during particle ignition.

\subsection{INTRODUCTION}

Pulverized coal ( $<200 \mu \mathrm{m}$ in size) is increasingly being used in combustion boilers for power generation. Knowledge of the burning rates of char, the solld pluduced from the pyrolysis of coal in the initial phase of coal combustion, is important for improving the design and operation of combustion systems. It is the burnout time of the char and its heat release which determines the size of combustion chambers.

The burning rate depends on the nature of the parent coal, the composition and temperature of the combustion gas, and the size and temperature of the particles. The burning rate is rontrolled by transport processes (oxygen particles) or by chemical reaction on the pore walls. The rate-limiting process depends on size and temperature of the particles $(1,2)$. 
The combustion of char particles produces both carbon dioxide and carbon monoxide. However, for particles < $100 \mathrm{\mu m}$ and at temperatures $>1400 \mathrm{~K}$, the primary product is generally considered to be carbon monoxide $(3,4,5,6)$. Carbon dioxide subsequently forms in the gas stream well beyond the boundary layer $(1,7)$. Lower temperatures as well as catalytic impurities result in both carbon monoxide and carbon dioxide as primary products $(6,8)$. However, the conditions determining the $\mathrm{CO}_{2} / \mathrm{CO}$ ratio are far from fully resolved. Since the heat of formation of carbon dioxide is three and one-half times that of carbon monoxide, uncertainty of the proportions can have a significant effect on calculations of particle temperatures from rate data and vice versa.

Most of the kinetic studies of pulverized char combustion have involved gas sampling measurements for determining rate data from which particle temperatures are calculated. Recently, researchers at Sandia National Laboratories $(9,10)$ developed an optical technique to measure simultaneously temperature, size, and velocity of burning particles, the dafa trom which burning rates can be determined. However. rate data on low rank U.S. cods using either technique are very limited. Only two brief studies have been reported, one on a Wyoming subbituminous coal char using the gas sampling technique (11) and the other, reported very recently (12), on a North Dakota Beulah lignite char using particle temperature measurements. A comparison of this data, where applicable (50-100 $\mathrm{m}$ marticles, 1300-1600K), shows the Wyoming char to be of higher reactivity. This result was unexpected as the Beulah lignite char was burning near the diffusion limit for conversion to carbon monoxide. Further comparative studies should be performed similar to a study that has been made for chars from several low-rank Australian coals, including brown coal $(13,14,15)$.

\subsection{GOALS AND OBJECTIVES}

The overall objective of the coal/char reactivity project is to expand the fundamental combustion data base to support existing and advanced atmospheric combustion systems. The investigations will focus primarily on elucidating the burning rates of chars under realistic flame conditions as a function of fuel and system parameters. The chars are to be derived mainly from low-rank coals. A key issue is the relative contributions of mineral matter, surface, and structural effects to the burning behavior of highly reactive chars. Tests will also be undertaken to ascertain the limits of bulk diffusion (i.e. mass transfer) control of the burning rate.

A second objective is to carry out an exploratory study of the ignition mechanlsms of coal combustion. One of the factors to be addressed is the role of moisture in the ignition of lnw-rank coalo. 


\subsection{ASSESSHENT OF RELATIVE INFLUENCE OF CATALYTIC GINERAL HATTER EFFECTS AND PHYSICAL STRUCTURE ON THE COMBUSTION BEHAVIOR OF HIGHILY REACTIVE CHARS.}

\subsection{EXPERIMENTAL EQUIPHENT AND PROCEDURES}

\subsubsection{The Combustion System}

An experimental bench-scale combustor has been constructed to examine single-particle combustion with optical and extractive techniques in an environment which can be closely controlled with respect to gas temperature and gas composition.

The distinguishing features of the single-particle reactor are as follows: 1) the particles are burned in a flameless gaseous environment enclosed by a vertical quartz chimney; 2) gas compositions and temperatures can be widely varied and independently controlled; and 3) particle temperatures are monitored by a three-color optical pyrometer. The system is depicted schematically in Figure 1.

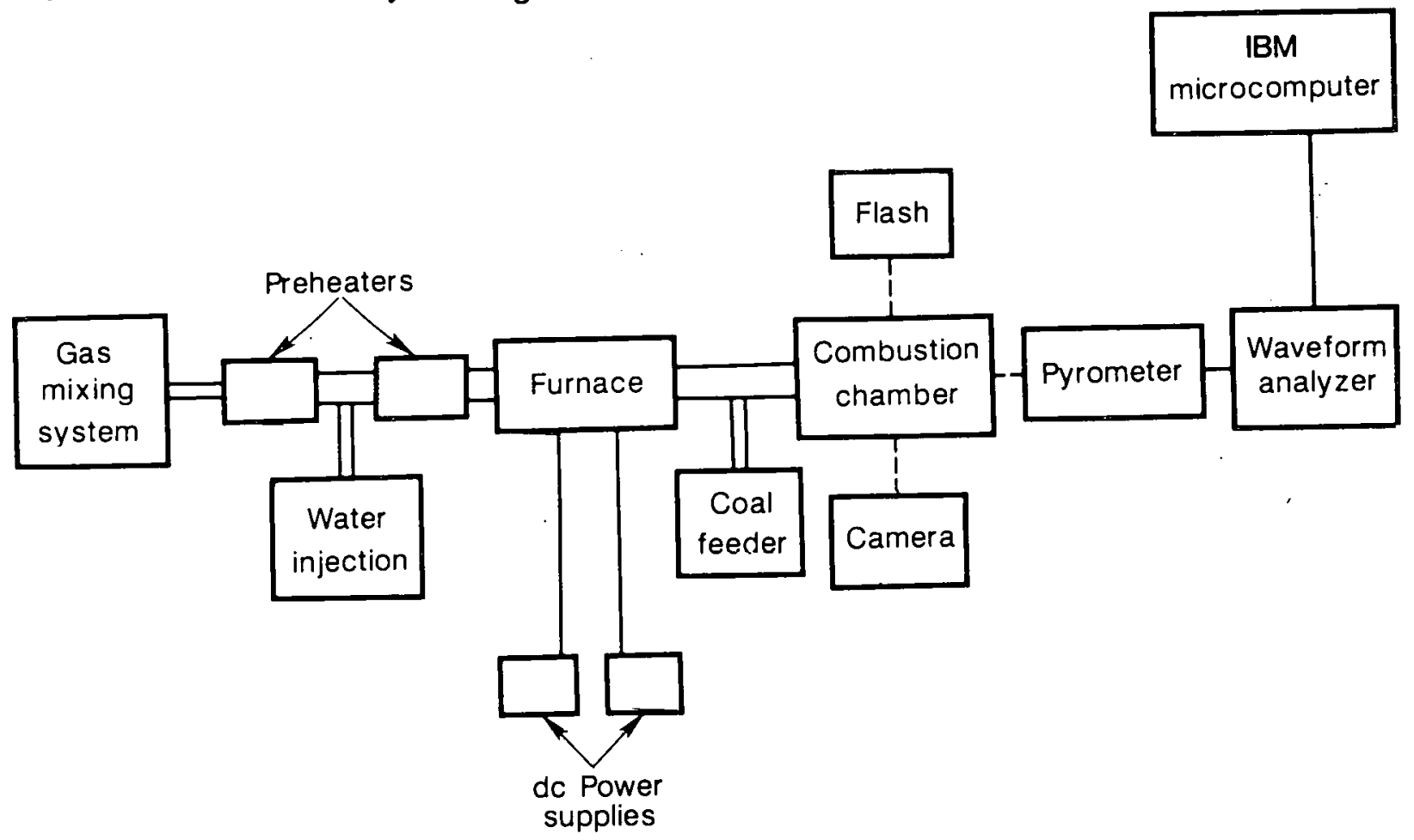

Figure 1. Schematic Representation of the SingleParticle Combustion Syetem.

A simulated combustion mixture of oxygen $(0-40 \quad \ell / m i n)$, nitrogen (0$100 \mathrm{l} / \mathrm{min})$, and other gases $\left(\mathrm{CO}_{2} 0-10 \mathrm{l} / \mathrm{min}\right.$ and $\left.\mathrm{SO}_{2} 0-10 \mathrm{l} / \mathrm{min}\right)$ is prepared as required with the aid of a mass flow controller with a metering accuracy within $1 \%$ of the full-scale range of each gas. As desired, water (0-25 $\mathrm{cc} / \mathrm{min}$ ) can be metered into the gas stream with a peristaltic pump prior to 
the second preheater. Before the preheaters, a small portion of the gas stream is diverted to the particle feeder. The remaining gas is preheated to approximately $775 \mathrm{~K}$ before entering the high temperature section of the furnace. Here the gas passes over 48 electrically heated molybdenum disilicide elements which have a maximum temperature rating of $2075 \mathrm{~K}$. These elements are energized by two $10 \mathrm{KW}$ DC power supplies.

The particle feeder consists of a slowly rotating cylindrical tube with several holes of uniform size at one end. Tubes having holes between 0.35 and $1.00 \mathrm{~mm}$ are used depending on the particle size being investigated. The particles are fed into the diverted portion of the gas stream in discrete pulses and subsequently exit through a water-cooled tube passing through a flow straightener at the base of a vertical quartz chimney.

The quartz chimney, shown in Figure 2, has internal dimersions of $86 \mathrm{~mm} \times$ $86 \mathrm{~mm} \times 305 \mathrm{~mm}$, and aflows optical pyrometry and photography of the burning particles to be carried nut perpendicular to the particle trajectory. At the top exit of the chimney, a stainless steel flow restrictor was constructed to fit over the quartz windows and tapored at a 45 deglet angle to a final $5.4 \mathrm{~cm}$ square exit. The flow restrictor prevents entrainment of room air into the chimney and back propagation of pressure fluctuations. The original design included a ceramic honeycomb flow straightener $0.5 \mathrm{~cm}$ thick with 1 mm square holes. The ceramic honeycomb has a relatively high emissivity, and was absorbing significant amounts of heat by conduction from the gas and then releasing the heat as radiation which was not reabsorbed by the gas and passed out the chimney windows. The ceramic was replaced with two layers of coarse nichrome screen with lower emissivity, resulting in an increase in chimney gas temperature as well as an improvement in the laminar gas flow. To reduce the radiation loss through the windows at the chimney base, the quartz windows were raised and $6 \mathrm{~cm}$ sections of $2.5 \mathrm{~cm}$ thick high temperature insulation were fitted below the windows at the chimney base.

The optical instrumentation, (see Figure 2) consists of a long-range microscope/camera, high speed flash lamp, three-color pyrometer, and rightangle particle focus detector, and is focused on the vertical centerline of the chimney. Mounted on optical benches, the instruments can be finely adjusted through a range of $76 \mathrm{~mm}$ in a vertical direction. The microscope/flash system may be slaved to the pyrometer system to trigger upon detection of a particle.

The optical head of the pyrometer scans a $1 \mathrm{~mm}^{3}$ volume on the centerline of the chimney through the use of two achromatic lenses and a $1 \mathrm{~mm}^{2} \mathrm{slit}$. The detection height can be varied as desired but most experiments have been carried out at $150 \mathrm{~mm}$ above the hnneycomb flow straighlener to ensure complete heating and devolatilization of the particles. The light emitted from the burning particles impinges on the optical head where it is split into three approximately equal signals and transmitted via a trifurcated fiber optics cable through three marrow-band pass filters centered at 550,700, and $800 \mathrm{~nm}$ with $10 \mathrm{~nm}$ band passes to three photomultiplier tubes. In contrast to the two color pyrometers employed by most other researchers, the additional wavelength allows an internal check on the temperature data as well as a better representation of the radiation from the particle. 


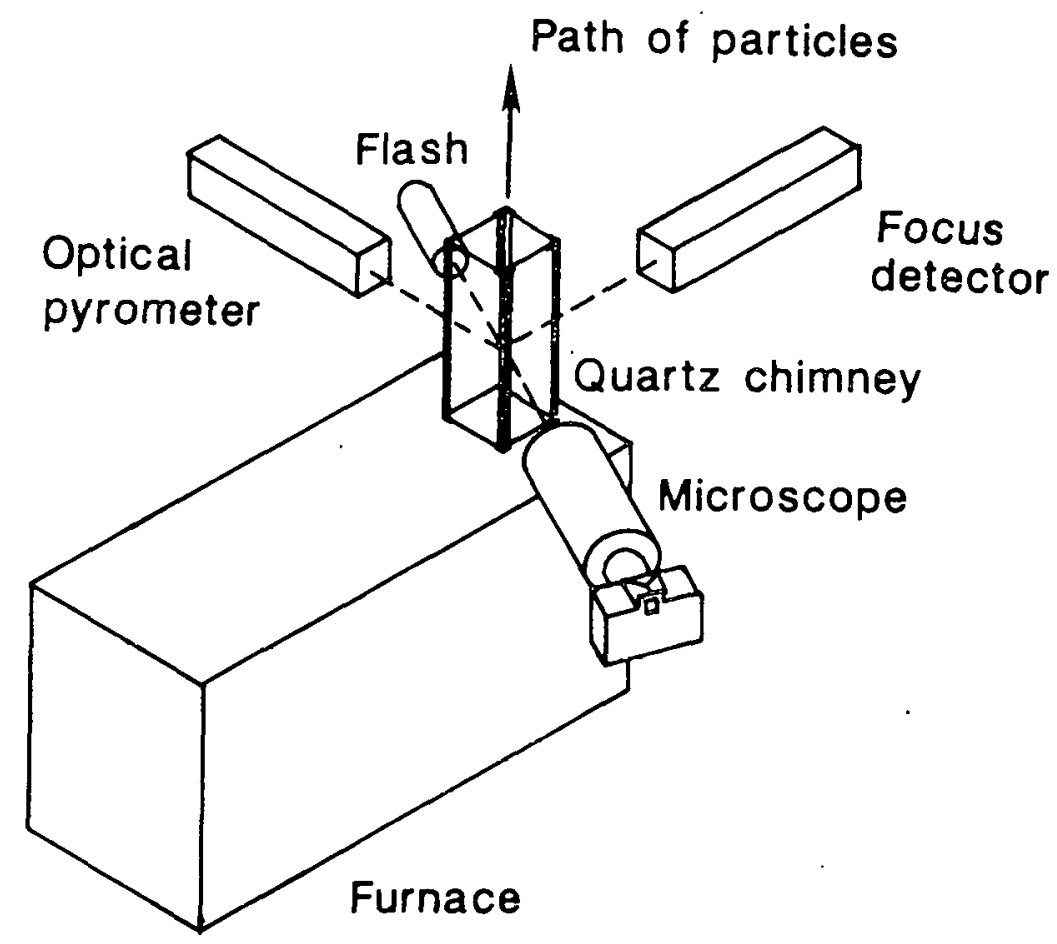

Figure 2. View of the Quartz Chimney and Arrangement of the Optical Equipment.

The focus detector consists of a second lensing system located at right angles to the pyrometer viewing axis and focused at the same point on the chimney centerline as the pyrometer. The signal from the focus detector is connected via a fiber optics cable to a fourth photomultiplier/amplifier assembly. The coincidence of a particle signal from the pyrometer and the focal detector ensures that the observed particle is within the $1 \mathrm{~mm}^{3}$ control volume.

The photomultiplier signals are amplified with combination socket assembly/wide band amplifiers and captured by a digital waveform analyzer. The data signals are low-pass filtered at $10 \mathrm{kHz}$ and stored by the waveform analyzer. A circular convolution procedure is then applied to each stored signal to smooth noise. Particle signals captured by the analyzer are than accepted manually if the pyrometer and focus detector signals are coincident and no multiple peaks or overranging of the pyrometer occurs. The signal records are then transferred to a floppy disc for subsequent analysis by a microcomputer. This procuedure provides a permanent record of each particle signal and allows analysis of the data with multiple processing schemes.

To prevent overranging the pyrometer, one or more neutral density filters are inserted in the pyrometer optical path as required. The filters have nominal densities of $0.3,0.5,1.0,2.0$, and 3.0 absorbence. The actual absorbence for each filter at 550,700, and $800 \mathrm{~nm}$ is carefully determined using UV-visible spectrometer and is corrected for when the neutral density filters are used in calibration and data collection. 
Calibration of the pyrometer is carried out using a tungsten strip lamp and pinholes of known size $(41,113,190 \mu \mathrm{m})$ which are either stationary or located on a rotating chopper wheel. In the case of the stationary pinholes, light passing through them is chopped, to simulate an incandescent moving particle. The temperature of the lamp is measured using a disappearingfilament optical pyrometer. The calibration procedure involves up to 8 sets of 16 chopped signals which are processed using an algorithm for determining peak height, peak area and background. A least-squares analysis of the data is carried out and the regression equation is subsequently used to calculate the particle temperature and its prediction interval.

Three peak height to area ratios can be determined for each burning particle but only two of them are independent. The ratios at 550/700 nm and $700 / 800 \mathrm{~nm}$ are selected for further processing as they give the most reliable temperature data. Two particle temperatures are thus determined for each particle signal and the validity of each particle temperature io tested by determining whether it falls within the $95 \%$ confidence interval of the mean calculated on the basis of the predicted response. Finally, the mean temperature for all acceptable signals is calculated.

Gas temperatures in the vertical square chimney are measured using a $\mathrm{Pt} / \mathrm{Rh}$ thermocouple, positioned $1 \mathrm{~cm}$ above the control volume. When a trigger signal is obtained, the chimney gas temperature is automatically read. For each acceptable particle observation the gas temperature is then recorded on floppy disc.

The microscope/flash assembly consists of a high intensity xenon strobe lamp adapted for use with the combustor and a long range microscope. The microscope combines a large depth of field with a $65 x$ magnification at a minimum focal distance of $56 \mathrm{~cm}$. A $35 \mathrm{~mm}$ camera is mounted on the microscope. The microscope/flash system may be slaved to the pyrometer system to trigger when a particle is detected by the pyrometer. The strobe light/microscope is mounted approximately 20 degrees off the pyrometer axis to keep reflection from the flashlamp from reaching the pyrometer and right-ang.le detceror optics.

In addition to the non-intrusive optical techniques, solid particle samples are obtained from the chimney with a nitrogen-quenching solids probe which collects particulate material in an in-line cyclone. Sampling with this probe is done at a high anisokinetic flow rate into the probe, which ensures collection of virtually all particulate material injected into the ehimney during the sampling period. A small (1.59 $\mathrm{mm}$ id) water-jacketed gas sampling probe may be used to determine bulk gas composition in the chimney and to attempt to identify gaseous combustion products. Gas samples are analyzed using a Hewlett-Packard $5880 \mathrm{~A}$ gas chromatograph equipped with a refinery gas analyzer. Due to the long analysis time the GC is operated off-line with manually injected gas samples. Because of the very dilute concentration of combustion products such as $\mathrm{CO}$ and $\mathrm{CO}_{2}$ in the bulk gas stream, only major components $\left(\mathrm{N}_{2}\right.$ and $\left.\mathrm{O}_{2}\right)$ can be quantitatively determined. 


\subsubsection{Char Production Burner}

An existing flame burner was modified to produce chars under realistic combustion conditions. The flame burner and a schematic of the flow control system are shown in Figures 3 and 4 , respectively. The burner currently operates with a compressed air/natural gas mixture and can be adapted to burn other gas mixtures.

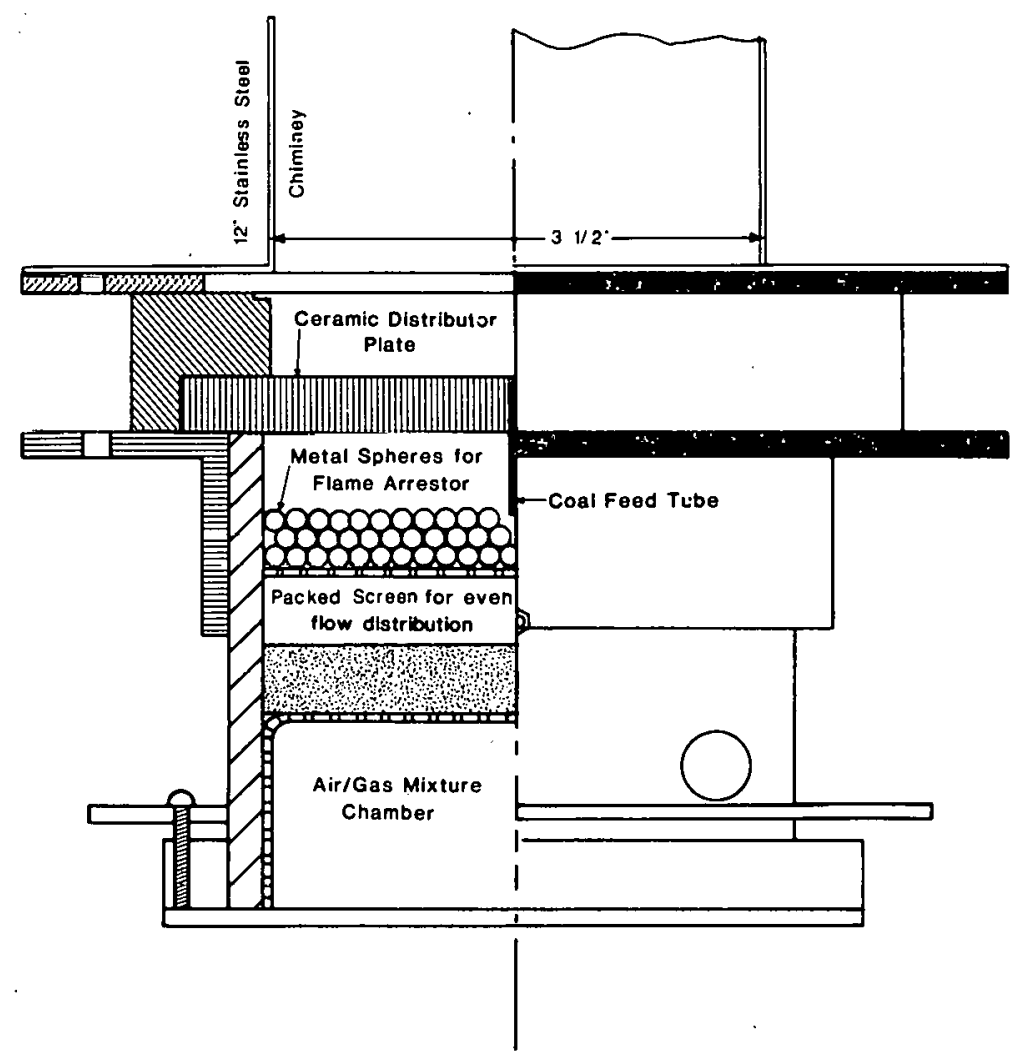

Figure 3. Diagram of Flame Burner for Char Preparation.

Testing of the flame burner was performed to determine the quality of the chars and reproducibility of char production. Chars were produced from 53$106 \mu \mathrm{m}$ low-sodium Beulah (ND) lignite that was used in previous char preparations and particle temperature measurement experiments. Three separate char production runs were made using the low-sodium Beulah to determine reproducibility of the gas flow rates and burner temperatures from a cold startup. The size distribution and volatile matter were measured for the three chars and were found to be nearly identical. Table 1 lists the flame burner operating parameters and gas chromatographic analyses of the burner flame for the three char preparations. Table 2 lists the physical properties of the chars produced. 


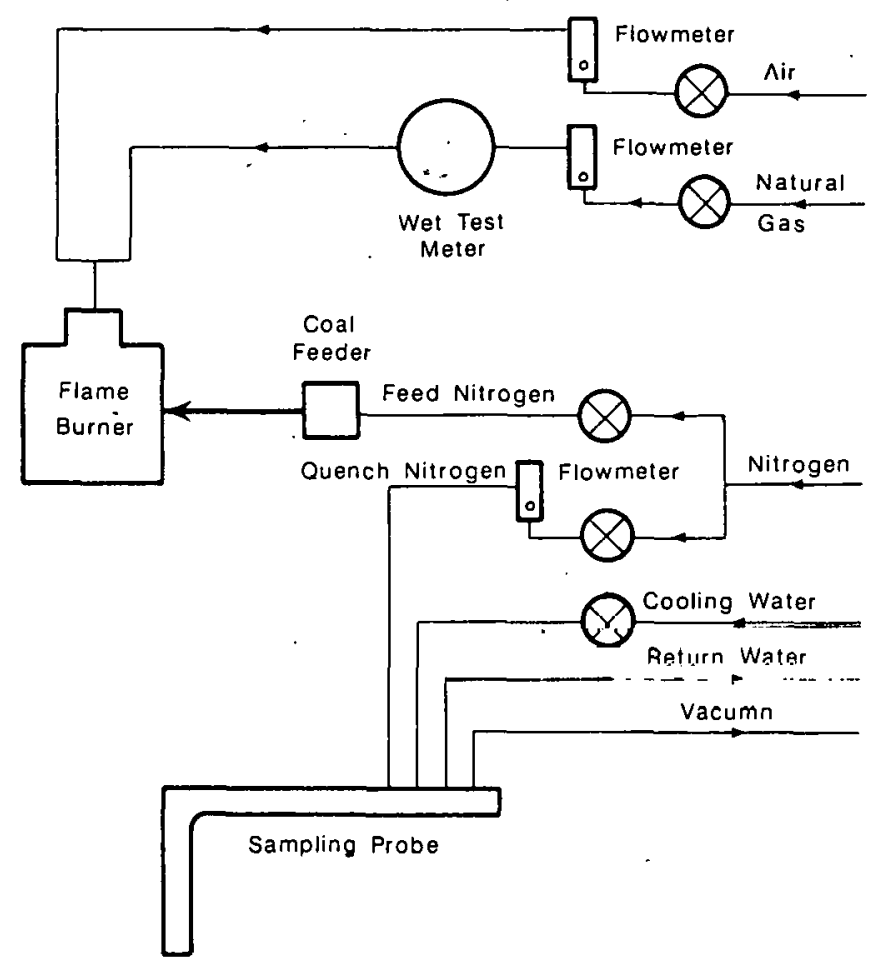

Figure 4. Diagram of Flame Burner and Flow Control System.

\subsubsection{Video_System}

A video system has been designed to measure the size of particles in addition to particle temperatures. Most of the major components of the video particle sizing system have been obtained, and preliminary testing is being carried out.

A diagram of the sizing system is shown in Figure 5. The optical components of the system consist of a high-intensity strobelight, a long range microscope, and a video camera (Panasonic WV 1550).

The video system will be operated in the following manner when determining the size of burning particles. When a particle is in the pyrometer field of view, a signal from the pyrometer's Data 6000 waveform analyzer will trigger the strobelight. The strobelight pulse is about 10 microseconds in duration which is much faster than the videocamera scan rate ( 30 Hertz). This is not a problem because the camera vidicon tube acts as a storage device which holds the image for three to four scans. The video camera image will be displayed on a monitor and continuously recorded by a video recorder (Panasonic NV8950). After the single-particle reactor test, the videotaped particle images will be scanned, treeze-tramed, and captured with a frame grabber (Chorus Data Systems PC1540) for particle size determinations using a microcomputer. 
TABLE 1

- FLAME BURNER OPERATING PARAMETERS FOR CHAR PRODUCTION TESTS :

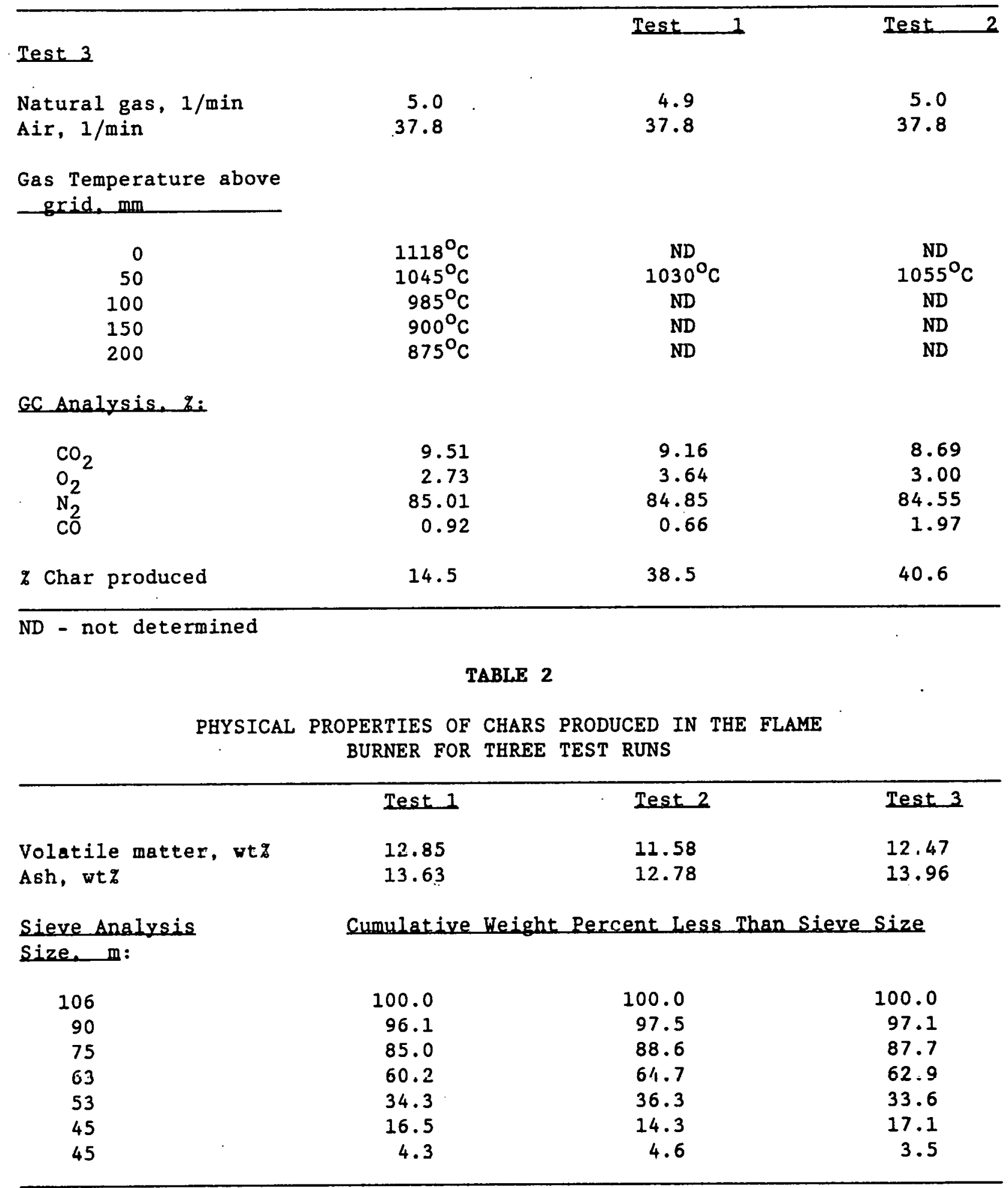



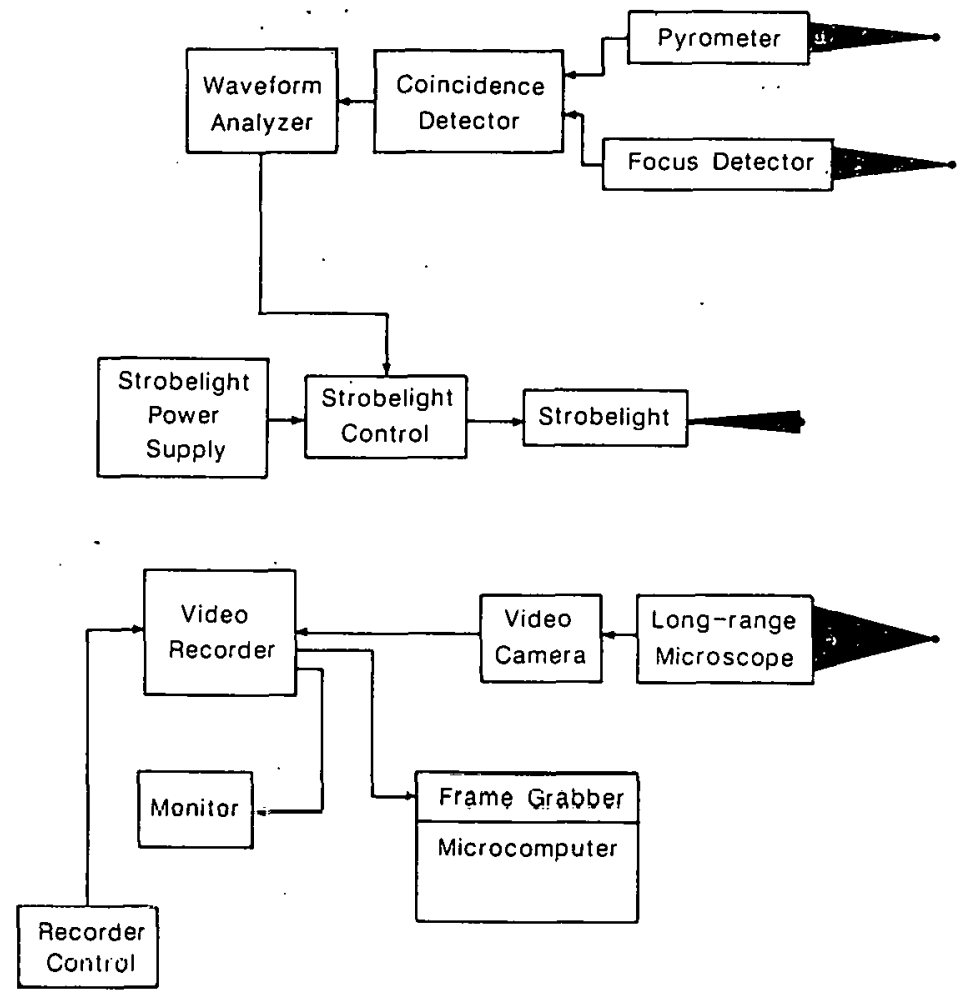

Figure 5. Diagram of Video Particle Sizing System.

\subsection{PREPARATION AND CHARACTERIZATION OF CHARS}

\subsubsection{Coal Characteristic's And Preparation}

Samples of Beulah-Zap lignite (North Dakota) and Smith-Roland subbituminous coal (Wyoming) were obtained from the Pennsylvania state University coal sample bank (PSOC 1507 and PSOC 1520, respectively). Subsequently, sized samples of New Mexico Blue (New Mexico) subbituminous coal (PSOC-1445-D) Lower Wilcox and Texas (subbituminous) (PSOC-1443-D) have been received. The Beulah-2ap lignite was chosen as the first coal to be tested because of prior UNDERC experience with lignites.

After removal of a reserve sample and a sample for petrographic analysis, the Beulah-zap lignite was air-dried and carefully ground to 53-106 microns. The 53-106 micron fraction was then split with a rotary riffler into subsamples, which were stored under argon until used. A flow chart shown in Figure $b$ illustrates the coal/char preparation and handling scheme. The proximate and petrographic analyses of the Beulah sample are summarized in Tables 3 and 4. 


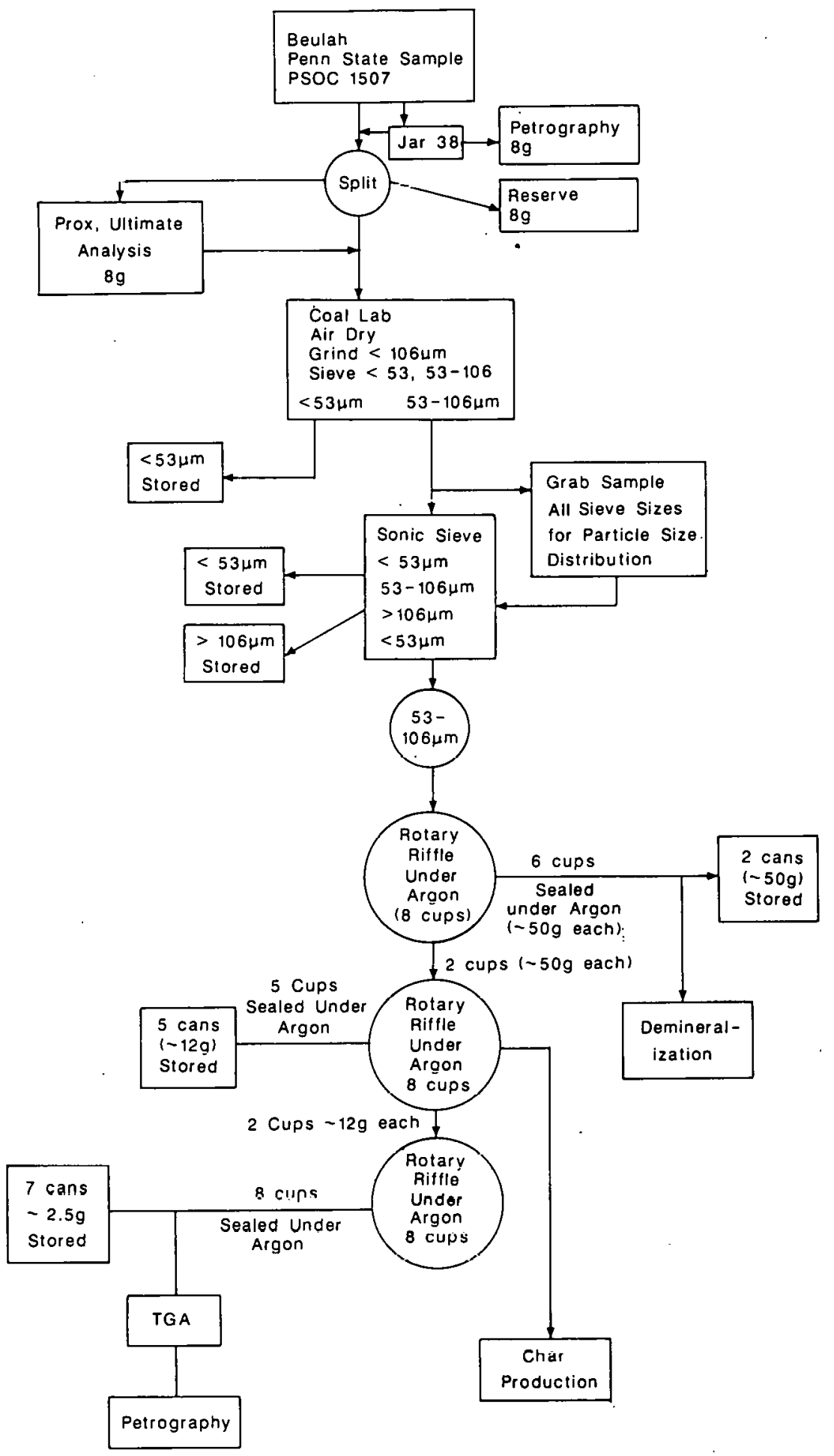

Figure 6. Coal/Char Preparation and Handling Scheme. 
PROXIMATE AND ULTIMATE ANALYSIS OF BEULAH-ZAP (PSOC 1507)

(ALL DATA REPORTED ON A DRY BASIS EXCEPT FOR THE MOISTURE DETERMINATION)

\begin{tabular}{|c|c|c|c|c|}
\hline Proximate & Dry Basis, wty & , & Ultimate & Dry Basis. wtg \\
\hline $\begin{array}{l}\text { Moisture } \\
\text { Volatile Matter } \\
\text { Fixed Carbon } \\
\text { Ash }\end{array}$ & $\begin{array}{r}33.57 \\
27.08 \\
31.06 \\
8.30\end{array}$ & & $\begin{array}{l}\text { Carbon } \\
\text { Hydrogen } \\
\text { Nitrogen } \\
\text { Oxygen } \\
\text { Sulfur }\end{array}$ & $\begin{array}{r}62.61 \\
4.41 \\
0.83 \\
18.21 \\
1.43\end{array}$ \\
\hline
\end{tabular}

*Determined by difference.

TADLE 4

QUANTITATIVE MACERAL ANALYSIS OF BEULAH-2AP LIGNITE (PSOC 1507)

\begin{tabular}{|c|c|c|c|c|c|}
\hline Huminite & Vol... & Liptinite & Vel... & Inertinite & Vel. \\
\hline Textinite & $\operatorname{Tr}$ & Sporinite & 4 & Fusinite & 5 \\
\hline Ulminite & 36 & Cutinite & $\operatorname{Tr}$ & Semifusinite & 8 \\
\hline Humodetrinite & 16 & Resinite & 3 & Macrinite & $\operatorname{Tr}$ \\
\hline Gelinite & 1 & Alginite & $\operatorname{Tr}$ & Sclerotinite & $\operatorname{Tr}$ \\
\hline Corpohuminite & 1 & Liptodetrinite & 5 & Inertodetrinite & 15 \\
\hline $\begin{array}{l}\text { Total Hum.: } \\
\text { Mineral Matte } \\
\text { Tr = Trace amc }\end{array}$ & $\begin{array}{r}54 \\
=\quad 5 \\
\text { unts }\end{array}$ & Total Lipt.: & 12 & Total Inert.: & 28 \\
\hline
\end{tabular}

\subsubsection{Preparation of Cation Loaded coals}

New Mexico Blue coal (PSOC-1445-D) and PSOC 1507 Beulah-2ap lignite have been prepared for char production. Demineralized, calcium-loaded, potassiumloaded, and sodium-loaded forms have been prepared.

Approximately 90 grams of coal were demineralized using the following procedure:

1. The coal was placed into a plastic beaker and $100 \mathrm{ml}$ of concentrated HCl was added and allowed to stir for 1 hour at $50^{\circ} \mathrm{C}$.

2. The $\mathrm{HCl}$ and residue were filtered using a vacuum millipore, HVLP filter paper and 1-100 ml distilled $\mathrm{H}_{2} \mathrm{O}$ wash; the filtrate was discarded. 
3. The residue was placed back into a plastic beaker and 100 mls of concentrated $\mathrm{HF}$ was added and allowed to stir for 1 hour at $50^{\circ} \mathrm{C}$.

4. Filter as above (2).

5. The residue was placed back into a plastic beaker and $100 \mathrm{mls}$ of concentrated $\mathrm{HCl}$ was added and allowed to stir about one hour at $50^{\circ} \mathrm{C}$.

6. The $\mathrm{HCl}$ and residue was filtered using a pressure millipore, HVLP filter paper, and twelve $100 \mathrm{ml}$ distilled $\mathrm{H}_{2} \mathrm{O}$ washes. About $I \mathrm{ml}$ of $\mathrm{AgNO}_{3}$ was added to the filtrate to determine if any residual chloride ions were present. As no $\mathrm{AgCl}$ was formed, it was assumed that the washing was complete.

7. The filtrate was discarded and the sample was dried using a vacuum desiccator.

The following example will illustrate the procedure used to load the demineralized coal with cations. During the demineralization procedure the strong acids protinate the ion-exchangeable sites on the coal; that is, the cations on these sites are all replaced by the $\mathrm{H}^{+}$. The hydrogens associated with the ion-exchange sites may then be replaced with the appropriate cation. In this example, potassium will be used. A 1.1 solution of potassium acetate was prepared and $1000 \mathrm{ml}$ of this solution were placed in a $2000 \mathrm{ml}$ Erlenmeyer flask. About 17 grams of demineralized coal was placed in the potassium acetate solution while stirring. The mixture was stirred for approximately 20 hours at room temperature and filtered. The $\mathrm{pH}$ of the filtrate was measured, and it had fallen from 8.44 to 6.74 , indicating an increase in the hydrogen ion content in the solution. The decrease in the $\mathrm{pH}$ occurs because the potassium ion replaces the hydrogen ion associated with the ion-exchanged site, resulting in the formation of acetic acid in the solution. Table 5 gives the cation concentration of the Beulah-2ap and New Mexico Blue samples as determined by ICP analysis. Within the accuracy of the ICP analysis, the cation loadings of the second set of Beulah-2ap samples (hereafter designated as Beulah 2) are comparible to the first set. It should also be noted that the untreated New Mexico Blue coal has only small amounts of calcium, potassium and sodium. Consistent with other New Mexico coals which have been found to have only small amounts of organically bound cations. Thus the demineralization step did not remove large amounts of cations as with the Beulah lignite. Further, the smaller amount ( $11000 \mathrm{ppm})$ of sodium loaded onto the New Mexico Blue coal indicates significantly fewer ion-exchangeable sites than for the Beulah coal.

\subsubsection{Char Preparation}

Chars were produced in the flame burner from the 53-106 micron size fraction of the following Beulah-Zap lignites: untreated Beulah-Zap lignite coal at 0.03 mole fraction excess oxygen, demineralized Beulah-2ap lignite at both 0.08 and 0.024 mole fraction excess oxygen, demineralized Beulah-2ap lignite which had been loaded with $34,000 \mathrm{ppm}$ calcium ion at 0.023 mole fraction excess oxygen, and demineralized Beulah-Zap lignite which had been loaded with $48,000 \mathrm{ppm}$ potassium ion at 0.0275 mole fraction excess oxygen. 


\section{Beulah-zap}

Untreated

Demineralized

32,000

$<220$

$\mathrm{Ca}^{++}$Loaded

$\mathrm{K}^{+}$Loaded

$\mathrm{Na}^{+}$Loaded

\section{Beulah-Zap2*}

Demineralized

$\mathrm{Ca}^{++}$Loaded

$\mathrm{K}^{+}$Loaded

\section{New Mexico Blue}

Untreated

Demineralized

$\mathrm{Na}^{+}$Loaded
1,500

40,000

$<500$

$$
\begin{array}{r}
820 \\
<\quad 220 \\
<250 \\
45,000 \\
<400
\end{array}
$$

7,900

420

$<250$

3,300

26,000

*Second preparation, referred to in text as Beulah2

Excess oxygen concentrations were determined using gas chromatrography. For all chars produced in the flame burner, the gas temperature ranged from approximately $1370 \mathrm{~K}$ at the coal injection point to approximately $1020 \mathrm{~K}$ at the particle collector. Particle residence time was estimated to be approximately $1.50 \mathrm{~ms}$.

Chars have also been produced from the untreated and dem1neralized 53-106 micron fractions of New Mexico Blue coal (PSOC 1445-D). Both sets of char were produced under similar flame burner conditions as the previous chars. Table 6 lists the chars produced and the excess oxygen mole fraction.

\subsubsection{Sieve Analysis And Observations}

Previous preparation of chars from the demineralized and cation loaded Beulah-zap coal gave some indication of possible swelling behavior for the demineralized coal. However, since the size distribution of the demineralized coal had not been measured, no qualitative statement could be made. 
TABLE 6

SIZE ANALYSIS OF COALS AND COAL CHARS

Coal

Excess $\mathrm{O}_{2} \quad$ zRecovered

$\begin{array}{ccc}\text { Mean Size } & \% \\ \text { Coal* Char } & 106 \mathrm{~m}\end{array}$

Beulah-Zap

$\begin{array}{lllllr}\text { Untreated } & 2.6 \% & 38.0 & 76 & 67 & 1.9 \\ \text { Demineralized } & 2.9 \% & 29.3 & 84 & 92 & 18.1 \\ \text { Ca }{ }^{++} \text {Loaded } & 2.75 \% & 30.0 & 80 & 75 & 3.5 \\ \mathrm{~K}^{+} \text {Loaded } & 2.0 \% & 29.0 & 75 & 93 & 24.2 \\ \mathrm{Na}^{+} \text {Loaded* } & 2.75 \% & 26.0 & - & 72 & 6.7\end{array}$

Nev Mexico Blue

Untreated

Demineralized

\section{$2.9 \%$}

$2.9 \%$
25.6

34.3
100

100

\section{4}

63
4.2

1.1

*First preparation

The char morphology analysis of the demineralized char showed a large number of cenospheres, also suggesting that the demineralized lignite is showing a swelling behavior.

Prior to the preparation of the second lots of the untreated, demineralized, and cation loaded Beulah chars, particle size distribution by sieve analysis was determined for the input coal sample, as well as for the char produced. Table 6 lists the mean particle sizes for the input coal and the char produced, as well as the percentage of input coal recovered as char and the fraction of recovered char $\mu 106$ microns.

Since the coal eamples were sieved after demineralization and cation loading, and only the 53-106 micron size fraction used in the flame burner to prepare the corresponding chars, a significant percentage of char of size >106 microns is a clear indication of particle swelling and/or agglomeration. This behavior is seen for the demineralized Beulah char and for the potassium loaded Beulah char. Conversely, the untreated and calcium-loaded Beulah chars show little, if any, swelling/agglomeration, and the sodium-loaded Beulah char shows a woderate increase.

A corresponding trend is seen in the change in mean particle size between the input coal and the coal char, with the mean particle size decreasing for the untreated and calcium-loaded Beulah chars and increasing for the demineralized and potassium-loaded Beulah chars. Comparison of the change in 
mean particle size between the coal and coal char should be treated with caution, as the char recovered is not quantitative and burnout of small particles may shift the mean size to a larger value.

The behavior of the New Mexico Blue coal is strikingly different than that of the Beulah coal during char preparation. The demineralized New Mexico coal actually formed less material in the $>106$ micron size range than did the untreated coal, and both chars had very little material in this size range. Further, the mean particle size decreased significantly for both, with the demineralized char showing a greater decrease in mean particle size than the untreated char.

An explanation for the diverse behavior of the Beulah and New Mexico Blue coals and treated coals upon charring is that, in the case of the Beulah coal, organically-bound cations inhibit any swelling and/or agglomeration, and this inhibition is removed upon demineralization. The readdition of cations by ion-exchange changes the coal properties back to nearly that of the untreated Beulah coal, although the behavior of the potassium-loaded Beulah coal is puzizi Luy.

Examination of other New Mexico coals suggest that little of the mineral matter is organically bound. Assuming that this is the case for the New Mexico Blue coal, demineralization of the New Mexico Blue coal would have little effect, on its behavior during char preparation, since the organically bound cations of significance in the Beulah lignite were not initially present in the New Mexico Blue coal.

\subsection{MORPHOLOGY GHAR}

\subsubsection{Intreduction}

The purpose of this petrographic investigation was to examine the effect of pretreatment on the morphology of the char particles produced during the rapid pyrolysis of low-rank coal. Past studies, mainly focused on bituminous coals, have suggested that the maceral composition of the coal significantly influences char morphology, although only several maceral types have been traced through the pyrolysis process. Jones (16) reports that vitrinite group macerals are responsible for the occurrence of the cenosphere morphology and the inertinite group macerais form the honeycomb and unfused morphotypes.

Low-rank coals, such as the Beulah-2ap North Dakota lignite used in this study, typically contain large percentages of the huminite (vitrinite) group macerals. Therefore, it would be anticipated that untreated Beulah-2ap lignite would produce a high percentage of cenospheres. Previous studies at UNDERC (17) show that chars produced from the Beulah-2ap are indeed rich in cenosphere morphotypes, but not as high as expected according to the maceral analysis. The results of the previous UNDERC study also suggest that the abundance of cenospheres in rapid pyrolysis derived chars increases with coal rank (17). 
The pretreatments used in this study included a demineralization process which has been used in previous UNDERC investigations (17). After the Beulahlap lignite was demineralized, the cations $\mathrm{Ca}^{++}, \mathrm{K}^{+}$, and $\mathrm{Na}^{+}$(in aqueous solution) were added back onto separate, representative, sample splits. Each of the cation loaded, demineralized, and untreated coals were subsequently used to produce char as previously described (17). A representative split of each of the chars were petrographically analyzed to determine the occurrence, abundance, and distribution of char morphotypes.

In addition to the bulk char morphology analyses, char residues collected at different heights along the single particle reactor were examined. This preliminary investigation was designed to determine if preferential burnout of the various char morphotypes occurs. Initial results suggest that the cenosphere and honeycomb char morphotypes experience significant distribution changes in the reactor chimney.

\subsubsection{Char Morphotype Terminology}

As reported earlier (17), the morphology of chars produced from the rapid pyrolysis of lignite varies slightly from that of higher rank coals. This creates a nomenclature problem when making direct comparisons between chars produced from different rank coals. The published literature (16), mostly from the examination of higher rank coal pyrolysis, uses three general classifications in describing char morphology. These types are 1) cenosphere, 2) honeycomb, and 3) unfused. Within these major classification there exists subjective subdivisions which adds to the nomenclature confusion.

A classification scheme similar to that of Jones (16) was employed in this petrographic examination. A subdivision of the cenosphere morphotype was made. The new term given to this subdivision is mesosphere. The mesospheres contain more internal structure than that of the cenospheres. The total ratio between solid material to open pore space is roughly equivalent; but whereas the cenospheres typically have less than three major pore cavaties, the mesospheres may have as many as ten. The distinction between the cenosphere and mesosphere is based on the number of major pore spaces and does not consider the small pores often associated with the thick, wall material.

One additional modification to Jones' classification was made for the purpose of examining low-rank coal chars. There appears to be a class of char particles which has characteristics similar to both the honeycomb and unfused morphotypes. This separate class has been given the temporary name inertosphere. As the name implies, a significant portion of these particles is derived from inertinite group macerals (specifically inertodetrinite). The unfused morphotypes are derived from inertinite macerals (fusinite, semifusinite, and macrinite). The inertospheres also show a minor degree of plastic deformation similar to that exhibited by the honeycomb morphotypes. This deformation is probably caused by the presence of the hydrogen-rich liptinite macerals associated with the inertinite. Liptinite macerals have been previously suspected of promoting swelling and deformation during rapid pyrolysis. The liptinite/inertinite maceral association in lignite is not commonly found in higher rank coals. This may explain why this distinction has not been made in earlier high-rank coal char studies. 


\subsubsection{Retrographic Techniques}

Since only a limited amount of sample was available, standard sample preparation techniques (18) were modified slightly. These modifications are described below. Approximately 0.05 grams of each char sample was embedded in a two part epoxy mounting medium. The resulting sample/epoxy "plug" has a one-inch diameter. The char was concentrated in the central portion of the epoxy plug by first placing the sample in a short section (approximately 0.37 inches long) of plastic tubing (inside diameter 0.25 inch). This technique prevented the small quantity of char sample from becoming dispersed throughout the entire epoxy plug. After the epoxy has cured, the plugs are polished through a series of steps using diamond polishing compounds. The final polishing step uses a 0.25 micron diameter diamond paste.

Char morphology analyses were performed using both reflected whiteincident and fluorescent light microscopy. The blue-light fluorescence was needed to determine the presence of unpyrolyzed coal particles. The presence of any coal particles would indicate possible sample contamination. A Nikon Labophot-pol polarizing-light microscope with a $40 \mathrm{x}$ oil immersion objective was used for all petrographic analyses.

Quantitative analyses were performed using standard petrographic pointcounting techniques (18). A total of 100 char particles were identified for each sample. Each char morphotype was reported as a volume percent of the total sample.

\subsubsection{Observations - Morphology of Cation Loaded Chars}

The morphology of chars which had first been demineralized then loaded separately with calcium, potassium, and sodium cations was compared with untreated and demineralized chars. The results of these analyses are given in Table 7. The coal which was used for char production was also examined in order to determine any variation in maceral content (Table 8). The results of the maceral analyses indicated that the sample splits were generally representative of the original coal. Also it was determined that the variations in maceral content were not significant enough to cause the differences observed in char morphology.

The most obvious change in particle morphology can be seen in the char produced from the demineralized coal. The demineralization procedure (17) includes hydrochloric and hydrofluoric acid treatments to remove carbonate and silicate minerals as well as the organically bound cations. This pretreatment appears to allow the coal to become more plastic during rapid pyrolysis than the untreated sample as indicated by the large increase in cenosphere morphotypes. The abundance of cenospheres in the cation loaded chars dramatically decreases to levels near that of the untreated char samples. The amount of cenospheres in the demineralized Beulah-2ap lignite is quite similar to the value previously found in untreated higher rank coals (6). 
TABLE 7

CHAR MORPHOLOGY ANALYSIS

BEULAH-ZAP LIGNITE

(Volume $\%$ )

\begin{tabular}{lccrrr} 
Morphotype & Untreated & Demineralized & $\begin{array}{c}\mathrm{Ca}^{++} \\
\text {Added }\end{array}$ & $\begin{array}{r}\mathrm{K}^{+} \\
\text {Added }\end{array}$ & $\begin{array}{c}\mathrm{Na}^{+} \\
\text {Added }\end{array}$ \\
Cenosphere & 2.0 & 40.0 & 2.8 & 7.8 & 8.0 \\
Mesophere & 38.0 & 41.0 & 46.8 & 64.0 & 60.8 \\
Honeycomb & 43.6 & 5.4 & 39.4 & 14.2 & 16.4 \\
Inertosphere & 7.2 & 2.8 & 3.8 & 4.8 & 8.2 \\
Unfused & 1.6 & 8.2 & 5.8 & 7.4 & 5.6 \\
Mineral-rich & 7.4 & 2.0 & 1.4 & 1.8 & 1.0 \\
\hline
\end{tabular}

TABLE 8

MACERAL ANALYSIS

BEULAH-ZAP LIGNITE

\begin{tabular}{|c|c|c|c|c|c|}
\hline \multirow[b]{2}{*}{ Maceral } & \multicolumn{3}{|c|}{ (Volume $z)$} & \multirow[b]{2}{*}{$\begin{array}{c}\mathbf{K}^{+} \\
\text {Added }\end{array}$} & \multirow{2}{*}{$\begin{array}{l}\mathrm{Na}^{+} \\
\text {Added }\end{array}$} \\
\hline & Untreated & Demineralized & $\begin{array}{l}\mathrm{Ca}^{++} \\
\text {Added }\end{array}$ & & \\
\hline Ulminite & 46.4 & 50.8 & 44.8 & 50.4 & 46.4 \\
\hline Humodetrinite & 11.8 & 10.0 & 11.2 & 12.0 & 13.6 \\
\hline Gelinite & 0.8 & 1.6 & 0.8 & 0.8 & 0.8 \\
\hline Corpohuminite & 1.6 & 2.0 & 1.6 & 1.6 & 2.0 \\
\hline Sporinite & 2.2 & 2.4 & 2.8 & 1.2 & 2.4 \\
\hline Cutinite & 1.2 & 0.8 & 0.8 & 0.4 & 0.8 \\
\hline Resinite & 0.2 & 2.4 & 1.6 & 1.2 & 2.0 \\
\hline Liptodetrinite & 2.4 & 4.4 & 3.6 & 2.4 & 2.4 \\
\hline Fusinite & 2.4 & 4.0 & 4.4 & 3.2 & 4.4 \\
\hline Semifusinite & 9.4 & 9.6 & 11.2 & 10.4 & 10.8 \\
\hline Macrinite & 0.6 & 0.0 & 1.6 & 0.8 & 0.8 \\
\hline Micrinite & 1.6 & 1.2 & 0.8 & 0.4 & 0.4 \\
\hline Inertodetrinite & 13.2 & 8.8 & 12.8 & 12.4 & 10.4 \\
\hline Mineral & 6.4 & 2.0 & 2.0 & 2.8 & 2.8 \\
\hline
\end{tabular}


It is also worth noting that the unfused and inertosphere morphotypes which are assumed to be derived from the inertinite macerals make up much less of the total char composition than anticipated. Two possibilities exist which may contribute to this observation. "First, it has been reported that the semifusinite is much more reactive (i.e. less inert) than the other inertinite macerals, especially in low rank coals (19). The semifusinite may contain enough volatile matter that upon pyrolysis, the particles become slightly plastic and vesiculated due to the release of gaseous products. Since these particles do not become as plastic as the coal which produces the cenospheres, the particles forming via this process would most likely be classified as honeycomb morphotypes.

The second explanation for the low unfused and inertosphere abundance in the chars is an artifact created in sample preparation. After the coal has been pyrolyzed, the char is size fractionated. It is possible that the pyrolysis process, including handiing, causes enough physical degradation of the highly friable, Inertinite wacerals to bias the size fractions. Since only the 63-75 micron size fraction was examined, the results may reflect this biàsed size classiflicalius.

\subsubsection{Char Residue Merphelegy}

Char residues were collected at three heights $(100,150$, and $200 \mathrm{~mm}$ above the sample injector) in the UNDERC single particle reactor in order to determine the variation in morphotype distribution. The samples used included the untreated, demineralized, and calcium and potassium loaded Beulah-2ap chars. The results from these petrographic analyses are given in Tables 9 through 13.

During the examination of the char residues, it was necessary to classify two additional types of particles not recognized in the initial char. These types were given the terms agglomerate and ferrosphere. the agglomerate type particles, as the name implies, are composed of small char fragments (<10 microns). The actual agglomeracion process of these particles may bc cither the result of char fragments fusing during heating, or as an artifact of sample collection in the cyclone. A more detailed examination is needed to determine the origin of these particles. The significance of these particles, regardless of the origin of the agglomeration phenomena, is that fine char particles are being produced-in the early stages of the single particle reactor.

The ferrospheres begin to develop between 100 and $150 \mathrm{~mm}$ above the sample injector. These particles are typically spherical, solid, less than 50 microns, and are composed almost entirely of iron (determined by. SEM microprobe analyses). Several of the observed ferrospheres exhibited internal crystalline structure. The crystals appeared to be elongated, doubleterminated, and generally oriented perpendicular to the surface of the sphere. The crystals were not found to terminate in the void space of the few 
TABLE 9

CHAR RESIDUE MORPHOLOGY

BEULAH-ZAP CHAR UNTREATED, $700^{\circ} \mathrm{C}$

(Volume \%)

\begin{tabular}{lcccc} 
Morphotype & Initial & 100mm* & 150mm* & 200mm* \\
\hline & & 2 & 1 & 4 \\
Cenosphere & 4 & 8 & 12 & 9 \\
Mesophere & 36 & 10 & 40 & 35 \\
Honeycomb & 32 & 6 & 22 & 14 \\
Inertosphere & 17 & 67 & 18 & 22 \\
Unfused & 6 & 1 & 2 & 3 \\
Mineral-rich & 5 & 1 & 3 & 5 \\
Agglomerate & 0 & & 2 & 3 \\
Ferrosphere & 0 & & & \\
\hline
\end{tabular}

*Height above sample injector

TABLE 10

CHAR RESIDUE MORPHOLOGY

BEULAH-2AP CHAR DEMINERALIZED, $700^{\circ} \mathrm{C}$

(Volume \%)

\begin{tabular}{lcccc} 
Morphotype & Initial & 100mm* & $150 \mathrm{~mm} *$ & $200 \mathrm{~mm}$ \\
\hline & 46 & 32 & 25 & 41 \\
Cenosphere & 38 & 55 & 35 & 21 \\
Mesosphere & 2 & 2 & 3 & 3 \\
Honeycomb & 2 & 2 & 15 & 16 \\
Inertosphere & 8 & 6 & 21 & 16 \\
Unfused & 4 & 2 & 1 & 1 \\
Mineral-rich & 0 & 1 & 0 & 0 \\
Agglomerate & 0 & 0 & 0 & 2 \\
Ferrosphere & & &
\end{tabular}

*Height above sample injector 
TABLE 11

CHAR RESIDUE MORPHOLOGY

BEULAH-ZAP CHAR $\mathrm{Ca}^{++}$LOADED, $600^{\circ} \mathrm{C}$

(Volume \%)

\begin{tabular}{lcccc} 
Morphotype & Initial & $100 \mathrm{~mm} *$ & $150 \mathrm{~mm}$ & $200 \mathrm{~mm}$ \\
\hline & & 6 & 2 & 2 \\
Cenosphere & 6 & 32 & 31 & 19 \\
Mesophere & 31 & 39 & 30 & 40 \\
Honeycomb & 38 & 8 & 11 & 17 \\
Inertosphere & 14 & 13 & 22 & 22 \\
Unfusad & 9 & 1 & 2 & 0 \\
Mineral-rieh & 2 & 1 & 2 & 0 \\
Agglomerate & 0 & 0 & 0 & 0 \\
Fcrosphere & 0 & & &
\end{tabular}

*Height above sample injector

TABLE 12

CHAR RESIDUE MORPHOLOGY

BEULAH-2AP CHAR $\mathrm{Ca}^{++}$LOADED, $700^{\circ} \mathrm{C}$

(Volumc \&)

\begin{tabular}{lcccc} 
Morphotype & Initial & $100 \mathrm{~mm}$ & 150mm* & $200 \mathrm{~mm}$ \\
\hline Cenosphere & 6 & 4 & 2 & 5 \\
Mosnphere & 31 & 21 & 2.2 & 1.7 \\
Honeycumb & 38 & 14 & 26 & 26 \\
Inertosphere & 14 & 17 & 18 & 18 \\
Unfused & 9 & 2 & 23 & 13 \\
Mineral-rich & 2 & 1 & 2 & 5 \\
Agglomerate & 0 & 0 & 0 & 3 \\
Ferrosphere & 0 & & & 13
\end{tabular}

*Height above sample injector 
TABLE 13

CHAR RESIDUE MORPHOLOGY

BEULAH-ZAP CHAR $\mathrm{K}^{+}$LOADED, $700^{\circ} \mathrm{C}$

(Volume \%)

\begin{tabular}{lcccc} 
Morphotype & Initial & $100 \mathrm{~mm} *$ & $150 \mathrm{~mm}$ & $200 \mathrm{~mm}$ \\
\hline Cenosphere & 8 & 50 & 3 & 7 \\
Mesosphere & 52 & 16 & 20 & 7 \\
Honeycomb & 21 & 7 & 14 & 11 \\
Inertosphere & 9 & 12 & 16 & 11 \\
Unfused & 8 & 1 & 45 & 40 \\
Mineral-rich & 2 & 9 & 0 & 6 \\
Agglomerate & 0 & 0 & 0 & 4 \\
Ferrosphere & 0 & & 2 & 4 \\
\hline
\end{tabular}

*Height above sample injector

hollow ferrospheres observed. The ferrospheres co-exist with spherical iron sulfide particles which were thought to be pyrite framboids from the coal. One pyrite framboid was found to have an outer "rind" which had a much lower sulfur to iron ratio than the inner portion of the particle. This may suggest that the ferrospheres have a direct relationship with pyrite framboids.

The results of the char residue morphology analyses are still preliminary. At the present time residues from each of the different pretreatments have not been petrographically examined. The general trends observed in the residues analyzed to date indicate that there may exist significant variation in the char morphotype distribution along the path of the single particle reactor (Tables 9 through 13). Probable causes for the variation include particle fragmentation and preferential burnout.

The unfused and inertosphere morphotypes increase in relative abundance at higher heights in the reactor chimney. This is probably due to their relative low reactivity which inhibits ignition and combustion. These particles also typically have a more solid internal physical structure making them more resistant to fragmentation.

The cenosphere abundance generally decreases with the noteable exception in the potassium loaded char at the $100 \mathrm{~mm}$ level (Table 13). The cenosphere abundance increased dramatically in this sample. In addition, the cenosphere structure became much more developed, that is, the walls became much thinner and the particles were very spherical. The rapid decrease in cenospheres at the $200 \mathrm{~mm}$ level may be attributed to preferential burnout. 
In samples which show a relative decrease in the abundance of the honeycomb morphotypes (Tables 12 and 13 ), there also exists an increase in the amount of agglomerated particles. This may indicate that the honeycomb structure is easily fragmented, thus acting as the major source of the fine char particles found in the residues. As eluded to earlier, the honeycomb morphotypes may originate from the semifusinite maceral. If the honeycomb morphotypes are from the relatively inert macerals, then it would be anticipated that the fragments would also be less reactive, thus resisting ignition and allowing for subsequent agglomeration.

\subsection{BURNING RATING OF CHARS}

\subsubsection{Combustion Test Matrix}

The New Mexico Blue (Penn State Coal Sample Bank PSOC - 1445 D) and the Beulah-Zap lignite coal (Penn State Coal Sample Bank PSOC-1507) were selected to be used in the first-demineralization and cation-loading tests. The cations, $\mathrm{Ca}^{++}$and $\mathrm{K}^{+}$were reloaded onto the demineralized coals. In all cases, the cation loading was the maximum possible. Intermediate cation loadings will be considered based on the results of the initial tests.

The test matrix was developed on the basis of coal char type and single particle reactor conditions. The five Beulah lignite char types included: untreated Beulah-zap (0.03) (the number in parenthesis indicates the mole fraction oxygen present in the flame burner when the char was prepared); demineralized Beulah-Zap (0.02); demineralized Beulah-Zap (0.08); calciumloaded Beulah-Zap (0.02), and potassium-loaded Beulah-Zap (0.028) chars. The three particle size ranges of chars include the following: 53-63,63-75, and 75-90 microns. The single-particle reactor conditions include: gas temperatures of approximately 900 and $1000 \mathrm{~K}$, and oxygen mole fractions of $0.05,0.10$, and 0.15 .

The first tests were performed to obtain particle temperature data at three oxygen concentrations and one gas temperature (1000K) for one particle size of all the Beulah-zap coal chars. Completion of this portion of the test matrix will allow for a quick comparison of the effect of demineralization and cation loading on char particle burning rates.

In later tests the combustion test matrix was slightly modified from the original design, based on the results obtained. The original tests were to include three particle sizes (53-63, 63-75, and 75-90 microns), three oxygen concentrations $(.05,0.10$, and 0.15 mole fraction oxygen), and two gas temperatures $(900$ and $1000 \mathrm{~K})$, at a single observation point $150 \mathrm{~mm}$ above the particle injection point.

From the results obtained, it was found that the 53-63 and $75-90$ micron size fractions gave trends essentially paralleling those of the 63-75 micron fraction. Further, the differences in reactivity of the various chars is reflected by changes in the position in the chimney where ignition and burnout are occurring. 
It was felt that, to ensure that the particle temperature measurements are made at steady-state burning conditions, the temperature measurements should be made at more than one height above the injection point. Three observation heights were selected: 100,150, and $200 \mathrm{~mm}$ above the injection point. To keep the test matrix at a reasonable size, and since the 53-63 and 75-90 micron size fractions give essentially the same information as the 63-75 micron fraction, further tests will concentrate on the 63-75 micron fraction only.

\section{4 .2 Combustion Tests}

Temperature of single burning particles were measured using the single particle reactor. Combustion tests were conducted at atmospheric pressure (approximately $0.97 \mathrm{~atm}$ ). Particle temperatures were measured using the three-color optical pyrometer. The optical detection volume was $150 \mathrm{~mm}$ above the particle injection point. For most of the tests, samples of char residue were collected close to the optical detection volume, approximately $160 \mathrm{~mm}$ above the injection point, using a nitrogen-quenched extraction probe. The collected residues were stored for later physical analysis.

Combustion tests were conducted at atmospheric pressure (approximately 0.97 atm.) in the single-particle reactor. Particle temperatures were measured using the three-color optical pyrometer at 100,150 and $200 \mathrm{~mm}$ above the particle injection point at $1000 \mathrm{~K}$ gas temperature and 0.1 mole fraction oxygen for physical analyses.

\subsubsection{Data Reduction}

Combustion rates were calculated from the measured particle temperatures by applying a steady state heat analysis to the burning particles. In this analysis, it is assumed that the particles are in thermal equilibrium with the local surroundings. It was further assumed that the primary reaction product is carbon monoxide. Thus, the heat balance is given by Equation 1.

$$
\rho \Delta H=\frac{N u_{\lambda}}{d}\left(T_{p}-T_{g}\right)+\varepsilon \sigma\left(T_{p}^{4}-T_{w}^{4}\right)
$$

where $\rho$ is the overall burning rate, $\Delta H$ is the heat of reaction ( 2300 $\mathrm{cal} / \mathrm{mole}$ at $1500 \mathrm{~K}$ for $\mathrm{CO}$ formation). Nu is the Nusselt number (taken as 2), $\lambda$ is the gas thermal conductivity, and $d$ is the diameter of the particle. Here $\mathrm{T}_{\mathrm{p}}, \mathrm{T}_{\mathrm{g}}, \mathrm{T}_{\mathrm{w}}$ are the particle, bulk gas, and wall temperatures, respectively, $\varepsilon$ is the emissivity of the particles (assumed to be 0.9 ) and $\sigma$ is the Stefan-Boltzmann constant.

A small correction to Equation 1 is required due to Stefan flow $(1,20)$ which arises from the net outflow of molecules from the boundary layer around each particle. The corrected form of Equation 1 is given by 


$$
\begin{aligned}
& \rho_{m} x^{\Delta} H=\frac{2 \lambda}{d}\left(T_{p}-T_{g}\right) \frac{\ell n\left(1+X_{2}\right.}{x_{O_{2}}^{\infty} 1-\frac{(1-X / L e)}{2}} x_{O_{2}}^{\omega}+t_{\varepsilon}\left(T_{p}^{4}-T_{w}^{4}\right) \\
& \text { where } \quad x=\frac{\rho}{m} \\
& \text { Le }=\frac{\lambda}{\bar{C}_{p g} \text { DC }}
\end{aligned}
$$

The $\lambda$ factor is the ratio of the overall burning rate to the diffusionlimited rate, $\rho \mathrm{m}$, which is defined by

$$
\mathrm{p}_{\mathrm{m}}=\frac{4 \mathrm{M}_{\mathrm{c}} \mathrm{DC}}{\mathrm{d}} \quad \ln \left(1+\mathrm{x}_{\mathrm{O}_{2}}\right)
$$

for the conversion to carbon monoxide. Here $M_{c}$ is the molecular weight of carbon and $x g \tilde{Q}$ is the mole fraction of oxygen in the bulk gas. Equation 4 defines the Lewis number and $\mathrm{C}_{p g}$ is the mean heat capacity of $\mathrm{O}_{2}$, and $\mathrm{CO}, \mathrm{d}$ is the bulk diffusion coefficient tor oxygen in nitrogen (equivalent to co in $\mathrm{N}_{2}$ ) and $C$ is the total molar concentration (equal to $P_{t} / R T_{m}$ where $P_{t}$ is the total pressure, $R$ is the universal gas constant, and $T_{m}=\left(T_{p}+T_{g}\right) / 2$, i.e., the mean temperature in the boundary layer around the particle).

\subsubsection{Results and Discussion}

A summary of the data obtained for the single-particle reactor experiments conducted with Beulah-Zap chars and the New Mexico Blue chars are given in the Appendix. The chars exhibited temperatures substantially higher than the gas temperature. This result is consistent with previous results (3). The temperature differential between particles and gas $\left(T_{p}-T_{g}\right)$ is dependent on oxygen mole fraction and gas temperature, as well as on the cation which was loaded.

The nearly linear dependence between $\left(T_{p}-T_{g}\right)$ and oxygen concentration for the various 63-75 micron chars is shown in Figure 7. This observation is similar to that observed previously for other coal chars. The same trend holds for the 53-63 and 75-90 micron fractions. Overall burning rates and values of $\left(x-p / p_{\max }\right)$ were calculated from Equations 1 and 3 , respectively. The high particle temperatures are reflected in high burning rates ( $X$ 0.7), indicating that mass transfer controls the burning rate. The $x$ values in Table 14 show that with an oxygen mole fraction less than 0.10 , the $X$ values exceed the theoretical value of unity. This was observed previously $(21,22$ and 23$)$.

The effect of demineralization and addition of calcium and potassium ion on particle temperature for the Beulah-Zap lignite coal was determintd. For example, particle temperature measurements were made for the appropriately prepared 63-75 micron chars at a gas temperature of approximately $1000 \mathrm{~K}$ and plotted versus oxygen concentration in Figure 3 . Taking the mean $\left(T_{p}-T_{g}\right.$ ) temperatures of the char produced from the untreated Beulah-2ap lignite as the 
Figure 7. Temperature Differential Between Burning Char Particles and Gas Versus Oxygen Concentration for 63-75 Micrometer Size Fraction of Beulah-2ap Char at a Gas Temperature of $1000 \mathrm{~K}$.

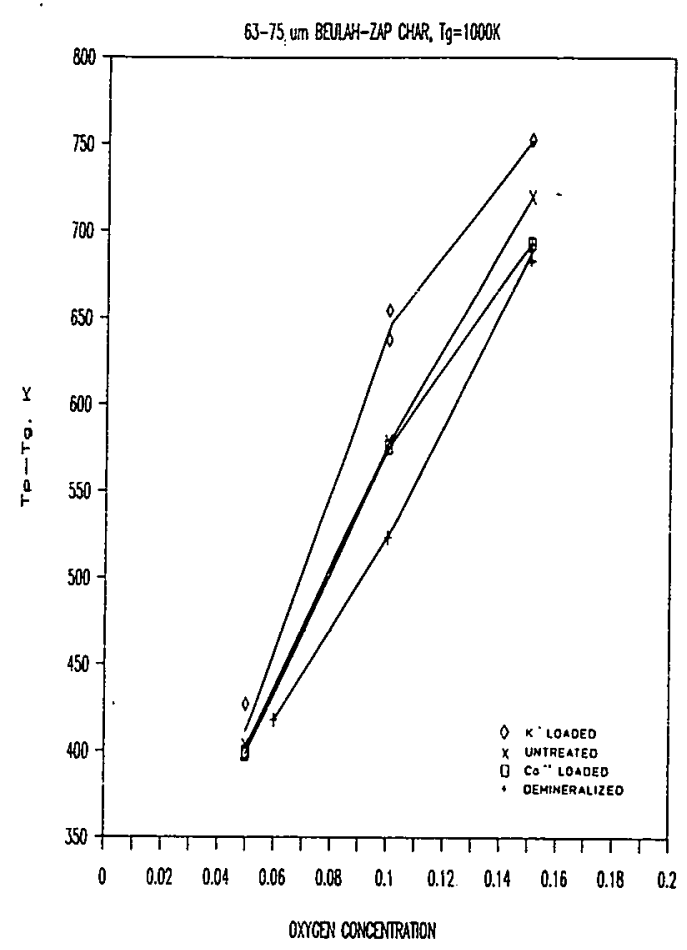
reference, the following points can be made: (1) The demineralized Beulah-2ap
$(0.024)$ char is the least reactive; (2) the loading of demineralized BeulahZap coal with calcium ion restored the reactivity to approximately that of the untreated coal char; and (3) the loading of the demineralized Beulah-zap coal with potassium ion increased the char reactivity to a level above that of the untreated coal char. Similar trends are noted for the other char size fractions and gas temperature as shown in Figures 8 and 9 . The $x$ values summarized in Table 14 follow the same trend, reflecting changes in the char burning rates due to the demineralization and cation loadings.

TABLE 14

$X$ VALUES FOR $63-75 \mu$ m BEULAH-2AP CHARS AT 1000K

Oxygen Mole Fraction

\begin{tabular}{llll}
\hline \multicolumn{1}{c}{ Char } & 0.05 & 0.10 & 0.15 \\
Untreated (UT) & 1.51 & 1.11 & 0.9 .5 \\
Demineralized (DM) & $1.31 *$ & 1.00 & 0.91 \\
Ca Added (CA) & 1.50 & 1.08 & 0.91 \\
$\mathrm{~K}^{+}$Added (K) & 1.59 & 1.24 & 0.99 \\
\hline
\end{tabular}

*burned at 0.06 mole fraction oxygen 
Figure 8. Temperature Differential Between Burning Char Particles and Gas Versus Oxygen Concentration From 75-90 Micrometer Size Fraction of Beulah- 2ap Char at a Gas Temperature of $1000 \mathrm{~K}$.

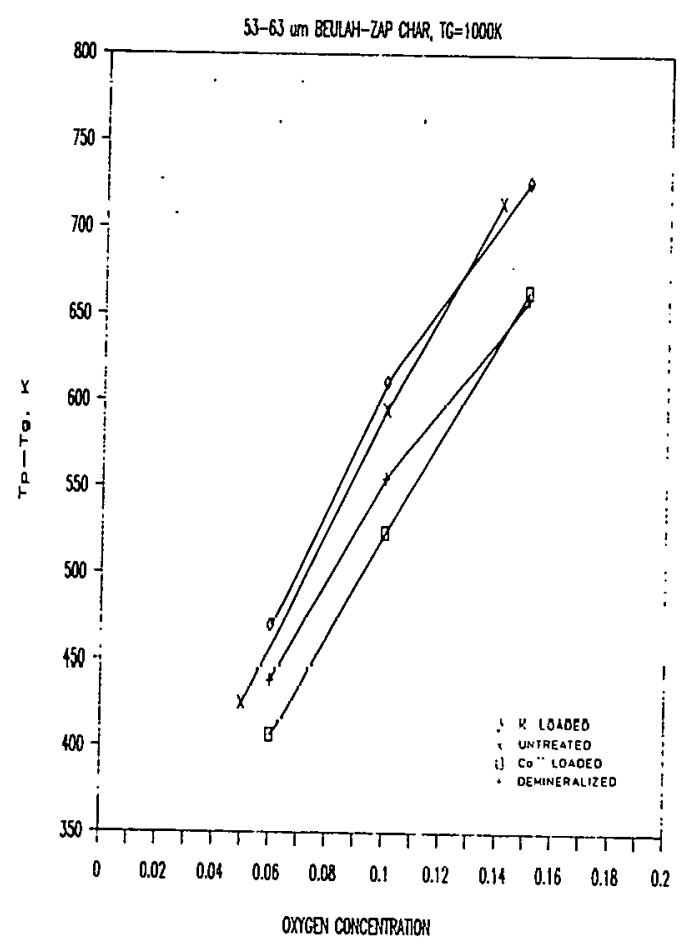

Figure. 9. Temperature Differential Between Burning Char Particles and Gas Versus Oxygen Concentration for 53-63 Micrometer Size Fraction of Beulah-2ap Char at a Gas Temperature of $1000 \mathrm{~K}$.

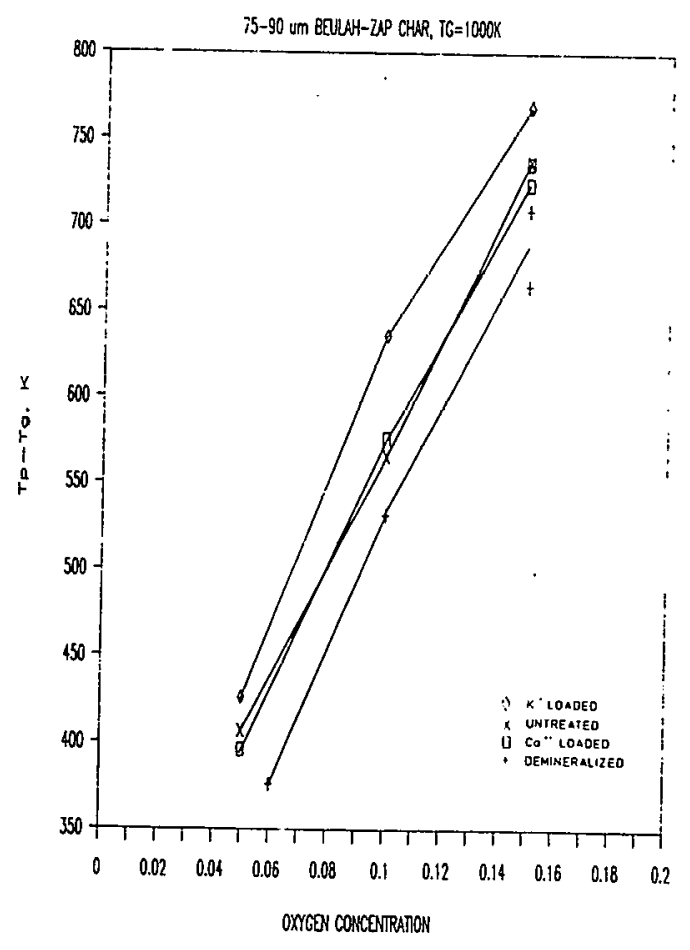


Although these trends are subject to some uncertainty due to the spread of individual particle temperatures about the mean temperature values, it should be noted that the distribution is approximately normal and successive experiments under the same conditions reproduce the mean temperatures within approximately $30 \mathrm{~K}$.

A difference in the volatile matter content for various chars was found. These determinations were made using thermogravimetric analysis (TGA) and are summarized in Table 15. The volatile content of the two demineralized chars showed a substantial decrease from that of the untreated char while the calcium loaded demineralized char which was prepared from the same demineralized coal sample gave a volatile mater content comparable to that of the untreated char. The potassium-loaded char had the highest volatile matter content.

TABLE 15

THERMOGRAVIMETRIC ANALYSES OF BEULAH-ZAP CHARS

Volatile Matter, Weight Percent

Chat

Demineralized (DM)

Untreated (UT)

Calcium Added ( $C A$ )

Potassium Added (K)
$23-63 \mu_{m}$

12.1

15.2

17.4

20.0

$$
63-75 \mu \mathrm{m}
$$

7.9

15.7

19.5

23.5
$75-204 \mathrm{~m}$

12.5

14.4

18.5

21.3

Results suggest that the presence of $\mathrm{Na}^{+}, \mathrm{Ca}^{++}$, and $\mathrm{K}^{+}$cations enhance the reactivity of the Beulah char. Figure 10 shows plots of $X$ values of the various chars versus the total cation concentration of the untreated, demineralized and cation loaded coals. There is a fair bit of scatter in the data, but there does not appear to be a cation-specific increase in char reactivity; rather the reactivity appears to be roughly linearly dependent on the total cation concentration.

A basis for the observed changes in the coal char burning rates can be provided by the promotion of $\mathrm{CO}_{2}$ production by the catalytic activity of the $\mathrm{Ca}^{++}$and $\mathrm{K}^{+}$cations $(23,24,25)$. At low temperatures $(663 \mathrm{~K})$, Walker et al. (26) ordered the catalytic activity of metal cations in lignite chars as $\mathrm{Na}^{+}>\mathrm{K}^{+}>\mathrm{Ca}^{++}>\mathrm{Fe}^{+++}>\mathrm{Mg}^{++}$. At 593-863K, Amariglio and Duval (27) ordered cations for the promotion of graphite combustion as $\mathrm{Cs}^{++}>\mathrm{Na}^{+}>\mathrm{Ba}^{++}$ $\mathrm{Sr}^{++}>\mathrm{Mg}^{++}>\mathrm{Ca}^{++}>\mathrm{Al}^{+++}$. Although the temperature of the burning char particles are substantially greater than the ranges cited previously. 

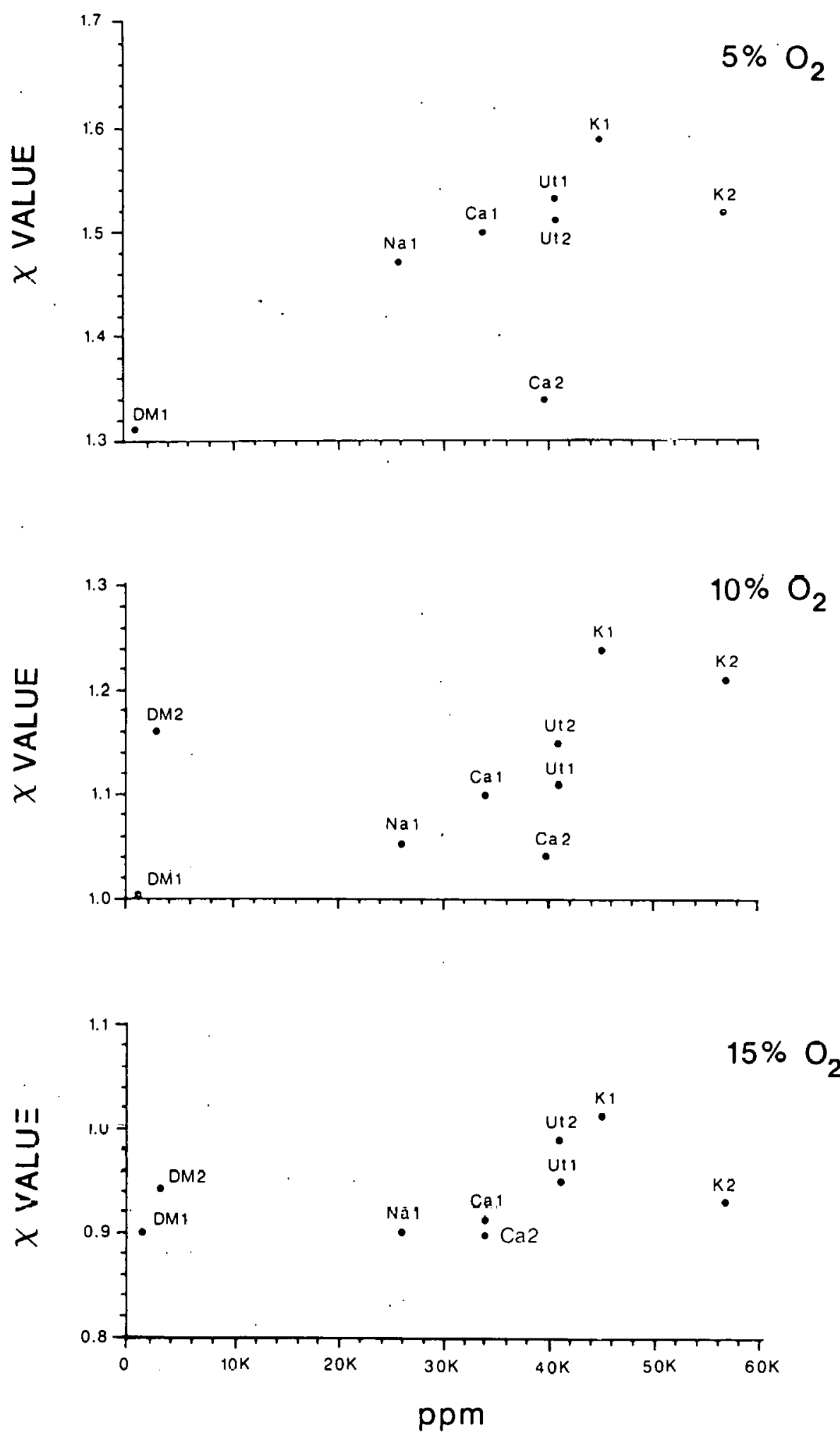

Figure 10. $X$ Values vs. Total Cation Concentration of Untreated, Demineralized, and Cation-Loaded Beulah Chars. 
The Beulah chars have been examined to date at two observation heights (100 and $150 \mathrm{~mm}$ ) at $0.05,0.10$, and 0.15 mole fraction oxygen. Since these measurements were an addition to the original test matrix, the temperature data sets taken were small. The mean particle temperatures and $x$ values, consequently, are not as reliable as for the original Beulah measurements.

Table 16 gives the mean particle temperatures and $X$ values obtained for the Beulah, Beulah2, and New Mexico Blue chars. The temperatures and values for the Beulah2 untreated, calcium-loaded, and potassium-loaded, and potassium-loaded chars are comparable to those for the first Beulah chars. However, the Beulah2 demineralized char gave temperature and $X$ values similar to those for the untreated and cation-loaded chars. This is rather puzzling, since visually the Beulah2 demineralized char did not appear to be burning well at all. Further measurements are underway, but possible explanations are either that this char was prepared differently from the first demineralized Beulah char or that the pyrometer was skewing the temperature measurements by detecting only the most reactive particles. A cursury examination of the morphology of the Beulah2 demineralized char indicates that it is different than the first sample.

Also given in Table 16 are the mean particle temperatures and $X$ values at two observation heights. Although the test matrix is not complete, some trends can be noted.

The New Mexico Blue untreated and demineralized chars show behavior significantly different from the Beulah chars. The untreated New Mexico char temperature decreases between the 100 and $150 \mathrm{~mm}$ observation points, while the demineralized char temperature is comparable to or higher than the untreated char temperature at $150 \mathrm{~mm}$. This appears to be the result of two possible factors: (1) since the New Mexico Blue untreated char did not have significant ion-exchangeable mineral content, the behavior of the untreated and demineralized chars is basically the same, and (2) from visual observation, the untreated char is somewhat more reactive and is burning out close to the $150 \mathrm{~mm}$ point, while the demineralized char is igniting close to the $100 \mathrm{~mm}$ point.

\section{4. . TGNTTTON BEHAVTOR}

\subsection{INTRODUCTION AND BACKGROUND}

Coal particle ignition is extremely complex involving simultaneous heat, mass, and momentum transfer. If a single particle of coal is exposed to a hot oxidizing environment. Ignition is thought to proceed by a series of steps which include:

1) heating of the particle,

2) devolatilization,

3) ignition of the volatiles or,

4) reaction at the surface. 


\section{TABLE 16}

(PARTICLE-GAS) TEMPERATURES AND $X$ VALUES FOR BEULAH AND NEW MEXICO BLUE CHARS AT $0.05,0.10$, AND 0.15 MOLE FRACTION OXYGEN

\begin{tabular}{|c|c|c|c|c|}
\hline Char & \multicolumn{2}{|c|}{$\begin{array}{c}\text { (63-75 micron char } \\
100 \mathrm{~mm}\end{array}$} & \multicolumn{2}{|c|}{$\begin{array}{c}\mathrm{Tg}=1000 \mathrm{~K}) \\
150 \mathrm{~mm}\end{array}$} \\
\hline Beulah-zap & & & & \\
\hline Untreated & - & $\begin{array}{l}- \\
-\end{array}$ & $\begin{array}{l}403 \\
579 \\
720\end{array}$ & $\begin{array}{l}1.51 \\
1.11 \\
0.95\end{array}$ \\
\hline DemLllelal Lzed & - & - & $\begin{array}{l}418 \% k \\
524 \\
688\end{array}$ & $\begin{array}{l}1.91 \\
1.00 \\
0.91\end{array}$ \\
\hline $\mathrm{Ca}^{++}$Loaded & - & - & $\begin{array}{l}399 \\
576 \\
693\end{array}$ & $\begin{array}{l}1.50 \\
1.08 \\
0.91\end{array}$ \\
\hline $\mathrm{R}^{+}$Loaded & $\begin{array}{l}\overline{-} \\
-\end{array}$ & $\begin{array}{l}\overline{-} \\
\overline{-}\end{array}$ & $\begin{array}{l}427 \\
646 \\
753\end{array}$ & $\begin{array}{l}1.59 \\
1.24 \\
0.99\end{array}$ \\
\hline $\mathrm{Na}^{+}$Loaded & - & - & $\begin{array}{l}393 \\
548 \\
687\end{array}$ & $\begin{array}{l}1.47 \\
1.05 \\
0.90\end{array}$ \\
\hline Beulah-2ap 2** & & & & \\
\hline Untreated & $\begin{array}{l}* * * \\
594 \\
694\end{array}$ & $\begin{array}{c}\star * * \\
1.13 \\
0.91\end{array}$ & $\begin{array}{l}403 \\
596 \\
748\end{array}$ & $\begin{array}{l}1.53 \\
1.15 \\
0.99\end{array}$ \\
\hline Demineralized & - & - & $\begin{array}{l}413 \\
610 \\
724\end{array}$ & $\begin{array}{l}-.- \\
1.16 \\
0.94\end{array}$ \\
\hline $\mathrm{Ca}^{++}$Loaded & $\begin{array}{l}\star \star \star * \\
544 \\
672\end{array}$ & $\begin{array}{l}* * * \\
1.04 \\
0.88\end{array}$ & $\begin{array}{l}427 * * \\
547 \\
-\end{array}$ & $\begin{array}{l}1.34 \\
1.04 \\
-\end{array}$ \\
\hline
\end{tabular}


TABLE 16 CONT.

(PARTICLE-GAS) TEMPERATURES AND $X$ VALUES FOR BEULAH AND NEW MEXICO BLUE CHARS

(63-75 micron char
$100 \mathrm{~mm}$
$\mathrm{Tp}-\mathrm{Tg}$
$\mathrm{Tg}=1000 \mathrm{~K})$
$150 \mathrm{~mm}$

Char

$\mathrm{Tp}-\mathrm{Tg}$

$\mathrm{TP}-\mathrm{Tg}$

Beulah-Zap 2**

$\mathrm{K}^{+}$Loaded
$\mathrm{Na}^{+}$Loaded

New Mexice Blue

Untreated

$\star \star * *$

377

1.41

583

1.12

540

1.02

670

0.88

630

0.82

Demineralized

$\begin{array}{llll}* * * & * * * & 434 * & 1.39 \\ 540 & 1.04 & 623 & 1.19 \\ 674 & 0.89 & 723 & 0.96\end{array}$

* second preparation

** at 0.06 mole fraction oxygen

*** unable to observe any signals

- not yet run

In addition, ignition of a cloud of particles is more complicated due to interparticle radiation effects.

Early efforts to measure the 1gnition temperature of small particles were concerned largely with cloud ignition $(28,29)$. Ignition data on single particles is sparse. In addition to pulverized carbon fuel ignition, the combustion of metal particles has also been studied. Cassel and Liebman (30) have studied the combustion of $\mathrm{Mg}$ particles using photographic techniques to study the lifetime of burning particles. Later the gas ignition temperature of sized particles was measured using a furnace arrangement while other work has centered on the ignition of clouds of $\mathrm{Mg}$ particles and on comparing the behavior of dilute and concentrated systems $(31,32)$. This material has also 
been studied by Law and Williams (1974) using high speed photography. In addition, boron particle ignition has been studied by a number of authors including Meinkohn (1985).

Several experimental procedures have been used to measure ignition points. For example, ignition of pulverized anthracite coal has been studied by observing the flame front (33). A packed bed of carbon particles has been found to spontaneously ignite at $400^{\circ} \mathrm{C}$ as determined by Hardman et al. (34). Also, graphite rods with imbedded thermocouples have been found to ignite at between 936 and $987^{\circ} \mathrm{C}$ for air flows of between 32 and $96 \mathrm{~cm} / \mathrm{sec}$ (35).

Single particles of brown coal have been observed by Thomas et al. (36) to determine whether ignition occurred in the gas phase volatiles or on the particle surface. Bandyopadhyay and Bhaduri (37) have measured the ignition temperature of anthracite, bituminous, lignite particles in a furnace by observing the flash point. They noted that the ignition temperature fell with increasing particle diameter. Karcz et al. (38) have observed the ignition temperature of bituminous and anthracite coal, noted the decrease in ignition temperature with particle size and estimated activation energies from the ignition data. A number of different criteria have been applied to the problem by Gomez and Vastola (39) who used $\mathrm{CO}, \mathrm{CO}_{2}$, and luminosity to detect ignition as a function of time.

There has been a more substantial effort to model the ignition behavior of single particles. These efforts generally involve the statement of the problem in terms of the differential equations of mass, energy, and momentum conservation and then making appropriate approximations to solve the mathematical problem. Early modelling efforts were those of Semenov (40) who developed the thermal theory of ignition and Van't Hoff (41). This approach begins with a steady state energy balance on the particle and solves for the minimum gas temperature needed for ignition which has also been used by Cassel and Liebman (3) and by Bandyopadhyay and Bhaduri (37) to correlate their experimental results in terms of an activation energy. Essenhigh and coworkers (42) have used this model to interpret their measurement of gas ignition temperature for a series of chars and cokes.

A number of workers have integrated the unsteady state energy balance (36, 43) and have calculated a temperature versus time curve which is typically sshaped. In addition, changes in the pore structure have been incorpurated (44). Other workers, among them Williams and co-workers (45) and Libby and co-workers $(46,47)$ have applied activation energy asymptotics to arrive at theoretical ignition times as well as the relative contributions of various terms and a calculation of the thermal history of carbon particles. Simultaneous devolatilization and combustion occurring in a single particle surrounded by a cloud of burning volatiles has also been considered. $(48,49,50,51)$. 


\subsection{CALCULATION OF GAS IGNITION TEMPERATURES}

Calculation of the conditions needed for particle ignition proceeds by assuming that a spherical char particle is contacted by hot gas. The particle then is heated by the environment and begins to react with the oxygen present in the atmosphere. The reaction then increases the particle temperature which can be substantially higher than the gas temperature. The particle temperature as a function of time is determined from unsteady state energy and mass balances:

$$
\begin{gathered}
\mathrm{dm} / \mathrm{dt}=-\rho \mathrm{A} \\
\mathrm{mC}_{\mathrm{p}} \mathrm{dT}_{\mathrm{p}} / \mathrm{dt}=\mathrm{A} \Delta \mathrm{H}-\mathrm{hA}\left(\mathrm{T}_{\mathrm{p}}-\mathrm{T}_{\mathrm{g}}\right)-\varepsilon \sigma A\left(\mathrm{~T}_{\mathrm{p}}^{4}-\mathrm{T}_{\mathrm{p}}^{4}\right)
\end{gathered}
$$

Here $m$ is the mass of the particle while $A$ is the surface area. The energy balance equation accounts for the heating of the particle by reaction where $p$ is the overall rate of reaction and $\Delta H$ is the heat of reaction and the loss of heat by conduction to the ambient gas and by radiation to surrounding walls. The temperatures of the particle, wall, and gas are $T_{p}, T_{w}$, and $T_{g}$ respectively. The heat transfer coefficient, $h$, is determined from the Nusselt number, Nu, which is given by

$$
\mathrm{NU}=\mathrm{hd} / \lambda
$$

The limiting value of the $\mathrm{Nu}$ is two and $\mathrm{Nu}$ depends on $\mathrm{d}$, the particle diameter and $\lambda$, the thermal conductivity of the gas which is a function of temperature. The emissivity is $\varepsilon$, taken to be unity, and $\sigma$ is the stefanBoltzmann constant.

The mass and area related to the diameter through

$$
\begin{aligned}
& \mathrm{m}=\pi_{\rho} \mathrm{d}^{3} / 6 \text { and } \\
& \mathrm{A}=\pi \mathrm{d}^{2}
\end{aligned}
$$

The overall rate of combustion is determined from the rate of diffusion of oxygen to the surface, $\rho \mathrm{dlff}$, and the rate of chemical reaction, $\rho \mathrm{chem}$ :

$$
\rho_{\text {diff }}=k_{\text {diff }}\left(P_{g}-P_{s}\right)
$$

where

$$
\kappa_{\operatorname{diff}}=48 \mathrm{D}_{0} / \mathrm{RdT}_{\mathrm{m}}
$$

and

$$
\rho_{\text {chem }}=k_{\text {chem }}\left(P_{s}\right)^{n}
$$


An Arrhenius form for the rate constant for chemical reaction is assumed:

$$
\rho_{\text {chem }}=A \exp (-E / R T)
$$

Since the surface pressure is unknown an approximation employed here is to use the maximum rate of both diffusion and reaction and to calculate the overall rate from a "resistances in series" formula:

$$
1 / \rho=1 / \rho_{\text {diff }}+1 / \rho_{\text {chem }}
$$

where $n$ has been assumed to be unity. The diffusion coefficient, $D_{0}$, depends on temperature and is evaluated at the mean temperature of the particle and the gas.

The enthalpy of reaction and the heat capacity are functions of temperature and in these calculations the char particle is assumed to be composed of carbon. Combustion proceeds to $\mathrm{CO}$ as product.

The Semenov analysis assumes a steady state particle temperature so that the energy balance becomes

$$
\Psi=\rho \Delta \quad H-h\left(T_{p}-T_{g i}\right),
$$

where the radiation term has now been ignored and is the sum of the generation and conduction terms. One of the Semenov criteria for ignition is that the heat generated by reaction is equal to that lost by conduction at the gas ignition temperature. The other condition is that the derivative of the generation term is equal to that of the loss term and the two conditions which serve to determine the gas ignition temperature are

$$
\Psi=0 \text { and } \mathrm{d} \Psi / \mathrm{d \textrm {T } _ { \mathrm { p } }}=0
$$

The ignition temperature is determined by calculating and $d / d T_{p}$ with $T_{g}$ as a parameter. A value for $\Delta H$ of $9791 \mathrm{~J} / \mathrm{g}$ was adopted in these semenov calculations (52) and $\rho$ was set equal to $\rho$ chem following Essenhigh (42).

The results of a number of such calculations for a series of coals have been summarized in a correlation proposed by Annamali and Durbetaki (49):

$$
1 / \theta_{I, g}=1.433 \ln (\mathrm{Dc}, \mathrm{h})
$$

where $D_{c, h}$ is a dimensionless Damkoler number given by

$$
D_{c, h}=e^{4.57}\left(D_{I V, w}\right)_{h} Y_{O}
$$

and $\theta \mathrm{I,g}$ is a dimensionless ignition temperature given by the equation

$$
\theta I, g=R T_{p, i} / E
$$


The subscript $h$ refers to heterogeneous ignition and the subscript w refers to the evaluation of the Damkoler number at the gas solid interface. $Y_{0}$ is the mass fraction of oxygen. $D_{I V, w}$ is given by

$$
\left(D_{I V, w}\right) h=\left(D_{I I I, w}{ }_{h} Q_{w}{ }^{+}\right.
$$

where

$$
\begin{gathered}
\left(D_{\text {III, }}{ }^{\mathrm{h}}=\mathrm{A}(\mathrm{d} / 2) \mathrm{P} / \text { gas }^{\mathrm{DE}}\right. \\
\mathrm{Q}_{\mathrm{w}}{ }^{+}=\mathrm{R} \text { H/ } \mathrm{C}_{\mathrm{p}} \mathrm{E}
\end{gathered}
$$

The term $Q_{w}{ }^{+}$is a dimensionless heat generation and $D_{\text {III }}$ is the ratio of the rate due to reaction to the rate of diffusion. A is the preexponential factor, $P$ the total pressure $\left(1.035 \times 10^{5} \mathrm{~Pa}\right)$, and gas is the density. The ignition temperatures computed from the unsteady gastate balances will be compared to those calculated from the Semenov criteria and the Damkoler correlation.

\subsection{EXPERIMENTAL APPROACH}

Initial testing using the single particle reactor was unsuccessful in determining the ignition behavior of coal particles. The single-particle reactor was designed for particle temperature measurements under quasi-steady state conditions. Particle ignition is a transient process. Since the particles are entrained in a moving gas stream, any deviation in the time and/or temperature will cause ignition to occur at a different vertical point along the chimney centerline. In addition, the existing photomultipliers of the three-color optical pyrometer are insensitive to light at wavelengths greater than $900 \mathrm{~nm}$. This places a lower temperature detection limit of approximately $1200 \mathrm{~K}$ for particles in the 100 micron range. Thus, with existing equipment, it is not possible to detect particles or to track moving particles until well after ignition has occurred.

An alternative technique will be used to examine the ignition behavior of individual particles. The technique that will be used was developed by Gomez and Vastola (39). It involves the continuous and simultaneous measurement of carbon monoxide and carbon dioxide production when a captive single coal particle is burnt after injection into an isothermal reactor swept with a premixed combustion gas mixture. A pyrometer will be used to measure the onset of ignition. In addition the particle size will be measured. The configuration of the system is shown in Figure 11. 


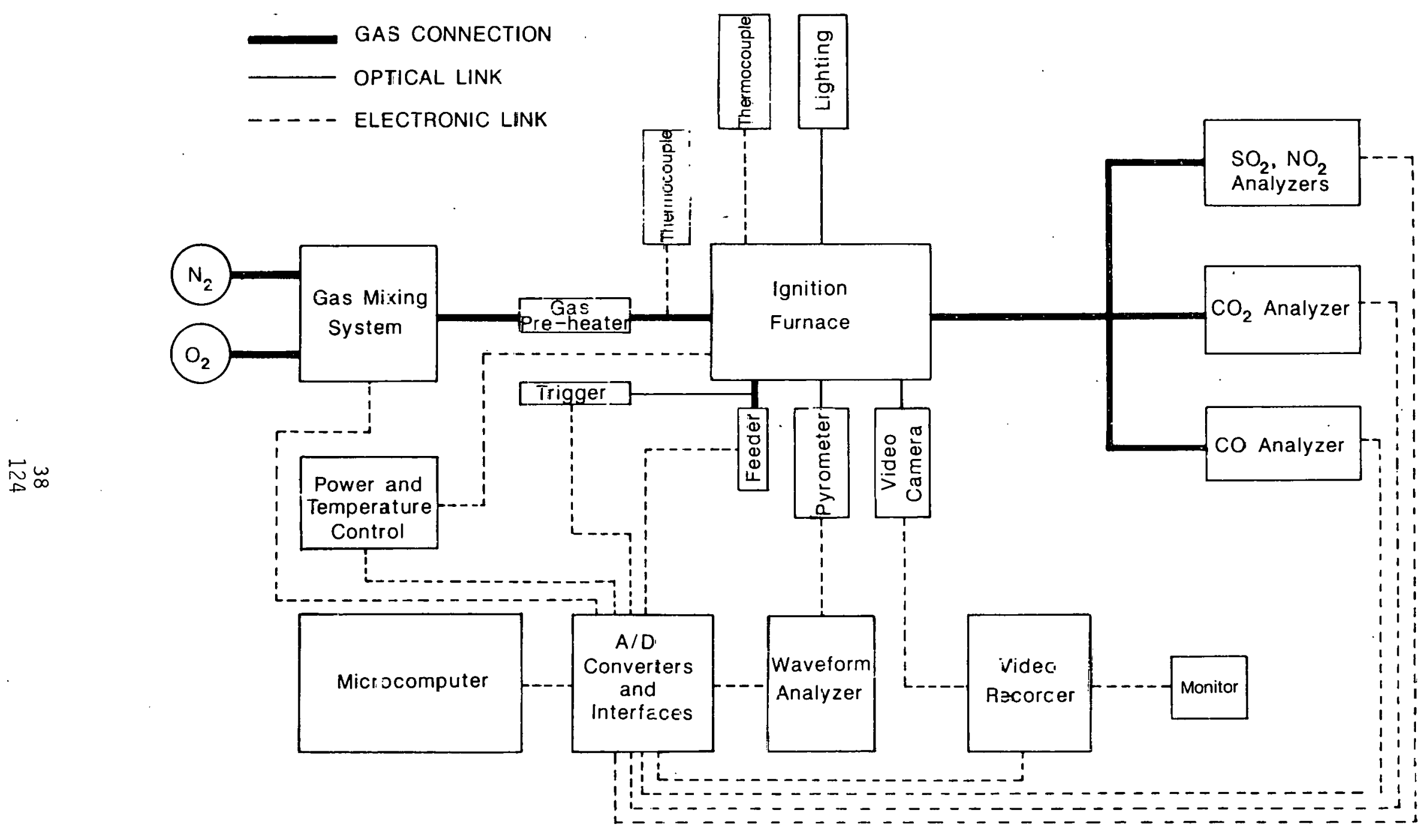

Figure 11. Scheratic Diagram of the Ignition Apparatus. 


\subsection{REFERENCES}

1. Field, M.A., D.W. Gill, B.B. Morgan, and P.G.W. Hawksley, Combustion of Pulverized Coal, Leatherhead, p. 191, 1967.

2. Smoot, L.D., and P.J. Smith, Coal Combustion and Gasification, Plenum Press, N.Y., p. 77, 1985.

3. Mulcahy, M.F.R. and I.W. Smith, Rev. Pure and Applied Chem., 18, 173, 1972 .

4. Ayling, B.A. and I.W. Smith, Combustion and Flame, 18, 173, 1972.

5. Essenhigh, R.H., Sixteenth Symposium (International) on Combustion, The Combustion Institute, Pittsburgh, p. 353, 1976.

6. Laurendeau, N.M., Progress in Energy and Combustion Science, 4, 221, 1978.

7. Mon, E. N.R. Amundson, Industrial and Engineering Chemistry Fundamentals, 17 (4) $313,1978$.

8. Heuchamp, C. and X. Duval, Carbon 4, 243, 1966.

9. Mitche11, R.E. and W.J. McLean, Nineteenth Symposium (International) on Combustion, The Combustion Institute, p. 1113, 1982.

10. Tichenor, D.A., R.E. Mitchell, K.R. Hencken and S. Niksa, Twentieth Symposium (International) on Combustion, The Combustion Institute, $p$. 1213,1984 .

11. Goetz, G.J., N.Y. Nsakala, K.L. Patel, and T.C. Lao, "Combustion and Gasification Kinetics of Chars from Four Commercially Significant Coals of Varying Rank," Second Annual Conference on Coal Gasification, EPRI, Palo Alto, California, October 1982.

12. Mitchel1, R.E., "Experimentally Determined Overall Burning Rates of Coal Chars", Spring Meeting of the Western States Section/The Combustion Institute, Banff, Canada, April 1986.

13. Hamor, R.J., I.W. Smith, and R.J. Tyler, Combustion and Flame, 21, 153, 1973.

14. Young, B.C., "The Chemistry of Low-Rank Coai", (ed. H.H. Schobert), ACS Symposium Series 264, Aüerican Chemieal Society, p. 243, 1984.

15. Paulson, C.A.J., Smith, I.W. and B.C. Young, Proceedings International Conference on Coal Science, Sydney, Australia p. 371, 1985.

16. Jones, R.B., McCourt, C.B., Morley, C., and King, K.: Maceral and Rank Influences on the Morphology of Coal Char: Fuel, vol. 64, p. 1460-1467, 1985 . 
17. UNDERC Quarterly Technical Progress Report for the Period April to June 1986. Combustion Research and Ash Fouling: DOE/FE/60181-1682, 1986.

18. Stach, E., Taylor, G.H., Mackowsky, M.T., Chandra, D., Teichmuller, M., and Teichmuller, R.; 3rd edition, Coal Petrology, GerbruderBorntraegger, Berlin-Stuttgart, p. 535, 1982.

19. Shibaoka, M., Microscopic Investigation of Unburnt Char in Fly-Ash: Fuel, vol. 64, p. 263-269, 1985.

20. Frank-Danumetskii, D.A., Diffusion and Heat Transfer in Chemical Kinetics, Plenum Press, N.Y., 2nd Ed p. 108, 1969.

21. Young, B.C., B.G. Miller, D.P. McCollor, K.D. Schnable, D.R. Kleesattel, and M.L. Jones, Fundamental Combustion Ash Fouling, Final Report, $\mathrm{DOE} / \mathrm{FE} / 60181-2126,1986$.

22. Young, B.C., and S. Niksa, Combustion Rates for Selected Low-Rank Coal Chars, Accepted for Publication in Fuel, 1987.

23. Young, B.C., D.P. McCollor, B.J. Weber, and M.L. Jones, Beulah Lignite Char Combustion in a Single-Particle Reactor, Submitted to Fuel, 1987.

24. Laurendeau, N.M., Prog. Energy Sci. 4, 221, 1978.

25. Henchamps, C. and X. Duval, Carbon 4, 243, 1966.

26. Walker, P.L. Jr., O.P. Mahajan, and M. Komatsu, Preprints of Paper, Division of Fuel Chemistry, American Chemical Society, Washington, D.C. 24, p. 10, 1979 .

27. Amariglio, H. and X. Duval, Carbon, 4, 323, 1966.

28. Palmer, K.W. "Dust Explosions and Fires", Chapman and Ha11, London, 1973.

29. Essenhigh, R.H. Dust Explosion in Factories: Ignition Testing and Design of a New Inflammator. Safety in Mines Research Establishment (UK) Research Report Number 118, 1960.

30. Cassel, H.M. and Leibman, I. The Mechanism in the Ignition of Dust Dispersions. Combustion and Flame 3, 467, 1959.

31. Casse1, H.M. and Leibman, I. Combustion of Magnesium Particles I. Combustion and Flame 6, 153, 1962.

32. Cassel, H.M. and Leibman, I. Combustion of Magnesium Particles IIIgnition Temperatures and Thermal Conductivities of Ambient Atmospheres. Combustion and Flame 7, 79, 1963.

33. Cutress, J.0.; Peirce, T.J. and Tucker, A.CN. Combust. Flame. 8, 289, 1964 . 
34. Hardman, J.S., Lawn, C.J. and Street, P.J. Further Studies of the Spontaneous Ignition Behavior of Activated Carbon. Fuel 62, 632, 1983.

35. Goard, P.R.C. and Mulcahy, M.F.R. A Study of the Ignition of Graphite. Carbon 5, 137. 1967.

36. Thomas, G.R., Stevenson, A.J. and Evans, D.G. Ignition of Coal Particles without Temperature Jump. Combustion and Flames 21, 133, 1973.

37. Bandyopadhyay, S. and Bdhaduri, D. Prediction of Ignition Temperature of Single Coal Particle. Combustion and Flame 18, 411, 1972.

38. Karcz, H., Kordylewski, W. and Rybak, W. Evaluation of Kinetic Parameters of Coal Ignition. Fuel 59, 798, 1980.

39. Gomez, O.C. and Vastola, F.J. Ignition and Combustion of Single Coal and Char Particles. Fuel 64, 558, 1985.

40. Semenov, N.N. "Chemical Kinetics and Chain Reactions", Clarendon Press, Oxford, 1935.

41. Van't Hoff, J.H. "Studies in Chemical Thermodynamics", Amsterdam, 1884.

42. Chen, M., Fan, L. and Essenhigh, R.H. Prediction and Measurement of Ignition Temperatures of Coal Particles. Twentieth Symposium (International) on Combustion. The Combustion Institute, Pittsburgh, PA, p. 1513-1521, 1984.

43. Stevenson, A.J., Thomas, G.R. and Evans, D.G. Modelling the Ignition of Brown-Coal Particles. Fuel 52, 281, 1973.

44. Srinivas, B. and Amundson, N.R. Intraparticle Effects in Char Combustion. II Transient Studies. The Canadian Journal of Chemical Engineering $59,728,1981$.

45. Linan, A. and Williams, F.A. Radiant Ignition of a Reactive Solid with In-Depth Absorption. Combustion and Flame 18, 85, 1972.

46. Libby, P.A. Ignition, Combustion, and Extinction of Carbon Particles. Combustion and Flame 38, 285, 1980.

47. Kassoy, D.R. and Libby, P.A. Activation Energy Asymptotics Applied to Burning Carbon Particles. Combustion and Flame 48, 287, 1982.

48. Choi, S. and Kruger, C.H. Modeling Coal Particle Behavior under Simultaneous Devolatilization and Combustion. Combustion and Flame 61, 131, 1985.

49. Annamali, K. and Durbetaki, P. A Theory on Transition of Ignition Phase of Coal Particles. Combustion and Flame 29, 193, 1977. 
50. Annamali, K. Critical Regimes of Coal Ignition. Trans. ASME 101, 576, 1979.

51. Kordylewski, W., Kruczek H. and Rybak, W. An. Analysis of Critical Ignition and Extinction Diameters of Solid Particles. Combustion Science and Technology 26, 157, 1981.

52. Mitchel1, R.E. and McLean, W.J. On the Temperature and Reaction Rate of Burning Pulverized Fuels, Nineteenth Symposium (International) on Combustion. The Combustion Institute, Pittsburgh, PA, 1113-1122. 


\section{APPENDIX}


FLINDAMENTAL CUMEUSTIUN RIUN SUMMGMYY

$$
\text { GY COAL/CHAR TYHE }
$$

STEFINA-COKRECTED CHI AIND RHO

CHAR TYPE $=8$ (C:A LOADED-2. $4 \%$ ) AVG SIZE* (MICKONS) $==8$

\begin{tabular}{|c|c|c|c|c|c|c|c|c|c|c|c|}
\hline$(x 025)$ & $\begin{array}{l}\text { VOL. MATTER } \\
(X W / W)\end{array}$ & $\begin{array}{r}\text { GAS } \\
\text { TEMP } \\
\text { (K) }\end{array}$ & $\begin{array}{r}\text { PART ICLE } \\
\text { TEMF } \\
\text { (K) }\end{array}$ & $\begin{array}{l}\text { WALL } \\
\text { TEMP } \\
\text { (K) }\end{array}$ & $\begin{array}{l}\text { NO. DHTH } \\
\text { USED }\end{array}$ & $\begin{array}{l}\text { TUIAL NU. } \\
\text { GHT HEKES }\end{array}$ & $\begin{array}{l}\text { STo } \\
\text { UEV }\end{array}$ & $\begin{array}{l}\text { Het } \\
\text { imilit) }\end{array}$ & LHI & Rhils & $\begin{array}{l}\text { DUIKL. } \\
\text { PHESSIJPLE }\end{array}$ \\
\hline 0.06 & 17.4 & 1011 & 1418 & 400 & 37 & $5^{\prime} y$ & $4 y$ & 150 & 1.24 & 0.0130 & 0.981 \\
\hline 0.10 & 17.4 & 1014 & $153 \theta$ & 400 & ie & bo & 45 & 150 & 0.97 & $0.01 \%$ is & 0. \\
\hline 0.15 & 17.4 & 1012 & 1676 & 400 & 14 & 30 & 5 & 150 & 0.84 & 0. (1207) & 0.981 \\
\hline
\end{tabular}

CHAR TYFE=B (CA LOHQED-E. 4\%) AVG SILE* (HICRONS) $=69$

\begin{tabular}{|c|c|c|c|c|c|c|c|c|c|c|c|c|}
\hline$(x 02)$ & $\begin{array}{l}\text { VOL. MATTER } \\
\text { (xW/W) }\end{array}$ & $\begin{array}{r}\text { GAS } \\
\text { TEMP } \\
\text { (K) }\end{array}$ & $\begin{array}{r}\text { FARTICLF } \\
\text { TEMF } \\
(K)\end{array}$ & $\begin{array}{l}\text { WHLLL } \\
\text { TEMMF } \\
\text { (K) }\end{array}$ & $\begin{array}{l}\text { ND. DHTH } \\
\text { USED }\end{array}$ & $\begin{array}{l}\text { TULAI_ ' } \\
\text { LATTHEI }\end{array}$ & $\begin{array}{l}\text { NU. } \\
\text { RED }\end{array}$ & $\begin{array}{l}\text { STD } \\
\text { VEtV }\end{array}$ & $\begin{array}{l}\text { HE I GHT } \\
\text { ( IMI) }\end{array}$ & $\mathrm{CHI}$ & RtiC & $\begin{array}{l}\text { TOLIHI- } \\
\text { PRESSURE: }\end{array}$ \\
\hline 0.05 & 19.5 & 1001 & 1400 & 400 & $3 e$ & & 60 & 58 & 1 ذu & 1.50 & $0.010 \%$ & 0.909 \\
\hline 0.10 & 19.5 & 1006 & 1582 & 400 & 36 & . & 60 & 48 & ISO & 1.08 & 0.0160 & ו 10.0 \\
\hline 0.10 & 19.5 & 904 & 1524 & 400 & 43 & . & 60 & $6=$ & 150 & 1.14 & $0.016=$ & 0.974 \\
\hline 0.15 & 19.5 & 1006 & 1699 & 400 & 27 & & 59 & 54 & 150 & 0.91 & $0.000 \%$ & 0.973 \\
\hline 0.15 & 19.5 & 902 & $1 \in B \overline{3}$ & 400 & 35 & . & 58 & 42 & $1 s c$ & 1.00 & 0.0019 & $\because .968$ \\
\hline
\end{tabular}

CHAR TYHE=B (CA LOHDED-2. 4\%) AVG STLE* (MICRONS) $=42.5$

\begin{tabular}{|c|c|c|c|c|c|c|c|c|c|c|c|}
\hline$(x 02)$ & $\begin{array}{r}\text { VOL. MATTER } \\
(\% W / W)\end{array}$ & $\begin{array}{l}\text { GAS } \\
\text { TEMP } \\
(K)\end{array}$ & $\begin{array}{r}\text { PART ICLE } \\
\text { TEMP } \\
\text { (K) }\end{array}$ & $\begin{array}{l}\text { WALL } \\
\text { TEML- } \\
\text { (K) }\end{array}$ & $\begin{array}{l}\text { NO. DATA } \\
\text { USED }\end{array}$ & $\begin{array}{l}\text { TOTAL NO. } \\
\text { LATHERED }\end{array}$ & $\begin{array}{l}\text { STD } \\
\text { DEV }\end{array}$ & $\begin{array}{r}\text { MË } 2 G H 7 \\
(\Omega \cap M)\end{array}$ & CHI & RHO & $\begin{array}{l}\text { TOTAL } \\
\text { PNESSURE }\end{array}$ \\
\hline 0.05 & 18.5 & 1000 & 1396 & 400 & 40 & 58 & 43 & 150 & 1.55 & 0.0094 & $0.9 \in 6$ \\
\hline 0.10 & 18.5 & 1002 & 1576 & 400 & 39 & 60 & 40 & 150 & 1.14 & 0.0143 & 0.974 \\
\hline 0.15 & 18.5 & 1001 & 1725 & 400 & 11 & 58 & 41 & 150 & 0.98 & 0.0189 & $0.9 / 4$ \\
\hline 0.15 & 18.5 & 1001 & 1737 & 400 & 19 & 56 & 33 & 150 & 1.01 & 0.0192 & 0.76 \\
\hline
\end{tabular}


CHAR TYHE $=E$ (DEM. HLLL- $3 \%$ ) AVG SILE* (IICKONS) $=6 \cdot 9$

\begin{tabular}{|c|c|c|c|c|c|c|c|c|c|c|c|}
\hline$(x 02)$ & $\begin{array}{r}\text { VOL. MATTER } \\
(\% W / W)\end{array}$ & $\begin{array}{r}\text { GAS } \\
\text { TEMF } \\
\text { (K) }\end{array}$ & $\begin{array}{r}\text { FART ICLE } \\
\text { TEMF } \\
\text { (K) }\end{array}$ & $\begin{array}{l}\text { WALL } \\
\text { TEMF } \\
\text { (K) }\end{array}$ & $\begin{array}{r}\text { NO. DATA } \\
\text { USED }\end{array}$ & $\begin{array}{l}\text { TOTAL NU. } \\
\text { GATHERED }\end{array}$ & $\begin{array}{l}\text { SID } \\
\text { Lit V }\end{array}$ & $\begin{array}{c}H E I G H I \\
(M(I))\end{array}$ & $\mathrm{EHI}$ & RHO & $\begin{array}{l}\text { TOThH } \\
\text { HRESSURE: }\end{array}$ \\
\hline $0.0 E$ & 13.6 & 992 & 1417 & 400 & 29 & 45 & 5,3 & $1 \leq 0$ & 1.34 & 0.0116 & 0. \\
\hline 0.10 & 13.6 & 1005 & 1504 & 400 & 37 & 5 & 4.3 & $1 \leqslant 0$ & 0.95 & 0.0141 & $0 .=10$ \\
\hline 0.15 & 13.6 & 1005 & 1605 & 400 & $1 \theta$ & 30 & $3 i$ & $1 \sqcup 0$ & $0.7 t$ & $0.01 / 4$ & $\because . \unlhd \leftrightarrow$ \\
\hline 0.15 & 13.6 & 1009 & 1616 & 400 & 36 & $\Xi i j$ & $4 B$ & 150 & 0.79 & 0.0177 & 0.575 \\
\hline
\end{tabular}

CHAR TYFE=E (DEMINERHL-E. 4\%) AVE SIZE* (MICKIJNS) = GH

\begin{tabular}{|c|c|c|c|c|c|c|c|c|c|c|c|}
\hline$(x 0 \Xi)$ & $\begin{array}{l}\text { WOL. MATTER } \\
(\% W / W)\end{array}$ & $\begin{array}{c}\text { GAS } \\
\text { TEMF } \\
(K)\end{array}$ & $\begin{array}{c}\text { FART ICLE } \\
\text { TEMḦ } \\
\text { (K') }\end{array}$ & $\begin{array}{l}\text { WALLL } \\
\text { TEMIF } \\
(K)\end{array}$ & $\begin{array}{l}\text { NO. DHTH } \\
\text { USED }\end{array}$ & $\begin{array}{l}\text { TOTAL NO. } \\
\text { GATHERED }\end{array}$ & $\begin{array}{l}\text { Sro } \\
\text { DEV }\end{array}$ & $\begin{aligned} & H E \text { I GHHI } \\
& \text { IIMMI }\end{aligned}$ & $\mathrm{CHI}$ & NHO & $\begin{array}{l}\text { TOUAL } \\
\text { FREESUU:?E }\end{array}$ \\
\hline $0.0 E$ & 1e. 1 & $100 e$ & 1440 & 400 & 19 & 30 & 30 & 150 & 1.34 & 0.0140 & 0.970 \\
\hline 0.10 & 12. 1 & 1001 & 1556 & 400 & 3e & EO & se & 150 & 1.03 & 0.018 ن & $0 . \rightarrow / 0$ \\
\hline 0.15 & 12.1 & $100 \theta$ & 1666 & 400 & 36 & 60 & 47 & 150 & 0.84 & 0. & $0.96=$ \\
\hline
\end{tabular}

CHAR TYFE=E (DEMINERAL-2. $4 \%$ ) AVG SIZE* (MICRONS) $=09$

\begin{tabular}{|c|c|c|c|c|c|c|c|c|c|c|c|}
\hline (XO巳) & $\begin{array}{r}\text { V.JL. MATTER } \\
(x W / W)\end{array}$ & $\begin{array}{l}\text { GAS } \\
\text { TEMP } \\
\text { (K) }\end{array}$ & $\begin{array}{r}\text { PART ICLE } \\
\text { TEMF } \\
\text { (K) }\end{array}$ & $\begin{array}{l}\text { WALL } \\
\text { TEMF } \\
\text { (K) }\end{array}$ & $\begin{array}{l}\text { NO. DHTH } \\
\text { USED }\end{array}$ & $\begin{array}{l}\text { TOTAL NO. } \\
\text { GATHERED }\end{array}$ & $\begin{array}{l}\sin \\
\text { DEV }\end{array}$ & $\begin{array}{l}\text { HE C I GH' } \\
\text { (TANA) }\end{array}$ & $\mathrm{LHI}$ & RHIJ & $\begin{array}{r}\text { TOTAL } \\
\text { FRESSSIIRTE }\end{array}$ \\
\hline 0.06 & 7.9 & 1009 & $14 \Xi 7$ & 400 & 19 & 30 & 5.3 & 150 & 1.31 & 0.0116 & $0.9 \%=$ \\
\hline 0.10 & 7.9 & 1010 & 1534 & 400 & 20 & 29 & 41 & $1 \pm 0$ & - & - & - \\
\hline 0.15 & 7.9 & 1009 & 1702 & 400 & 7 & 13 & 73 & 150 & 0.90 & $0.0=07$ & 0.978 \\
\hline 0.15 & 7.9 & $\therefore 010$ & 1694 & 400 & 14 & 32 & 76 & 150 & 0.91 & 0. 0204 & 0.9 .1 \\
\hline
\end{tabular}

CHAR TYFE=E (DEMINERAL-2. 4\%) AVG SIZE* (MICRONS) $=8 \%$.

\begin{tabular}{|c|c|c|c|c|c|c|c|c|c|c|c|}
\hline (xő: & $\begin{array}{r}\text { VOL. MATTER } \\
(\% W / W)\end{array}$ & $\begin{array}{l}\text { GAS } \\
\text { TEMF } \\
\text { (K) }\end{array}$ & $\begin{array}{r}\text { FART ICLE } \\
\text { TEMF- } \\
\text { (K) }\end{array}$ & $\begin{array}{l}\text { WALL } \\
\text { TEMF } \\
\text { (K) }\end{array}$ & $\begin{array}{l}\text { NO. DATA } \\
\text { USED }\end{array}$ & $\begin{array}{l}\text { TOTAL ND. } \\
\text { GATHERED }\end{array}$ & $\begin{array}{l}\text { STD } \\
\text { LEV }\end{array}$ & $\begin{array}{l}\text { HE IGHT } \\
\text { (irM) }\end{array}$ & CHI & FHO & $\begin{array}{r}\text { IUTAI- } \\
\text { PRESSSINRE }\end{array}$ \\
\hline 0.06 & 12.5 & 1024 & 1400 & 400 & 17 & Es & 50 & 150 & 1.83 & $0.00+1$ & $0.78=$ \\
\hline 0.10 & 12.5 & 999 & 1531 & 400 & 46 & 60 & $S . j$ & 150 & 1.05 & $6.01 \% 0$ & 0.9 \\
\hline 0.15 & 12.5 & 1000 & 1709 & 400 & 13 & 2 & 41 & $1 \Xi 0$ & 0.9. & 0.0184 & $w+7:$ \\
\hline
\end{tabular}




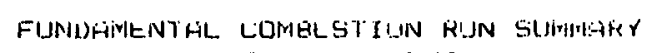

STEFM-CORMECIED CHI AND VRTO

CHAR TYPE $=E$ (JIEMINERHL-Z. $6 \%$ ) AVI SIZE* (MICKONS) $=4 \% .5$ (conti inued)

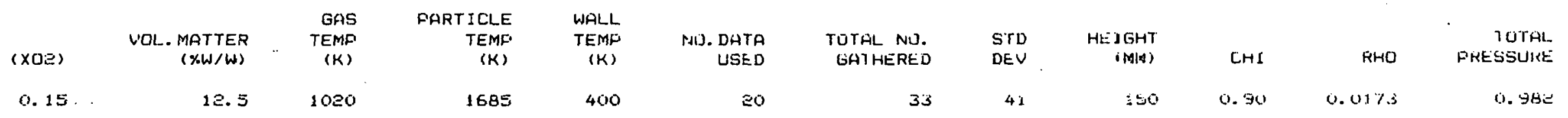

CHAR TYFE=B (DEMIHERHL-9\%) AVG SILE* (MLCR(INS) $=5.8$

\begin{tabular}{|c|c|c|c|c|c|c|c|c|c|c|c|}
\hline$(x 02)$ & $\begin{array}{r}\text { VOL. MATTER } \\
(\% W / W)\end{array}$ & $\begin{array}{r}\text { GAS } \\
\text { TEMP } \\
(K)\end{array}$ & $\begin{array}{r}\text { PART ICLE } \\
\text { TEMF } \\
(K)\end{array}$ & $\begin{array}{l}\text { WALL } \\
\text { TEMF: } \\
\text { (K) }\end{array}$ & $\begin{array}{r}\text { NO. DATA } \\
\text { USED }\end{array}$ & $\begin{array}{l}\text { TOTHL NIJ. } \\
\text { EHTHEKED }\end{array}$ & $\begin{array}{l}\text { STD } \\
\text { LEEV }\end{array}$ & $\begin{array}{l}H \in I S H T \\
\text { SMNI! }\end{array}$ & LHI & Fulit & 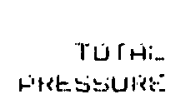 \\
\hline 0.10 & 7.1 & 1006 & 1531 & 400 & 11 & $1 \ddot{\theta}$ & $5 x$ & $1=0$ & $\because .94$ & Q & 0.960 \\
\hline 0.15 & 7.1 & 1001 & 1634 & 400 & 36 & 00 & 53 & $1=0$ & 0.80 & o. & 0.570 \\
\hline
\end{tabular}

CHAR TYFE=E (DEMINE:RAL-QXX) AVG SIZE* (MILRONS) $=39$

\begin{tabular}{|c|c|c|c|c|c|c|c|c|c|c|c|}
\hline$(x O \gtrsim)$ & $\begin{array}{c}\text { VOL. MATTER } \\
(\% \cdot W / W)\end{array}$ & $\begin{array}{l}\text { GAS } \\
\text { TEMP } \\
\text { (K) }\end{array}$ & $\begin{array}{r}\text { PART ICLE } \\
\text { TEMIF } \\
\text { (K) }\end{array}$ & $\begin{array}{l}\text { WALL } \\
\text { TEMF. } \\
\text { (K) }\end{array}$ & $\begin{array}{r}\text { NE. DATA } \\
\text { USED }\end{array}$ & $\begin{array}{l}\text { TOTHL NO. } \\
\text { LATHERED }\end{array}$ & $\begin{array}{l}\text { SID } \\
\text { DEV }\end{array}$ & $\begin{array}{l}\text { HE I GF' } \\
\text { I (a) }\end{array}$ & $\mathrm{CHI}$ & RHO & $\begin{array}{l}\text { TOTAL } \\
\text { PKESSURE }\end{array}$ \\
\hline 0.06 & 6.9 & 1028 & 1459 & 400 & ت3 & 30 & 6is & $\therefore 50$ & 1. & $0.012=$ & 0.946 \\
\hline 0.10 & 6.5 & 1013 & 1508 & 400 & 37 & 57 & 44 & $=50$ & 0.96 & 0.0140 & 0.564 \\
\hline 0.15 & 6.9 & 1021 & 1641 & 400 & 10 & 31 & 58 & $: 50$ & 0.81 & 0.01 is 4 & 0.916 \\
\hline 0.15 & 6.9 & 911 & 1662 & 400 & ت & 5.3 & $5 B$ & 150 & 0.56 & $0.0 \times 10$ & 0.965 \\
\hline
\end{tabular}

CHAR TYFE=E (DE MINERHL-6\%) AVG SIZE* (MICRONS) =8\%. 5

\begin{tabular}{|c|c|c|c|c|c|c|c|c|c|c|c|}
\hline (X02) & $\begin{array}{l}\text { VOL. MATTER } \\
\text { (\%W/W: }\end{array}$ & $\begin{array}{r}\text { GAS } \\
\text { TEMFI } \\
(K)\end{array}$ & $\begin{array}{r}\text { FARTICLE } \\
\text { TEMF } \\
(K)\end{array}$ & $\begin{array}{l}\text { WALL } \\
\text { TEML- } \\
\text { (K) }\end{array}$ & $\begin{array}{l}\text { NIT. DATA } \\
\text { USED }\end{array}$ & $\begin{array}{l}\text { TUTAL NU. } \\
\text { WHATHEGED }\end{array}$ & $\begin{array}{l}\text { Sid } \\
\text { ijeV }\end{array}$ & 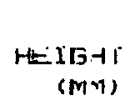 & LHI & $\mathrm{RHO}$ & $\begin{array}{r}\text { TOTAL } \\
\text { FRESSURE }\end{array}$ \\
\hline 0.10 & 7.6 & 1006 & 1514 & 400 & $1 \equiv$ & 18 & $\leq y$ & 150 & 1.00 & 0. 0124 & O. 9 - \\
\hline
\end{tabular}


FUNUGMENTHL COINESS I IUN RUN SUMPIAKY

10:43 Mongav. Jure is 1 yol bo

STEFFIN-CORFECIED CHI AND HIHI

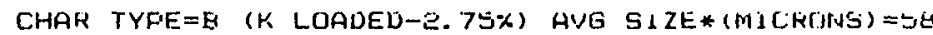

\begin{tabular}{|c|c|c|c|c|c|c|c|c|c|c|c|c|c|}
\hline ( $\times 0 \Xi)$ & . & VOL. & $\begin{array}{l}\text { ATTER } \\
x(W / W)\end{array}$ & $\begin{array}{r}\text { GAS } \\
\text { TEMF } \\
\text { (K) }\end{array}$ & $\begin{array}{r}\text { FARTICLE } \\
\text { TEMF } \\
(K)\end{array}$ & $\begin{array}{l}\text { WALL } \\
\text { TEML: } \\
\text { (K) }\end{array}$ & $\begin{array}{l}\text { NU. DHTA } \\
\text { USED }\end{array}$ & $\begin{array}{l}\text { TOTHL NOJ. } \\
\text { GATHEKED }\end{array}$ & $\begin{array}{l}\text { STD } \\
\text { UtV }\end{array}$ & 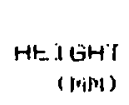 & CHI & RHO & $\begin{array}{r}\text { IUIAL } \\
\text { I-RESSIIRE }\end{array}$ \\
\hline 0.06 & & $\cdot \ldots$ & 20.0 & 1008 & 1478 & 400 & 36 & 60 & $3 \%$ & 150 & 1.4 .5 & 0.015 & 0.971 \\
\hline 0.10 & & . & 20.0 & 1005 & 1616 & 400 & 37 & 54 & 47 & 150 & 1.13 & 0.0204 & 0.971 \\
\hline 0.15 & & $\therefore$ & 20.0 & 1010 & 1737 & 400 & 17 & 37 & 30 & 150 & 0.90 & $0.0=53$ & 0.970 \\
\hline
\end{tabular}

CHAR TYFE $=B$ (K LOADED-2. 75\%) AVG SILE* (MICRONS) $=69$

\begin{tabular}{|c|c|c|c|c|c|c|c|c|c|c|c|}
\hline$(x 02)$ & $\begin{array}{r}\text { WOL. MATTER } \\
(\% W / W)\end{array}$ & $\begin{array}{r}\text { GAS } \\
\text { TEMP } \\
(K)\end{array}$ & $\begin{array}{r}\text { FART ICLE } \\
\text { TEMF } \\
\text { (K) }\end{array}$ & $\begin{array}{l}\text { WALL } \\
\text { TEMF } \\
\text { (K) }\end{array}$ & $\begin{array}{r}\text { NU. DHTA } \\
\text { USED }\end{array}$ & $\begin{array}{l}\text { TOTAL_NIS. } \\
\text { GATHERED }\end{array}$ & $\begin{array}{l}\text { STI } \\
\text { UEV }\end{array}$ & $\begin{array}{l}\text { HE TGHT } \\
\text { (Min) }\end{array}$ & $\mathrm{CHI}$ & Fit!O & 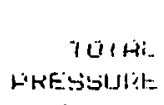 \\
\hline 0.05 & 23.5 & 1002 & $14 \approx 9$ & 400 & 27 & 45 & 46 & 150 & 1.5 & 0.0118 & 0.710 \\
\hline 0.10 & 23.5 & 1004 & $164:$ & 400 & 9 & $\therefore 0$ & 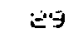 & $.1 \div 0$ & 1. こご & O. OLसठ & $0.7 x, 5$ \\
\hline 0.10 & 23.5 & 1006 & 1661 & 400 & ك & 59 & 3 & 100 & 1.25 & $0.019=$ & a. 514 \\
\hline 0.15 & E3. 5 & 1000 & 1755 & 400 & 15 & 30 & $4 \div$ & $1 \doteqdot 0$ & 0.99 & $0.0=8$ & 0.071 \\
\hline
\end{tabular}

CHAR TYFE=B (K LOADED-E. 75\%) AUG SIZE* (MICRONS) = 9. 5

\begin{tabular}{|c|c|c|c|c|c|c|c|c|c|c|c|}
\hline (XOE) & $\begin{array}{r}\text { S'OL. MATTER } \\
(\% W / W)\end{array}$ & $\begin{array}{l}\text { GAS } \\
\text { TEMP } \\
\text { (K) }\end{array}$ & $\begin{array}{r}\text { FARTICLE } \\
\text { TEMF } \\
\text { (K) }\end{array}$ & $\begin{array}{l}\text { WALL } \\
\text { TEMF' } \\
\text { (K) }\end{array}$ & $\begin{array}{l}\text { NO. DATA } \\
\text { USED }\end{array}$ & $\begin{array}{l}\text { TOTAL NO. } \\
\text { GATHERED }\end{array}$ & $\begin{array}{l}\text { SiD } \\
\text { DEV }\end{array}$ & $\begin{array}{r}\text { HEIGH } \\
\text { (MM) }\end{array}$ & $\mathrm{CHI}$ & RHO & $\begin{array}{l}\text { TOTHL } \\
\text { FRESSIJKE }\end{array}$ \\
\hline 0.05 & 21.3 & 999 & 14 Е5 & 400 & 29 & 60 & 49 & 150 & 1.65 & 0.0101 & 0.975 \\
\hline 0.10 & 22.3 & 999 & 1635 & 400 & 27 & 60 & 43 & $1=0$ & $1 .=7$ & 0.0160 & $0.56:$ \\
\hline 0.15 & 21.3 & 993 & 1762 & 400 & 22 & 60 & 3 & 150 & 1.05 & 0.000 & 0.960 \\
\hline
\end{tabular}

CHAR TYFE=E (NA LOAEED-2. $76 \%$ ) AVG SIZE*(MICRONS) $=69$

\begin{tabular}{|c|c|c|c|c|c|c|c|c|c|c|c|}
\hline$(x 02)$ & $\begin{array}{r}\text { WQL. MATTER } \\
(x W / W)\end{array}$ & $\begin{array}{r}\text { GAS } \\
\text { TEMF } \\
(K)\end{array}$ & $\begin{array}{r}\text { PARTICLE } \\
\text { TEMF } \\
(K)\end{array}$ & $\begin{array}{l}\text { WALL } \\
\text { TEMF: } \\
\text { (K) }\end{array}$ & $\begin{array}{r}\text { NU. DATA } \\
\text { USED }\end{array}$ & $\begin{array}{l}\text { TUTAL_NU. } \\
\text { GATHEKEOU }\end{array}$ & $\begin{array}{l}\text { Siv } \\
v \in V\end{array}$ & $\begin{array}{c}\text { HE I GHT } \\
\text { (IAPI) }\end{array}$ & $\mathrm{C:HI}$ & RHO & $\begin{array}{r}\text { TUTHL } \\
\text { PRESSUIKE }\end{array}$ \\
\hline 0.05 & 25.2 & 1005 & 1338 & 400 & 35 & 60 & 43 & $1 \Xi 0$ & 1.47 & 0.0100 & $0.9 \%$ \\
\hline 0.10 & 25. 2 & 1009 & 1557 & 400 & 21 & bu & 4.3 & 150 & 1.us & U.015/ & 0.977 \\
\hline 0.14 & 25. & 1008 & 1671 & 400 & Eo & 59 & $3 y$ & 150 & 0.93 & 0.0196 & $0.97=$ \\
\hline 0.15 & 25.2 & 1008 & 1695 & 400 & 17 & 30 & 63 & 150 & 0.90 & 0.0505 & o. $5 \%$ \\
\hline
\end{tabular}


STEFGHY-CORRECTED CHI AIND RHO

CHAR TYFE $=8$ (NA LOADED-E. 7E\%) AVG SILE*(MICHONB)=LIL.S

\begin{tabular}{|c|c|c|c|c|c|c|c|c|c|c|c|c|}
\hline (x০e) & $\cdots$ & $\begin{array}{r}\text { VOL. MATTER } \\
(\% W / W)\end{array}$ & $\begin{array}{r}\text { GAS } \\
\text { TEMP } \\
(K)\end{array}$ & $\begin{array}{r}\text { FART ICLE } \\
\text { TEMF } \\
\text { (K) }\end{array}$ & $\begin{array}{l}\text { WALL } \\
\text { TEMP } \\
\text { (K) }\end{array}$ & $\begin{array}{r}\text { NU. DHTA } \\
\text { USED }\end{array}$ & $\begin{array}{l}\text { TORAL NO. } \\
\text { WATHEKED }\end{array}$ & $\begin{array}{l}\text { SID } \\
\text { DEV }\end{array}$ & $\begin{array}{l}\text { HE I GH } \\
\text { (MNI) }\end{array}$ & $\mathrm{CHI}$ & FiHi) & $\begin{array}{r}\text { IUTHL } \\
\text { FKESSURL }\end{array}$ \\
\hline 0.05 & & 24.7 & 1010 & 1402 & 400 & 33 & 60 & 53 & $15 i x$ & 1. & ن. Ougt & 0.9 .91 \\
\hline 0.10 & & 24.7 & 1011 & 1556 & 400 & 9 & $2 e$ & 41 & 150 & $1.0 \theta$ & $\therefore .036$ & $0.9 / \theta$ \\
\hline 0.10 & & 24.7 & 1000 & 1540 & 400. & 36 & 5 & St & 10 & 1.05 & 0.0131 & 0.979 \\
\hline 0.15 & & 24.7 & 1005 & 1606 & 400 & 34 & 60 & 39 & 150 & 0.92 & 0.0170 & 0.981 \\
\hline
\end{tabular}

CHAR TYFE=E (UNTREATED-3X) AVG SIZE* (MICRONS) $=5 \theta$

\begin{tabular}{|c|c|c|c|c|c|c|c|c|c|c|c|}
\hline$(x 02)$ & $\begin{array}{r}\text { VOL. MATTER } \\
(x W / W)\end{array}$ & $\begin{array}{r}\text { GAS } \\
\text { TEMP } \\
\text { (K) }\end{array}$ & $\begin{array}{r}\text { FART IOLE } \\
\text { TEMP } \\
\text { (K) }\end{array}$ & $\begin{array}{l}\text { WALL } \\
\text { TEMF } \\
\text { (K) }\end{array}$ & $\begin{array}{l}\text { NIJ. DATA } \\
\text { USED }\end{array}$ & $\begin{array}{l}\text { TUTAL NO. } \\
\text { GATHERED }\end{array}$ & $\begin{array}{l}\text { STD } \\
\text { DEV }\end{array}$ & $\begin{array}{r}\text { HE XEHTI } \\
\text { (MPI). }\end{array}$ & $\mathrm{CHI}$ & RHO & $\begin{array}{l}\text { IORAL } \\
\text { PKESEUURE }\end{array}$ \\
\hline 0.05 & 15.2 & 1008 & 1427 & 400 & 21 & 32 & 30 & 150 & $1.53^{\circ}$ & تثت 01301 & 0.994 \\
\hline 0.10 & 15.2 & 1004 & - & 400 & $\varepsilon$ & 0 & - & 150 & . & - & 0.96 .3 \\
\hline 0.10 & 15.2 & $\$ 024$ & 1619 & 400 & 36 & $5 B$ & 44 & 150 & 1.11 & 0.0101 & 0.907 \\
\hline 0.14 & 15.2 & 1006 & 1721 & 400 & 15 & 56 & 41 & 150 & 0.37 & 0.0247 & 0.5 \\
\hline
\end{tabular}

CHAR TYFE=E (UNTFEATED-3*) AVG SIZE* (MICRONS) $=69$

\begin{tabular}{|c|c|c|c|c|c|c|c|c|c|c|c|}
\hline$(x 02)$ & $\begin{array}{r}\text { VOL. MATTER } \\
(x W / W)\end{array}$ & $\begin{array}{r}\text { GAS } \\
\text { TEMP } \\
\text { (K) }\end{array}$ & $\begin{array}{r}\text { PART ICLE } \\
\text { TEMP } \\
\text { (K) }\end{array}$ & $\begin{array}{l}\text { WALL } \\
\text { TEML } \\
\text { (K) }\end{array}$ & $\begin{array}{l}\text { NO. DATA } \\
\text { USED }\end{array}$ & $\begin{array}{l}\text { TOTAL NIS. } \\
\text { GATHERE'D }\end{array}$ & $\begin{array}{l}\text { STD } \\
\text { veV }\end{array}$ & $\begin{array}{l}\text { HEIGH' } \\
\text { IMM: }\end{array}$ & $\mathrm{CHI}$ & RHO & $\begin{array}{r}\text { TOTAL } \\
\text { PRESSURE }\end{array}$ \\
\hline 0.05 & 15.7 & 1000 & 1403 & 400 & 28 & 50 & 45 & 150 & 1.51 & 0.0110 & 0.972 \\
\hline 0.10 & 15. 7 & 1014 & 1593 & 400 & 9 & 54 & 44 & 150 & 1.11 & 0.0168 & 0.971 \\
\hline 0.10 & 15.7 & 900 & 1525 & 400 & 29 & 47 & 42 & 150 & 1.16 & 0.0106 & 0.971 \\
\hline 0.12 & 15.7 & 907 & 1605 & 400 & 11 & 21 & 68 & 150 & 1.09 & 0.0191 & 0.970 \\
\hline 0.15 & 15.7 & 1011 & 1731 & 400 & 11 & 30 & 42 & 15 & 0.95 & $0.0 \div 17$ & $\because 96=$ \\
\hline 0.15 & 15.7 & 903 & 1673 & 400 & 12 & $=4$ & 30 & 15 & 0.48 & $0.0 \mathrm{~d} 1$ & 0.575 \\
\hline
\end{tabular}


CHAR TYFE=E LUNTREATED-3\%) AVG SILE* (IMICRONS)=UE. 5

\begin{tabular}{|c|c|c|c|c|c|c|c|c|c|c|c|}
\hline$(x 02)$ & $\begin{array}{r}\text { VOL. MATTER } \\
(\times W / W)\end{array}$ & $\begin{array}{l}\text { GAPS } \\
\text { TEMP } \\
\text { (K) }\end{array}$ & $\begin{array}{r}\text { FARTICLE } \\
\text { TEMF } \\
\text { (K) }\end{array}$ & $\begin{array}{l}\text { WALL } \\
\text { TEMF } \\
\text { (K) }\end{array}$ & $\begin{array}{l}\text { NO. DATA } \\
\text { USED }\end{array}$ & $\begin{array}{l}\text { TOTAL NO. } \\
\text { GATHERED }\end{array}$ & $\begin{array}{l}\text { SID } \\
\text { DEV }\end{array}$ & $\begin{array}{c}H E \geq G H T \\
\text { (MIN) }\end{array}$ & $\mathrm{CH}_{1}$ & RHO & $\begin{array}{l}\text { TUIAII } \\
\text { PRESSURK: }\end{array}$ \\
\hline 0.05 & 14.4 & 1020 & 1427 & 400 & 42 & 00 & 35 & 15 & 1.60 & $0.00 \exists \theta$ & $0.3 /=$ \\
\hline 0.10 & 14.4 & $10=0$ & 1586 & 400 & 18 & SE & $5 \dot{~}$ & 150 & 1.12 & 0.0143 & $0.9 \%$ \\
\hline 0.15 & 14.4 & 1012 & 1749 & 400 & 27 & 60 & 30 & 150 & 1.01 & 0.0193 & 0.973 \\
\hline
\end{tabular}

CHAR TYFE=HE (CA LOADED- - 75\%) AVIS SIZE* (MICRONS) =6.

\begin{tabular}{|c|c|c|c|c|c|c|c|c|c|c|c|}
\hline ( $\times \square \Xi)$ & $\begin{array}{r}\text { WLL. MATTER } \\
(\% W / W)\end{array}$ & $\begin{array}{l}\text { GAS } \\
\text { TEME } \\
\text { (K) }\end{array}$ & $\begin{array}{r}\text { FARTICLE } \\
\text { TEMF } \\
\text { (K) }\end{array}$ & $\begin{array}{l}\text { WALL } \\
\text { TEMF' } \\
\text { (K) }\end{array}$ & $\begin{array}{l}\text { NiJ. DHTA } \\
\text { USED }\end{array}$ & $\begin{array}{l}\text { TOTAI_ NU. } \\
\text { LATHEKED }\end{array}$ & $\begin{array}{l}\text { SID } \\
\text { DEV }\end{array}$ & $\begin{array}{l}H E I G H I \\
\text { (MM) }\end{array}$ & $\mathrm{CHI}$ & $\mathrm{RHO}$ & $\begin{array}{l}\text { TOTAL } \\
\text { PKESSUKE }\end{array}$ \\
\hline 0.06 & 23.3 & 1006 & 1433 & 400 & $\Sigma 1$ & 30 & 37 & 150 & 1.34 & 0.0118 & 0.978 \\
\hline 0.10 & 23.3 & 1006 & 1550 & 400 & $e s$ & 59 & 44 & 100 & 1.04 & 0.0155 & $0.9 / 0$ \\
\hline 0.10 & 23.3 & 1006 & 1553 & 400 & 9 & 30 & 49 & $1 \vdots 0$ & 1.04 & 0. & 0.978 \\
\hline 0.15 & 23.3 & 1005 & 1677 & 400 & 14 & $\Xi \beta$ & 43 & 100 & $0 . \Delta 8$ & $0.019 y$ & $0 . \$ 70$ \\
\hline$\omega_{\sigma}^{\omega} 0.15$ & 23.3 & 1009 & 1676 & 400 & 28 & 60 & $4 E$ & 100 & 0.83 & 0.0193 & 0.968 \\
\hline 0.15 & 23.3 & 1009 & 1688 & 400 & 29 & 59 & 43 & 150 & $0 . \bar{B} B$ & 0.0 ene & $0.9 \%$ \\
\hline
\end{tabular}

CHAR TYFE=EE (DEMINERAL-2. $23 \%$ ) AVG SIZE* (MICRONS) $=69$

\begin{tabular}{|c|c|c|c|c|c|c|c|c|c|c|c|}
\hline$(x 0 \Xi)$ & $\begin{array}{l}\text { WOL. MATTER } \\
(\% W / W)\end{array}$ & $\begin{array}{r}\text { GAS } \\
\text { TEMP } \\
\text { (K) }\end{array}$ & $\begin{array}{r}\text { FART ICLE } \\
\text { TEMF } \\
\text { (K) }\end{array}$ & $\begin{array}{l}\text { WALL } \\
\text { TEMF } \\
\text { (K) }\end{array}$ & $\begin{array}{l}\text { NO. DHTA } \\
\text { USED }\end{array}$ & $\begin{array}{l}\text { TOTHL NO. } \\
\text { I.jHTHEKEDD }\end{array}$ & $\begin{array}{l}\text { STD } \\
\text { UEV }\end{array}$ & $\begin{array}{l}H=\text { HEHT } \\
\text { (MrN) }\end{array}$ & $\mathrm{CHC}$ & $\mathrm{RHO}$ & $\begin{array}{r}\text { TUTHL } \\
\text { FRESSURE }\end{array}$ \\
\hline 0.05 & 13.2 & 1006 & 1376 & 400 & $\Xi$ & 30 & 35 & 100 & 1.39 & 0.0101 & 0.981 \\
\hline 0.05 & 13.3 & 1012 & 1444 & 400 & 13 & 30 & 75 & 150 & 1.61 & 0.0130 & $0.9 \% 3$ \\
\hline 0.10 & 13.2 & 1006 & 1617 & 400 & 11 & 30 & 'ز' & 100 & 1. 16 & 0.0177 & 0.991 \\
\hline 0.10 & 13.3 & 1012 & 1628 & 400 & 13 & 30 & 32 & 150 & 1.16 & 0.0178 & 0.978 \\
\hline 0.15 & 13.2 & 1006 & 1709 & 400 & 15 & 29 & 23 & 100 & 0.91 & 0.0210 & $0.94 x$ \\
\hline 0.15 & 13.2 & 1012 & 1736 & 400 & 14 & 30 & 56 & 150 & 0.94 & $0.0 \doteq 19$ & $0.9 / 3$ \\
\hline
\end{tabular}


STIEHH-CORRECTED CHI ANND RHO

\begin{tabular}{|c|c|c|c|c|c|c|c|c|c|c|c|}
\hline$(x 02)$ & $\begin{array}{r}\text { VOL. MATTER } \\
(x W / W)\end{array}$ & $\begin{array}{r}\text { GHS } \\
\text { TEMP } \\
\text { (K) }\end{array}$ & 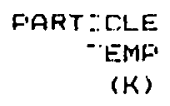 & $\begin{array}{l}\text { WHLLL } \\
\text { TE.MF } \\
\text { (K) }\end{array}$ & $\begin{array}{l}\text { YO. NHTA } \\
\text { USED }\end{array}$ & $\begin{array}{l}\text { TUTAL NIJ. } \\
\text { GATHERED }\end{array}$ & $\begin{array}{l}\text { STO } \\
\text { DEV }\end{array}$ & $\begin{array}{l}\text { HEISH T } \\
\text { (INM) }\end{array}$ & $\mathrm{CHI}$ & FHO & $\begin{array}{l}\text { TUTAL } \\
\text { PHESEURE }\end{array}$ \\
\hline 0.05 & ЕЕ. 4 & 1005 & $: 351$ & 400 & 15 & 30 & 51 & 100 & 1.31 & 0.0094 & 0.976 \\
\hline 0.05 & 2e.. 4 & 1004 & 1411 & 400 & 16 & 29 & 64 & 150 & 1.52 & 0.0112 & 0.0231 \\
\hline 0.10 & $2 e .4$ & 998 & 1599 & 400 & 34 & 60 & 30 & 100 & 1.14 & 0.0173 & $0.97: 5$ \\
\hline 0.10 & 2e. 4 & 1004 & 1593 & 400 & 13 & 30 & $E=$ & 100 & 1.10 & $0.01 \% 0$ & $6.91 \%$ \\
\hline 0.10 & ze. 4 & 1004 & 1645 & 400 & 3 & 30 & 3 & $1 \Xi 0$ & $1 . \approx 1$ & $0.0118 \%$ & 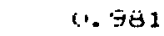 \\
\hline 0.15 & Еᄅ. 4. & 1004 & 1694 & 400 & 15 & 30 & 37 & 100 & 0.50 & 0.0005 & 0.915 \\
\hline 0.15 & 2e. 4 & 1004 & 1719 & 400 & 13 & -9 & E⿱一⿻上丨冖 & 150 & 0.9 .3 & (1). 614 & 0.981 \\
\hline
\end{tabular}

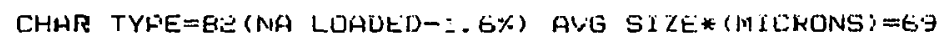

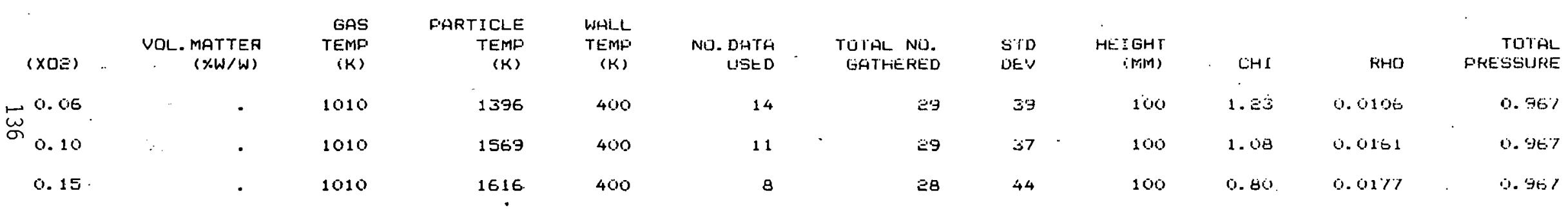

CHAR TYFE=BZ (UNTREATEU- $2.6 \%$ ) AVG SIZE* (MICRONS I=69

\begin{tabular}{|c|c|c|c|c|c|c|c|c|c|c|c|}
\hline (xOE) & $\begin{array}{l}\text { VOL. MATTER } \\
(\% W / W)\end{array}$ & $\begin{array}{r}\text { GAS } \\
\text { TEMF } \\
(K)\end{array}$ & $\begin{array}{r}\text { FARTICLE } \\
\text { TEMF! } \\
\text { (K! }\end{array}$ & $\begin{array}{l}\text { WALL } \\
\text { TEMF } \\
\text { (K) }\end{array}$ & $\begin{array}{l}\text { NU. DATA } \\
\text { USED }\end{array}$ & $\begin{array}{l}\text { TOTAL NO. } \\
\text { GATHERED }\end{array}$ & $\begin{array}{l}\text { STD } \\
\text { DEV }\end{array}$ & $\begin{array}{r}H=X G H T \\
(M M)\end{array}$ & C:HI & KHO & $\begin{array}{l}\text { TUTAL } \\
\text { FRESSULKE }\end{array}$ \\
\hline 0.05 & 14.7 & 1013 & 14IE & 400 & 19 & 30 & 40 & 150 & 1.5 & $0.011 \mathrm{E}^{\circ}$ & 1. $96 ?$ \\
\hline 0.10 & 14.7 & 1010 & 1604 & 400 & $1 E$ & $\therefore 8$ & 39 & 100 & 1.13 & $0.017 \%$ & 0.975 \\
\hline 0.10 & 14.7 & 1013 & 1609 & 400 & 17 & 30 & 30 & $1 \pm 0$ & 1.15 & 0.0173 & 0.967 \\
\hline 0.15 & 14.7 & 1010 & 1706 & 400 & 12 & $\ddot{2}$ & 37 & 100 & 0.51 & 0.0008 & 0.915 \\
\hline 0.15 & 14.7 & 1013 & 1761 & 400 & 15 & 30 & 59 & 150 & 0.93 & $0.0=\theta$ & 0.967 \\
\hline
\end{tabular}


IN RLIN SLIMIIHKY

EY COALCHAL TYFE

STEFAN-CORRECTED CHI ANO HIIU

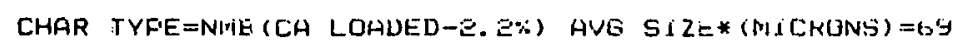

\begin{tabular}{|c|c|c|c|c|c|c|c|c|c|c|c|}
\hline$(x 02)$ & $\begin{array}{r}\text { VOL_. MATTER } \\
(\% W / W)\end{array}$ & $\begin{array}{l}\text { GAS } \\
\text { TEMF } \\
\text { (K) }\end{array}$ & $\begin{array}{r}\text { FART ICLE } \\
\text { TEMP } \\
(K)\end{array}$ & $\begin{array}{l}\text { WALL } \\
\text { TEML- } \\
(K)\end{array}$ & $\begin{array}{l}\text { NIJ. DHTA } \\
\text { USEO }\end{array}$ & $\begin{array}{l}\text { TOIAL NIJ. } \\
\text { GHTHEKEL }\end{array}$ & $\begin{array}{l}\text { SID } \\
\text { DEV }\end{array}$ & $\begin{array}{l}H E Y G H T \\
(\operatorname{lnM})\end{array}$ & $\mathrm{CHI}$ & RHO & $\begin{array}{r}\text { 10THL } \\
\text { PKESSUKE }\end{array}$ \\
\hline 0.06 & - & 1013 & 1391 & 400 & 16 & ت̈ & $=7$ & 100 & 1.20 & 0.0104 & 0.968 \\
\hline 0.06 & - & 1011 & 1446 & 400 & 35 & tio & 39 & 150 & $1.3 \theta$ & $0.01 こ 1$ & 0.967 \\
\hline 0.10 & - & 1014 & 1574 & 400 & 35 & 5 is & $\mathbf{3}$ & 100 & 1.07 & 0.0160 & $0.9 \% 9$ \\
\hline 0.10 & - & 1032 & 1633 & 400 & 23 & 44 & $\therefore E$ & 150 & 1. . 16 & $0.01 \% 8$ & $0.9 / 6$ \\
\hline 0.15 & - & 1016 & 1711 & 400 & 15 & 28 & 34 & 100 & 0.91 & 6.0269 & 0.919 \\
\hline 0.15 & - & 1011 & 1729 & 400 & $2 \Xi$ & 60 & 41 & 150 & 0.55 & $0.0 \geq 17$ & 0. ๑ヒ' \\
\hline
\end{tabular}

CHAR TYFE $=$ NME (DEMINERAL-E. $9 \%$ ) AVG SIZE* (MICRONS) $=69$

\begin{tabular}{|c|c|c|c|c|c|c|c|c|c|c|c|}
\hline (XEE) & $\begin{array}{l}\text { VOL. MATTER } \\
(x W / W)\end{array}$ & $\begin{array}{r}\text { GAS } \\
\text { TEMK: } \\
\text { (K) }\end{array}$ & $\begin{array}{r}\text { FART ICLE } \\
\text { TEMF } \\
\text { (K) }\end{array}$ & $\begin{array}{l}\text { WALL: } \\
\text { TEML: } \\
\text { (K) }\end{array}$ & $\begin{array}{l}\text { NO. VATA } \\
\text { USEO }\end{array}$ & $\begin{array}{l}\text { TOTAI_NÜ. } \\
\text { GATHERED }\end{array}$ & $\begin{array}{l}\text { STL } \\
\text { OEV }\end{array}$ & $\begin{aligned} H:= & 1 \text { l: } \mathrm{H} \text { l } \\
& \text { (Mm) }\end{aligned}$ & $\mathrm{C}: \mathrm{Hi}$ & $\mathrm{KHO}$ & $\begin{array}{r}\text { TURAL } \\
\text { PRESSIUKE }\end{array}$ \\
\hline 0.01 & 54.2 & 1005 & 1439 & 4000 & $1 \geq$ & 30 & 41 & $1 \leq 0$ & 1.39 & 0.0100 & $0.9 \% 7$ \\
\hline 0.10 & 54.2 & 1009 & 1559 & 400 & $a z$ & 30 & 62 & 100 & 1.06 & 0.0158 & 0.569 \\
\hline$\omega^{0.10}$ & $54 . ?$ & 1011 & 1540 & 400 & 26 & 30 & 54 & 100 & 1. & 0.0151 & 0.960 \\
\hline$v 0.10$ & 54.2 & .1006 & $16=9$ & 400 & 30 & 58 & 43 & 150 & 1.19 & 0.0181 & $0.97 \Xi$ \\
\hline 0.15 & 54.2 & 1011 & 1685 & 400 & 38 & 71 & 5 & 100 & 0.83 & 0.0001 & 0.968 \\
\hline 0.15 & 54.2 & 1005 & $17 \approx 88$ & 400 & 24 & $5 s$ & 65 & 150 & 0.96 & $0.0 Е 17$ & $0.0 \% 7$ \\
\hline
\end{tabular}

CHAR TYFE=NME (K LOADED-Z. E\%) AVG SIZE* (MICRONS) $=69$

\begin{tabular}{|c|c|c|c|c|c|c|c|c|c|c|c|}
\hline$(x \square \Xi)$ & $\begin{array}{r}\text { UOL. MATTER } \\
(x W / W)\end{array}$ & $\begin{array}{l}\text { GAS } \\
\text { TEMP } \\
(K)\end{array}$ & $\begin{array}{r}\text { PART ICLE } \\
\text { TEMF } \\
(\mathrm{K})\end{array}$ & $\begin{array}{l}\text { WALL } \\
\text { TEMF } \\
\text { (K) }\end{array}$ & $\begin{array}{l}\text { NO. DATA } \\
\text { USED }\end{array}$ & $\begin{array}{l}\text { TOTAL NO. } \\
\text { GATHERED }\end{array}$ & $\begin{array}{l}\text { STD } \\
\text { DEV }\end{array}$ & $\begin{array}{l}\text { HE I GHT } \\
\text { (WHI) }\end{array}$ & $\mathrm{CHI}$ & Riti.J & $\begin{array}{r}\text { IUIAL. } \\
\text { WRESSI JTRE }\end{array}$ \\
\hline 0.06 & 42.3 & 1008 & 1403 & 400 & 11 & ن' & $5 x$ & 160 & 1. & $0.010 \%$ & 0.904 \\
\hline 0.06 & 2.2. 4 & 987 & 1451 & 400 & 16 & $=3$ & $40^{\circ}$ & $1=0$ & 1.47 & $0.012 \%$ & 0.956 \\
\hline 0.06 & ㄹ․ 4 & 1003 & 1469 & 400 & $\Xi 1$ & 30 & 40 & 150 & $1.4 \%$ & 0.0130 & 0.960 \\
\hline 0.10 & 42.3 & 1010 & 1583 & 400 & 30 & 60 & 34 & 100 & 1.10 & 0.0165 & 0.911 \\
\hline 0.10 & E:. 4 & 1011 & 1594 & 400 & 36 & 57 & sed & 150 & 1.13 & 0.0163 & 0.960 \\
\hline 0.15 & 42.3 & 1010 & 1684 & 400 & 34 & 60 & 37 & 100 & 0.88 & $0.0=01$ & $0.9 / 1$. \\
\hline
\end{tabular}


FUNDAMENTAL COMBUSTION RUIN SUMMARY

10:43 Moridav. Jure 8. 1997 65

GY COQL /CHHR TYRE

STEFHN-CORRECTED CHI AIND FHO

CHAR TYFE=NMB $\mathrm{KK}$ LQADED-Z. $3 \%$ ) AVG SIZE* (MICRONS) $=69$ (cont i rued)

\begin{tabular}{|c|c|c|c|c|c|c|c|c|c|c|c|}
\hline (XOE) & $\begin{array}{r}\text { VOL. MATTER } \\
(x W / W)\end{array}$ & $\begin{array}{r}\text { GAS } \\
\text { TEMP } \\
\text { (K) }\end{array}$ & $\begin{array}{r}\text { PART ICLE } \\
\text { TEMP } \\
\text { (K) }\end{array}$ & $\begin{array}{l}\text { WALL } \\
\text { TEMF' } \\
\text { (K) }\end{array}$ & $\begin{array}{l}\text { NO. DATA } \\
\text { USED }\end{array}$ & $\begin{array}{l}\text { TUTAL NO. } \\
\text { GAT HERED }\end{array}$ & $\begin{array}{l}\text { SID } \\
\text { DEV }\end{array}$ & $\begin{array}{r}H E(G H I) \\
\text { ( } M \text { im) }\end{array}$ & $\mathrm{CHI}$ & hHO & $\begin{array}{l}\text { TUIHI.. } \\
\text { PRESSIUREE }\end{array}$ \\
\hline 0.15 & Eอ. 4 & 994 & 1683 & 400 & 15 & 30 & 49 & 150 & $0 . y_{1}$ & 0.0003 & U. 95is \\
\hline 0.15 & eᄅ. 4 & 1010 & 1725 & 400 & 10 & 39 & $=6$ & 150 & 0.74 & $0.0 \pm 15$ & 0.967 \\
\hline
\end{tabular}

CHAR TYPE=NMB (NA LOADED-2. $2 x)$ AVG SIZE* (MICRUNS) =69

\begin{tabular}{|c|c|c|c|c|c|c|c|c|c|c|c|}
\hline$(X 0 \Xi)$ & $\begin{array}{r}\text { VOL. MATTER } \\
(x W / W)\end{array}$ & $\begin{array}{l}\text { GAS } \\
\text { TEMFI } \\
\text { (K) }\end{array}$ & $\begin{array}{r}\text { PART ICLE } \\
\text { TEMP } \\
\text { (K) }\end{array}$ & $\begin{array}{l}\text { WALL } \\
\text { TEMP } \\
\text { (K) }\end{array}$ & $\begin{array}{l}\text { NO. DATA } \\
\text { USED }\end{array}$ & $\begin{array}{l}\text { TOTAL NO. } \\
\text { GATHERED }\end{array}$ & $\begin{array}{l}\text { STD } \\
\text { UEV }\end{array}$ & $\begin{array}{c}H E \text { I } \\
\text { (isim) }\end{array}$ & $\mathrm{CHI}$ & FHO & $\begin{array}{r}\text { TDTAL_ } \\
\text { FRESSUURE }\end{array}$ \\
\hline 0.05 & 18.8 & 999 & 1358 & 400 & 20 & 30 & 37 & 100 & 1.36 & 0.0097 & $0.98 \%$ \\
\hline 0.06 & 18.8 & 1023 & 1436 & 400 & 18 & 30 & 47 & 150 & 1.32 & 0.0116 & $0.76 \theta$ \\
\hline 0.10 & 18.8 & 1006 & 1527 & 400 & 22 & 35 & 49 & 100 & 1.01 & 0.0148 & 0.964 \\
\hline 0.10 & 18.8 & 993 & 1604 & 400 & 29 & $5 \cdot \theta$ & 50 & 150 & 1.18 & 0.0173 & 0.456 \\
\hline 0.10 & 18.8 & 1017 & 1596 & 400 & 13 & $2 \cdot 3$ & 65 & 150 & 1.13 & 0.0168 & 1. \\
\hline 0.10 & 18.8 & 1017 & 1607 & 400 & 17 & $\because 9$ & 43 & 150 & 1.14 & $0.017 \ddot{3}$ & $0.96 \pi$ \\
\hline 0.15 & 18.8 & 1002 & 1686 & 400 & 27 & 55 & 30 & 100 & 0.88 & 0.0203 & 0. 9A6 \\
\hline 0.15 & 18.8 & 1016 & 1747 & 400 & 14 & 30 & 38 & $1 \Xi 0$ & 0.96 & $0.0 \mathrm{Ez}$ & 0. $\exists 6 \mathrm{~B}$ \\
\hline
\end{tabular}

CHAR TYPE=NME (UNTREATED-2. 9*) AVG STZE* (MICRONS $)=69$

\begin{tabular}{|c|c|c|c|c|c|c|c|c|c|c|c|}
\hline$(x \square \Xi)$ & $\begin{array}{r}\text { VOL. MATTER } \\
(\% W / W)\end{array}$ & $\begin{array}{r}\text { GAS } \\
\text { TEMP } \\
\text { (K) }\end{array}$ & $\begin{array}{r}\text { PART ICLE } \\
\text { TEMP } \\
\text { (K) }\end{array}$ & $\begin{array}{l}\text { WALLL } \\
\text { TEMP } \\
\text { (K) }\end{array}$ & $\begin{array}{l}\text { NO. DATA } \\
\text { USED }\end{array}$ & $\begin{array}{l}\text { TOTAL NO. } \\
\text { GATHEFED }\end{array}$ & $\begin{array}{l}\text { STD } \\
\text { DEV }\end{array}$ & $\begin{array}{l}\text { HEIGHI } \\
\text { (MINt) }\end{array}$ & $\mathrm{CHI}$ & KHO & $\begin{array}{r}\text { TUTAL } \\
\text { F'RESSUKE }\end{array}$ \\
\hline 0.05 & 20.5 & 1009 & 1386 & 400 & 36 & 57 & 47 & 150 & 1.41 & 0.0103 & ت. \\
\hline 0.10 & 20.5 & 1006 & 1589 & 400 & 30 & 59 & 31 & 100 & $1.1 E$ & 0.01604 & 0.960 \\
\hline 0.10 & 20.5 & 1009 & 1549 & 400 & 47 & 60 & 52 & 150 & 1.00 & 0.0154 & $0.99 \%$ \\
\hline 0.10 & 20.5 & 902 & 1577 & 400 & 33 & 60 & 36 & $1 \Xi 0$ & $1 .-44$ & $0.018 E$ & $0.9: 19.3$ \\
\hline 0.15 & 20.5 & 1005 & 1682 & 400 & 11 & 30 & 40 & 1.10 & 0.97 & 0.0501 & 1. yens \\
\hline 0.15 & 20.5 & 1006 & 1668 & 400 & 34 & 57 & 44 & 100 & 0.87 & U. & 0.910 \\
\hline 0.15 & 20.5 & 1009 & 1639 & 400 & E: & Sit & 5 is & $1 \div 0$ & $0.8:$ & 0.0185 & 0.945 \\
\hline 0.15 & 20.5 & 902 & 1671 & 400 & قe & o & 44 & 150 & $0.9 \%$ & $0.0 \Xi 14$ & 0.94 .3 \\
\hline
\end{tabular}




\begin{tabular}{|c|c|c|c|}
\hline 1. Program/Project Identification No. & $\begin{array}{l}\text { 2. Program/Project Tille } \\
\text { REACTIVITY OF COALS/CHARS }\end{array}$ & & $\begin{array}{l}\text { 3. Reporling Period } \\
4 / 1 / 86 \\
\end{array}$ \\
\hline 4. Name and Address & Dakota & $C=0$ & $\begin{array}{c}\text { 5. Program/Project Slart Date } \\
4 / 1 / 86\end{array}$ \\
\hline Box 8213, University & Station, Grand Forks, & ND $\quad 58202$ & 6. Completjon Oate $31 / 92$ \\
\hline
\end{tabular}

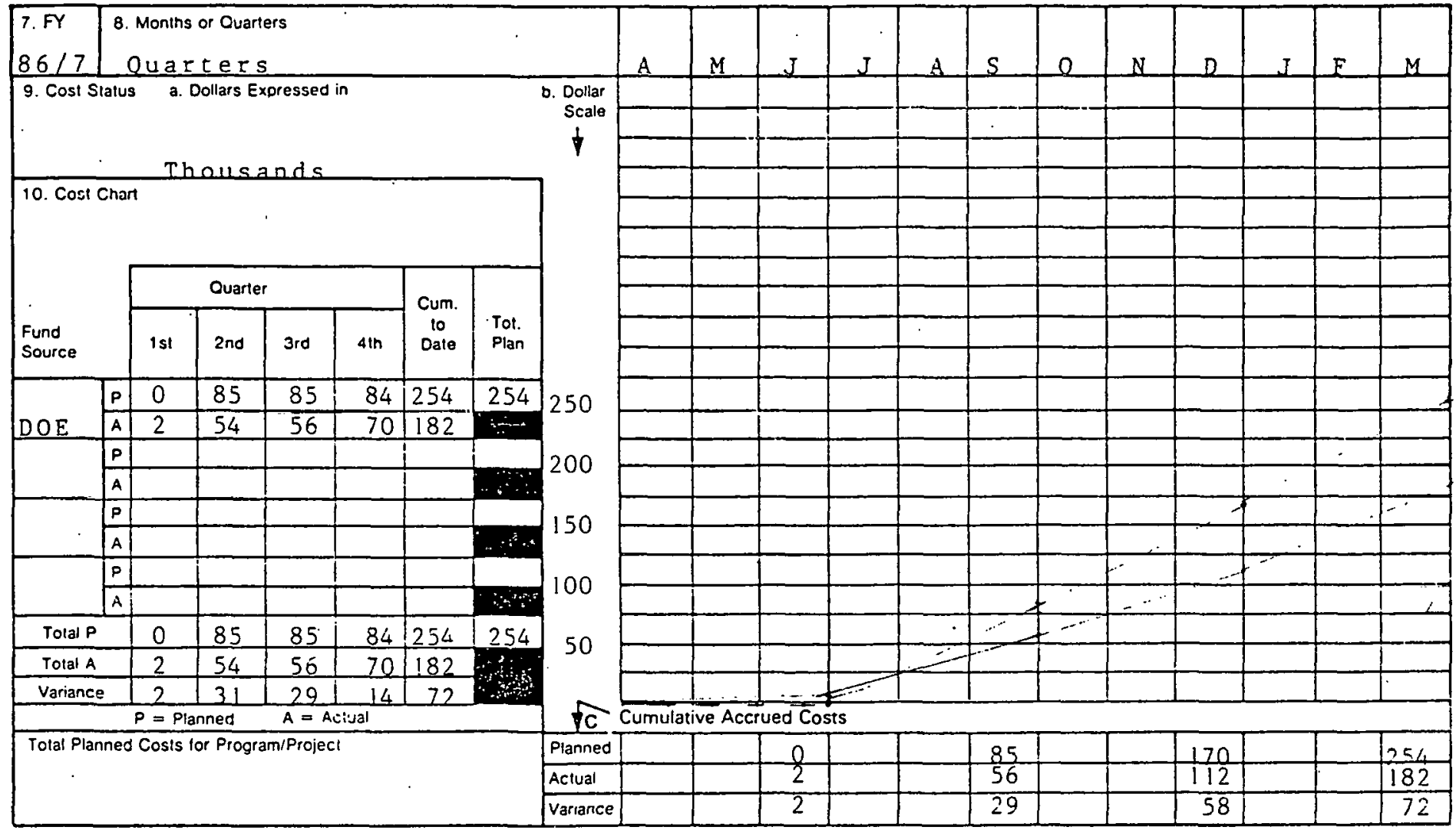

\begin{tabular}{|c|c|}
\hline 11. Major Milestone Status & Units Planned \\
\hline . & Units Complete \\
\hline a. Assessment of mineral & $\mathbf{P}$ \\
\hline and structural effects & C \\
\hline & $\mathbf{P}$ \\
\hline & C \\
\hline b. Bulk diffusion & $\mathbf{P}$ \\
\hline & C \\
\hline & $\mathbf{P}$ \\
\hline & C \\
\hline c. Ignition phenomenon of & $\mathbf{P}$ \\
\hline coal particles & C \\
\hline & $P$ \\
\hline & $\mathrm{C}$ \\
\hline & $\mathbf{P}$ \\
\hline & C \\
\hline & $\mathbf{P}$ \\
\hline & $\mathrm{C}$ \\
\hline & $\mathbf{P}$ \\
\hline & C \\
\hline & $\mathbf{P}$ \\
\hline & C \\
\hline & $\mathbf{P}$ \\
\hline & $\bar{C}$ \\
\hline & $P$ \\
\hline & $\mathbf{C}$ \\
\hline & $p$ \\
\hline
\end{tabular}


Page ol

1. Programprolect ldentilication No.

2. ProgramiProlecl Tille

REACTIVITY OF COALS/CHAR

3 aesoninn Perrod

4. Name and Address

University of North Dakota Energy Research Center

Box 8213, University Station, Grand Forks, ND 58202 $4 / 1 \% 6^{\text {nnougn }} 3 / 31 / 8$

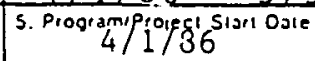

6. Completion Date

$3 / 31 / 92$

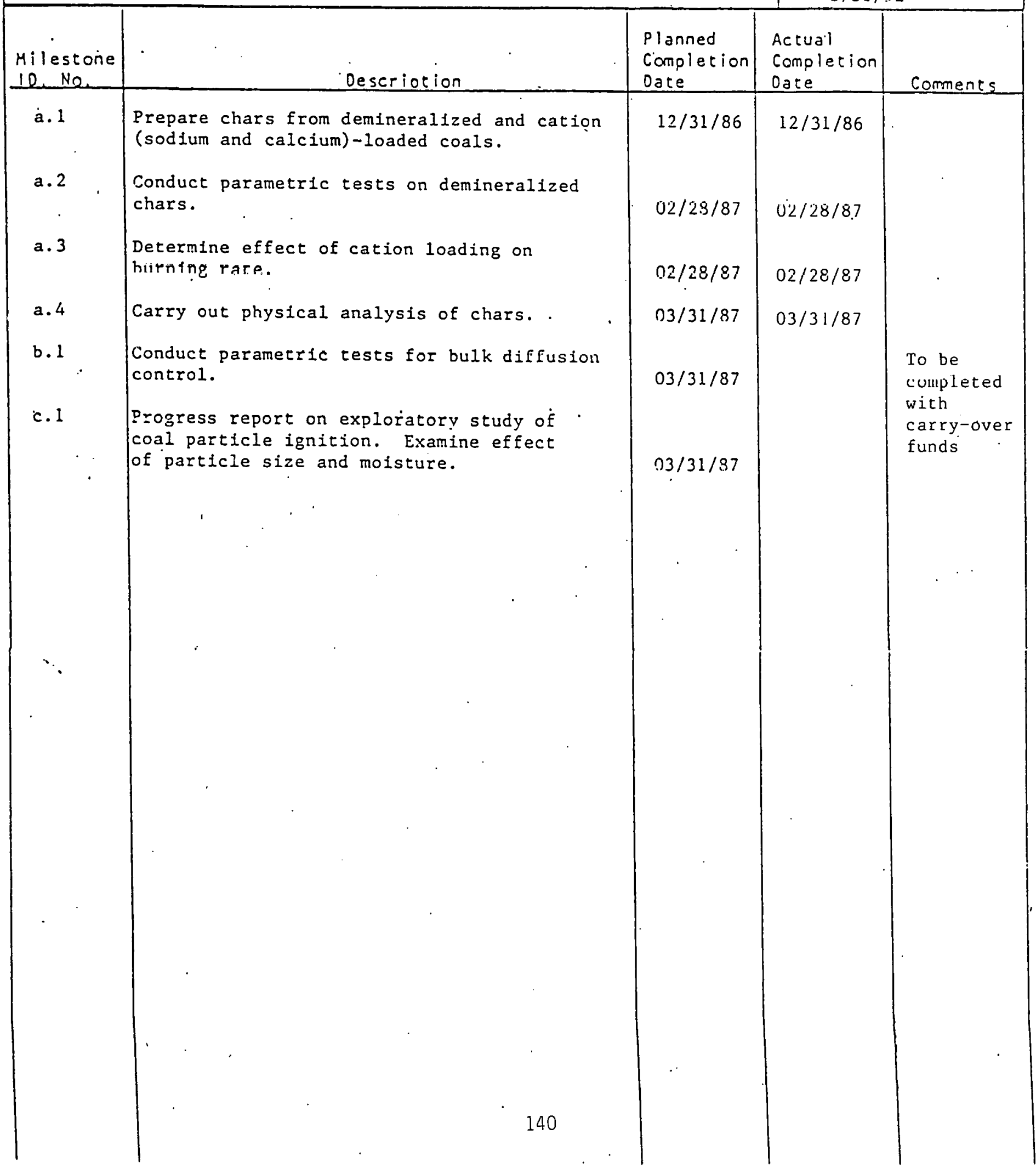




\section{LIQUEFACTION REACTIVITY OF LOH-RANK COALS}

Annual Technical Report for the Period April 1, 1986 - March 31, 1987 including. the

Quarterly Technical Progress Report for Period January through March 1987

by

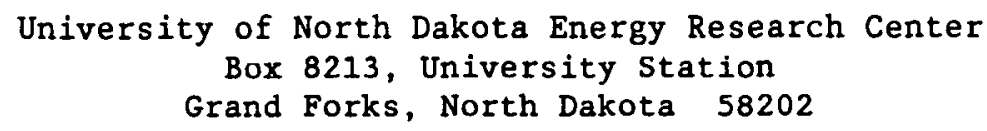

April 1987

Contracting Officer's Technical Representative: Nand K. Narain

Prepared for

United States Department of Energy

office of Fossil Energy

Morgantown Energy Technology Center

Morgantown, West Virginia

Under Connerative Agreement No, DE-FC21-86MC10637-T3 
THIS PAGE

\section{WAS INTENTIONALLY \\ LEFT BLANK}


TABLE OF CONTENTS

Rage

1.0 EXECUTIVE SUMMARY OF FIRST-YEAR RESEARCH $\ldots \ldots \ldots \ldots \ldots \ldots \ldots \ldots$

2.0 GOALS AND OBJECTIVES ........................ 4

3.0 ACCOMPLishments............................ 4

3.1 Task A: Development of Methods for Oxygen-Containing

Functional Groups in Low-Rank Coals and Resultant

Liquids and for Molecular Weight Distribution of the

Coa1-Derived Macromolecules.................... 4

3.1.1 Quantitative Determination of Polar Organic

Acids using Gas Chromatography/Fourier

Transform Infrared Spectroscopy.............. 4

3.1.1.1 Synthesis of ${ }^{18} 0$-Carboxylic Acids....... 4

3.1.1.2 Calibration of the Nicolet 20SXB

GC/FTIR system.................. 5

3.1.2 Measurement of Molecular Weights using

Corrected Rayleigh Scattering Factors.......... 11

3.2 Task B: Liquefaction of Big Brown Lignite in

Hydrogenated Anthracene $0 i l$ Solvent................. 14

3.3 Task D: Determination of Reactivity of Low-Severity

Liquefaction Product with Reducing Agents........... 16

3.3 .1 Catalytic Hydrotreatment................ 16

3.4 Task E: Determination of Reactivity of Stable Latexes of Low-Rank Coals to Reducing and Oxidizing Reagents..... 17

3.4 .1 Particle sizes....................... 17

3.4.1.1 Stabilization of Low-Rank Coal Latexes

with Amino Acids................. 17

3.4.2 Conversion of Peat to a Colloidal Dispersion...... 20

3.4.3 Ash and Sulfur Content of the Coal Latex

Particles............................ 20

3.4.4 Liquefaction of Big Brown Lignite Latex......... 21

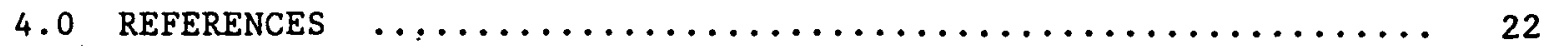


THIS PAGE

WAS INTENTIONALLY

LEFT BLANK 


\section{LIQUEFACTION REACTIVITY OF LOY-RANK COALS}

\subsection{EXECUTIVE SUMMARY OF FIRST-YEAR RESEARCB}

The major goals in the first year have been the development of new methods for the study of the reactivity of low-rank coals and the characterization of oxygen functional groups which are important to the reactivity under lowseverity liquefaction conditions. In Task A progress has been made in the methods for determination of carboxylic acid groups and the basis for a new ether determination has been established. Accurate methods for the quantitation of carboxylic acid groups is very important, since the number of these is large and changes considerably during coal processing above $300^{\circ} \mathrm{C}$. The new method is a modification of the barium ion exchange method but uses high-speed blending which allows for a rapid and reliable determination. The determination of ether groups is also very important, since benzyl ethers are believed to be labile linkages between aromatic clusters in the coal structure which are cleaved in liquefaction, and no reliable methods currently exist for ether determinations. The reaction upon which the determination is based is an oxidative cleavage of benzyl ether groups with aromatic peracids. Studies on the determination of ether groups in coals by oxidation with 4-nitroperbenzoic acid have led to a novel reactivity test. The rates of heat evolution from fresh and old coal samples have been measured in a recording calorimeter; the exposed coal samples exhibit a lower heat of reaction and rate of reaction is slower.

The analysis of liquefaction products containing oxygen functional groups w1ll be significantly advanced by the development of combined instrumental techniques which separate components of complex mixtures by gas chromatography and obtain infrared and mass spectra of the eluting components. A serial gas chromatograph, Fourier transform infrared spectrometer, mass spectrometer (GC/FTIR/MS) system has been developed using an ion trap detector or mass analyzer which is interfaced to the light pipe in the FTIR spectrometer. A modification of the manufacturer-supplied open-split interface to the ion trap was required to obtain chromatographic results free of discrimination and activation effects. The flow rate of the helium make-up gas in the light pipe was used to control the amount of material which enters the ion trap. Hydrogen carziei gas was uacd for the chromatngraphic separations with no adverse effects on the mass spectra obtained.

Using this instrumentation, progress has been made in the development of methods for the characterization of oxygen containing compounds which will result from low-severity liquefaction conditions and other reactions. The quantitative analysis of polar carboxylic acids has been advanced by the use of isotopic dilution with standards enriched in deuterium and oxygen-18, followed by gas chromatography/mass spectrometry with an ion trap mass spectrometer. Reliable and accurate analyses were performed on a series of aliphatic and aromatic polycarboxylic acids found in coal oxidation products. The gas chromatograph/Fourier transform infrared/mass spectrometer system described above was used in investigations of various oxygen-containing fractions from liquefaction tests. It was very effective in characterizing different phenclic-type compounds and in distinguishing dibenzofurans from aryl and alkyl ethers. 
An important advance was also made in the analysis of polar organic species using isotope dilution/gas chromatography/Fourier transform infrared (ID/GC/FTIR) spectrometry. A number of 180 -enriched standard carboxylic acids were prepared, and a method was found for integrating the reconstructed absorbance chromatograms for selected wave number ranges, which are different for the analyte and ${ }^{18} 0$-labeled standard. A calibration method was devised which fits the peak area ratio and mole ratio to a third degree polynomial expression by a least squares method. A linear expression cannot be used because of the overlap in absorption frequencies. Linearization of the ratios by existing methods was invalid, due to chromatographic separation of the analyte and standard peaks. Calibration tests using the polynomial expression gave highly accurate determinations.

Liquefaction reactions have been carried out in Task B using a Big Brown (Texas) lignite under low-severity conditions in an aromatic solvent (1methylnaphthalene) at $375^{\circ} \mathrm{C}$ and in hydrogen-donor solvents (hydrogenated anthracene oil and tetralin/phenol) at $325^{\circ} \mathrm{C}$. The effects of different water concentrations on the yields have been examined in the series of liquefactions in methylnaphthalene. Methods. for product work-up have been investigated. The study of the nature and amount of the oxygen functional groups and the molecular weight distributions in these products produced under different moisture conditions is still in progress. One of these low-severity products was determined to have a weight average molecular weight of 1.3 million, a value similar to that of macromolecules solubilized from the original coal under ambient conditions.

A major improvement has been made in the measurement of molecular weights of coal macromolecules in this quarter. The Cabannes factors, which correct the Rayleigh factors in light scattering determinations for anicotropic effects, have for the first time been determined for coal macromolecules. The Cabannes factors for humate derivatives and low-severity liquefaction products are higher than we had expected, based on values reported for synthetic polymers and biological macromolecules such as proteins. This important discovery will allow more accurate molecular weight determinations to be performed on coal macromolecules and will also solve a problem in explaining slopes of the reciprocal Rayleigh plots. Using the uncorrected Rayleigh factors, the slopes were negative and implicated association effects; however, using the Rayleigh factors which have been corrected for anisotropic polarization, the slopes are positive, and there may be no need for further correction due to association effects.

Separations of the liquefaction products by HPLC and various solvent systems have been initiated. Several types of columns were evaluated for effectiveness in analysis and potential for preparative separations.

In Task $C$, the reactions of oxygenated compounds with low-rank coals was studied. For this work, the semicontinuous reactor was restored to operation and operators trained. Several reactions were carried out in the flow-through system using water and methanol in the supercritical state to facilitate removal of the solubilized coal. Molecular weight distributions were determined for two of these products, indicating that the molecular weight for products from this reactor is also very high. Efforts will be made to study the relationship between this product material and the product obtained in the 1-methylnaphthalene solvent. 
A set of reactions of oxygenated compounds dissolved in water or methanol with lignites in a flow-through reactor was completed. The effects of added compounds on the yield of extracted material were negligible; however, the nature of the coal residue remaining after the reaction was different in several experiments in the aqueous systems. The formate, formaldehyde, and methanol appeared to effect a reduction of the coal, whereas phenolics had no effect. The reaction is worthy of more thorough investigation. Repolymerization of solubilized material was shown to be unimportant in this system since the material obtained in the presence of free radical scavengers had as high a molecular weight as that obtained without the scavenger.

In Task D, catalytic (presulfided Co-Moly) hydrotreating of the low-severity products, which were obtained earlier, was carried out in tubing bomb tests at $410^{\circ}$ in tetralin and in hydrogenated anthracene oil, both with and without hydrogen. The products are currently being analyzed.

The preparation of stable suspensions (latexes) of low-rank coals has been carried out in Task $E$. Light scattering studies confirm the colloidal nature of these products. The effects of $\mathrm{pH}$ or type of base and the effects of coal type on the conversion have been investigated. All low-rank coals and peat gave good conversions to the colloidal form in dilute sodium hydroxide solution at ambient temperatures, but bituminous coal failed to give the latex in sodium hydroxide. Some coals gave a very low ash humate after precipitation $(0.83 \%)$, indicating that mineral matter was effectively removed and that the potential for a coal-cleaning process is good. Sulfur removal was also effected. The effects of oxygen on the solubilization of low-rank coals was studied in a series of blender experiments. Oxygen was shown to have a small positive effect of the yields of latexes, but was not able to effect oxidation to highly soluble small molecular weight species by prolonged blending with air injection or heating the latex to $100^{\circ} \mathrm{C}$.

This task concerned with preparation and reactivity of low-rank coal latexes was terminated with determinations of particle size to establish the colloidal nature, stabilization studies at neutral $\mathrm{pH}$ which were successful, and a liquefaction or thermal reduction study which indicated that the colloidal form offers no advantage over particulate coal in liquefaction in a basic aqueous medium.

The determination of the nature and amount of specific kinds of hydroaromatic groups in coals and in the liquefaction products has been studied in Tasks F and G. A novel method for determining the fate of hydroaromatics following dehydrogenation with dicyanodichloroquinone has been developed. Comparison of the ruthenium tetroxide oxidation products from the Big Brown lignite and the dehydrogenated Big Brown lignite shows a significant decrease in the yield of succinic acid, which can be attributed to conversion of dihydrophenanthrene or dihydropyrene structures in the coal to aromatic systems. A decrease in the adipic acid yield might be attributed to conversion of tetrahydroaromatics or tetralin structures to the aromatic system, although the amount is an order of magnitude smaller than the dihydroaromatics conversion. Similar studies involving dehydrogenation of the low-severity liquefaction product and subsequent oxidation with ruthenium tetroxide show that the liquefaction decreases the amount of succinic acid but increases the amount of adipic acid. The 
increase of adipic acid can be related to a hydrogenation of aromatics during the processing. Further work with other aliphatic carboxylic acid products will give more detailed information on the coal structure and the hydrogens available for radical capping and hydrogen shuttling.

\subsection{GOALS AND OBJECTIVES}

The first objective of this project is to investigate and test mechanisms which cleave carbon-oxygen bonds during liquefaction processing of low-rank coals. Research efforts will address the quantity and distribution of oxygencontaining components present in coal and products resulting from low-severity or first-stage liquefaction, the reactivity of these components to a variety of hydrogenation reagents and treatments, the characterization of these coal components and their subsequent products by oxygen functional group analysis and appropriate molecular weight determinations, and the development of methods to cleave carbon-oxygen bonds that are resistant to, or formed by, mild low-rank coal liquefaction conditions.

\subsection{ACCOMPLISHMENTS}

3.1 Task A: Development of Methods for Oxygen-Containing Functional Groups in Low-Rank Coals and Resultant Liquids and for Molecular Veight Distribution of the Coal-Derived Macromolecules

\subsubsection{Quantitative Determination of Polar Organic Acids using Gas} Chromatography/Fourier Transform Infrared_Spectroscopy

Gas chromatography/Fourier transform infrared (GC/FTIR) spectrometry has been very useful in qualitative analysis of volatile mixtures, especially those with polar functional groups which have intense absorptions in the infrared. Development of quantitative capabilities have awaited with preparation of suitable isotopically enriched standards to be used in isotope dilution methods. A number of ${ }^{18} 0$-labeled carboxylic acids have now been prepared, and a calibration using on-the-fly GC/FTIR detection of the carbonyl of the labeled standard and the analyte in various mixtures has been accomplished. Analyses of unknown concentrations of various carboxylic acids using the GC/FTIR method can be simultaneously carried out with the mass spectrometer (MS) analyses obtained in the GC/FTIR/MS system.

\subsubsection{Synthesis of 180 -Carboxylic Acids}

Octanoic acid- ${ }^{18} \mathrm{O}_{2}$, octandioic (suberic) acid- ${ }^{18} \mathrm{O}_{\text {fs }}$ propanedioic (malonic) acid- ${ }^{18} \mathrm{O}_{4}$, and $1,2,4,5$-benzenetetracarboxylic acid- ${ }^{+8} \mathrm{O}_{8}$ were synthesized from the corresponding nitrile or polynitrile (octanonitrile, 1,6-dicyanohexane, malonitrile, and 1,2,4,5-teracyanobenzene, respectively) by reaction with water- ${ }^{18} 0$ with anhydrous hydrogen bromjde catalyst in sealed ampules at $85^{\circ} \mathrm{C}$. The reaction is illustrated in scheme 1 for malonic acid. 
Synthesis of Malonic Acid $-{ }^{18} \mathrm{O}_{4}$<smiles>N#CCC#N</smiles>

Scheme 1

High yields of product ( $86 \%$ to $97 \%$ ) were obtained from the reactions of the aliphatic nitriles, with no side reaction products. A lower yield (44\%) of the pure labeled standard was obtained in the preparation of the benzenetetracarboxylic acid- $18_{8}$. Benzenehexacarboxylic (mellitic) acid- $180_{4}$ was obtained as a mixture of isotopically labeled species from the hydrolysis/exchange of mellitimide with $18_{0}$-labeled water and anhydrous hydrogen bromide. This preparation is illustrated in scheme 2 .

Synthesis of Mellitic Acid $-{ }^{18} \mathrm{O}_{\mathrm{u}}$<smiles>O=C(O)c1c(C(=O)O)c(C(=O)O)c(C(=O)O)c(C(=O)O)c1C(=O)O</smiles>

Scheme 2

\subsubsection{Calibration of the Nicolet 20SXB GC/ETIR System}

The absorption maxima of the carbonyl peaks of methyl esters prepared by treatment of the ${ }^{18}$-labeled carboxylic acids with diazomethane were approximately $33 \mathrm{~cm}^{-1}$ lower than the maxima of the esters prepared from the unlabeled analyte acids. Because of the natural peak broadening at the base, there was always some overlap of absorbances of the labeled and unlabeled esters. Absorbance reconstructed chromatograms were generated over the desired frequency range for each labeled standard and unlabeled analyte. A range or window of $8 \mathrm{~cm}^{-1}$ was selected component over which each of the peaks is reconstructed. These frequency ranges are given in Table 1 . 
INFRARED RECONSTRUCTION FREQUENCIES

\begin{tabular}{|c|c|c|c|}
\hline Compound & $\begin{array}{c}\text { Frequencies } \\
\frac{(C M-1)}{}\end{array}$ & ISTD & $\begin{array}{c}\text { Frequencies } \\
(\mathrm{CM}-1) \\
\end{array}$ \\
\hline Malonic Acid & $1772-1764$ & $\begin{array}{l}\text { Malonic } \\
\text { Acid-018-2 }\end{array}$ & $1738-1730$ \\
\hline Octanoic Acid & $1763-1755$ & $\begin{array}{l}\text { Octanoic } \\
\text { Acid-018-2 }\end{array}$ & $1730-1722$ \\
\hline Suberic Acid & $1763-1755$ & $\begin{array}{l}\text { Suberic } \\
\text { Acid }=010-4\end{array}$ & $1730-1722$ \\
\hline $\begin{array}{l}1,2,4,5 \text {-Benzenetetra- } \\
\text { carboxylir Arid }\end{array}$ & $1758-1750$ & $\begin{array}{l}1,2,4,5- \\
\text { Benzenetetra- } \\
\text { carboxy1ic } \\
\text { Acid-013-8 }\end{array}$ & $1726-1718$ \\
\hline $\begin{array}{l}\text { Benzenehexa- } \\
\text { carboxylic Acid }\end{array}$ & $1764-1756$ & $\begin{array}{l}\text { Benzenehexa- } \\
\text { carboxylic } \\
\text { Acid-018-12 }\end{array}$ & $1732-1724$ \\
\hline
\end{tabular}

Reconstructed absorbance chromatograms over the selected ranges are shown below for the methyl ester of malonic acid and malonic acid- ${ }^{18} \mathrm{O}_{4}$ (Figures 1 and 2), run as the mixture, as one example of the type of peaks which we are integrating in the subsequent steps of the quantitation. A representative FTIR spectrum corresponding to one point on the chromatogram of suberic and suberic- $-{ }^{18} \mathrm{O}_{4}$ is shown in Figure 3 .

In each absorbance reconstructed chromatogram, the beginning and ending integration points of the peak were then selected by using the on-screen cursor, and the Nicolet integrator with baseline correction enabled was used to calculate the area under the peak. Baseline correction references the integration to the chromatogram baseline. If this feature were disabled, the integration would be referenced to zero. This mode of operation was found to produce significant errors. The calculated areas were then used to produce the calibration curves, which are plots of concentration ratios versus area ratios. Calibration plots for octanoic and suberic acids are shown in Figures 4 and 5. The nonlinearity is believed to result from the base overlap, as mentioned above. This same problem arises in quantitation using isotope dilution mass spectrometry when the analyte and standard have peaks with $\mathrm{m} / \mathrm{z}$ values which overlap, and a hyperbolic relationship exists between the isotope ratio and the mole ratio. 


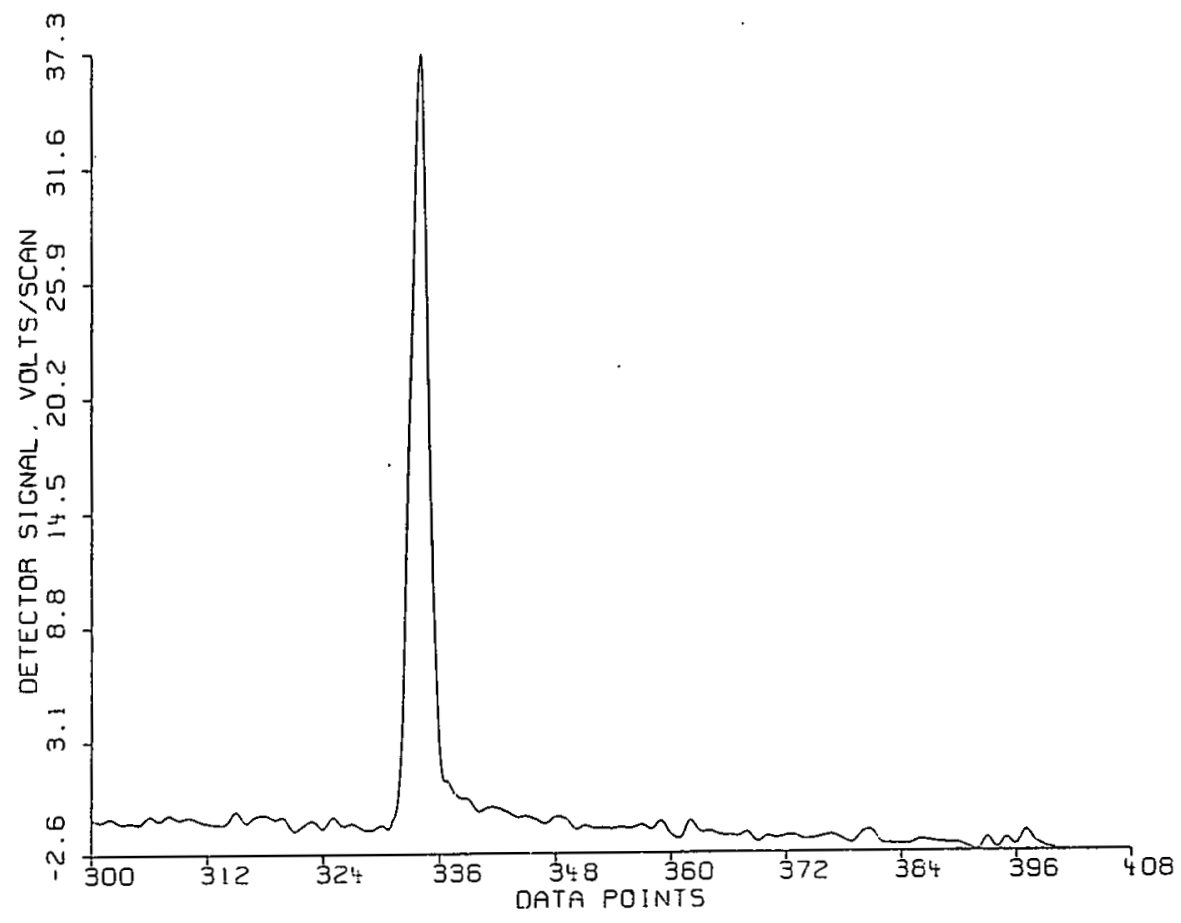

Figure 1. Reconstructed absorbance chromatogram of methyl malonate (1782-1759 $\mathrm{cm}^{-1}$ )

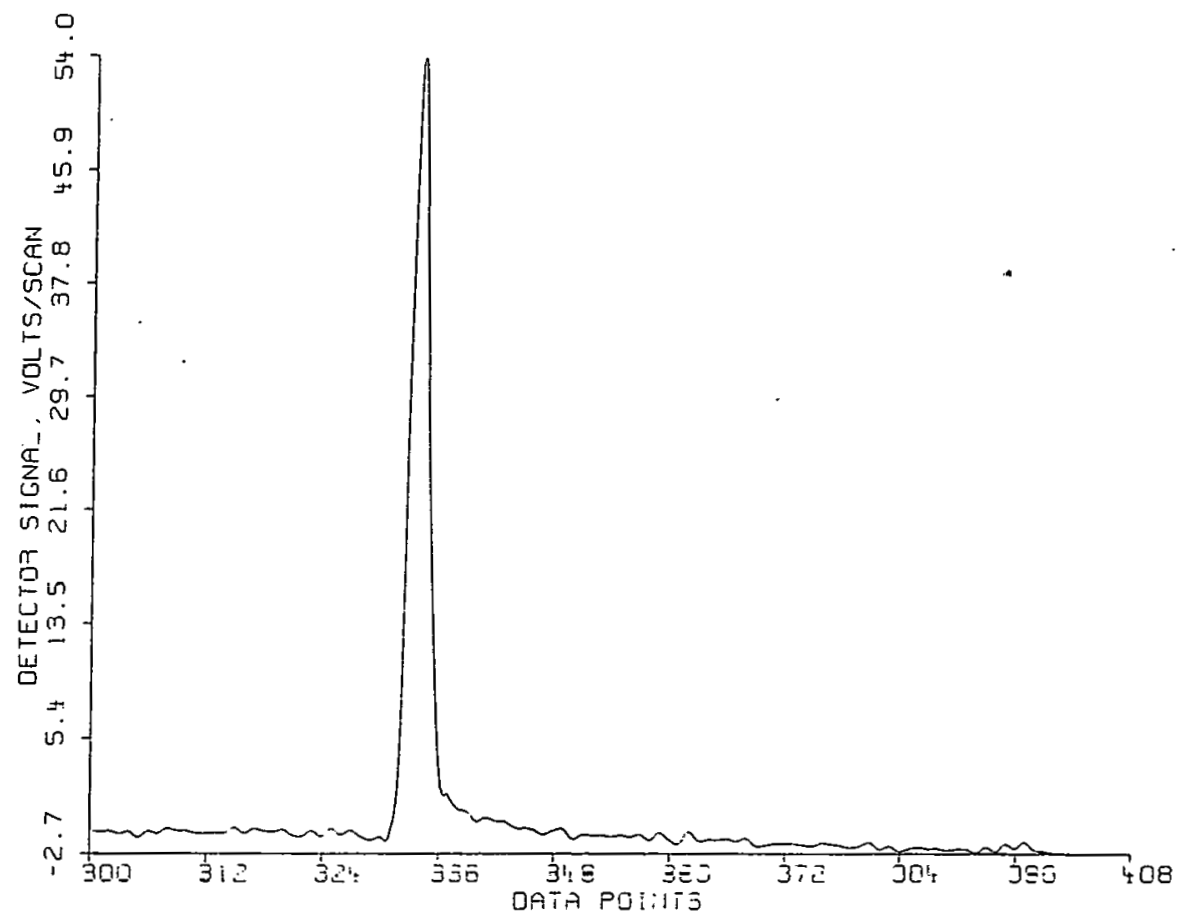

Figure 2. Reconstructed absorbance chromatogram of methyl malonate- ${ }^{18} \mathrm{O}_{4}$ $\left(1743-1720 \mathrm{~cm}^{-1}\right)$ 


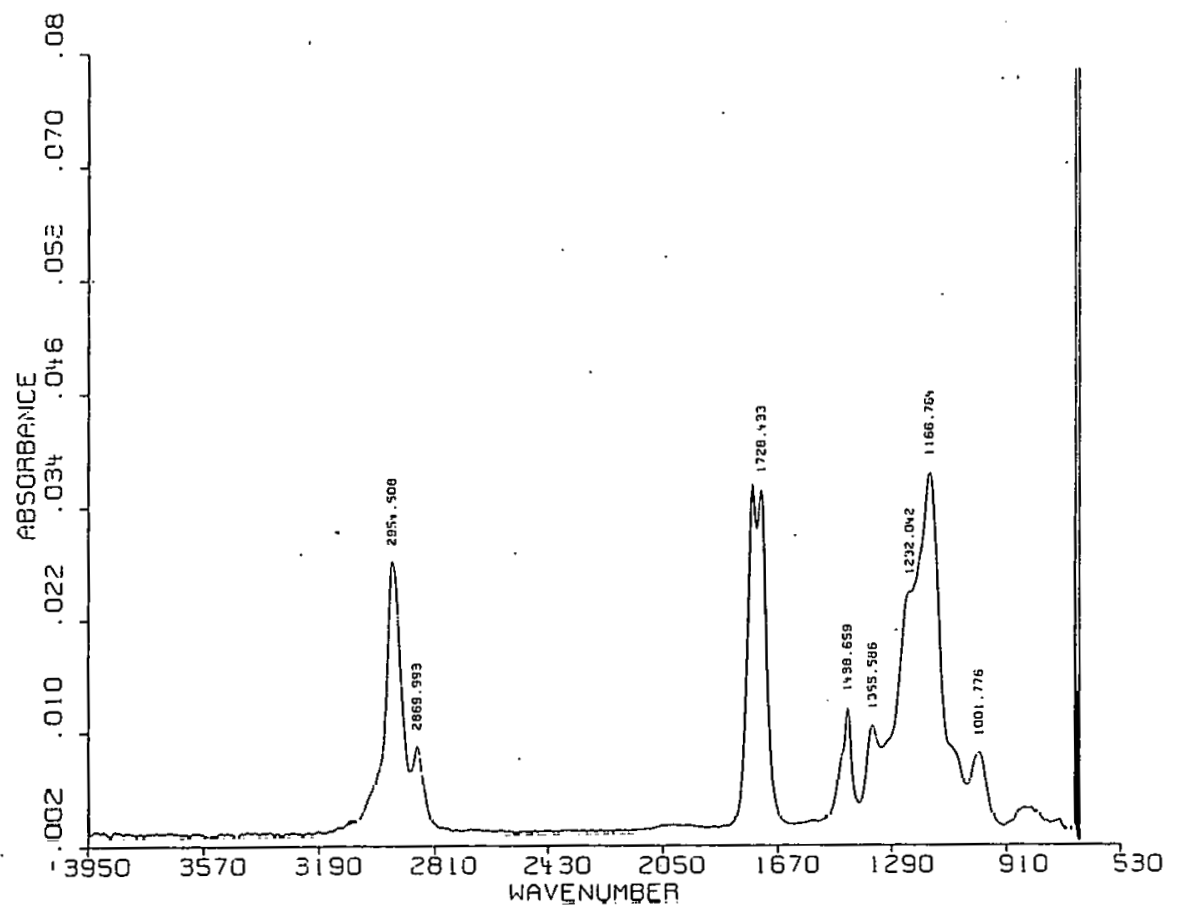

Figure 3. FTIR of mixture of methyl suberate- ${ }^{18} \mathrm{O}_{4}$ and methyl suberate

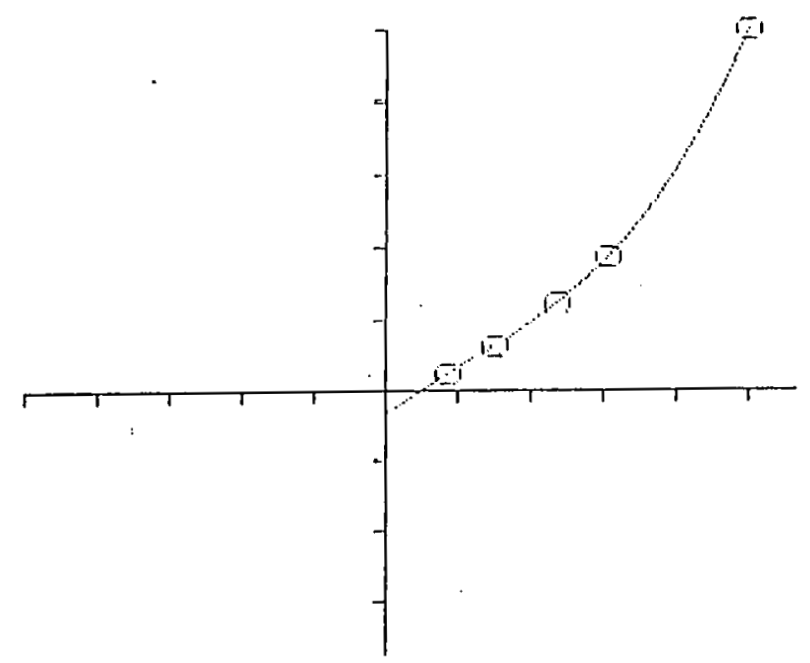

Figure 4. GC/FTIR calibration curve for octanoic acid 


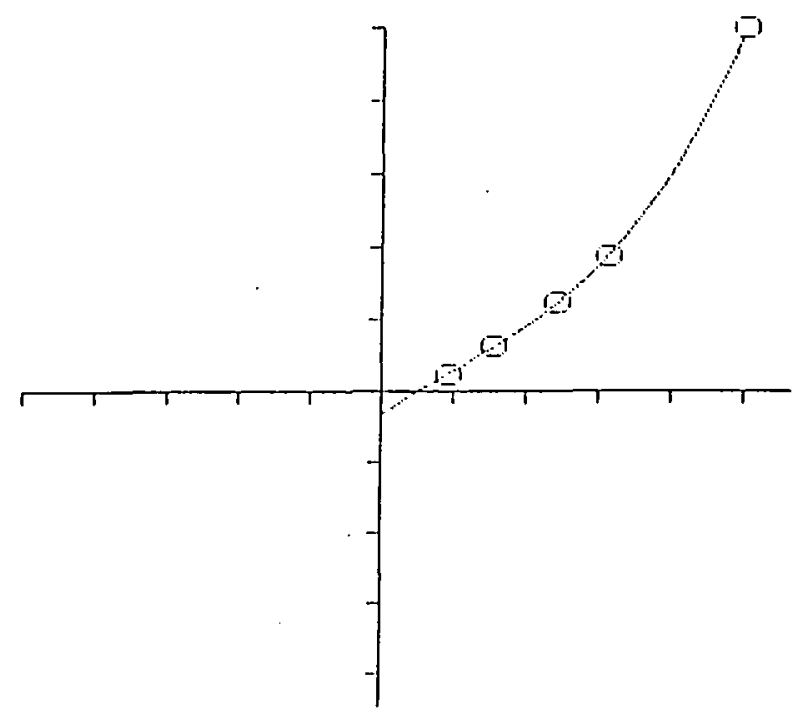

Figure 5. GC/FTIR calibration curve for suberic acid

Initially, the peak ratio data for several of the acids in our study was linearized using a function similar to the Colby-McCaman formulation (1) for treating mass spectrometer ratios. This approach did indeed produce a linear curve from the infrared data; however, the method was extremely sensitive in that small deviations of ratios from the points defining the curve were magnified, and thus repetitive runs gave large standard deviations and large errors in calibration tests with known concentrations of analyte.

Rather than transforming the data to a linear mode1, the alternative approach to calibration is to fit the data to a curvilinear equation. This endeavor was aided by the availability of a nonlinear statistical program in the ASYST software package. A polynomial expression shown in Equation $I$ was used to fit the peak area data by a method of least squares. This was limited to a third degree function to avoid oscillation of the calibration curve $(2,3)$.

$$
Y=a_{0}+a_{1} X+a_{2} X^{2}+\ldots a_{n} X^{n}
$$

Equation 1.

$Y$ is the mole ratio of and $X$ is the peak are ratio. A good fit to the five data points for each analyte/standard pair was obtained with the third degree pnlynnmial expression. The effect of chromatographic separation of the analyte and labeled standard is not of any significance when the polynomial analysis is used, whereas it destroys the validity of the basic isotope dilution equation and the subsequent calculation procedures ( 3 ). 
The curves illustrated in Figures 4 and 5 correspond to polynomial Equations 2 and 3 for octanoic and suberic acid respectively. Calibration tests with known

$$
\begin{aligned}
& Y=-0.2717+1.7866 x-0.8944 X^{2}+0.7811 x^{3} \\
& Y=-0.2543+1.6324 X-0.8214 X^{2}+0.8306 x^{3}
\end{aligned}
$$

concentrations of octanoic acid as the analyte $(0.2076 \mathrm{mg} / \mathrm{ml})$ gave a mean error of $0.0018 \mathrm{mg} / \mathrm{ml}(0.87 \%$ error). Similar high accuracy was observed for suberic acid ( $0.96 \%$ mean error) and 1,2,4,5-benzenetetracarboxylic acid ( $1.5 \%$ mean error) at this concentration ( 6 tests). Somewhat higher mean errors were found for the malonic $(4.0 \%)$ and benzenehexacarboxylic acid (5.0\%). Since these acids are highly water soluble, most other analytical methods are inappropriate and give large errors. The benzenehexacarboxylic acid is a component of the $\mathrm{RuO}_{4}$ oxidation mixtures, as is the benzenetetracarboxylic acid and sometimes the octanoic and suberic. A FTIR spectrum from one point of the chromatogram of the benzenehexacarboxylic acid and the labeled standard is shown in Figure 6 .

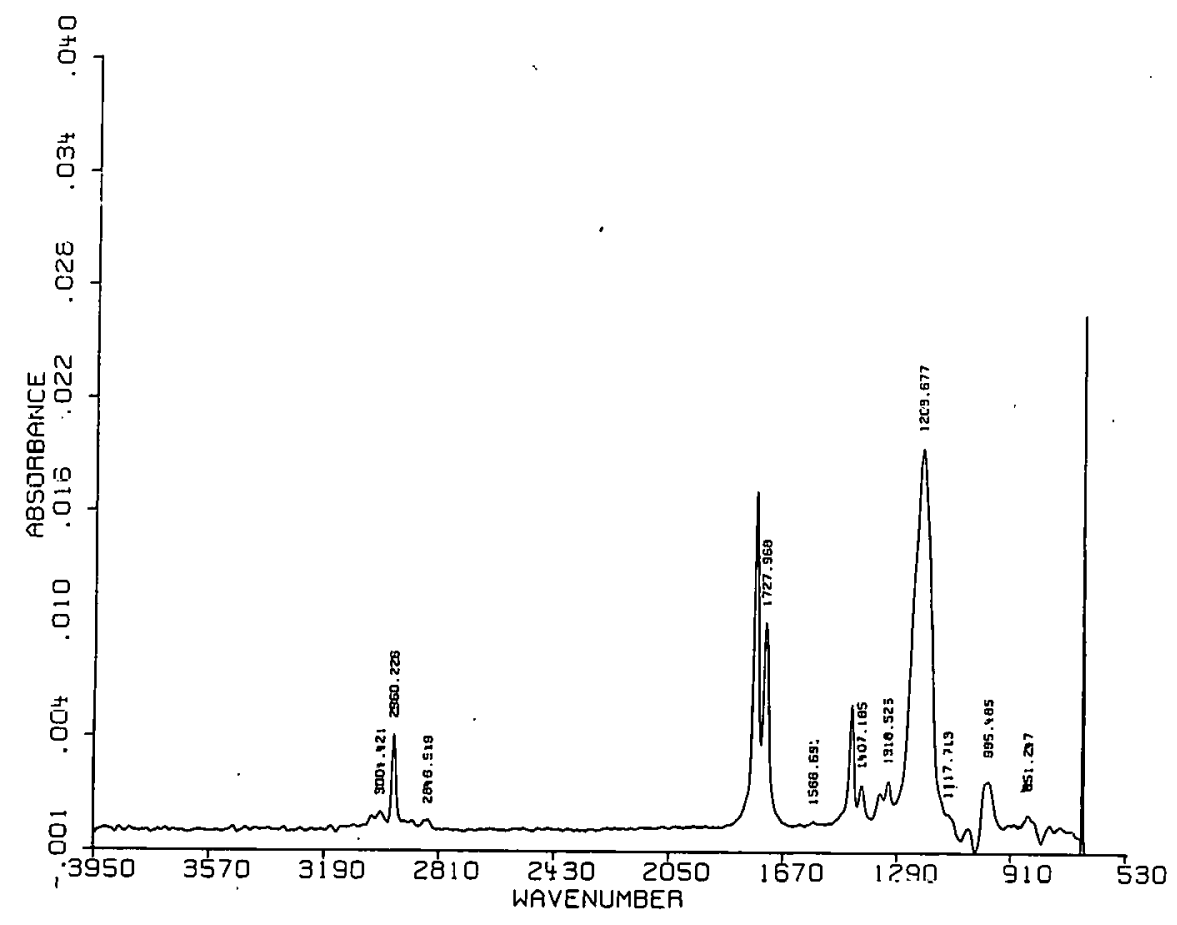

Figure 6. FTIR of methyl benzene hexacarboxylate $-{ }^{18} \mathrm{O}_{\mathrm{u}}$ and methyl benzene hexacarboxylate 
The exchange of the ${ }^{18} \mathrm{O}$ atoms in the standards were investigated using an acidic aqueous solution and GC/MS of the methyl esters. The exchange rate was found to be negligible. However, when the actual analysis of carboxylic acids obtained by oxidation of coal with $\mathrm{RuO}_{4}$ was carried out, exchange of some of the ${ }^{18} \mathrm{O}$ atoms in the labeled benzenepolycarboxylic acid standards was observed by GC/MS of the esters, and consequently the GC/MS analysis and the GC/FTIR analysis did not agree. Alternative methods for work-up of the acid products are being investigated to avoid the exchange problem which may significantly affect the accuracy of the GC/FTIR determination.

\subsubsection{Measurements of Melecular Weights using Corrected Bayleigh Scattering Factors}

The determination of accurate molecular weights is an important part of this liquefaction reactivity research project. The observation of a decrease in the molecular weight distribution as liquefaction processing is carried out is a way to assess the importance and extent of depolymerization of the coal macromolecules during the forming of liquids from the solid coal. We have previously used low-angle laser light scattering photometry in the determination of weight average molecular weights and molecular weight distributions $(4,5)$. In these determinations, no correction was applied to the Rayleigh scattering factors for the enhancement of scattering due to optical anisotropy of the coal molecules. The calculation of molecular weights from the Rayleigh Factor measurements is valid only for optically isotropic molecules, that is those with identical polarizabilities on all axes (6). For the anisotropic molecules, the observed Rayleigh Factor $\left(R_{\theta}\right.$ obs) must be divided by a correction factor $\left(C_{\theta}\right)$ called the Cabannes factor (Equation 4). The resulting scattering factor $\left(R_{\theta}\right.$ iso $)$ can be used in the usual reciprocal scattering plot to determine the molecular weight.

$$
R_{\theta} \text { iso }=R_{\theta \text { obs }} / C_{\theta}
$$

Equation 4

As the molecular weight of a polymer increases, the anisotropy generally decreases; hence the correction is usually insignificant for high polymers (7). An analyzing polarizer was not initially available on our light scattering instrumentation, and no corrections for anisotropy were performed. The slopes of the reciprocal scattering factor plots were generally negative when the static LALLS photometer was used. Since most synthetic polymers exhibit positive slopes, the plots for the coal macromolecules caused some concern. In a number of biological macromolecules, the observation of negative slopes was ascribed to association of the macromolecules. However, that association was the reason for the negative slopes in the scattering plots for the coal macromolecules was never adequately explained.

In this quarter an analyzing polarizer was installed in the KMX- 6 between the sample cell and the photomultiplier tube. The depolarization ratio, $\bar{\rho}$, was calculated from the intensity of horizontally polarized scattered 1 ight, $G_{\theta}{ }^{H}$. and the intensity of the vertically polarized scattered light, $G_{\theta}$, using Equation 5.

$$
\bar{p}=G_{\theta}{ }^{\mathrm{H}} / G_{\theta}{ }^{V}
$$

Equation 5 
In order to apply the Cabannes factor in the case of vertically polarized incident light used in the $\mathrm{KMX}-6$ rather than the unpolarized incident light used in the $90^{\circ}$ optics in conventional instruments, the depolarization ratio for vertically polarized light, $\rho_{v}$, was calculated according to Equation 6 ,

$$
\rho_{\mathbf{v}}=\left(1+\cos ^{2} \theta\right) /\left(2-\bar{\rho}+\cos ^{2} \theta\right) \quad \text { Equation } 6
$$

where $\theta$ is the annulus angle. The conventional depolarization ratio, $\rho$, was then calculated using Equation 7,

$$
\rho=2 \rho_{v} /\left(1+\rho_{v}\right)
$$

Equation 7

and then the Cabannes factor from Equation 8.

$$
\begin{aligned}
& c_{\theta}=1+\rho+(1-\rho) \cos ^{2} \theta \\
& \left(1-(7 / 6 \rho)\left(1+\cos ^{2} \theta\right)\right.
\end{aligned}
$$

Equation 8

A program was written to calculate Cabannes factors from the observed intensities, $G_{\theta}^{H}$ and $G_{\theta}$ tor any number of concentrations and apply the cabannes factor to the Rayleigh Factor for both the solution and the solvent. The program then executes the reciprocal scattering plot of $\mathrm{Kc} / \overline{\mathrm{R}}_{\theta}$ iso (where $\overline{\mathrm{R}}_{\theta \text { iso }}$ is $R_{\theta}$ iso solution $-R_{\theta}$ iso solvent) and finds the molecular weight from the intercept of the line obtained from the least squares regression.

The sample used for the initial measurement of depolarization ratios was a reduced methyl humate obtained from a Beulah (ND) lignite by blending with base in a blender with air injection for two hours. The sample, after exhaustive methylation and reduction with zinc in acetic anhydride (1), was similar to previously studied reduced methyl humates and had a weight average molecular weight of 897,000 using the uncorrected (anisotropic) Rayleigh Factors. The reciprocal Rayleigh Factor plot had a negative slope $\left(A_{2}=-8.3\right.$ $\left.\times 10^{-5}\right)\left(r^{2}=.86\right)$ as did the previously observed reduced methyl humates.

Cabannes factors for eight concentrations of the reduced methyl humate were calculated from the depolarization ratios of the eight solutions. Mean variations in ten determinations of the Cabannes factor for one of the solutions of the reduced methyl humate were +0.03 , or about $1 \%$. A plot of the Cabannes factors versus concentrations of the reduced methyl humate sample is shown in Figure 7. The values obtained for the factors were quite large compared with anything observed for polystyrene or biopolymers (7). The curve through the points was linear at the lower concentrations and deviated somewhat at high concentrations. I'he reason for the drop at high concentrations may be due to plugging of the particulate filter under high concentration load, such that the actual concentrations present were less than the original aliquots would have given. These points were dropped in the subsequent reciprocal scattering plot of the corrected Rayleigh Factors, $\overline{\mathrm{R}}_{\theta}$ iso. There seems to be no reason why the curve should not be linear. 


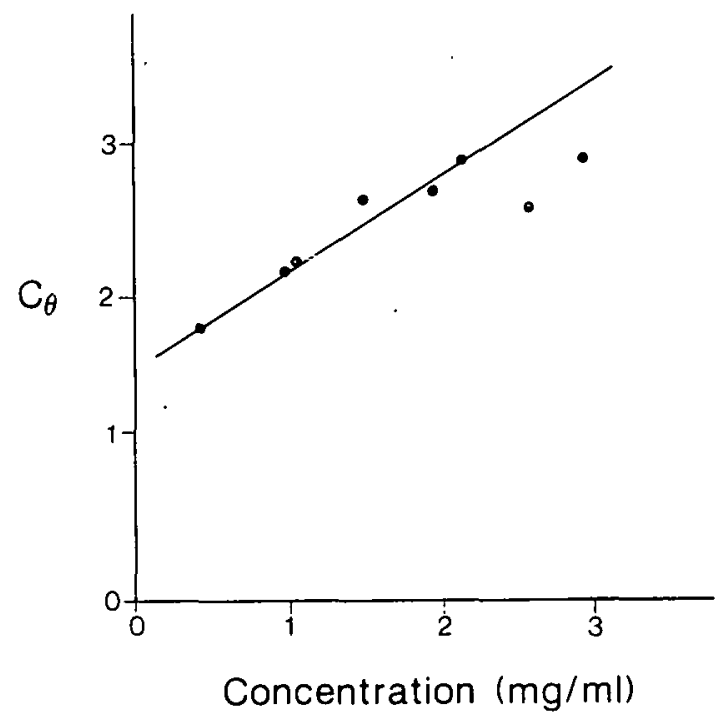

Figure 7. Cabannes factors versus concentration for Beulah humate derivative

The reciprocal plot of corrected Rayleigh scattering factors, $\overline{\mathrm{R}}_{\theta}$ iso, for the remaining points is shown in Figure 8 . Most importantly, the slope of the line is now positive $\left(A_{2}=8.5 \times 10^{5}\right)$. This means that association effects are not necessarily significant in these macromolecules and the extrapolation of the line to zero concentration will give the reciprocal of the molecular weight (except for any additional correction to the $\mathrm{dn} / \mathrm{dc}$ value which was discussed in our previous paper) (5). The apparent molecular weight from the intercept is now 521,000 daltons for the reduced methyl humate obtained by air injection blending of Beulah lignite. The correction factors are now being applied to a number of other humate derivatives and the liquefaction products.

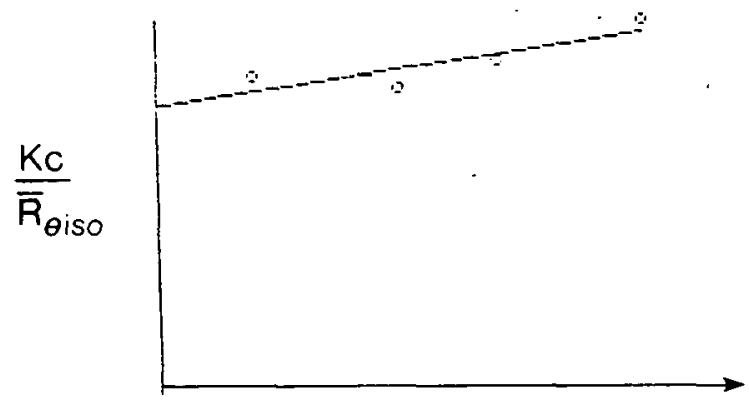

Concentration

Figure 8. $\mathrm{Kc} / \mathrm{R}_{\theta}$ iso versus $\mathrm{c}$ plot for Beulah humate derivative 


\subsection{Task B: Liquefaction of Big Brovn Lignite in Hydrogenated Anthracene 0il Solvent}

The objective of this task is to provide a low-severity liquefaction stage as a part of a two-stage process for converting low-rank coals to liquid products. The presumption is that the first-stage product will be a high molecular weight material with a high oxygen content. The second stage(s) of the project involve further depolymerization and hydrodeoxygenation in order to achieve a high conversion to a low-oxygen liquid product. Accurate oxygen analysis at the various stages and mechanistic studies of oxygen cleavage are important goals of the project.

The results of low-severity treatment of Big Brown lignite at $365^{\circ} \mathrm{C}$ for one hour using methylnaphthalene solvent and $\mathrm{CO}$ and $\mathrm{H}_{2} \mathrm{~S}$ as reducing agents have been reported in an earlier quarterly report. The work-up of the product slurry from the liquefaction experiments has now been improved, since the earlier method was found to be inefficient when large samples were extracted for use in subsequent liquefaction experiments. The bulk methylene chloride soluble fraction from one of the previous liquefaction reactions (Run No. $\mathrm{N}-372$ ) was re-extracted according to the new method (Scheme 3 ). This bulk sample was thus shown to consist of some $\mathrm{CH}_{2} \mathrm{Cl}_{2}$ insolubles, some $\mathrm{CH}_{2} \mathrm{Cl}_{2}$ solubles, and some pentane solubles (Table 2). This knowledge of the composition of the bulk samples helped clear up ambiguities relating to small- and large-scale work-ups. The yield data reported in the earlier quarterly report were obtained using a work-up of a very small sample, thus may be regarded as valid.

TABLE 2

RESULTS OF PRODUCT WORK-UP OF $\mathrm{MECl}_{2}$-SOLUBLE FRACTION FROM N-372

Sample

$\mathrm{MECl}_{2}$ Insol.

$\mathrm{MECl}_{2}$ Sol.

Pentane Sol.

Bottoms

OVHDS

N-372

$\mathrm{MECl}_{2}$ Sol.

$5.13 \mathrm{~g}$

$14.82 \mathrm{~g}$

$27.89 \mathrm{~g}$

$23.90 \mathrm{~g}$

$(\mathrm{A}+\mathrm{PA})$

$47.84 \mathrm{~g}$

A decision was made to look for alternative solvents and reaction conditions to allow a lowering of the process temperature and improve the conversion. With this end in view, hydrogenated anthracene oil was chosen as the solvent and a temperature of $320^{\circ} \mathrm{C}$ was used. Big Brown coal and hydrogenated anthracene oil were heated in a one-gallon autoclave at $320^{\circ} \mathrm{C}$ for 1 hour (cold charge) using a mixture of $\mathrm{CO}$ and $\mathrm{H}_{2} \mathrm{~S}$ (900 psi $\mathrm{CO}$ and $100 \mathrm{psi} \mathrm{H}_{2} \mathrm{~S}$ ). The raw product slurry was separated into five different fractions according to scheme 3 , and the yields and weight average molecular weights ( $\mathbb{F}_{w}$ are given in Table 3. The reaction of the Big Brown 1ignite with tetralin and phenol was also investigated at two solvent compositions (Table 3 ). 


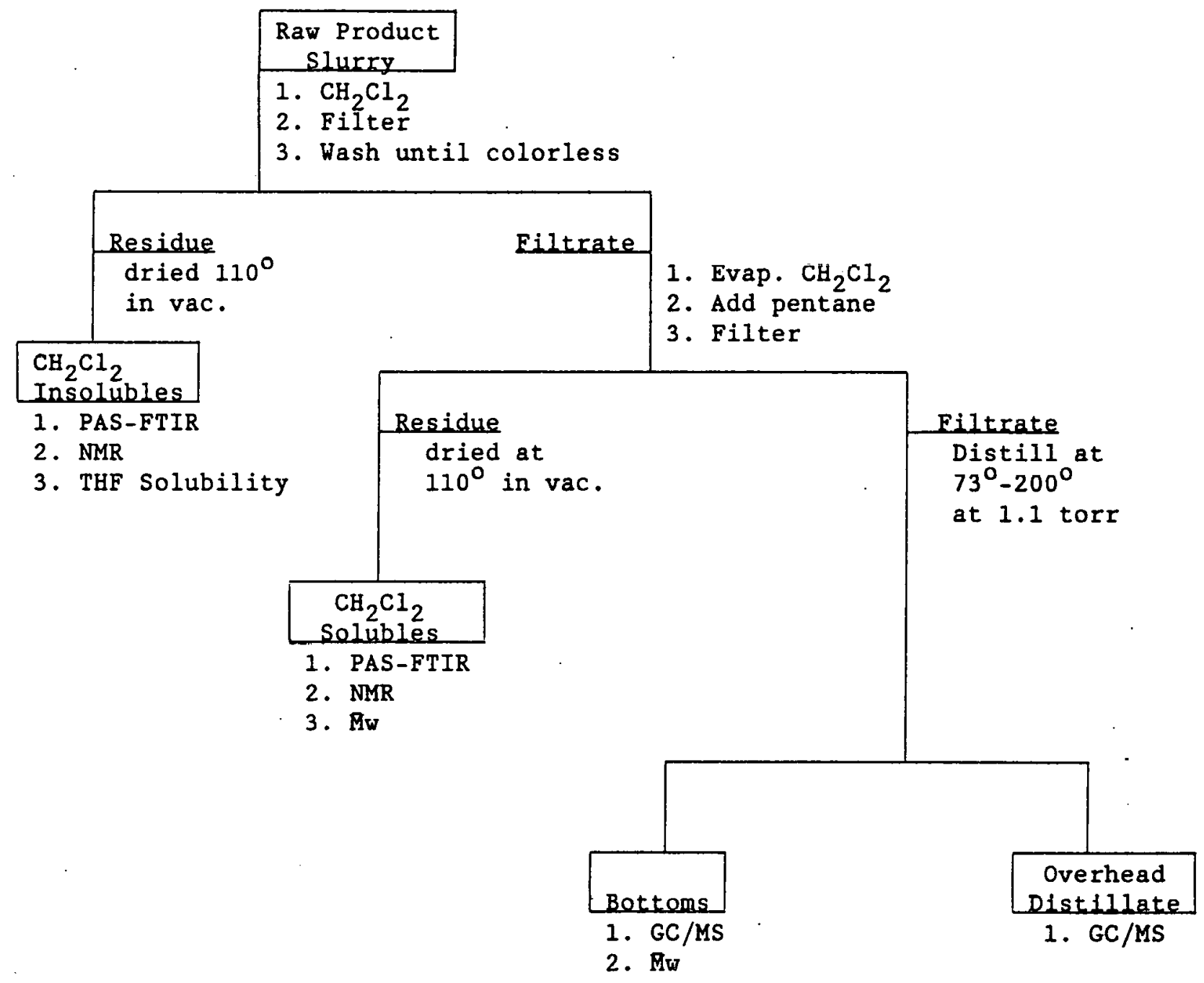

Scheme 3. New Work-up Procedure 
TABLE 3

FIRST-STAGE LIQUEFACTION WITH H-DONOR SOLVENTS -- BIG BROWN II K

\begin{tabular}{|c|c|c|c|c|c|}
\hline \multirow[b]{2}{*}{ Solvent/Conditions } & \multicolumn{3}{|c|}{ Product Yields (wt\% mf) } & \multicolumn{2}{|c|}{$\mathrm{Bw}$} \\
\hline & $\begin{array}{l}\text { Bottoms } \\
\text { (Pentane } \\
\text { Soluble) }\end{array}$ & $\begin{array}{l}\mathrm{CH}_{2} \mathrm{Cl}_{2} \\
\text { Soluble }\end{array}$ & $\begin{array}{l}\text { Solids } \\
\left(\mathrm{CH}_{2} \mathrm{Cl}_{2}\right. \\
\text { Insol. }\end{array}$ & Bottoms & $\begin{array}{r}\mathrm{CH}_{2} \mathrm{Cl}_{2} \\
\text { Soluble }\end{array}$ \\
\hline 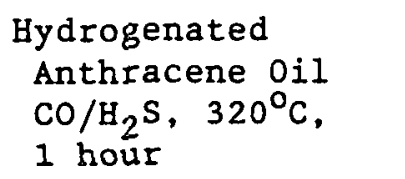 & $13 \%$ & $25 \%$ & $87 \%$ & $410 \mathrm{~K}$ & $558 \mathrm{~K}$ \\
\hline $\begin{array}{l}\text { Phenol/Tetralin } \\
(20 / 80) \\
325^{\circ} \mathrm{C}, 1 \text { hour }\end{array}$ & $21 \%$ & $14 \%$ & $89 \%$ & $621 \mathrm{~K}$ & $804 \mathrm{~K}$ \\
\hline $\begin{array}{l}\text { Phenol/Tetralin } \\
(33 / 67) \\
325^{\circ} \mathrm{C}, 1 \text { hour }\end{array}$ & $29 \%$ & $16 \%$ & $76 \%$ & $567 \mathrm{~K}$ & $1090 \mathrm{~K}$ \\
\hline
\end{tabular}

The yields of soluble materials from these treatments in hydrogen donor solvents at low temperatures were comparable with those obtained with methylnaphthalene at a higher temperature: Although the conversion was poor, material for hydrotreatment studies was obtained, and it is a very high molecular weight, lightly processed material.

\subsection{Task D: Determination of Reactivity of Lor-Severity Liquefaction Product with Reducting Agents}

\subsubsection{Catalytic Hydrotreatment}

The products from Run N-372 were chosen for high-severity catalytic hydrotreatment. Two fractions, namely the methylene chloride insoluble and the methylene chloride soluble fractions, were used as received. In view of the discussion in Task $B$, the methylene chloride soluble fraction is a mixed solubility fraction; therefore the results of the hydrotreatment may not easily interpretable in terms of changes in solubility. The product solubility is in Itself, however, a valid characterization. Two different solvents were used, tetralin and hydrogenated anthracene oil. Coal samples and the solvents were heated at $410^{\circ} \mathrm{C}$ for 30 minutes with and without hydrogen. The product slurry obtained from these reactions were worked up according to scheme 3 . The results show that the methylene chloride insoluble fraction was only partially converted to soluble material. Because of the small conversion of the methylene chlorlde soluble fraction, no conclusion can be drawn about the reaction except that breakdown of the coal macromolecules did not progress very far under these conditions. The investigations in this task will be repeated when new first-stage material is available in the second year. 


\subsection{Task E: Determination of Reactivity of Stable Latexes of Low-Rank Coals to Reducing and Oxidizing Reagents}

\subsubsection{Particle Sizes}

The conversion of coals into oils, solutions, or dispersions is of great interest in the production of new liquid fuels. Further investigations of the stability and reactivity of the hydrosols or latexes prepared by blending coals with sodium hydroxide were carried out in this quarter.

Although much of the coal latexes prepared from low-rank coals passed through a 0.45 micron filter, further verification of the colloidal nature of the dispersions was desired. The submicron sizes are beyond the lower limit ( 1 micron) for resistazone coulter counting. Intense scattering of laser light by the dispersion was observed previously (Tyndall effect); however, light scintillations were too intermittent, and an extremely noisy output was obtained in the KMX-6 low-angle laser light scattering photometer. Thus the intensity of light could not be measured. Nevertheless, dynamic light scattering at higher angles could be used to determine particle diffusion coefficients and particle size distributions in the range 0.003 to 3 microns which would be appropriate, for the coal latexes. Two samples were submitted for particle size analysis using a Malvern photon correlation spectroscopy system. High resolution data were obtained at a scattering angle of $45^{\circ}$. The latex prepared from Beulah lignite with air injection into the blender had a 2 -average mean size of $415 \mathrm{~nm}$ with a bimodal distribution over the range 250 to $1300 \mathrm{~nm}$ (Figure 9) Figure 10 shows the mass distribution curve for the latex particles and the bimodal aspect is more evident.

The latex prepared under the nitrogen atmosphere had a similar bimodal. distribution ( $Z$-average size $=410 \mathrm{~nm})$. The bimodal distribution is an interesting feature and may be related to the maceral content of the coal.

\subsubsection{Stabilization of Low-Rank Coal Latexes with Amine Acids}

The stabilization and destabilization of colloidal suspensions are important factors in the utilization of coal material as a fuel. Our previous research demonstrated that the latexes were generally unstable at low $\mathrm{pH}$, because of the neutralization of the negative charges of the carboxylate and phenolate anions of the colloidal particles by converting them to the carboxylic acid and phenol forms. Collapse of the electric double layer then leads to coagulation of the particles. Although results were variable, it was usually difficult to keep humic acid material from coals in suspension at a pH of 7 . On the other hand, the humate material produced by fungal cultures on leonardite was reported to to form a stable suspension at this $\mathrm{pH}$. The increased suspendability could not be attributed to a smaller molecular weight macromolecule, since in fact the molecular weight was still large. Since these fungal preparation contained large amounts of nitrogen, a hypothesis could be advanced that the stabilization is due to conversion from an electrostatic mechanism to a steric mechanism as a result of particles bonding to amino acids derived from the fungi. 


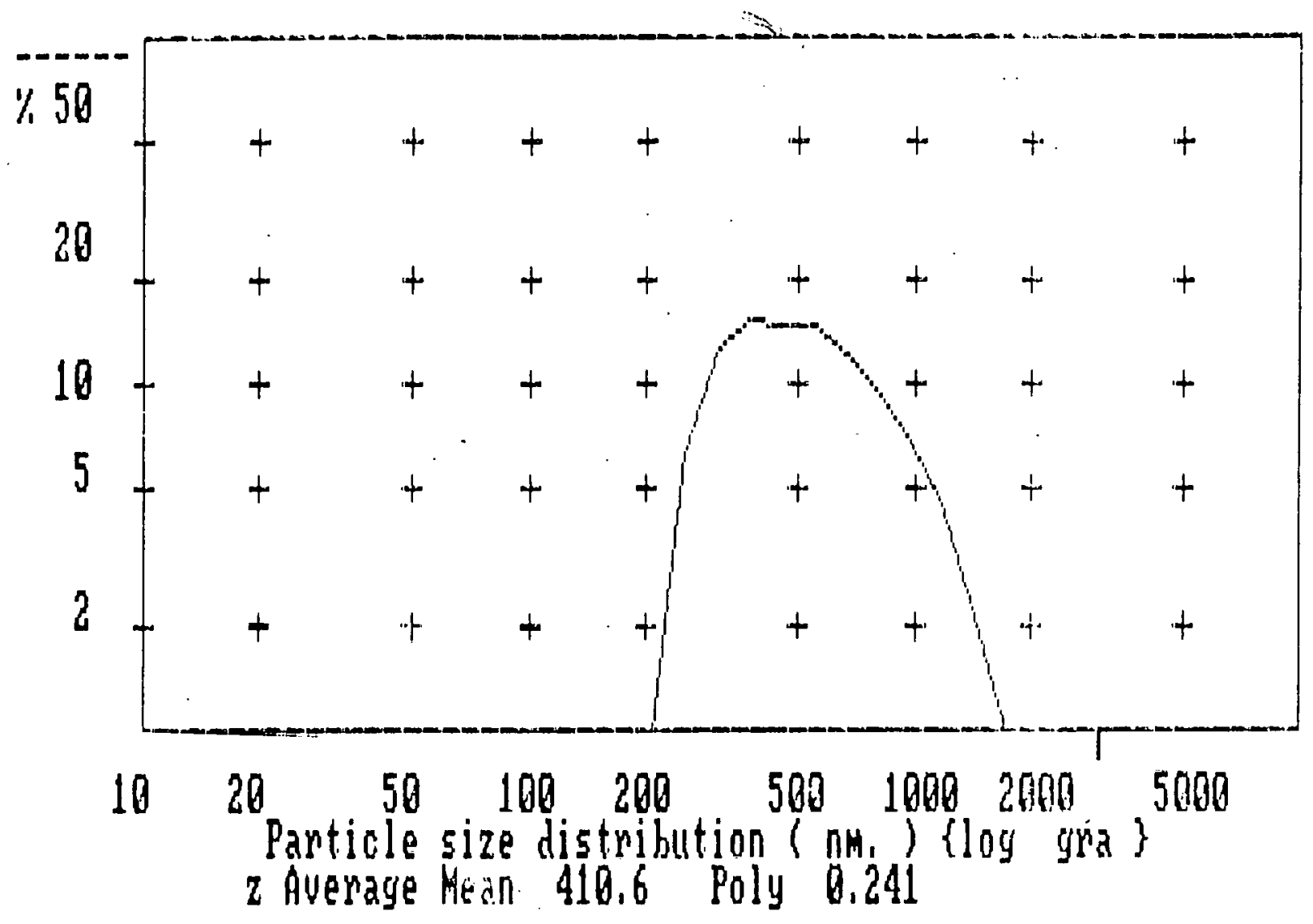

Figure 9. Particle size distribution by intensity for Beulah latex.

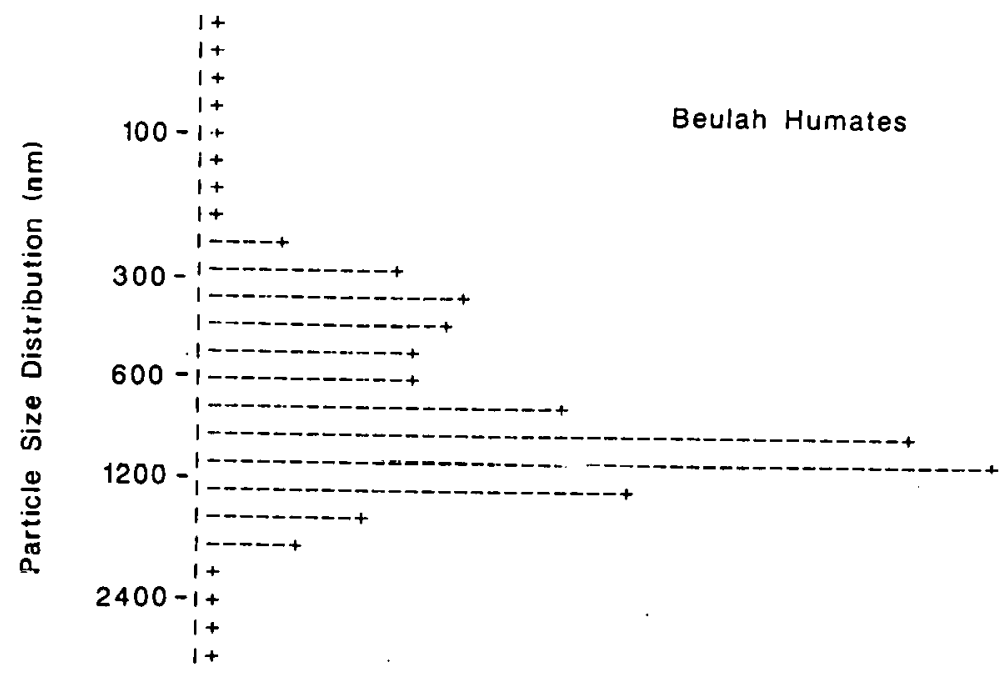

Figure 10. Particle size distribution by mass for Beulah latex. 
A latex sample, which was produced by blending with air injection, was precipitated with acid, and the humic acid titrated with the amino acid lysine to a $\mathrm{pH}$ of 7 . The resulting suspension was centrifuged and was found to give no precipitate. Thus the ability of amino acids to stabilize the submicron coal particles was demonstrated. A further experiment with glycine also gave a stable suspension.

\section{4 .2 Conversion of Peat to a Colloidal Dispersion}

In order to complete a study of the effect of coal type on the conversion to the latex form, a bituminous coal (Pittsburgh) and a peat were investigated. The bituminous coal gave no latex, only nonsuspendable residue $A$ sample of Hemic peat ( $87 \%$ moisture) was blended with sodium hydroxide to give a small amount of insoluble residue (19\% on a moisture-free basis) and a latex which gave a yield of $45 \%$ ( $m f$ basis) humic acids on addition of acid. The remaining $36 \%$ of unrecovered material is probably the soluble fulvic acids and soluble mineral matter. The blending process thus represents a way to convert peat to a low-ash fuel (see discussion below on ash content).

\subsubsection{Ash and Sulfur Content of the coal Latex Particles}

The utilization of blended coal a fuel depends on the effectiveness with which mineral matter can be removed. The cost of the the blending process must be offset by the extra value of a super-clean fuel with less than $1 \%$ ash and low sulfur. Existing mineral matter reduction processes are directed at removing discrete minerals which often occur in discrete bands or partings in coal or material inadvertently included during mining. The principles for separation of clean coal from discrete mineral matter are simple and based primarily on differences between coal and mineral surface properties of specific gravities. Removal of a major portion of the finely divided minerals, interspersed in the coal physical structure, requires processing to ultrafine size so that the minerals can be removed. This can be accomplished by the blending process rather than grinding.

Ash analysis was completed on samples of the residues and the recovered humic acids from three coals, Beulah, Big Brown, and Wyodak, and Hemic peat (Table 4). The mineral contents of the recovered humic acid from the Beulah lignite and the Hemic peat result in about $1 \%$ ash, whereas the ash produced by the Big Brown and Wyodak appear to be quite large. The reason could be incorporation of sodium during the precipitation which is not easily washed out of the precipitated humic acids from these coals. All the residues gave high ash values.

Sulfur analyses of the precipitated humic acids and the residues demonstrate that sulfur contents of both the product humic acids and the residues are lower than that in the starting coal (Table 5). A especially low value was found for the Wyodak humic acid. Whether the sulfur removed is organic or inorganic is not yet known and thus the mechanism for sulfur removal is also unknown. 
TABLE 4

ASH ANALYSES OF BLENDER PRODUCTS (WT\%, MOISTURE FREE)

\begin{tabular}{lccc} 
& Residue & Humic_Acid & eriginal \\
Beulah & 19 & 0.83 & 8.4 \\
Big Brown & 30 & 8 & 13 \\
Wyodak & 20 & 13 & 8.2 \\
Hemic Peat & 17 & 1 & 7 \\
\hline
\end{tabular}

TABLE 5

SULFUR ANALYSES OF BLENDER PRODUCTS (WT\% MAF)

\begin{tabular}{lccc}
\hline & Residue & Humic Acid & Original \\
Beulah & 0.73 & 0.75 & 1.3 \\
Big Brown & 0.73 & 0.58 & 1.2 \\
Wyodak & 0.51 & 0.06 & 0.7 \\
\hline
\end{tabular}

\subsubsection{Liquefaction of Big Brown Lignite Latex}

The reactivity of the colloidal form of coals in reductive thermal processing (Iiquefaction) offers an alternative method for conversion of coals to a liquid fuel. A large surface area of coal is exposed to the reducing agent during the heating and the capping of radicals formed during thermal cleavage of bridging groups between clusters might be expected to occur more readily than in larger particles of coal, where access of the reducing reagent may be sterically hindered or diffusion iimited. The Big Brown latex was heated in a stirred autoclave with carbon monoxide $(1000 \mathrm{psi})$ at $300^{\circ} \mathrm{C}$. After cooling and release of pressure, the suspension was centrifuged to separate the solid product that had come out of the suspension. The solubilities of the product in methylene chloride, tetrahydrofuran, and sodium hydroxide were determined. The solid product was insoluble in all reagents. An infrared spectrum of this product indicated only a small decrease in carboxylic acid groups had occurred. The aqueous phase contained a small amount of phenols with a distribution normally found in pyrolysis. 
The major conclusion of the experiment was that very little conversion to a liquid occurred and that this product was mainly phenols. Similar solid and phenolic products have been found for particulate lignite under these conditions, and the hypothesis is that at this low heating temperature the coal actually becomes more highly cross-linked. Thus particles are covalently joined together and no longer are able to form the colloidal suspension, even though carboxylic acid groups are present which could still generate an electric double layer. The $\mathrm{pH}$ dropped in the experiment, because of sodium formate formation from the $\mathrm{CO}$ and NAOH. This might have contributed to collapse of the double layer and coagulation which became irreversible on formation cross-linking bonds. The experiment will be repeated once with Beulah lignite and less carbon monoxide, so that the $\mathrm{pH}$ does not drop. Numerous other experiments could be conceived using added organic and hydrogen donor solvents along with surfactants; however, this work was not proposed in the work plan for 1987.

\subsection{REFERENCES}

1. Colby, R.N. and McCaman, M.W. Biomed. Mass. Spectrom. (1978) 6, 225-30.

2. Schoeller, D.A. J. Clin. Pharmacol. (1986) 26, 396-9.

3. Jonckheere, J.A., De Leenheer, A.P. and Steyaert, H.L. Anal. Chem. (1983) $55,153-5$.

4. Olson, E.S., Dieh1, J.W. and Froehlich, M.L. Fuel Proc. Tech. (1987) 15, $319-326$.

5. Olson, E.S., Diehl, J.W. and Froehlich, M.L. Fuel (1987) In press.

6. Kaye, W. and McDaniel, J.B. Appl. Opt. (1974) 13, 1934-7.

7. Geiduschek, E.P. J. Polymer Sci. (1954) 13, 408-10. 
Page _ o of -

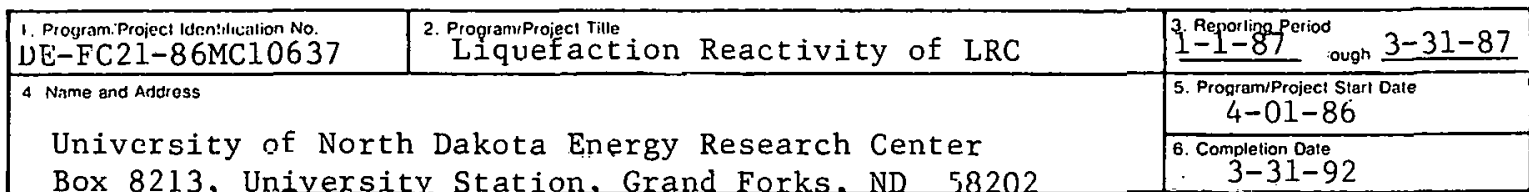
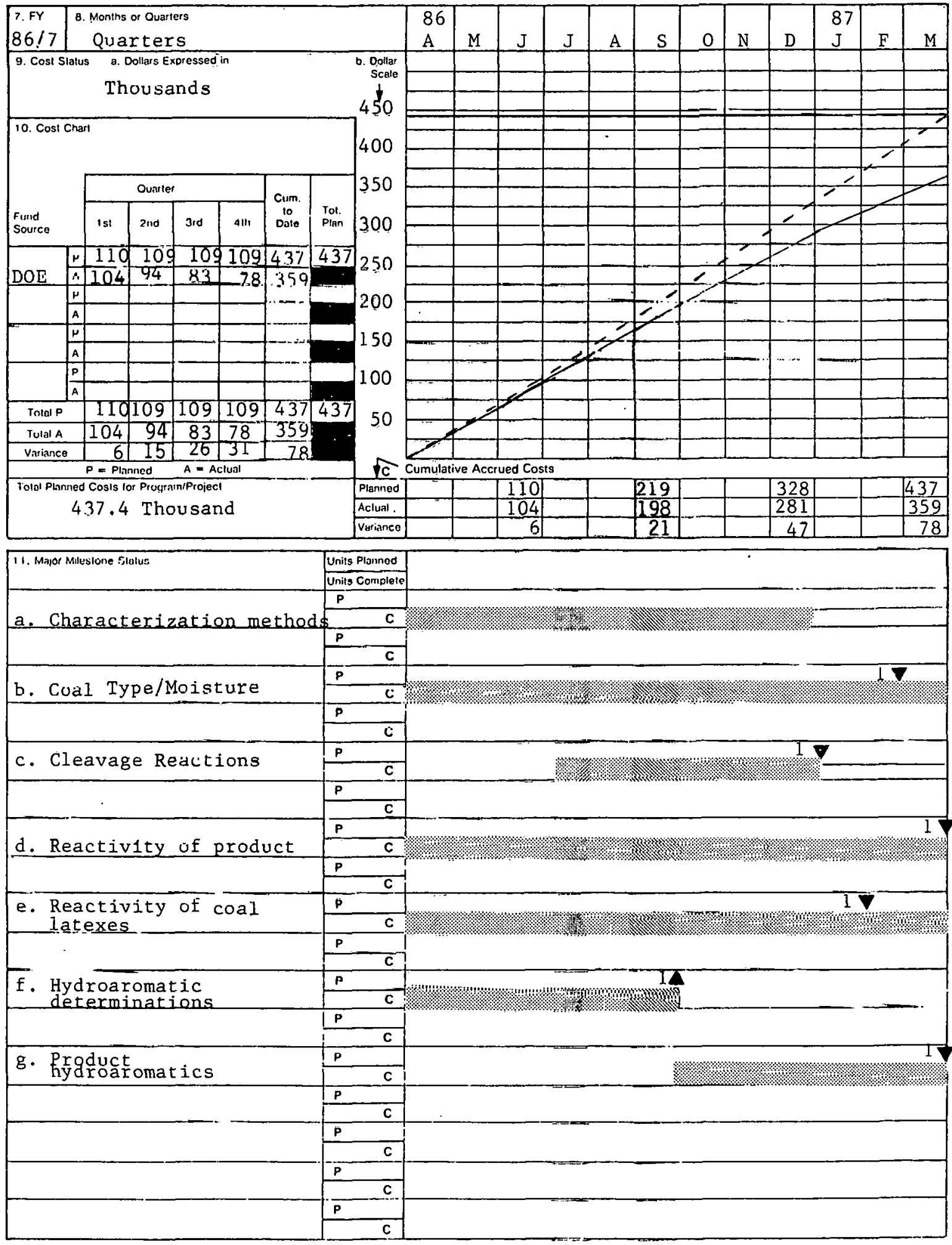


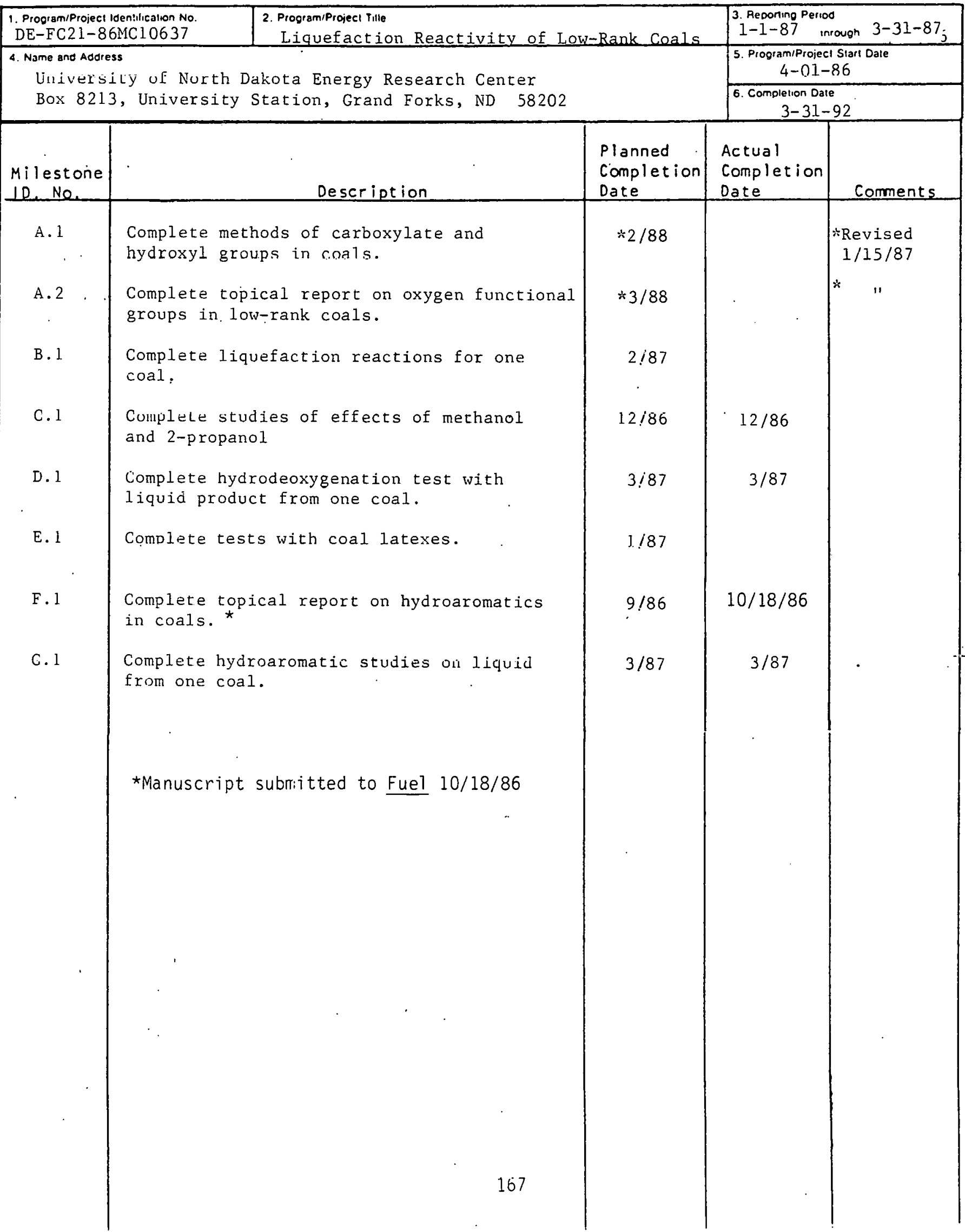




\section{THIS PAGE}

\section{WAS INTENTIONALLY}

LEFT BLANK 


\section{ASH AND SLAG CHARACTERIZATION}

Final Technical Report for the Period April 1, 1986 - to March 31, 1987 including the Quarterly Technical Progress. Report for the Period January through March 1987

Principal Investigator: Sharon K. Falcone

Work Performed Under Cooperative Agreement No. DE-FC21-85MC10637

For

U.S. Department of Energy

office of Fossil Energy

Morgantown Energy Technology Center

Morgantown, West Virginia

By

University of North Dakota

Energy Research Center

Grand Forks, North Dakota 
The formation, physical properties and behavior of ash in coal gasification systems can have a major impact on the design and subsequent operation of the systems. Indeed, the behavior of the ash has to be considered in order to decide whether a given coal is suitable for utilization in a given system. The overall objective of the program is to obtain laboratory and bench-scale data on the formation, flow, and sticking behavior of coal ash and slag under gasification conditions. The eventual outcome will be a unified picture of the behavior of inorganic species within the gasifier. This will include a set of models with which the behavior of an ash can be successfully predicted. The unified picture will be invaluable to the designers and gasifier operators in assessing a coal for utilization in gasification systems.

In order to accomplish the objective of this program, specific goals were set. These were: the determination of mineralogical and composition changes of ashes and synthetic mixtures under reducing conditions, study of the volat1lization of organically associated inorganics, the determination of the viscosity of ash melts and synthetic mineral mixtures on various refractory substrates. An associated goal was the establishment of an extensive data base of the data obtained from this study and other sources.

The coals studied were: Beulah high sodium lignite, Gascoyne Blue lignite, Gascoyne Red lignite, Velva lignite, Wyodak subbituminous, Indian Head lignite, Martin Lake lignite, Pittsburgh No. 8 bituminous. The Velva, Wyodak, Indian Head, Martin Lake, and Pittsburgh No. 8 coals were chosen for detailed study as these coals are to be tested in a pilot-scale fluidized bed gasifier at UNDERC under a separate program sponsored by METC. It is planned that the data obtained from the laboratory-scale study of these coals can be compared to the results obtained from the characterization of the bed material and associated agglomerates from the pilot-scale data. This will show the significance of laboratory-scale data and derived models to the industrial process.

The Wyodak, Velva, Indian Head, Martin Lake, and Pittsburgh No. 8 coals were ashed under air and reducing conditions at $1000^{\circ} \mathrm{C}$. This data was used to establish what chemical and mineralogical changes occur in the samples during ashing for each coal. A computer program called solGASMIX was used to evaluate the effects of temperature, pressure, and oxygen concentration on the relative amount of sodium phases for the Indian Head and Gascoyne White samples. The program is based on the method of themochemical daca and can be used to predict the relative amount of solid, liquid and gaseous phases. It is planned to use this program extensively to evaluate the species that should be present in a gasifier under equilibrium conditions.

A bench-scale pyrolysis reactor was used to prepare chars from Indian Head, Velva, and Martin Lake lignites. The chars will be used to lowtemperature ashed and subjected to chemical composition analysis and crystalline phase analysis. The data will show what effect pyrolysis has on the mineralogical and chemical composition. This is important as the initial reaction in a gasification process is pyrolysis and therefore changes that occur during this process can have a direct effect on the formation and behavior of ash. 
The viscosity of a series of slags was determined under reducing atmosphere. The starting material for the viscosity runs were ashes produced under reducing and oxidizing conditions. This was to enable the effects of ashing method on the flow properties of slags to be evaluated. This is important as most slag viscosity studies use normal oxidized ash. It is a major premise of this project that the preparation of the ash can have a marked influence on the chemical and mineralogical composition of the ash. This will in turn affect the physical properties of ash and slag in laboratory-scale experiments. Furthermore, the data should be more applicable to ash behavior in gasifiers than that derived from the use of oxidized ash.

A computer data base of viscosity has been established. The data includes over 300 chemical compositions with viscosity ranging from 1 to $10^{10}$ poise $\left(10^{-1}\right.$ to $\left.10^{9} \mathrm{Pas}\right)$ over a temperature range $900-1600^{\circ} \mathrm{C}$. The data base includes all the pertinent data on the experimental technique, such as measurement device, cooling rate, type of analysis. The temperature of critical viscosity, where measured, was also included. All types of U.S. coal ashes as well as Australian and British coal ashes have been included in the data base. A unique feature is the inclusion of viscosity/temperature data for simple oxide systems. The extensive data base will provide a solid base from which an accurate model of the flow properties of slags or partially molten ash can be developed.

Two predictive viscosity equations have been evaluated. These are the Urbain and modified Urbain. The latter was developed at UNDERC for low-rank coal ash in slagging gasifiers. A total of 31 coal slags (lignites, subbituminous, and bituminous) were used in the evaluation. The results show that the Urbain equation gives a better fit, generally, to the experimental data than the modified equation.

An important aspect of this project is to relate the results and understanding obtained on the laboratory investigation of ash to that observed in pilot-scale and full-scale gasification systems. The Lurgi gasifiers at the Great Plains Gasification Project has a recurring problem with excessive clinkering of ash. A sample of non-agglomerated ash and clinker were collected and analyzed at UNDERC. The chemical composition and crystalline phases present in the two samples were quite different indicating a difference in the composition of the coal ash. Calculation of the viscosity of the two ashes using the Urbain equation showed that, at a given temperature, the clinker had a much lower viscosity than the non-agglomerating ash. The lower viscosity would result in a relatively higher degree of sintering to occur in the clinker sample. The observations could be directly attributed to the higher calcium oxide content of the clinker which was due to high calcite levels in the coal.

The effect of composition variation on the temperature of critical viscosity $\left(T_{C V}\right)$ has been studied. The $T_{C V}$ is important as it represents the lower temperature 1 imit of the Newtonian flow regime. Therefore, $T_{c v}$ can bo taken as the lower operation temperature for slagging gasifiers. The results show that increase in $\mathrm{CaO}$ tends to reduce the $\mathrm{T}_{\mathrm{Cv}}$ whereas increase in total silica content increases the value of $\mathrm{T}_{\mathrm{Cv}}$. 
A major physical property of molten coal ash is its ability to stick to a surface. In slagging systems it is necessary for the newly formed ash particles to stick to the slag. This sticking behavior can play a major role in ash agglomerating processes. Also, as the metal walls of the gasifiers are protected by refractory it is important that the molten ash does not stick and attack the refractory. The ability of a liquid phase to stick to a surface is due to surface tension. The surface tension of twenty-two slags were measured under reducing, oxidizing, and inert atmospheres using the sessile drop method. The surface tension was measured on vitreous carbon. The results show that, in general, the surface tension of a slag is greater in a reducing or inert atmosphere than in an oxidizing atmosphere.

As part of the approach to develop a more unified picture of ash behavior in gasification systems an initial evaluation of the relation of surface tension to slag composition and viscosity was made. This evaluation was based on the Raask model of ash sintering and used data from ash fouling tests at UNDERC. It was found that viscosity was more sensitive to compositional parameters than the surface tenslon. However, the ratin of surface tension to viscosicy (calculated at the same temperature at which the surface tension was measured) gave a reasonable indication of agglomerating potent1al. The lover the value of the ratio, the lower the eintering/agglomerating potential. 


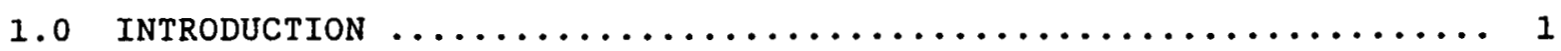

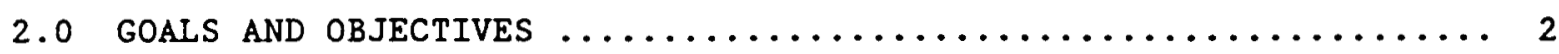

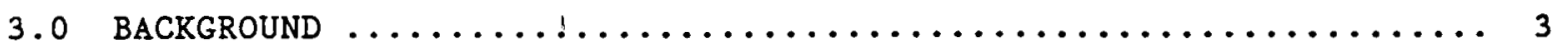

3.1 TASK A - MINERAL TRANSFORMATION STUDIES $\ldots \ldots \ldots \ldots \ldots \ldots \ldots \ldots$

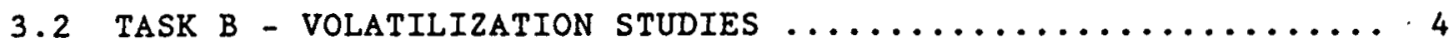

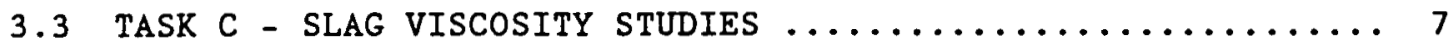

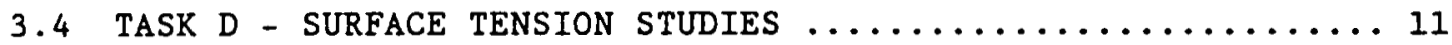

3.5 INTERELATIONSHIP BETWEEN VISCOSITY AND SURFACE TENSION $\ldots \ldots 11$

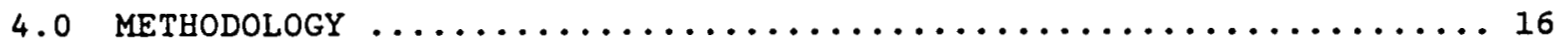

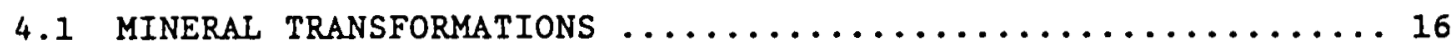

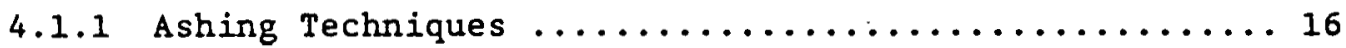

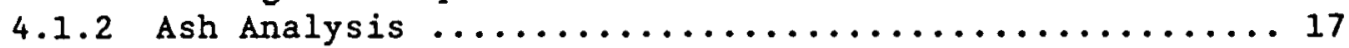

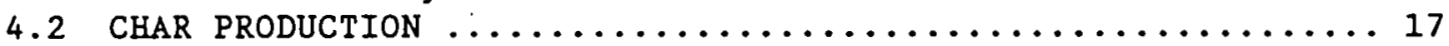

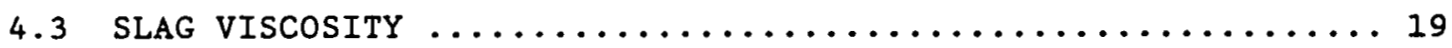

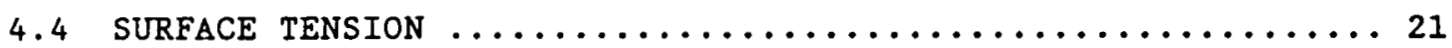

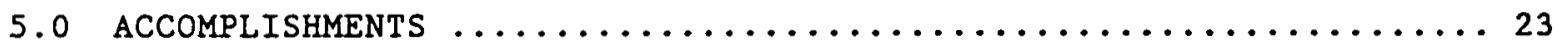

5.1 ASHING OF COAL UNDER REDUCING CONDITIONS - COMPARISON OF LAB ASHES GENERATED UNDER OXIDIZING VERSUS REDUCING ATMOSPHERES. . 23

5.2 VAPORIZATION OF INORGANICS DURING THE GASIFICATION PROCESS $\ldots 24$

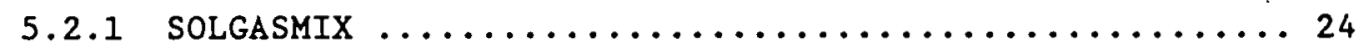

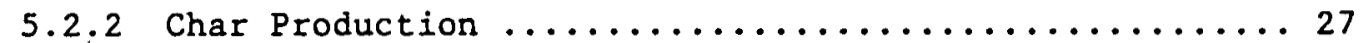

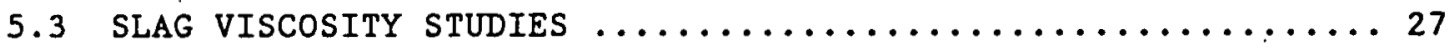

5.3 .1 Preparation of Coal Ash Viscosity Data Base ........ 32

5.3 .2 Evaluation of Predictive Viscosity Equations ........ 34

5.3.3 Viscosity Study of Commercially-Generated Agglomerated Versus Non-Agglomerated Ash Samples (Great Plains

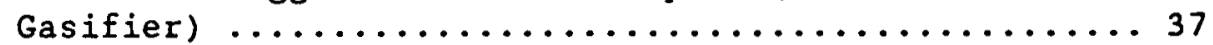

5.3.4 Effect of Slag Composition on the Critical Viscosity

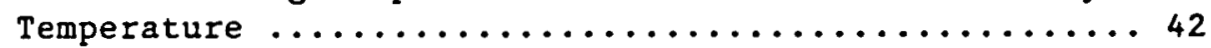

5.3 .5 The Effect of Atmosphere on Viscosity .......... 43

5.4 SLAG SURFACE TENSION STUDIES $\ldots \ldots \ldots \ldots \ldots \ldots \ldots \ldots \ldots \ldots \ldots \ldots . \ldots 4$

5.4.1 The Effect of Atmosphere on the Surfact Tension of slags ............................... 44

5.4.2 Relation of Surface Tension to Slag Composition and

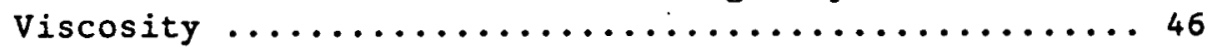

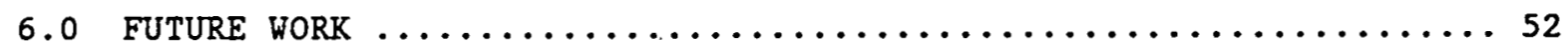

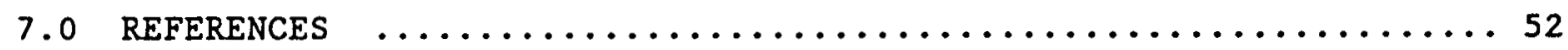


THIS PAGE

\section{WAS INTENTIONALLY \\ LEFT BLANK}




\section{GASIFICATION ASH AND SLAG CHARACTERIZATION}

\subsection{INTRODOCTION}

Gasification processes may be either of the slagging type where operating temperatures are sufficiently high to allow removal of the coal ash as a liquid slag or of the dry-ash (nonslagging) type where operating temperatures are maintained below the fusion temperature of the ash. Whichever type of gasification process is used, the reactivity and caking properties of the coal and the properties of the coal ash and slag are major concerns. In fact, properties of the coal ash may determine whether a coal is suited for any specific dry ash or slagging process. For a wet or dry bottom system to be efficient the behavior and composition of the ash as it goes through the gasification process should be understood. While large-scale trials are expensive it would be advantageous to be able to predict the behavior of ash and slag from an understanding of the processes operating on the inorganic components of the coal. The inorganic constituents in the coal are altered during gasification resulting in specific high-temperature ash and slag compositions and behavior thereby affecting gasification operation and design. Therefore, the use of laboratory and pilot-scale testing simulating gasification conditions for fundamental research is desirable.

The inorganic components of low-rank coal occur as 1) organically-bound cations associated with carboxyl groups, 2) as coordinated complexes and 3) discreet mineral matter.

The most important benefit of this research is the development of a unified picture of coal chemical and mineralogical changes occurring during gasification and of the effect of those changes in determining the composition and fluid properties of the resulting slags. The development of this unified picture will serve to bring together previously unrelated empirical observations and will provide interpretation of those observations. These seemingly disconnected empirical observations must have common explanations which have not yet been developed or, in some cases, not even sought. The overall objective of this work, and the most important benefit to be derived from it, will be a unified understanding of the behavior of inorganics and minerals in gasification systems which on the one hand interprets previously unrelated observations and on the other hand provides equipment designers and engineers with predictive tools for design applications.

A secondary benefit of this research is the establishment of an enlarged data base on ash composition and mineralogy and slag composition, viscosity and surface tension for a suite of carefully characterized coals of all ranks under reducing as well as oxidizing conditions. This data base will allow any future researcher interested in developing his own interpretive methods or needing data to test models to track ash and slag composition and mineralogy and the viscosity or surface tension behavior as a function of composition for the same materials in the melt phase. One cohesive data base collected from a suite of well-characterized coals will be of far mcre value than a large number of disjointed observations on a more or less haphazard array of coals. 
The most unique feature of this project which distinguishes it from previous and, in some cases, current projects is the preparation of ash under both reducing and oxidizing conditions with and without steam for use in the study of mineral transformations, slag viscosity and slag wetting behavior.

\subsection{GOALS AND OBJECTIVES}

The goal of this project is to identify the mechanisms of formation of specific ash and slag compositional components under coal gasification conditions. Of particular concern are the influences of certain coupositional parameters on the physical properties (i.e., viscosity and surface tension) of the molten phase. The specific mechanisms of interest which alter the inorganic phases are those which relate to slagging and agglomeration processes seen in wet- and dry-bottom gasifiers. The project will also identify the form of specific inorganic coal components within the gasification environment as solid, liquid, or gas phases and their influelle on gasification rates. Sperific arcas to be invrsigaced include: (1) the mechanisms operating on the inorganic portion of the coal resulting in mineral transformations at high temperatures. (2) the nature of the volatile inorganic species released from coal char versus ash under gasification conditions, and (3) the relation of slag composition to viscosity and surface tension. In addition this information shall be compiled along with currently, available coal ash and slag compositional and viscosity data to support modeling studies of predictive equations.

The three year objectives for this project are broken down into four areas of study. Task A deals with the characterization and identification of mechanisms responsible for mineral transformation during the gasification of low-rank coals. This work will initially involve generating ash and slag samples in bench-scale and pilot scale units simulating gasification environments. In addition to studying the mineral transformation of coal samples, model mixture studies simulating coal mineralogy will be conducted to isolate specific component systems. These samples will be ueed in Tasks $C$ and $D$ for slag studies. Comparisons of results will be made to ashes and slags produced in uxidizing environments.

Task $B$ involves studying the vaporization of inorganics during the gasification process. This task wil include theoretical phase diagraw work using a computer simulation of solid-gas phase equilibria in high temperature systems. The SOLGASMIX database developed at Pennsylvania State University will be expanded to include inorganic species of interest to this cpecific project. By establishing a thermodynamic basis for specific chemical species behavior in the program, different inorganic volatiles of interest can be studied under specific atmospheric conditions. Experimental work will involve coal char and ash samples used in Taok A to nute differences in the release of alkalies during the gasification process due to the difference in interactions of ash and fixed carbon on alkali vaporization. 
Task $C$ evaluates slag viscosity behavior under reducing and oxidizing conditions as related to gasifier operation. This task includes the study of compositional and behavioral properties of slag produced from reduced coal ash and the development of predictive viscosity equation. Viscosity studies will be conducted under reducing and oxidizing atmospheres. The effects of steam addition on the viscosity of the slag under reducing conditions will also be investigated. Studies will concentrate on mathematically defining (as a function of slag composition) the Newtonian flow region and the critical temperature at which flow behavior changes from Newtonian to Non-Newtonian. Different additive studies and model mixture studies will be performed to understand what specific compositional parameters affect the shape and temperature profile of the viscosity curve. These studies will concentrate on those inorganic compounds common to low- and high-rank coals. In each case, comparisons of viscosity data obtained using oxidized coal ash under reducing conditions will be made to evaluate their appropriate application to gasifier operation. This task also includes the compilation of existing slag and glass compositions and viscosity data base for the statistical support of experimental data generated in this study.

Task $D$ deals with slag surface tension properties. This study will evaluate the surface tension of slags on inert substrates under reducing and oxidizing atmospheres and investigate the effects of steam. The techniques employed will involve optically observing the wetting behavior of slags.

The project objectives as stated are in direct support of and complement concurrent gasification research as summarized at the Sixth Annual Gasification Project Contractors Meeting. Specific areas of research projects supported by this project include the behavior and role of mineral matter in determining deposition on gasification surfaces, ash agglomeration and slag removal. Current research in the related fossil energy programs concentrate on the effect of coal mineral matter variation on the behavior of ash in fluidized-bed gasification and the reaction rates of specific minerals as a function of temperature, pressure, and gas composition. The tasks as outlined in this project are to provide a unified study in mineral transformations, ash volatilization, slag viscosity and surface tension as related to ash and slag chemical and mineralogical compositions under gasifier conditions. The specific areas of operational problems to benefit from this research include slag flow maintenanse, ash agglomeration, and the nature of volatiles deposited on turbine surfaces. The tasks relating slag composition to slag viscosity and surface tension, specifically the development of predictive viscosity equations, are unique to this project. Results from this project and other Fossil Energy projects will serve as a guide for evaluating coals for gasifier use and new directions in gasification technology.

\subsection{BACKGROUND}

The initial part of this project is to generate high-temperature ashes under oxidizing and reducing conditions for mineral transformation studies and subsequent studies on slag viscosity, surface tension, and composition of slag generated under reducing and oxidizing atmospheres. 


\subsection{TASK A - MINERAL TRANSFOREATION STUDIES}

In the past, mineralogical determinations in combustion and gasification studies used ASTM ash formed at the standard temperature of $750^{\circ} \mathrm{C}$ under oxidizing conditions. Minerals identified were often not originally present in the raw coal but were artifacts of the ashing procedure. This was due to the alteration of minerals by oxidation, dehydration and other processes at high temperatures. Often the mineral assemblages identified in the ASTM ash were believed to reflect the original coal inorganic and ash content. This approach is particularly inappropriate in regard to low-rank coals in which highly reactive alkali species are released during decarboxylation and react with other inorganic components of the coal or are volatilized and carried out of the system. In addition, lignitic coals are generally high in clay minerals (e.g. kaolinite, smectites, and illite) which undergo dehydration at approximately $400-500^{\circ} \mathrm{C}$. Some lignites as well as bituminous coals are also high in pyrite, which oxidizes to hematite at approximately $500^{\circ} \mathrm{C}$ releasing sulfur into the system. Under reducing conditions, pyrite is not oxidized but retains its sulfur. Since all these reactions occur by the time the ash reaches $750^{\circ} \mathrm{C}$ it is almost impossible to rely soley on ASTM ash mineralogical and bulk chemical analyses to accurately reflect the original coal mineralogy and subsequent high temperature transformations. The problem is to determine the best ashing technique by which the coal minerals are retained in their original condition. The reason for this is that it is necessary to accurately identify the original coal minerals to track their transformations up to $1000^{\circ} \mathrm{C}$ under oxidizing as well as reducing conditions.

Recent studies by Miller et al. (1), Frazer and Belcher (2), and O'Gorman and Walker ( 3 ) concentrated on relating raw coal mineralogy to mineralogy of ash generated at low temperatures.' The technique used involves lowtemperature ashing of coal at approximately $150^{\circ} \mathrm{C}$ using an oxygen plasma generated by a radio frequency generator. Low-temperature ashing (LTA) theoretically would enable one to obtain the true mineralogical composition of a coal since little mineral alteration occurs at typical LTA temperatures of $150^{\circ} \mathrm{C}$.

Mitchell and Gluskoter (4) expanded this concept to study low to high temperature mineral transformation in ash of subbituminous and bituminous cuals. The purpose of theif study was to erplne the relatione betgecn coal minerals and ash formed in the temperature range from $400^{\circ}$ to $1400^{\circ} \mathrm{C}$. They demonstrated that there exists a rough correlation between the mineralogy of the low-temperature ash and the chemical composition of the coal. However, in the case of lignite there is often great discrepancy between the mineralogy of the low-temperature ash and the bulk chemical composition of the coal. often significant amounts of the major alkali elements are unaccounted for by the mineral matter but are present as organically-bound cations.

\subsection{TASK B - VOLATILIZATION STUDIES}

In addition to the study of the ash components of low-rank coals, the identification of volatile species released from the char and uleimately the ash during the gasification process is important. The coal ash or slags formed during gasification processes are varied in composition due to the variety of coals used, the interaction of inorganic species and partial volatilization of inorganic species. 
Therefore, as the temperature of the coal increases, the composition of the ash is undergoing change. Any type of reaction that occurs, be it an internal reaction completely within the char, ash, or slag mass or a reaction that involves loss of gases or vapors from the slag mass, results in a change of composition of the ash or slag and a resultant change in its physical characteristics, specifically viscosity and surface tension.

Heating of the ash will ultimately involve the loss of specific chemical components through volatilization or vaporization which could lead to problems in a gasification reactor such as alkali atack of refractory. Another potential problem area can be the vaporization of ash components and exiting of these vaporized components with the product gas stream where they would ultimately appear in the wastewater stream.

The Year 1 work concerned with the vaporization of inorganics is more theoretical in nature. The nature of different species at various temperatures, pressures, and atmospheres can be calculated based on thermochemical equilibria data. A number of methods have been used to calculate complex thermochemical equilibria and are based on those of Brinkley $(5,6)$ or White et al. (7). The approach used by Brinkley requires the formulation of independent chemical reactions and the simultaneous solution of equilibrium constant expressions. White et. al. (7) suggested a better approach involving the computation of the composition that minimizes the free energy of the system.

Computer programs have been developed to calculate complex phase equilibria by free energy minimization. Eriksson $(8,9)$ and Eriksson and Rosen (10) have made a significant contribution by developing programs called SOLGAS and SOLGASMIX. These programs are capable of handling systems containing multiple condensed phases, ideal and nonideal solutions, and mixtures at constant total pressure and temperature. Liao and Spear (1I) have adapted this program for use with an IBM-PC computer.

The basic equations used to make the equilibrium calculations are based on free energy minimization (9). The total free energy of the system, $G$, can be expressed by the following equation:

$$
G=\sum_{i} n_{i} \mu_{i}=\sum_{i} n_{i}\left(\mu_{i}^{u}+\operatorname{RTIna} a_{i}\right)
$$

where $\mathrm{n}$ is the amount of a substance, $\mu$ is its chemical potential, $\mu^{\circ}$ is its standard chemical potential, $a$ is the activity, $R$ is the gas constant and $T$ is the temperature in kelvins. In high temperature systems, chemical species appear in gaseous solution phases, in liquid and solid solutions, and as pure condensed phases. The above equation is rewritten to include each phase type. The free energy is minimized in accord with mass balance constraints. These procedures are explained in detail by Eriksson and Rosen (10). The equilibrium composition is obtained through a series of iterations where the set of $n$ values are determined which minimize the total free energy of the system. The procedure uses the first approximated n-values to calculate 
improved n-values which are used in subsequent iterations. This method is possible when the set of phases chosen are consistent with the equilibrium phases. When condensed phases are considered they must exist together in accord with Gibbs phase rule. The basis for equilibrium diagrams is the Gibbs phase rule which is the interrelation between the number of phases $P$, and the degrees of freedom $F(p, T, x)$, to the number of components $c$.

$$
F=C-P+2
$$

In addition, if the quantity of a substance drops below $10^{-10}$ moles during the iteration process the substance is deleted in order to increase the rate of convergence. After the mixture (gases, liquids, and solid solutions) that minimizes the free energy of the system has been determined additional tests are applied for the condensed phases of invariant stoichiometry. If the test indicates that the phase in question must be included, the composition of the liquid and solid mixtures, is redetermined and then the final equilibrium phases are found.

The total free energy of the system is determined by specifying the values of $\mu \% / R T$ for all species being considered in Equation 1 . The quantity $\mu^{\circ} / R T$ is calculated using either of two methods:

$$
\text { a) }(\mu / R T)=\Delta G_{f}^{0} / R T
$$

where $\Delta G_{f}^{0}$ can be expressed as a function of temperature as follows:

$$
\Delta G_{f}^{0}=a / T+b+c T+d T+e T+f T I n T
$$

which is the Gibbs free energy of formation, or

$$
\text { b) }\left({ }_{\mu}^{\circ} / \mathrm{RT}\right)=1 / \mathrm{R} \quad\left[\left(\mathrm{G}^{\circ}-\mathrm{H}_{298}^{\circ}\right) / \mathrm{T}\right]+\Delta \mathrm{E}_{f, 298} / \mathrm{RT}
$$

where $\left[\left(G^{\circ}-H_{298}^{\circ}\right) / T\right]$ is the free energy function and $\Delta H_{f, 2.98}$ is the heat of formation at $2980_{\mathrm{K}}$. Either of these methods provides the same results for the equilibrium calculations.

The data base is the most important part of the calculation. care and accuracy are essential in obtaining the correct and most reliable data. Thermochemical data can be found in a number of sources including JANAF (12), Robie et al. (13), Barin and Knacke (14), Rein and Cipman (15) and Kelly (16). A major limitation in the accuracy of determining equilibrium composition is the uncertainties in thermochemical data. 
Data bases for SOLGASMIX were set up using thermochemical data from the JANAF Tables (12). Two data sets were compiled and used in understanding the behavior of gas, liquid, and solid phases during the combustion of coal under equilibrium conditions. The first data base compiled was similar to those examined by Wibberley and Wall (18) and Carling et al. (19) which concentrated on the interactions of $\mathrm{Na}, \mathrm{Si}$, and $\mathrm{S}$ with $\mathrm{C}, \mathrm{H}, \mathrm{N}$, and $\mathrm{O}$. This data base was used to examine the partitioning of $\mathrm{Na}$. between $\mathrm{Si}$ and $\mathrm{S}$ as a function of temperature and oxygen partial pressure. In addition, it was used to test the SOLGASMIX program used in a microcomputer in comparison to that of larger computing systems.

All of the thermodynamic data was taken from the JANAF Tables (12) at $1400 \mathrm{~K}$ which is in the middle of the temperature range of interest (20). The Gibbs free energy of formation term shown in Equation 5 can be represented in the form of $\Delta G=\Delta H-T \Delta S$ where the coefficients $b$ and $c$ correspond to $\Delta H$ and - $\Delta S$, respectively. The number of coefficients can be selected when setting up the data base for the SOLGASMIX program. The change in entropy was determined from the $\Delta \mathrm{H}_{f}$ and $\Delta \mathrm{G}_{\mathrm{f}}$ values at $1400 \mathrm{~K}$.

The National Bureau of Standards (21-24) has compiled a thermodynamic data base for liquid and solid mixtures to study the behavior of coal slag systems containing up to seven oxide components. Their primary concern is the loss of alkali seed $\left(\mathrm{K}^{+}\right)$and deposition in MHD systems. Their research goals are to combine experimental and modeling techniques to predict vaporization properties of coal slags.

Hastie et al. (2l-24) have also experimentally examined silicate slag systems containing up to $20 \% \mathrm{~K}_{2} \mathrm{O}$. They placed these slags inside a mass spectrometer and measured the partial pressure of $K$ as a function of temperature and composition. They were able to get good agreement between the predicted partial pressure of $K$ and experimental data. The results of their calculations in one specific case of interest indicate that higher Cao contents increase the activities of $\mathrm{K}_{2} \mathrm{O}$, thus increasing the $\mathrm{K}$-pressures. It was shown that $\mathrm{CaO}$ removes $\mathrm{SiO}_{2}$ and $\mathrm{Al}_{2} \mathrm{O}_{3}$ through the formation of stable liquid $\mathrm{CaSiO}_{3}$ and $\mathrm{CaO} \cdot \mathrm{Al}_{2} \mathrm{O}_{3} \cdot 4 \mathrm{SiO}_{2}$ and solids $\mathrm{Ca}_{2} \mathrm{SiO}_{4}$ and $2 \mathrm{CaO}^{\cdot} \mathrm{Al}_{2} \mathrm{O}_{3} \cdot \mathrm{SiO}_{2}$, resulting in less liquid $\mathrm{K}_{2} \mathrm{SiO}_{3}$ and $\mathrm{KAlSiO}_{4}$ and higher $\mathrm{K}_{2} \mathrm{O}$ activity. The $\mathrm{K}_{2} \mathrm{O}$ activity is particularly sensitive to the relative stabilities of melilite species such as $\mathrm{KCaAlSi}_{2} \mathrm{O}_{7}, \mathrm{Ca}_{2} \mathrm{Al}_{2} \mathrm{SiO}_{7}$ and $\mathrm{CaAl}_{2} \mathrm{Si}_{2} \mathrm{O}_{8}$ liquid or solid components. In addition, the model predicted a substantial decrease in the liquids temperatures with added $\mathrm{CaO}$.

\subsection{TASK C - SLAG VISCOSITY STUDIES}

With increased temperature the ash is converted to slag resulting in changes in chemical composition and physical behavior. of particular concern is its viscosity. Viscosity of coal ash slag and its relationship to temperature predicts the degree of suitability for coals in slagging gasification units and agglomeralion potential. Inability tn properly initiate and maintain slag flow for any coal prolibits its use in a slagging gasifier operation. Flow properties for coal ash slags have been investigated to some extent but additional investigation covering coal ash produced under reducing conditions is desirable to more accurately characterize coal ash slag chemistry physical properties, to refine predictive equations, and to aid in proper cual selection for ultimate use. 
In the case of non-Newtonian flow behavior the relation of shear stress and shear rate is not linear. At least three regimes of non-Newtonian flow exist (28):

1. Pseudoplastic flow in which viscosity decreases with increasing shear rates.

2. Plastic flow in which viscosity decreases with increasing shear rates following an initial yield stress.

3. Thixotropic flow in which viscosity decreases with increasing duration of the applied shear stress.

Most coal ash slags exhibit an area of Newtonian flow characteristics at the high temperature end of their liquid region, then, as temperature decreases, reach a point referred to as the temperature of critical viscosity $\left(T_{C V}\right)$ where the flow changes to non-Newtonian in character. These characteristics differ for each coal and are very dependent on the composition of the coal ash.

Ash composition for all ranks of coals is variable, with low-rank coals exhibiting wide variations within a mine as well as among mines. Thus slag viscosities determined from samples obtained within any mine can be significantly different from one another in spite of their similar geologic setting. When this fact is related to operation of a slagging gasifier unit it is not difficult to see that trouble-free slag tapping for one ash composition could change to problem flow when the ash composition changes. It would be beneficial to be able to accurately predict slag behavior based on the composition of the coal ash in order that necessary adjustments, such as higher or lower temperatures in the reaction zone, flux addition, or coal blending, could be made to insure satisfactory operation.

Past attempts have been made to define the linear or Newtonian portion of the temperature-viscosity curve based on the composition of the coal ash. In the mid-1960's workers at the British Coal Utilization Research Association (BCURA) developed two correlations based on work with British (bituminous) coals, now referred to ash the Watt-Fereday (29) and $s^{2}(30,31)$ correlations. Unfortunately, attempts to apply this correlation to low- as well as high-rank coal slags have been generally unsuccessful.

The possible reasons why these predictive equations fail for low-rank coals are (28):

1. Ash constituents in low-rank coals fall outside the compositional concentration range of most bituminous coals.

2. The BCURA predictive equations are based on ash analyses. Significant losses of certain elements may occur as the ash from low-rank coals is heated to the melting point thereby changing the actual sample composition. 
3. Sulfur retention is more prevalent in low-rank ashes due to the generally higher calcium contents.

4. In lignites, $30 \%$ to $50 \%$ of the ash-forming constituents can consist of cations attached to the organic matter in ion-exchangeable form on carboxyl groups or as chelate complexes, rather than being present as distinct mineralogical species (32).

The Watt-Fereday equation is approximately a linear equation of the form (23): $\log \eta=m X f(T)+c$ based on the Arrhenius form of the viscosity equation: $\quad \eta=A \exp (E / R T)$. Their equation is a re-evaluation of earlier work by Reid and Cohen (33) on British coals. Reid and Cohen developed a nomograph which allowed calculating the viscosity at any temperature provided that either the viscosity at $2600^{\circ} \mathrm{F}$ or the "silica percentage" is known, where the silica percentage is the $\mathrm{Z}_{\mathrm{SiO}_{2}}$ when the sum $\mathrm{SiO}_{2}+\mathrm{Fe}_{2} \mathrm{O}_{3}+\mathrm{MgO}+\mathrm{CaO}$ is normalized to $100 \%$.

Another aspect of the work by Reid and Cohen was a method for predicting the temperature of critical viscosity $\left(T_{c v}\right)$. Among the important variables considered were the ferric percentage, defined as the percent of the iron existing as $\mathrm{Fe}_{2} \mathrm{O}_{3}$ but not reduced to $\mathrm{FeO}$; the percentage of lime in the slag; and the equivalent $\mathrm{Fe}_{2} \mathrm{O}_{3}$. The equivalent $\mathrm{Fe}_{2} \mathrm{O}_{3}$ is defined as the percent of $" \mathrm{Fe}_{2} \mathrm{O}_{3}$ " (expressing all iron as $" \mathrm{Fe}_{2} \mathrm{O}_{3}{ }^{n}$ ) calculated when the sum of $\left(\mathrm{SiO}_{2}+\right.$ $\mathrm{Al}_{2} \mathrm{O}_{3}+\mathrm{Fe}_{2} \mathrm{O}_{3}+\mathrm{MgO}$ ) is normalized to $100 \%$.

The equation derived by Watt and Fereday was based on the inclusion of alumina in the composition of British coal ashes where $\mathrm{SiO}_{2}+\mathrm{Al}_{2} \mathrm{O}_{3}+$ Eqv. $\mathrm{Fe}_{2} \mathrm{O}_{3}+\mathrm{CaO}+\mathrm{MgO}=100$ (wt $\%$ ). The viscosity was defined as:

$$
\log \text { viscosity }(n)=\left[10^{7} m /(T-150)^{2}\right]+C
$$

where $m$ and $C$ are the slope and intercept of the temperature-viscosity line respectively.

The terms $m$ and $C$ include the correlation of composition variables where:

$\mathrm{m}=0.00835 \mathrm{Sin}_{2}+0.00601 \mathrm{Al}_{2} \mathrm{O}_{3}-0.109$

$\mathrm{C}=0.0415 \mathrm{SiO}_{2}+0.0192 \mathrm{Al}_{2} \mathrm{O}_{3}+0.0276 \mathrm{Eqv} \cdot \mathrm{Fe}_{2} \mathrm{O}_{3}+0.0160 \mathrm{CaO}-3.92$

$\mathrm{SiO}_{2}+\mathrm{Al}_{2} \mathrm{O}_{3}+\mathrm{Eqv} \cdot \mathrm{Fe}_{2} \mathrm{O}_{3}+\mathrm{CaO}+\mathrm{MgO}=100(\mathrm{wt} \%)$

Assumptions made by Watt and Fereday include (29):

1. the viscosity of a slag in a totally liquid state is determined only by its temperature and composition;

2. the minor oxides, such as $\mathrm{Na}_{2} \mathrm{O}$, have little effect on slag viscosity;

3. the oxidation state of iron is neglected; and

4. the change in composition of an ash to a slag due to volatilization is negligible except for iron in affecting slag viscosity. 
More recently, two correlations were developed in France in studies with metallurgical slags: The IRSID correlation, published by Riboud et al., (34) and the Urbain correlation (36). Ihese two correlations are more appealing because unlike the BCURA correlations, which are based on the Arrhenius form of the viscosity equation where:

$$
\eta=A \exp (E / R T)
$$

the IRSID and Urbain correlations are based on the Frenkel relation where:

$$
n=A T \exp \left(10^{3} \mathrm{~B} / \mathrm{T}\right)
$$

which is the preferred form since it considers:

1. all slag constituents rather than the five major oxides used by Watt and Fereday (29);

2. slag constituents expressed as mole fractions instead of weight. percentages; and

3. the $\mathrm{SiO}_{2}-\mathrm{Al}_{2} \mathrm{O}_{3}-\mathrm{CaO}$ pseudotemary phase system which predominates in low-rank coal slags.

A further review of past mathematical models developed for various ranks of coal was compiled by schobert (36). In this preliminary report, schobert evaluates the application of early models to low-rank coals. For the most part the major problem in direct application of these equations to low-rank coals is that they 1 ) consider a limited number of compositional variables; 2) base their correlation coefficients on high-rank rnal ash and slag compositions; and 3 ) rely on the Arrhenius equation as their basic line form. For these reasons the Urbain equation was determined to be the hest. starting point to derive an appropriate viscosity equation for low-rank coals.

Work by Schobert et al. (37) and Streeter et al. (28) determined that the Urbain equation gave fair to good correlation of low-rank coal slag viecocity tests. Therefore a modified version of the Urbain equation was deveoped by Steeter at BCR National Laboratory and Schobert at UNDERC to adapt it to lowrank coal ash slag viscosity by adding an empirically-derived term ", "and by developing separate sets of equations of low-, intermediate-, and high-silica slags (37). The modified equation:

$$
\ln \eta=\ln \mathrm{A}+\ln \mathrm{T}+10^{3} \mathrm{~B} / \mathrm{T}-\Delta
$$


where $T$ is temperature in degrees Kelvin, $A$ and $B$ are functions of composition and $n$ is calculated in poises. The term " $\Delta "$ is the difference between the actual and computed values of the $\log$ of viscosity ( $I n n$ ). Since $1 n n$ is a linear function of temperature above $T_{c v}$ in the Newtonian flow region, $\Delta$ will also be a linear function of temperature where:

$$
\Delta=\mathrm{mT}\left({ }^{\mathrm{O}} \mathrm{K}\right)+\mathrm{b}
$$

For each slag, values for $m$ and $b$ are derived from the experimental viscosity data which define the linear or Newtonian portion of the viscositytemperature curve by the modified Urbain equation.

The slags were then subdivided into three groups according to the magnitude of the parameter $B$ representing an activation energy term in the Frenkel equation for viscous flow related to the $\mathrm{SiO}_{2}-\mathrm{Al}_{2} \mathrm{O}_{3}-\mathrm{CaO}$ ternary phase diagram. Equations based on the results of 23 tests are shown in Table 1. The criteria for the low-, intermediate-, and high-silica classification of low-rank coal ash slags are presented in Table 2. Results showing the observed and claculated viscosities for the original versus modified Urbain equations are shown in Figure 1.

\subsection{TASK D - SURFACE TENSION STUDIES}

Another area of concern in gasifier operation is related to the property of slag surface tension. Surface tension of a liquid is a measure of the ability or inability of the liquid to "wet" a surface. Surface tension of molten slag is not only dependent on the composition of the coal ash, the atmosphere surrounding the ash, and the temperature at which the determination is made, but it is also affected by the surface on which the slag droplets are formed. A preliminary study of a slag's surface tension on a particular inert surface is of value in assessing the effect of different compositional parameters on surface tension under reducing and oxidizing conditions. In the operation of a slagging gasification unit or wet-bottom gasifier the effect of "wetting" any surface could be detrimental. If the surface is a refractory material inside a gasifier, the "wetting" activity could involve penetration of cracks and pores, could lead to erosion and degradation of the refractory, and could ultimately cause failure. Less severe is the possible build-up of slag on wall and hearth surfaces that could lead to constrictions in gasifier diameter. Ideally, a high value for surface tension is desirable, for that would indicate the tendency for the slag to stick to or infiltrate a surface is limited, allowing molten slag to readily flow to and through the slag tap, leaving the refractory surfaces clean.

\subsection{TNTERELATIONSBIP BETUEEN VISCOSITY AND SURFACE TENSION}

In dry bottom gasifiers, the viscosity as well as the surface tension of a slag or partially molten ash particle could be responsible for the adhesion of ash particles to form agglomerates or clinkers. In dry bottom gasifiers it is essential that the ash particles agglomerate sufficientiy to be removed effectively. This can be a critical control parameter as inefficlent ash 


\section{Classification}

High-Silica Slag:

$$
\begin{aligned}
& 10 \mathrm{~b}=-1.7137\left(10^{3} \mathrm{~m}\right)+0.0509 \quad(R=-0.990 \text { for } 5 \text { of } 5 \text { data points }) \\
& 10^{3} \mathrm{~m}=-1.7264 \mathrm{~F}^{\circ}+8.4404 \quad(R=-0.971 \text { for } 5 \text { of } 5 \text { data points }) \\
& \text { where: } \\
& \mathrm{F}=\mathrm{SiO}_{2} /\left(\mathrm{CaO}+\mathrm{MgO}+\mathrm{Na}_{2}+\mathrm{K}_{2} \mathrm{O}\right) \text {, mole fractions. }
\end{aligned}
$$

Intermediate-Silica Slag:

$$
\begin{aligned}
& \begin{array}{rlrl} 
& b=-2.0356\left(10^{3}\right)+1.1094 & (R=-0.998 \text { for } 7 \text { of } 8 \text { data points }) \\
10^{3} m=-1.3101 F^{1}+0.9279 & (R=-0.982 \text { for } 5 \text { of } 8 \text { data points })
\end{array} \\
& \text { where: } \\
& \mathrm{F}^{1}=\mathrm{B}\left(\mathrm{Al}_{2} \mathrm{O}_{3}+\mathrm{FeO}\right) \text {, mole fractions } \\
& \text { where: }
\end{aligned}
$$

Low-Silica Slag:

$$
\begin{aligned}
& 10^{3} \mathrm{~m}=-1.8244\left(10^{3} \mathrm{~m}\right)+0.9416 \quad(R=-0.999 \text { for } 6 \text { of } 10 \text { data points }) \\
& \text { where: } \\
& \mathrm{F}^{1 \mathrm{I}}=\mathrm{CaO} /\left(\mathrm{CaO}+\mathrm{MgO}+\mathrm{Na}_{2} \mathrm{O}+\mathrm{K}_{2} \mathrm{O}\right) \text {, mole fractions. }
\end{aligned}
$$

TABLE 2

CRITERIA FOR THE CLASSIFICATION OF LOW-RANK COAL ASH SLAGS FOR APPLICATION OF THE MODIFIED URBAIN EQUATION (TABLE 7)

\section{Classification}

High Silica

Intermediate Silica

Low Silica

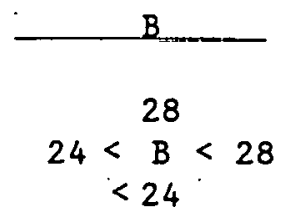

Weight percent $\mathrm{SiO}_{2}$

46
$38<\mathrm{SiO}_{2}<46$
$<42.4$ 


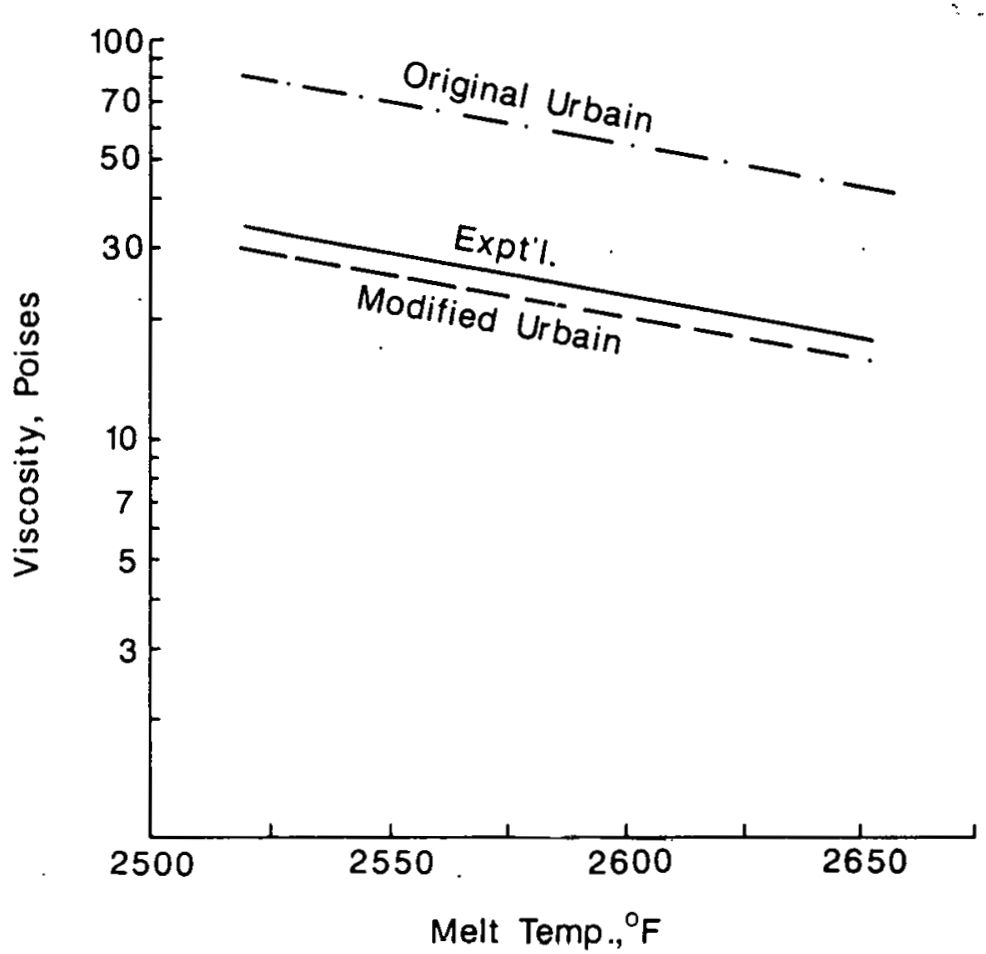

Figure 1. Observed and Callculated Viscosities by the Urbain and Modified Urbain Equations Versus Observed Viscosities.

removal increases the ash in the gasifier and hence reduce conversion. If agglomeration become excessive, clinkers can form which are difficult to remove. This also results in inefficient gasifier performance and sometimes complete shutdown. In wet bottom gasifiers the ash is captured and removed as a molten slag. In order for the ash to be captured and removed the ash material has to adhere to molten slags and become assimilated. Therefore, the slag has to have a sufficiently low surface tension and a relatively low viscusily. The curface tension affects the initial contact as well as the ash particle/slag contact angle. This will affect the contact surface area and hence the rate of assimilation. After adhesion the rate of assimilation to produce a homogeneous slag will depend on viscosity, composition of the slag and nature of the ash particle. There are a number of critical parameters: (1) ash particles are assimilated at a rate which presents a predominantly molten slag layer to ensuing particles; (2) the slag layer does not "wet" the refractory surface; (3) limited crystallization occurs, crystallization will affect both the flow of slag; (4) the viscosity of the slag is sufficiently low to allow removal through the slag tap. 
Therefore for both wet and dry bottom gasifier, both ash viscosity and surface tension are related to the mechanism of ash removal: However, it is necessary for individual particles or ash particles/slag to bind together. This process is called sintering. Kuczynski $(25-26)$ has outlined four sintering mechanisms. These mechanisms are: viscous flow, vapor condensation, diffusiuon, and surface tension. Raask has shown that, for coal utilization systems, that the major mechanism is that of viscous flow with a reactive liquid phase. The reactivity of the liquid phase is important as the molten phase taking part in viscous flow sintering can dissolve the intact portions of the particles. This, of course, increases the amount and nature of liquid phase available for sintering. For this mechanism, the extent of sintering, measured by the square of the radius of the contact area $\left({ }^{2}\right)$ for a given time, $t$, is given by the Frenkel model (27):

$$
x^{2}=\frac{3 Y r t}{2 n 1}
$$

$r=$ radius of the initial (spherical) particles

$Y=$ surface tension of the liquid phase

$n_{1}=$ viscosity of the liquid phase

It is clear from Equation 11 that, for a given time, the extent of sintering is inversely proportional to the viscosity of the Iiquid phase and proportional to the surface tension. It is known that viscosity and surface tension are dependent on composition and local atmosphere. Figure 2 shows the variation of surface tension, viscosity and rate of sintering with temperature. Viscosity decreases markedly with temperature. Surface tension tends to be insensitive, comparatively, to changes in temperature. Therefore. Figure 2 indicates that, this idealized model, that sintering, as a function of temperature is dependent primarily on the viscosity.

However, while the eurface tension does not appear to be an important parameter in terms of rate of sintering, it does affect the critical adhesion of particles. The Frenkel model, as with most sintering models, is based on ceramic studies. In the fabrication of sintered ceramics, the particles are ground and closely packed before heat treatment. Therefore, the particles are in contact with neighbors and the rate of sintering is due to the formation and viscous flow behavior of a liquid phase. However, in coal utilization systems the ash particles are in motion relative to one another and sintering can only begin when ash particles collide and adhere either to each other or to the slag layer. During the initial contact the surface tension of the respective surfaces can play a rate-limiting role as it affects the adhesion. The lower the surface tension the greater the contact area and therefore the greater the degree of adhesion. Of course, there are many other factors which affect the degree of adhesion such as temperature, atnosphere, size of particle, relative particle velocity/momentum and nature of particle 

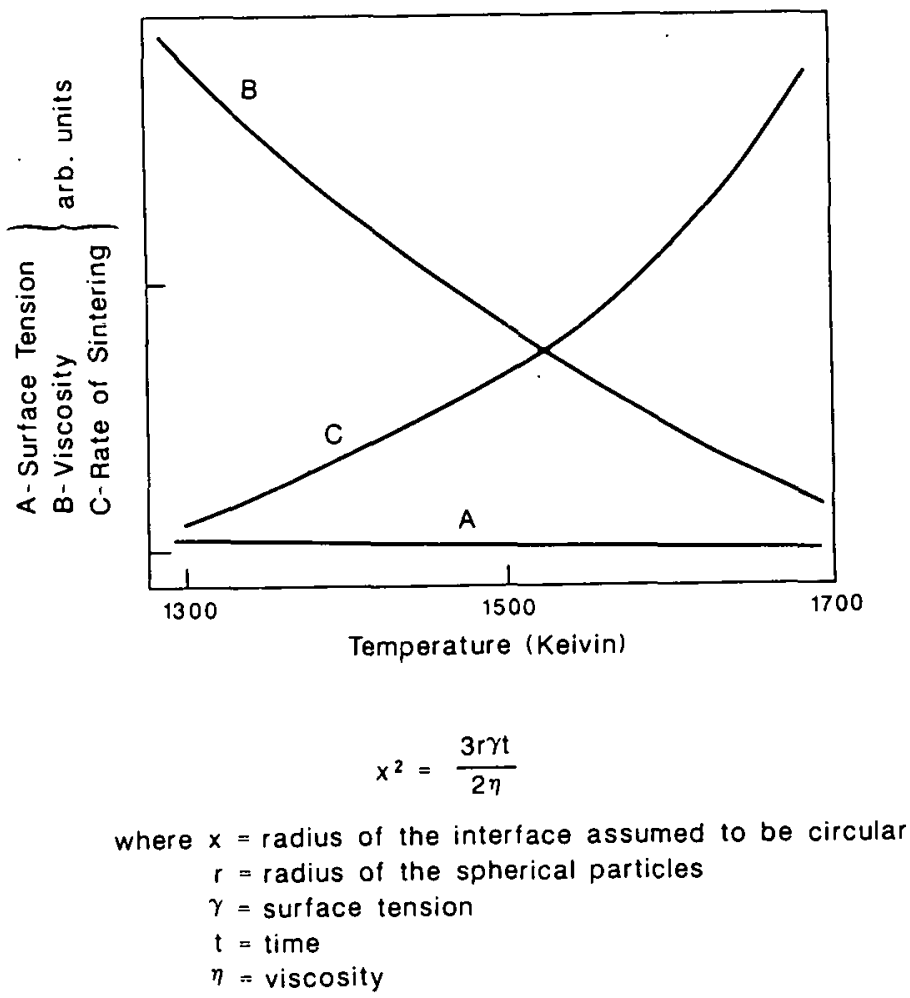

\section{Figure 2. Relationship of Surface Tension, Viscosity and Sintering to Temperature.}

surface. However, the surface tension can be considered in terms of a simple model to be a rate limiting parameter. If the surface tension is sufficiently high then limited adhesion will occur. This would result in limited sintering. Of course this could be the case even for particles with lowviscosity liquid phases. The converse can also be the case. If two particles with relatively high viscosity collide and the surface tension is very low, initial adhesion can occur which could lead to agglomeration. However, the degree of sintering (in terms of $x^{2}$ ) can be limited resulting in a relatively weak agglomerate or low rate of assimilation.

Therefore, for the case of gasifiers the modification of the Frenkel model can be made:

$$
x^{2}=f\left[\frac{1}{r}, t_{1}, r, \frac{1}{n}\right]\left[\frac{3 r}{{ }^{3} t_{2}} \frac{}{2 n}\right]
$$

where $t_{1}$ refers to the contact time and $t_{2}$ refers to time after initial contact.

The function term indicates the probability and extent of initial adhesion of the probability approaches zero (high $\gamma$ ) then the degree of sintering will approach zero. However, after $t_{1}$, the degree of sintering will follow the Frenkel model. It is important to stress that in the probability function the inverse of surface tension is the parameter whereas in the Frenkel model the rate is proportional to the surface tension. This is 
because at initial contact, as mentioned above, the higher the surface tension the less the liquid "wets" the adjacent surface. However, after formation of a "neck" (after $t_{1}$ ) surface tension is a force which pulls liquid material from the convex surfae of the concave surface at the region of the neck. The higher the surface tension the greater the force. This shows quite clearly why both surface tension and viscosity are important parameters to the effective removal of ash in gasifier systems.

\subsection{METHODOLOGY}

\subsection{MINERAL TRANSFORMATIONS}

\subsubsection{Ashing Techniques}

Low Temperature Ashing: Low temperature ashing (LTA) is a process of oxidizing a coal sample by exposing it to oxygen excited by a radio frequency oscillator. The process occurs at approximately $150^{\circ} \mathrm{C}$ which removes the organic material from the coal with little alteration of the inorganic portion. The fact that little alteration of the mineral matter occurs allows for detailed study of the original mineralogy of the coal.

An LFE four chamber low temperature asher (Model 504) is used for generating the ash samples. The radio-frequency generator operates at 13.56 $\mathrm{MHz}$ and delivers an output level up to 500 watts. An output level of approximately 150 watts is used or roughly 37 watts per channel. The oxidation chambers are composed of Pyrex and are approximately $102 \mathrm{~mm}$ in diameter and $216 \mathrm{~mm}$ in length. Pyrex boats are used for containing the sample during oxidation. A 1.5 gram sample of minus 60 mesh coal is weighed into each boat. One boat is placed in each chamber which is then evacuated to $0.2 \mathrm{~mm} \mathrm{Hg}$. Oxygen is then introduced into each chamber at a total flow rate of 100 cubic centimeters per minute at 2 psi. The chamber pressure stabilizes at $1.0 \mathrm{~mm} \mathrm{Hg}$. The $\mathrm{RF}$ power is inçreased to ignite the oxygen plasma and then stabilized at 150 watts.

During the first eight hours of operation the samples are stirred every two hours to expose unoxidized coal. During the remaining ashing time the samples are stirred and weighed every twenty-four hours. The samples are cooled to room temperature in a vacuum dessicator prior to weighing. The ashing process is considered to be complete when two consecutive weights obtained after two 24-hour ashing periods differ by less than two milligrams.

Every sample is treated prior to ashing with ammonium acetate to extract exchangeable alkali ions from the organic portion of the coal. The removal of ion exchangeable cations results in a reduction of the time required for ashing without altering the inorganic portion of the coal. In addition, the reduction in the LTA ashing time results in increased relative intensities in the x-ray diffraction pattern. This pattern is used to identify mineral phases present. 
ASTM Ashing: The standard ASTM test method D 3174-73 for ash in coal and coke is used as outlined in the 1979 Annual ASTM Standards Part 26 for Gaseous Fue1s; Coal and Coke; and Atmospheric Analysis. Untreated minus 60 mesh coal is used for the ash generated at $750^{\circ} \mathrm{C}$ under an oxidizing atmosphere (air).

High Temperature Ashing: Coal samples are ashed in an oxidizing (air) atmosphere at $1000^{\circ} \mathrm{C}$ and a reducing atmosphere also at $1000^{\circ} \mathrm{C}$. The reducing atmosphere used is $8 \%$ hydrogen in nitrogen. A fifteen gram sample of untreated minus 60 mesh coal is placed in alumina boats. An excess air flow rate of 200 cubic centimeters per minute is used during ashing. The temperature of the furnace is raised to $1000^{\circ} \mathrm{C}$ over a period of two and a half hours. The furnace temperature is then maintained at $1000^{\circ} \mathrm{C}$ for one hour. The furnace is then turned off and cooled to $500^{\circ} \mathrm{C}$. Samples are then removed and placed into a vacuum desiccator until cool. The samples are then weighed to determine the ash percent.

\subsubsection{Ash Analysis}

Mineralogical and bulk chemical analyses are performed on every ash sample by $x$-ray diffraction and $x$-ray fluorescence, respectively. Ash percentages are also calculated for each sample. The $x$-ray diffraction technique provides a qualitative determination of the crystalline phases in the ash.

$X$-ray diffractograms are generated by the diffraction of $x$-rays off of the various planes within a crystalline structure. The $x$-ray detector is rotated through a 70 degree angle as $x$-rays striking the sample are reflected and thereby diffracted at set angles off of crystalline planes. The diffracted $x$-rays enter a detector opposite the source. Most mineral phases have an established crystalline structure and a set of reflection peaks that can be used to identify its structure. The peak intensities are a reflection of the degree of crystallinity and the amount of the mineral present in the sample. In most minerals there are defects in the crystalline structure. In some cases, crystal defects are due to (1) the absence of cations from their normal sites in the structure or relocation in other interstitial sites or (2) the introduction of a foreign atom into a vacant interstitial site. The presence of crystal defects in a mineral can vary the number, intensity, and occurrence of reflection peaks observed. For this study crystalline phases identffied in each ash are reported in decreasing order of peak intensities and occurrence (Table $A-3$ ). This technique only identifies the crystalline phases present. The chemistry of amorphous, non-crystalline phases cannot be identified by XRD.

\subsection{CHAR PRODUCTION}

The Bench-Scale Pyrolysis Reactor System (Figure 3) is used for the production of char and is designed to allow for the pyrolysis of coal under a variety of experimental conditions and the subsequent trapping of watersoluble organic compounds produced. The experimental conditions which can be varied include the type of gas atmosphere (including steam), pressure, gas flow rate, heating rate, and final temperature. 


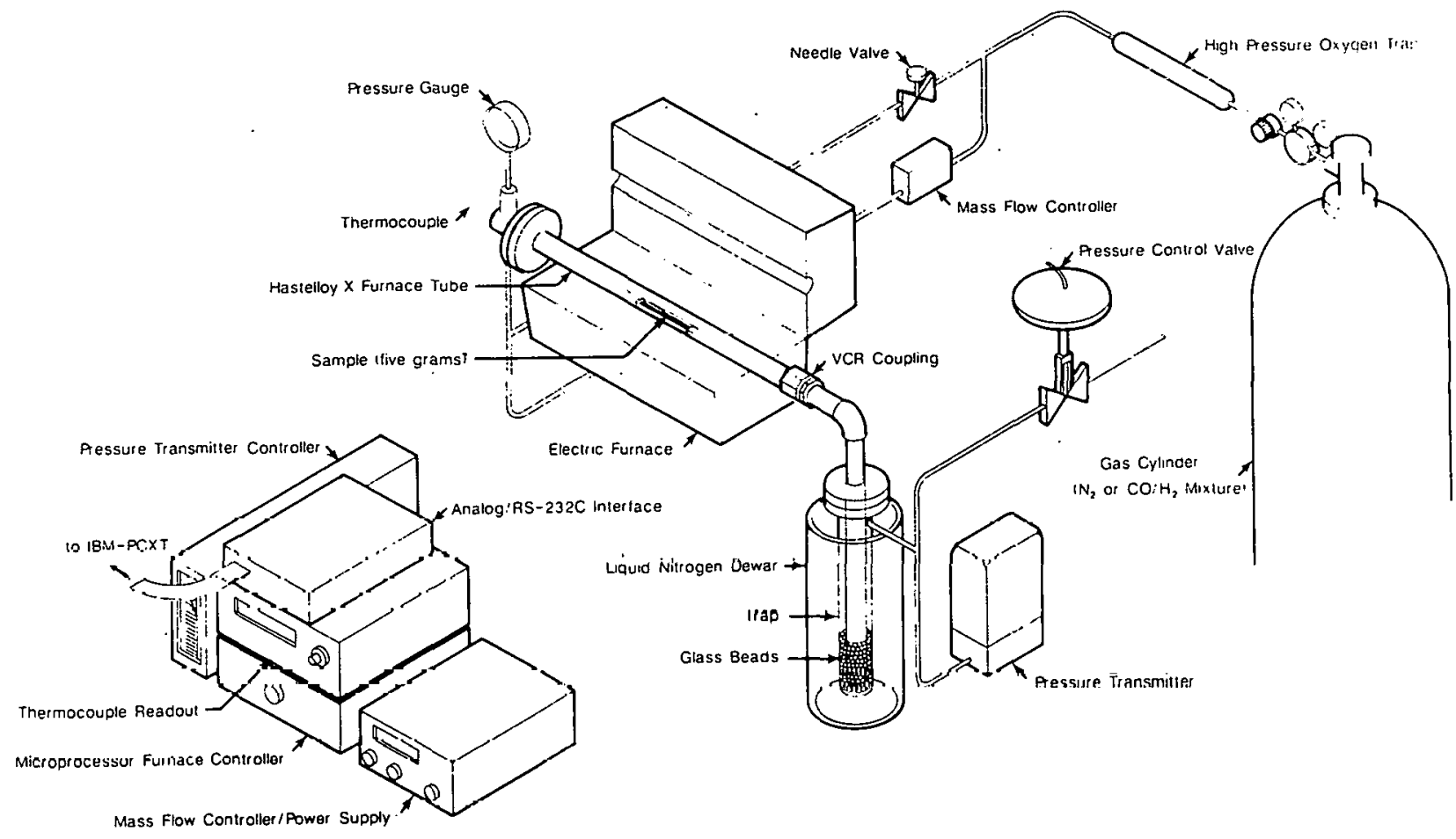

Figure 3. Pressurized Small Pyrolysis Reactor System.

The system is pressurized using an ordinary gas cylinder containing the desired gas mixture. The entire system is constructed of 304 stainless steel, 316 stainless steel, and Hastelloy $X$ and can accommodate a variety of corrosive gas mixtures. The pressure is controlled using a two-stage regulator with a maximum delivery pressure of 500 psig. The gas passes through a high-pressure oxygen trap which removes oxygen to a residual level of less than $0.1 \mathrm{ppm}$. A mass flow controller is used to regulate the flow rate of gas through the furnace tube. The range of available flow rates is $0-100 \mathrm{cc} / \mathrm{min}$ at $400 \mathrm{psig}$ outlet pressure or $0-2821$ standard cc/min (approximately 3 liters/min at atmospheric pressure). A needle valve is used to bypass the mass flow controller, allowing the system to be brought from atmospheric pressure to $400 \mathrm{psig}$ in a matter of seconds.

The steam is produced by injecting water from a HPLC pump into the reactor tube (not shown). By injecting water inco the reactor in liquid forw, the need for a preheater is eliminated. The HPLC pump is capable of pumping against up to $5000 \mathrm{psi}$, well above the $400 \mathrm{psi}$ normal operating conditions of the pyrolysis reactor.

The furnace tube is made of Hastelloy $X$, a nickel-base superalloy, which allows the system to be operated safely at 400 psig and $900^{\circ} \mathrm{C}$. The furnace tube has an outside diameter of 1.05 inches and a wall thickness of 0.125 inches and can accommodate a variety of sample holders or pans. A porcelain tray capable of holding approximately five grams of coal has been used in the 
tests conducted to date. A type $\mathrm{K}$ thermocouple is placed directly above the sample and is in close proximity to the coal. The gases produced pass through a liquid nitrogen-cooled stainless steel trap partially filled with $3-4 \mathrm{~mm}$ glass beads to trap the water-soluble organic effluents. The trap can be removed from the system in seconds using a quick disconnect Cajon VCR coupling. A pressure transmitter, controller, and pressure control valve are used to maintain the desired pressure and allow for the release of sweep gas out of the system.

The electric split-type tube furnace is coupled to a microprocessor which allows for the control of both heating rate and final temperature. The heating rate is adjustable from $0-23^{\circ} \mathrm{C} / \mathrm{min}$ and the maximum furnace temperature is $1100^{\circ} \mathrm{C}$. Time/temperature profiles are displayed and stored on an IBM PC/XT which is interfaced to the reactor by a two channel analog RS-232C interface.

The experimental conditions of the bench-scale pyrolysis reactor are as follows: 1) constant pressure of $400 \mathrm{psi}$; 2) nitrogen inert atmosphere with a flow rate of $33 \mathrm{cc} / \mathrm{min}$; and 3 ) a heating rate of $23^{\circ} \mathrm{C} / \mathrm{min}$ with the final temperature of $850^{\circ} \mathrm{C}$. Approximately 5 grams of coal are used in each pyrolysis run. A total of three pyrolysis runs ( 15 grams of coal) are needed to produce sufficient quantities of each char for subsequent analyses. The average char yield from each lignite was approximately 40\%. In addition to the chars produced at elevated pressure, each of the three lignites are also pyrolyzed at ambient pressure. The analytical results of the chars produced at ambient pressure are to used to determine the effect of elevated pressure on the inorganic composition.

\subsection{SLAG VISCOSITY}

A Haake RV-2 Rotovisco (rotating bob viscometer) unit with a DMK 50/500 dual measuring head is used for viscosity determinations (Figure 4). The torque on the viscometer bob (proportional to shear stress) is converted to an electric signal that is a function of the rotational speed of the bob (shear rate). Automatic temperature programming at a rate of about $0.6^{\circ} \mathrm{Cmin}^{-1}$ and stepwise bob rotation from 0 to $64 \mathrm{rev}$ min $^{-1}$ in increments of 4 rev $\mathrm{min}^{-1}$ is used.

A molybdenum bob is used during the viscosity tests. The bob is approximately $25 \mathrm{~mm}$ long with a $30^{\circ}$ taper machined on both ends. The top of the bob terminates in a $16 \mathrm{~mm}$ long, $6 \mathrm{~mm}$ diameter shaft which accomodates a $420 \mathrm{~mm}$ long, $3 \mathrm{~mm}$ diameter stem.

Each coal sample is pulverized to -60 mesh $(250 \mathrm{~m})$ and ashed for 3 hours at $1000^{\circ} \mathrm{C}$ according to the high temperature ashing procedure outlined earlier. The resulting ash is sieved at 60 mesh and then compressed into 16 $\mathrm{mm}$ diameter pellets weighing $5 \mathrm{~g}$ each. The ash pellets are dropped into a heated sample crucible, A typical coal ash charge is 60-70 g. The crucible is composed of high purity alumina measuring $32 \times 75 \mathrm{~mm}$. The sample crucible is contained in a larger alumina guard crucible with the annular space between the two crucibles packed with 60 mesh alundum. 


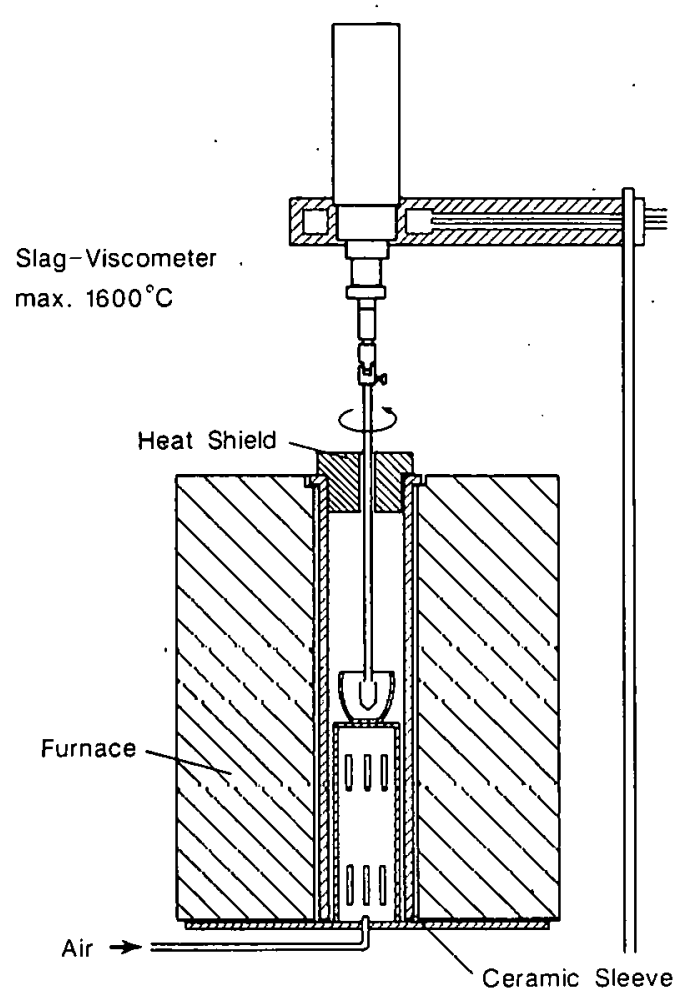

Figure 4. Viscometer Schematic.

Each ash sample is heated up and maintained at approximately $1450^{\circ} \mathrm{C}$ for one hour to ensure complete melting. The bob is then fully immersed into the slag. A cool down cycle is initiated with readings taken every $10^{\circ} \mathrm{C}$. The sample is equilibrated for 20 minutes at each temperature when viscosity measurements are made. Viscosity measurements are taken at each temperature over a period of two minutes and averaged for the data presented here.

The temperature is decreased until the upper limit of the measuring head is approached (typically 3000 poises or $300 \mathrm{~Pa} . \mathrm{S}$ ). The slag is then reheated to observe the viscosity behavior during a second heating cycle.

Measured values from the viscometer are related to viscosities by an instrument factor determined from tests using National Bureau of Standards glass viscosity standard No. 710. The instrument factor is related to the viscosity by the equation

Viscosity (poises) = Instrument factor $x$ torque reading

Bob speed (RPM) 
The solidified slag samples are analyzed for chemical and mineralogical content by energy-dispersive $x$-ray fluorescence spectrometry and $x$-ray diffraction, respectively.

\subsection{SURFACE TENSION}

A schematic diagram of the apparatus is shown in Figure 5 . It consists of a resistance-heating furnace capable or temperatures up to $1750^{\circ} \mathrm{C}$, a long focal length microscope, and a $35 \mathrm{~mm}$ camera.

\section{Generalized Sketch of Surface Tension Measuring System \\ (not to scale)}

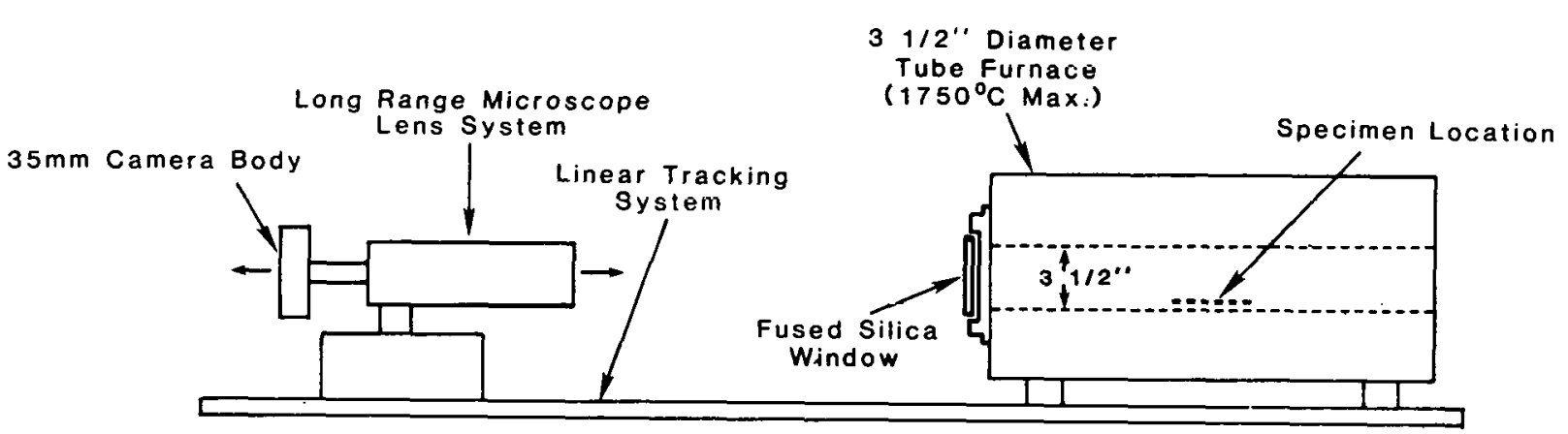

Figure 5. Surface Tension Apparatus.

For the sessile drop method of measuring surface tension, a sample of ash, previously prepared by high-temperature ashing of the coal at $1000^{\circ} \mathrm{C}$ is used. The ash is formed into a pellet, weighed, and centered on a plaque of vitrenus carbon. The vitreous carbon acts as a relatively inert and nonreactive substrate on which a slag bead forms during heating. The bead shape is determined by the surface tension forces between the liquid, gas, and solid phases in contact with each other. Therefore, the sessile drop technique requires geometric definition of the bead at any one temperature. The ash sample is placed in the horizontal tube furnace preheated to $1000^{\circ} \mathrm{C}$. A continuous flow of air $(900 \mathrm{cc} / \mathrm{min})$ is maintained throughout the experiment. The normal melting temperature range for surface tension determinations is typically between $1200^{\circ} \mathrm{C}$ and $1400^{\circ} \mathrm{C}$. The temperature heatup in that interval is approximately $1.6^{\circ} \mathrm{C}$ per minute. The pellet image is photographed at $1000^{\circ} \mathrm{C}$ and $1200^{\circ} \mathrm{C}$. Above $1200^{\circ} \mathrm{C}$, photographs covering the melting point of the pellet are taken at $5^{\circ} \mathrm{C}$ intervals until the plaque is completely wetted or a temperature of $1400^{\circ} \mathrm{C}$ is reached. By $1350_{0} \mathrm{C}$ almost all of the ash pellets are molten and little, if any, change occurs up to $1400^{\circ} \mathrm{C}$. 
At the completion of the experiment the $35 \mathrm{~mm} f$ ilm is developed and the images are projected onto a sheet of graph paper with the image of the plaque faces parallel to the graph paper axis. The droplet dimensions are measured, adjusted to account for magnification, and used to calculate the best fit parameters of " $B$ " and " $b$ " from which the surface tension is calculated.

The small slag drops will tend to be spherical because surface forces depend on the surface area which decreases as the square of the linear dimension. Distortions due to gravitational effects depend on the volume which decreases as the cube of the linear dimension. Simply, the surface tension of a liquid is the force per unit length on the surface that opposes the expansion of the surface area. When gravitational and surface tensional effects are comparable, the surface tension can be determined from measurements of the shape of the drop.

Several methnds of calculating surface tensiun flum the sessilc drop have been proposed $(38,39,40)$. The method chosen for this investigation was proposed by Maze and Bernet (41). The basic equation describing the free surface of the goesile drop:

$$
\mathrm{b} \frac{\mathrm{d}^{2} z}{\mathrm{dx} \mathrm{x}^{2}}+\frac{\mathrm{b}}{\mathrm{x}}\left[1+\left(\frac{\mathrm{dz}}{\mathrm{dx}}\right)^{2}\right] \frac{\mathrm{dz}}{\mathrm{dx}}=\left(2+\frac{\mathrm{Bz}}{\mathrm{b}}\right)+\left[1+\left(\frac{\mathrm{d} z}{\mathrm{dx}}\right)^{2}\right]^{3 / 2}
$$

has no analytical solution. This makes it necessary to use various techniques for obtaining drop profile coordinates.

The method used in this study is based on defining the maximum radius of the bead $\left(x_{\max }\right)$ (Figure 6 ). The distance along a line from the bead apex perpendicular to the maximum radius ( $x_{\max }$ ) is defined as $z_{\max }$. The ratio $x_{\max } / z_{\max }$ is defined as $" \beta^{n}$, the shape factor, which is actually a reflection of the eccentricity of the bead.

The radiuo of survature at the apex of the drop is defined as " $b$ ". The two parameters are related by the equation:

$$
B=b^{2} \rho g
$$

where $\rho$ is the density difference between the liquid and the surrounding medium, $g$ is the gravitational acceleratiun, and $O$ is the intcrfacial eurface tension. The parameless $p$ and g arc caoily obtained. " $\beta$ " and "h" are based on the geometry of the bead. The values of " $b$ " and " $B$ " are considered estimates and are re-evaluated in the context of fitting a calculated bead shape to fit the measured bead shape. The values " $b$ " and " $\beta$ " are varied until a "best set" of values is obtained. At this point a minimum sum of squares between the measured and calculated $x$-coordinates is achieved. The computing process is accomplished through a series of iterations to interpolate the $x$ coordinates in differential form for each given $z$ value by varying " "and " $b$ " at which point the surface tension is calculated according to Equation 15 . A total of ten iterations are used to calculate the surface tension data for this project. 


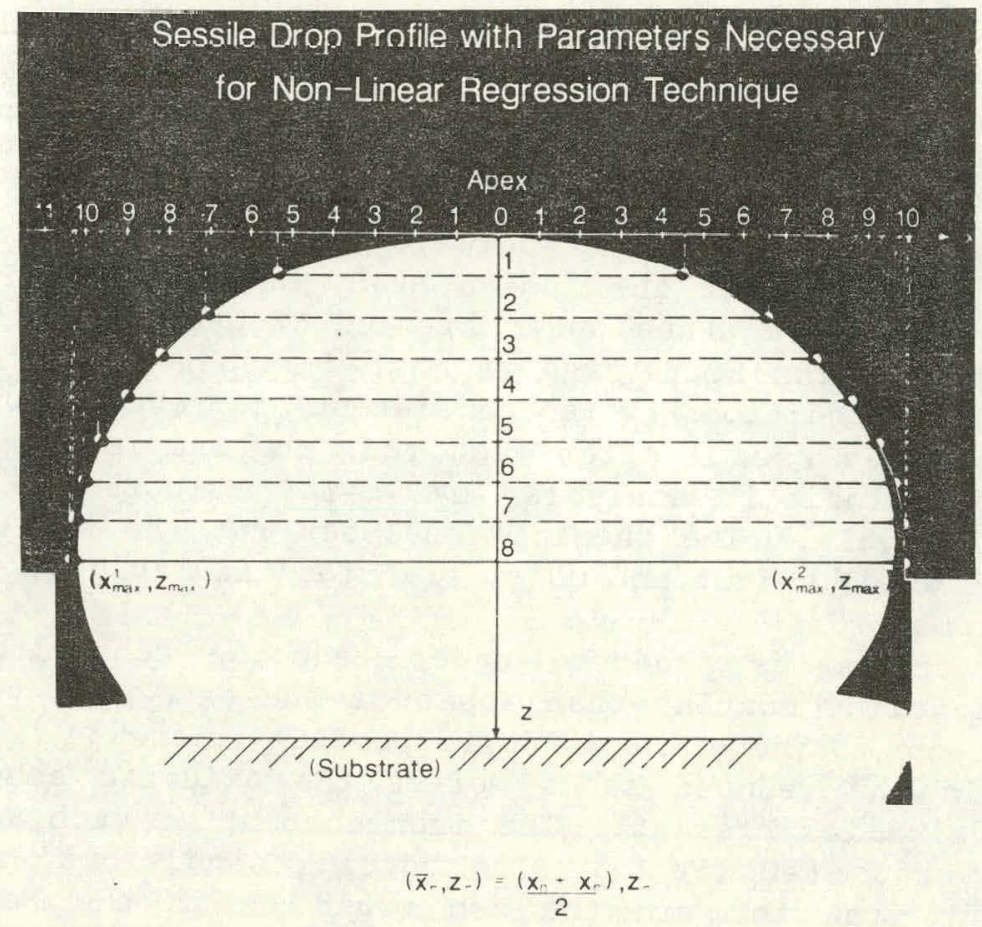

Figure 6. Measurements of Sessile Drop Profile Used for Calculation of Surface Tension.

\subsection{ACCOMPLISHMENTS}

\subsection{ASHING OF COAL UNDER REDUCING CONDITIONS - COMPARISON OF LAB ASHES GENERATED UNDER OXIDIZING VERSUS REDUCING ATMOSPHERES}

A primary goal of this project is to evaluate in the laboratory the inorganic chemical and physical changes of coal ash and slag which occur at high temperature $\left(\leq 1500^{\circ} \mathrm{C}\right)$. The original inorganic matter in the coal changes composition and forms in the following manner: (1) by forming an assembly of high-temperature minerals or agglomerates, (2) partially vaporizing, or (3) melting to form slag. One important step in understanding this sequence of events is to examine the ash at an intermediate temperature prior to sintering and complete melting. Obvious changes in the chemical composition of slags due to volatilization and recrystallization will affect the physical properties of the slag. The physical properties of concern in this study are surface tension and viscosity. Both surface tension and viscosity are important parameters in determining the sintering behavior or agglomeration of ash in dry bottom gasifiers and the maintenance of slag flow in wet bottom gasifiers. Most studies relating slag composition to physical 
properties have relied on the use of ashes generated under oxidizing conditions and then slagged under reducing conditions. If changes in the chemistry between ashes produced under different atmospheres occurs then it is necessary to generate and study slags from ashes produced under reducing conditions, as well as oxidizing conditions.

As outlined in Task A of the Annual Project Plan a total of five coals were to be ashed. Samples of the Indian Head, Martin Lake, Pittsburgh \#8, Wyodak and Velva coals were ashed under air and $8 \%$ hydrogen in nitrogen at a temperature of $1000^{\circ} \mathrm{C}$. The Pittsburgh $\# 8$ coal was substituted for a low-rank coal. The ashing conditions were consistent in every run except for variations in the gases used. After each run, the sample was submitted for chemical and mineralogical analysis by $x$-ray fluorescence and $x$-ray diffraction, respectively. The chemical analyses for the ashes are reported according to their oxide weight and molar fractions in Table 3.

In general, the ashes produced under reducing conditions have lower sulfur and calcium oxide content than ashes of the same coal generated under oxidizing conditions. There is a corresponding increase in the silicon dioxide content in the reduced ashes versus the oxidized ashes due to the reduced level of alkalies present. The iron content of each ash is analyzed as $\mathrm{Fe}_{2} \mathrm{O}_{3}\left(\mathrm{Fe}^{+3}\right)$ versus $\mathrm{FeO}\left(\mathrm{Fe}^{+2}\right)$. In reducing conditions, it is expected that the prevalent iron form in the ash would be in the $\mathrm{Fe}^{+2}$ state. In melting an oxidized ash in a reducing atmosphere the iron would be reduced at that time and should be similar to the iron in a slag formed from a reduced ash of the same coal possibly forming metallic iron.

The selection of coals in this study was in part based on the fact that they are in use in a concurrent METC-funded project on hydrogen production. The hydrogen production project involves the construction of a pilot scale fluidized bed gasifier. The pilot scale gasifier has undergone initial shakedown runs with the first run planned in the summer of 1987 . At this time, the Velva coal is planned to be the initial coal tested. Pilot scalegenerated ashes from the unit will be available for this study. These ashes will be compared to those generated in the lab. The pilot scale ashes will also be included in surface tension and viscosity studies. The results of this work could be used to explain any problems with excessive bed agglomeration and the in-bed sulfur capture techniques that may be observed during the pilot scale runs. The availability of pilot scale samples could also validate the use of lab samples in gasification studies.

\subsection{VAPORIZATION OF INORGANICS DURING THE GASIFICATION PROCESS}

\section{2 .1 SOLGASMIX}

The goal of this task is to evaluate preliminary theoretical phase diagram work based on thermodynamic phase equilibria data in the form of a computer program. The SOLGASMIX program can evaluate the effects of temperature, oxygen, and pressure on different sodium phases as discussed in the background section. Table 4 lists the sodium, silica, and sulfur phases currently in the data base. 
TABLE 3

HIGH TEMPERATURE ASH CHEMICAL ANALYSES (X-RAY FLUORESCENCE - XRFA)

OXIDE WEIGHT PERCENT BY XRFA

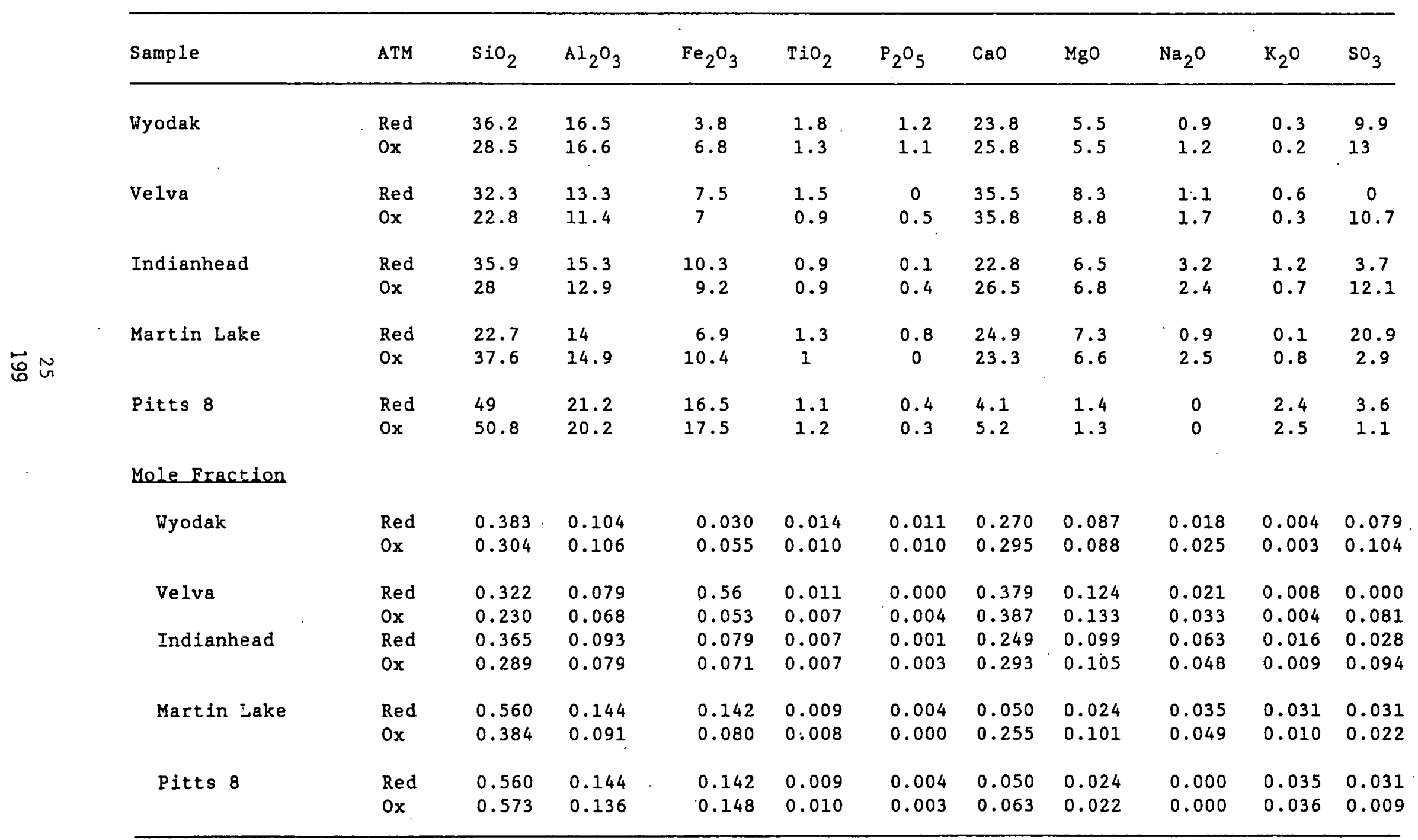


TABLE 4

SOLGASMIX (SODIUM AND SULFUR DATA BASE - NASSI)

Gas Phases Liquid Phases Solid Phases

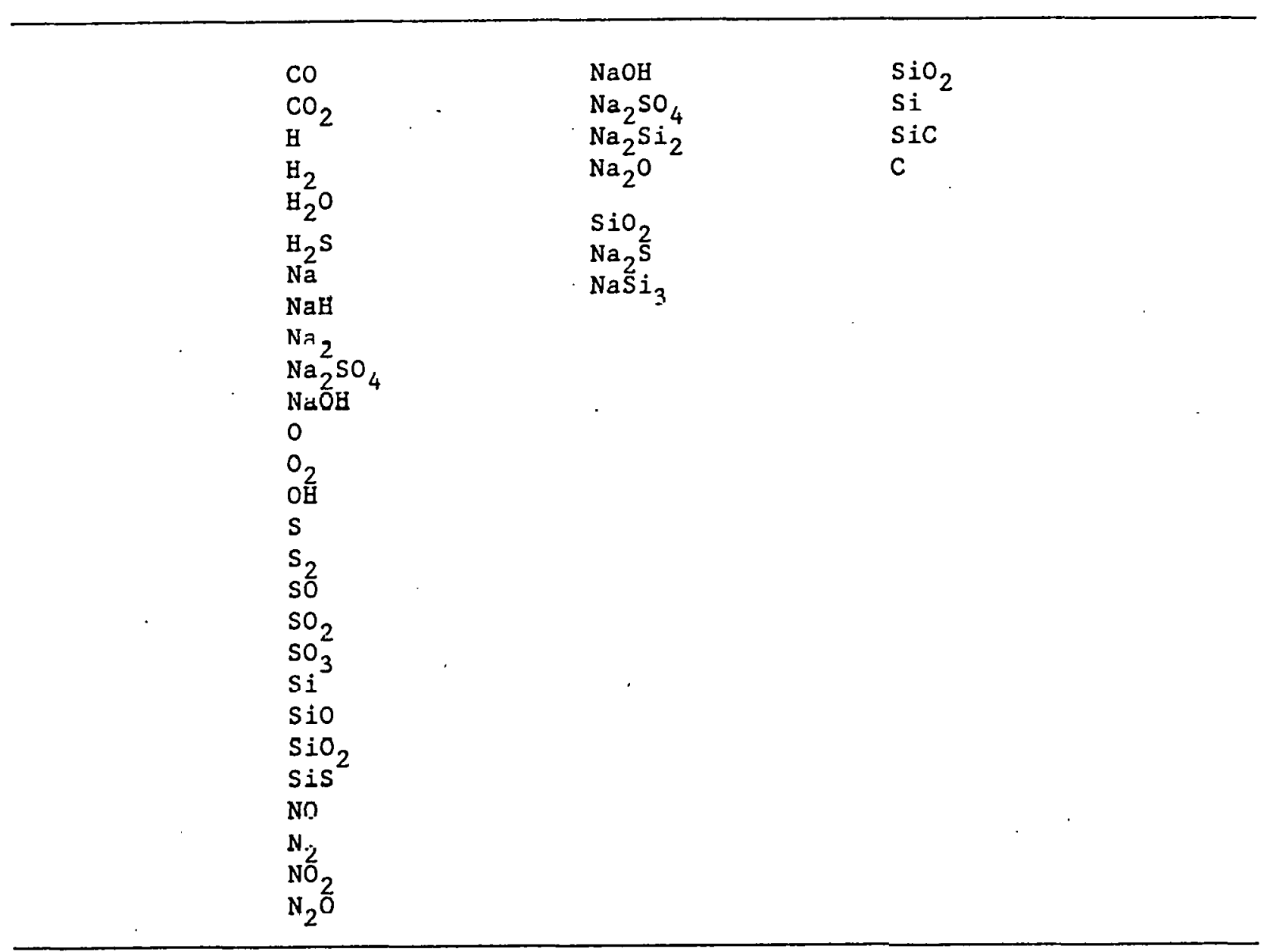

As a preliminary evaluation of solGASMIX, the inorganic components, proximate, and ultimate anlaysis of the Indian Head and Gascoyne White coals (Table 5) were produced under oxidizing and reducing conditions of various pressures. In Figures 7 through 10 the sodium phases that would be present in a system are graphed at various temperatures for both coals. The thermo chemical data base used to generate these graphs is based on equilibrium conditions. The graphs are presented here simply as an example as to the data obtainable through SOLGASMIX. As such, the SOLGSMIX program will be used in Year 2 as a tool for evaluating the volatilization of inorganics in chars and slags and the formation of liquid phases at elevated temperatures. 


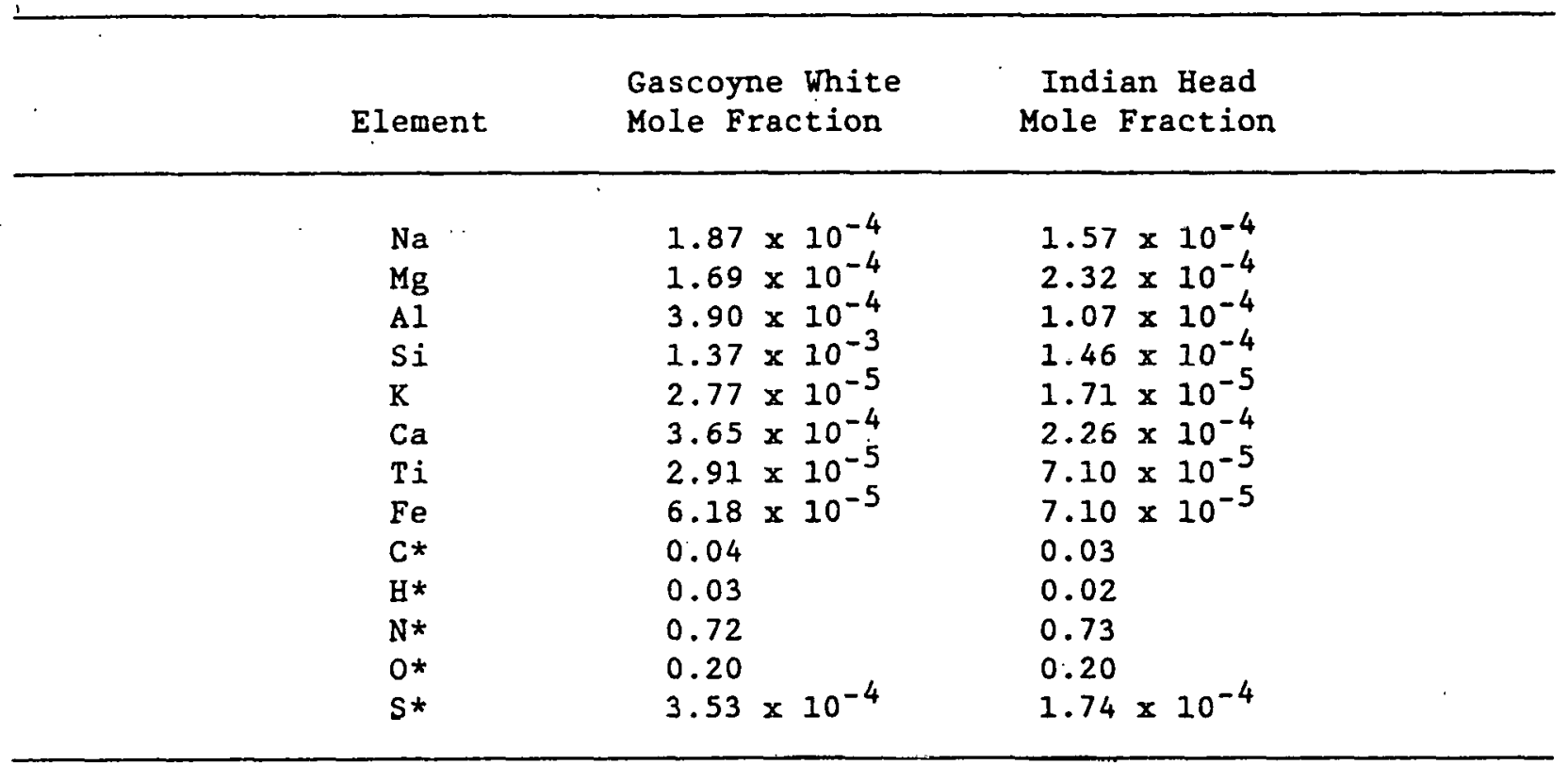

*From ultimate analysis (moisture, ash-free basis).

\section{2 .2 Char Production}

Chars from three low-rank coals (lignite) and one bituminous coal were prepared in the bench-scale pyrolysis reactor. These coals include Indian Head and Velva lignites, from North Dakota, the Martin Lake lignite (Texas) and the Pittsburgh $\# 8$ bituminous coal. The chars will be low-temperature ashed (LTA) and subsequently analyzed for the inorganic elemental composition as determined by $x$-ray fluorescence and $x$-ray diffraction.

\subsection{SLAG VISCOSITY STUDIES}

This task includes the study of the chemical, mineralogical, and rheological properties of slag produced from reduced and oxidized coal ash and the development of predictive viscosity equations. Viscosity studies will be conducted under reduced and oxidized atmospheres and ultimately investigate the effects of steam. Studies will concentrate on mathematically defining (as a function of slag composition) the Newtonian. flow region and the critical temperature at which flow behavior changes from Newtonian to non-Newtonian. Different additive studies and model mixture studies will be performed during years 2 and 3 to understand what specific compositional parameters affect the shape and temperature profile of the viscosity curve. These studies will concentrate on those inorganic compounds common to low- and high-rank coals. In each case, comparisons of viscosity data obtained using oxidized coal ash under reducing slag conditions will be made to evaluate their appropriate application to gasifier operation. 

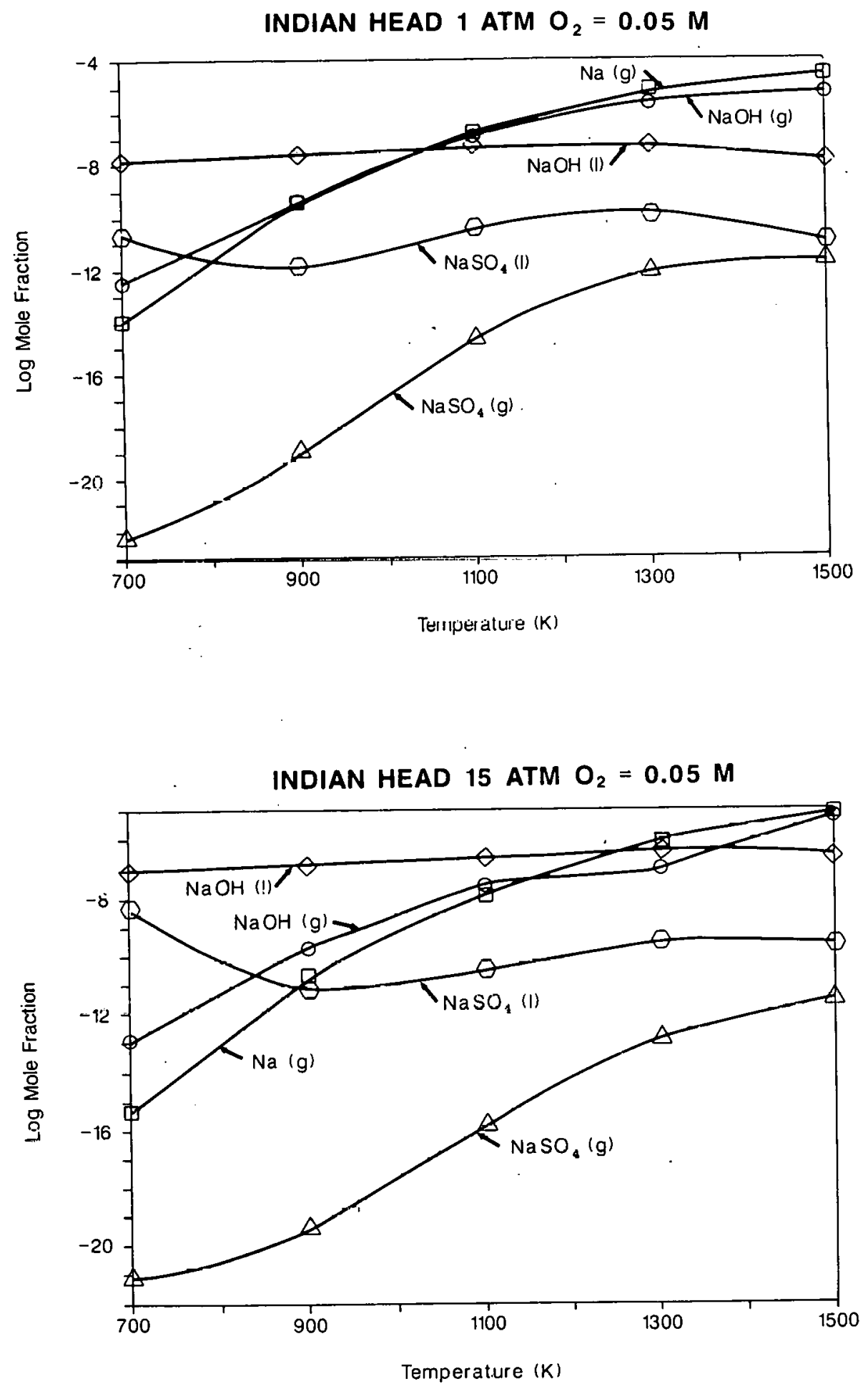

Figure 7. SOLGASMIX Predictions for Sodium Species for Indian Head Coal Ash at 1 and 15 Atm for 0.05 Mole Fraction Oxygen. 

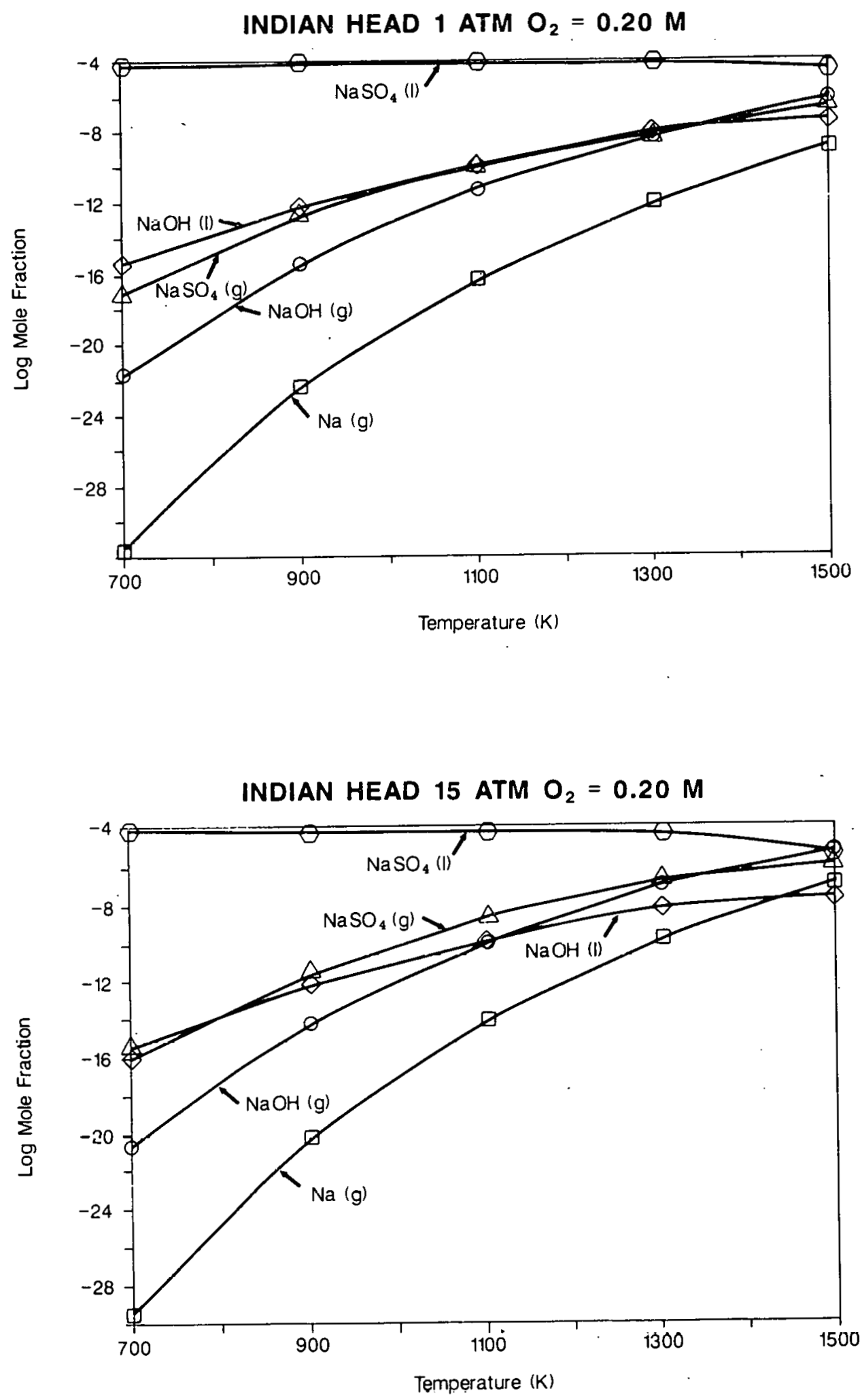

Figure 8. SOLGASMIX Predictions for Sodium Species for Indian Head Coal Ash at 1 and $15 \mathrm{Atm}$ and 0.20 Mole Fraction Oxygen. 

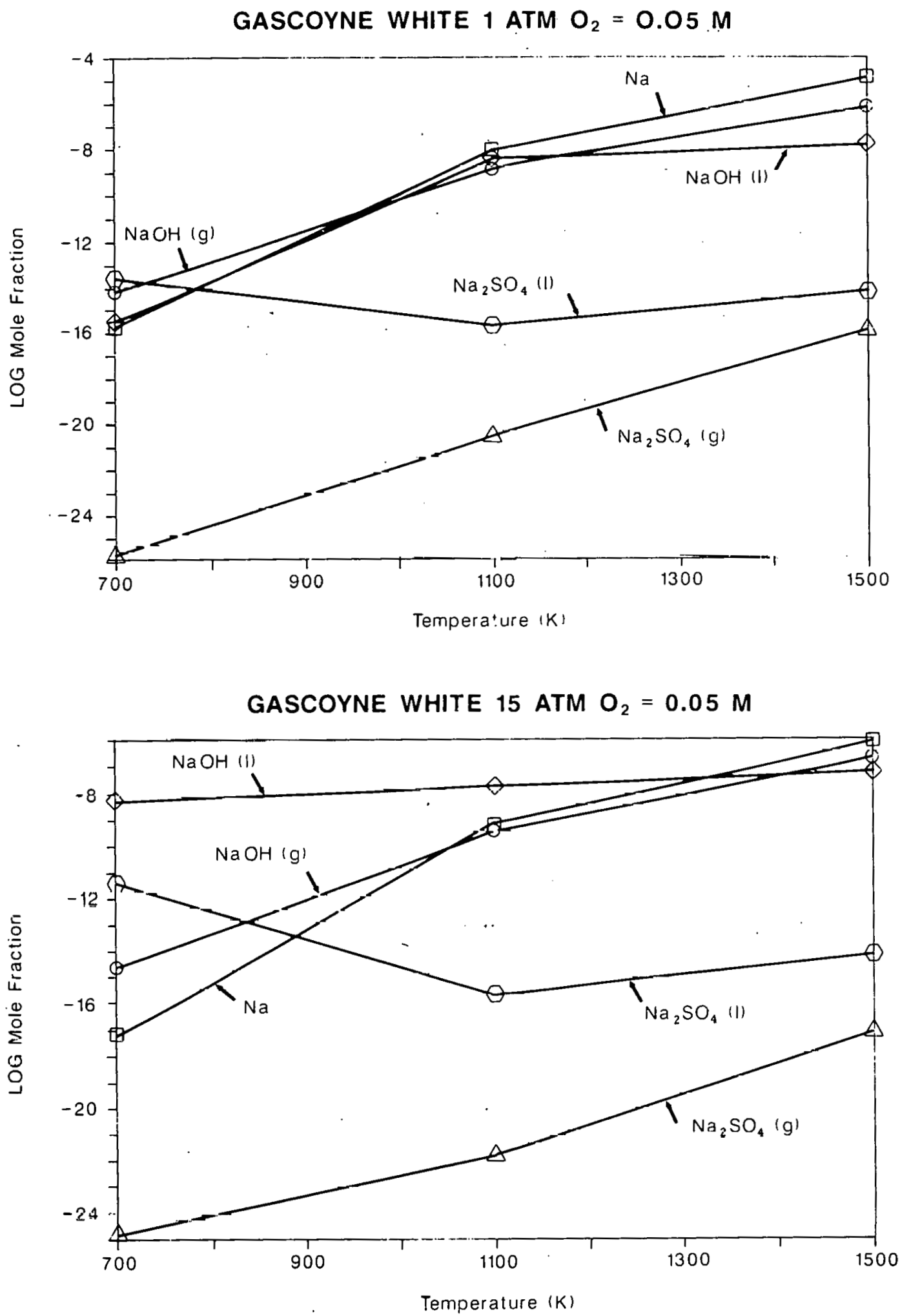

Figure 9. SOLGASMIX Predictions for Sodium Species for Gascoyne White Cosl Ash at 1 and $15 \mathrm{Atm}$ and 0.05 Mole Fraction Oxygen. 
GASCOYNE WHITE 1 ATM $O_{2}=0.20 \mathrm{~m}$

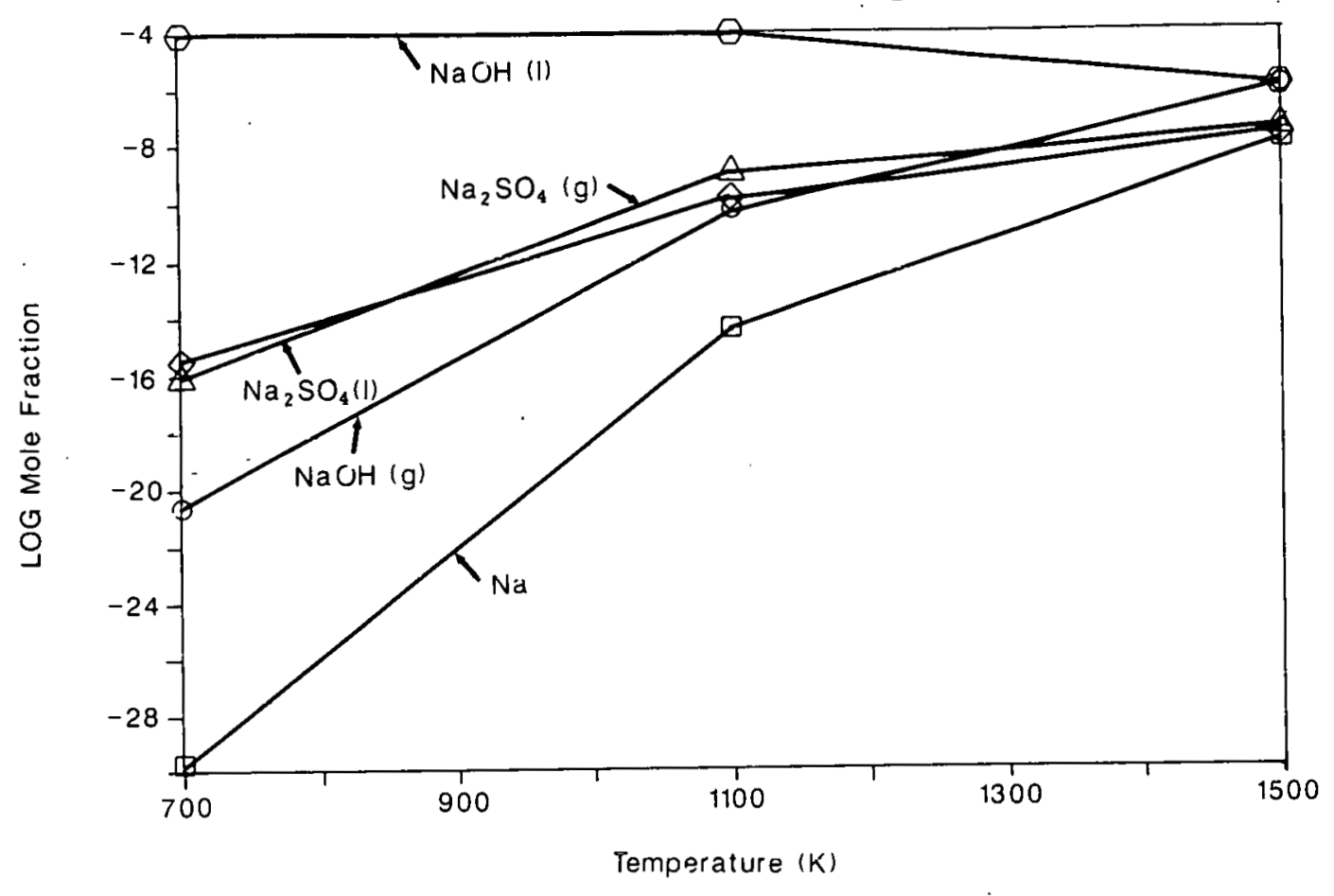

GASCOYNE WHITE 15 ATM $O_{2}=0.20 \mathrm{M}$

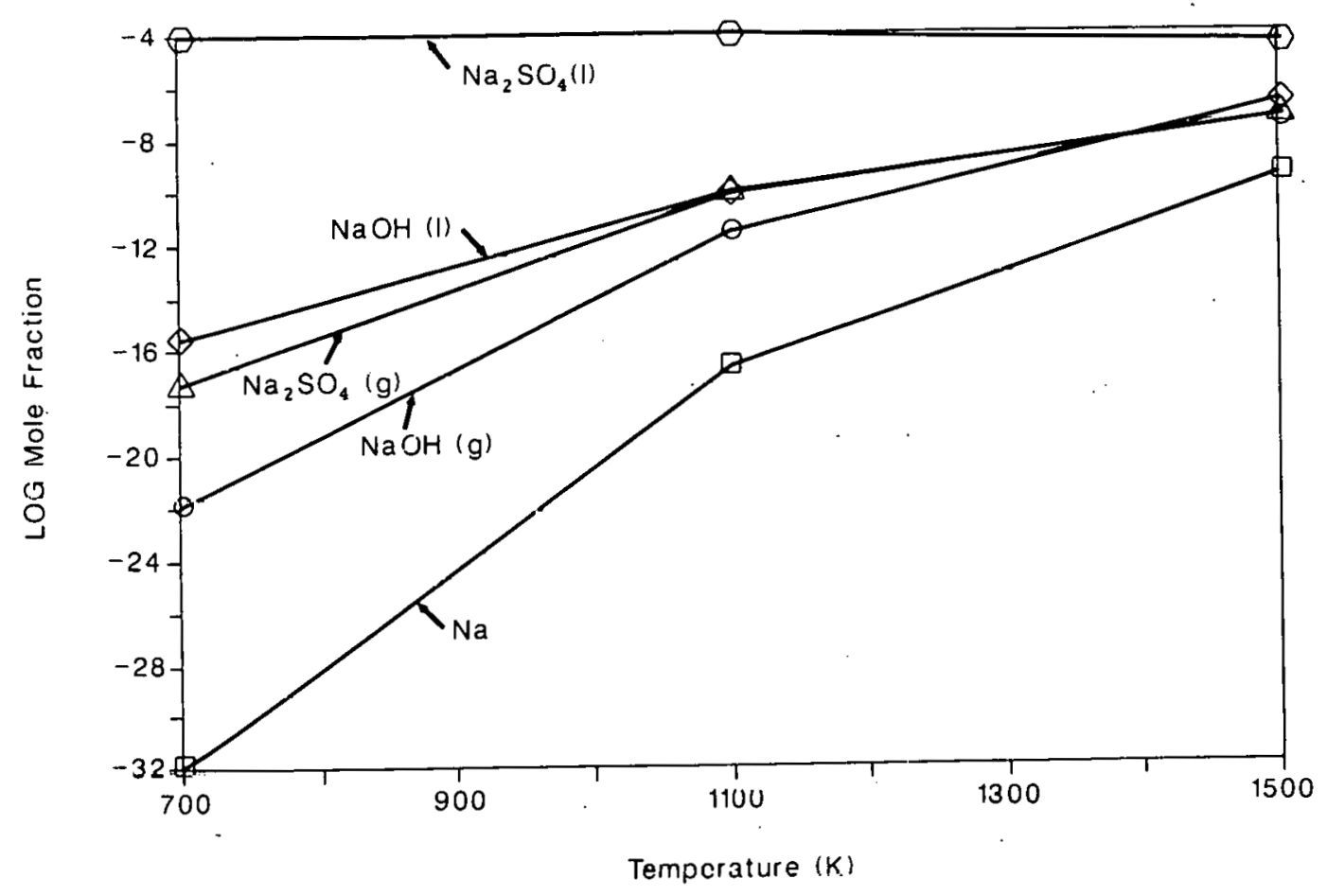

Figure 10. SOLGASMIX Predictions for Sodium Species for Gascoyne White Coal Ash at 1 and $15 \mathrm{Atm}$ and 0.20 Mole Fraction Oxygen. 
During the first year the following topics were investigated: (1) the formation of a viscosity data base to test various pred. eq.; (2) viscosity tests of pilot versus lab-generated ashes, (3) the effect of slag composition on the temperature critical viscosity $\left(\mathrm{T}_{\mathrm{cv}}\right)$, (4) the effect of atmosphere on viscosity, and (5) the application of the Urbain and Modified Urbain equations to slag viscosity behavior under oxidizing and reducing conditions.

\subsubsection{Preparation of Coal Ash Viscosity Data Base}

In order to establish a reasonable data base from which a meaningful and accurate model of coal ash viscosity can be developed an extensive literature search was undertaken. The parameters considered important for the data base are as follows:

\section{a. Chemical composition (including oxidation states of iron) \\ b. Atmospheric conditions (partial pressure of oxygen) \\ c. Viscosity/temperature values \\ d. Phases present in quenched samples \\ e. Indication of temperature of critical viscosity \\ f. Hysteresis (heating and cooling cycles)}

The complation of data was not limited to coal ashes only, but included glass and ceramic data as well. The data sources, number and nature of samples and the viscosity ranges represented are listed in Table 6 . Previous predictive models of coal ash viscosity tend to be rank-dependent but are sometimes used erroneously to predict the viscosity values for coal ashes outside the composition range for which it was developed as discussed in section 3.3. An example of this is the widespread use of the. Watt-Fereday method. The equation was based on British bituminous ashes and used the values of the components: $\mathrm{SiO}_{2}, \mathrm{Al}_{2} \mathrm{O}_{3}, \mathrm{Fe}_{2} \mathrm{O}_{3}, \mathrm{CaO}$, and $\mathrm{MgO}$. However, it is known that $\mathrm{Na}_{2} \mathrm{O}, \mathrm{K}_{2} \mathrm{O}$ and other minor components can have marked effects on the viscosity. Furthermore, coal ashes from different regions can have appreciable quantities of the "minor" components. Another reason for increasing the scope is due to the presence of crystalline phases in coal ash melts. These phases are either the unmelted grains of refractory coal minerals (for example quartz) or phases formed due to a recrystallization process occurring when the melt is cooled below the liquidus. Crystallization in coal ash melts is evidenced by a parameter called temperature of critical viscosity $\left(T_{C V}\right)$. $T_{r r}$ also is used to represent the limit of Hewtoniall behavior of the coal ash melt. The value has sometimes been used erroneously as a measure of the liquidus temperature. $T_{C V}$ is a physical effect and is related more to the amount and nature of the crystalline phases thas simply the presence of a crystalline phase in the melt. Also, the occurrence of $T_{c v}$ can depend on the experimental technique used to measure viscosity as it is not necessarily an equilibrium value. The amount of crystalline phases necessary to be present in a melt in order for the melt to exhibit $T_{C v}$ depends 
TABLE 6

CURRENT SOURCES FOR VISCOSITY DATA BASE

\begin{tabular}{|c|c|c|c|c|c|c|c|c|}
\hline Source $(\operatorname{Re} f)$. & $\begin{array}{l}\text { Type/Number } \\
\text { of Samples }\end{array}$ & ATM & $\begin{array}{l}\text { Viscosity Range } \\
\text { (Log Poises) }\end{array}$ & Method & Analysis & $\mathrm{XRD}^{+}$ & Hysteresis & $\mathrm{T}_{c \mathrm{~V}}$ \\
\hline Gijb il) & British Bit (9) & Ox/Re & $4.0-10.0$ & Penet. & Prior $(0 x)$ & No & Yes & No \\
\hline Boow i2) & $\begin{array}{l}\text { Australian }+(9) \\
1 \text { Synthetic }\end{array}$ & $0 x$ & $2.0-8.0$ & Penet. & Prior (ox) & No & No & No \\
\hline $\begin{array}{l}\text { Nicho:19\& } \\
\text { Reid (3) }\end{array}$ & U.S. Bit. (7) & $0 x$ & $1.0-3.0$ & ค. 3. & Post & $\begin{array}{l}\text { No } \\
\text { ! }\end{array}$ & No & No \\
\hline B.C.U.R.A. (4) & $\begin{array}{l}\text { British Bit. }{ }^{\&} \\
\text { Synthetic }(200)\end{array}$ & $0 x / \operatorname{Re}$ & $0.0-3.0$ & R.B. & Post & Yes & Yes & Yes \\
\hline Streeter (5) & U.S. Western (17) & $0 x / \operatorname{Re}$ & $1.0-3.0$ & R. 3. & Post & No & No & No \\
\hline Hoy et al. (6) & British Bit. (5) & $0 x$ & $1.0-3.0$ & & Post & No & No & Yes \\
\hline $\begin{array}{l}\text { Mach1 et al. } \\
(7,8:\end{array}$ & $\begin{array}{l}\mathrm{CaO}-\mathrm{MgO}-\mathrm{Al}_{2} \mathrm{O}_{3}- \\
\mathrm{SiO}_{2} \mathrm{Glasses}(115)\end{array}$ & $0 x$ & $0.0-2.0$ & R. 3. & Prior & No & No & No \\
\hline
\end{tabular}

$+X R D$ of quenched samples.

\section{References:}

1. W.H. Gibb, Power Industry Research, 1981, Vol. 1, pp. 29-42.

2. J. Boow, Fuel, 1969, Vol. 48, pp. 171-178.

3. P. Nicholls \& W.T. Reid, Trans. ASME, 1940, Vol. 62, pp. 141-153.

4. B.C.U.R.A., Document Numbers A/CON/2574 (1962) and A/CON/644 (1963).

5. R.C. Streeter, E.K. Diehl anj H.H. Schobert, "Chenlstry of Low-Rank Coals", Ed. H.H. Sahobert, ACS Symposium Series No. 264, Washington, D.C., 1984, pp. 195-209.

6. H. R. Hoy, A.G. Roberts, D.M. Wilkins, J. Inst. Fuel, 1958, Vol, 3, pp. 1144-457.

7. J.S. Machin and D.L. Hanna, J. Arer, Ceram. Soc., 1945, Vol. 28, pp. 310-316.

8. J.S. Hanna, T.B. Yee, D.L. Hanna, J. Amer. Ceram. Soc., 1952, Vo1. 35, pp. 322-325. 
on the size and composition of the phase. For example, small crystals of low aspect ratio (spherical) would be expected to have limited effect on the flow properties as the liquid phase would be expected to flow around them. However, large dendritic crystals of high aspect ratio would be expected to give greater resistance to the flow of fluid. The composition of the crystalline phase is also important as the precipitation of a phase from a melt of different composition alters the composition of the liquid phase. A simple example of this would be the precipitation of cristobalite $\left(\mathrm{SiO}_{2}\right)$ from a coal ash melt. The residual liquid phase then becomes relatively depleted in $\mathrm{SiO}_{2}$ and enriched in other components. It does not take extensive crystallization before the composition of the liquid phase falls outside the range of coal ash compositions.

Therefore the data base should include viscosity temperature data for alumino-silicates melts. The most notable work of relevance is that of Machin et al. (42) who studied the system $\mathrm{CaO}-\mathrm{MgO}_{\mathrm{Al}} \mathrm{AO}_{3}-\mathrm{Sin}_{2}$. Relevant data from glass and coramic snurses have also been obtained including aluminosilicate melts with sodium.

Despite extensive studies of coal ash viscosity there is relatively limited published data when one considers the variability of coal ash and the importance of flow properties in utilization systems. The most extensive data base is that of Watt and Fereday (29) who studied the viscosity of coal ashes and synthetic slags both in air and under controlled atmospheric conditions. The work of Reid et al. (33) at the U.S. Bureau of Mines is also notable. In fact it was the work by Reid which showed the temperature critical viscosity $\left(T_{C V}\right)$ and the relationship between coal ash viscosity and the deposition of slag in wet-bottom boilers.

While the various dara of coal ash viscosity is important the published data has to be scrutinized carefully due to the variability of experimental techniques.

The value of such a data base is to evaluate the experimental data obtained in this study within a statistically random population. An extended data base is extremely important in determining the use of predictive viscosity equations.

\section{$5: 3.2$ Evaluation of Predictive Viscosley Equabiums}

As discussed in section 3.3 on the hackground of slag viscosity there have been numerous approaches to the development of equations to predict viscosity based on slag composition. Work by Schobert et al (37) determined that the Urbain equation (Equation 9) gave fairly good correlations or "fit" of calculated viscosities to measured viscosities. The inlent was to ues the Urbain equation as a starting point from which to refine an equation appropriate for low rank coals. The modified Urbain equation was the result of the work by Schobert et al (37). The major modifications to the original Urbain equation was the introduction of a term " $\Delta$ " and the distinction of low-, intermediate-, and high-silica slags (37) (Tables 1 and 2). The reason for devising a classification scheme for the silica content of slags is based on the relative importance of silica to other oxide concentrations. 
Urbain classifies the constituents of silicate melts as "glass formers" $\left(\mathrm{SiO}_{2}, \mathrm{P}_{2} \mathrm{O}_{5}\right)$, "modifiers" ( $\left.\mathrm{CaO}, \mathrm{MgO}, \mathrm{Na}_{2} \mathrm{O}, \mathrm{K}_{2} \mathrm{O}\right)$ and "amphoterics" $\left(\mathrm{Al}_{2} \mathrm{O}_{3}\right.$, $\mathrm{Fe}_{2} \mathrm{O}_{3}$ ) which can act either as glass formers or modifiers (37). For highsilica slags the correlating factor is the ratio of $\mathrm{SiO}_{2}$ to modifiers due to the higher degree of polymerization and rapid rate of nucleation and crystallization which is enhanced by large amounts of silica in the system. In turn, this behavior produces higher viscosities, thereby inhibiting movement of ions and reducing crystal size. These slags tend to behave as glasses or Newtonian fluids with no $\mathrm{T}_{\mathrm{Cv}}$.

For low-silica slags the correlating term is the ratio of CaO to modifiers or alkalies. Alkalies tend to inhibit nucleation by weakening the bonds between silica tetrahedra and increase the rate of crystal growth by reducing viscosity thereby permitting more rapid movement of ions. Therefore these slags tend to have definite breaks, or $T_{C v}$, in the temperature-viscosity curve form Newtonian to non-Newtonian flow due to the physical and chemical interaction of solid and liquid phases. For intermediate-silica slags, the correlation term involves the "amphoterics," suggesting that the role of these constituents becomes more important when the viscosity behavior of the slag cannot be well-defined by its silica content (37). The consideration of the relative amounts of silica to alkalies is valid.

Equation 10 shows the relation of the variables in the modified Urbain equation. The term " $\Delta$ " is the difference between the actual and computed values of the $\mathrm{log}$ of viscosity. The " $\Delta$ " term is also a function of temperature as shown in Equation 11. The values which determine the value of " $\Delta$ " are based on the experimetal values of the slope of the Newtonian portion of the viscosity curve and its $y$-intercept. The problem with this " "term is that it is specific to the statistical population from which is derived. For this reason it was decided that both the Urbain and modified Urbain equations would be studied. In addition, it was decided that since both oxidizing and reducing systems are to be studied the form of iron would be included in two separate calculations as $\mathrm{Fe}_{2} \mathrm{O}_{3}$ and FeO.

The original Urbain equation has no " $\Delta$ " term and does not classify slags as low-, intermediate-, or high-sllica. According to Urbain (35) the precision of the equation remains good even when the sum of the major oxides $\left(\mathrm{SiO}_{2}, \mathrm{Al}_{2} \mathrm{O}_{3}\right.$, and $\left.\mathrm{CaO}\right)$ is below fifty percent. The major oxides are all considered in both the Urbaln and modified Urbain equations.

Actual calculations were conducted on coals ranging in rank from lignite to bituminous. In Figures 11 and 12 an example of the results from two viscosity runs: Pittsburgh $\$ 8$ (bituminous) and the Baukol-Noonan (1ignite) slags. Also included are the curves generated by the Urbain and modified Urbain equations. There are two curves for the modified Urbain equation representing different species of iron which would be present in reducing versus oxidizing environments (VISCALRE and VISCALOX).

The Pittsburgh 8 measured viscosities were matched equally well by the Urbain and the modified Urbain (assuming $100 \% \mathrm{FeO}$ ) equations (Figure 11). The Baukol-Noonan measured viscosities version of the modified Urbain equation somewhat better than either version of the modified Urbain equation (Figure 12). The Urbain equation was generally better at matching the measured viscosities of most of the coal slags. This may be explained by the fact that 


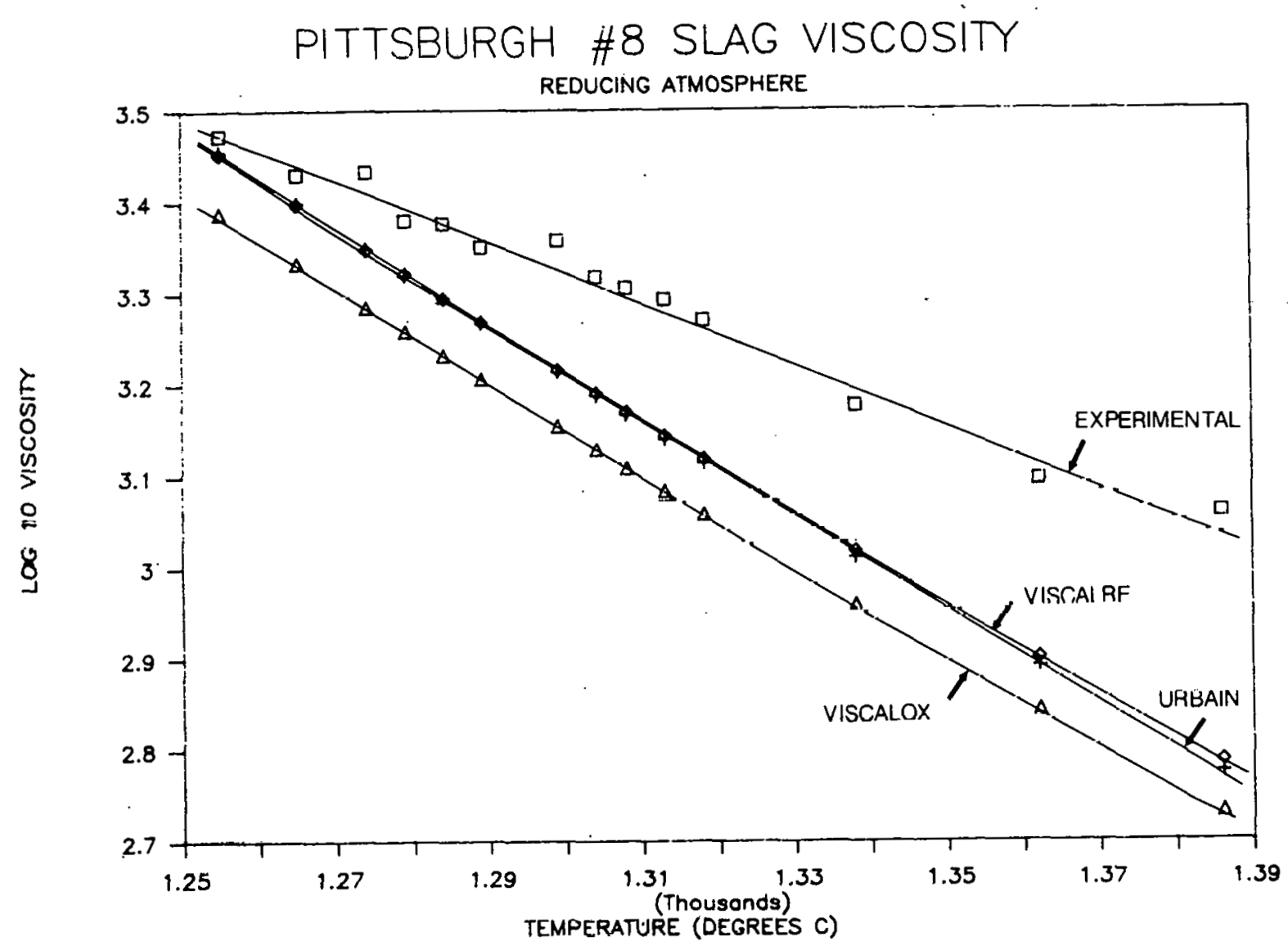

Figure 11. Viscosity-Temperature Curve Comparing Experimental Values with Predicted Values for Pittsburgh $\$ 8$.

the Velva slag froths considerably during the heat up stage of the viscosity run. The action of frothing or the concentration of gas along the immersed bob generally gives incorrect viscosity measurements. In addition, the bulk analysis of the slag chemistry is generally eliuntus.

A total of thirty-one coal slags were tested. Sixteen of the coal slags were run under an oxidizing atmosphere while the remaining fifteen slags were run under reducing atmospheres. Of the viscosity curves generated under either atmosphere the majority were predirted bettcr by the Urbain equation (twenty out of thirty-two).

At this time, the statistical significance of the measured versus calculated viscosities for each equation is not available. This work is slated for Year 2 of the project. 


\section{BAUKOL-NOONAN SLAG VISCOSITY}

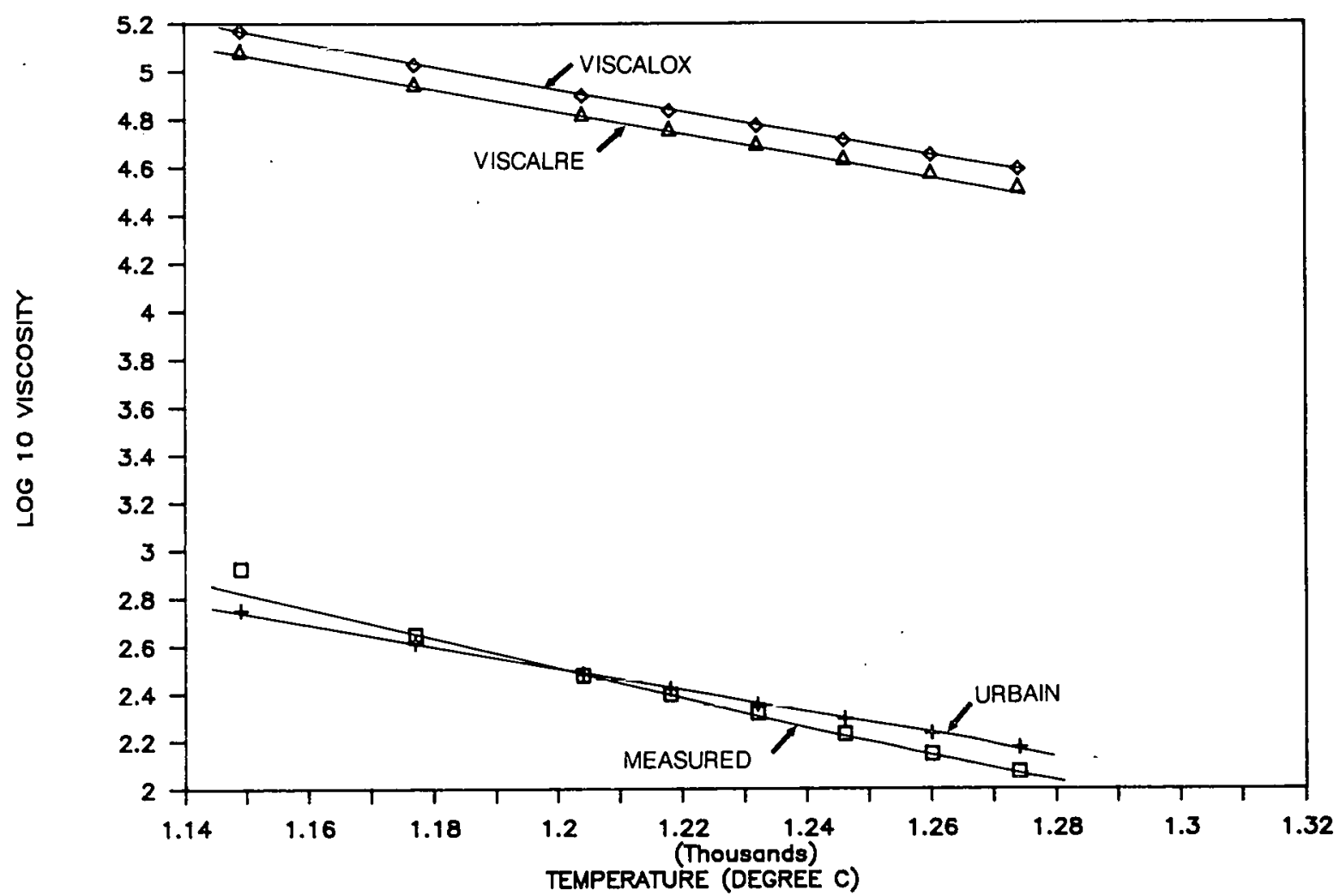

Figure 12. Viscosity-Temperature Curve Comparing Experimental Values with Predicted Values for Baukol-Noonan.

Another feature of using a more universal predictive viscosity equation is the ease at which additive studies can be made. By simply adjusting the mole fractions of any chosen oxide the effect on viscosity can be determined. In Figures 13 and 14 additions of $5 \%$ sodium oxide and $5 \%$ calcium oxide were made. In each case the viscosity curves are depressed with the addition of alkalies to the system.

\subsubsection{Viscosity Study of Commercially-Generated Agglomerated Versus Non-Agglomerated_Ash Samples (Great Plains Gasifier)}

A comparison of two commercially-generated ashes, one agglomerated and one non-agglomerated, was made to better understand the relation of ash and slag chemistry to agglomeration potential. The two samples came from the Great Plains Gasification Project in North Dakota. The coal used in the gasifier is a North Dakota lignite from the Freedom mine. The one sample represents non-agglomerated ash easily removed through the ash grate. The 


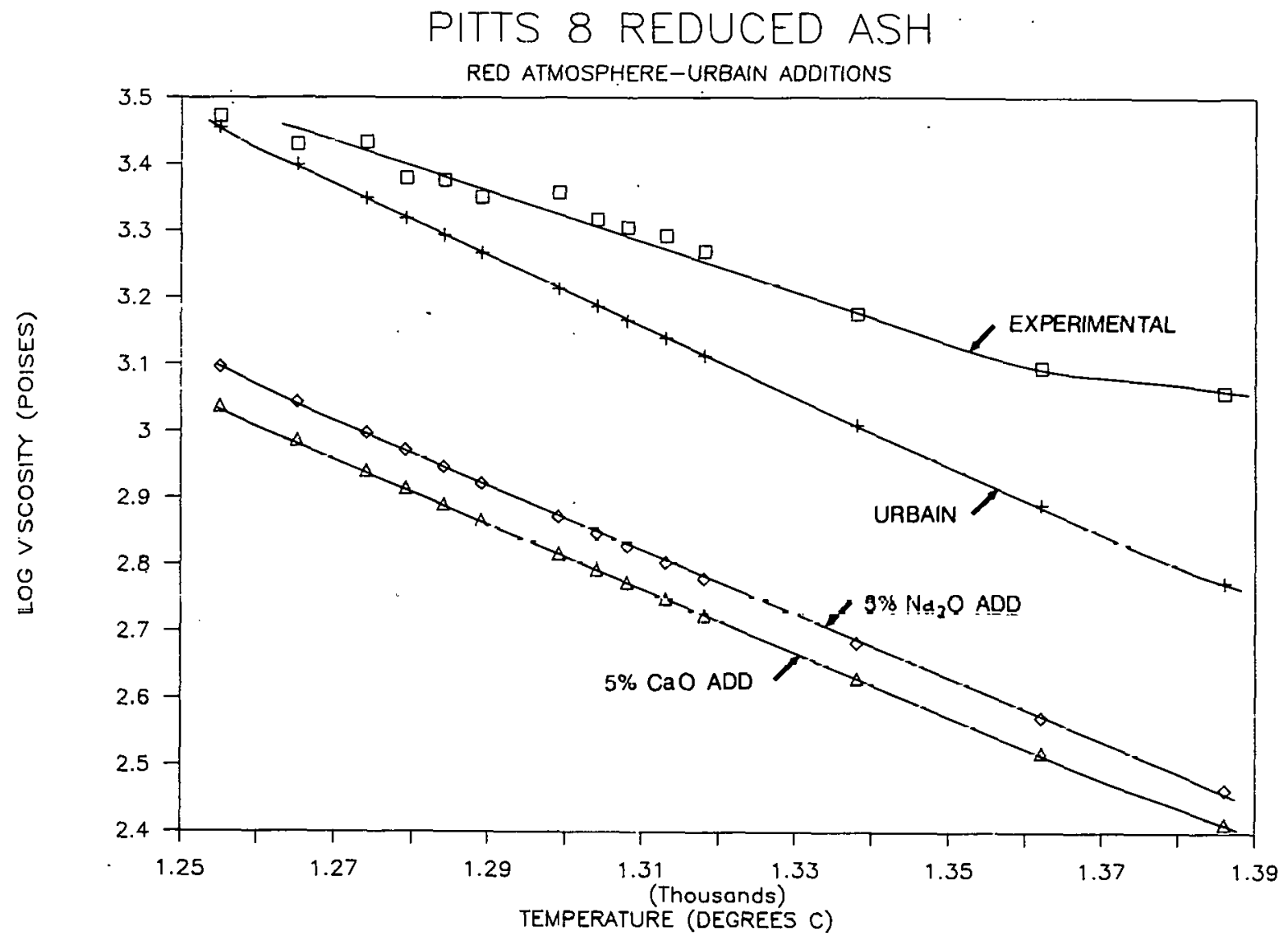

Figure 13. Effect of Addition of $\mathrm{Na}_{2} \mathrm{O}$ and $\mathrm{CaO}$ on Calculated Viscosity of Pittsburgh $\$ 8$ Slag.

other sample represents clinker of unacceptable size for proper removal. These clinkers may slag to the point of adhering to the slag wall refractory or may agglomerate enough to be too large to pass through the ash grate for removal. The problem with clinker formation at Great Plains is a reoccurring one resulting in a reduction in load capacity at times.

Ultimate and proximate analysis of the Freedom coal is listed in Table 7. Compositional data of the two samples is listed in Table 8 . The compositions of the two samples differ significantly in silica, calcium, sodium and sulfur content. The silica content is much lower in the ash clinker compared with the coal ash. The total alkali metal content ( $\mathrm{CaO}+\mathrm{MgO}$ $+\mathrm{Na}_{2} \mathrm{O}+\mathrm{K}_{2} \mathrm{O}$ ) is similar, however, the relative amounts of each alkali vary. The amount of calcium oxide in the clinker is much higher than in the ash while sodium oxide is reduced. In addition, there is a corresponding enrichment of sulfur in the clinker. 


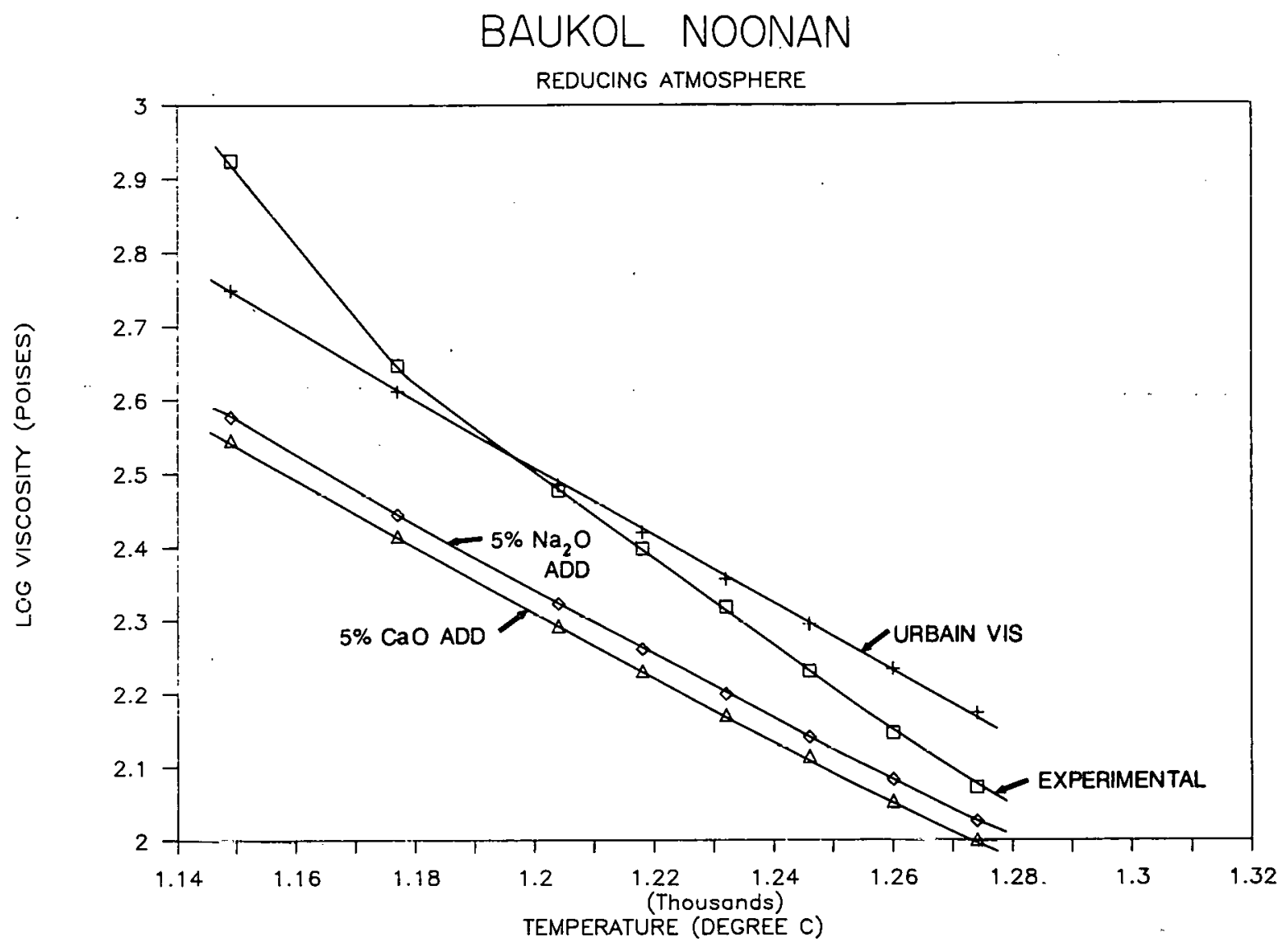

Figure 14. Effect of Addition of $\mathrm{Na}_{2} \mathrm{O}$ and $\mathrm{CaO}$ on Calculated Viscosity of Baukol-Noonan Slag.

TABLE 7

ANALYSIS OF FREEDOM COAL

(As Received Basis)

Air Dry Loss $=15.4$

Proxmate Analysis:

Moisture

Volatile Matter

Fixed Carbon (Ind)

Ash

Ultimate Analysis:

Hydrogen
Carbon
Nitrogen
Sulfur
Oxygen (Ind)
Ash

34.1

28.3

30.4

7.1

$$
\begin{array}{r}
6.63 \\
40.62 \\
0.52 \\
0.58 \\
44.54 \\
7.1
\end{array}
$$


BULK CHEMICAL AND MINERALOGICAL ANALYSIS OF FREEDOM COAL FEED ASH AND ASH CLINKER FROM THE GREAT PLAINS GASIFICATION PLANT, BEULAH, NORTH DAKOTA

\begin{tabular}{|c|c|c|}
\hline Major Oxides* & $\begin{array}{l}\text { Freedom Coal Feed Ash } \\
z \text { of Ash (Normalized) }\end{array}$ & $\begin{array}{l}\text { Ash Clinker } \\
\text { \% of Ash } \\
\text { (Normalized) }\end{array}$ \\
\hline Silica, $\mathrm{SiO}_{2}$ & 24.9 & 11.0 \\
\hline Aluminum Oxide, $\mathrm{Al}_{2} \mathrm{O}_{3}$ & 13.0 & 8.8 \\
\hline Ferric Oxide, $\mathrm{Fe}_{2} \mathrm{O}_{3}$ & 10.3 & 6.4 \\
\hline Titanium Oxide, Tin 2 & 1.1 & 0.7 \\
\hline Phosphorous Pentoxide, $\mathrm{P}_{2} \mathrm{O}_{5}$ & 0.1 & 0.8 \\
\hline Calcium Oxide, CaO & 27.1 & 41.1 \\
\hline Magnesium Oxide, Mgo & 6.9 & 5.4 \\
\hline Sodium Oxide, $\mathrm{Na}_{2} \mathrm{O}$ & 14.8 & 8.5 \\
\hline Potassium Oxide, $\mathrm{K}_{2} \mathrm{O}$ & 0.3 & 0.1 \\
\hline Sulfur Trioxide, $\mathrm{SO}_{3}$ & 1.3 & 17.2 \\
\hline Major Crystalline Phases ${ }^{+}$: & $\begin{array}{l}\mathrm{CaO} \\
. \mathrm{CaSO}_{4} \\
\mathrm{MgO}\end{array}$ & $\begin{array}{l}\mathrm{MgFe}_{2} \mathrm{O}_{4} \\
\mathrm{Fe}_{2} \mathrm{SiS}_{4}(?) \\
\text { (Matched peaks } \\
\text { but chemistry } \\
\text { highly unlikely) }\end{array}$ \\
\hline
\end{tabular}

$\star X-$ ray fluorescence

$+x$-ray diffraction

There are also differences in the sample mineralogies (Table 8 ). The clinker consists of minerals which generally have a lower melting point than those seen in the non-agglomerated ash. Tho clinkel also contains a substantial amount of amorphous phase material which acts as a cementing agent for particles.

The differences in composition should reveal something about the potential of the ash to agglomerate in the gasifier system. By using the Urbain equation, as discussed in section 5.3.2, the theoretical viscosity of the ash, if melted, can be calculated. The viscosity values are approximations at best since the bulk composition is being used to calculate the viscosities. However, at least a relative comparison of the viscosities can be made. The viscosity curves for both samples are shown in Figure 15 and listed in Table 9. The calculated viscosity of the ash clinker is 


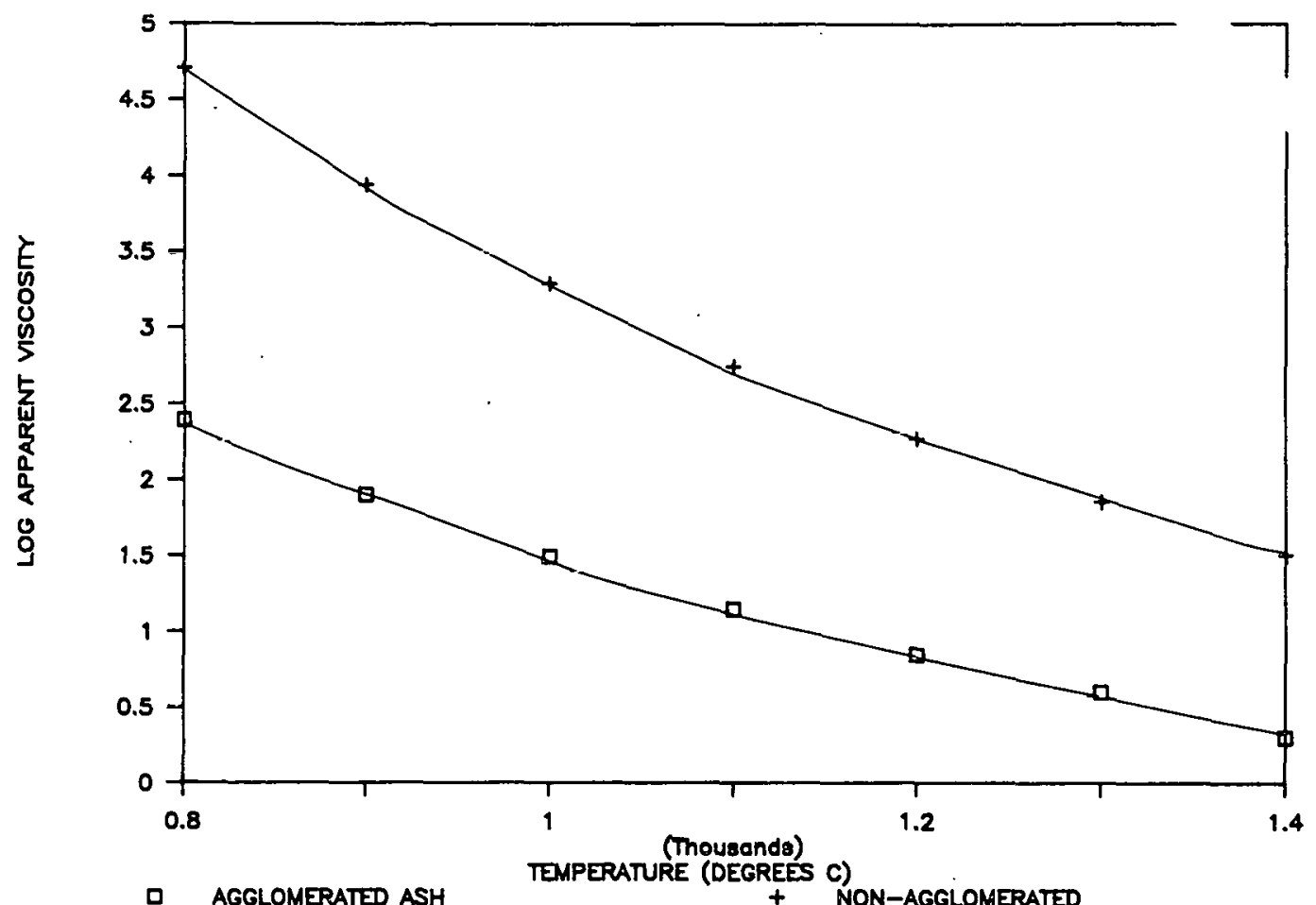

Figure 15. Comparison of Calculated Viscosity for Ash Samples from Great Plains Gasifier.

significantly lower than the non-agglomerated ash. The presence of a substantial amount of an alkaline earths ( $\mathrm{CaO}$ ) in the clinker is probably the caused for the reduced viscosities. In fact, studies of the Freedom Mine show the presence of a calcite seam associated with the coal. Within the context of the Raask sintering model, as discussed in the background section, the results are consistent with the explanation that reduced viscosity results in increased sintering and agglomeration.

TABLE 9

CALCULATED VISCOSITIES (POISES) FOR GREAT PLAINS SAMPLES

\begin{tabular}{lccccccc}
\hline & $800^{\circ}$ & $900^{\circ}$ & $1000^{\circ}$ & $1100^{\circ}$ & $1200^{\circ}$ & $1300^{\circ}$ & $1400^{\circ}$ \\
\hline Sample & 81,317 & 87805 & 1965 & 554 & 186 & 72 & 32 \\
\hline $\begin{array}{c}\text { Non-Agglomerated } \\
\text { Ash } \\
\begin{array}{c}\text { Agglomerated } \\
\text { (Clinker) }\end{array}\end{array}$ & 247 & 79 & 31 & 14 & 7 & 4 & 2 \\
\hline
\end{tabular}




\subsubsection{Effect of Slag Composition on the Critical Viscosity Temperature}

The critical temperature $\left(T_{C V}\right)$ is defined as the temperature at which flow behavior changes from Newtonian to non-Newtonian. In slags, $T_{c y}$ is represented as a definite break in slope of the temperature/viscosity curve representing the onset of crystallization in the melt with cooling. The $T_{\mathrm{CV}}$ is not defined in a high silica, glassy slag where the behavior is essentially Newtonian during the entire cooling process. Results to date suggest the following:

1. Increasing $\mathrm{CaO}$ content showed a greater influence in reducing the $\mathrm{T}_{\mathrm{CV}}$ than any other single alkali.

2. Increasing the total $\mathrm{SiO}_{2}$ content, thereby increasing the ratio $\mathrm{SiO}_{2} /\left(\mathrm{Na}_{2} \mathrm{O}+\mathrm{CaO}+\mathrm{MgO}+\mathrm{K}_{2} \mathrm{O}\right)$ increased the $\mathrm{T}_{\mathrm{Cv}}$. This is shown in Figure 16 .

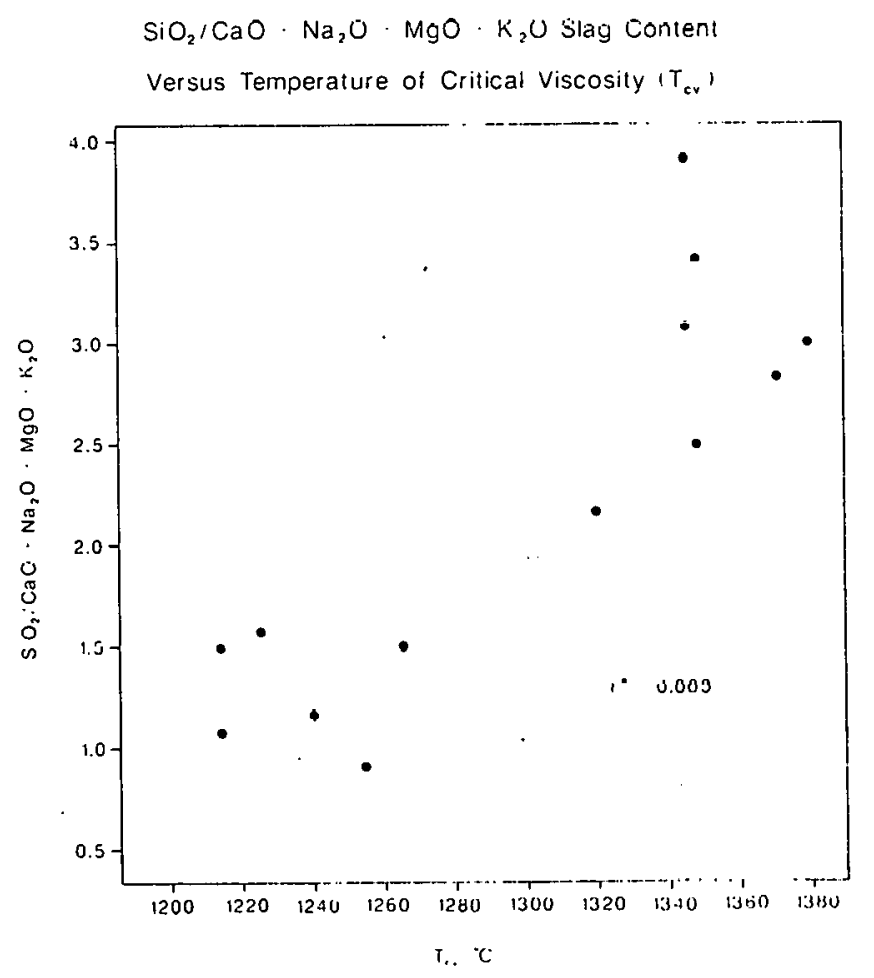

Figure 16. Relationship Between $\mathrm{SiO}_{2}$ to Alkali + Alkali Earth Ratio and Temperature of Critical Viscosity. 
The value of understanding the nature of the occurrence of $T_{C v}$ is in the fact that most predictive equations deal with the Newtonian portion of the temperature-viscosity curve. In this portion of the curve, there is only a liquid phase present and the composition of the liquid is constant, whereas in the non-Newtonian portion of the temperature-viscosity curve, there are two phases present, a liquid and a solid phase. In addition, the composition of the liquid phase is constantly changing as it reacts with the solid phase. Since predictive viscosity equations are compositionally dependent, the development of a viscosity equation describing the non-Newtonian portion of the temperature viscosity curve is extremely difficult, if not impossible, at this time. However, if the occurrence of $\mathrm{T}_{\mathrm{cv}}$ can be predicted the temperature limit for application of any predictive equations for Newtonian flow behavior can be established.

\subsubsection{The Effect of Atmosphere on Viscosity}

The concept of a sintering model in studying ash agglomeration is a useful tool in that it relates the physical properties of viscosity and surface tension as discussed in section 3.4. Viscosity is shown to be inversely proportional to sintering while surface tension is shown to be directly proportional to sintering (Figure 2).

Work conducted at the Bituminous Coal Research National Lab (BCRNL) and UNDERC have shown that there are differences in slag behavior in oxidizing, reducing, and neutral atmospheres. The temperature/viscosity curves generated by a series of viscosity tests run under various atmospheres using a BaukolNoonan slag are presented in Figure 17. The results show the temperature viscosity curve to be depressed under reducing environments versus an oxidizing environment. Baukol-Noonan slag meets the 100 poise at $1300^{\circ} \mathrm{C}$ specification for most slag tap design and would be tapped easily under reducing conditions. However, the viscosity at $1300^{\circ} \mathrm{C}$ is well above 100 poises in an oxidizing atmosphere. If the conditions in a gasifier changed, as in the case of fuel bed bridging to produce an oxidizing environment, the slag viscosity would increase drastically. As a result of the increase in slag viscosity, the slag may be impossible to tap. In the case of a drybottom gasifier, the concem may be in the area of viscous flow sintering of individual ash particles causing ash agglomeration. While this project is currently studying bulk slag oamplos, it shnuld be stressed that the environment surrounding an ash particle also influences the viscosity of melts on the surface of an ash particle.

The discussion presented here on the effect of atmosphere and composition on viscosity show the following relationships:

1. Slag viscosity decreases under a reducing atmosphere,

2. An increased silicon dioxide content increases the viscosity surface tension of a slag, and

3. An increased sodium oxide content (possibly total alkali content) decreases viscosity of a slag.

Given that the main mode of sintering is by viscous flow, the observations made to data suggest that the sintering potential of an ash is greater in a reducing environment than in an oxidizing environment. 


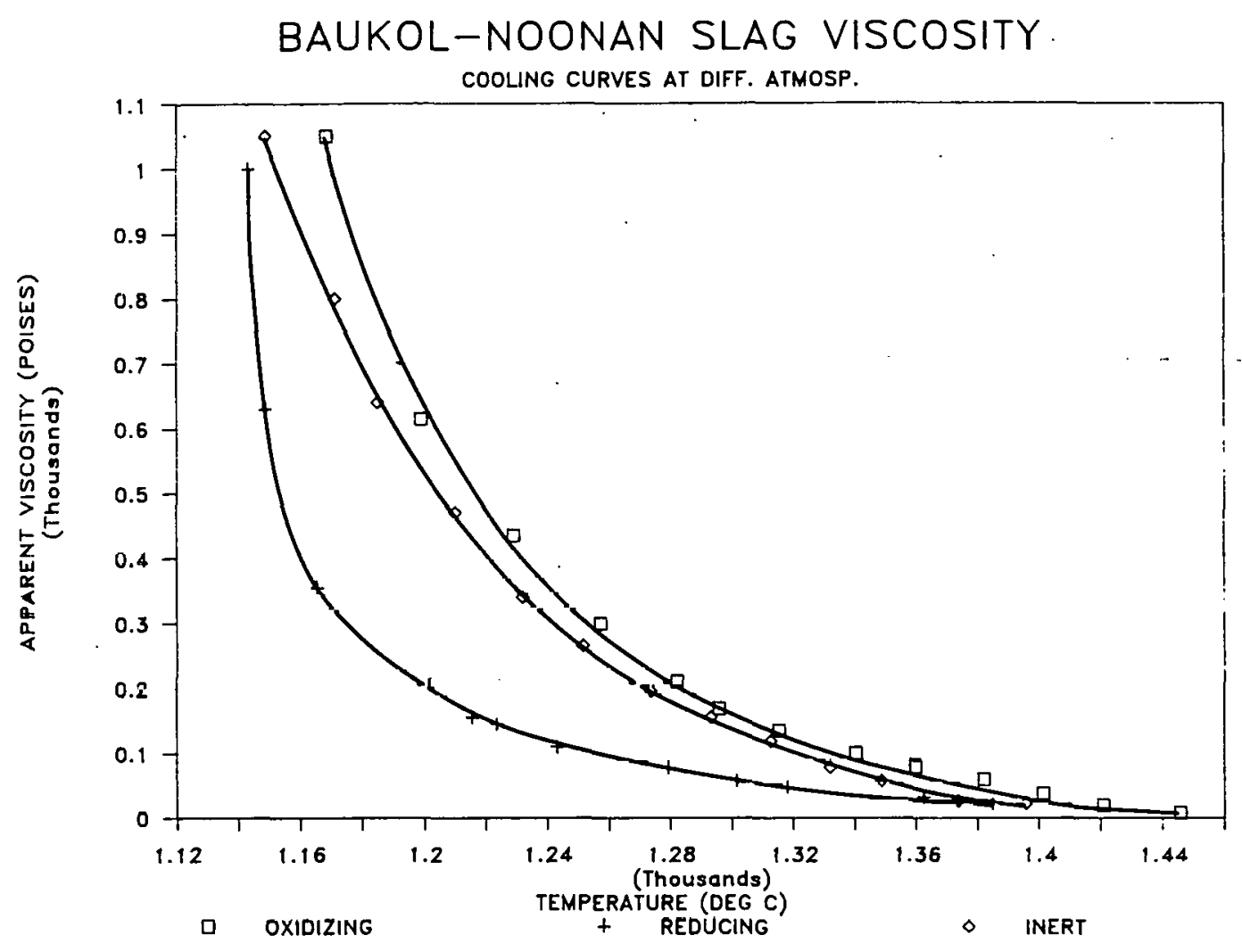

Figure 17. Effect of Atmosphere on Viscosity.

\subsection{SLAG SURFACE TENSION STUDIES}

While the compositional and atmospheric effects on viscosity have been discussed in relation to a sintering model, there remains the aspect of surface tension to be considered. Surface tension is known to vary substantially with chemical composition and local atmosphere and to a limited extent with temperature.

\subsubsection{The Effect of Atmosphere on the Surface Tension of Slags}

The sessile drop technique has been determined to be the most appropriate technique for the determination of bulk slag surface tension. The technique has been described in detail in previous quarterly reports (University of North Dakota Energy Research Center) (UNDERC) DOE Quarterly Report April-June 1986 Section 13. To date, a total of thirty-five surface tension runs have been conducted on twenty-two coal slags. The initial runs were conducted to determine the appropriate experimental design and calculation procedures suited for coal slags. The recent work has concentrated on observing the effect of an oxidizing versus reducing atmosphere on surface tension. 
The results from four different coal slag surface tension runs conducted using air (oxidizing), nitrogen (inert) and $8 \%$ hydrogen in nitrogen (reducing) atmospheres are presented in Table 10. A plot of temperature versus surface tension of the various slags is shown in Figure 18. Each point is labeled to identify the coal slag and the atmosphere under which the test was run. The oxidizing, reducing, and inert runs for each slag are connected with a straight line.

TABLE 10

SURFACE TENSION DATA FOR A SERIES OF COALS
UNDER OXIDIZING, REDUCING, AND INERT ATMOSPHERES

\begin{tabular}{|c|c|c|c|c|}
\hline Coal Slag Sample & ID & ATM & $\begin{array}{l}\text { Temp. } \\
\left({ }^{\circ} \mathrm{C}\right)\end{array}$ & $\begin{array}{l}\text { Surface Tension } \\
\text { (Dynes/Cm) }\end{array}$ \\
\hline \multirow[t]{3}{*}{ Beulah High Sodium } & BSR & Reducing & 1255 & 480 \\
\hline & BSO & Oxidizing & 1275 & 225 \\
\hline & BSI & Inert & 1285 & 138 \\
\hline \multirow[t]{3}{*}{ Gascoyne Blue } & GBR & Reducing & 1260 & 378 \\
\hline & GBO & Oxidizing & 1310 & 262 \\
\hline & GBI & Inert & 1280 & 647 \\
\hline \multirow[t]{3}{*}{ Gascoyne Red } & BRR & Reducing & 1235 & 454 \\
\hline & GRO & Oxidizing & 1250 & 327 \\
\hline & GRI & Inert & 1260 & 378 \\
\hline \multirow[t]{4}{*}{ Velva } & VVR & Reducing & 1450 & .774 \\
\hline & vvo & Oxidizing & 1290 & 545 \\
\hline & vvo & Oxidizing & 1370 & 358 \\
\hline & VVI & Inert & 1370 & 367 \\
\hline
\end{tabular}

In general, the surface tension of a slag is greater in a reducing atmosphere of hydrogen-nitrogen or nitrogen versus an oxidizing atmosphere. Another trend that has become apparent in these samples and others is that the temperature at which the slag bead becomes completely liquid is higher in oxidizing atmospheres than in reducing atmospheres with the exception of the Velva slag. In addition, an increase in temperature appears to slightly decrease the surface tension of a slag bead as stated by Raask (27). Assuming a constant composition, viscosity decreases under reducing environments while surface tenoion increases. Given these facts the potential for sintering is enhanced in reducing versus oxidizing environments. 


\section{TEMPERATURE VERSUS SURFACE TENSION}

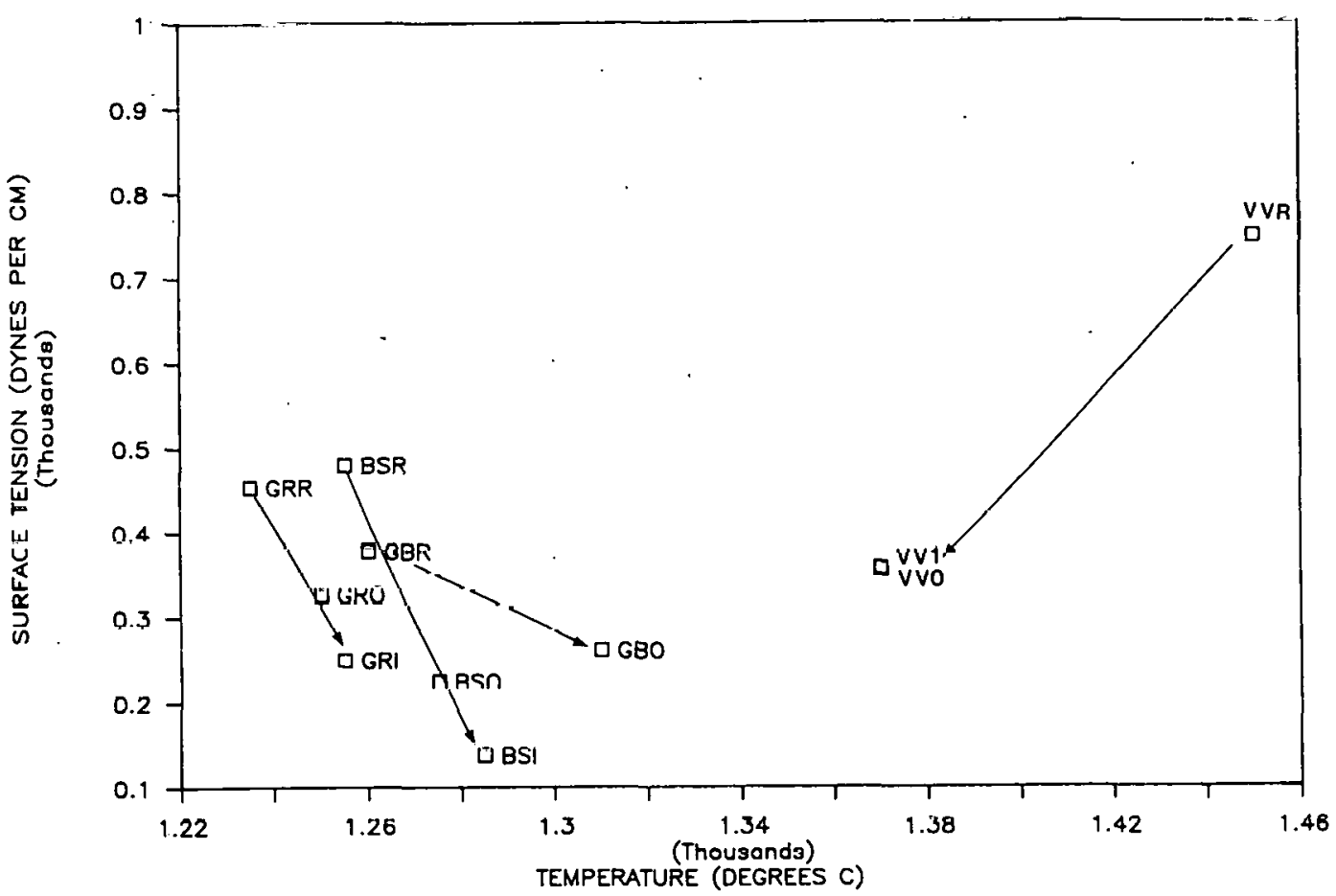

Figure 18. Surface Tension Versus Temperature (See Table 10 for Sample Identification).

\subsubsection{Relation of Surface Tension to Slag Composition and Viscosity}

Surface tension and viscosity are the two principal parameters whicl govern the rate of sintering and therefore the tendency of particles lo agglomerate. Both surface tension and viscosity decrease with temperature while the rate of sintering increases (Figure 2). According to Raask (27) the coefficient of surface tension is small (Curve A, Figure 2) and is proportional to the inverse of the square root of temperature. Viscosity (Curve B, Figure 2) changes exponentially with temperature as has been observed in most slags having a silicon dioxide content of approximately less than fifty percent by weight. Consequently the rate of ash sintering will show an inverse relationship with viscosity and increase rapidly as the temperature of the coalescing particles is raised (27).

A series of fifteen slags were analyzed for their bulk chemlcal composition and measured for their surface tension under an oxidizing atmosphere. The temperature at which the surface tension is measrued varies due to the different melting. points of each slag and the temperature at which a completely liquid spherical or elliptical bead forms. In an effort to relate bulk composition to surface tension correlation coefficients were determined and graphs constructed. The compositional variables used were the major oxide analysis of each slag. Composition was then correlated with surface tension, and $\log$ viscosity calculated at the surface tension temperature. At this point the compositions have been plotted as single, multiple, or ratio variation of the various oxides. 
The results show sodium and silica to have a relationship with surface tension (Figures 19,20,21). Slags having higher silica content tend to have higher surface tension. On the other hand, slags having higher sodium content have lower surface tensions. It appears that the sodium level alone is not what determines surface tension but rather the relative amount of silica to sodium.

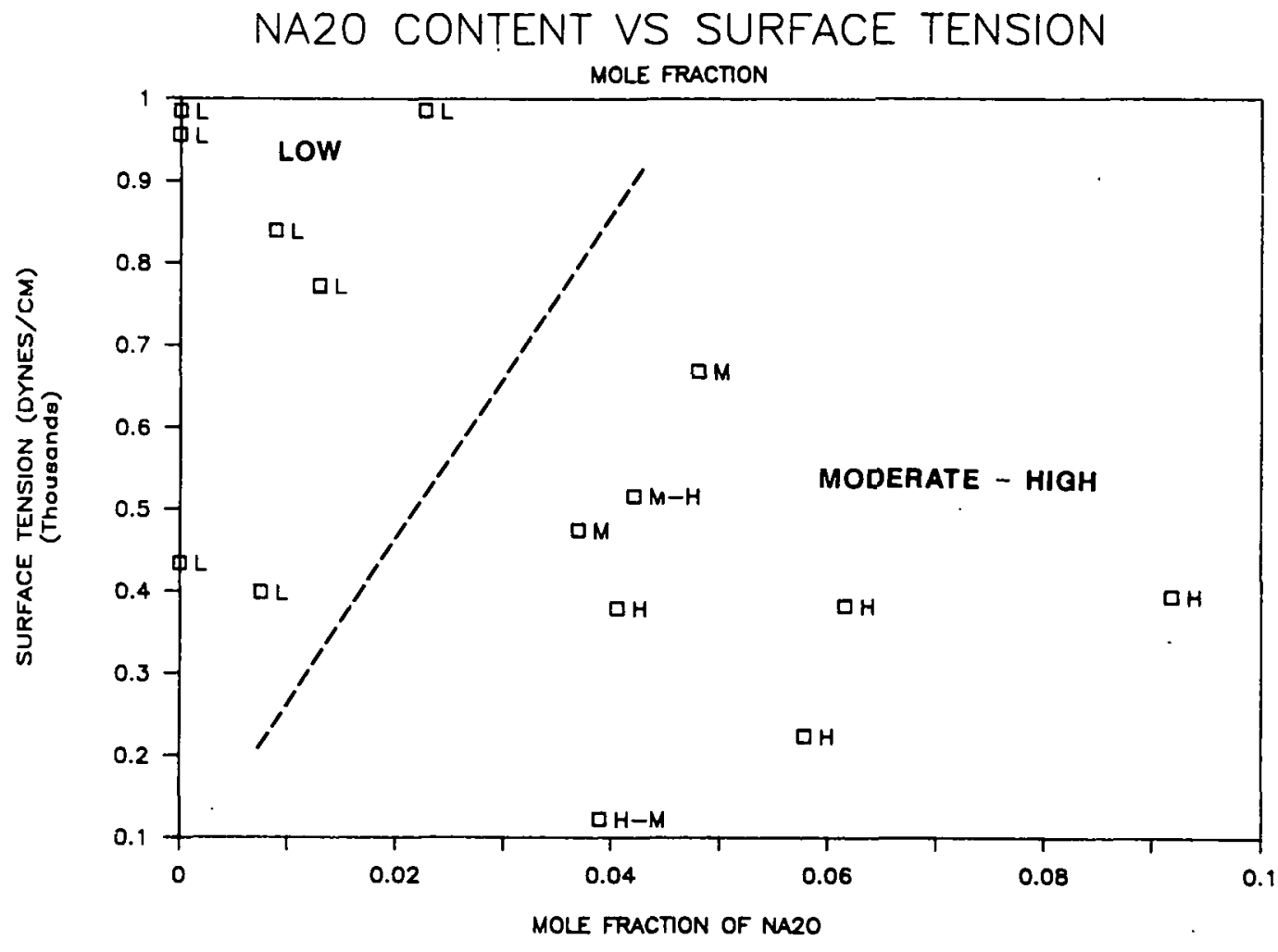

Figure 19. Surface Tension Versus Mole Fraction $\mathrm{Na}_{2} \mathrm{O}$.

In Figures 19, 20, and 21 the distribution of the data points are shown for silicon dioxide, sodium oxide and the ratio of silicon dioxide to sodium oxide versus surface tension. Each data point shown is also labelled as to that particular ashes tendency to sinter based on previous work with that coal. Ashes which tend to agglomerate are designated with a " $\mathrm{H}^{\text {" }}$ or "M" for high or moderate. Ashes with a low low potential to agglomerate or sinter are designated with a " $\mathrm{L}$ ". Agglomeration tendency was based on results from ash fouling deposits. The classification is qualitative and determined by pilotscale results. In Figures 19-21, there is a consistent clustering between those ashes which tend to have a higher tendency to sinter or agglomerate and those ashes which have a lower tendency to sinter or agglomerate and border designated on each graph between these ash types is arbitrary. In Figure 21 the plot of surface tension versus ratio of silicon dioxide to sodium oxide 


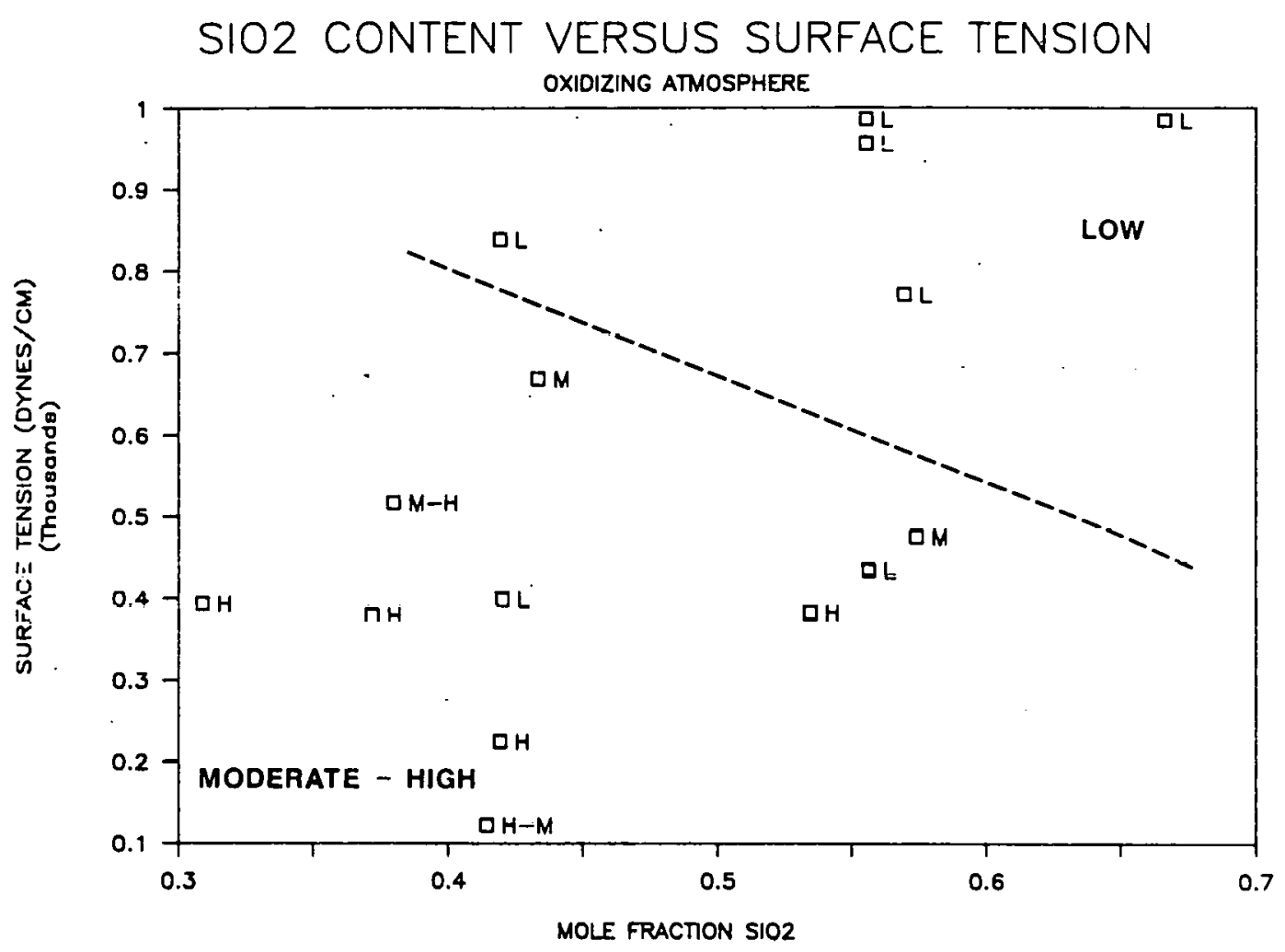

Figure 20. Surface Tension Versus Mole Fraction $\mathrm{SiO}_{2}$.

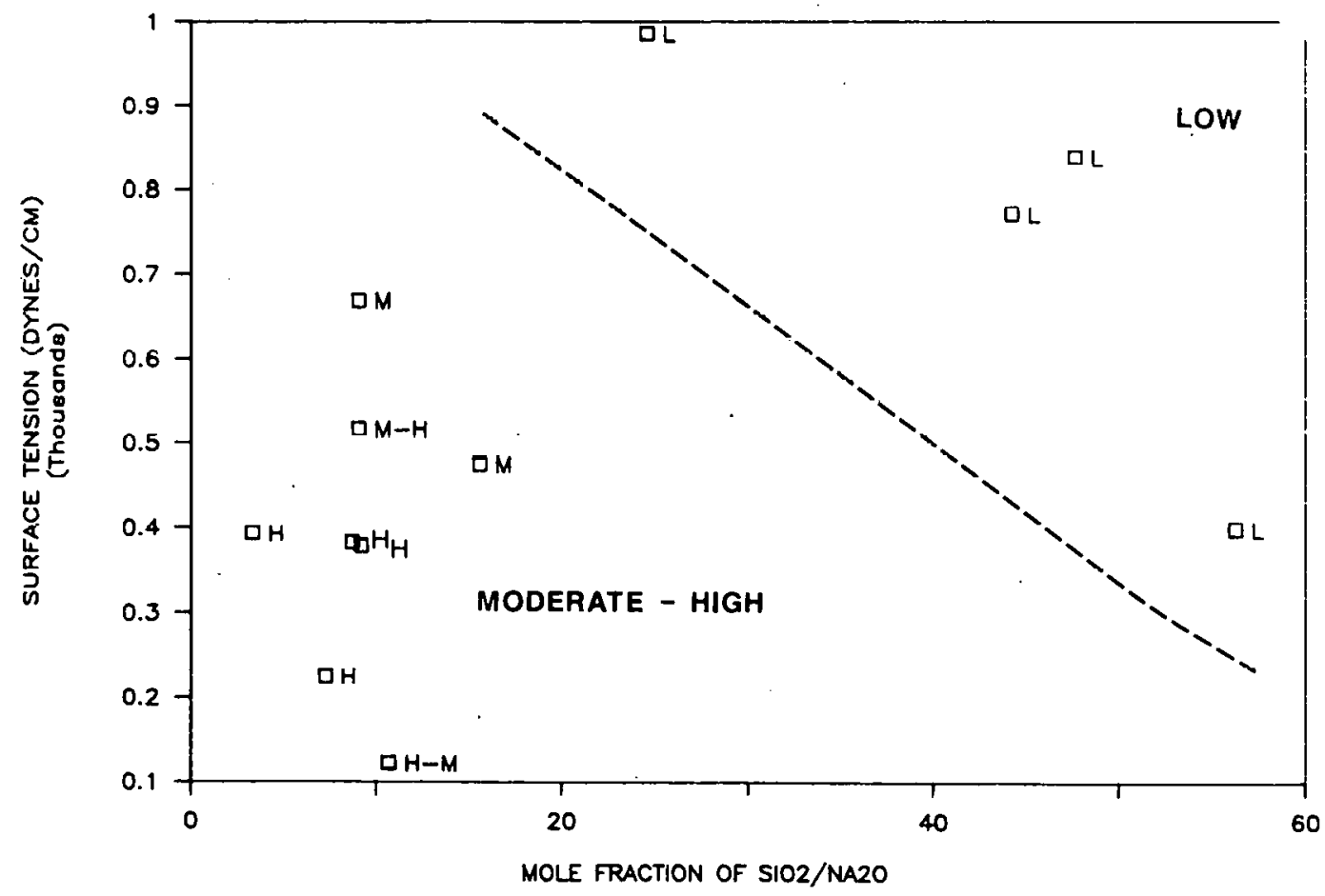

Figure 21. Surface Tension Versus Ratio of $\mathrm{SiO}_{2} / \mathrm{Na}_{2} \mathrm{O}$. 
shows an improvement in the clustering of low versus high agglomerating ashes. The imporved clustering verifies that a combination of elements are important in effecting surface tension. To define a linear relation for these graphs is not applicable since the relations are not simple and linear. What is important is to identify the clustering phenomena of the ash potential to agglomerate.

Within the context of the Frenkel sintering model discussed earlier one would assume:

- higher silicon dioxide levels result in increased sintering since surface tension is increased, and

- increased sodium oxide levels would result in decreased sintering or agglomeration since surface tension is decreased.

The problem with these assumptions based soley on surface tension data is that it is known that increased sodium tends to increase, not decrease, ash agglomeration. On the other hand, increasing the silicon dioxide content tends to decrease sintering contrary to these results. From viscosity studies it has been shown that silica tends to increase viscosity while sodium additions decrease viscosity. So when considering viscosity, $\mathrm{SiO}_{2}$ tends to decrease sintering while sodium oxide increases sintering. The point of these results is that one cannot consider the property of surface tension alone in considering the change in sintering potential of an ash with changes in composition. In Figure 2, the surface tension of an liquid phase changes only slightly with increase temperature while viscosity decreases markedly. Therefore the role of viscosity is much more important than surface tension alone in determining sintering potential of an ash with increasing temperature. The relation becomes even more complicated when dealing with numerous ash compositions at different tempertures. In fact, it is the ratio of surface tension to viscosity as it relates to temperature and composition which is the key to determining the differences in the sintering or agglomerating potential of an ash.

To determine the relationship of surface tension and viscosity as it varies with composition it was decided to use a combination of experimental surface tension data with calculated viscosity values. The following assumptions were made:

- The particle radius $(r)$ and time $(t)$ in the Frenkel equation were assumed to be constant. Therefore $x^{2}$ (the radius of the neck bridge between particles) is proportional to $\gamma / \eta$ (surface tension/viscosity),

- The Urbain equation was used to calculate the viscosity of the molten phases at the temperature at which the surface tension measurements were taken. The Urbain equation was used based on its successful application in predicting viscosities as discussed earlier. 
By comparing the composition of a slag to its surface tension and viscosity at a specific temperature a better idea of the relation of the three parameters can be made. In Figure 22 a plot of the $10 g 10$ viscosity versus surface tension is shown. The clustering is not as distinct as in other plots, however, a trend is revealed which relates to the first assumption listed above. The ratio of surface tension (measured) to viscosity (calculated) is related to sintering ( $x^{2}$ proportional to $\left.\gamma / \eta\right)$. Those ashes observed to have low sintering potential have surface tension to viscosity ratios of .024 or less. Those ashes which tend to exhibit sintering at combustion temperatures have ratios in the area of 0.11 through 2.08 . The results suggest the following:

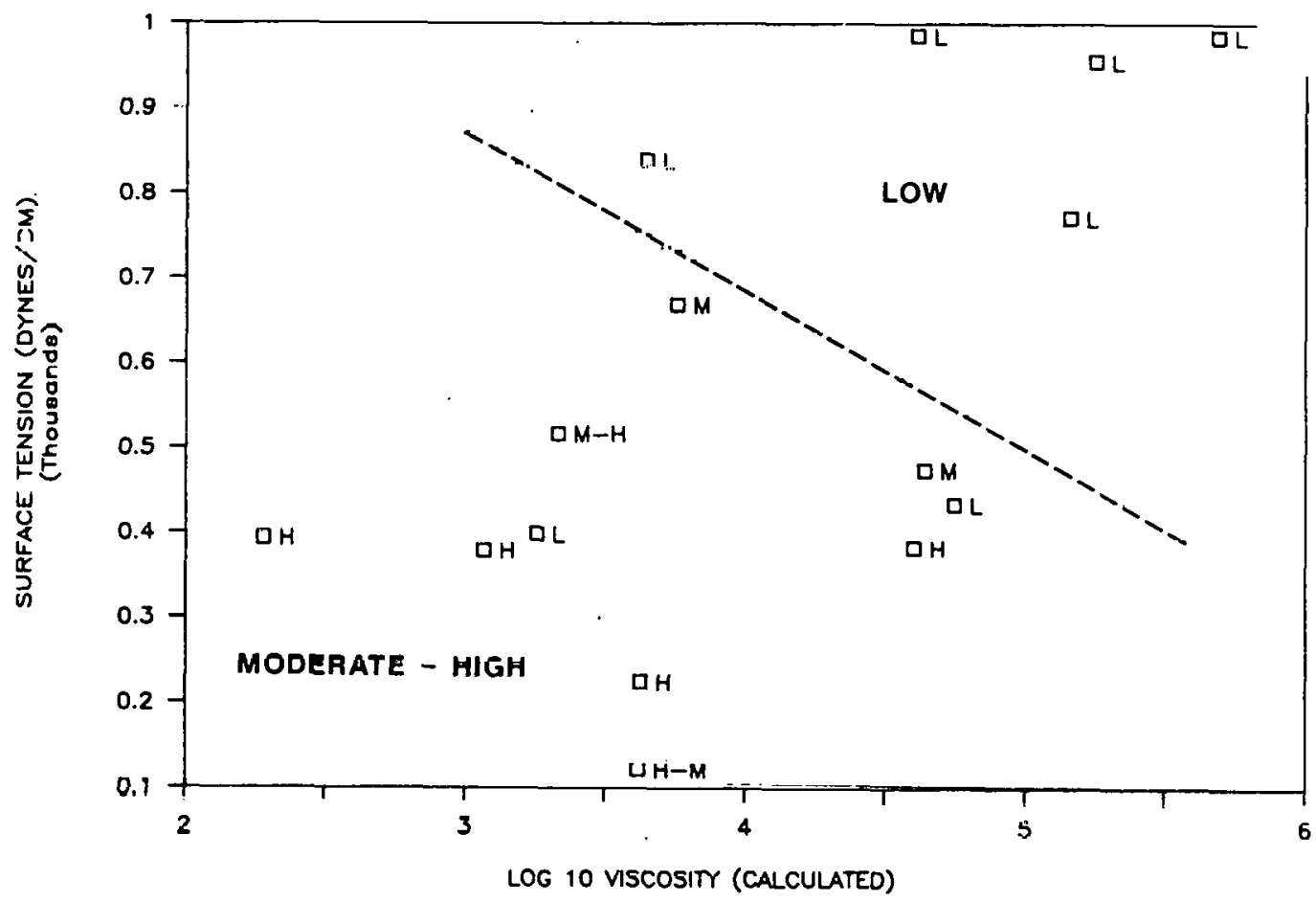

Figure 22. Surface Tension Versus Log Viscosity.

D Those ashes which tend not to sinter or agglomerate form molten phases which have higher viscosities relative to their surface tension at a given temperature.

- Those ashes which tend to agglomerate form molten phases which have lower viscosities relative to their surface tension at a given temperature.

The mole fraction ratio of silicon dioxide to sodium oxide content versus viscosity was plotted (Figure 23). The purpose of such a comparison was to relate a compositional parameter to viscosity via surface tension. The result of the comparison reveals a much thighter clustering of ash types related to viscosity than surface tension. The results suggest that the viscosity factor is much more susceptible to compositional parameters than surface tension. 


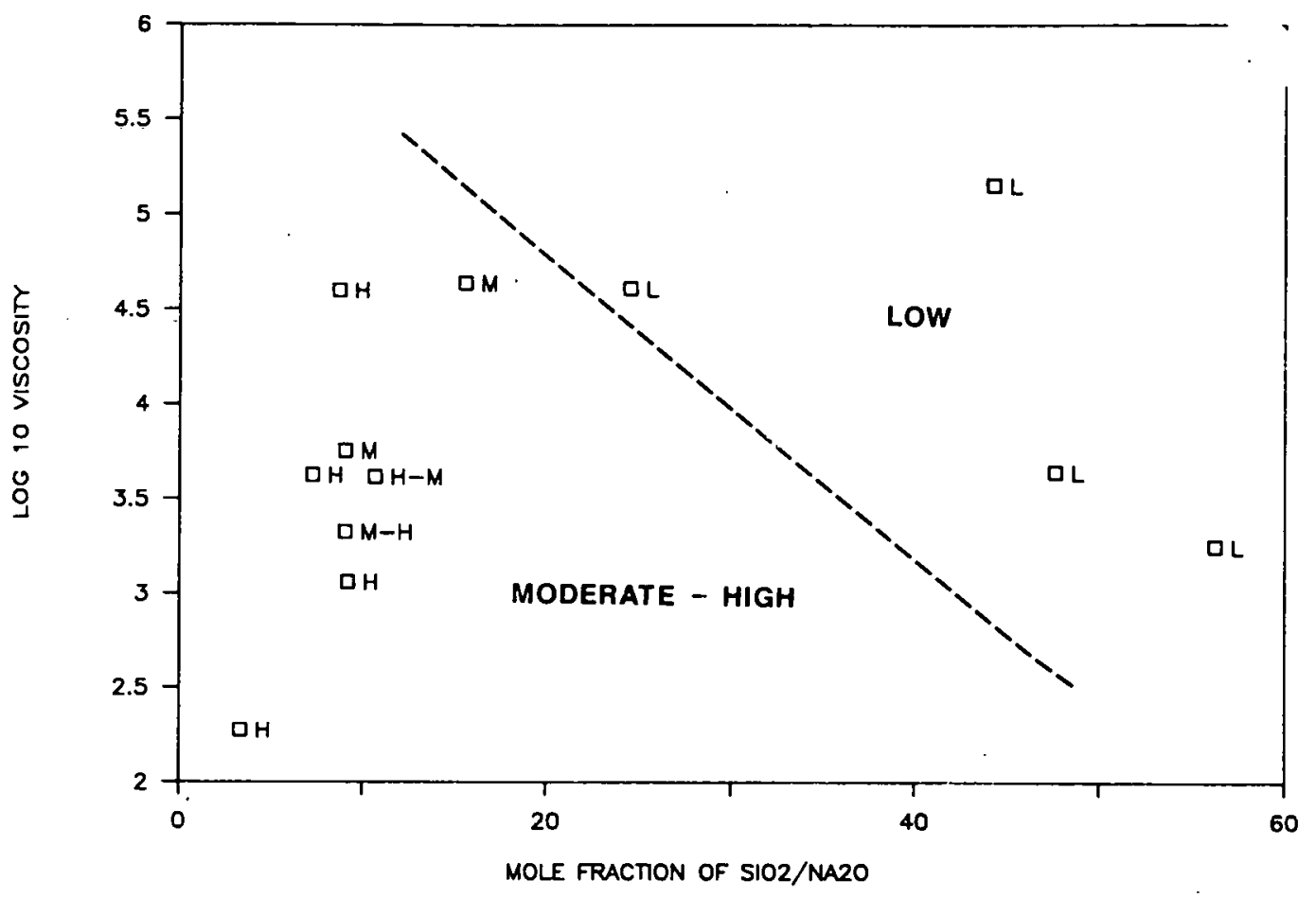

Figure 23. Log Viscosity Versus Ratio of $\mathrm{SiO}_{2} / \mathrm{Na}_{2} \mathrm{O}$.

Therefore one can conclude that even though surface tension is elevated by increased silicon dioxide content those ashes which have higher silicon dioxide to sodium dioxide ratios at a given temperature tend to have higher viscosities relative to their surface tension. As a result these ashes tend to exhibit reduced sintering and agglomerating. While sodium oxide tends to decrease surface tension, it tends to decrease viscosity at a greater rate resulting in increased viscous flow sintering.

The discussion presented here on the effect of atmosphere and composition on surface tension show the following relationships:

- slag viscosity decreases under a reducing atmosphere

- slag surface tension increases under a reducing atmosphere

- an increased silicon dioxide content increaseses viscosity of a slag at a greater rate than the surface tension. The net result is reduced sintering.

- an increased sodium oxide content (possibly total alkali content) decreases the viscusity of a slag at a greater rate than the surface tension. The net result is an increase in sintering. 


\subsection{FUTURE HORK}

The future work plan of this project is to pursue the study of the effect of ash and slag chemical composition as it relates to ash agglomeration and slag flow behavior. Additional ashes to be used in the surface tension and viscosity studies will include the following: ashes generated in a drop-tube furnace, pilot-plant ashes generated in a fluidized bed gasifier, and ashes produced under static conditions with an without the addition of steam. Also included is the use of synthetic slags for modeling purposes.

The scale of the project to date has considered bulk ash and slag chemistry, bulk physical properties, and vaporization. In a study of slag flow initiation and maintenance this approach is quite acceptable. The use of a bulk slag approach is acceptable in the early stage of studying agglomeration phenomena, however, detailed particle to particle interactions must be investigated. The intent of the surfact tension and viscosity work in Year 2 is to evaluate the detailed particle to particle aspects of 3 intering under various atmospheres. In this way the specific components which are more important in effecting various physical parameters can be isolated. Additional detailed work to expand the SOLGASMIX data base will be compared to actual experimental data to test the data base system. The viscosity data base will be used to statistically evaluate and refine predictive equations.

\subsection{REFERENCES}

1. Miller, R.N., R.F. Yarzab, and P. Given, Euel, 1979, 58, 4.

2. Frazer, F.W., and C.B. Belcher, Fuel, 1973, 52, 41.

3. O'Gorman, J.V., and P.L. Walker, Euel, 1973, 52, 71.

4. Mitchell, R.S., and H.J. Gluskoter, Euel, 1976, 55, 90.

5. Brinkley, S.R., Journal of Chemical Physics, 14, 563, 1946.

6. Brinkley, S.R., Journal of Chemical Physics, 15, 107, 1947.

7. White, W.B., S.M. Johnson, and G.B. Dantzig, "Chemical Equilibrium in Complex Mixtures", Journal of Chemical Physics, 28(5), 1958.

8. Eriksson, G. "Thermodynamic Studies of High Temperature Equilibria III", ACTA Chemica Scandinavica, 25, 7, 1971.

9. Eriksson, G., "Thermodynamic Studies of High Temperature Equilibria XII", Chemica Scripta, 8, 100, 1975.

10. Eriksson, G. and E. Rosen, "Thermodynamic Studies of High Temperature Equilibria VIII", Chemica Scripta, 4, 193, 1973.

11. Liao, P.K. and K.E. Spear, SOLGASMIX with HETTA for the IBM-PC and Compatibles, Materials Research Laboratorles, Penrsylvaula 3tate University, University Park, PA, 1985.

12. JANAF Thermochemical Tables, 2nd Ed., D.R. Stull and H. Prophet, Project Directors, National Bureau of Standards, 37, June, 1971.

13. Robie, R.A., Hemingway, B.S. and Fisher, J.R.: 1979, Themodynamic Properties of Minerals and Related Substances at $298.15 \mathrm{~K}$ and 1 Bar ( $10^{5}$ Pascals) Pressure and at Higher Temperatures", Geol. Survey Bull 1452 (Washington, DC: U.S. Govt. Printing Office).

14. Barin, I., Knacke, 0.: 1973, "The rmochemical Properties of Inorganic Substances" (New York: Springer Verlag).

15. Rein, R.H. and Chipman, J.: 1965, Trans, Metall, Soc. AIME, 233, p. 415.

16. Kelley, K.K., "Contributions to the Data on Theoretical Metallurgy (Reprint of Bulletins 383, 384, 393, and 406)", U.S. Bureau of Mines Bulletin, 601, 1962 . 
17. Wibberley, L.J. and T.F. Wall, "Alkali-Ash Reactions and Deposit Formation in Pulverized Coal-Fired Boilers: The Thermodynamic Aspects Involving Silica, Sodium, Sulfur, and chlorine", Fuel, 61, 87, 1982.

18. Carling, R.W., R.W. Mar, and A.S. Nagelberg, "Application of Complex Equilibrium Calculations to the Study of Mineral Matter During Coal Combustion", Sandia Report, SAND82-8035, 1982.

19. Benson, S.A. "Laboratory Studies of Ash Deposit Formation During the Combustion of Western U.S. Coals", Ph.D. Thesis, The Pennsylvania State University, May 1987.

20. Hastie, J.W. and D.W.j Bonnell, "A Predictive Phase Equilibria Model for Multicomponent Oxide Mixtures Part II: Oxides of $\mathrm{Na}-\mathrm{K}-\mathrm{Ca}-\mathrm{Mg}-\mathrm{Al}-\mathrm{Si}$, High Temperature Science, 19, 3, 275, 1985.

21. Hastie, J.W., D.W. Bonnell, and E.R. Plante, "A Predictive Phase Equilibria Model for Multicomponent Oxide Mixtures Part III: MHD Slags". Paper $\$ 3$ in Proceedings of the 23rd SEAM, June, 1985.

22. Hastie, J.W., D.W. Bonnell, E.R. Plante, and W.S. Horton, "Thermodynamic Activity and Vapor Pressure Models for Silicate Systems Including Coal Slags", in Thermochemistry Today and Its Role in the Immediate Future, M.A.V. Ribeiro da Silva, Ed., Reidal Publication, Boston, 1983.

23. Hastie, J.W., W.S. Horton, E.R. Plante, and D.W. Bonnell, "Thermodynamic Models of Alkali-Metal Vapor Transport", High Temperatures _ High Rressures, 14, 669, 1982.

24. Kuczynski, G.C, 1949 Self Diffusion in Sintering of Metallic Particles, Jour. Metals, February, p. 169.

25. Kuczynski, G.C. 1977, Science of Sintering I. Science Sintering p. 243.

26. Raask, Erich, 1985. Mineral Impurities in Coal Combustion. Hemisphere Pub. Corp., Washington, 484 pp.

27. Streeter, R.C., E.K. Dieh1, and H.H. Xchobert, In "Measurement and Prediction of Low-Rank Coal Slag Viscosity", The Chemistry of Low-Rank coals, Schobert, ed., American Chemical Society, Washington, 1984, Chapter 12.

28. Watt, J.D., and F. Fereday, J. Inst. Euel, 1969, 42, 99.

29. Hoy, H.R., A.G. Roberts, and D.M. Wilkens, Insta. Gas. Engrs. Publication, 672, 1964.

30. "Development, Testing, and Evaluation of MHD Materials," National Bureau of Stnadards Quarterly Reports Nos. 1-5, Contract No. E (49-18)-1230, $1974-75$.

31. "Investigation of the Distribution of Minerals in Coals by Normative Analysis," U.S. Department of Energy Report FE-2494-TR-2, 1980.

32. Reid, W.T., and P. Cohen, Trans. Amer. Soc. Mech. Engrs., 1944, 66, 83.

33. Riboud, P.B., Y. Roux, L.D. Lucas, and H. Gaye, Eachberichte Huttenpraxis Metallweiterverarbeitung, 1981, 12, 859.

34. Urbain, G., F. Cambier, M. Deletter, and M.R. Anseau, Trans. J. Br. Ceram. Soce, 1981, 80, 139.

35. Schobert, H.H., An Informal Review of Viscosity - Composition Correlations Applied to Low-Rank Coal Ash Slags.

36. Schobert, H.H., R.C. Streeter, and E.K. DiehI, Euel, 1985, 64, 1611.

37. Kozakevitch, P. and G. Urbain, Mem. Sci. Rey. Met., 1961, 58, 40.

38. Butler, J.N. and B.H. Bloom, Surface Sci, 196, 4. 1.

39. Dorsey, N.E., J. Wash. Acad.SCi., 1928, 18, 505.

40. Maze, C. and G. Burnet, Surfact Sci,, 1969, 13, 451; 1971, 24, 335.

41. Machin, J.S.. and D.L. Hanna, J.Amer. Ceram. Soc., 1945, 28, 310-316. 


\begin{tabular}{|c|c|c|c|}
\hline 1. Program/Propect Identilicalion No. & $\begin{array}{l}\text { 2. Programipropect ritle } \\
\text { GASIFICATION ASH AND SLAG }\end{array}$ & & $\begin{array}{l}\text { 3. Reportine Period } \\
01 / 0.1 / 87^{\text {inrough } 03 / 31 / 87}\end{array}$ \\
\hline \multirow{2}{*}{$\begin{array}{l}\text { 4. Name and Address } \\
\text { University of North } \\
\text { Box } 8213 \text {, University }\end{array}$} & & & $\begin{array}{l}\text { 5. Program/Project Start Date } \\
4 / 1 / 86\end{array}$ \\
\hline & $\begin{array}{l}\text { Dakota tnergy kesearcn } \\
\text { Station, Grand Forks, }\end{array}$ & ND 58202 & 6. Compleyon Qate $3 / 92$ \\
\hline
\end{tabular}

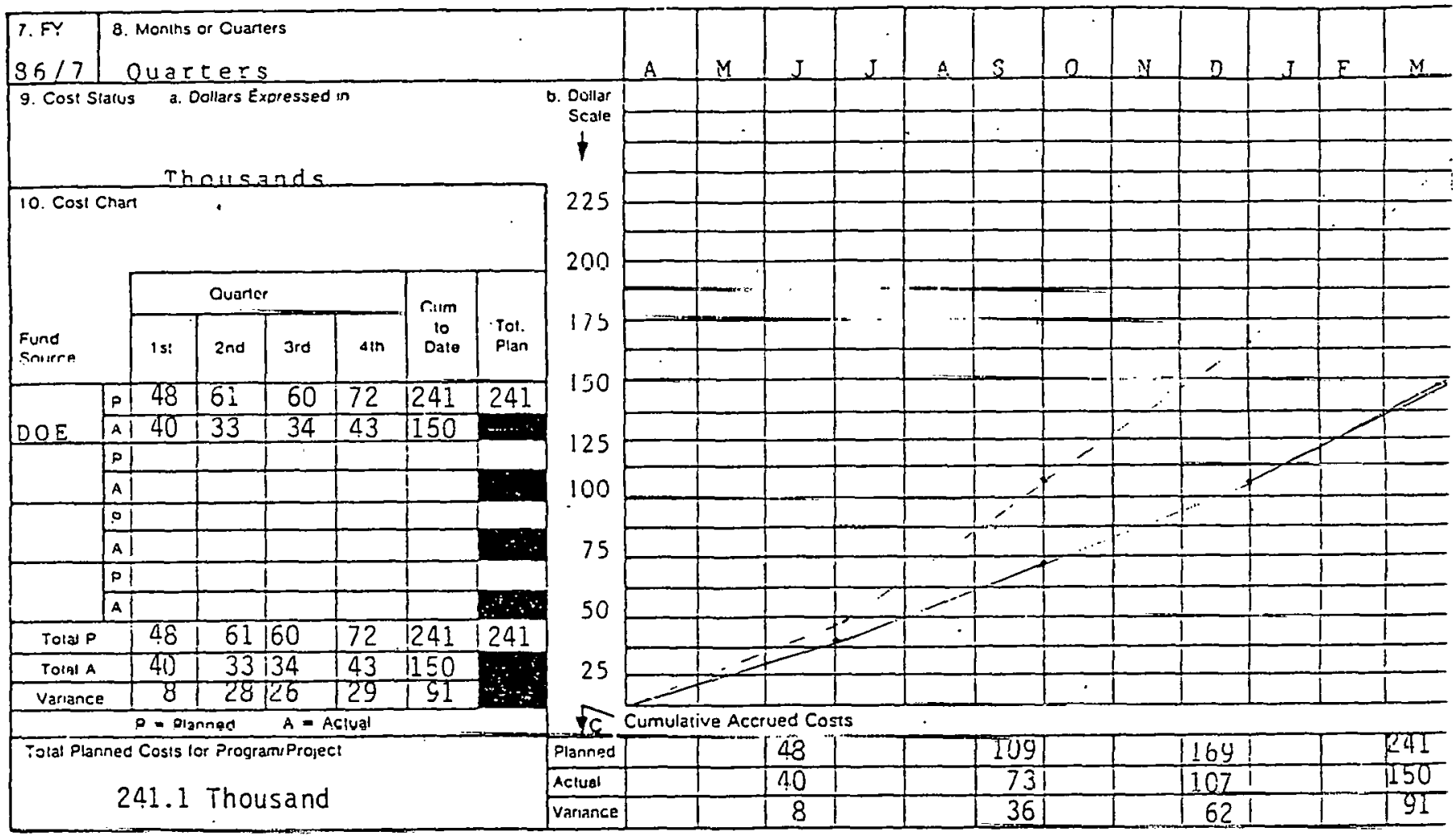

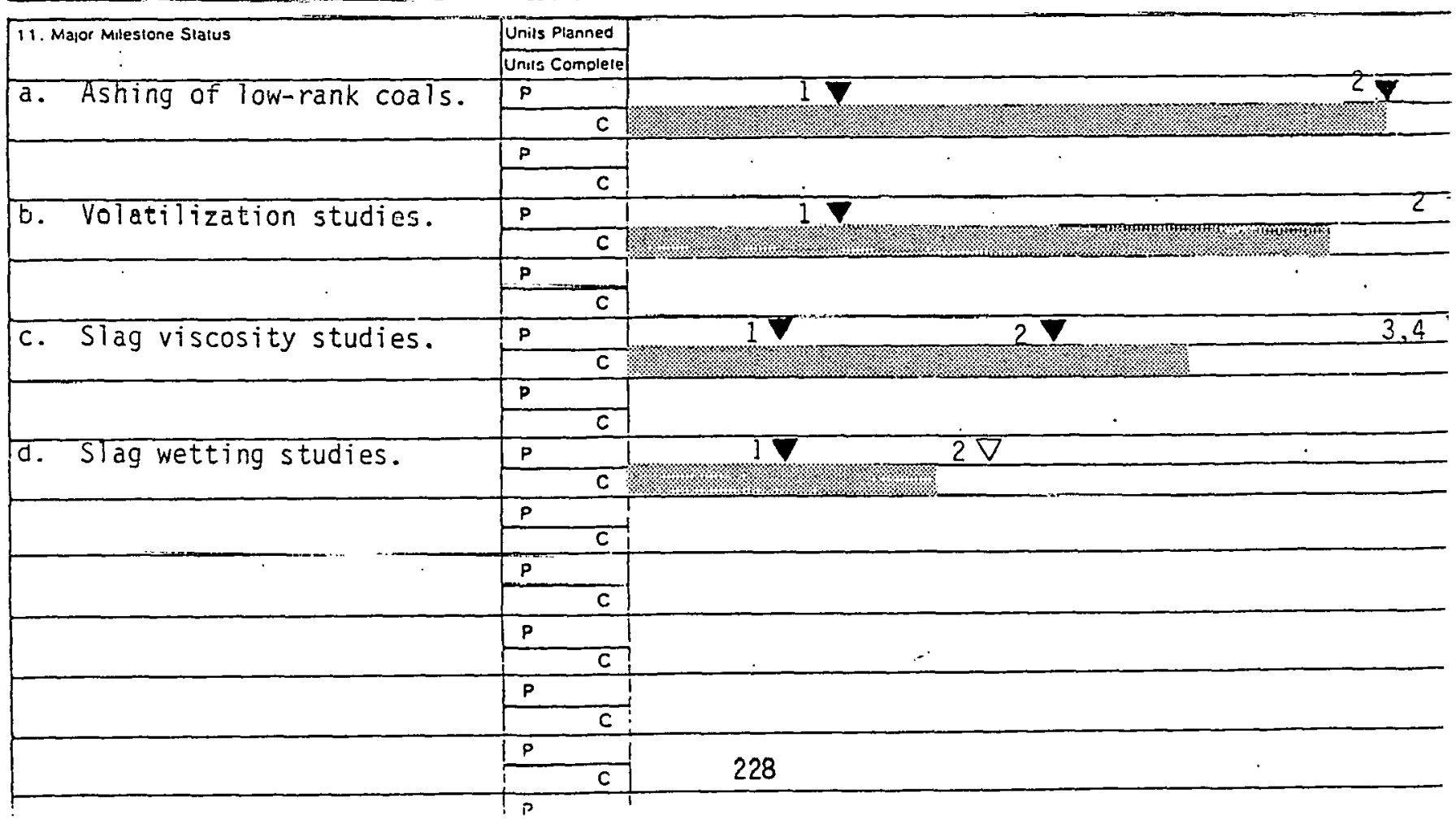




\begin{tabular}{|c|c|c|}
\hline 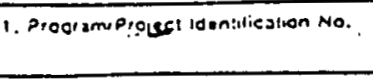 & $\begin{array}{l}\text { 2. Programiproper Pul } \\
\text { GASIFICATION ASH \& SLAG }\end{array}$ & $01 / 01 / 87$ mrougn $03 / 31 / 87$ \\
\hline $\begin{array}{l}\text { 1. Numb and Adoress } \\
\text { University of Nort }\end{array}$ & ta Energy Research Cencer & 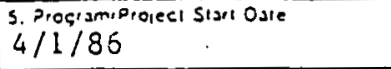 \\
\hline $80 \times 8213$, Universi & arion, Grand Forks, ND 58202 & $\begin{array}{l}\text { 6. Comitietion cule } \\
3 / 31 / 92\end{array}$ \\
\hline
\end{tabular}

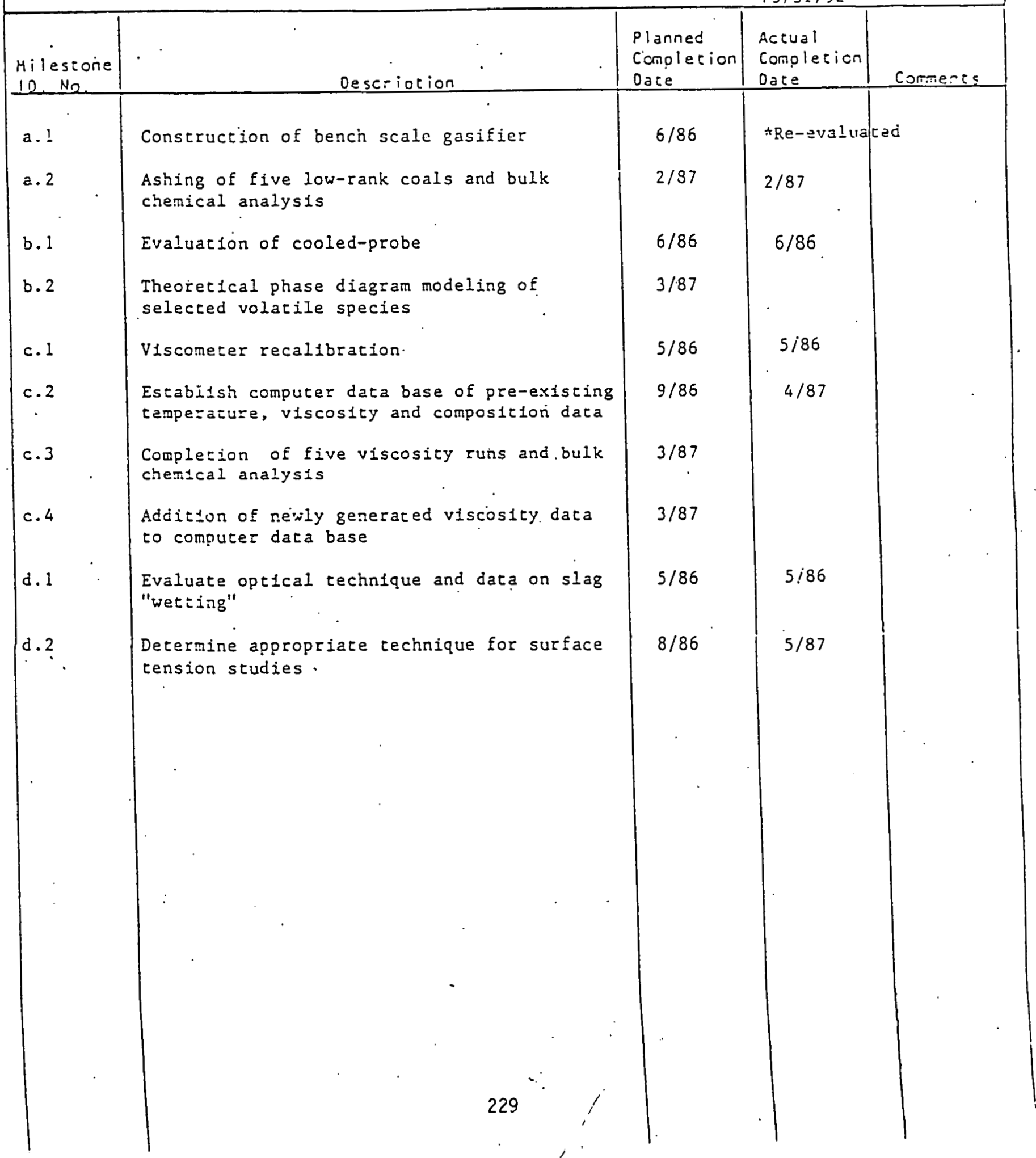




\section{THIS PAGE}

WAS INTENTIONALLY

LEFT BLANK 


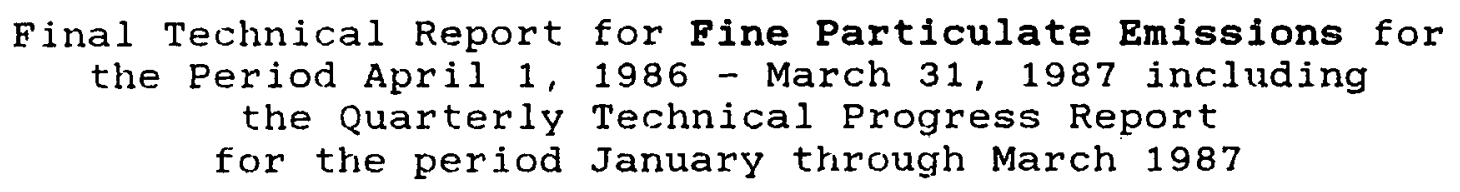

By

S.J. Miller and D..L. Laudal

University of North Dakota Energy Research Center

P.O. Box 8213 University Station

Grand Forks, North Dakota 58202

Work Performed Under Cooperative Agreement

No. DE-FC21-86MC10637

For

U.S. Department of Energy

Pittshurgh Eriergy Technology Center

Contracting officer's Technical Representative- - Dr. Soung S. Kim

June 1987 


\section{THIS PAGE}

WAS INTENTIONALLY

LEFT BLANK 


\section{TABLE OF CONTENTS}

\subsection{OBJECTIVES AND SUMMARY}

Page

2. O BACKGROUND

$1-1$

3.O BASIS FOR PARTICULATE CONTROL

$2-1$

$3-1$

3.1. Health Effects 3-1

3.1.1. Fine Particulate Matter in the Atmosphere 3-2

3.1.2. Inhalation and Respiratory Deposition 3-5

3.1.3. Trace Element Enrichment

3.1.4. Long Range Transport

$3-9$

$3-13$

3.1 .5 .

Health Effects Studies

$3-15$

3.1 .6 .

References

$3-17$

3.2. Visibility Effects

$3-20$

3.2 .1 .

Scattering and absorbtion

$3-21$

3.2 .2 .

Haze

$3-23$

3.2.3.

Long Term Monitoring studies

$3-26$

3.2 .4 .

Ambient Particulate Levels

$3-27$

3.2 .5 .

References

$3-31$

3.3. Regulations-Clean Air Act

$3-33$

$3 \cdot 3 \cdot 1$.

National Ambient Air Quality Standards

3.3 .2 .

New Source Performance Standards

$3 \cdot 3 \cdot 3$.

Prevention of Significant Deterioration

3.3 .4 .

Best Available Control Technology

3.3.5.

Visibility Protection

3.3 .6 .

Proposed Ambient PM 10 Standard

3.3.7.

Impact of Stricter Regulation

$3-34$

$3-35$

$3-37$

$3-39$

$3-40$

$3-41$

$3-42$

\section{O TECHNICAL EVALUATION OF CONVENTIONAL AND EMERGING}

PARTICULATE CONTROL TECHNOLOGY

$4-1$

4.1. Inertial Separation

$4-2$

4.1.1 References

$4-4$

4.2. Wet scrubbers

4-2

4.2.1. Conventional Wet Particulate Collectors

4.2.2. Emerging Technologies for Wet Particulate

\section{$4-5$}

$4-8$

$4 \cdot 2 \cdot 3$. scrubbing

References

4-11 
4.3.1. Conventional Technology

$4-12$

4.3.2. Enhancement Technologies

$4-14$

4.3.2.1. Design Improvements

$4-15$

4.3.2.2. Hot-side Electrostatic Precipitators

$4-20$

4.3.2.3. Chemical Conditioning

$4-22$

4.3.2.4. Pulse Energization

$4-26$

4.3.2.5. Multi-stage Electrostatic Precipitators

4.3.2.6. Wet Electrostatic Precipitators

4.3.3. Summary

$4-27$

$4-30$

4.3 .4 .

References

$4-31$

$4-32$

4.4. Fabric Filtration

$4-37$

4.4.1. Conventional Fabric Filtration 4-39

4.4.2. Fabric Development

$4-41$

4.4 .3

Emerging Technologies

$4-44$

4.4.3.1. Soritc Horns

4.4.3.2. Electrostatic Enhanced Fabric

$4 \cdot-45$

\subsubsection{Fistration}

$4-46$

4.4.3.3. Flue Gas Conditioning

$4-50$

$4 \cdot 4 \cdot 4$.

Summary

$4-51$

$4 \cdot 4 \cdot 5$.

References

$4-52$

4.5. Granular Bed Filtration

$4-55$

$4 \cdot 5 \cdot 1$

Moving Bed Granular Filtration

$4-56$

$4.5 \cdot 2$.

Backflushed Granular Bed Filtration

$4 \cdot 5 \cdot 3$.

Electrostatically Auginented Granular

Bed Filtration

4.5.4. Summary

4.5 .5 .

References

$4-57$

$4-58$

$4-60$

$4-60$

4.6. Acoustic Agglomeration

$4=81$

1.6.1.

References

$4--67$

4.7. Summary

$4-68$

\section{O FLUE GAS CONDITIONING FOR FABRIC FILTER PERFURMANCE} IMPROVEMENT

$5-1$

5.1. Collection and Penetration Mechanisms 5-1

5.1.1. Classical Collection Mechanisms 5-2

5.1.2. Penetration Mechanisms 5-7

5.1.3. Inadequacy of Existing Penetration Models $5-10$

5.1.4. References 
Page

5.2. Ash Characteristics Affecting Collectibility 5-13

5.2.1. Particle Size Distribution 5-13

5.2.2. Fly Ash Chemical Composition 5-15

5.2.3. Cohesiveness

5.2.4. Electrical Effects 5-26

5.2.5. References 5-29

5.3. Dust Cake Properties Affecting Pressure Drop 5-32

$\begin{array}{llr}5.3 .1 . & \text { Permeability } & 5-32 \\ 5.3 .2 . & \text { Flow Resistance } & 5-34 \\ 5.3 .3 . & \text { Porosity } & 5-36 \\ 5.3 .4 . & \text { Pore Structure } & 5-37 \\ 5.3 .5 . & \text { References } & 5-38\end{array}$

5.4. Fabric Effects $\quad$ 5-41

5.4.1. Fiber Composition 5-40

5.4.2. Fabric Construction 5-41

5.4.3. Pore Size 5-43

5.4.4. References 5-44

5.5. Flue Gas Conditioning Results 5-45

5.5.1. Introduction $5-45$

5.5.2. Experimental Approach 5-48

5.5.2.1. Particulate Test Combustor and Baghouse 5-48

5.5.2.2. Particulate Sampling and Measurement 5-51

5.5.2.3. Sulfur Trioxide and Ammonia Injection 5-55

5.5.2.4. Chemical Analyses 5-57

5.5.2.5. Physical Characterization 5-58

5.5.2.6. Test Parameters 5-58

5.5.3. Effects of $\mathrm{SO}_{3}$ and Ammonia Conditioning

5.5.4. Effects of Conditioning on Baghouse
Pressure Drop

5.5.5. Effect of Conditioning on Physical
Ash Properties

5.5.6. Chemistry of Conditioning Process 5-81

5.5.7. Mechanisms of Conditioning 5-87

5.5.8. References 5-90

6.0 ECONOMIC ANALYSIS OF PARTICULATE CONTROL TECHNOLOGY 6-1

6.1. Inertial Separation 6-1

6.2. Wet Scrubtiers $6-2$ 
6.3. Electrostatic Precipitators 6-3

6.3.1. Electrode Geometry and Construction Design 6-5

6.3.2. Hot-Side ESPS 6-6

6.3.3. Flue Gas Conditioning of an ESP 6-7

6.3.4. Pulse Energization 6-7

6.3.5. Precharging 6-9

6.4. Fabric Filtration 6-11

6.4.1. Sonic Horns 6-13

6.4.2. Electrically Stimulated Fabric Filtration 6-14

6.4.3. Flue Gas conditioning of a Fabric Filter 6-16

6.5. Granular Bed Filtration 6-18

6.6. Acoustic Agglomeration 6-19

6.7. Summary 6-20

6.8. References 6-21

7.0 CONCLUSIONS AND RECOMMENDATIONS 7-1

\section{LIST OF FIGURES}

№.

Caption

Page:

3-1 Bimodal distribution of ambient particulate matter showing the sudden growth in the coarse aerosol mude due to a local dust storm.

3-2 Histogram of number of sites versus anrual geometric. mean TSP concentration in the U.S. in 1978 .

3-3 Calculated deposition of aerosol particles in the human respiratory system.

3-4 Light scattering and absorption per volume concentration as a function of particle size. 
3-5 Visual range as a function of fine particle mass concentration, assuming $K=3.9$.

4-1 Fractional collection efficiency curve for a high efficiency cyclone.

4-2 Fractional collection efficiency of the Electroclone.

4-3 Fractional efficiency curve as a function of pressure drop for a Venturi scrubber.

4-4 Fractional collection efficiency comparison: Venturi scrubber vs electrostatically enhanced Venturi scrubber. 4-10

4-5 Typical fractional efficiency curve for an ESP.

4-6 Fly ash resistivity as a function of temperature.

4-7 Typical fractional efficiency curve for a baghouse.

4-8 The effect of precharging on pressure drop, as a function of time, when collecting lead smelter dust in a fabric filter.

4-9 Fractional efficiency curve for a granular bed filter.

4-10 Fractional efficiency curve of an electrostatically enhanced granular bed filter.

4-11 Fractional collection efficiency for high efficiency cyclones with and without a Braxton Acoustic Agglomera tor.

4-12 Particle size distribution before and after being conditioned with the Aerojet/PSU Acoustic Agglomerator. 4-66

4-13 Collection efficiency of acoustically augmented cyclones. 4-66

5-1 Dust cake porosity as a function of the effective angle of internal friction.

5--2 Penetration as a function of $\mathrm{Na}_{2} \mathrm{O}$ in the fly ash. 5-46

5-3 Penetration as a function of $\left(\mathrm{Na}_{2} \mathrm{O}+0.4 \mathrm{MgO}+2.8 \mathrm{P}_{2} \mathrm{O}_{5}\right) \cdot 5-46$

5-4 Schematic of particulate test combustor and baghouse. 5-50

5-5 Schematic of: APS 33. $5-52$ 
5-6 Schematic of Particulate Sampling System (APS, DMPS and dilution system).

5-7 Schematic of sulfur trioxide and ammonia injection system using funing sulfuric acid.

5-8 Sulfur Trioxide and ammonia injection system using $\mathrm{SO}_{3}$ generator.

5-9 Particle size distributions (0.5 to $15 \mu \mathrm{m})$ for South Hallsville lignite as measured using the ARs 33.

5-10 Respirable mass emissions vs time fur Falkirk, Big Brown, and South Hallsville ligrites without bag cleaning.

5-11 Respirable mass emissions vs time with ard wllluul conditioning for Falkirk ligrite using shaker bag cleaning.

5-12 Respirable mass emissions vs time with and without conditioning for Big Brown lignite using shaker bag cleaning.

5-13 Respirable mass emissions vs time with and without conditioning for South Hallsville lignite using shaker bag cleaning.

5-14 Respirable mass emissions vs time with and without conditioning for Monticello lignite using shaker bag cleaning.

5-15 Respirable mass emissions vs time with and without conditioning for Indiana bituminous coal using shaker bag cleaning.

5-16 Respirable mass emissions vs time with and withuut conditioning for sarpy creek coal using shaker bag cleaning.

5-17 Respirable mass emissions vs time with and without conditioning for South Hallsville ligrite using

felted bags in pulse jet chamber (no bag cleaning).

5-18 Submicron particle emissions for Monticello lignite.

5-19 Submicron particle emissions for Sarpy creek subbituminous coal.

5-20 Submicron particle emissions for Indiana bituminous coal. 5-71 
5-21 Submicron particle size distribution with and without conditioning for an Indiana bituminous coal as measured by the DMPS.

5-22 Pressure drop vs time with and without conditioning for Falkirk lignite using shaker bag cleaning.

5-23 Pressure drop vs time with and without conditioning for Big Brown lignite using shaker bag cleaning.

5-24 Pressure drop vs time with and without conditioning for South Hallsville lignite using shaker bag cleaning.

5-25 Pressure drop vs time with and without conditioning for South Hallsville lignite using felted bags in pulse jet chamber (no bag cleaning).

5-26 Pressure drop vs time with and without conditioning for South Hallsville lignite using shaker bag cleaning.

(50 hour tests).

5-27 Pressure drop vs time with and without conditioning for Morticello lignite using shaker bag cleaning.

5-28 Pressure drop vs time with and without conditioning for Indiana bituminous coal using shaker bag cleaning.

5-29 Pressure drop vs time with and without conditioning for Sarpy Creek subbjtuminous coal using shaker bag cleaning. 5-77

5-30 Particle size distribution for conditioned and nonconditioned Big Brown fly ash, measured with a six-stage multicyclone.

6-1 Fabric filtration capital costs as a function of air-to-cloth ratio. 


\section{LIST OF TABLES}

No.

Title

Page

3-1 CONCENTRATIONS, ENRICHMENT FACTORS, PERMISSIBLE

EXPOSURE LIMITS AND TOXICITY OF SELECTED ELIEMENTS

$3-12$

3-2 GRAVITATIONAL SETTLING VELOCITIES FOR SPHERICAL PARTICLES, SPECIFIC, GRAVITY OF 2 , IN AIR AT $25^{\circ} \mathrm{C}$, AND 1 ATMOSPHERE

4--1 NOVEL SCRUBBERS

$4-8$

4-2 PROPERTIES OF FIBERS USED FOR FABRIC FILTRATION

$4-43$

5-1 PTC OPERATING PARAMETERS

$5-49$

5-2 BAGHOUSE OPERATING CONDITIONS

$5-50$

5-3 ACGIH RESPIRABLE MASS DEFINITION

$5-52$

5-4 TEST PARAMETERS

$5-61$

5-5 PERCENT BAGHOUSE REMOVAI, EFFICIENCY DETERMINED BY EPA METHOD 5 DUST LOADINGS

$5-63$

5-6 SPECIFIC DUST CAKE RESISTANCE

$5-78$

5-7 COHESIVE STRENGTH OF FIY ASHES AS MEASURED BY.

UNDERC'S COHESIVE TEST METER

$5-80$

5-8 ULTIMATE AND PROXIMATE COAL ANALYSES

$5-82$

5-9 XRF ASH ANALYSIS OF BAGHOUSE HOPPER ASH

$5-83$

5-10 ESCA ANALYSIS FOR NITROGEN AND SULFUR

$5-84$

5-11 ESCA ANALYSIS FOR NITROGEN AND SULFUR OF SIZE

FRACTIONATED BIG BROWN ASH

5-12 AMMONIA BALANCE

$5-86$

6-1 CAPITAL AND OPERATING COSTS FOR CONVENTIONAL WET SCRUBBERS FOR A 500 MW PLANT

6-2 COLLECTION EFFICIENCY FOR PARTICLES LESS THAN 2.5 MM AND OVERALL POWER CONSUMPTION FOR WET SCRUBBERS 
6-3 CAPITAL COST FOR A COLD-SIDE ESP FOR A 500 MW PLANT ( $1.9 \times 10^{6}$ ACFM@496 SCA)

$6-4$

6-4 ESTIMATED OPERATING AND. MAINTENANCE COSTS FOR A COLD-SIDE ESP FOR A 500 MW PLANT

( $\left.1.9 \times 10^{6} \mathrm{ACFM} @ 496 \mathrm{SCA}\right)$

$6-5$

6-5 CAPITAL INVESTMENT FOR ESP ALTERNATIVES WHEN

COLLECTING A HIGH RESISTIVITY ASH FOR AN 500 MW Plant

$6-8$

6-6 ANNUAL OPERATING AND MAINTENANCE COSTS FOR

ALTERNATIVE ESP COLLECTION SYSTEMS FOR A 500 MW PLANT 6-9

6-7 COSTS OF RETROFIT ESP ALTERNATIVES FOR HIGH RESISTIVITY ASH FOR A 500 MW PLANT

$$
6-10
$$

6-8 CAPITAL COST FOR A FABRIC FILTER FOR A 500 MW PLANT (1.9 $\times 10^{6}$ ACFM)

6-9 ESTIMATED ANNUAL OPERATING AND MAINTENANCE COSTS FOR A FABRIC FILTER FOR A $500 \mathrm{MW} \operatorname{PLANT}\left(1.9 \times 10^{6}\right.$ ACFM) 6-13

6-10 COMPARISON OF COSTS FOR ESFF AND CONVENTIONAL

FABRIC FIITRATION FOR A 500 MW PLANT

$6-15$

6-11 COMPARISON OF CAPITAL COSTS FOR FABRIC FILTRATION SYSTEMS WITH AND WITHOUT FLUE GAS CONDITIONING FOR A 500 MW PLANT

6-12 COMPARISON OF OPERATING AND MAINTENANCE COSTS FOR A FABRIC FILTRATION SYSTEM WITH AND WITHOUT CONDITIONING 6-17

6-13 SUMMARY OF THE CAPITAL COST AND LEVELIZED ANNUAL COST FOR DIFFERENT PARTICULATE CONTROL TECHNOLOGIES EVALUATED FOR A 500 MW PLANT 


\subsection{OBJECTIVES AND SUMMARY}

This report is the Annual Final Technical Report for the Fine Particulate Emissions project conducted by the University of North Dakota Energy Research Center (UNDERC), for DOE under Cooperative Agreement No. DE-FC21-86MC10637. The report also includes research conducted the last quarter of the Cooperative Agreement year, January through March, 1987, and therefore, serves as the Quarterly Technical Progress Report for that period.

The objectives of the Fine Particulate Emissions project for the year, April 1986 through March 1987 are to: 1) make a technical and economic comparison between chemical gas conditioning, as a method of reducing fine particulate emissions from a fabric filter, and other state-of-the-art or emerging techniques; and 2) determine the effectiveness of chemical gas conditioning with ammonia and sulfur trioxide $\left(\mathrm{SO}_{3}\right)$ in reducing fine particulate emissions from a fabric filter for several coals.

The work in support of objective 1 consisted of literature review and study in three main areas. The first area, presented in section 3.0 , is a review of the basis for fine particulate control and includes discussion of health effects of fine particulate matter in the atmosphere, the effect of fine particulate emissions on visibility, and the particulate control requirements of existing and possible future regulations. The second area is a technical and economic evaluation of existing particulate control technologies including flue gas conditioning applied to fabric filters. The comparative technical assessment of existing and emerging technologies is presented in section 4.0. The assessment of the economics of various technologies including flue gas conditioning applied to fabric filters is given in section 6.0. The third area, in support of objective 1 , is a detailed technical discussion of flue gas conditioning applied to fabric filtration which is presented in Section 5.0. It includes an evaluation of fundamental collection and penetration mechanisms in fabric filtration, an evaluation of basic ash properties which affect fine particulate emissions, and previous 
results with flue gas conditioning.

Work in support of objective 2 consisted of experimental research to determine the effects of injection temperature and coal type on the overall effectiveness of conditioning. This recent work is also presented in section 5.0 along with previously generated results. Section 5.5 contains the most up-to-date and comprehersive results of flue gas conditioning applied to fabric filtration by this project.

Fine particles in the atmosphere have the potential for adverse health effects because hazardous trace metals concentrate on them, and they deposit in the lower respiratory system through normal breathing. Fine particles in the atmosphere are also the major cause of visibility impairment, both in cities and in remote pristine areas such as national parks. While existing regulations do not specifically limit fine particulate emissions (as opposed to total particulate emissions), visibility protection and prevention of significant deterioration aspects of the law may require better control than is currently available.

The best proven available control technology for fine particulate matter appears to be fabric filtration. Several other emerging technologies may also offer high levels of control but have not not yet been proven to be both technologically sound and economical. Conventional fabric filtration, however, may not be able to meet the level of control that is needed. When combined with flue gas conditioning, fabric filtration has the potential to provide better fine particle control than any other known viable method. Flue gas conditioning would add about $y \%$ tó the cost of a cunvenliural tabric filter, but this. cost may be more than revuvered if life size of the fabric filter could be reduced because of lower pressure drop. It appears, from a technical and economic analysis, that flue gas conditioning could be applied with an overall cost savings compared to current technologies.

The process of flue gas conditioning applied to fabric filtration involves the injection of small amounts of ammonia and $\mathrm{SO}_{3}$ into the flue gas, upstream of. the baghouse. Results show substantial reductions in fine particulate emissions with this metrod. For 
several coals which produce difficult-to-collect ashes, particulate emissions were reduced by up to four orders of magnitude. This represents an increase in particulate removal efficiency from $90 \%$ to 99.999\%. Tests with both lignite and higher rank coal show that conditioning is an effective method of greatly reducing fine particulate emissions from a fabric filter. As a bonus, results show that baghouse pressure drop is also reduced, making the process even more attractive. Since injection technology for conditioning agents has been well developed for use with electrostatic precipitators, this method is readily available. Longer term and larger scale testing, however, is needed to more fully evaluate the potential of conditioning agents to improve fabric filter performance. Possible applications of flue gas conditioning applied to fabric filtration include immediate retrofit applications where emissions or pressure drop are higher than acceptable and future retrofit or new plant applications to meet stricter control regulations. 


\subsection{BACKGROUND}

Particulate control in flue gases produced from coal combustion is a complex problem because of the orders of magnitude of particle sizes that one must deal with and wide range in particulate removal efficiency that is available from various control devices. Particle size in gas process streams may range from $0.01 \mu \mathrm{m}$ to $100 \mu \mathrm{m}$, where the smaller particles are, for all practical purposes, permanently suspended in the gas stream (i.e. they will not settle out by gravitational forces), while the larger particles are the size of a small grain of sand and will settle out of air at a rate of $5 \mathrm{~cm} / \mathrm{s}$. The smallest particles $(0.01 \mu \mathrm{m})$ are only 1.5 orders of magnitude larger than gas molecules and are very much subject to mass transfer by diffusion. On the other hand, for $100 \mu \mathrm{m}$ particles, inertial effects dominate mass transfer operations. Since the aerodynamic effects of the largest and smallest particles are grossly different, particle control immediately becomes complex. A good method for removing larger particles may be completely ineffective for small particles. For example, cyclone separators are highly efficient at removing 20 to $100 \mu \mathrm{m}$ particles, but 0.01 to $1 \mathrm{\mu m}$ particles pass through cyclones with essentially no removal.

Adding to the complexity of particulate control is the fact that removal efficiency may range from 90 to $99.999 \%$ of the total particulate mass, depending on the control method. It might appear that there is a small difference between 99 and $99.999 \%$ removal, but this represents three orders of magnitude difference in the amount of pollutant material that enters the atmosphere.

current best control technology for large coal-fired boilers can generally remove from 99 to $99.9 \%$ of the incoming particulate mass. This already seems to be a remarkable achievement compared to $\mathrm{SO}_{2}$ removals of 70 to $90 \%$ and $\mathrm{NO}_{x}$ removals of about $50 \%$. The obvious immediate question is, "Is there a need for improved particulate control?", and indeed this question will be addressed in this report. The complexity of the particulate issue, however, does not stop here. Added to the four orders of magnitude range of particle size and 
particle penetration is the variation in the type of particles which may be present in a gas stream. For example, fly ash from a coalfired boiler may have a mass median diameter of $10 \mu \mathrm{m}$, but particles will range from 0.01 to $100 \mathrm{~km}$. The smallest particiles will in most cases have a different composition than larger ones, and other particle characteriștics such as shape, morphology, electrical resistance, electrical charge, and adhesion tendency may also be size dependent. This size dependence is especially important in cases where hazardous constituents concentrate in smaller particles and there is a need to control. the given hazardous constituent. In such cases one would have to address, specifically, the control of the smaller particles rather than total mass particulate emissions.

Present New Source Performance standards for utility coal-fired boilers limit particulate emissions to 0.03 lk/million Btu and require $20 \%$ or lower opacity. The control device removal efficiency required to meet this standard varies from about 99 to $99.9 \%$ depending on the heating value and ash content of the coal. For example, an inlet grain loading of 3 grains/scf would require about 99.5\% removal. Electrostatic precipitators or baghouses are the technologies which have most often been employed to meet the current standard. If pruperly designed, there technologies have heen successful in most cases.

Present emission standards do not address fine particle emissions. Emissions of fine particles (defined as particles smaller than 2.5 $\mathrm{\mu m}$ ) are of concern because these particles are likely to be deposited in the lower respiratory system through normal breathing. The problem is further compounded because havardous lrate telemeit:s such as selenium and arsenic are known to be concentrated on such fine particles. Control device removal efficiency is lowcst for respirable particles, so a situation exists where the most hazardous particles from coal combustion are collected with the lowest removal efficiency. In addition to causing adverse health effects, $f$ ine particle emissions have an impact on atmospheric visibility. Particles which are the most efficient at scattering light are in the 0.2 to $2 \mu \mathrm{m}$ range. These particles do not readjly settle out of the 
atmosphere and are subject to long range transport. When present in sufficient concentrations, these fine particles will cause serious visibility impairment, otherwise known as haze. Thus, the emission of fine particles is an issue because of potential adverse health effects and visibility impairment in the atmosphere.

current technology can achieve $99.9 \%$ particulate removal efficiency on a total mass basis, but the removal efficiency for the fine particle fraction may be much less. The present level of control must meet current emission standards and should also allow operation with a clear stack for good public relations. Beyond that, there is no driving force for utilities or industries to implement higher levels of control. Until such time that stricter fine particulate emission regulations are implemented, there is no need for industry to be concerned with better particulate control.

Forgetting current regulations for the moment, what would be a long-range goal for particulate control that would ensure the protection of health and reduce visibility impairment? It would appear that if it is technically feasible, the long-range goal should be emissions no greater than ambient particulate levels. The current national primary ambient air quality standard for total suspended particulates (TSP) is $75 \mu \mathrm{g} / \mathrm{m}^{3}$ on an annual geometric mean basis. If particulate emissions exiting a plant are no greater than the ambient air drawn into the plant (i.e. combustion air), there can be no net increase in pollutant levels in the atmosphere. This does not take into account that the type of particulate emissions from a plant may be more hazardous than those present in the ambient air. To achieve such a low emission level would require a particulate removal efficiency of about $99.999 \%$. This would be a 100 fold reduction in emissions compared to the current available control level of 99.9\%. Reducing particulate emissions by a factor of 100 may appear ridiculous, because immediately one thinks of increasing the size of particulate collectors and the corresponding economic hardship to industry. However, an approach that might achieve a 100 fold reduction in emissions is flue gas conditioning applied to fabric filtration. 
Most particulate collectors are designed for a given dust. In other words, given a dust with a known particle size distribution, concentration, resistivity, composition, eti., control devices are constructed to collect the dust at a certain design efficiency. One exception to this is flue gas conditioning applied to electrostatic precipitation which improves collection efficiency by changing resistivity, a property of the dust. Flue gas conditioning, however, is usually an add-on method which is applied when the original design does not meet expectations or when new regulations require reduced emissions. If it is possible to modify the dust making it easier to collect by conventional melluds, which results in a 100 fold reduction in particulate emissions and improves the operability of the collection device, then a method would be available which could reduce particulate emissions to ambient levels without a severe economic penalty.

Recent test results at the University of North Dakota Energy Research Center (UNDERC) show that a 100 fold or greater reduction in particulate emissions is possible when flue gas conditioning is applied to fabric filtration. Furthermore, the conditioning also reduces pressure drop across the filter, improving operability. This is an exciting development in particulate control because it has the potential to significantly improve collection efficiency without a severe economic penalty. Actual emissions in some of the tests have been about an order of magnitude lower than ambient levels.

The main objective of this report is to assess the potential uf flue gas conditioning applied to fabric filtration as a means of reducing fine particulate emissions. 'l'he reporl includea a reviow of the basis for fine particulate control including health effects, visibility effects, and regulatory factors. An assessment of particulate control technologies is presented for comparison of flue gas conditioning (both technically and economically) with other state-of-the-art and emerging technologies for fine particulate control. The report presents a technical evaluation of flue gas conditioning including fundamental collection and penetration mechanisms, and recent experimental data. Finally, the report 
presents recommendations, based on technical and economic considerations, to further the development of flue gas conditioning applied to fabric filters. 


\subsection{BASIS FOR PARTICULATE CONTROL}

\subsection{Health Effects}

The primary basis for existing air pollution regulations consists of the adverse effects of air pollution on public health. Episodes of air pollution in London in 1952 and 1956 were blamed for thousands of deaths (1). Subsequently, in 1956 Britain implemented a Clean Air Act to reduce air pollution. In the U.S., a four day air pollution episode in Donora, $\mathrm{Pa}$. In 1948 resulted in illness to half of the town's inhabitants. Ten years later residents who had been acutely ill during that episode were found to have a higher rate of sickness and death than the average for the town (1). These examples show that high levels of air pollution can have severe short and long term health effects on exposed populations. The quantitative effects of specific concentrations of individual pollutants, however, are much more difficult to measure. Both gaseous contaminants such as $\mathrm{sO}_{2}$ and particulate matter may individually cause health problems, but when present together may produce an amplified, synergistic health effect. The effect of particulate matter on health is highly dependent on the size of particulate matter present in the atmosphere, composition as a function of size, and the deposition rate of particles in the lungs. Added to the complexity of possible health effects is the fact that certain hazardous trace elements such as arsenic and selenium are known to be highly enriched in respirable particulate matter. once fine particles are entrained in the atmosphere, they are subject to long range transport. Therefore, the problem not only occurs near the pollution source, but is of national concern as well. The relation between particulate pollutants in the atmosphere and adverse health effects, as seen in epidemiologic health studies, is another important consideration. 


\subsubsection{Fine Particulate Matter in the Atmosphere}

Monitoring networks have been established throughout the U.S. to measure ambient particulate levels in both major cities and rural areas. As a result, a large data base exists which documents particulate levels in the atmosphere as a function of location and time. Studies (2) show the particle size distribution of atmospheric particulates to be bimodal, with a coarse particle mode which peaks at about 3 to $10 \mu \mathrm{m}$ and a fine particle mode is which peaks in the 0.1 to $0.5 \mathrm{\mu m}$ range. The dividing line between the coarse and fine modes is frequently given as $2.5 \mathrm{\mu m}$, but the separation is not fixed. An example of thic bimerlal distribution of ambient particulates is shown in Figure $3-1$. The relative distribution between the coarse and fine modes is highly dependent on location and time, but generally at least $50 \%$ of the Total Suspended Particulates (TSP) mass

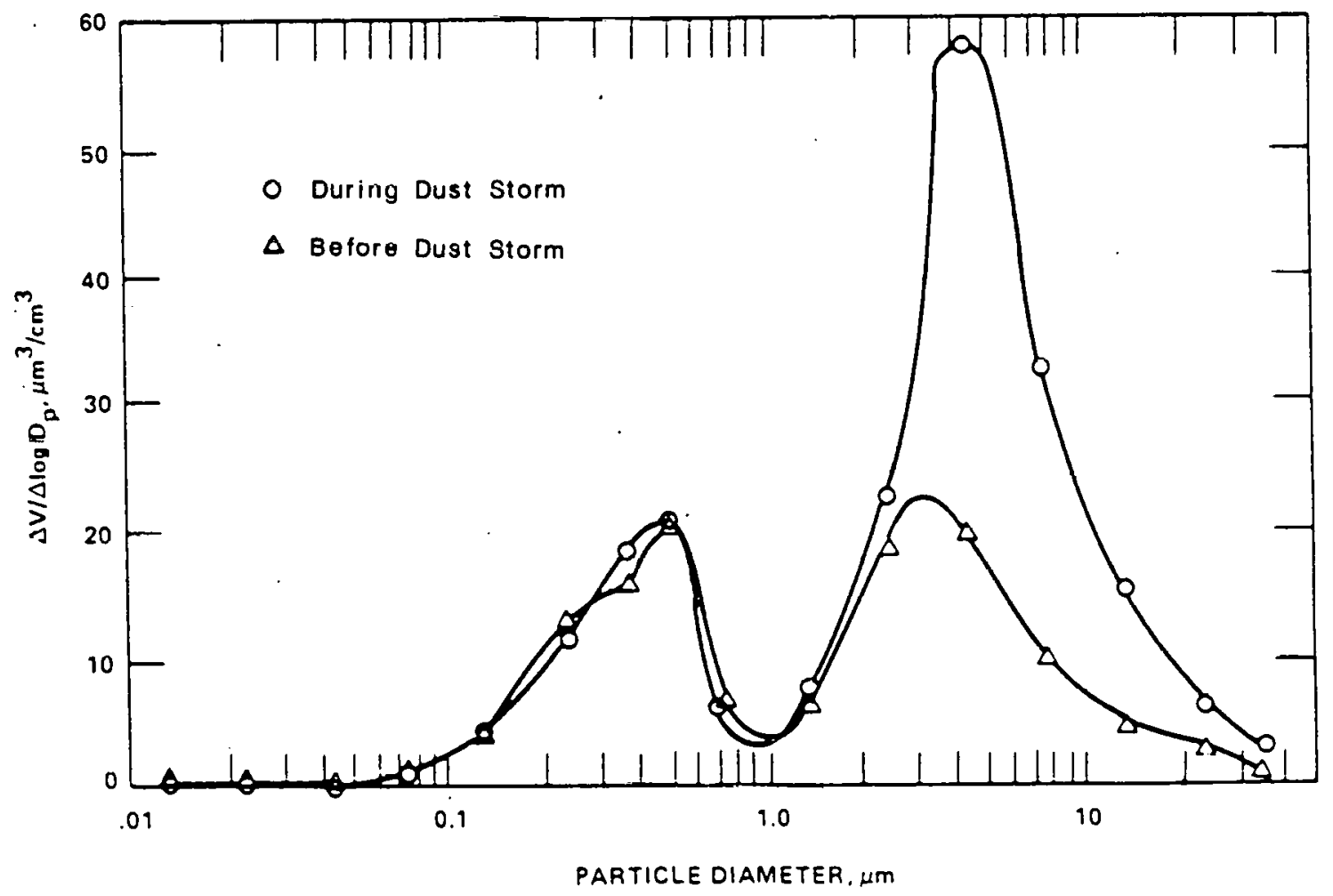

Figure 3-1. Bimodal distribution of ambient particulate matter showing the sudden growth in the coarse aerosol mode due to a local dust storm (Ref. 2). 
will be in the fine mode (3). The actual TSP concentration over the U.S. may vary from $10 \mu \mathrm{g} / \mathrm{m}^{3}$ in rural areas to over $250 \mu \mathrm{g} / \mathrm{m}^{3}$ in major industrial cities. Factors such as local dust storms will greatly influence TSP, but wind entrained dust adds mainly to the coarse particle mode (see Figure 3-1). An example of annual average TSP levels across the country is shown in Figure 3-2. Ambient particulate matter is a mixture of particles from many sources, each with its own unique size distribution, but when these are superimposed, there is still a bimodal distribution composed of the fine and coarse modes.

The fine particles are produced from industrial emissions, combustion sources, or any process that emits pollutants which were once in vapor form and then condense into fine particles. A significant portion of the fine particles are secondary particulates, which means that they are produced from gaseous emissions which are transformed into fine particulates in the atmosphere. An example of this is the transformation in the atmosphere of $\mathrm{SO}_{2}$ into secondary sulfates such as sulfuric acid, ammonium sulfate, or metal sulfates. The coarse particle mode is produced largely from mechanical processes such as wind entrainment of dust or the breakup of solids in industrial operations. In general, the larger particles originated from materials which remained as solids (or liquids as in coal combustion where ash particles may be in the liquid state during the combustion process) throughout the process of particle formation and dispersion into the air. The fine particles originated as gases or vapors in a process and then through nucleation and coagulation formed submicron particles. The coarse particles are composed mainly of the crustal elements such as silicon, aluminum, iron, and calcium and enter the atmosphere primarily through mechanical breakup rather than vaporization and condensation. The makeup of the fine particle fraction is of interest, especially with regard to health effects. One of the primary constituents in the fine particle fraction is sulfates. Other major components include organic material, elemental carbon, nitrates, and crustal material. 


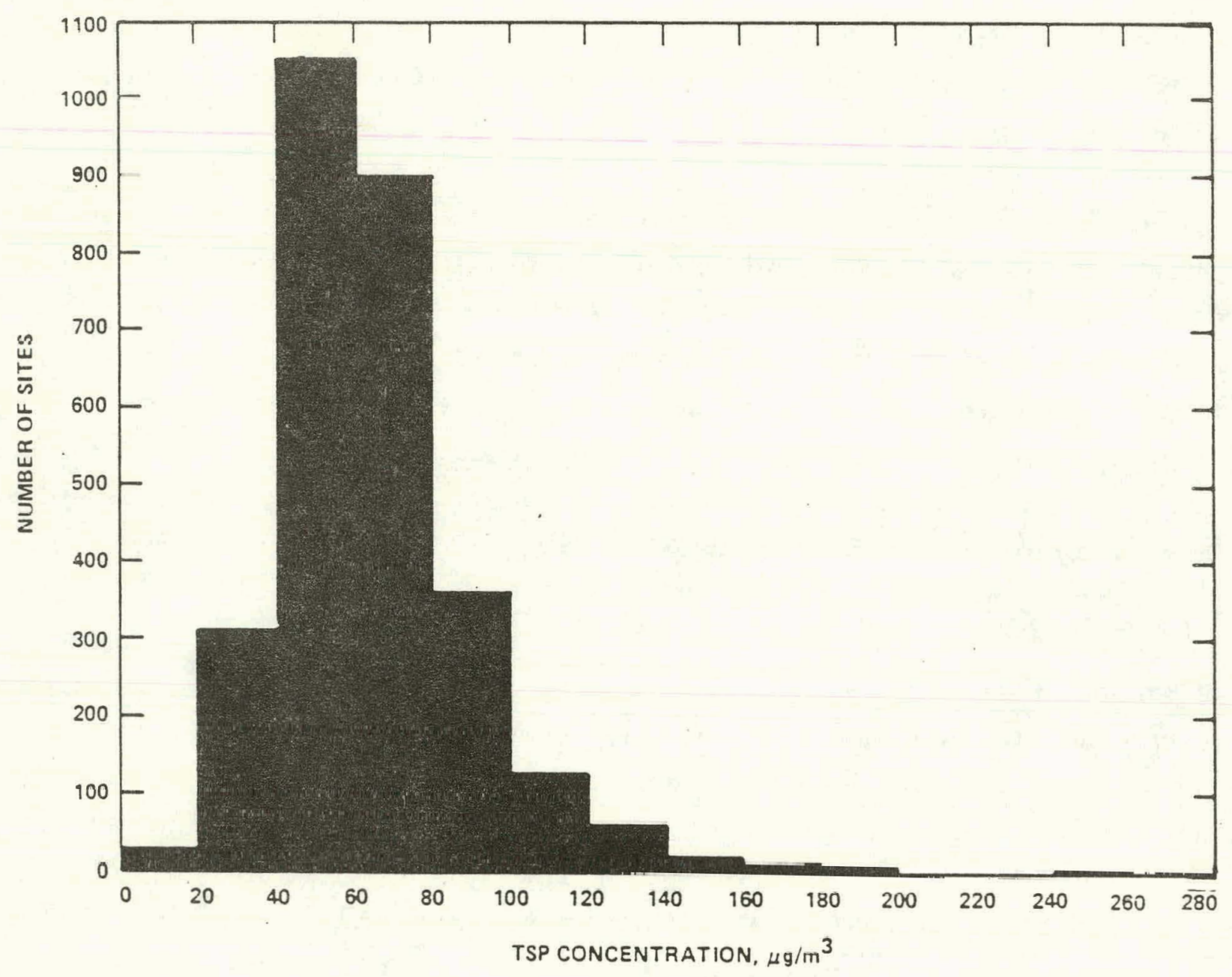

Figure 3-2. Histogram of number of sites versus annual geometric mean TSP concentration in the U.S. in 1978 (Ref. 2). 


\subsubsection{Inhalation and Respiratory Deposition}

Particles which are suspended in the air will be inhaled in the normal breathing process, but different-sized particles will have different health effects because of variations in both aerodynamic properties and chemical composition with changes in particle size. A comprehensive discussion of respiratory tract deposition and fate of inhaled aerosols is given in the EPA assessment document, Air Quality Criteria for Particulate Matter and sulfur oxides (4). Two terms, inhalable particulates and respirable particulates, are sometimes used to describe suspended aerosols in the air. The term inhalable particulates generally refers to particles which can enter the body through normal breathing. For the purpose of measurement and regulatory concern, inhalable particulates are defined as particles smaller than $15 \mu \mathrm{m}$. Respirable particulates refer to particles which reach the lower pulmonary section of the lungs, once inhaled. The American Council of Governmental Industrial Hygienists define respirable particulates by using a welghted sum of particles 5 um and less, which includes $25 \%$ of $5 \mu \mathrm{m}$ particles, $50 \%$ of $3.5 \mu \mathrm{m}$ particles, 75\% of $2.5 \mu \mathrm{m}$ particles, and $90 \%$ of all particles smaller than $2 \mu \mathrm{m}$. In the more general sense, respirable particulates refer to all particles < $2.5 \mu \mathrm{m}$.

The respiratory system can be divided into three main sections for the purpose of analyzing the fate of inhaled particles. The upper respiratory system, known as the nasopharyngeal system, consists of the nasal passages and cavities extending to the entrance to the trachea. The tracheobronchial region is a series of tubes which subdivide as many as 32 times between the trachea and the pulmonary tract, the third main region. The pulmonary system is the gas exchange region of the lungs and consists of respiratory bronchioles, alveolar ducts, and alveoli. The alveoli, which are membranous air sacs, have a large surface area to facilitate exchange of oxygen and carbon dioxide with the blood capillaries surrounding them. 
The main factor which determines where airborne particles will be deposited in the respiratory system is particle size. There are five mechanisms by which particles may be deposited in the respiratory system--electrostatic attraction, interception, impaction, gravitational settling, and diffusion (4). Electrostatic attraction would be significant only for highly charged particles and for this reason is considered to have a very minor role in respiratory deposition. Interception refers to noninertial incidental meeting of a particle and a surface and is also expected to play a minor role in deposition. Impaction is inertial deposition which occurs when the momentum of a particle causes it to cross streamlines when there is an alupt change in streamline direction. Impaction dominates as the main deposition mechanism for particles larger than 3 pm ln lie nasopharyngeal and tracheobronchial regions. The rate of gravitational settling decreases with decreasing particle size, and as a result influences deposition only for particles larger than $0.5 \mathrm{\mu m}$. Deposition by diffusion is caused by the random Brownian motion of small particles due to bombardment by gas molecules. It is important only for particles smaller than $0.5 \mu \mathrm{m}$ but is the primary deposition mechanism for particles between 0.01 and $0.1 \mathrm{\mu m}$.

In studying deposition ln the rcopiratory system, the probability of particle deposition in the whole system should be distinguished from deposition in the pulmonary region. For example, with nose breathing almost complete deposition in the nasopharyngeal region car be expected for all particles larger than $4 \mu \mathrm{m}$, while for mouth breathing complete deposition in this region occurs only for particles greater than about $10 \mu \mathrm{m}$. The differenre is because mouth breathing bypasses the excellent filtration capabilities of the nasopharyngeal region. The largen particles which penetrate the nasopharyngeal system are likely to be deposited in the tracheobronchial system, which will collect 80 to $90 \%$ of 8 to $10 \mu \mathrm{m}$ particles but less than $10 \%$ of particles smaller than $1 \mu \mathrm{m}$. Pulmonary deposition is most significant for particles from 1 to $3 \mu \mathrm{m}$ and for particles smaller than $0.1 \mu \mathrm{m}$. Above 2 to $3 \mu \mathrm{m}$ deposition in the pulmonary region falls off simply because few of the larger 


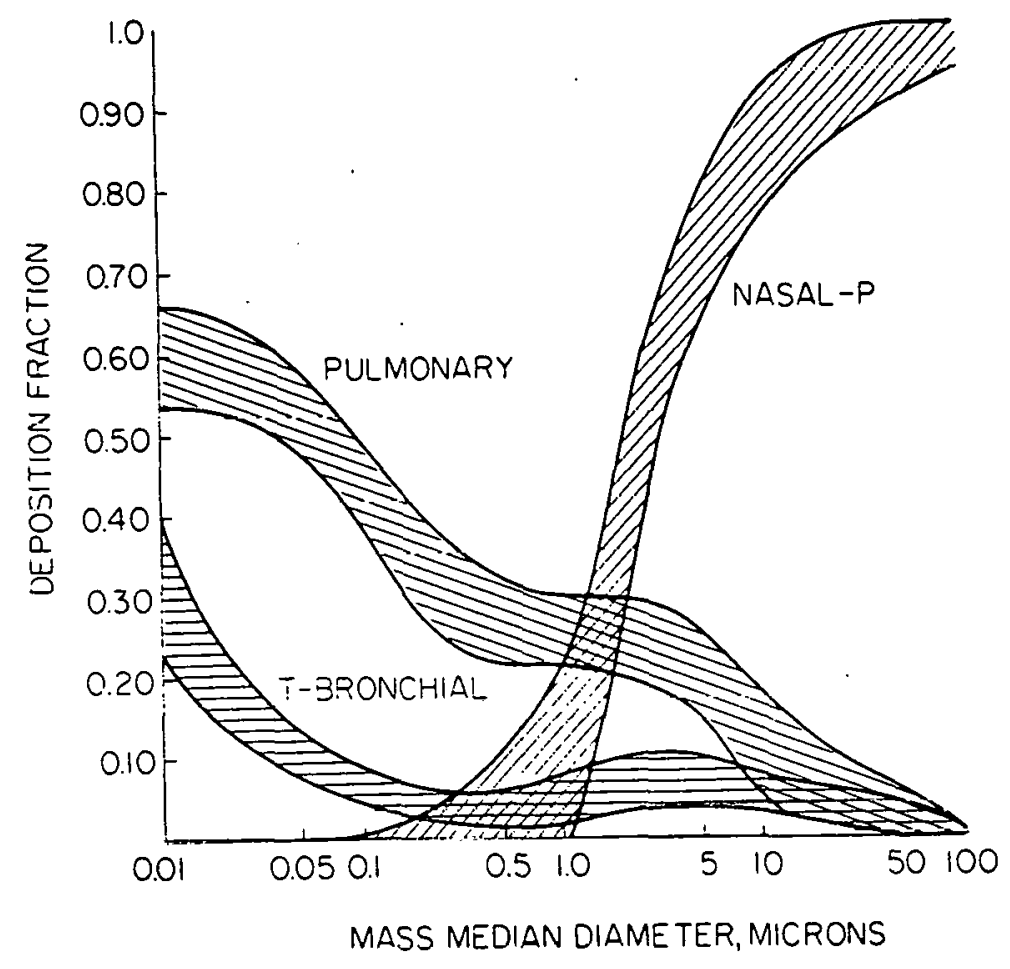

Figure 3-3. Calculated deposition of aerosol particles in the human respiratory system (Ref. 5).

particles escape upper respiratory trapping. Particles from 1 to $3 \mathrm{\mu m}$ are deposited in the pulmonary region by gravitational settling and particles smaller than $0.1 \mu \mathrm{m}$ are deposited primarily by diffusion. There is a minimum at about $0.2 \mu \mathrm{m}$ for which pulmonary deposition is lowest (5). Figure $3-3$ is a graphical depiction of respiratory deposition as a function of particle size.

The fate. of particles, once deposited, is determined by the particle characteristics and the location of deposition. Particles deposited in the anterior regions of the nasal passages are cleared forward by nose blowing and sneezing, while particles deposited in the pharyngeal and oral regions are cleared by swallowing. Insoluble particles that deposit in the tracheobronchial region are cleared 
upward by mucociliary action and are then swallowed. Clearance from the nasopharyngeal region is on the order of minutes to hours while clearance from the tracheobronchial system is somewhat longer, from one to two days. However, particles deposited in the pulmonary region may be retained for several hundred days. Particles which are soluble are readily cleared from the respiratory system by absorption into the lymphatic system or blood stream, but dissolution and absorption of substances competes with mechanical clearance processes. The amount absorbed depends upon the dissolution rate and the mechanical clearance rate, which varies significantly for different regions of the respiratory tract due to different retention times. This cledrly show the hoalth significancc of flut buticles smaller than $2.5 \mu \mathrm{m}$. Not only are these particles likely to be deposited in the pulmonary region of the respiratory system, but they also are retained there for extended periods of time. The large surface area of the fine particles compounds the problem because more surface area is exposed to pulmonary tissue increasing the dissolution and absorption of low solubility substances. This is especially significant when considering that substances such as sulfates and trace elements are known to be surface enriched in fine fly ash particles from coal combustion. The actual biological response to inhaled palticulate matter is difficult to measure bcoause the toxicity of particulate matter depends highly upon its chemical composition. Suspended particulate matter is quite heterogeneous in composition and may vary from one location to another and with time at a given location. Nevertheless, the adverse effect of fine particulate matter on the public has been alitipsacd in health studies. Trace element enrlchmenl in finc particulate matter and health effects studies will be further discussed in the following sections. 


\subsubsection{Trace Element Enrichment}

The annual coal consumption in the U.S. is over 700 million tons (6). Assuming an average $8 \%$ ash content which is converted to fly ash and is controlled at $97 \%$ removal efficiency, fly ash emissions to the atmosphere are on the order of 1 to 2 million tons per year. Fly ash from coal combustion is composed mainly of the earths primary crustal elements such as silicon, aluminum, iron, and calcium, however, there are at least 58 elements including trace elements which are present in coal $(7,8)$. Many of the trace elements in coal are considered to be hazardous to human health but are usually present in coal in very small quantities. Trace elements from coal reported to be of greatest health concern include arsenic, boron, cadmium, lead, mercury, molybdenum, and selenium while elements which are of moderate concern include chromium, copper, Fluorine, nickel, vanadium, and zinc (9). It would appear, however, that boron and molybdenum would be of more moderate concern compared to the other trace elements listed in the first group since they are less toxic.

The concern over hazardous trace elements in coal is not simply due to the absolute concentration of the element in the coal but also depends on the fate of the element during combustion and particle formation. Some of the trace metals are volatilized during combustion and condense on the surface of fine fly ash particles which subsequently become greatly enriched in trace metal concentration compared to the bulk ash. Elements which have been shown to be significantly enriched with decreasing fly ash particle size include arsenic, antimony, barium, gallium, selenium, vanadium (10), zinc, mercury, nickel, cesium (11), cadmium, chromium, lead, and thallium (7). The actual reported enrichment ratios when comparing larger particle concentrations to fine particle concentrations may be as high as 100. In addition, many of these elements are surface enriched (12) which means that the elemental concentration in contact with respiratory tissue would be much greater than for the average bulk fine particle concentration. 
A recent review of particulate trace elements in the atmosphere reported very high enrichment ratios, with respect to crustal concentrations, for arsenic, cadmium, lead, mercury and selenium (13). Except for arsenic, the mass median diameters for these elements were less than $1 \mu \mathrm{m}$, which were among the smallest for all particulate elements measured. Arsenic had a mass median diameter just slightly higher at $1.1 \mu \mathrm{m}$. Enrichment ratios for these elements with respect to the earth's crust ranged from a low of 310 for arsenic to a high of 3100 for selenium. The elements which are of significant health concern, lead, mercury, cadmium, selenium, and arsenic, have been shown to be significantly enriched in fine fly ash particles, are highly enriched in atmospheric particles, and are largely present as submicrun particles in atmospherir aernsols. Thus, there is a basis for concern over fine particle emissions into the atmosphere because of enrichment of hazardous trace elements. The actual biological concern for the these trace elements is as follows (14):

Cadmium is considered to be a dangerous cumulative toxicant causing insidious, progressive poisoning in mammals and $f$ ish since the metal is excreted at a very low rate. Cadmium collects in the kidney, liver, pancreas, and blood vessels. Some cadmium is absorbed from the lungs following inhalation and 1 t car cause lung cancer.

Arsenic toxicity depends on. the form it is in; in general trivalent compounds are more toxic than pentavalent compounds. Arsenic is a cumulative poison with long-term chronic effects on both aquatic organisms and mammals. Human target organs include the respiratory system, liver, skin, blood, and endocrine system. It can cause cancer of the mouth, esophagus, larynx, and bladder.

Lead has many detrimental effects on humans with acute toxicity being most common in children. The major uptake in man is through the gastrointestinal tract and lungs. Upon inhalation,

$$
3-10
$$


absorption takes place easily from the respiratory tract and symptoms develop more quickly. Target organs include the gastrointestinal tract, central nervous system, blood, and kidneys. Increasing amounts of lead bujld up in the body until hemolytic and renal poisoning occurs.

Mercury is a dangerous toxicant due to its high volatility and ability to be transformed. into an alkylated form which is most toxic to man. Mercury compounds accumulate in the central nervous system and may also be transmitted across the placenta. Their highly toxic effect on developing tissue make them particularly dangerous to man.

Selenium in trace amounts is essential for normal growth of some animals. Deficiency or excess is associated with serious disease in Iivestock. Elemental selenium has low acute systemic toxicity, but dust or fumes can cause serious irritation of the respiratory tract. It is a suspected carcinogen of the liver and thyroid.

Table $3-1$ is a summary of some of the trace element concentrations for a variety of U.S coals, enrichment factors, and health effects. The factors which determine the level of health hazard include the concentration of the element in the coal, the extent to which the element is enriched in fine respirable particulate matter, and toxic or carcinogenic effect on humans.

In summary, elements which are highly enriched in fine particles, have highly toxic acute or chronic effects on humans, and are suspected or knowr carcinogens include arsenic, cadmium, lead, and selenium. Mercury is highly toxic and enriched in fine particles but is not considered to be carcinogenic. Chromium and nickel are highly toxic and known carcinogens but show much less enrichment in fine particles. It would appear that these seven trace elements in coal present the most significant health hazard in fine particle emissions from coal combustion. The level of hazard is highly dependent on the 
TABte 3-1

CONCENTRATIOYS, ENRICHMENT FACTORS, PERHISSIBLE EXPOSJRE LIMITS AND TOXICITY OP SELECTED TRACE ELEMFNTS

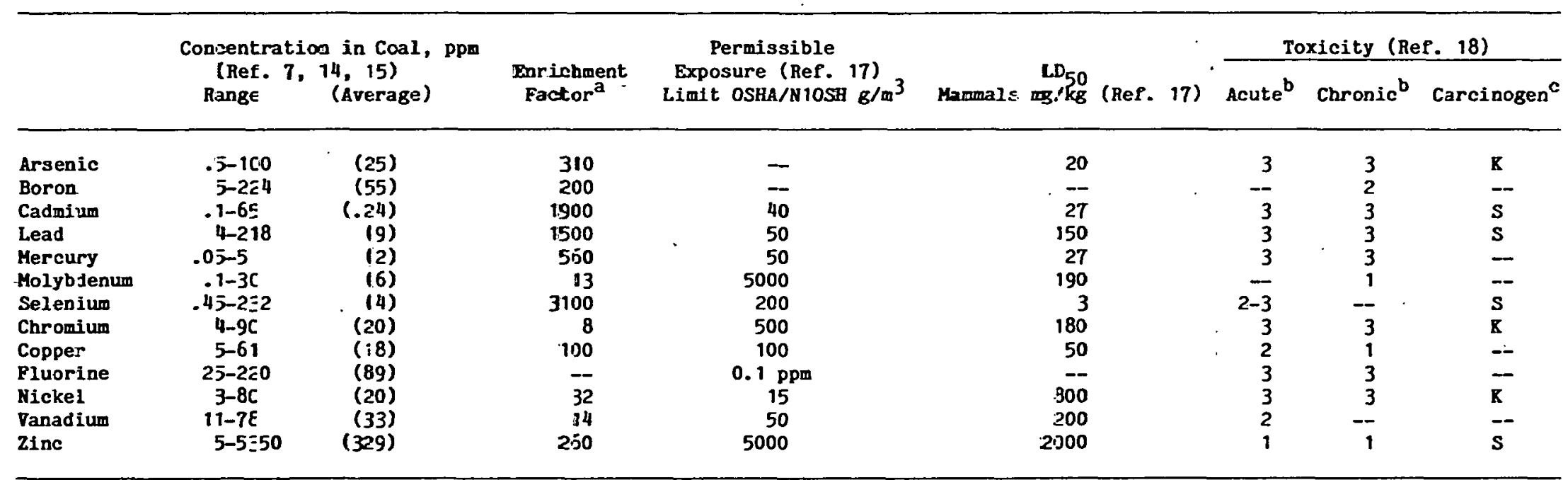

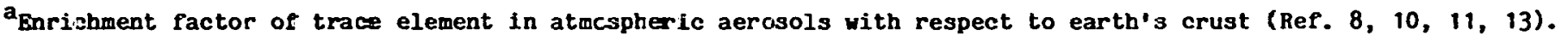

b 1 slight, 2 = moderate, 3 = high

c $\mathbf{K}=$ Known, $\mathbf{S}=$ Susfected 
trace element concentration in the coal which varies widely across the country. For example, cadmium concentration in coal is generally less than 1 ppm but concentrations as high as 65 ppm have been reported for Illinois coal (9). Selenium concentration in coal is generally less than 10 ppm but concentrations over 200 ppm have been reported for some Texas lignites (15). Assuming $10 \%$ ash and an enrichment factor of 100 between the submicron fraction and bulk fly ash, if all of the selenium remained in the fly ash, the potential selenium concentration in the submicron fly ash particles would be $200,000 \mathrm{ppm}$, or 20\%. These assumptions may be rather bold, but they demonstrate the potential for high trace element concentrations in respirable particulate matter. Tests conducted at UNDERC revealed a selenium concentration of $540 \mathrm{ppm}$ in submicron fly ash for a $6 \mathrm{ppm}$ selenium coal (16). Assuming the same enrichment, if the coal selenium concentration was $200 \mathrm{ppm}$, this would correspond to 18,000 ppm or about $2 \%$ selenium in the respirable fly ash; however, the actual surface concentration of selenlum is expected to be much higher. Similar arguments can be made for the other hazardous trace elements. They are significantly enriched in fine respirable fly ash, are known to be highly toxic, are carcinogenic, and therefore, are of public health concern.

\subsubsection{Long Range Transport}

The primary factor which determines the length of time a particle will stay suspended in the air is particle size. Atmospheric aerosols may range from less than $0.1 \mu \mathrm{m}$ to $100 \mu \mathrm{m}$ depending on distance from a source and wind velocity. For large $100 \mu \mathrm{m}$ particles, gravitational setliing is eufficient to cause rapid deposition, while for $0.1 \mathrm{\mu m}$ particles gravitational settling is insignificant. Table 3-2 1 ists settling velocities for spheres with a specific gravity of 2 in air at $25^{\circ} \mathrm{C}$ and 1 atmosphere. It would appear that submicron particles would remain in the atmosphere 
TABLE $3-2$

GRAVITATIONAL SETTLING VELOCITIES FOR SPHERICAL PARTICLES, SPECIFIC GRAVITY OF 2, IN AIR AT $25^{\circ} \mathrm{C}$, AND 1 ATMOSPHERE.

$\begin{array}{clc}\begin{array}{c}\text { Particle size } \\ \mu \mathrm{m}\end{array} & \begin{array}{l}\text { Settling velocity } \\ \mathrm{cm} / \mathrm{sec}\end{array} & \begin{array}{c}\mathrm{m} / \mathrm{day} \\ 0.1\end{array} \\ 1.0 & 0.0002 & 0.17 \\ 10 & 0.007 & 6.0 \\ 100 & 0.6 & 518 \\ & 50 & 43,200\end{array}$

indefinitely since updrafts would likely predominate over the small settling velocities. However, these small particles act as nucleation sites for moisture condensation and are deposited on the ground via moisture precipitation. From Table $3-2$ it can be inferred that submicron particles are subject to very long range transport (perhaps thousands of miles) if they are not captured by moisture condensation, and evidence indicates that this is the case. Haze over the western Arctic Ocean is caused in part by transport of pollutants on the order of $6000 \mathrm{miles}$ from sources in northern Europe (19). This haze contains sulfate levels 10 to 20 times greater than expected from natural sources in the region. Also, excess vanadium in this haze gives strong evidence than it is the result of anthropogenic emissions. At the Mauna Loa observatory in Hawaii, a spring dust episode in 1981 was attributed to sources in Asia (20) which again demonstrates the occurrence of very long range transport of fine particulate matter in the atmosphere. Residence time for fine particles in the atmosphere appears to be on the order of one week (21), which means that within the continental U.S., air contamination of clean pristine areas from remote sources is likely to be a problem. For example, visibility impairment and sulfate pollution in northern Vermont have been traced to major pollution sources in the ohio River Valley (22). In addition, high velocity nocturnal air jets may compound the problem because they may transport plumes long distances overnight with minimal 
dispersion (23). Extensive modeling of pollution sources, weather patterns, and visibility measurements (especially in the southwestern U.S.) has shown that pollution episodes in protected class I areas, such as national parks can be traced to distant sources (24). Evidence is conclusive that once fine particulate matter enters the atmosphere, it is subject to very long range transport and can therefore affect atmospheric visibility and public health of regions hundreds of miles away.

\subsubsection{Health Effects Studies}

Determination of health effects of specific particulate air pollutants is difficult because of the complexity of chemical species present, the particle size of individual species, correct measurement of pollutant concentrations, and length of time for effects to surface. Nevertheless, health effects have been extensively studied based on existing data from significant air pollution episodes. Epidemiologic assessments of health effects due to exposures to ambient particulate matter have also been completed based on human health data and known levels of atmospheric particulate matter. A very extensive review and assessment of scientific information on the health and welfare effects associated with exposure to various concentrations of sulfur oxides and particulate matter in ambient air is presented in the EPA document, Air Quality Criteria for Particulate Matter and Sulfur oxides, Volume III (25). Acute effects are reported separately from chronic effects. When ambient particulate levels are at least $1000 \mu \mathrm{g} / \mathrm{m}^{3}$, acute effects include a clear increase in mortality among the elderly and persons with preexisting respiratory or cardiac disease. For particulate levels of 500 to $1000 \mu \mathrm{g} / \mathrm{m}^{3}$, there are some indications of increases in daily mortality. At lower concentrations of 250 to $500 \mathrm{\mu g} / \mathrm{m}^{3}, a$ worsening of health status among chronic bronchitis patients can be expected. Below $250 \mu \mathrm{g} / \mathrm{m}^{3}$ there were no detectable acute effects in most bronchitis patients, but chronic effects are likely. It appears 
that respiratory function in children can be adversely affected by long term simultaneous exposure to particulate levels of 230 to $300 \mu \mathrm{g} / \mathrm{m}^{3}$ and $\mathrm{SO}_{2}$ levels of 180 to $275 \mathrm{\mu g} / \mathrm{m}^{3}$. Also, there is evidence that health improvements have occurred with decreases of TSP levels from 180 to $130 \mathrm{\mu g} / \mathrm{m}^{3}$. Based on results reported in the EPA review, it is not possibie to give an exact threshold value for suspended particulate matter which is a threat to public health; however, TSP levels greater than $130 \mathrm{\mu g} / \mathrm{m}^{3}$ may be expected to result in adverse health effects in a subset of the population such as children, elderly, or those with preexisting disease.

In the last four years, the Energy and Environmental policy Center at Harvard University has been conducting a study to develop quantitative information on the nature and the magnitude of potential health effects associated with exposures to airborne particles. Health and Environmental Effects Documents (HEEDs) from this study were published in 1982, 1983, and 1986 (26). The Harvard studies have added significant new conclusions concerning health effects of airborne particles. The study states, "From analysis of the existing epidemiology and extensive new epidemiologic investigations, we conclude that particulate pollution should be a public health concern because, even at current ambient concentrations, it may be contributing to excess mortality and morbidity. Furthermore, our recent analyses, as supported by the previously reported studies, indicate that fine particles $(<2.5 \mu \mathrm{m})$ and sulfates are among the most harmful particles to public health." It is important to note that it is the fine particles that correlate strongly with adverse health effects rather than TSP or even inhalable particles (<15 $\mu \mathrm{m})$. In addition, some evaluation of effects of specific particles on human health was conducted, which showed that the most significant fine particle predictors of total mortality were from the coal and metals industries whereas, the fine particles from soil were the least significant. These results demonstrate the importance of considering particle size and composition data in the modeling of particulate pollution health effects. 
The report presents quantitative data on mortality risk coefficients, based on 14 years of data from New York City, which link fine particulates to excess deaths. However, it is still not possible to establish exact threshold levels for which fine particulates are a health hazard, nor is it possible to Identify the exact particulate species (other than sulfates and fine particulates) which are the main health concern. At present, no reliable scientific data exist which directly demonstrate effects in humans as a result of long-term exposures to atmospheric trace metals at the levels found in ambient air. There is an extensive data base which demonstrates that serious biological effects have been observed in animals as a result of short term exposures to trace metals at concentrations above those found in ambient air. This suggests that long-term chronic exposure to atmospheric trace metals may result in a real, but as yet unquantifiable, risk to human health.

\subsubsection{References}

1. Wark, K. and C.F. Warner, AIR POLLUTION Its origin and Control. Harper and Row, New York, NY, p.2-3, 1981.

2. Air Quality Criteria for Particulate Matter and sulfur Oxides. Volume II. EPA-600/8-82-029bF, p. 5-52, December 1982 .

3. Pace, T.G. Ambient Particulate Baseline Conditions-Sources and Concentrations. Proceedings: The Technical Basis for a size Specific Particulate standard Parts $I$ and II. Air Pollution Control Association, pp 26-39, March 1980.

4. Air Quality Criteria for Particulate Matter and Sulfur Oxides, Volume III. EPA-600/8-82-029c, December 1982 .

5. Silverman, L., C.E. Billings, and M.W. First, Particle Size Analysis in Industrial Hygiene. Academic Press, New York, NY, pp. 261-268, 1971.

6. National Coal Association 1983 Forecast. Coal News, December 1982 .

7. Radian Corporation. Trace Metals and Stationary Conventional Combustion sources. Volume 1 Technical Report, EPA-600/7-80155a, August 1980 . 
8. Ray, S. and F. Parker. Characterization of Ash From Coal-Fired Power Plants. EPA-600/7-77-010, January 1977.

9. Harvey, R.D., R.A. Cahill, C.L. Chou, and J.D. Steel. Mineral Matter and Trace Elements in the Herrin and springfield Coals, Illinois Basin Coal Field. EPA-600/7-84-036, March 1984.

10. Markowski, G.W. and R. Filby. Trace Element Concentration as a Function of Particle Size in Fly Ash from a Pulverized Coal Utility Boiler. Environmental Science and Technology, Vol. 19, No. 9,1985 .

11. MCElroy, M.W., R.C. Carr, D.S. Ensor, and G.R. Markowski. Size Distribution of Fine Particles from Coal Combustion. Science, Vol. 215, No. 4528, 1982 .

12. Hansen, L.D. and G.L. Eisher. Elemental Distribution on Coal Fly Ash Particles. Environmental Science and Technology, Vol. 14, No. 9, pp. 1111-1117, September 1980 .

13. Milford, J.B., and C.I. Davidson. The Sizes of Particulate Trace Elements in the Atmosphere-A Review. Journal of the Air Pollution Control Association, Vol. 35, No. 12, pp. 1249-1260, December 1985 .

14. Torrey, S. Trace Contaminants from Coal. Noyes Data Corp., pp. $159-175,1978$.

15. Allen, S.C. Selenium in Lignite Distribution. Environmental Agency Policies and Solutions. Proceedings: Gulf Coast Lignite Conference, November 1982 .

16. Miller, S.J. and D.L. Laudal. Particulate Characterization. Low-Rank Coal Research, Quarterly Technical Progress Report for the Perlod July-Dec.1985, DOE/UNDERC/QTR-85/3-4.

17. NIOSH/OSHA Guide to Chemical Hazards. DHEW (NIOSH) Publication, No. 78-210, Fourth Printing, August 1981 .

18. Sax, N.I. Dangerous Properties of Industrial Materials. Fourth Edition, Van Nostrand Reinhold Company, 1975.

19. Godish, T. Air Quality. Lewis Publishers Inc., Chelsea, MI, p. 83, 1986 .

20. Braaten, D.A. and T.A. Cahill. Size and Composition of Asian Dust Transported to Hawaii. Atmospheric Environment, Vol. 20, No. 6, pp. 1105-1109, 1986.

21. Air Quality Criteria for Particulate Matter and Sulfur Oxides. Vol.I, EPA External Review Draft No. 2, February 1981. 
22. Poirot, R.L. and P.R. Wishinski. Visibility, Sulfate and Air Mass History Associated with the Summertime Aerosol in Northern Vermont. Atmospheric Environment, Vol. 20, No. 7, pp. 1457-1469, 1986 .

23. Rogers, D. and J.L. Bowen. The Meteorology of Regional Haze and Its Influence on Visibility in the Southwestern United states. Presented at: The APCA. International specialty Conference on Visibility Protection-Research and Policy Aspects, Grand Teton National Park, WY, September 1986, Proceedings forthcoming.

24. Iyer, H.K. and W.C. Malm. A Mass Balance Method for Estimating the Fractional Contribution From Various Sources to a Receptor Site. Presented at: The APCA International specialty Conference on Visibility Protection-Research and Policy Aspects, Grand Teton National Park, WY, september 1986, Proceedings forthcoming.

25. Air Quality Criteria for Particulate Matter and Sulfur Oxides, Volume III. EPA-600/8-82-029c, December 1982.

26. Ozkaynak, H. and J.D. Spengler. Health Effects of Airborne Particles. Energy and Environmental Policy Center, Harvard University, MA, February 1986. 


\subsection{Visibility Effects}

Visibility impairment caused by air pollution is a moderate or significant problem in almost every major U.S. city. Furthermore, pollution induced visibility problems in pristine areas such as national parks have been documented, and this has led to a visibility protection clause in the clean Air Act (see next section on regulations). The public has shown reluctance to accept anthrnpogenic degradation of air quality, whether it be visible emissions from a stack or a layer of haze over a city. A situation exists where visibility impairment is much greater than is acceptable. Even though haze or smog problems in major cities may be somewhat improved from 10 years ago, poliutant levels are still significant enough to cause major visibility degradation.

Almost all cases of visibility impairment are caused by the presence of particles (solid or liquid), and except for dust storms, it is the fine particles less than $2 \mu \mathrm{m}$ which are the primary contributors to the impairment. The type of fine particles causing the reduced visibility is largely known, but the exact source of the particles is more difficult to prove. One might think that natural sources of particulate matter in the atmosphere are the primary causes of reduced visibility. Examples are dust storms, fog, snow or rain, forest fires, sea spray, volcanic eruptions, and vegetative emissions. With few exceptions, however, these 1ntense but infrequent events do not dominate the averagt ainual visual range within the Continental U.s. unly a small percertage of hours involve storms or fog. In the arid West, wind blown dust can be significant, but suspended crustal material in a dust storm usually consists of coarse solid particles with a volume mean diameter greater than 10 to $20 \mu \mathrm{m}$, which means they will quickly settle and not contribute to long term visibility impairment. A very thorough review of visibility effects of airborne particles is given in the EPA criteria document, Air Quality Criteria for Particulate Matter and sulfur oxides-Volume III (1). Much of the information for this section was 
obtained from that reference. Visibility protection was the subject of a recent international specialty conference sponsored by the Air Poilution Control Association (2). Some of this work has focused on attributing visibility impairment to specific types of particles and tracing them to their source.

\subsubsection{Scattering and Absorption}

The best visibility in the U.S. occurs in the southwest where the median yearly visual range is from 70 to $80 \mathrm{miles.} \mathrm{A} \mathrm{particle-free}$ atmosphere at sea level would have a visual range of about $200 \mathrm{miles}$, which is limited by Rayleigh scattering of light by air molecules. Rayleigh scattering decreases with the fourth power of wavelength, which means that blue light is scattered much more effectively than red light. This explains why the sky appears blue and why the sun appears red at sunset.

The intensity of a beam of light in the direction of an observer decreases with distance from the source because some of the light is absorbed or scattered out of the beam. Over a short interval this decrease is proportional to the path length and intensity of the beam:

$$
-d I=\sigma_{\text {ext }} I d x
$$

where $-d I$ is the decrease in intensity, $\sigma_{\text {ext }}$ is the proportionality or extinction coefficient, $I$ is the intensity at the beginning of the interval and $d x$ is the path length. Solving this equation for $I$ yields:

$$
I=I_{0} \exp \left(-\sigma_{\text {ext }} \mathbf{x}\right)
$$

The extinction coefficient is made up of absorption and scattering components for both gases and particles. For an observer looking at a distant object there are two effects which limit the visual range or clearness of the object. First, light from the object is 
diminished because some of the light is absorbed or scattered to the side. The second effect is that extraneous light is scattered into the line of sight and is superimposed on the light from the object. This tends to make the object appear hazy or less distinct. The net effect is that contrasts between dark and bright objects are diminished--dark objects appear brighter and bright objects appear darker. At sufficient distances dark or bright objects approach the horizon brightness. For a black object or target the distance at which it becomes indistinguishable is referred to as the visual range or visibility.

As mentioned, there are four main components which make up the total extinction coefficient, scattering and absorption coefficients for gases and scattering and absorption coefficients for particles. Almost all cases of visibility impairment are caused by particles, the sole exception being discoloration caused by $\mathrm{NO}_{2}$. The contribution of $\mathrm{NO}_{2}$ to total extinction, however, is usually minor. In Denver, Colorado, which is known to have a brown haze problem, a 1978 study showed that only $6 \%$ of the total light extinction could be attributed to $\mathrm{NO}_{2}$. Brown plumes can occasionally be seen downwind from a power plant. In these cases $\mathrm{NO}_{2}$ is thought to be the main cause of the discoloration (3), but once the plume is dispersed into the atmosphere, $\mathrm{NO}_{2}$ is no longer the major contributor to general haze. The scattering component of atmospheric gases contributes only to background Rayleigh scattering and is therefore not the cause of reduced visibility. For example, at a visual range of 25 miles (fairly good visibility), Rayleigh scattering would make up only about $1 / 8$ of the total extinction.

With atmospheric particles the situation is more complex because both the scattering and absorption components for a wide range of particle sizes and particle species nust be considered. Particle scattering accounts for 50-95\% of the total extinction depending on location, with urban sites in the 50-80\% range and nonurban sites in the 80-95\% range. The primary difference is in the elemental carbon concentration which is more significant in urban sites. Elemental carbon such as soot has a high absorption coefficient which can cause 
particle absorption to account for up to $50 \%$ of the total extinction. The particles which account for most of the scattering are those from 0.1 to $2 \mu \mathrm{m}$ in diameter. Particles smaller than $0.1 \mu \mathrm{m}$ may be present in high numbers, but they are inefficient at scattering light and contribute very little to visibility impairment. Particles larger than $2 \mu \mathrm{m}$ are usually present in relatively small numbers compared to the smaller particles and contribute very little to visibility loss due to particle scattering. Figure 3-4 illustrates the strong dependence of scattering efficiency on particle size.

\subsubsection{Haze}

The appearance of layers of smoggy haze over cities and across rural vistas is one of the most widely noticed effects of air pollution. The cause of haze is known to be elevated levels of fine particulate matter in the atmosphere. Because scattering and absorption coefficients are dependent on chemical species and particle size, the exact relationship between particle concentration and extinction is complex. However, particle mass concentrations

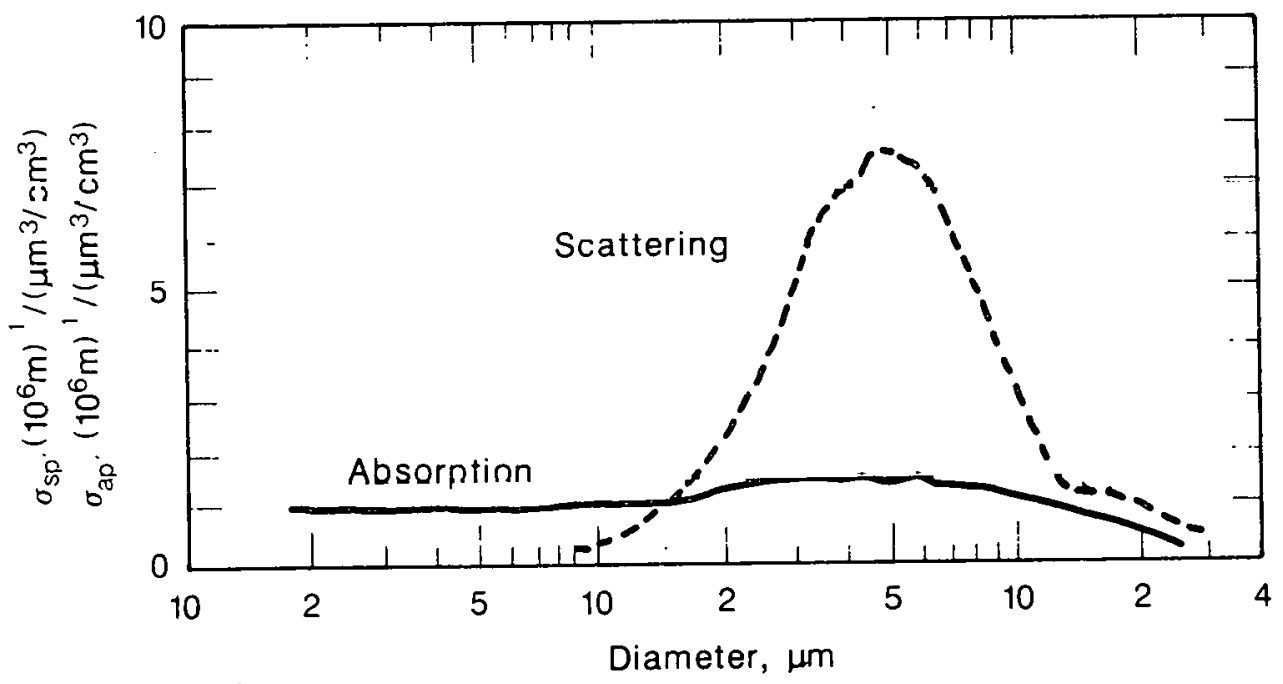

Figure 3-4. Light scattering and absorption per volume concentration as a function of particle size (Ref. 1). 
are the most common measure of atmospheric aerosols. Figure 3-5 shows the relationship between fine particle mass concentration and visual range. Two constants are taken into account in these graphs. First, the constant $K$ simply refers to an observer's contrast threshold which is assumed to be 3.9. Plots are given for several values of the second constant, $\gamma$. This constant is dependent on particle size, particle type; and relative humidity and refers to the scattering and absorption efficiency of a given fine particle mass (more will be said about the effect of relative humidity on visibility in the next section). Iooking at Figure $3-5$, it is apparent liat there ic a pronounced decrease in visibility with a relatively small increase in fine particulate matter. Thus, visibility can be significantly impaired by a fine particle mass concentration of only $25 \mathrm{\mu g} / \mathrm{m}^{3}$. The current national ambient air

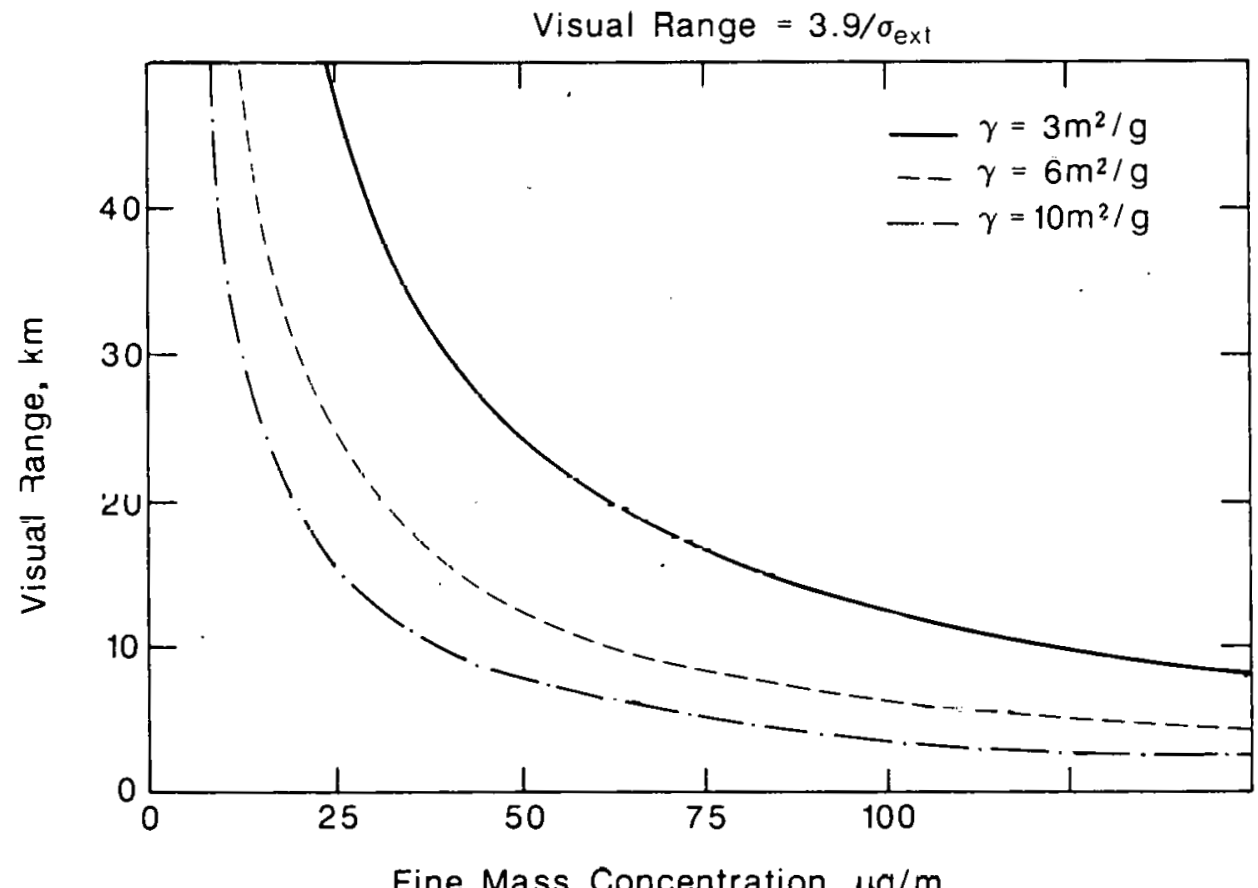

Fine Mass Concentration, $\mu \mathrm{g} / \mathrm{m}$

Figure 3-5. Visual range as a function of fine particle mass concentration, assuming $K=3.9$ (Ref. 1 ). 
quality standard. for TSP is $75 \mu \mathrm{g} / \mathrm{m}^{3}$ on an annual geometric mean basis. For many TSP and fine particulate measurements across the U.S., at least half of TSP has been in the fine particle mode. Assuming 50\%, the current ambient standard would limit the fine particle mass to $3.5 \mu \mathrm{g} / \mathrm{m}^{3}$ which is above the level of noticeable visibility impairment.

We frequently think of reduced visibility in terms of. the negative aesthetic effect, and it is true that haze reduces the perceived beauty of scenic vistas. However, aerosol haze can also degrade the view of the night sky. Star brightness is reduced by light scattering and absorption, but near urban areas night sky brightness is significantly increased by particle scattering of artificial light. The combination of extinction of starlight and increased sky brightness significantly decreases perceived star brightness even at low fine particle concentrations of 10 to $30 \mu \mathrm{g} / \mathrm{m}^{3}$.

The benefits of good visibility go beyond those mentioned. Both automobile and aircraft safety may be affected by pollution related reductions in visual range. Reduced visibility by pollution has been correlated to negative effects on human behavior and increased automobile accidents (4). Also, particles in the atmosphere affect direct solar radiation. On a hazy day, the direct solar radiation may be reduced to about one-half of that on a clear day, but most of the energy reappears as diffuse skylight. There is, however, a loss of up to about 10 to $20 \%$ of the radiation reaching the surface. An additional consequence of a hazy atmosphere in an otherwise cloudless sky is the disappearance of a sharp shadow contrast. On a global scale the effects of man-made pollutants are still a matter of debate, but the attenuation of solar radiation from scattering and absorption by particles in the atmosphere is probably an important factor in climatic change. Effects could result from the redirection of photon energy which may influence the structure and distribution of clouds. 


\subsubsection{Long Term Monitoring Studies}

Over the past 10 to 15 years, monitoring of ambient particulates has provided a fairly extensive data base as to concentrations of suspended particulate matter in the atmosphere. Since the 1977 amendments to the clean Air Act (which specifically call for the protection of visibility) were implemented, a number of studies were initiated to monitor visibility $(2,5)$. This has provided quantitative data on visibility trends with time, and along with analytical data on the chemical nature of particulates, has allowed apportioning visibility impairment to specific pollutarts. studies have also included modeling of weather patterns to facilitate tracing pollutants back to their source. Much of the work has focused on the Southwest because that region has the highest background visibility of any region in the country and is therefore more susceptible to noticeable impairment. Also, that region has a number of class I designated areas which are required by law to be protected to maintain good visibility.

Some of the strongest evidence relating regional visibility patterns with source emissions is the correlation between copper smelter emissions and sulfate concentrations in the southwest. During 1967-68 there was a strike which shut down plants for 9 months. Copper production accounted for $90 \%$ of the $\mathrm{SO}_{\mathrm{x}}$ emissions in the southwest at that time, and visibility impairment from copper smelting was primarily through its contribution to sulfate loadings. During the strike there were substantial drops in sulfate concentrations in five locations within 70 miles of copper smelters (Tucson, Phoenix, Maricopa County, White Pine, and salt lake city). Perhaps even more signiticant, sulfate concentrations dropped by more than 60\% at Grand Canyon and Mesa Verde national parks, which are located 200 to 300 miles from the main smelter area in southeast Arizona. During this time, it was also found that the large decrease in sulfates in Phoenix was accompanied by a substantial improvement in visibility. In 1980, there was another copper smelter strike which shut down 9 of 11 smelters for three months. Ambient air was 
extensively studied before, during, and after the strike. It was concluded that the highest sulfate levels at remote areas in Arizona and southern Utah occurred when wind trajectories were from copper smelter locations. During the strike period, mean sulfate concentrations decreased from 50 to $90 \%$ throughout Arizona compared to levels before the strike. Other studies have shown that hazy air masses from southern california, when transported to the desert Southwest, had a significant impact on visibility degradation. Another example of long range transport of pollutants resulting in visibility degradation is in Northern Vermont, where sulfate particulates accounting for over $80 \%$ of the variation in light extinction, have been traced to the ohio River valley (6). Studies to date have established baseline data as to visibility trends throughout the U.S., but research is continuing to provide better data on how visibility changes with time and weather patterns for a given location. The National Park service has established an extensive monitoring network (especially in the western U.S.) which has operated since 1978 (7). When particulates at a site are measured as to concentration and chemical species, both the species that contribute to extinction and their source can be obtained. The next section gives further information on the particulate species that are normally found in ambient air and their relative contributions to visibility impairment.

\subsubsection{Ambient Particulate Levels}

The distribution of 1978 annual arithmetic means for TSP was shown in Figure 3-2. About half of the nation's monitoring sites for this year had annual mean TSP values less than $60 \mu \mathrm{g} / \mathrm{m}^{3}$, but values ranged from 9 to $256 \mu \mathrm{g} / \mathrm{m}^{3}$. Analysis of daily or $24 \mathrm{hr}$. TSP data suggests that most of the U.S. population might experience ambient TSP concentrations exceeding $100 \mu \mathrm{g} / \mathrm{m}^{3}$ for at least 36 days of the year. TSP, however, is a poor index of visibility degradation or adverse health effects since both visibility and health are impacted mustly by the fine particle fraction. As a result, the EPA 
established a network of 250 stations to measure fine particle mass separate from TSP. Results show that airborne particles exist in two distinct size ranges, fine particles below about $1 \mu \mathrm{m}$ and coarse particles above about $3 \mu \mathrm{m}$ with relatively little mass in the intermediate sizes. The coarse and fine fractions differ in origin, composition, geographic distribution, and physical behavior. Since it is the fine particle fraction that has the most impact on visibility and public health, only the fine particle composition will be further considered here.

The primary constituents which make up the fine particle fraction inciude sulfates, elemental carbon, ulganic material, ammonium, nitrate, and crustal material. Sulfates occur predominately in the fine particle mass as opposed to the coarse fraction. Furthermore, the sulfate ion generally constitutes 30 to $50 \%$ of the fine mass over a wide variety of sites. The sulfate is usually associated with the ammonjum ion which typically accounts for 5 to $15 \%$ of the fine particle mass, although sometimes the sulfate is associated with hydrogen ions.

Elemental carbon will generally have a relatively greater contribution to the total extinction than to the fine particle mass because fine carbon particles absorb light as well ds scatter it. Most studies show that elemental carbon is a significant contributor to visibility impairment. Studies in the southwest revealed that elemental carbon contributed 20 to $30 \%$ of the total light extinction in Arizona and the Mojave desert in California (8,9), while in Denver elemental carbon accounted for. $38 \%$ of the extinction beyond background (1). Organic carbon also has accounted for 23 to $33 \%$ of the total extinction $(1,9)$. Nitrates contribute a smaller portion to extinction, on the order of $10 \%$ or less.

studies show that crustal material (often referred to as soil dust) contributes on the order of 10 to $20 \%$ of the fine particle extinction. It is incorrect, however, to aseume that this fraction is entirely from natural causes. Most studies do not distinguish between fly ash particles (which contain the primary crustal elements) and true "soil dust". This makes it difficult to determine 
the exact contribution of coal fly ash to light extinction, although it is clear that coal fly ash is not the main cause of light extinction since the total extinction is usually dominated by sulfates, elemental carbon, and organic carbon. In a study of atmospheric aerosols in the Eastern U.S. in which fly ash was specifically identified, the fly ash made up $9 \%$ of the coarse mass but only $5 \%$ of the fine particle mass (10). In this study it was found that up to $95 \%$ of the particles in the 0.3 to $2 \mathrm{\mu m}$ range were pure ammonium sulfate or acidic ammonium sulfate.

one additional atmospheric constituent that can have a large effect on visibility is water. It is well known that on very humid days there also tends to be haze. Water affects visibility only when it is in the liquid or solid phase. When haze is associated with high relative humidity, it is not caused by the higher vapor content of the air, but by increased light scattering due to particles. The effect of relative humidity on visibility is usually associated with growth of preexisting particles resulting in increased scattering. Thick hazes or fogs are often dismissed as being caused by high humidity, whereas in some cases they might not have formed without the presence of anthropogenic hygroscopic nuclei. In general, relative humidities above $70 \%$ can be expected to reduce visibility due to the size growth of common aerosol species such as ammonium sulfate. The exact role of water in visibility impairment is difficult to predict accurately, however, because it is highly dependent on the presence of natural and anthropogenic hygroscopic particles. Also, relative humidity changes rapidly making it difficult to correlate long term samples with humidity conditions.

Many of the particulate constituents in the atmosphere can be attributed to specific sources. The primary source of atmospheric sulfates is thought to be $\mathrm{sO}_{2}$ emissions which are converted to sulfates in the atmosphere. Such sulfates are referred to as secondary sulfates. One significant source of elemental carbon is soot from combustion sources. Sources of ammonium and organic carbon are not well known.

If one is interested in correcting visibility impairment, it $3-29$ 
would appear that reducing sulfate concentrations in the atmosphere should be the first step. Sulfate concentrations in the eastern U.S. are about 10 times higher than in the west, except for the Los Angeles area. In the West, annual mean sulfate levels are about $2 \mu \mathrm{g} / \mathrm{m}^{3}$ compared to $20 \mu \mathrm{g} / \mathrm{m}^{3}$ in the East (11). High sulfate levels are so widespread in the East that rural and urban concentrations are nearly the same, Concentrations have been sufficiently high for such a long period of time that no real background measurements for fine particulate matter are available east of the Mississippi. $\mathrm{SO}_{2}$ concentrations in the atmosphere range from less than $10 \mu \mathrm{g} / \mathrm{m}^{3}$ to over $100 \mathrm{\mu g} / \mathrm{m}^{3}$ or an annual mean basis, but in general are higher than sulfate levels. Since 1 to $10 \%$ of $\mathrm{SO}_{2}$ in the atmosphere is converted to sulfate every hour, there is continual generation of sulfate. This means that, as long as ambient so $\mathrm{s}_{2}$ levels are high, visibility impairment by sulfates will continue to be a problem, and that significant improvements in visibility would result from better control. of $\mathrm{SO}_{2}$ emissions.

The relative magnitude of the problem can be brought into perspective if one considers that in 1978, estimated $\mathrm{SO}_{2}$ emissions from coal combustion were 18 million metric tons while particulate emissions from coal combustion were only $3 \mathrm{million}$ tons (12). of the 3 million tons of particulates, at most only about $1 / 3$ would be classified as fine particulates smaller than $2.5 \mu \mathrm{m}$. Therefore, $\mathrm{SO}_{2}$ emissions from coal combustion were at least 18 times greater than fine particulate emissions. Since the half-life of $\mathrm{SO}_{2}$ in the air is short, most of the $\mathrm{SO}_{2}$ would be expected to be converted to sulfates. It is readily apparent why sulfates contribute much more to visibility problems than fine fly ash particles. However, one should not dismiss fine particles from coal combustion as being an insignificant contributor to light extinction, because it is not well documented what portion of fine particle mass is from coal combustion compared to natural crustal sources. At present, fly ash may contribute only $5 \%$ to the fine particle mass, but this is $11 k e l y$ to be highly dependent on sampling location. Within the region of power plants with low $\mathrm{so}_{2}$ emissions and an otherwise low background level., 
fine fly ash particles could become more significant. Also, within the next decade, it is likely that total so $\mathrm{s}_{2}$ emissions will be significantly reduced, which means that if fine particle emissions remain constant, coal fly ash will make up a larger fraction of the fine particle mass in the future. A similar argument can be made for soot emissions such as from diesel engines. If they are better controlled in the future, fine fly ash particles could make up a larger portion of total light extinction.

\subsubsection{References}

1. Air Quality Criteria for Particulate Matter and sulfur oxides, Volume III. EPA-600/8-82-029C, pp. 9-1 to 9-112, December 1982 .

2. Specialty Conference on Visibility Protection-Research and Policy Aspects. Grand Teton National Park, WY, Air Pollution Control Association, September, 1986, Proceedings forthcoming.

3. A.H. Vanderpol and M.E. Humbert. Coloration of Power Plant Plumes-NO 2 or Aerosols. Atmospheric Environment, Vol. 15, No. 10/11, pp. 2105-2110, Great Britain, 1981 .

4. Hoehn, J. Visibility Related Behavior as an Indicator of Visibility Values. Presented at: The APCA International Specialty Conference on Visibility Protection-Research and Policy Aspects, Grand Teton National Park, WY, September 1986, Proceedings forthcoming.

5. Sloalle, S.S. and W.H. White. Visibility: An Evolving Issue. Environmental Science and Technology, Vol. 20, No. 8, 1986.

6. Pnirnt, B.L. and P.R. Wiohingki. Visilulllly, sultate and Air Mass History Associated with the Summertime Aerosol in Northern Vermont. Atmospheric Environment, Vol. 20, No. 7 pp. 1457-1469, 1986 .

7. Malm. W.C. and J.V. Molenar. Visibility Measurements in National Parks in the Western United States. Journal of the Air Pollution Control Mssociation, Vol.34, Nu. 9, September 1984 .

8. Sutherland, J.L. and F.S. Bhardwaja. Elemental Characteristics of Aerosols in Northern Arizona and Southern Utah. Presented at: The APCA International specialty Conference on Visibility Protection-Research and Policy Aspects, Grand Teton National Park, WY, September 1986, Proceedings forthcoming. 
9. Trijonis, J.C. and M. Pitchford. Preliminary Extinction Budget Results from the RESOLVE Program. Presented at: The APCA International specialty Conference on Visibility protectionResearch and Policy Aspects, Grand Teton National Park, WY, September 1986, Proceedings forthcoming.

10. Mamane, Y. and T.G. Dzubay. Characteristics of Individual Particles at a Rural site in the Eastern United States. Journal of the Air Pollution Control Association, Vol. 36, No. 8, 1986 .

11. Eldred, R.A., T.A. Cahill, and P.J. Feeney. Regional Patterns in Particulate Matter from the National Park Service Network form June 1982 to May 1986. Presented at: The APCA International Specialty Conference on Visibility Protection-Research and Policy Aspects, Grand Teton National Park, WY, September 1.986, Proceedings forthcoming.

12. Air Quality Criteria for Particulate Matter and Sulfur oxides, Vuluine II. ENA 600/8-82-028bb, P. 4-14, ner:emker 1982 . 


\subsection{Regulations / Clean Air Act}

The Clean Air Act is viewed today as a landmark law that has improved the quality of life in the united states by cleaning up air pollution. According to Leon Billings, former staff director of the Senate Environment and Public Works Subcommittee on Environmental Pollution, "Urban centers would be virtually uninhabitable if there were no Clean Air Act today". The original Clean Air Act was passed in 1955 (PL 84-159) authorizing a research program, and has been modified piecemeal as the program has developed. Amendments in 1960, 1963, and 1965 addressed research in motor vehicle pollution and fuel desulfurization, provided for the development of air quality criteria, and included investigation of new sources of pollution. In 1967, the Clean Air Act was replaced by the Air Quality Act of 1967 (PL 90-148), but the former name was retained. Amendments in 1970 (PL 91-604) resulted in establishing the Environmental Protection Agency (EPA) and required the EPA to set ambient air quality standards for the protection of public health and welfare, to control emissions from stationary and mobile sources, to control emissions from new stationary sources, and to control hazardous air pollutants.

In 1977, the Act was further amended (PL 95-95) to provide a standardized basis for rulemaking concerning ambient standards, performance standards and emissions standards. In addition, these amendments established two programs to protect air quality in pristine dreas where crieting ambient standards would not be sufficient, which included a program to prevent significant deterioration of air quality and a program to protect visibility. since that time, relatively minor changes have been made. As a result of the regulations, data show that between 1975 and 1982 levels of lead in the ambient air dropped by 64\%, sulfur diuxide levels were reduced by $33 \%$, and particulate matter was reduced by 15\%. There is now the recognition and acceptance by industry (such as automobile, utility, and paper industries) that air pollution control is a permanent part of the cost of doing business. Neverthelcss, some parts of the clean Air Act are just beginning to 
be implemented. Many states have not yet completed the state Implementation Plans (SIP) called.for by the law to clean up areas which are not in compliance. Also, the visibility protection aspects of the law have not been fully implemented and episodes of visibility degradation in Class I national parks are still common.

As it stands today, the clean Air Act has many provisions which affect the level of pollution control required. The national primary and secondary ambient air quality standards provide the first index of whether or not a region needs to reduce air pollution. Regions which are not in compliance with the ambient ctandard must dinplement plans to improve air quality and regions wlich are in compliance must have plans to maintain air quality. A second level of contrnl is the New Source Performance standards (NSPS) for stationary sources. These are emission limits on the amount of an individual pollutant a plant is allowed to emit; however, states may require stricter emission limits if they so choose. The law also calls for prevention of significant deterioration of air quality from background levels and requires that the best available control technology (BACT) be applied to control emissions. The visibility protection aspect of the law may impose even more restrictions on emissions and requires installation of best available retrofit technology to correct visibility impairment.

\subsubsection{National Ambient Air Quality Standards}

Ihe EPA has issued ambient air standards for six pollutants: carbon monoxide, lead, nitrogen oxides, total suspended particulates, photochemical oxidants, and sulfur dioxide. For Total suspended Particulates (TSP), the primary standard on an annual geometric mean basis is $75 \mu \mathrm{g} / \mathrm{m}^{3}$, while the secondary standard is $60 \mu \mathrm{g} / \mathrm{m}^{3}$. The 24hour primary standard for TSP is $260 \mu \mathrm{g} / \mathrm{m}^{3}$ and the secondary standard is $150 \mathrm{\mu g} / \mathrm{m}^{3}$. The 24-hour standard is not to be exceeded more than once per year. For sulfur dioxide, the primary standard on an annual arithmetic mean basis is $80 \mu \mathrm{g} / \mathrm{m}^{3}(0.03 \mathrm{ppm})$, while the 24-hour standard is $365 \mu \mathrm{g} / \mathrm{m}^{3}(0.140 \mathrm{ppm})$. The only secondary standard for 
sulfur dioxide is a 3 -hour standard which is set at $1,300 \mu \mathrm{g} / \mathrm{m}^{3}$ $(0.50 \mathrm{ppm})$. The 24-hour primary and 3-hour secondary standards for sulfur dioxide are not to be exceeded more than once per year. The primary standards must reflect the level of attainment necessary to protect public health, allowing for an adequate margin of safety. secondary standards are designed to protect public welfare, in addition to health, and are therefore somewhat more stringent than primary standards.

Both the EPA and individual states have established monitoring stations to measure ambient air quality throughout the country. states are required, as part of their SIPs, to designate those cities, portions of cities, or counties that have failed to meet primary or secondary standards for any of the regulated ambient air pollutants. Any such locations must be designated as nonattainment areas and plans must be implemented to bring about attainment in these areas.

One further point should be made concerning ambient air quality standards. According to section 109d of the clean Air Act, air quality criteria must be reviewed by the EPA at least every five years, and the national ambient air quality standards are to be revised if new information indicates the need. This means that it is very likely that standards will become stricter if health studies and other criteria show that lower levels of regulated pollutants are needed to protect long-term public health and welfare.

\subsubsection{New Source Performance Standards}

The EPA has set emission standards along with monitoring and reporting requirements for a large number of different industrial sources. These standards represent the use of best demonstrated technology and also represent a minimum criteria for best available control technology. Standards of performance are not intended to achieve any specific air quality level, but are designed to reflect best demonstrated technology (taking into account costs) for the source in question. For electric utility steam generating units with 
a heat input of $73 \mathrm{MW}$ or greater for which construction commenced after september 18, 1978, the particulate emission limit is 0.03 $1 \mathrm{~b} / \mathrm{million} \mathrm{Btu}(13 \mathrm{ng} / \mathrm{J})$. In addition, the opacity of emissions cannot exceed $20 \%$ over a six minute average, except for one six minute period per hour of not more than $27 \%$ opacity. Also, when burning solid fuel such as coal, 99\% particulate removal is required; but this constraint is usually not an issue since more than $99 \%$ removal is required for most coals to meet the $0.031 \mathrm{~b} / \mathrm{million}$ Btu emission limit. As of June 19, 1984, the EPA proposed a new source performance standard for smaller industrial/commercial steam generating units, which applies to units with a heat input of more than $29 \mathrm{MW}$ but less than $7.3 \mathrm{MW}$. The emission limit fol these coal fired boilers is $0.05 \mathrm{lb} / \mathrm{million} \mathrm{Btu}(22 \mathrm{ng} / \mathrm{J})$ which is somewhat higher than the limit for larger boilers, but the six-minute opacity standard is the same at $20 \%$.

New source performance standards represent the maximum emissions which are allowable under any conditions. It should be recognized that stricter emission limits could be required under other provisions of the law. For example, individual states may choose to impose stricter standards, BACT may be available which subsequently results in lower emission standards, prevention of signiticant. deterioration (PSD) requirements may allow only a very small iricrease in emissions because of previous allowable increments, or lower emissions may be required because of visibility protection measures.

Present emission standards for parelculate matter require cunlrul of total mass particulate emissions and make no distinction between fine particle emissions and total mass emissions. In view of the interest in an ambient fine particle standard and the strong correlation between fine particles and adverse health effects and visibility impairment, it would appear likely that a fine particle emission standard will also be promulgated. However, as of this time, a fine particle emission standard has not been proposed, so one would appear to be at least several years away. 


\subsubsection{Prevention of Significant Deterioration}

The Prevention of Significant Deterioration (PSD) aspects of the clean Air Act are among the most complex and most variable in application. According to section 160 of this law, the purposes of this part are:

1. "to protect public health and welfare from any actual or potential adverse effect which in the Administrator's judgement may reasonably be anticipated to occur from air pollution (or from exposures to pollutants in other media, which pollutants originate as emissions to the ambient air), notwithstanding attainment and maintenance of all national ambient air quality standards:"

2. "to preserve, protect, and enhance the air quality in national parks, national wilderness areas, national monuments, national seashores, and other areas of special national or regional natural recreational, scenic, or historic value;"

3. "to insure that economic growth will occur in a manner consistent with the preservation of existing clean air resources;"

4. "to assure that emissions from any source in any state will not interfere with any portion of the applicable implementation plan to prevent significant deterioration of air quality for any other State; and"

5. "to assure that any decision to permit increased air pollution in any area to which this section applies is made only after careful evaluation of all the consequences of such a decision and after adequate procedural opportunities for informed public participation for the decisionmaking process."

The PSD program is intended to preserve air quality in areas where ambient standards have been met, which basically means the whole country except for nonattainment areas. However, states are required to implement plans for nonattainment areas to meet ambient standards. Therefore, as new plants are added, emissions must be reduced in existing plants so there is no net increase in the nonattainment pollutant over the given area or "bubble". New stationary sources with controlled emissions of over 100 tons per year of any pollutant subject to regulation under the Clean Air Act, if located in an area 
that is in attainment for that pollutant, are subject to PSD requirements. The EPA specifically lists 28 industrial catagories, including fossil-fuel steam electric plants larger than 73 MW heat input, for which PSD regulations apply. All new facilities with controlled emissions of over 250 tons per year of any pollutant are subject to PSD if located in applicable areas.

PSD requires preconstruction ambient air monitoring for all criteria pollutants if the impact on ambient air is greater than certain de minimis amounts, which for TSP is 25 tons per year. PSD provisions do not limit emissions to a specific level other than NSPS but rather limit the increase of the pollutant in ambient air. For a olaoe I area. the maximum allowable increase in particulates is $5 \mu \mathrm{g} / \mathrm{m}^{3}$, for a class II area the maximum is $19 \mu \mathrm{\mu g} / \mathrm{m}^{3}$, and for class III areas is $37 \mu g / \mathrm{m}^{3}$, all on an annual geometric mean basis. Maximum allowable 24-hour increments for particulate matter are 10, 37, and $75 \mu \mathrm{g} / \mathrm{m}^{3}$, respectively. At present, Class I areas are specifically designated and, except for nonattainment areas, all other areas are considered to be Class II. Designation of areas as Class III, which supposedly applies to areas of heavy industrial development which meet ambient air quality standards, has not been completed to date. This means that for present PSD increments, the Class II level is the maximum allowed. All plants in the vicinity (for example, 100 miles) of a class I area are likely to be subject to the smaller increment of $5 \mathrm{\mu g} / \mathrm{m}^{3}$. The increments are measured over so called "baseline concentrations" which reflect air quality in a given area as of January 6, 1975 .

PSD requirements are especially significant for plants near Class I areas or for plants in Class II areas which are already close to the maximum alluwed increase, since the small allowable increments in ambient air may require much stricter control than existing NSPS for a plant. In such cases, if a superior and economical control technology is not available, the plant may never be constructed. This clearly demonstrates the need for improved, but economical technology to meet variable requirements of regulations such as PSD provisions. The previously mentioned de minimis value for TSP is 25 
tons per year. If plant emissions for particulates were less than 25 tons per year, then the plant would not be subject to PSD scrutiny for that pollutant. A current 500 Megawatt coal-fired plant with 99.9\% particulate removal would. emit about 150 tons per year of particulate matter and would meet the NSPS of $0.031 \mathrm{~b} / \mathrm{million}$ Btu. However, because emissions would be greater than 25 tons per year, the permitting process would involve PSD scrutiny for particulate matter (as well as for other pollutants such as nitrogen oxides and sulfur dioxide). If it could be demonstrated that the plant could attain a removal efficiency of $99.99 \%$ through the use of a superior control technology, particulate emissions would be only 15 tons per year and the costly process of PSD permitting for that pollutant could be avoided. Therefore, an incentive exists for a plant to employ a superior technology not only to avoid the PSD scrutiny, but also to streamline the long term and complicated permitting process.

\subsubsection{Best Available Control Technology}

One of the preconstruction requirements of the PSD provisions of the Clean Air Act (Section 165a) is that the proposed facility is subject to the best available control technology (BACT); for each poliutant subject to regulation under the Act. Furthermore in Section 169, BACT is defined as, "an emission limitation based on the maximum degree of reduction of each pollutant subject to regulation under this Act emitted from or which results from any major emitting facility, which the permitting authority, on a case-by-case basis, taking into account energy, environmental, and economic impacts and other costs, determines is achievable for such facility through application of production, processes and available methods, systems, and techniques, including fuel cleaning or treatment or innovative fuel combustion techniques for control of each such pollutant. In no event shall application of best available control technology result in emissions of any pollutants which will exceed the emissions allowed by any applicable standard pursuant to section 111 or 112 of this Act." 
The BACT provision of the law is an additional emission limitation that may or may not apply, depending on the permitting authority. It seems likely that with improvements in control technology, industry will be required to install control devices which represent the lowest achievable emissions. This means that even though all other provisions of Clean Air Act regulations may be met, lower emissions limits may be required as superior technologies become available. In requiring BACT, economic factors are to be considered, but the balance between econcmic and technical constraints is not well defined and is again subject to the permitting authority.

\subsubsection{Visibility Protection}

Section $169 \mathrm{~A}$ of the Clean Air Act deals with visibility protection of class I areas. The purpose for this provision is straightforward as given in section 169, "Congress hereby declares as a national goal the prevention of any future, and the remedying of any existing, impairment of visibility in mandatory class I federal areas which impairment results from marmade air pollution".

This regulation has very significant implications because, as mentioned in section 3.2 of this report, for areas with good visibility only a small increase in fine particulate matter can result in noticeable impairment. The law also has a provisior to require that best available retrofit technology be installed on each major stationary source that emits any air pollutant which may reasonably be anticipated to cause or contribute to any impairment of visibility in class I areas, for the purpose of eliminating or reducing any such impairment. All such sources which were in existence 15 years prior to the date of enactment of this section of the Clean Air Act (1977) are subject to this regulation. As such, this portion of the law is unique because it specifically requires retrofit control technology for preexisting sources. The EPA has proposed a phased approach for implementation of this section of the law. Initially, the EPA has focused on significant visibility

$$
3-40
$$


impairment traced to a single existing source (plume blight), and requires states to implement visibility monitoring strategies and visibility impact reviews of major new stationary sources. A second phase requires state action on the review of existing sources for visibility impact and requires procedures to protect integral vistas identified by federal land managers. This includes consideration of best available retrofit technology to correct visibility impairment caused by existing sources. States are also required to develop long term strategies for visibility protection.

The requirement of best available retrofit technology is one of the more powerful aspects of the law which to date has not been utilized. There are a number of legal questions which have yet to be resolved regarding this part of the law. For example, it was previously mentioned that visibility impairment in northern vermont (in a class $I$ area) has been attributed to emissions in the ohio River valley. The state of Vermont in its state implementation plan is required to develop a plan to correct the existing visibility impairment in its Class I designated area. However, since the state itself has no major sources of the pollutants causing the visibility impairment, its implementation plan must call for the reduction of emissions in other states. It is possible to trace pollution episodes to a given distant region, but it would be difficult if not impossible to name the exact source(s). To correct visibility impairment in an area such as northern vermont would require wide scale implementation of best available retrofit technology over a multi-state region such as the ohio River valley. Such a requirement is likely to face major opposition. Nevertheless, the law is presently on the books and will likely be utilized in the near future to correct visibility impairment.

\subsubsection{Proposed Ambient PM 10 standard}

According to Section 109 of the Clean Air Act, the Administrator is required to review air quality criteria and ambient air quality standards and to promulgate new standards as appropriate. Such a 
review has resulted in a proposed PM 10 ambient standard to replace the current TSP ambient standard (Federal Register March 20, 1984, pp 10408-10462). The proposed changes include:

1. that TSP as an indicator of particulate matter be replaced by a new indicator that includes only those particles with an aerodynamic diameter smaller than or equal to a nominal 10 micrometers,

2. that the 24-hour primary standard be changed from the current $260 \mu \mathrm{g} / \mathrm{m}^{3}$ to a value to be selected from a range of 150 to $250 \mu \mathrm{g} / \mathrm{m}^{3}$,

3. that the currest drindal primary standard be changed from $75 \mathrm{\mu g} / \mathrm{m}^{3}$ to a value to be selected from a range of 50 to $65 \mu g / m^{3}$, and

4. that the current 24 -hour secondary TSP standard of $150 \mu \mathrm{g} / \mathrm{m}^{3}$ be replaced by an annual TSP standard selected from a range of 70 to $90 \mathrm{\mu g} / \mathrm{m}^{3}$ expected annual arithmetic mean.

A range for the standards was proposed to solicit additional comment and information from the public to be considered before promulgating the final regulation. However, the Administrator is inclined to select the levels of primary standards from the lower portion of the given ranges. To date, the proposed standard has not been promulgated.

\subsubsection{Impact of Stricter Regulation}

The only proposed stricter regulation (presently being seriously considered) affecting fine particulate emissions is the PM 10 standard. Looking at the range of proposed ambient PM 10 standards, however, they don't appear to be significantly more restrictive than current TSP standards. In some cases, the lower range for PM 10 of $50 \mathrm{\mu g} / \mathrm{m}^{3}$ as an annual primary standard may be no more iestrictive than the current TSP standard of $75 \mu \mathrm{g} / \mathrm{m}^{3}$ since a portion of TSP is larger than $10 \mu \mathrm{m}$. For example, if $33 \%$ of a $75 \mu \mathrm{g} / \mathrm{m}^{3} \mathrm{TSP}$ level is larger than $10 \mu \mathrm{m}$, the $P M 10$ level would be $50 \mu \mathrm{g} / \mathrm{m}^{3}$ and both would be equivalent as far as meeting an ambient standard. In cases where present TSP levels may be made up entirely of particles smaller thin 
$10 \mathrm{\mu m}$, the proposed PM 10 standard would require a maximum reduction of suspended particulate mass of 33\%. Therefore, the proposed PM 10 standard would not have a significant impact on the permissible level of fine particle emissions from coal-fired power plants and would not require significantly improved control technology from that which is currently available.

The question then is, "How strict would fine particulate emission standards have to be for current technology to be inadequate to meet them?" Section 4 of this report reviews the capabilities of current available technologies to control fine particulate matter. Electrostatic precipitators (ESPS) and baghouses can achieve 99.9\% removal on a total mass basis, but baghouses and especially ESPs have a sigrificantly reduced collection efficiency for fine particles smaller than $2 \mu \mathrm{m}$. An ESP which has an overall efficiency of $99.9 \%$ may have only a 95\% efficiency for particles from 0.1 to $1.0 \mu \mathrm{m}$; baghouse which has an overall efficiency of $99.9 \%$ may have a minimum efficiency of $99 \%$ (see sections 4.3 and 4.5). Therefore, current ESPs would have difficulty meeting a requirement of $99 \%$ removal of fine particle mass and baghouses may have difficulty in meeting a 99.9\% removal requirement of fine particle mass. The percentage of fine particle mass in fly ash is highly dependent on the specific coal and firing method, but in general from about 1 to $20 \%$ of the fly ash would be expected to be smaller than $2.5 \mu \mathrm{m}$. A fly ash mass median diameter (MMD) of $5 \mathrm{\mu m}$ with a geometric standard deviation of 2.5 will have $22 \%$ of the mass smaller than $2.5 \mu \mathrm{m}$, while a MMD of $15 \mu \mathrm{m}$ with a geometric standard deviation 2.1 will have $1 \%$ smaller than $2.5 \mu \mathrm{m}$. Suppose a fine particle emission standard were implemented that set a fine particle emission limit of 0.003 $1 \mathrm{~b} / \mathrm{million} \mathrm{Btu}$ for particles < $2.5 \mathrm{\mu m}$ compared to the current total mass particulate NSPS of $0.03 \mathrm{lb} / \mathrm{million} B \mathrm{tu}$. Such a standard would require about $99.8 \%$ removal of fine particles smaller than $2.5 \mu \mathrm{m}$, for an ash with $20 \%$ of the mass in this size range, which would be beyond the capability of conventional ESPs. If the standard was stricter and allowed fine particle emissions of only $0.001 \mathrm{lb} / \mathrm{million}$ Btu, 99.9+\% fine particle removal, for the same ash, would be 
required and improved control technology over what current baghouses can achieve would be needed.

A strict fine particulate emissions standard is not likely in the near future, but clearly adverse health effects and visibjlity impairment are associated with fine particles rather than $T S P$. It therefore seems logical that stricter control of fine particles at their source would follow, and better control technology for fine particulate matter will be required some time in the future. 


\subsection{TECHNICAL EVALUATION OF CONVENTIONAL AND EMERGING PARTICULATE CONTROL TECHNOLOGY}

Since the early 1900s, particulate control devices have been used in industrial processes. The first devices used were mechanical separators, such as gravitational settling chambers and cyclones. As the need for increased collection efficiency became apparent, other more sophisticated devices, such as electrostatic precipitators (ESPS), wet scrubbers, and fabric filters were developed. By the mid 1970 s regulations required 95 to $99 \%$ particulate removal and today up to $99.9 \%$ of the total particulate matter may have to be removed. This, along with more stringent gaseous emission standards, has put a strain on existing particulate removal equipment, especially in the utility industry where ESPs dominate. Current regulatory trends toward fine particulate control have spurred substantial research in control technologies. Many collectors, such as EsPs and wet scrubbers have relatively low efficiencies for particles between 0.1 and $1.0 \mathrm{~km}$ in size. This section of the report is a technical evaluation of conventional and novel particulate removal equipment, focusing primarily on fine particulate control. 


\subsection{Inertial Separation}

Cyclones are gas cleaning devices that employ centrifugal forces, generated by spinning the particle laden gas stream, to separate the particulate matter from the gas. There are two major types of conventional cyclone separators, vane-axial and involuted. The only difference between the two is the method of introducing the gas stream. For both types, removal of particles depends on their tendency to move in a straight line when the direction of the gas stream is changed. The particles then hit the wall of the cyclone and slide into a collection hopper. Although they are relatively cheap to install and have low maintenance cost, their very low efficiencies for particles less than $10 \mu \mathrm{m}$ in diameter have made them all but obsolete as primary particle collection devices for utilities. A typical particulate collection efficiency curve for a high efficiency cyclone is shown in Figure 4-1. Their primary uses today are to remove entrained raw materials from gas streams or to protect delicate machinery. In some utilities where they were once the primary particle collection device, they are still operated as precutters to remove large particles before the gas stream enters other particulate control devices.

Because of their simplicity and ease of operation, there has been research conducted to make inertial collection more efficient. Electrostatically augmented cyclones were considered one of the most promising developments (1). General Electric Corporate Research and Development Center has been working for the past 5 years to develop an electrostatic high efficiency cyclone, referred to as an Electroclone (2). Electrostatic forces have been shown to aid, and in some cases dominate, the separation performance characteristics of cyclones $(1,2)$. Particles are electrically charged by a precharger before entering a conventional high efficiency cyclone. Efficiencies of conventional cyclones are very dependent on the inlet gas velocity and cyclone size. However, by electrically charging the particles, the size dependency is very much reduced and the overall efficiency of larger cyclones is greatly increased. As is shown in Figure 4-2, 


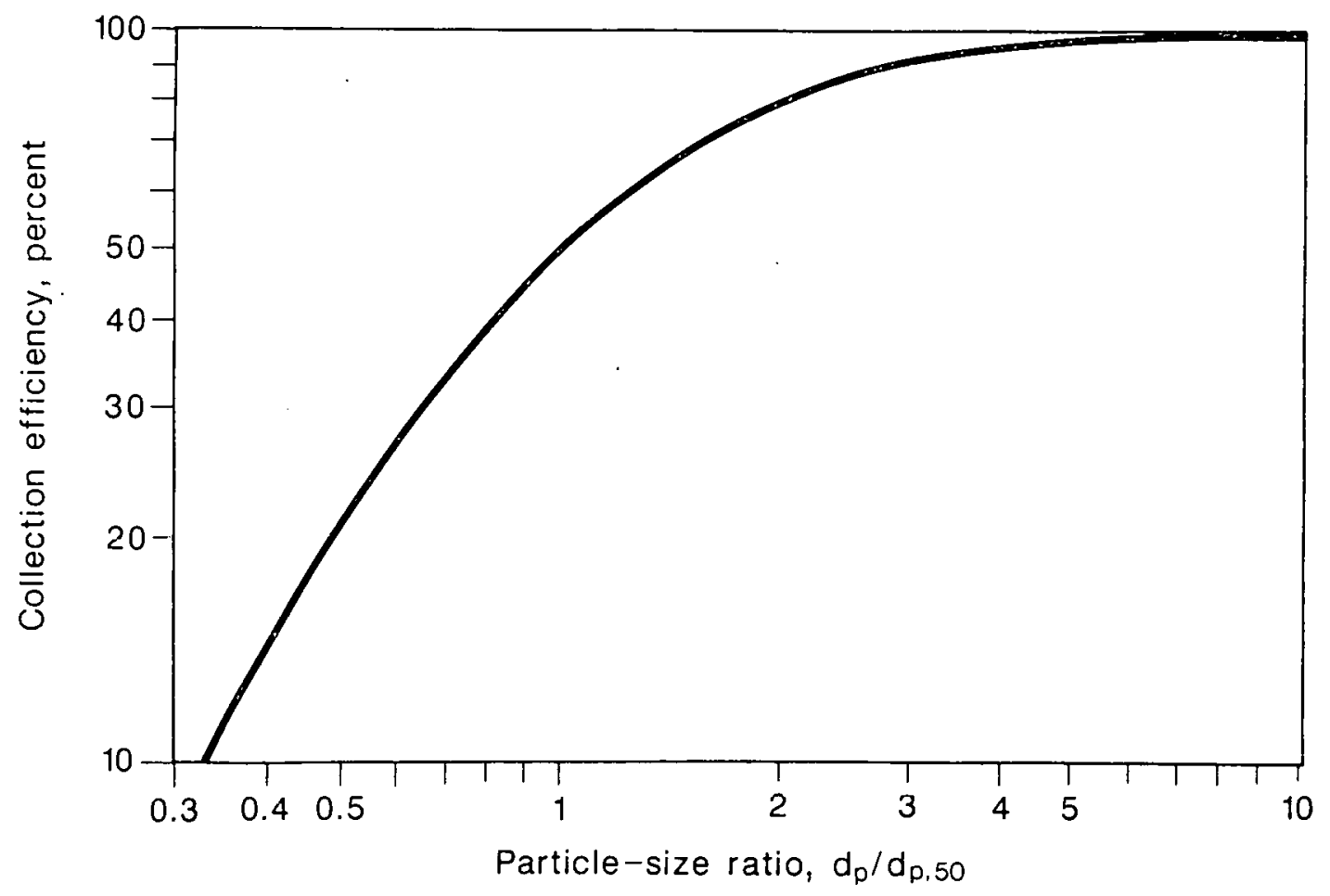

Figure 4-1. Fractional collection efficiency curve for a high efficiency cyclone (Ref. 3 ).

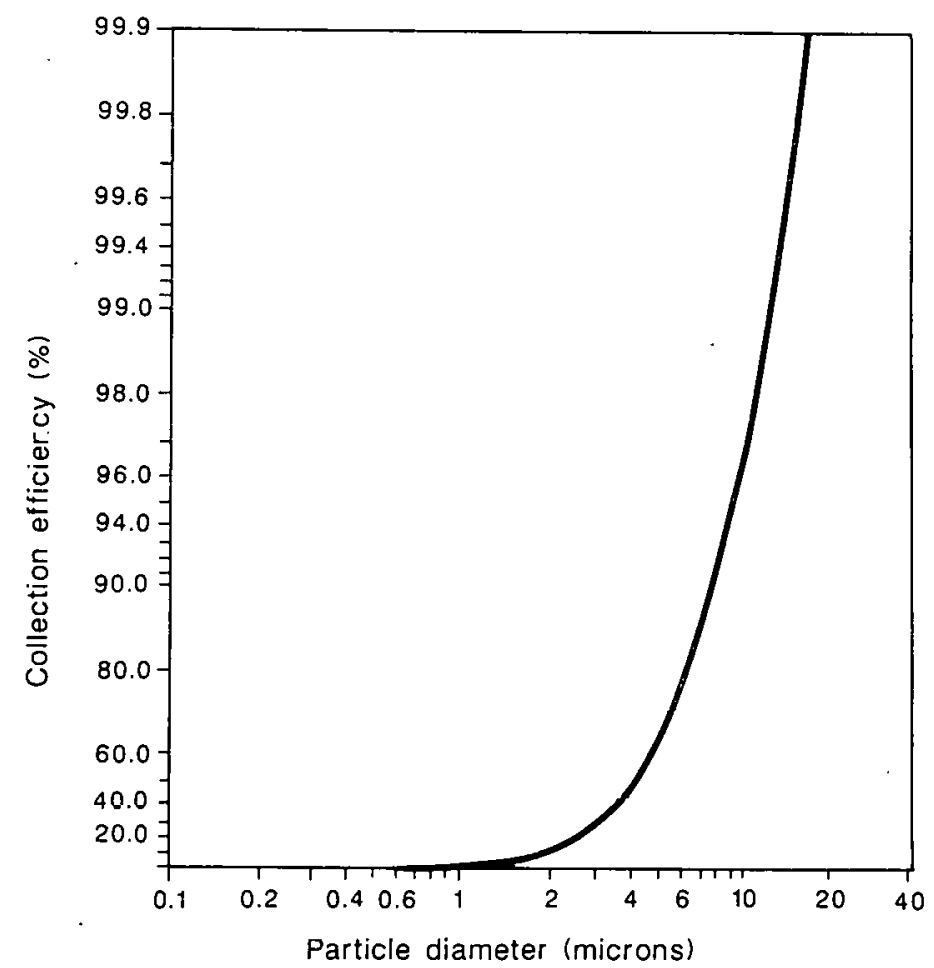

Figure 4-2. Fractional collection efficiency of the Electroclone (Ref. 4). 
the overall collection efficiency of these cyclones can approach $95 \%$ compared to 85 to $90 \%$ for most high efficiency cyclones. However, for submicron particles the efficiency of an electroclome is less than $30 \%$. This still precludes their use as primary particle collection devices for utilities. However, due to their exceptional durability as well as the advent of high temperature and high pressure boilers, they may well play a role as part of an overall particulate control system.

\subsubsection{Referencee}

1. Dietz, P.W. Cyclones and Electrostatically Augmented Cyclurts fur Particulate Control. General Electric Company, Corporate Research and Development, Schenectady, NY.

2. R.R. Boericke, W.G. Giles, P.W. Dietz, G. Kallio, and J.J. Kuo. Electroclone for High Temperature/Pressure Dust Removal. Presented at: AIAA 19th Aerospace Sciences Meeting, St. Louis, MO, pp. 135-145, January 1981 .

3. Perry, R.H. and C.H. Chilton. Chemical Engineer's Handbook. McGraw-Hill Book Company, 5th Edition, pp 20-120 and 121, 1973.

4. Case, G.D., K. Ushimaru, G.S. Knoke, S. Bernstein, and P.J. Bekowies. Evaluation of Particulate Collection Devices Developed for Pressurized Eluidized-Bed Combustors as Applied to Coal Gasification Processes. DOE/MC/20035-1702, U.S. Department of Energy, Office of Fossil Energy, METC, Morgantown, WV, October 1984 . 


\subsection{Wet Scrubbers}

Wet scrubbers have been used on coal-fired boilers for many years because of their inherent ability to effectively remove both particulate and gaseous pollutants. Wet scrubbers can be designed as single stage devices where particulates and $\mathrm{SO}_{2}$ emissions are removed from the flue gas stream simultaneously or as multi-stage units where the two functions are separated.

In a wet collector, a liquid, usually water, is used to trap particles and remove them from the gas stream. The mechanisms of collection are direct interception, inertial impaction, or diffusion. In inertial impaction the gas stream moves in streamiines around the water droplet, but the inertia of the particle causes it to continue in a straight line, where it impacts the water droplet and is trapped. The larger the particle the less likely it is to change directions. In direct interception, the particle follows the streamline, but contacts the water droplet at the closest point of approach and is trapped. For submicron particles, diffusion is the dominant mechanism of collection. These particles follow the streamlines but, due to their small size, they also exhibit Brownian motion. This random motion of the particles cause them to come in contact with the water droplet and there they are captured.

\subsubsection{Conventional Wet Particulate collectors}

There have been a wide variety of scrubber systems developed in the last 10 years, but only four types are presently being used in the electric utility industry:

1. Venturi scrubbers.

2. Flooded fixed bed scrubivers.

3. Preformed scrubbers.

4. Moving-bed scrubbers. 
of these, the Venturi scrubber is most commonly used for coalfired boilers. A Venturi is used to produce high gas velocities and then by introducing the scrubbing liquid at right angles to the gas, very small water droplets, with a large surface area, are produced. In addition, these water droplets are moving at high velocities, 200$400 \mathrm{ft} / \mathrm{sec}$. This increases the contact of the droplets with the entrained particulates, thereby, increasing collection efficiency. The Venturi is only a gas conditioner and therefore must be followed by a separating section for the elimination of entrained droplets and collected particles from the gas stream. The collection efficiency of a Venturi scrubber is drectly relaled to lle Venturi pressure drop. The smaller the Venturi the greater the gas velocity, collection efficiency, and pressure drop. A typical efficiency diagram for a Venturi scrubber is shown in Figure 4-3 (1). As the figure shows, a Venturi scrubber producing a 10 inch W.C. pressure drop can remove $5 \mathrm{\mu m}$ particles with greater than $99 \%$ efficiency. However, to remove $95 \%$ of the particles less than 1.0 mm would require a pressure drop of over 40 inches W.C.

A flooded fixed-bed scrubber is composed of a packed-bed that is operated such that a highly turbulent layer is formed above the bed. The gas then moves through the packing where it interacts both in the bed and turbulent layer. Packing increases contact between the water and particles in the gas stream to improve collection efficiency. BY using multiple packed beds, collection efficiency can be improved even more. Pressure drop is usually 4 to 6 inches W.C. for each packed bed. Although collection efficiencies between 98 and $99 \%$ have been reported on a total mass basis, the efficiency decreases rapidly for small particles. For particles less than $1 \mathrm{\mu m}$ the efficiency drops to $70 \%$ and for $0.3 \mu \mathrm{m}$ particles the collection efficiency is only $25 \%(2)$.

Another type of wet collector is the preformed scrubber, which is essentially a high pressure Venturi scrubber. High pressure spray nozzles are used to generate small liquid droplets that are projected at high velocities at a membrane made up of closely spaced vertical bars which act as linear Venturis. Large particles are captured by 


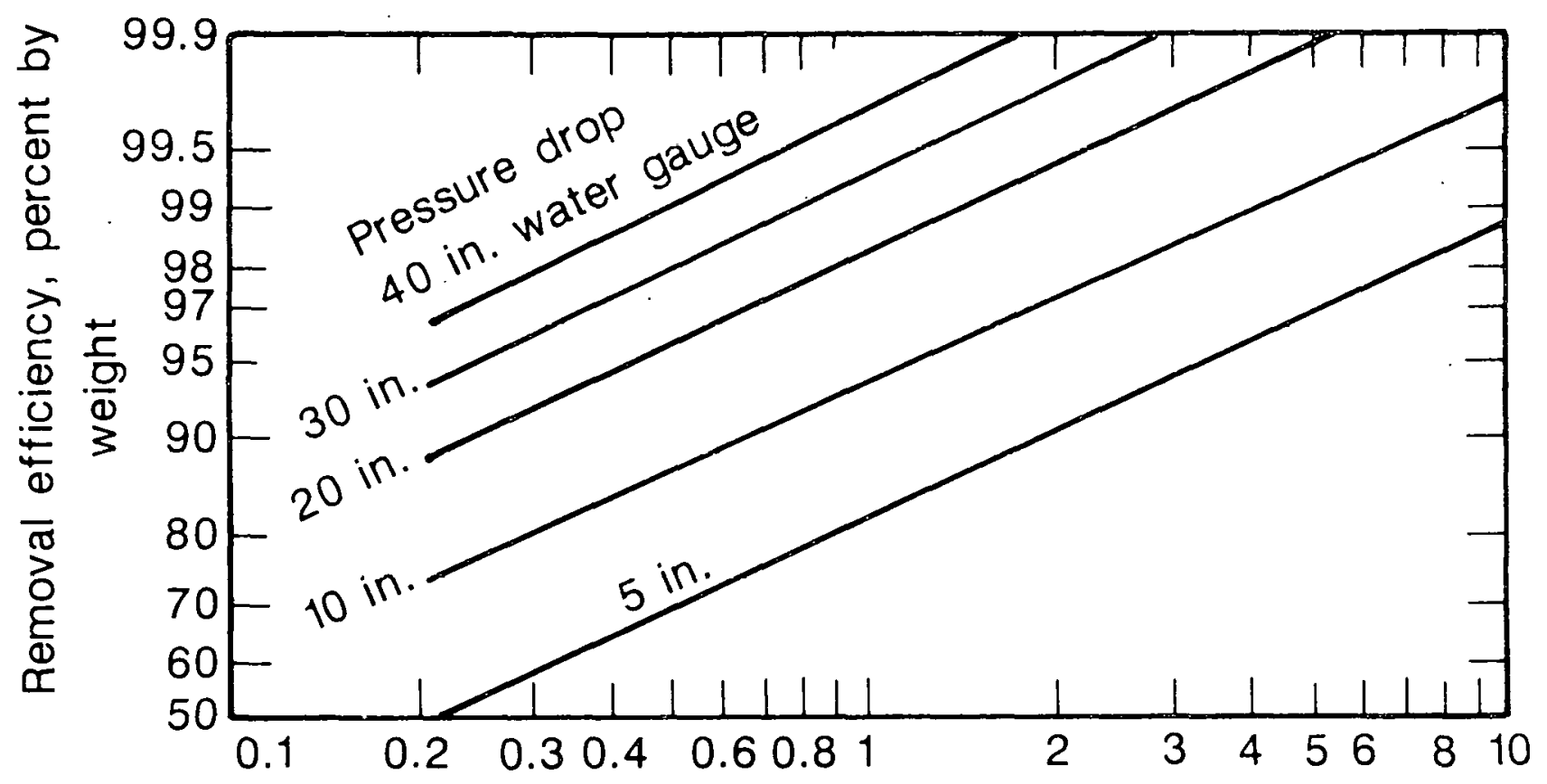

Particle size, microns

Figure 4-3. Fractional efficiency curve as a function of pressure drop for a Venturi scrubber (Ref. 1).

the high speed water droplets with additional scrubbing of smaller particles occurring at the membrane, where the incoming gas is suddenly accelerated. Since gas retention is very short, 2 to 3 seconds, the scrubber is not very effective in capturing submicron particles. For particles greater than $2 \mu \mathrm{m}$, the overall collection efficiency is about $98 \%$ but to obtain $50 \%$ collection efficiency for $0.5 \mathrm{\mu m}$ particles, a pressure drop of 100 inches $W . C$. would be requjred (3).

Moving-bed scrubbers use a zone of movable packing where gas and liquid become closely contacted. The packing is kept in continuous motion between two retaining grids. Pressure drop typically ranges from 3 to 5 inches W.C. (per theoretical stage). For a three stage moving bed scrubber the collection efficiency was reported to be $97 \%$ for $2 \mu \mathrm{m}$ particles and $70 \%$ for $0.5 \mu \mathrm{m}$ particles (3).

$$
\text { 4-7 }
$$




\subsubsection{Emerging Technologies For Wet Particulate Scrubbing}

Most developments in wet particle collection technology increased contact between the water droplets and entrained particles. This has been done principally, by increasing droplet velocity and contact surface area. By making the water droplets smaller or by increasing surface area through the addition of a fiber filter or packing, the collection efficiency of a wet scrubber can be improved. A wide variety of novel scrubbers have been developed in the past 10 years. Some of the more developed systems are listed in Table 4-1. However, none of these scrubbers has been shown to be as efficient for fine particulates as more conventional techniques such as ESPs and fabric filters. The one exception is the steam-hydro scrubber developed by Lone star steel. This scrubber is very effective for the removal of fine particulates, but due to its high energy usage, $(0.2 \mathrm{~kW} / \mathrm{acfm})$, it is only economical for processes that produce large amounts of high quality waste heat $(2,4)$. . None of the novel scrubbers would be capable of meeting the NSPS of $0.031 \mathrm{~b} / \mathrm{milli}$ ion $\mathrm{Btu}$ at a reasonable cost and most are very inefficient for fine particulates. As was reported in a study by Buonicore et.al. (2), wet collection devices have very high energy requirements compared to ESPS and fabric filters. They reported that most novel scrubbers required at least 6 times more energy than ESPS or fabric filters at the same throughput.

TABLE 4-1

NOVEL SCRUBBERS (Ref. 2,4)

Type of Scrubber

1. Two-phase Jet Scrubber

2. Centripetal Vortex Scrubber

3. Diffusion Scrubber

4. Steam-hydro Scrubber

5. Enhanced Fixed-bed Scrubber

6. Enhanced Venturi Scrubber
Company.

Aronetics

Centrifield

Dynactor

Lone Star steel

Mystaire

Pentapure 
A different approach to improving the collection efficiency of wet particulate scrubbers is electrostatic enhancement. These low energy devices are capable of obtaining relatively high collection efficiencies. In one type, developed by the University of Washington $(2,5)$, particles are negatively charged and collected by positively charged spray droplets. The scrubber is divided into two sub-units, the first, consisting of a corona section and the second, a spray chamber and mist eliminator. In the first subsection, the particles and gas flow countercurrently to the water spray. In the second subsection the particles and gas flow in the same direction as the water spray. Separation of the particles and water droplets takes place primarily in the spray chambers and mist eliminators, but some particle collection also occurs on the corona electrode. The collection efficiency of these scrubbers, installed on a coal-fired boiler, is about $95 \%$ for particles between 0.5 and $2.5 \mu \mathrm{m}$, which is still lower than a properly designed ESP or fabric filter.

Another type of electrostatic scrubber is the ionizing wet scrubber. These units consist of an electrostatic charger followed by a Venturi scrubber. An electrode, placed upstream of the Venturi, charges the inlet particles. Water, sprayed countercurrently to the gas flow, is accelerated by a Venturi, resulting in the charged particles being collected by highly polarized water molecules. The gas and particle-laden water droplets are then separated in a cyclonic separator with the sludge sent to a settling tank.

An example of an ionizing wet scrubber, developed by Air pollution systems (APS), is the Scrub-E (6). This unit uses APS's High Intensity Ionizer to precharge the particles prior to entering a variable throat Venturi. The Scrub-E has been shown to improve fine particulate collection efficiency while requiring $1 / 2$ to $2 / 3$ the energy of a conventional scrubber. Since it is only necessary to add the precharger, the design is relatively easy to retrofit in an existing Venturi scrubber. An electrostatically enhanced Venturi scrubber, when operated at 5 inches W.C. pressure drop, improves the collection efficiency of $1 \mathrm{\mu m}$ titanium dioxide particles.from $83 \%$ to $94 \%$, as is shown in Eigure $4-4$. 


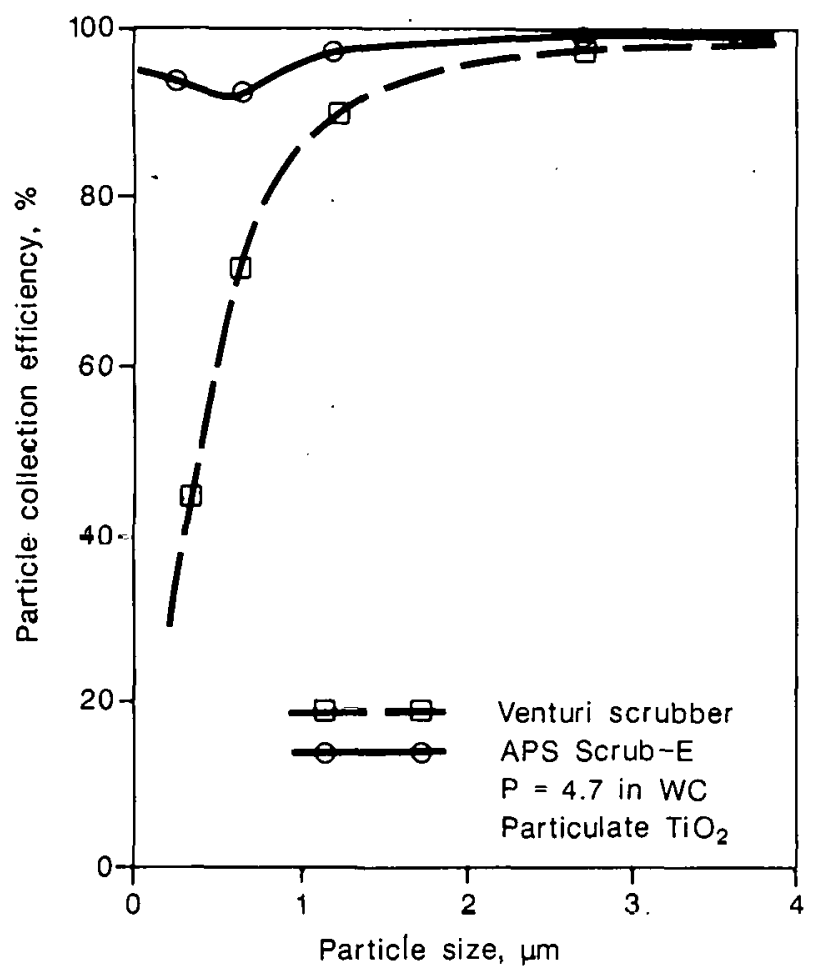

Figure 4-4. Fractional collection efficiency comparison: Venturi scrubber vs electrostatically enhanced Venturi scrubber. (Ref. 6).

A major disadvantage of wet scrubbers in general is the generation of a large amount of waste material in the form of a slurry, which is often difficult and costly to handle. To keep costs down and to meet waste disposal regulations, slurries must be sent to a thickener where as much of the water as possible is removed and recycled. However, some makeup water is still needed due to increasing concentrations of dissolved solids and evaporatire losses. Maintenance can also be a problem for wet scrubbers. Scaling of pipes and ducts can cause plugging which may necessitate shutting down the unit. Another disadvantage of wet collectors is the need to reheat the outlet gas to prevent condensation and to provide enough gas buoyancy in the stack.

$$
4-10
$$


The EPA is not very enthusiastic in its endorsement of scrubbers compared to baghouses or ESPS (Z). Generally, scrubbers cannot perform quite as well, they use more energy, need, large amounts of water, and produce a liquid waste stream. The more stringent particulate regulations become, the less likely scrubbers will be used as a primary particulate control device.

\subsubsection{References}

1. Wark, K. and C.F. Warner. AIR POLLUTION Its Origin and Control. Harper and Row Publishers, New York, NY, p. 208, 1981.

2. Buonicore, A.J., J.P. Reynolds and I. Theodore. Control Technology for Fine-Particulate Emissions. Chemical Engineering Department, Manhattan College for Argonne National Laboratory, ANL/ECT-5, 1978 .

3. Calvert, S., N.C. Jhaveri and S. Yung. Fine Particle Scrubber Performance Tests. Environmental Protection Technology Series, EPA-650/2-74-093, October 1974 .

4. Burns and Roe Service Corporation and Science Applications International Corporation. Fine Particulate Control Technology Assessment. Draft Final Report, DOE Contract No.DE-AC2284 PC72571 subtask 7.3. June 28, 1985.

5. Cooper, D.W., R. Wang, and D.P. Anderson. Evaluation of Eight Novel Fine Particle Collection Devices. EPA-600/2-76-035, GCA Corporation, Bedford, MA, February 1976.

6. Kearns, M.T. and D.I. Harmon. Demonstration of a High Field Electrostatically Enhanced Venturi Scrubber on a Magnesium Furnace Fume Emission. Proceedings: Second symposium on the Transfer and Utilization of Particulate Control Technology Vol. 3, Denver, CO, pp. 61-79, September 1980 .

7. The Bureau of National Affairs, Inc. Air Pollution Control. Control Technologies: int Scrubbers, No. 37, p. 181:401, 1983 . 
Electrostatic precipitators (ESPS) have been used for particulate collection since 1924, when large pulverized coal (pc-fired) boilers came into use. Pc-fired boilers produced large volumes of flue gas and very small particles that were not easily removed by control devices of the day, such as settling chambers and cyclones. ESF's were able to effectively remove particles of all size ranges, from very large to the submicron. Because of this, and their ability to handle large volumes of flue gas, they became the dominant particulate control device in the electric utility industry.

\subsubsection{Conventional Technology}

Electrostatic precipitation is a three step process consisting of corona generation, particle charging, and transport of the charged particles to the collection surface. An electric field and corona current are created by applying a large potential difference between two electrodes, a smaller discharge electrode and a larger grounded collection electrode, with the two separated by an insulating gas. A charge is applled to lie discharge elcctrode and the ynltage raised until a corona is formed. A corona is an incomplete breakdown of the gas molecules and usually appears as a highly active glow. The greater the electric field generaced the better an ESP will operate. However, if the voltage is raised too high, a complete breakdown of the gas occurs, referred to as sparkover, which lecreaseg EsP performance.

When particles pass through the ESP they acquire an electric charge of the same polarlty as llat of the diacharge electrodea. Two distinct particle charging mechanisms occur: bombardment of the particles by ions moving under the influence of the applied electric field, and attachment of the ionic charges to the particles by ion diffusion. The diffusion mechanism is most important for charging of submicron particles, while the larger particles are usually charged by bombardment (1). Once the particles are charged, they migrate to 
the collection electrode. The speed at which they move is called the migration or drift velocity, and results from the electrical and viscous drag forces acting upon the suspended charged particles.

ESPs are used extensively by utilities for the following reasons:

1. A properly designed ESP can provide fairly high collection efficiencies for a wide particle size distribution.

2. ESPs alone, among methods of particulate collection, act solely on the particles to be collected not on the entire gas stream. Therefore, the pressure drop across the unit is very low, resulting in a more economical operation compared to other collection techniques.

3. ESPs can treat very large volumes of gas.

4. ESPs can operate efficiently for a wide range of gas temperatures, from 200 to $800^{\circ} \mathrm{F}$.

5. ESPS have a long useful life.

While ESPs have many advantages that make them popular, they do have some disadvantages that are causing many utilities to consider other particulate collection technologies for new installations. Some of the disadvantages of ESPs are:

1. ESPS have a very high capital cost.

2. Although the overall collection efficiency is high, there is a substantial drop in efficiency for particles between 0.1 to $1.0 \mu \mathrm{m}$ in diamcter.

3. Collection efficiency is very dependent on flue gas and fly ash composition.

4. ESPs are very sensitive to fluctuations in gas steam conditions such as gas flow rates, temperature, and particulate loadings.

5. Retrofitting to meet changes in regulations is in many situations very difficult or impossible.

6. Relatively sophisticated and well trained maintenance personnel are needed. 
A typical fractional efficiency curve for an ESP with a specific collection area (SCA) of $340 \mathrm{ft} / 1000$ acfm, burning an easterr bituminous coal, is given in Figure 4-5. This clearly demonstrates the decreased collection efficiency for submicron particles. This is an inherent characteristic of electrostatic precipitation, due to particles of different diameters having different effective migration velocities. To improve collection of these particles it would be necessary to increase the specific collection area (SCA). However, by doing so, the installation cost increases substantially as does the operating cost.

As sulfur dioxide controls became mandalowy, many utilities awitched to lower sulfur coals. This had a major impact on the collection efficiencies of ESPS. Many of the fly ashes produced from these coals had very high resistivities (>2 $\left.\times 10^{11} \mathrm{ohm}-\mathrm{cm}\right)$ due to the low amount of $\mathrm{SO}_{3}$ generated during combustion, resulting in low ESP collection efficiency. When the resistivity of the collected particulate layer is sufficiently high, electrical breakdown of the collected dust layer will occur, at a current density that is undesirably low. This will cause the formation of back corona, which is detrimental to ESP performance (3-5).

\subsubsection{Enhancement Technologies}

Most enhancement techniques for ESPS have been developed to improve collection efficiency when burning coals producing high resistivity ash. Examples of these technologies are:

1. Improvements in ESP design, including electrode geometry, electrode spacing, and rapping mechanisms.

2. Hot-side ESPS.

3. Chemical conditioning.

4. Pulse Energization.

5. Prechargers. 


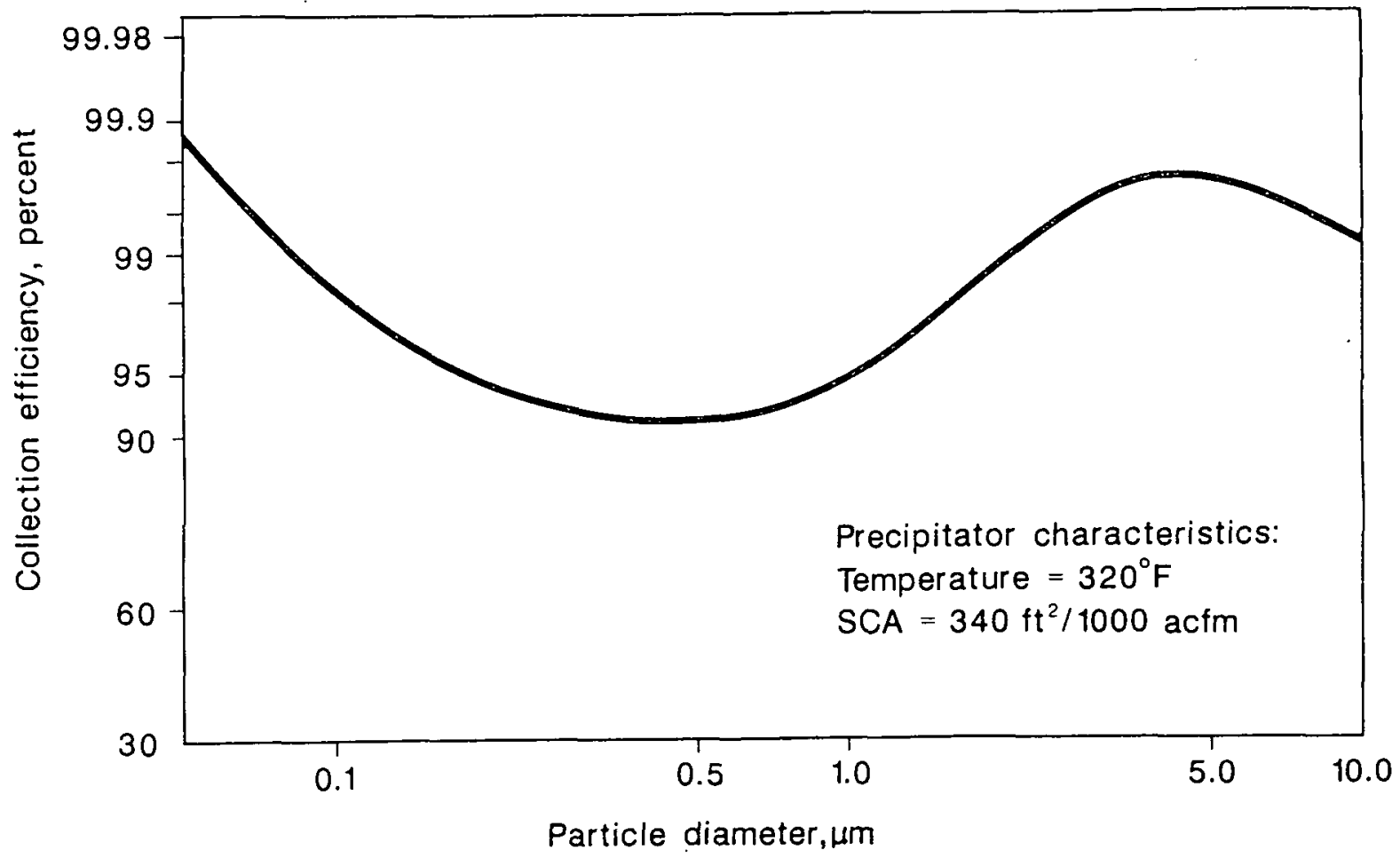

Figure 4-5. Typical fractional efficiency curve for an ESP (Ref. 2).

\subsubsection{Design Improvements}

Proper design of the electrodes is a very important parameter for obtaining optimum ESP performance. Primarily due to market forces, conventional utility ESPs in the United States have been of the weighted wire type. Originally, requirements for particulate removal were not very stringent, therefore, the goal was to produce ESPs as cheaply as possible and still meet emission standards. In a weighted wire design, the discharge electrodes are held in place by a weight that extends from below the collection plates to the top of the collection hopper. If the hopper is overfilled, the electrode will ground, resulting in decreased ESP performance and eventually damage to the electrode.

In Europe, an entirely different approach was taken by ESP manufacturers. Due to heavy population densities and a more socialized form of government, air pollution problems were dealt with 
earlier and more stringent regulations were put in place. Therefore, manufacturers developed much more conservatively designed equipment and placed a higher premium on reliability. To meet these demands, Europeans developed rigid-frame ESPS. In a rigid-frame ESP the discharge electrodes are attached at both ends and the overall design is much more rugged (6). Some of the advantages of the rigid-frame type are:

1. The collection plates are rapped individually and therefore puffing (reentrainment) is virtually eliminated, improving collection efficiency.

2. The discharge electrodes do not extend below the collecting plates and therefore dite ist as vilncrable to damage frim overfilled collection hoppers.

3. Maintenance is much easier and can be done while the unit is in operation.

4. Less maintenance is required due to less breakage of discharge electrodes and more rugged materials of construction.

For these reasons, most of the new ESPs coming on line are of the rigid-frame design.

There seems to be a considerable number of upinions as to what geometry is best for corona discharge electrodes, as evidenced by the fact that so many different kinds are in commercial use. Examples of discharge wire shapes are: smooth, barbed, square twisted, spiral, and star shaped. Although the lype of wire thät worke busil is site. specific, and depends on collecliull lequiremento, ach compositinn, and ESP design, many vendors choose a single type and use it for all applications.

Research has attempted to maximize the electric field and current strength by the use of novel electrode geometries. Variations in current flow, within limits, can be controlled by the type and size of the discharge electrodes used (7). It is usually considered advantageous to have sharp points on the wires to facilitate formation of a corona by increasing current density at each point, 
but at the same time it is important that ash deposits do not form on the wire. In general, increasing surface roughness decreases the voltage necessary for the inception of the corona, reducing operational costs (B).

A novel geometry developed by McGill Corporation is the needle discharge electrode (9). Large energy savings can be realized by its efficient use of the electric field. The electrode consists of a multitude of very sharp needles mounted on the edges of a flat plate. The sharpness of the needle tips permits corona generation at relatively low voltages, about $25 \mathrm{kV}$ compared to $50 \mathrm{kV}$ for conventional ESPs, because the work required to attain a given surface charge density is less than for conventional electrode designs. Not only is the operating voltage lower but so is the corona current flow, which results in decreased power consumption. since the needle discharge electrodes are attached to the plates, there is significant collection surface area of both polarities, resulting in higher collection efficiencies.

Research-Cottrell has developed a new rigid discharge electrode, called the Dura-Trode, which offers exceptionally long life and better performance then conventional electrodes (10). Units using this design have been tested successfully at both coal-fired generating stations and industrial plants since 1975 .

For high resistivity dusts, fine wire discharge electrodes may not perform as well as larger diameter wires or rods. With large diamcter electrodes, the electric fleld strength is emphasized over current density. Southern Research Institute (SoRI) determined, in a series of laboratory and pilot scale experiments, that larger diameter wires resulted in significantly improved performance (11). Although penetration in these tests was reduced by $30 \%$ for low resistivity ash and by a factor of four for high resistivity ash, it should not be anticipaled that similar improvements will occur for all applications. It will depend on sparking characteristics and the extent of back corona formation. 
Collecting electrodes are. the individual grounded surfaces on which the particulate matter is collected. Important design considerations are stiffness of the plates and shielding of the collected dust layer to prevent reentrainment. It is important that the electrode is able to transmit the rapping impact to all parts of the plate as uniformly as possible to facilitate uniform dust removal. There have been three main types of collection electrodes used: panel sections, extended curtain sheets, and flat plates. The most common ESP collection electrode in the U.S. is the shielded flat plate electrode. Many other geometries have also been proposed to decrease losses due to dust reentrainment. Some of the more successful types are offset plates, Lurgi, VEE, and pocket plates.

In recent years, particularly in Japan, research has been conducted to determine optimum electrode spacing to achieve maximum performance from an ESP. The well known Deutsch equation for efficiency predicts the maximum performance at very small spacings, but this is now being questioned. In a review of Esp research, Heinrich (12) reported that a study in 1956 showed that wide spacings between electrodes gave higher particulate collection efficiencies than did narrow spacings. It has subsequently been reported that migration velocity changes proportionally with the spacing between electrodes, while the current density remains constant (13). There has also been substantial work done in Japan on conventional and novel ESP designs utilizing wide spacings (14).

The phenomena of wide electrode spacing are still not fully understood or accepted, but it has been reported that electrical field strength distribution is increased near collecting plates with increased electrode spacing $(15,16)$. This could account for the increase in effective migration velocity. The net result is a smaller SCA than would be needed for conventionally spaced electrodes in order to obtain a specified collection efficiency. In addition, reentrainment losses would be less with wide spacings because of the decreased number of collection plates that would be required. 
Although wide spacing has been shown to improve collection efficiency, there are limitations to its application. In cases of high inlet dust loading with very fine dusts, high space charges and corona quenching are quite often the result. In addition, optimum spacing must be determined for each application. Optimum electrode spacing is dependent on ESP design specifications and composition of the gas and particulates.

The important point to be made about electrode geometry is that there is no best choice for all cases. Many factors must be taken into account, such as gas and dust composition and collection requirements, when deciding on the type of electrode geometry that would be best for any given application.

Proper rapping is essential for optimum ESP performance. Many of the problems associated with poor ESP particulate collection can be related directly to degradation in the performance of the rapper system. Generally, rapping impulses are provided by either single impact mechanisms or vibratory type systems. Prevention of ash reentrainment once the collection plate has been rapped is necessary for high ESP collection efficiency. Reducing ash reentrainment results in less penetration of the ash through the system. New rapping technology has concentrated on proper sequencing and improvement in control devices. Computerized controls allow continuous on-line monitoring of the system so that any malfunction can be corrected before serious degradation of ESP performance occurs. Increasing the time interval between raps can provide a significant improvement in collection efficiency of an ESP. Oglesby and Nichols (17) reported that when the rapping interval on a pilot scale unit was extended from 12 to 52 minutes, the collection efficiency increased from $92.5 \%$ to $98.5 \%$. A means of adjusting the intensity and the time cycle of the rappers, therefore, is important. The first field should be rapped more often since it sees a higher dust loading than the others. The second should be rapped more often than the third, etc.. This will help to minimize reentrainment. Multi-level rapping also has been shown to be an effective method for improving ESP performance for low sulfur coals. By rapping the plate 
not only at the top or bottom but also along its vertical length, less intense rapping is needed, thereby reducing reentrainment. It has been reported that multi-level rapping improved collection efficiency of a pilot-sale ESP from $92 \%$ to $99.34 \%$ over a 1 year period for the same $1 \%$ sulfur coal at the same throughput (18).

4.3.2.2. Hot-Side Electrostatic Precipitators

One of the most difficult problems manufacturers and users of ESPs have had to deal with is high resistivity ash. These ashes are very difficult to collect in an ESP due to formation of back corona on the collecting plates. This degrades the electric field, resulting in poor collection efficiency. Utilities that have elected to stay with ESPS have attempted to minimized the problem in four ways :

1. Increase the SCA of the ESP.

2. Installation of hot-side, ESPS.

3. Use of chemical conditioning.

4. Use of pulse energization.

Although each of these methods has advantages and disadvantages, depending on the coal and the existing ESP, all are substantially more costly than conventional ESP designs for low resistivity ash. High resistivity fly ash reduces the effectiveness of an ESP, but does not totally destroy its collection function. Therefore, increasing the ESP SCA will result in an improvement in collection efficiency. However, for a given application, the increace in installation cost is roughly proportional to the sca value. Therefore, increasing the SCA will substantially increase both the installation and operating costs of an ESP. Advantages of this approach are that it requires no particular or unusual operating procedures and very high removal efficiencies can be obtained on an overall mass basis.

$$
4-20
$$


In general, fly ash resistivity increases with temperature until it reaches a maximum, and thereafter decreases as is shown in Figure 4-6. BY placing the ESP in front of the air preheater, entering flue gas temperatures will be much hotter $\left(700^{\circ} \mathrm{F}\right)$, and therefore ash resistivity will be lower. At these temperatures, the controlling conduction mechanism in the precipitated ash layer is intrinsic, or volume conduction, instead of the surface conduction mechanism, which predominates on the cold side of the air preheater. At higher temperatures, fly ash resistivity is not as sensitive to the $\mathrm{so}_{3}$ or moisture content of the flue gas (19). Thus, high temperature operation of an ESP would provide good performance for low sulfur coals without additional SCA. The decrease in precipitator size for a hot-side ESP compared to over designing a cold-side ESP is moderated by two factors. First, at higher temperatures the gas volume is substantially increased. Secondly, decreased gas density at higher temperatures results in lower operating voltages prior to sparkover than for a cold-side ESP. Other economic disadvantages associated with increased temperature include the following:

1. Special expansion provisions are needed.

2. Increased insulation is needed to prevent heat loss:

3. Larger fans may be needed to handle the increased gas volume.

4. The cost of materials of construction is increased.

Recent reports by Bickelhaupt $(20.21)$ have shown that in some hot-side ESPS, a time dependent degradation of performance, called electrode polarization or sodium depletion, occurs. A thin layer of ash permanently coats the electrodes, and sodium ions, which serve as charge carriers, are depleted, leaving a thin layer of very high resistivity ash next to the electrode surface. The result is that the electrical conditions are very unpredictable, making hot-side ESPs less attractive as an option. 


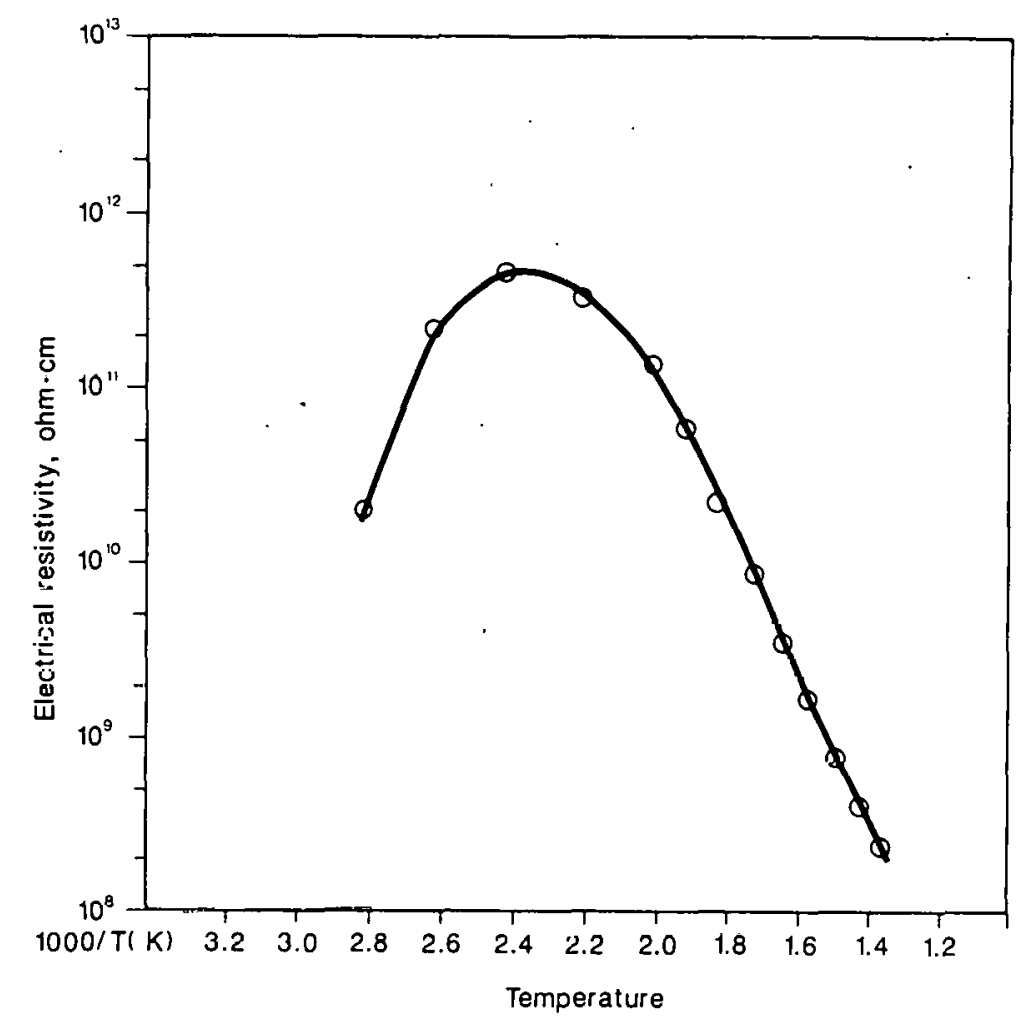

Figure 4-6. Fly ash resistivity as a function of temperature (Ref. 5).

\subsubsection{Chemical Conaitioning}

Chemical treatment of either the coal or flue gas has been shown to be an effective and relatively simple method of improving ESP collection efficiency for some high resistivity ashes. The effect of most conditioning agents is to increase the conductivity of the surface film of the dust particles making up the collected layer. There are several agents available that have been found to improve the collection efficiency of ESPs when collecting high resistivity ashes. These include: ammonia, water, sodium or sodium compounds, sulfur trioxide $\left(\mathrm{SO}_{3}\right)$ and several proprietary compounds.

Water has been used for years as a conditioning agent, primarily in the portland cement and non-ferrous metallurgical industries. Dust resistivity is lowered by increasing the humidity in the gas stream. Success in a coal-fired boiler has been limited, as 
injection of water into the boiler results in decreased boiler efficiency and injection downstream of the air preheater is very difficult, as the gas temperature is often too low for water to be easily vaporized.

It has been reported (22) that if a coal produces an ash that is high in sodium, even though the coal is low in sulfur, resistivity is not a problem. This has encouraged research in the use of sodium additives in the coal, with mixed results. An extensive study was conducted by SORI and the EPA using sodium carbonate as an additive. The results from theses tests indicated minimal improvement in ESP performance (22). The most effective use of sodium compounds has been to prevent sodium depletion in hot-side EsPs. Besides unpredictable results, the major drawback of using sodium or sodium compounds as conditioning agents for high resistivity ashes is increased fouling, slagging and corrosion on the walls and superheater region of the boiler.

Ammonia is available at a relatively low cost and the injection system is simple, although the results of its use have been mixed. The most successful test took place at a utility burning a Pennsylvania coal. Ammonia conditioning allowed full boiler load to be maintained within the maximum opacity limit of 20\% (23). At other plants, ammonia conditioning had no effect at all. The most beneficial effects of ammonia conditioning occur for those ashes that are acidic in nature $(24,25)$. Ammonia does not appear to change ash resistivity but rather produces a beneficial space charge effect that allows an increase in the operating voltage for a given current density. This effect can be large enough to make a significant improvement in precipitator performance. Ammonia may also suppress reentrainment of the ash as a result of increasing the ash cohesiveness. In addition, ammonia can reduce opacity by preventing sulfuric acid mist from forming in the plume (24).

The most widely used flue gas conditioning agent is $\mathrm{SO}_{3}$, with over 50 installations according to Wahlco Inc., one of the major suppliers of $\mathrm{SO}_{3}$ generation and injection systems. $\mathrm{SO}_{3}$ produces a two-fold effect. First, by adsorbing on the ash particle, $1 t$ 
provides an increased conduction path and thereby reduces back corona. Secondly, $\mathrm{SO}_{3}$ increases the cohesiveness of the ash, which helps to reduce particle reentrainment (17). Both the fly ash chemistry and flue gas temperature influence the amount of $\mathrm{SO}_{3}$ required for effective conditioning. Highly basic ashes will require a greater concentration of $\mathrm{SO}_{3}$ to produce results since calcium in the ash reacts with the adsorbed sulfuric acid layer to form calcium sulfate, neutralizing the effect (23).

Sulfur trioxide can be generated by either starting with $\mathrm{SO}_{2}$ or, as is the case for most large facilities, oxidizing elemental sulfur to $\mathrm{SO}_{2}$. The $\mathrm{SO}_{2}$ is then heated to 800 to $900^{\circ} \mathrm{F}$ and caldylically converted to $\mathrm{SO}_{3}$. Regardless of the type of injection system used, careful attention must be given to the design at the interface of the injection system with the flue gas stream. It must permit efficient mixing of the $\mathrm{SO}_{3}$ stream with large volumes of flue gas. If inefficient mixing occurs, $\mathrm{SO}_{3}$ will react with water vapor and condense as a sulfuric acid mist that will not be adsorbed uniforinly on the surfaces of the individual fly ash particles. This generally has occurred when expected improvements in ESP performance were not obtained with $\mathrm{SO}_{3}$ conditioning (24).

In a study by Dismukes (23), test results using $\mathrm{SO}_{3}$ injection at three utilities, two burning low sulfur western şubbituminous coals and one a low sulfur eastern bituminous coal, were reported. Concentrations of $\mathrm{SO}_{3}$ between 12 and $14 \mathrm{ppm}$ were used and all three showed an improvement in ESP performance. Two of the plant.s, which originally had very poor efficiencies, 65 and $75 \%$, improved to $77 \%$ and $94 \%$, respectively after initiating $\mathrm{so}_{3}$ conditioning. The collection efficiency for the third utility, burning an eastern coal, improved from $02.6 \%$ to $97 \%$ :

In another example, a utility that was burning a high sulfur coal in 1971 had ESPs installed on two $58 \mathrm{MW}$ boilers. These units had no difficulty in obtaining the designed efficiersy of $97.5 \%$. Then in 1976, the utility switched to a low sulfur coal to meet so $_{2}$ standards. Immediately, ESP collection efficiency dropped to an average of $57 \%$ and opacity was well above regulations. After 
installing an $\mathrm{SO}_{3}$ conditioning system, the ESP again operated at the designed collection efficiency (25).

Although $\mathrm{SO}_{3}$ conditioning offers several attractive benefits, there are some disadvantages associated with its use.

1. An injection system must be installed and maintained.

2. Installation of an $\mathrm{SO}_{3}$ system is a major expense.

3. $\mathrm{SO}_{3}$ is a hazardous compound.

4. The catalytic bed degrades with time and must be replaced.

5. The effects of conditioning cannot always be predicted in advance.

6. Corrosion problems may occur.

7. Possible future regulations concerning $\mathrm{SO}_{3}$ emissions may be enacted.

8. Although $\mathrm{SO}_{3}$ conditioning does improve the overall ESP collection efficiency for high resistivity ash, there is still a significant decrease in the collection efficiency of submicron particles.

9. $\mathrm{SO}_{3}$ injection may actually increase the concentration of fine particles in the flue gas stream by forming sulfates.

It is important to note that $\mathrm{SO}_{3}$ conditioning will only improve ESP performance due to limitations associated with high resistivity ash.

Combined $\mathrm{SO}_{3}$ and ammonia conditioning has been used at Texas Utility's Big Brown Station and at Detroit Edison's Monroe station to improve ESP performance for high resistivity ashes. These results have shown that a combination of conditioning agents is more effective then either alone. The Monroe Power Plant began using ammonia as a conditioning agent to meet particulate standards which was very successful (26). In 1980 they switched to a low sulfur coal to meet $\mathrm{SO}_{2}$ emission standards and almost immediately they began to have problems. Since ammonia did not help to reduce the ash resistivity, they began adding $\mathrm{SO}_{3}$ as well. Since that time they have achieved a collection efficiency of $99.7 \%$ and opacity 
measurements of 9 to $12 \%$. At the Big Brown station, similar results were obtained. A synergistic effect on collection efficiency was reported when the two conditioning agents were used together. For a small ESP $(S C A=166)$, efficiencies between 98 and $99 \%$ were obtained. Without conditioning, the predicted collection efficiency was well below $90 \%(27,28)$.

\subsubsection{Pulse Energization of ESPS}

PuJse energization of an ESF can help to overcome much of the difficulty associated with collecting high resistivity aeh. BY superimposing a very high voltage impulse of short duration and steep wave-front on an underlying relatively constant potential, a strong uniform corona is generated. By properly adjusting pulse parameters such as pulse width and frequency, the adverse effects of excessive sparking and back corona can be avoided. The net result is a significant improvement both in current density and in uniformity of the distribution, compared to conventional energization.

Patents were first issued for a pulse energization process in 1931, but it was not until the middle 1970 s when solid state electronics and relatively cheap high voltage sources became available that pulse energization became economical and reliable. The first commercial pulse energization system was installed at Carolina Power and Light Company's L.V. Sutton Station in 1980 by ResearchCottrell. Precipitators there had degraded to a point where the boiler was limited to $50 \%$ of its design capacity in order to maintain opacity below a $40 \%$ standard. After installation of the pulse energization system, full load opacity was $38 \%$ and collection efficiency improved from $97.7 \%$ to $99.0 \%$ (29). These results are in agreement with studies done at other utilities $(30,31)$.

Although pulse energization has been shown to improve ESP performance when collecting a high resistivity ash, it does not appear to improve efficiency or be more cost effective than other techriques such as flue gas conditioning. For pulse energization to be effective, it is essential the ESP be in good mechanical condition 
(31). As was the case for flue gas conditioning, pulse energization can only return an ESP to the design specifications established when collecting low resistivity ash. For most older units it would not provide an improved level of fine particulate control.

Pulse energization systems are commercially available from General Electric and Research-cottrell. These systems are essentially the same and can be retrofitted to an existing ESP.

\subsubsection{Multi-Stage Electrostatic Precipitation}

Multi-stage electrostatic precipitation has always been attractive, in theory, as a means of optimizing the use of electrostatic forces for the collection of fine particles. Until recently multi-staged ESPs have not proven to be practical for treating large volumes of flue gas, such as that generated by electric utilities. With the advent of solid state electronics, however, an ionizer section can be built in arrays, making the first stage of an ESP small, even for very high volumetric gas flow rates. Much of the work in multi-stage electrostatic precipitation has been funded by Electric Power Research Institute (EPRI) and the Environmental protection Agency (EPA).

The basic concept of a multi-staged ESP is that the particle charging and collection functions are separated such that particles are charged in the first stage and collected electrostatically in the secind slaye. By precharging the particles, the voltage to the discharge electrodes can be raised without sparkover, resulting in significantly higher charging fields, 3 to 5 times higher than those in conventional precipitators (32). Although for high resistivity ash the back corona problem is not eliminated, by taking a two-stage approach the high current density necessary for good collection efficiency is mantalned only in a small portion of the unit. This reduces the plate area requiring special treatment to prevent back discharge. Prevention of back corona has been accomplished by a variety of methods, such as using vanes on the anode to prevent accumulation of dust, using a semiconducting material to prevent the 
avalanche process in the dust layer, or to heat or cool the electrode such that resistivity is not a problem. Since the treated section is relatively small, methods that would be uneconomical in conventional ESPs can be used to reduce ash resistivity.

Five different types of prechargers have been developed. The first is the High Intensity Ionizer, developed by Air Pollution systems and EPRI. This is a powerful, high-speed charging device that. uses a Venturi-like anode and a single disc-shaped cathode facing the throat of the anode. This device, while producing a strong charge, does not perform well for high resistivity dusts. Although methods have been developed to reduce the problem, its best application is likely to be for low resistivity dusts $(33,34)$.

The Tri-electrode Precharger, developed by SoRI and the EPA, has a grid-like third electrode near its anode plate. The purpose of the grid is to protect the charging zone from penetration of positive jons from back corona on the anode. The precharger will only work if back corona never occurs on the grid itself and this is only possible when the potential is large enough so that negative ions are not collected on the grid. Hence, careful control of the grid voltage is required. Test results indicate that this precharger can be used for high resistivity dust without formatiun uf back corona if it ie properly designed and operated $(33,35)$.

In the water cooled precharger, developed by the Denver Research Institute and the EPA, back corona is avoided by lowering dust temperature and thereby reducing its resistivity. Advantages of this precharger are its simplicity in both construction and operation, and its small size, enabling a retroflt installation in a limited space. cooling the ash does not decrease resistivity uniformly for all compounds, and therefore careful cunsideration is nccded ln fuyalding dust properties and gas composition. The cost of the system, including a heat exchanger, largely depends on the cooling water temperature needed to reduce dust resistivity such that back corona does not appear. It is also likely that mechanical scrapers, which are more expensive than rappers, will be necessary to clean the electrodes $(33,36)$. 
The Boxer-charger, developed at the University of Tokyo, has two ionizers that are operated using a sinusoidal ac voltage. The ionizers are synchronized such that the first is charged during the first half-cycle of the ac field and the other during the second half. Hence, negative ions move back and forth across the charging zone and bombard the particles from both sides. When high resistivity dust contaminates an ionizer, negative charges do build up, but before back corona can form, the polarity of the ac field changes. The charge accumulation stops and collected negative ions are neutralized by generated positive ions. Hence, the charge neutralization and back corona abatement are made on each ionizer. unit in each cycle of the ac voltage (33).

Studies are currently being conducted at Florida state University to develop an electron beam precharger (37). When an electron beam passes through air, it ionizes the air molecules, forming a plasma of positive ard negative ions. These ions can be separated and collected by applying an electric field. Ion current densities greater than 500 times those of conventional ESPs can be obtained. The results have shown that a low energy beam produces more effective particle charging since there is less scattering of the ions. currently, electron beam charging is still very much in the experimental stage.

In a fleld test conducted by Air pollution Systems, Inc. using their High Intensity Ionizer at TVA's John sevier steam Plant, penetration was reduccd by $70 \%$ fur a low sulfur coal (35). For pilot-scale tests conducted at the EPA's Industrial Environmental Research Laboratory, using the Tri-electrode precharger, an average collection efficiency of $99.5 \%$ for a high resistivity ash was obtained (35). In a field test at the EPA/DRI Valmont Electrostatic Test Facility, using a water-cooled precharger, a collection efficiency of $99.4 \%$ for a $0.6 \%$ sulfur coal using an ScA of $235 \mathrm{ft}^{2} / 1000 \mathrm{acfm}$ was obtained (36).

Although research on prechargers for utility EsPs is still in the pilot stage; the potential for high levels of fine particulate removal is very good, pren for high resiotivity ashes. The lack of 
reliable efficiency data for large-scale ESPS is currently the major drawback of precharging. Additionally multi-staging an ESP adds more complexity to an already complex system.

\subsubsection{Wet Electrostatic Precipitators}

Wet electrostatic precipitators use water to clean the collecting electrodes and thereby, reducing ash resistivity by saturating the flue gas with moisture. A wet ESP generally has a higher collection efficiency, and an abilily to collect substanres that are difficult to collect in a conventional ESP ( 3 ).

A two-stage electrostatic device called ar Electro-Tube was developed and marketed on an industrial scale (up to 40,000 scfm) by Beltran Incorporated (39). The system is a tubular ESP with a central rod electrode and wetted-wall collector. Particle saturation charge is substantially increased by first passing the gases through a high-intensity ionizer. This increased charge allows a more effective migration of fine particles in the collecting electric field of the precipitator. Coliection efficiencies of $98 \%$ have been reported for 0.1 to $0.5 \mathrm{\mu m}$ particles, generated in a sulfite pulp mill recovery furnace.

Fluid Ionics vivision of Envirotech manufactures a wet precipitator, the Hydro-Precipitrol, that is available to handle up to $30,000 \mathrm{scfm}$ (39). This unit contains a tangential presaturator with water sprays at the inlet. The gas stream passes through concentric cylinarical collection. plates with discharge electrode cages spaced between them. The preclpitator had a $94.3 \%$ collection efficiency when tested at a sulfite pulp mill recovery boiler from which $90 \%$ of the emissions are less than $1.0 \mu \mathrm{m}$.

Mikropul developed a wet precipitator that is physically similar to conventional parallel-plate ESPs, but is equipped with water sprays at the inlet and collection sections (39). The precipitator has been used in mineral and metal refining operations at gas flow rates up to 150,000 scfm. At a coking facility a collection efficiency of $98.5 \%$ was reported. 
A two-stage wet precipitator, the Two stage Plus, developed by Combustion Engineering, consists of a low pressure drop rod scrubber followed by a spray tower and a wet ESP. Pilot performance tests, at Northern States Power's Sherburne County station, resulted in outlet particulate emissions of $0.013 \mathrm{lbs} / \mathrm{million} \mathrm{Btu}$, which is less than the NSPS limit of 0.03 lbs/million Btu (39).

Although wet ESPS are used extensively by mineral refining industries, wet ESPS have not been accepted by the utility industry. They have not been demonstrated on a large scale and do not provide enough economic or technical advantages over other, more conventional particulate control technologies.

\subsubsection{Summary}

ESPs are currently the dominant particulate collection devices for utilities and are likely to continue to be in the near future for existing plants. Given proper design, they have the capability of removing a high percentage of particulates over a broad particle size distribution and most facilities are meeting current particulate control standards.

A major concern in the utility industry is the dependence of ESPS on coal and flue gas composition. As $\mathrm{SO}_{2}$ emission regulations became more stringent, utilities began switching to low sulfur coals. These coals many times produce ashes that have high resistivities and, thereforc, arc a problem for E3Ps. Mally utilitles that previously were not having any difficulty in meeting particulate emissions and opacity standards found themselves out of compliance. The bulk of the research in ESP technology has been to address this problem.

Although well designed ESPs can remove $99.9+\%$ of particulates, there is a decrease in collection efficiency for 0.1 to $1.0 \mu \mathrm{m}$ diamcter particles, which have been shown to be the most harmful. To collect these particles with the same efficiency as the larger particles, the unit must have a much greater SCA than current designs. This would dramatically increase the cost of the unit and it would no longer be competitive with other particulate collection 
devices such as baghouses, which can provide higher collection efficiencies for fine particulates.

Most ESP enhancement technologies have been developed to improve performance of existing ESPS or decrease the size required for new installations when collecting a high resistivity dust. These technologies, such as flue gas conditioning, hot-side EsPs, and pulse energization, generally do allow an ESP to meet original design specifications and to comply with current standards. However, in general, they cannot improve performance above the design specifications, nor do they provide superior collection efficiency for fine particles.

One ESP techrology that has shown promise, for all types of coal, is multi-staging. By precharging the particles before they enter the collection stage, high collection efficiencies for fine particulates can be obtained. A unit can be designed to provide collection efficiencies of $99.9+\%$ for all particle sizes. Currently, the technology has not been developed past pilot-scale testing, and there has been decreased research in the U.S. in this area.

With the possible exception of multi-staging, ESP technological advances have been to provide adequate collection efficiencies to meet particulate control standards for all types of coal. Not any of these technologies will provide superior (99.99\% removal) control for fine particulates.

\subsubsection{References}

1. Robinson, M. Electrostatic Precipitation. Air-Pollution Control, Vol. 1, Werner strauss, Ed., Wiley-Interscience, New rork, pp. 227-335, 1871 .

2. Buonicore, A.J., J.P. Reynolds and L. Theodore. Control Technology for Fine-Particulate Emissions. Chemical Engineering Department, Manhattan College for Argonne National Laboratory, ANL/ECT-5, 1978 .

3. MacDonald, J.R. and A.H. Dean. A Manual for the Use of Electrostatic Precipitators to Collect Fly Ash Particles. EPA600/8-80-025, U.S. Environmental Protection Agency, Research Triangle Park, NC, pp 323-332, May 1980. 
4. Selle, S.J., P.H. Tufte, and G.H. Gronhovd. A Study of Electrical Resistivity of Fly Ashes from Low-Sulfur Western Coals Using Various Methods. Paper 72-107, Presented at: 65th Annual Meeting of the Air Pollution Control Association, Miami Beach, FL, June 1972 .

5. Bickelhaupt, R.E. A Technique for Predicting Fly Ash Resistivity. EPA-600/7-79-204, U.S. Environmental Protection Agency, Research Triangle Park, NC, August 1979.

6. Wright, R.A., N.D. Graves. Rigid-frame vs Weighted-wire Electrostatic Precipitators Comparison and Evaluation. Paper TIS6383, Presented at: Coal Technology 179 2nd International Coal Utilization Conference, Houston, TX, November 1979.

7. MCDonald, J.R. and A.H. Dean. A Manual for the Use of Electrostatic Precipitators to Collect Fly Ash Particles. EPA600/8-80-025, U.S. Environmental Protection Agency, Research Triangle Park, NC, pp. 37-47, May 1980.

8. Taha, E.H., M. Abdel-Salam, and A.A. Ibrahim. Effect of Surface Roughness on the Inception Levels of Discharge Voltages in GasInsulated Systems. Proceedings: IEEE Industry Applications Society Annual Meeting, Los Angeles, CA, 29-F, pp. 723-728, October 1977 .

9. No]1, C.G. The Electric Field and Air Flow Effects on the Current and Ion Densities in the Needle-Plate in Duct Geometry. Proceedings: IEEE Industry Applications Society Annual Meeting, Los Angeles, CA, 29-B, pp. 700-706, October 1977.

10. Electric Light and Power, Vol. 55, No. 6, p. 31, June 1978 .

11. Pontius, D.H. and L.E. Sparks. Effects of Wire Diameter on Particle Charging and Collection Efficiency in Electrostatic Precipitators. Proceedings: Second International conference on Electrostatic Precipitation, Senichi Masuda, Editor, Kyoto Japan, pp. 269-274, November 1984 .

12. Heinrich, D.O. Der grosse Gassenabstand in Elektorfilterbau. Staub, Vol. 38, No. 11, pp. 445-451, 1978 .

13. Engelbrecht, H.L. Increased Plate-to-Wire Spacing to Enhance Electrostatic Precipitator rerformance. Paper 83-55.6, presented at: 76th Annual Meeting of the Air Pollution Control Association, Atlanta, GA, June 1983.

14. Nichols, G.B. Electrostatic Precipitator Technology Assessment: Visits in Japan, November 1977. EPA-600/7-78-110, U.S. Environmental Protection Agency, Research Triangle Park, NC, pp. 314-316, June 1978 . 
15. Miska, T., K. Sugimoto, and H. Yamada. Electric Field Strength and Collecting Efficiency of Electrostatic Precipitator Having Wide Collecting Plate Pitches. Proceedings: Csiro Conference on Electrostatic Precipitation, Leura, N.S.W., Australia, Paper 11, August 1978 .

16. S. Matts. Some Experiments with Increased Electrode Spacing. Proceedings: Csiro Conference on Electrostatic Precipitation, Leura, N.S.W., Australia, Paper 13, August 1978.

17. Oglesby, S. and G. Nichols. Particulate Control Highlights: Research on Electrostatic Precipitator Technology. EPA- 600/877-020a, U.S. Environmental Protection Agency, Research Triangle Park, NC, p. 11, December 1977 .

18. K.H. Pearson. operating Experiences with Improved Rapping on Electrostatic Precipitators Treating Fly Ash from High and Low Sulphur Coals. Combuslien, pp. 45*50, April 1980 .

19. MCDonald, J.R. and A.H. Dean. A Manual for the Use of Electrostatic Precipitators to Collect Fly Ash Particles. EPA600/8-80-025, U.S. Environmental Protection Agency, Research Triangle Park, NC, p. 527, May 1980.

20. Bickelhaupt, R.E. High Resistivity Behavior of Hot-side Electrostatic Precipitators. EPA-600/7-80-076, U.S. Environmental Protection Agency, Research Triangle Park, NC, April 1980 .

21. Bickelhaupt, R.E. An Interpretation of the Deteriorative Performance of Hot-side Preclpitators. Journal of the Air Pollution Control Association, Vol. 30, No. 8, pp. 882-888, August 1980 .

22. Gooch, J.P.' R.E. Bickelhaupt, and L.E. Sparks. Ely Ash Conditioning By coprecipitation with sodium Carbonate. U.S. 1980 .

23. Dismukes, E.B. Conditioning of Fly Ash with Sulfur Trioxide and Ammonia. Environmental Protection Technology series, EPA600/2-75-015, TVA-F75 PRS-5 U.S. Environmental Protection Agency, Research 'lriangle Park, NC and Tennesise Valley $\Lambda$ uthority, Chattanooga, TN, August 1975 .

24. Dismukes, E.B., A Review of Flue Gas Conditioning with Ammonia and Organic Amines. Paper 83-41.3, Presented at: 76 th Annual Meeting of the Air Pollution Control Association, Atlanta, GA, June 1983 . 
25. Ferrigan, J.J. and J.D. Roehr. Improved Electrostatic Precipitator Performance operating on Low Sulfur coal. proceedings: Second Symposium on the Transfer and Utilization of Particulate Control Technology Vol. 1, Denver, Co, pp. 170-183, September 1980 .

26. Fletcher, H.G., Coal Selection and Dual Flue Gas Conditioning to Aid in Meeting Air Pollution Control Regulations. Paper 85-53.1, Presented at: 78 th Annual Meeting of the Air Pollution Control Association, Detroit, MI, June 1985.

27. Dahlin, R.S., M.H. Guillaume, J.P. Gooch, R.E. Bickelhaupt, and D.R. Sears. On-Site Field Tests for Study of Low-Rank Western Coal Fly Ash. DOE-GFPO-10225-4, U.S. Department of Energy, Grand Forks, ND, August 1984.

28. Dahlin, R. S., J.P. Gooch, M.H. Marchant, R.E. Bickelhaupt, D.R. Sears, and R.F. Altman. A Field Study of a Combined $\mathrm{NH}_{3}-\mathrm{SO}_{3}$ Conditioning system on a cold-Side Fly Ash Precipitator at a Coal-Fired Power Plant. Proceedings: Fifth Symposium on the Transfer and Utilization of Particulate Control Technology Vol. 2. pp. 6-1 to 16, Kansas City, Mo, February 1986.

29. Feldman, P.L. and P.J Aa. operating Results From the First Commercial Pulse Energization System to Enhance Electrostatic Precipitator Performance. Proceedings: American Power Conference, Chicago, IL, Vol. 43, pp. 379-383, April 1981.

30. Porle, $K$. and $K$. Bradburn. Full Scale Experience with Pulsed Energization of Electrostatic Precipitators. Proceedings: Fifth Symposium on the Transfer and Utilization of Particulate control Technology, Kansas City, Mo, Vol. 2, pp. 13-1 to 21, February 1986 .

31. Landham, E.C.. J.L. DuBard, W. Piulle, and L.E. Sparks. Precipitator Perfurmance Enhancement with Pulsed Energization. Proceedings: Fifth Symposium on the Transfer and Utilization of Particulate Control Technology, Kansas City, MO, Vol. 2, pp. 191 to 15 , February 1986.

32. Tassicker, 0 . and J. Schwab. High-Intensity Ionizer for Improved ESP Performance. EPRI Journal, Electric Power Research Institute, pp. 56-61, Jure/July 1977 .

33. Masuda, S. State of the Art of precharging. Proceedings: Second International Conference on Electrostatic Precipitation, Senichi Masuda, Editor, Kyoto, Japan, pp. 177-193, November 1984. 
34. Cooper, J., J. Schwab, and J. Parsons. Description of APS High Intensity. Ionizer Equipment. Presented at: Dedication Ceremonies at ERRI's Advanced Farticulate Control Facility, Public Service Co. of Colorado, Arapahoe Station, Denver, CO, June 23, 1977.

35. Sparks, L.E., G.H. Ramsey, and B.E. Daniel. Collection of Fly Ash with High Electrical Resistivity in a Pilot Plant Electrostatic Precipitator Preceded by the EPA/SORT .. Precharger. Journal of the Air Pollution Control Association, Vol. 29, No. 7, pp. 745-747, July 1979 .

36. Durham, M., G. Rinard, D. Rugg, T. Carney, J. Armstrong, and L.E. Sparks. Field Study of Multi-stage Electrostatic Precipitators. Proceedings: Fifth Symposium on the Transfer and Utilization of Particulate Control Technology, Kansas Cily, MO, Vol. 2, pp. 161 to 13 , February 1986.

37. Clements, J.S., A. Mizuno, and R.H. Davis. Particle charging with an Electron Beam Precharger. Proceedings: Fifth Symposium on the Transfer and Utilization of Particulate control Technology, Kansas City, MO, Vol. 1, pp. 15-1 to 16, February 1986 .

38. Okuda, S. and $M$. Wada. Wet Type Electrostatic Precipitators Installed in Waste Incinerators in Japan. Proceedings: Second International Conference on Electrostatic Precipitation, Senichi Masuda, Editor, Kyoto, Japan, pp. 726-733, November 1984.

39. Stanley, C.L. Survey and Evaluation of Modern Electrostatic Concepts Applied to High Resistivity Fly Ash. DOE/FC/10226-T1, Acurex Corporation, Morrisville, NC, December 1980. 
Fabric filtration is one of the earliest known methods of removing particulates from a gas stream. The original design was patented in 1852 and has been used for a large number of industrial and utility applications since that time. The original intent of fabric filtration was as a collection mechanism to recycle valuable raw materials or products that were entrained in waste gas streams. Today the main driving force for their use is environmental concerns.

A fabric filter, consisting of a porous flexible layer of textile material through which a dusty gas stream is passed, collects entrained particles by impaction, interception and diffusion. As the dust is collected on the fabric, a layer of particles builds up and forms a dust cake, which acts as the primary filtering media. Fabric filter performance then is dependent on the physical and chemical characteristics of the dust cake. It must be thick enough to provide an effective filtering matrix, but at the same time it cannot be allowed to become so thick that the pressure drop becomes unreasonably high. To keep pressure drop within acceptable limits, the bags are periodically cleaned by reversing the gas flow, shaking, or pulsing with compressed air.

Wide spread usage in the utility industry has only come in the last 15 years. There are a variety of reasons for this:

1. It was only recently that durable fabrics became available that would provide long bag life at operating temperatures of 300 to $350^{\circ} \mathrm{F}$.

2. The high level of particulate control that baghouses provide was not previously needed to meet regulations.

3. ESPs were already in place and worked well.

4. There is a reluctance in the utility industry to change technologies. "Why fix it when it ain't broke?"

With more stringent $\mathrm{SO}_{2}$ regulations, utilities began switching to low sulfur coals which often produced high resistivity ash. ESPs had a difficult time collecting these ashes at a level that would allow 
the utility to be in compliance with particulate standards. Problems with ash resistivity as well as more stringent particulate control standards have become the driving forces allowing baghouses to penetrate the utility industry. Some of the advantages of fabric filters are:

1. Baghouses have very high collection efficiencies over a wide range of particle sizes.

2. Baghouses can be designed to operate for a wide range of dusts, dust loadings, and temperatures.

3. Baghouses can handle very large flow rates.

4. Baghouses are not as sensitive to ash composition as ESPS.

5. Baghouses have reasonable pressure drop and energy requirements.

For these reasons, since 1974 when the first baghouse was installed on a pc-fired utility boiler, over 110 utility baghouses are now in operation.

Fabric filtration, when compared to ESPs, is considered by many researchers to be the superior technology for fine particulate control (1-3). A typical fractional efficiency curve for a baghouse is given in Eigure 4-7. As the figure shows, the overall collection efficiency for a baghouse is 99.8 to $99.9 \%$. AJthough the minimum collection efficiency is in the same particle size range for fabric filters $(0.1-1.0 \mathrm{\mu m})$ as for ESPs, the collection efficiency of these particles for a typical baghouse is $99 \%$, compared to $95 \%$ for an ESP (Compare Figure 4-5 to Figure 4-7).

Figure 4-7 represents data for the sunbury steam Electric Station, which was the first full-scale baghouse installed at a U.S. utility. Other baghouses since that time have reported even higher collection efficiencies. Examples include: Nevada Power Company's Reid Gardner station where an average collection efficiency of $99.97 \%$ was reported, and Utah Power and Iight, with a reported collection efficiency of $99.93 \%$ at their Hunter station (4). In a field test 


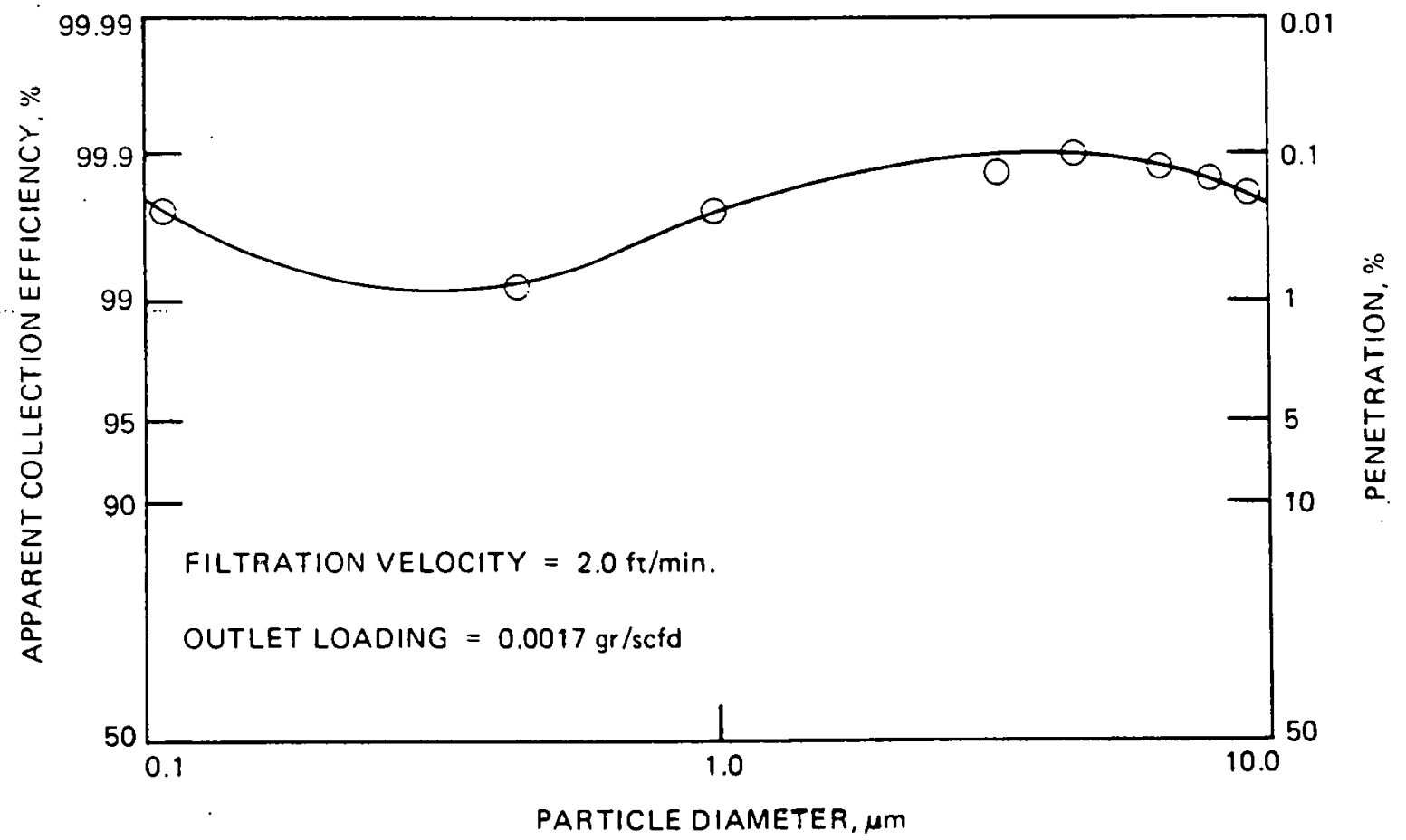

Figure 4-7. Typical fractional particulate collection efficiency curve for a baghouse (Ref. 1 ).

conducted by SoRI at Public Service Company of Colorado's Arapahoe station reverse air baghouse, a collection efficiency of $99.983 \%$ was reported (5).

\subsubsection{Conventional Fabric Filtration}

The two major types of baghouses are: inside collectors, which are most often used by electric utilities, and outside collectors, which have had more acceptance in the industrial sector, The bags for inside collectors, are closed at the top and are held in place by clamping the bottom of the bag to a thimble on the tube sheet. Attached to the top of the bag is a cap, which is suspended to provide tension to the bags. Dust laden gases enter at the bottom through the tube sheet with the particles collected inside the bag and the cleaned gas exiling at the ourside.

$$
4-39
$$


The three modes of cleaning used with inside collecting baghouses are reverse air, shaker, and shake-deflate. The most common mode used by U.S. utilities is reverse air. In reverse air cleaning, the direction of gas flow is reversed, which causes the bag to deflate, thereby resulting in the release of the dust cake. Shaker cleaning uses a mechanical shaker that periodically agitates the bags to dislodge the dust cake, and shake-deflate is a combination of reverse air and shaker cleaning. The most common fabric for inside collectors is woven fiberglass. Typical face velocities are 1.5 to $2.5 \mathrm{ft} / \mathrm{min}$, with bag cleaning occurring every 1 to 8 hours, depending on dust cake characteristics.

outside collectors, referred to as pulse jet baghouses, collect dust on the outside of the bag with the cleaned gas exiting on the inside. The bags are cage mounted and cleaned by pulsing with compressed air and since the bags are not under tension, either felted or wover fabrics can be used. Pulse jet baghouses usually operate at face velocities of 3.5 to $4.5 \mathrm{ft} / \mathrm{min}$ but for some industrial baghouses, face velocities as high as $20 \mathrm{ft} / \mathrm{min}$ have been reporter. Pulse jet bags are usually cleaned every 10 to 15 minutes.

In the United States, utilities have generally opted for inside collectors since the cleaning is less rigorous and therefore not as many bag replacements are necessary, resulting in lower uptrating costs. In addition, pulse jet baghouses are more complex and utilities tend toward simpler designs. However, pulse jet baghouses have found greater acceptance in the industrial sector because of their smaller size and lower capital cost.

Maintaining a reasonable pressure drup liss traditionally been considered the primary problem associated with fabric filtration. If pressure drop is a problem, then frequent bag cleaning may become necessary, which decreases bag Iife and may increase particulate emissions. Other possible disadvantages of baghouses are:

1. Large space requirements.

2. Special fabrics may be needed if the flue gas is caustic or corrosive, greatly increasing operating costs. 
3. For certain dusts there may be the possibility of a dust explosion or fire.

4. A minimum collection efficiency occurs for particles between 0.1 and $1.0 \mathrm{\mu m}$ in diameter, although not as severe as that exhibited by ESPS.

5. Some coals have been shown to produce ashes that are difficult to collect in a baghouse.

Fabric filtration research has primarily focused on four areas:

1. Dust cake formation, structure and modeling.

2. Fabric development for specialized applications.

3. Techniques for reducing pressure drop.

4. Enhancement of fine particulate collection.

Dust cake properties and modeling are discussed in detail in section 5 of this report.

\subsubsection{Fabric Development}

Increased used of fabric filters for both industrial and utility applications has come about primarily due to advancements in fabric development. Early fabrics were made from natural fibers such as cotton, wool, or flax. However, these fabrics were useful only at lower temperatures $\left(<200^{\circ} \mathrm{F}\right)$ and if the material to be collected was chemically inert; therefore baghouses had very limited applications. Since the late 1940 s and the advent of the polymer industry, man-made fibers such as acrylics, nylon, fiberglass, Teflon and Ryton ${ }^{\circledR}$ have become available. Fabrics made from these fibers have greatly extended the use of fabric filtration in both the utility and industrial sectors. These fibers are able to withstand higher temperatures and are more resistant to chemical attack.

The development of flberglass fabrics began in the late 1930s, but the early fabrics were not very durable. It was not until 1950 when colloidal graphite and silicon finishes were developed that 
fiberglass fabrics were made with a flexural life which was acceptable for fabric filter applications. Today, fiberglass is the fabric of choice by most utility baghouse operators, because it can operate at temperatures up to $500^{\circ} \mathrm{F}$ and has a proven bag life, making it economical. The major disadvantage of fiberglass fabric is its vulnerability to abrasion damage. This has restricted its use to gentle cleaning techniques such as reverse air or reverse air with gentle shaking, although recently heavier, more durable fiberglass fabrics have been developed for pulse jet applications. When operated at low face velocities (< $3 \mathrm{ft} / \mathrm{min})$ with the proper cleaning cycle, fiberglass with a Tefion or acid resistant finish has been shown to provide a bag life of 5 years or longer. However, because of low face velocity requirements, large baghouses with their associated high capital costs are needed. In addition, low energy cleaning also means low cleaning efficiency, which for some coal ashes results in an unacceptably high pressure drop. Therefore, research in fabric development has continued in an attempt to provide improved fabrics and fabric finishes at a reasonable cost, with extended bag life, for a wide variety of applications. In recent years, a large number of fabrics have become commercially available. Some of these are listed in Table 4-2.

Teflon fabrics have beer developea that are virtually impervious to chemical attack up to 400 to $450^{\circ} \mathrm{F}$ and have good abrasion resistance. Although these Teflon fabrics can provide long life, they are extremely expensive, therefore, E.I. du Pont has developed a combination felted fabric called Tefaire ${ }^{\circledR}$, which uses both fiberglass and Tefion fibers. This fabric retains many of the advantages of Tefion but at a lower cost.

Nomex ${ }^{(B)}$ a nylon derivative, has good temperature and flexural properties but has proven vulnerable to degradation in flue gases with high $\mathrm{SO}_{2}$ concentrations. This has limited the use of Nomex in coal combustion systems. However, with the advent of dry flue gas desulfurization upstream of the baghouse, Nomex ${ }^{\circledR}$ may again find a market in coal combustion fabric filters. Ryton ${ }^{\circledR}$ is a newly 


\begin{tabular}{|c|c|c|c|c|c|}
\hline Fiber & $\begin{array}{l}\text { Acid } \\
\text { esistance }\end{array}$ & $\begin{array}{c}\text { Alkali } \\
\text { Resistance }\end{array}$ & $\begin{array}{c}\text { Heat } \\
\text { Resistance } \\
\left({ }^{\circ} \mathrm{F}\right)\end{array}$ & $\begin{array}{c}\text { Abrasion } \\
\text { Resistance }\end{array}$ & $\begin{array}{c}\text { Relative } \\
\text { Cost }\end{array}$ \\
\hline Cotton & Poor & Good & $200-250$ & Moderate-Good & Low \\
\hline Wool & Moderate & Poor & $175-200$ & Good & Low-Moderate \\
\hline Nylon & Poor & Excellent & $200-250$ & Excellent & Low-Moderate \\
\hline polyester & Good & Moderate & $300-350$ & Excellent & Low-Moderate \\
\hline Acrylic & Good & Moderate-Good & $250-300$ & Moderate-Good & Moderate \\
\hline polypropylene & e Good & Good & $200-250$ & Good & Low \\
\hline Nomex & Moderate & Good & $425-500$ & Excellent & High \\
\hline Teflon & Excellent & Excellent & $450-525$ & Moderate & Very High \\
\hline Glass & Excellent & Moderate & $550-600$ & Poor & Moderate \\
\hline Ryton ${ }^{B}$ & Excellent & Excellent & 392 & Good & High \\
\hline PBI & Excellent & Excellent & 500 & Good & Very High \\
\hline Tefaire ${ }^{\circledR}$ & Excellent & Excellent & $450-550$ & Moderate & High \\
\hline Nextel(a) & Excellent & Moderate & $>2000$ & Moderate & Very High \\
\hline
\end{tabular}

developed fiber that has recently become commercially available. Its chief advantage is its long-term retention of textile properties at elevated temperatures, even in the most acidic conditions. However, its temperature margin is narrow and just a small excursion above its rated value can result in catastrophic bag failure.

Another relatively new synthetic fiber is Polybenzimidazole (PBI), manufacturea by cianese Corporation. It has a high temperature rating, along with good chemical and abrasion resistance, but it is also very costly.

$3 \mathrm{M}$ has developed a ceramic fabric called Nextel ${ }^{\circledR}$ that is currently being tested at a pilot baghouse at the University of North Dakota (8). This fabric is designed to permit baghouse operation at the very high flue gas temperatures $\left(>1200^{\circ} \mathrm{F}\right)$ that would be needed for hot gas cleanup.

In summary, while fiberglass fabrics are the current choice of utilities, their low abrasion resistance has promoted research in fabric devclopment. A wide variely of flbers has been developed for 
selected applications, but no fiber has currently been produced that combines high abrasion resistance with all of the advantages of fiberglass at a comparable cost.

\subsubsection{Emerging Technologies}

Pressure drop across a baghouse is one of the major contributors to the operating cost. In many installations, the maximum permissible pressure drop is determined by the capacity of existing fans. Most utilities prefer to operate a baghouse between 2 and 8 inches w.i. pressure drop, however, the actual pressure arnp may be higher due to errors in desigr, high dust cohesiveness, smaller than expected dust particle size, changes in operating conditions, or changes in the air-to-cloth ratio. Current methods of dealing with high pressure drop are:

1. Decreasing the air-to-cloth ratio of the baghouse.

2. Changing the cleaning cycle by either cleaning more often or by using a more vigorous cleaning mechanism.

3. Using sonic horns.

Decreasing the air-to-cloth ratio is a very costly method of dealing with high pressure drop. It can be accomplished by adding extra compartments to an existing baghouse, installing a new one or by decreasing the inlet gas volume by reducing the load on lhe boiler. None of these options are very acceptable to utilities.

Changing the cleaning cycle is the solution most often employed. The bags are simply cleaned more often or more vigorously, tliereby reducing pressure drop across the fabric. The disadvantages of this are that it is self limiting, a decrease in bag life, and may increase emissions due to an increased dust reentrainment. These disadvantages have encouraged utilities to search for alternate solutions. 


\subsubsection{Sonic Horns}

Sonic horns are a relatively new technology that some utilities have begun utilizing to reduce pressure drop. Sonic horns typically consist of a wave generator that produces a driving force and a resonance tube that acts as a multiplier. The wave generator can be either electrically or pneumatically activated to produce a sound wave. The effect of the sound-wave action on the filter bag. dust cake is to create a shear force at some boundary layer within the cake. Boundary layer depth and the corresponding level of cleaning enhancement is dependent on the dust and gas flow characteristics. Although testing of sonic horns at various installations has shown that a minimum level of sound pressure is required for effective cleaning, the relative cleaning effectiveness and bag area covered is determined by a combination of the sound-pressure level and wave frequency. Research has indicated that the minimum sound-pressure level required for effective cleaning is about 130 decibels (9).

Sonic horn size is determined by the amount of bag cleaning desired for each horn with the amount of area cleaned being proportional to the horn size. For example, a very large horn would clean a much greater area than a smaller horn but would require more energy to drive it to the needed decibel level. Therefore, a compromise must be made between the size of the horn and filter area to be cleaned. Generally sonic horns are most effective when used in combination with reverse dir cleaning.

Much of the sonic horn research has been done by EPRI and SORI. From a test conducted at EPRI's Arapahoe pilot baghouse, it was reported that sonic horns used in conjunction with reverse air cleaning were able to reduce pressure drop by as much as $60 \%$ (10). The Public service Company of Colorado tested sonic horns at its Arapalioe uilit $\mathrm{Nu} .3$, and reported that the flange-to-flange pressure drop decreased from 9.5 to 6.5 inches W.C., a $32 \%$ improvement (11).

The beneficial effects of sonic horns may be related to the basic ineffectiveness of reverse air cleaning. The reduction in pressure drop by sonic horns is much less when used to augment shaker 
cleaning. In fact, greater pressure drop reductions usually can be realized by optimizing the shaking intensity and frequency. consequently, sonic horns offer little attraction for shaker applications (12).

A penalty for the use of sonic horns in reverse gas cleaning, may be increased particulate emissions. Cushing et.al. (10) reported a significant increase in total outlet mass emissions when sonic horris were used. In the worst case, reverse air cleaning occurring simultaneously with sonic assist, the outlet emissions increased from $0.00078 \mathrm{lb} / \mathrm{milli}$ ion Btu to $0.015 \mathrm{lb} / \mathrm{million}$ Btu. Although, this increase in emissions may be reduced, sonic rorrs would be detrimental to obtaining high fine particulate collection efficiency.

Another problem with sonic horns is that successful operation is very site specific. There have been examples where sonic horns provided only a minimal decrease in pressure drup. For example, at Baltimore Gas and Electric's C.P. Crane station, installation of sonic horns only decreased pressure drop by an average of one inch W.C., even when operated at very high sound-pressure levels (13). Although sonic horns did stabilize the pressure drop, the baghouse was still operating at an unacceptable level. Therefore, it is essential that sonic horns be tested at the operating conditions for which they are intended before being installed in a full-scale unit.

\subsubsection{Electrostatically Enhanced Fabric Filtration}

The electrostatic characteristics of the fabric and dust are known to play a role in fabric filter performance (14). Although substantial research and modeling efforts have been made in recent years to determine the mechanisms by which electrostatic effects are manifested, the interaction attributable to electric forces is still missing from all general fabric filtration models. A more detailed description of electrostatic effects in a fabric filter will be discussed in section 5.2 of this report. Enhancement of the electrostatic characteristics of either the dust or fabric has been shown to reduce operating pressure drop by up to $60 \%$ and may improve 
collection efficiency, depending on the dust and collecting fabric (15). There are two methods of obtaining electrostatic enhancement in a fabric filter. First is to use a precharger to charge the dust particles prior to reaching the fabric. The second method is to supply an external electric field to the surface of the fabric. The major stimulus behind this research is to provide a method of operating a baghouse at much higher air-to-cloth ratios and still maintain a low pressure drop and high collection efficiency.

The most extensive work on corona charging of dust in a laboratory scale fabric filter was by Humphries et.al. (16) on the collection of lead smelter dust. The test unit consisted of a two compartment shaker baghouse using a tube-wire precharger for each compartment. The data showed a substantial reduction in pressure drop with precharging, indicating that the charged particles may be forming a more porous dust cake on the filter cloth. Figure 4-8 illustrates the effect of precharging on pressure drop when collecting lead smelter dust at $140^{\circ} \mathrm{F}$. An overall reduction in power consumption of $0.56 \mathrm{~W} / \mathrm{ft}^{2}$ of fabric (volume flow rate $\mathrm{x}$ pressure drop) was reported. A smaller pressure drop reduction was reported for tests at higher temperatures due to back corona effects. This made it necessary to water cool the electrodes for higher temperature testing.

American Precision Industries has developed a commercial hybrid electrostatic precipitator/fabric filter called the Apitron which has been evaluated at lie pilut scale by both the EHA and EPRI. $\AA$ full size unit was operated for over two years on a municipal waste incinerator (17). The results from these tests were similar to those obtained by Humphries et.al.. SORI with EPA support (18), tested the Apitron on a pc-fired boiler. With corona wires on, pressure drop across the fabric filter decreased by $40 \%$ and collection efficiencies ranged frim 99.6 to 99.9\%. However, the energy consumed (charger energy plus fan energy) was 2.5 times higher than with the corona wires off. In this test operating costs would favor corona off operation. Precharging the particles was reported to have a neutral effect on the collection efficiency for submicron particles. In 


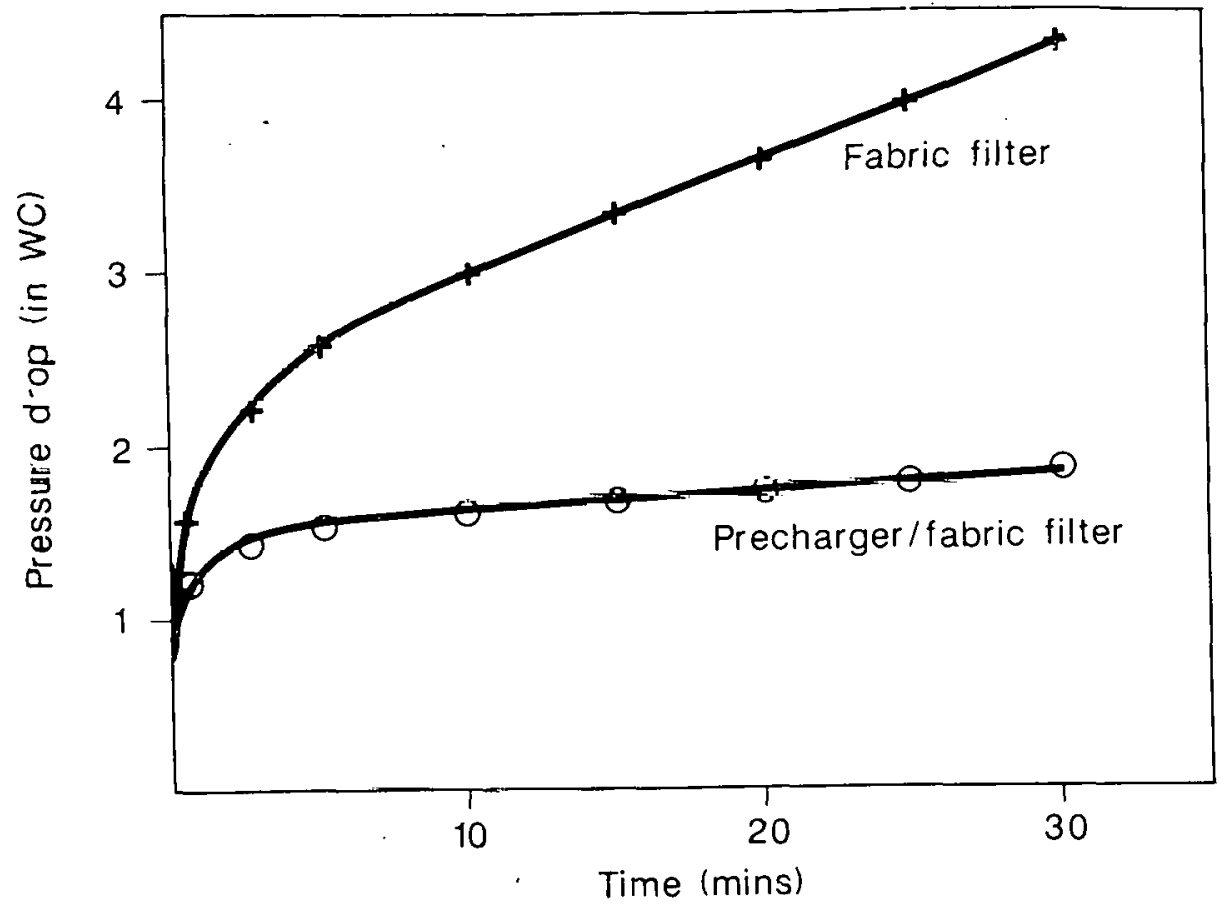

Figure 4-8. The effect of precharging on pressure drop as a function of time, when collecting lead smelter dust in a fabric filter (Ref. 16).

another test, collecting redispersed silica dust, less energy was consumed with the corona wires on. Therefore, energy consumption is dependent on the physical and chemical characteristics of the dust.

Although this process has been shown to reduce pressure drop and increase overall collection efficiency, it suffers from the same back corona problem as ESPS. If the resistivity of the dust is high then the process does not work as well, and such techniques as water cooling of the electrodes must be used.

Ancther method of utilizing ejectrostatic effects to anhance baghouse performance consists of applying an external electrical 
field to the surface of the fabric. This process is called electrically stimulated fabric filtration (ESFF). An electric field can be achieved by applying a voltage across very fine stainless steel electrodes woven into the cloth in the warp direction, to electrodes attached to the fabric surface, or to a center wire with grounded bags. This technique has been shown to reduce residual and operating pressure drop substantially with no apparent loss in collection efficiency.

Laboratory studies conducted by Textile Research Institute (TRI) have shown that $\mathrm{ESFF}$ is an effective method of reducing the operating pressure drop (19). Enhancement of collection efficiency is more pronounced for felted fabrics compared to woven fabrics. The application of an electric field results in more of the particles being collected on the surface of the felted fabric rather then penetrating into the fabric, thereby reducing seepage. Seepage of particles through the fabric is thought to be the dominant penetration mecharism in felted fabrics.

Data from pilot scale tests at the Harrington station, with electrodes woven into the fabric operated at an air-to-cloth ratio of $4.0 \mathrm{ft} / \mathrm{min}$, showed a decrease in residual pressure drop of $50 \%$ when voltage was applied (20). In a 40 day extended test using reverse air cleaning at an air-to-cloth ratio of $3 \mathrm{ft} / \mathrm{min}$, electrostatic enhancement decreased pressure drop from 6 inches to 3 inches W.C., with the outlet dust loading remaining the same.

A disadvantage of this method is that it requires an elaborate array of electrical hardware distributed over the entire surface of the filter or woven into the bags. Thus, for retrofit applications, major structural changes would be necessary. Hardware requirements for ESFF include: a power supply and controls, electrodes for each bag, and wiring to connect the two. A.field strength of $7.6 \mathrm{kV} /$ inch is necessary to provide sufficient electrical force on the particles to collect them at the electrode. Control circuitry would be similar to that used by ESPS. For ESFF applications it is very important that sparking be kept at a minimum because sparks could produce holes in the bags, thereby producing high penetration. 
of the different ESFF configuration, the center-wire concept has been shown to provide the best performance (21). This concept produces corona charging of the particles to augment an external electrical field. To supply a $3 \mathrm{kV} /$ inch electric field for this configuration, a power supply would have to provide a voltage of $45 \mathrm{kV}$. Pilot plant data results indicate that the required current is approximately $1.86 \mathrm{~mA} / \mathrm{bag}$. Therefore, assuming 400 bags per compartment, a $44 \mathrm{kV}, 1$ Ampere power supply could provide ESFF power for one compartment.

\subsubsection{Flue Gas Conditioning}

One of the primary goals of fabric filtration research is to enhance the collection efficiencies of fabric filters for fine particulates (< $2.5 \mathrm{\mu m}$ ). Although fabric filters have much more uniform fractional collection efficiencies than ESPs, there is still an increase in penetration for particles between 0.1 and $1.0 \mu \mathrm{m}$. In addition, it is known that several coals produce fly ashes that are difficult to collect in a fabric filter (22). Research conducted at Texas Utilities' Monticello Station and at the University of North Dakota Energy Research Center (UNDERC) has shown flue gas conditioning to be an effective method of enhancing the collection efficiency of fabric filters $(23-26)$

ESPs at the Monticello station, where a wilcox Texas lignite is burned, were experiencing difficulty in meeting particulate and opacity standards, even with the addition of conditioning agents. Therefore, a baghouse was installed which was designed to take $80 \%$ of the flow. After coming on line, this baghouse experienced high opacity spikes after cleaning, a higher than expected pressure drop, and short bag life. SoRI, under contract to EPRI, tested ammonia conditioning as a technique to improve baghouse performance at the Monticello power station. In the initial tests, using a slip stream sampler with a Teflon $B$ finished fiberglass fabric, they reported that ammonia conditioning improved collection efficiency from 97.5 to 
99.97\%. Subsequent baghouse compartment tests also showed improvement in collection efficiency and reduced opacity levels (23).

Although ammonia conditioning had no effect on the pressure drop, the bags had already collected a residual dust cake prior to conditioning. It has not been reported what effect ammonia conditioning would have on pressure drop if injection began with all new bags. In addition, no fractional efficiency data has yet been reported; therefore, the effect of ammonia conditioning on fine particulate collection at the Monticello station is not known.

Conditioning tests were made in a pilot-scale baghouse at UNDERC $(24,25,26)$ with several coals that produce difficult-to-collect ashes including the Texas lignite used at the Monticello station. Results have shown that simultaneous conditioning with ammonia and $\mathrm{SO}_{3}$ is a very effective method for improving not only overall collection efficiency, but the collection efficiency for fine particulates as we11. A decrease in penetration of fine particles of up to 4 orders of magnitude was reported. In addition, there was a decrease in the flange-to-flange pressure drop of 30 to $75 \%$. Details of these tests are given in section 5 of this report.

\subsubsection{Summary}

Although fabric filters are the best available technology for high efficiency removal of fine particulates at a reasonable cost, their pcrformalice lias been tound to be somewhat coal specific. For many coals, the primary disadvantage of a baghouse is the high operating pressure drop resulting in high operating costs. If reducing pressure drop in an existing baghouse is necessary, generally the first alternative is to increase cleaning frequency. This will unfortunately, result in shorter bag life and possibly higher emissiors. If more frequent cleaning does not solve the problem or cannot be done, then installation of sonic horns would be more economical than reducing the boiler load or retrofitting additional compartments. However, sonic horns are not the solution for all baghouses experiencing pressure drop problems because they do 
not always produce the desired effect. In addition, particulate emissions may also be increased.

For new units, ESFF may be a viable alternative that will allow operation at higher air-to-cloth ratios. The economics seem favorable if the technology can be transferred successfully from pilot-scale to full-sçale testing.

The technology with the greatest potential is ammonia and $\mathrm{SO}_{3}$ conditioning. This is the only known fabric filter technology that may provide substantially reduced fine particulate emissions and, in addition, allow operation at a lower pressure drop or higher air-tocloth ratio. Kesearch necessary to fully develni this technology for oommexsfal apulications, has a high return for the investment.

\subsubsection{References}

1. Buonicore, A.J., J.P. Reynolds and L. Theodore. Control. Technology for Fine-Particulate Emissions. Chemical Engineering Department, Manhattan College for Argonne National I.aboratory, ANL/ECT-5, 1978 .

2. Wys3, A.W., M.A. Shackleton, and R.S. Merrill. Fractiunal Efficiencies of Available Control Techniques. proceedings: The Technical Basis for a Size Specific Particulate standard parts I \& II, Air Pollution Control Association specialty Conference, pp. 295-311, April 1980 .

3. Preston, G, I'. The Impact of Coming Paxticulate control Requirements on the Utility Industry. Proceelings: Fifth Symposium on the Transfer and Utilization of Particulate coritrol Technology, Kansas City, Mo, Vol. 1, pp, 2-1 to 7, February 1986.

4. Barranger, C.B. Full Scale Operation and Performance of Two New Baghnuse Installations. Proceedings: Fifth symposium on the Transfer and Utilization of Particulate contrul Technology, Kansas City, MO, Vol. 3, pp. 8-1 to 14, February 1986.

5. Dahlin, R. S., M.H. Marchant, J.P. Gooch, R.E. Bickelhaupt, D.R. Sedr's. On.Site Field Tests for study of Low-Rank Western Coal Fly Ash. DOE/FC/10225-1650, Southern Research Institute. Birmingham, AL, August 1984 . 
6. Donovan, R.P: Fabric Filtration for Combustion Sources. Marcel Dekker, Inc., New York, NY, pp. 22-26, 1985.

7. Billing, C.E., and J. Wilder. Handbook of Fabric Filter Technology, Vol I: Fabric Filter systems study. PB-200 648 GCA Corporation, Bedford, MA, pp. 4-25, 7-42, December 1970.

8. White, L.R., D.L. O'Brien, and G.A. Schmitt. Ceramic Fabrics for Filtration at $\mathrm{High}$ Temperatures, 550-1600\% $\mathrm{F}$. Presented at: Third EPRI Conference on Fabric Filter Technology for Coal-Fired Power Plants. Scottsdale, AZ, November 1985.

9. Makansi, J. Select the Right Sonic Horn for Your Fabric Filter. Power, Vol. 127, No. 9, pp. 43-44, September 1983.

10. Cushing, K.M., D.H. Pontius, and R.C. Carr. A study of Sonic Cleaning for Enhanced Baghouse Performance. Proceedings: Second Conference on Fabric Filter Technology for Coal-fired Power Plants, EPRI CS-3257, Denver, CO, pp. 18-1 to 27 , November 1983 .

11. Menard, A.R. ard R.M. Richards. The Use of Sonic Air Horns as an Assist to Reverse Air Cleaning of a Fabric Dust collector. Proceedings: Second Conference on Fabric Filter Technology for Coal-fired Power Plants, EPRI, CS-3257, Denver, Co, pp. 26-1 to 43, November 1983 .

12. Vandewalle, A.Th.M. and H.F. Johnson. Fabric Filter Research and Development in Australia. Presented at: The Third Conference on Fabric Filter Technology for Coal-fired Power Plants, Scottsdale, $A Z$, November 1985 .

13. Shilling, N.Z., K.R. Murphy, and C.P. Gunzelman. Operating Experience with Fabric Filter on the Cyclone Fired Boilers at Baltimore Gas and Electric C.P. Crane Station. Presented at: The Third Conference on Fabric Filter Technology for Coal-fired Power Plants, Scottsdale, AZ, November 1985.

14. Donovan, R.P. Fabric Filtration for Combustion Sources. Marcel Dekker, Inc., New York, NY, pp. 287-296, 1985.

15. Viner, A.S., D.W. Vanosdell, K.D. Carter, and I.S. Hovis. Study of Electrostatically stimulated Filtration Fundamentals. Proceedings: The Sixth Symposium on the Transfer and Utilization of Particulate control Technology, EPA/EPRI, New orleans, LA, Vol. 3, pp. 2-1 to 18, Fehriary 1986.

16. Humphries, W., J.J. Madden and M. Miceli. The Effect of Particle Precharging on the Performance of a Fabric Filter Collecting Lead Smelter Dust. Aerosol Science and Technology, Vol. 3, No 4, pp. $381-395,1984$. 
17. Crask, R.I. and G.D. Applewhite. Electrostatic Augmentation: Field Results. Paper 83-55.5, Presented: 76th Arnual Meeting of the Air Pollution Control Association, Atlanta, GA, June 1983.

18. Felix, L.G. and J.D. McCain. Apitron Electrostatically Augmented Fabric Filter Evaluation. EPA-600/7-79-070, U.S. Environmental Protection Agercy, Office of Research and Development, Washington, DC, February 1979.

19. Greiner G.P., D.A. Furlong, D.W. Vanosdell, L.S. Hovis. Electrostatic Stimulation of Fabric Filtration. Journal of the Air Pollution Control Association, Vol. 31, No. 10, pp. 11251130 , October 1981 .

20. Chambers, R., J.J Spivey, and D. Harmon. ESFF Pilot Plant Operation at Harrington Station. Proceedings: Fifth Symposium on the Transfer and Utilization of Particulate Control Technology, Kausas oity, MO, Vol. 3, pp. 25-1 to 17, February 1986.

21. Hovis, L.S. and A.S. Viner. Economics of Advanced Electrostatic Stimulation of Fabric Filtration. Proceedings: The Sixth Symposium on the Transfer and Utilization of Particulate control Technology, EPA/EPRI, New Orleans, LA, Vol. 3, pp. 7-1 to 15, February 1986 .

22. Milier, S.J. and D.R. Sears. The Influerice of Coal-Specific Fly Ash Properties Upon Baghouse Performance: A Comparison of Two Extreme Examples. Proceedings: Fifth Symposium on the Transfer and Utilization of Particulate Control Technology, Kansas City, MO, Vol. 3, pp. $22-1$ to 21 , February 1986.

23. Felix, L.G., R.L. Merritt and K. Duncan. Improving Baghouse Performance at the Monticello Generating Station. Journal of the Air Pollution Control Association, Vol. 36, No. 9, pp. 10751085, September 1986 .

24. Miller, S.J. and D.I. Laudal. Particulate Removal Enharicement of a Fabric Filter Using Flue Gas Conditioning. Presented at: Third EPRI Conference on Fabric: Filter Technology for Coal-Fired Power Plants. Scottsdale, AZ, Nuvember 1.985.

25. Laudal, D.I. and S.J. Miller. Flue Gas Conditioning for Improved Baghouse Performance. Proceedings: The Sixth Symposium on the Transfer and Utilization of Particulate Control Technology, EPA/EPRI, New orleans, LA, Volo 3, 14-1 to 16, February 1986.

26. Laudal, D.L. and S.J. Miller. Flue Gas Conditioning for Baghouse Performance Improvement with Low-Rank Coals. Presented at: he Fourteenth Biennial Lignite Symposium on the Technology and Utilization of Low-Rank Coals, Dallas, TX, May 1987. 


\subsection{Granular Bed Filtration}

In a granular bed filter (GBF), a particle laden gas stream is passed through a dense bed of granular material where entrained particulates are separated from the gas stream. These filters have been used for years to clean contaminated liquids, but for airborne particles the technique is relatively new.

In recent years, almost all GBF research has been directed toward developing the technology for high pressure and temperature applications. GBF is ideally suited for this application for the following reasons:

1. The filter media can withstand very high temperatures and pressures without degradation.

2. Very high collection efficiencies can be obtained.

3. The relatively high pressure drop would not be as much a problem for high pressure applications.

Figure 4-9 presents a typical fractional efficiency curve for a counterflow, moving-bed GBF, operating at $1590^{\circ} \mathrm{F}$. The overall particulate collection efficiency is in excess of $99 \%$ but there is a substantial decrease in collection efficiency for particles less than $3 \mu \mathrm{m}$ (1). Factors that effect GBF performance include:

1. Cleaning mechanism for the filter media.

2. Depth of the filter bed.

3. Face velocity.

4. Particle size of the filter media.

Collection efficiency of a GBF is dependent on both pressure drop and filter media size. The smaller the filter media size the greater the surface area, resulting in increased collection efficiency. However, the pressure drop is also increased. In addition, pressure drop is dependent on the depth of the filter bed and the face velocity. 


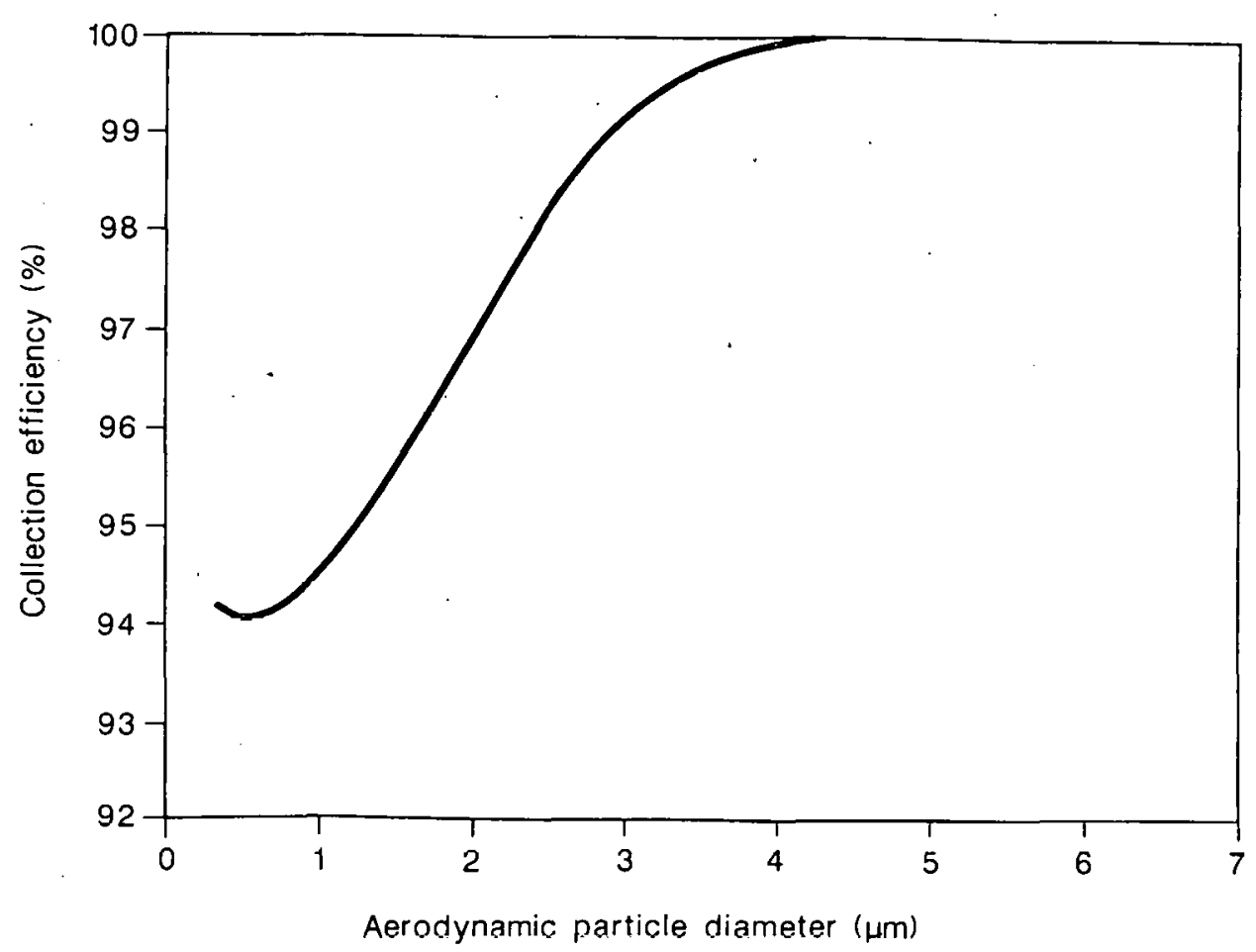

Figure 4-9. Fractional particulate collection efficiency curve for a granular bed filter (Ref. 1).

\subsubsection{Moving Bed Granular Filtration}

There are two basic methods for cleaning GBFs: moving bed and backflushing. In the moving bed GBF, such as that developed by Combustion Power Company (CPC), the filter media is slowly removed, cleaned off-line and then recycled back to the filter. There are two types of moving bed GBFs. In the first, referred to as crossflow GBF, the filter media is held in place by a screen, with holes large enough for the gas to escape but small enough to prevent elutriation of filter media. Cleaned gas then flows out through the middle of the collection chamber. Early in CPC's testing program plugging of the screens occurred, leading to excessively high pressure drops (1). Therefore, modifications were necessary leading to the development of the counterflow GBF. In a counterflow GBF, no screens are used and 
the dirty gas enters through a duct imbedded in the filter media. cleaned gas then exits through annuli at the top of the chamber. Dirty filter media is taken from the filter bottom, cleaned, and returned at the top. This filter performed very well during CPC's testing, as it provided collection efficiencies greater than $99 \%$ at pressure drops between 15 and 20 inches W.C. (1). It is important that the design specifications be such that the gas flowing into the filter does not fluidize the filter media. Once the system has been installed, operational flexibility, therefore, is severely limited.

\subsubsection{Backflushed Granular Bed Filtration}

The backflushing method of cleaning is typified by the GBF developed by Ducon, Inc. (2). In this unit, the filter compartment consists of a shallow ( 0.5 to 3 inch) bed of fine sand supported on a perforated distributor plate. Dust laden gases enter the filter compartment through a screen covering an opening above the filter bed. Gas flows downward through fine granular bed material, depositing entrained particulates onto the filter media. The filter is clearied on-line by reversing the flow of cleaned flue gas or by injecting pressurized air back through the media bed, thereby fluidizing the sand and dislodging accumulated dust. Dislodged dust is carried back through the filter compartment inlet opening, located above the bed, and collected at the bottom of the collection chamber. After extensive testing, Exxon reported that screens placed over the inlet openings would blind and that significantly higher freeboard height would be required to prevent bed media elutriation (3). Since the system was cleaned on-line, dust reentrainment was also a problem.

In an attempt to modify this design for high temperature and pressure applications, Westinghouse used multiple filter elements to allow off-line cleaning. In addition, the filter media was dense enough so that the minimum fluidization velocity would not be obtained during normal cleaning cycles but could still be operated in a fluidized mode for scheduled maintenance. When modifications were 
made, a collection efficiency of $99.2 \%$ was reported at a face velocity of $50 \mathrm{ft} / \mathrm{min}$. Effective removal of collected particles by backflushing, requires relatively high air velocities. In addition, the filter media must be as small as possible to obtain high collection efficiencies, therefore, high density filter media must be used to prevent fluidization. Development of an appropriate bed media is essential if shallow bed GBF technology to be used for particulate collection for high temperature and pressure applications.

\subsubsection{Electrostatically Augmented Sranular Bed Filtration}

GBFs have two disadvantages that make them less desirable for utility applications than ESPs and baghouses, decreased collection efficiency for fine particulates and high pressure drop. Electrostatic enhancement has been shown to improve GBFs in both of these areas $(4,5)$. Figure 4-10 shows a fractional efficiency curve for an electrostatically enhanced GBF at various voltage loads. There is a substantial decrease in efficiency for particles less than $2.5 \mathrm{\mu m}$ at zero voltage. When $20 \mathrm{kV}$ is applied, the decrease in collection efficiency for submicron particles is eliminated. Because the electric field enhances the collection efficiency of the gianular media, the size of the media can be increased, giving more void volume, thereby decreasing pressure drop.

CPC has electrostatically enhanced a moving granular fllter by inserting an electrostatic grid into the filter media (4). A high voltage is applied to the grid and the electric field is generated between a conductor and the inner and outer screers. Commercial electrostatic granular bed filters are available for a variety of process requirements. They have been designed for a maximum of 125,000 scfm, which is large enough for many industrial applications but not large enough for utilities. For utility applications, a modular designed multiple unit would be necessary. 


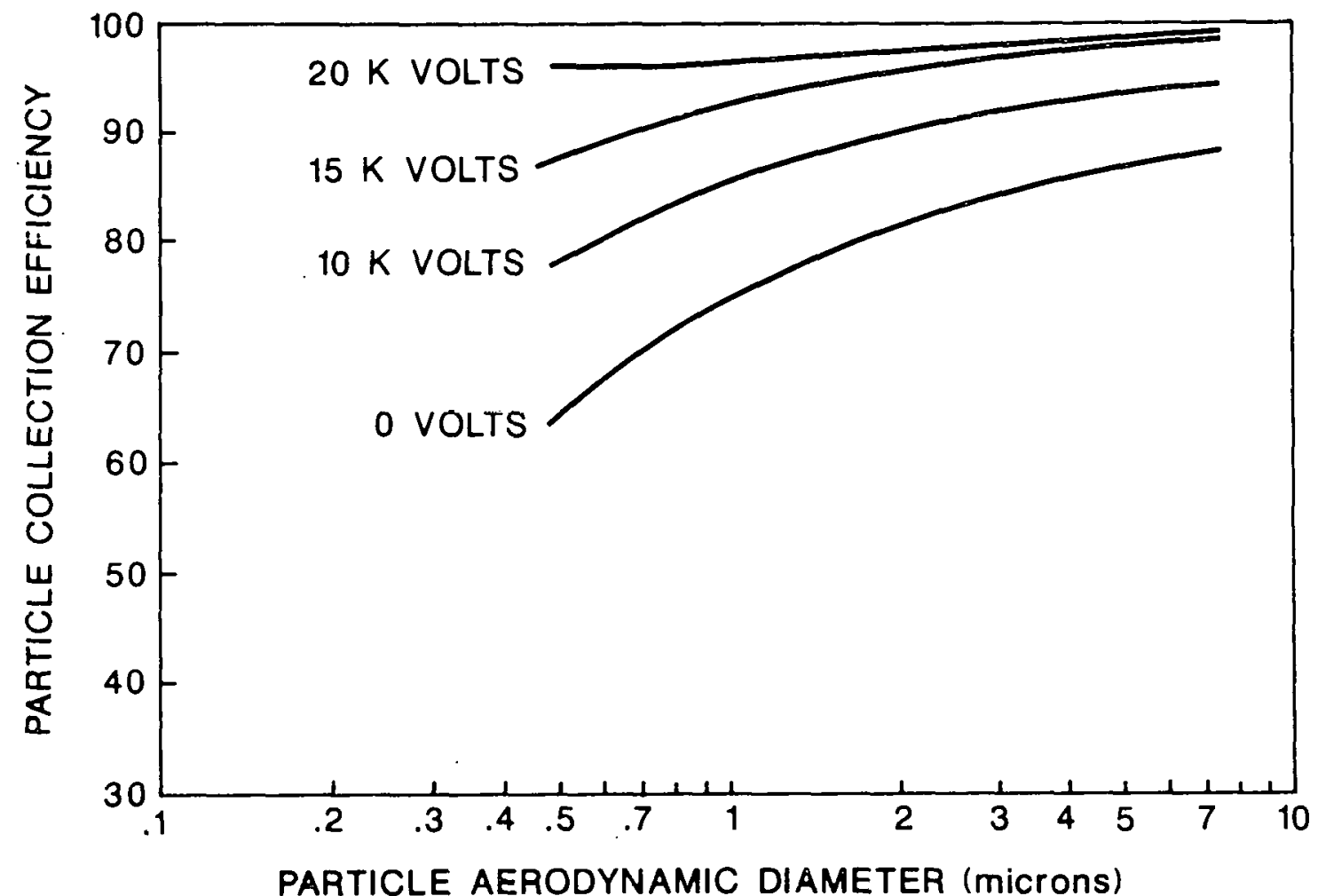

Figure 4-10. Fractional particulate collection efficiency for an electrostatically enhanced granular bed filter (Ref. 4).

Battelle, Pacific Northwest Laboratories has developed and patented an Electrostatic Fiber Bed Filter (5). This device charges the particulate matter in a corona chamber. Ion generation in the chamber is accomplished by a corona discharge between two electrodes. The filter bed is made of dielectric fibers, which collect the charged particles. Since the fibers occupy only 5 to $8 \%$ of the total bed volume, the pressure drops and energy requirements necessary to pase the gas through the system is very low.

The process has been evaluated in a laboratory-scale unit with resuspended $f l y$ ash. With corona charging, using a teflon fiber bed, collection efficiency improved from $74 \%$ to $96 \%$ and operated at less than 1 inch w.C. pressure drop at a bed face velocity was $300 \mathrm{ft} / \mathrm{min}$. 


\subsubsection{Summary}

GBFs are one of the leading technologies being studied for inclusion in PFBC systems. They can operate at the temperatures and pressures needed and can be designed to provide very high levels of particulate control ( $99.99+\%$ collection efficiency). In addition, they have the potential to remove fine particulates at this same level of control. However, GBFs are generally not being considered for conventional power plants due to high operating costs and the availability of other established technologies such as baghouses and ESPS.

\subsubsection{References}

1. Guillory, J., J. Cooper, J. Ferguson, G. Goldback, and F. Placer. Granular Bed Filter Development Program. Phase II. Final Report, DOE/ET/10373-T10, Combustion Power Company, Inc., Menlo Park, CA, May 1983 .

2. Lippert, T.E. Testing ard Verification of Granular Filters For Removal of Particulate and Alkalies. DOE/ET/17093-1741, Final Report, Westinghouse Electric Corporation, Pittsburgh, PA, April 1984.

3. Hoke, R.C. Miniplant Studies of Fressurized Fluidized Bed Coal Combustion. Final Report, EPA-600-7-80-013, pp. 123-147, January 1980 .

4. Grace, D.S., J.I.. Guillory, and F.M. Placer. Electrostatic Enhancement of Moving-Bed Granular Filtration. Proceedings: Second Symposium on the Transfer and Utilization of particulate Control Technology Vol. 3, Dénver, CO, pp. 288-308, september 1380 .

5. Bamberger, J.A. and W.K. Winegardner. Fiber Bed Filter System Control of Fly Ash Particulates. 81-WA-APC-1, ASME Air Pollution Control Division, November 1981. 
4.6. Acoustic Agglomeration

The particles that are most difficult to collect for almost all particulate control technologies are those between 0.1 and $2.5 \mu \mathrm{m}$ in diameter. These particles are small enough that interception and impaction are no longer effective collection mechanisms, but are too large to be collected by diffusion. If a technique could be used to agglomerate these particles to allow them to be collected by inertial separation to a much greater degree, then conventional technologies such as cyclones would collect these particles more efficiently. One such method is acoustic agglomeration.

The first experiments with acoustic agglomeration took place in 1931 when it was discovered that aerosol particles are quickly agglomerated in a standing-wave sound tube. Shortly afterward, other independent tests were conducted that confirmed the earlier results. This generated great enthusiasm for acoustic agglomeration and eventually large-scale industrial testing of its effectiveness were conducted. The results of the large-scale tests were discouraging, primarily due to high power consumption for sound generation. This greatly reduced interest in the U.S. and research was almost discontinued after 1953 (1). Renewed interest began in the late 1970 with increases in fuel costs and more stringent particulate control standards. New unconventional methods of utilizing coal, such as gasification and pressurized fluidized beds, created a need for unconventional particulate emission control devices that would operate effectively under extreme conditions. Acoustic agglomerators are being considered as one of the primary candidates to aid in the removal of dust particles for hot gas cleanup. In addition, they are being tested in conjunction with standard cyclones to provide a simple and fairly inexpensive particulate control device for conventional boilers.

Agglomeration is a growth process caused by the collision and subsequent sticking of two suspended particles. A strong acoustic field gives rise to an oscillating motion to airborne particles suspended in the field. Although the mechanisms of sonic 
agglomeration are not completely understood, results of experiments show a strong coupling of sonic and aerosol flow fields, giving the particulate matter both translational and vibrational motion. This motion increases the collision rate between the particles, thereby resulting in an agglomeration of the smaller particles (2).

High efficiency sound generation is a vital component of acoustic agglomeration. There are three methods of generating sound waves to provide an acoustical field. For much of the early work in acoustic agglomeration, mechanically activated pistons were used. Power requirements necessary to activate mechanical pistons are very high because of their low efficiencies. Therefore, the high intensity and frequency sound waves that are necessary to achieve good agglomeration cannot be obtained without a very large energy input.

An example of this type of device, evaluated by GCA Corporation, was the Braxton Sonic Agglomerator, which was designed as a means of allowing the use of cyclones or low energy scrubbers to control fine particulate emissions (3). The unit incorporates an electromagnetically driven piston that produces sound intensities of about 165 decibels at a frequency of $366 \mathrm{~Hz}$. Dust laden gases are then passed through the acoustic field and water is added at the top through atomizing nozzles.

GCA Corp. measured the collection efficiency of the Braxton sonic agglomerator in conjunction with a high efficiency cyclone using a cupola furnace to provide particulate matter. A cascade impaclor was used to collect size fractionated particles and plots were made of collection efficiency as a function of time for both the agglomerator with the cyclone and for the cyclone alone. Even with the agglomerator, as is shown in Figure 4-11, the cyclone only provides 50-55\% collection efficiency for particles less that $2.5 \mathrm{um}$. This does not compare favorably to other conventional devices such as ESPS and fabric filters. It was later shown by Shaw and Wegrzyn (1) that frequencies of 2500 to $3000 \mathrm{~Hz}$ were necessary to provide optimum agglomeration. The unit designed by Braxton corp. only operated at $366 \mathrm{~Hz}$ which explains the poor results that were obtained. 


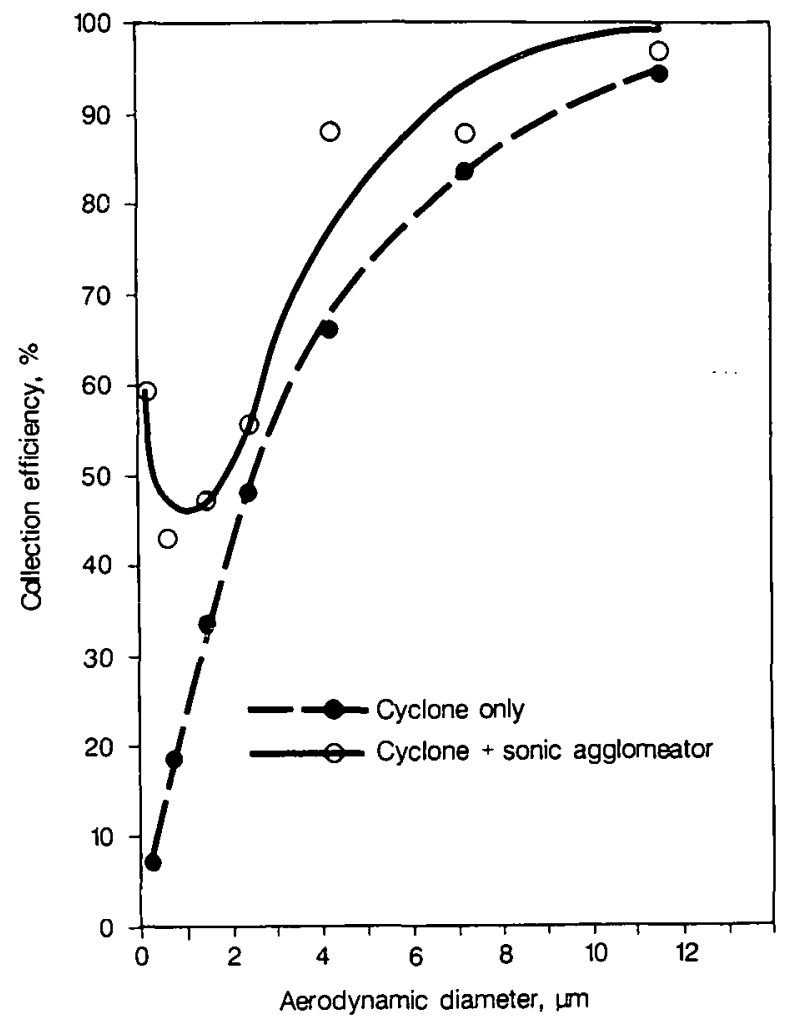

Figure 4-11. Fraction collection efficiency for high efficiency cyclones with and without the Braxton Acoustic Agglomerator (Ref. 3).

A second type of acoustical agglomeration sound wave generation method is the high efficiency air siren. High power sirens were originally developed by Bell Telephone Laboratories under a Department of Defense contract, as a warning signal for air raids during the second World War. Commercial high power sirens for acoustic agglomeration applications were developed by Ultrasonic Corporation in the 1950 s and in the late $1970 \mathrm{~s} \mathrm{high} \mathrm{efficiency} \mathrm{sirens}$ were designed (4).

A siren produces high intensity sound waves by forcing high pressure air through small openings in the siren housing. A disk with teeth is electrically rotated and periodically shuts off the compressed air stream coming out of the openings producing pulses which impart vibrational motion to the gas stream. This produces a $4-63$ 
high intensity sound wave and the frequency is then amplified by an exponential horn. The intersity and frequency of the sound wave is determined by the rotor speed, air velocity, and horn size.

Much of the developmental work using sirens as the sound source for acoustic agglomeration is being done by Aerojet Energy Conversion Company and Pennsylvania state University $(4,5)$. Their primary focus is to develop a particulate collection device for PFBC. They determined that the most effective agglomeration for fly ash occurs at an intensity level of $158 \mathrm{db}$ and a frequency of $2530 \mathrm{~Hz}$.

The third method is to use a combustion pulsor.. This unconventional techuique, being investigatcd at pennsylvania state University and by scott et.al. $(5,6)$, consists of a small combustor attached to an acoustical horn. Pre-mixed air and natural gas are burned in an unstable mode of combustion to give high intensity pulsations of hot gas that are transformed in the horn to acoustic waves. The sound wave is no longer sinusoidal but produces progressive saw-tooth acoustic fields.

This device was evaluated by the University of Toronto and Argonne National Laboratory (6). Using the pulsor combustion method allowed major simplifications in the agglomeration chamber which yiplded both capital and operating cost savings compared to sirens and mechanically actuated pistons. There are several promising aspects of generating a sound wave using a pulsor combustor. First, the heat of combustion for the pulsor simply adds to the overall process heat. Although the power requirements will in principle be zero, the cost per heating unit for the pulse-jet would be somewhat higher than coal. Secondly, the pulsor combustor can run at higher power levels due to elevated pressures, therefore it is expected to be a more effective sound generator for hlgh lemperdlure ard pressure applications. The overall result of this testing was that the mean particle size was increased 5-7 times. The device 1 s also currently being tested at Pennsylvania state University (5) in order to compare the results with those obtained from sirens. This work is ongoing and the data from the tests using this configuration have not yet been published. 
With the development of high intensity, high frequency sound generators, the effectiveness of acoustic agglomerators has dramatically improved since the work done by Braxton Corp. in 1974, when the results showed only small increases in mean particle size using acoustic agglomeration. Figure 4-12 shows the particle size distribution before and after acoustic agglomeration. There is a substantial shift in the particle size distribution toward a larger mass mean diameter. Figure 4-13 presents the fractional collection efficiency of acoustically augmented cyclones. From the Figure 4-13, it can be seen that the collection efficiency of the cyclones for fine particulate is greatly enhanced by acoustic agglomeration. Recent versions of acoustic agglomerators can provide a particle size distribution to a cyclone such that NSPS can be met, but several problems remain. First, the technology must be demonstrated on a commercial-scale unit. To date, tests have only been made at the pilot-scale. Secondly, the effect of sonic agglomeration on ultra fine-particles $(<0.5 \mu \mathrm{m})$ must be evaluated. If these particles agglomerate, they may form particles in the 0.1 to 1.0 pm range which are the most difficult to collect and are also the most harmful. Thirdly, the effects of high intensity sound waves on operation personnel must be minimized. The level of sound intensity that is required is well above the threshold of pain and several test plants were dismantled due to the harmful effect of the vibration on persons in the vicinity (7). Minimizing these effects will require heavy sound insulation on full-scale units that will substantially increase the capital cost.

Another disadvantage of acoustic agglomerators is that the effectiveness tends to decrease as the grain loading decreases. Experiments have shown that they work best at loadings of 10 grains/scf or higher, and that their effectiveness decreases until at 1 grain/scf they have almost no effect. Most coals produce dust loadings to the inlet of a collection device between 3 and 4 grains/scf, which is considerably less than the optimum loading for acoustic agglomerators. 


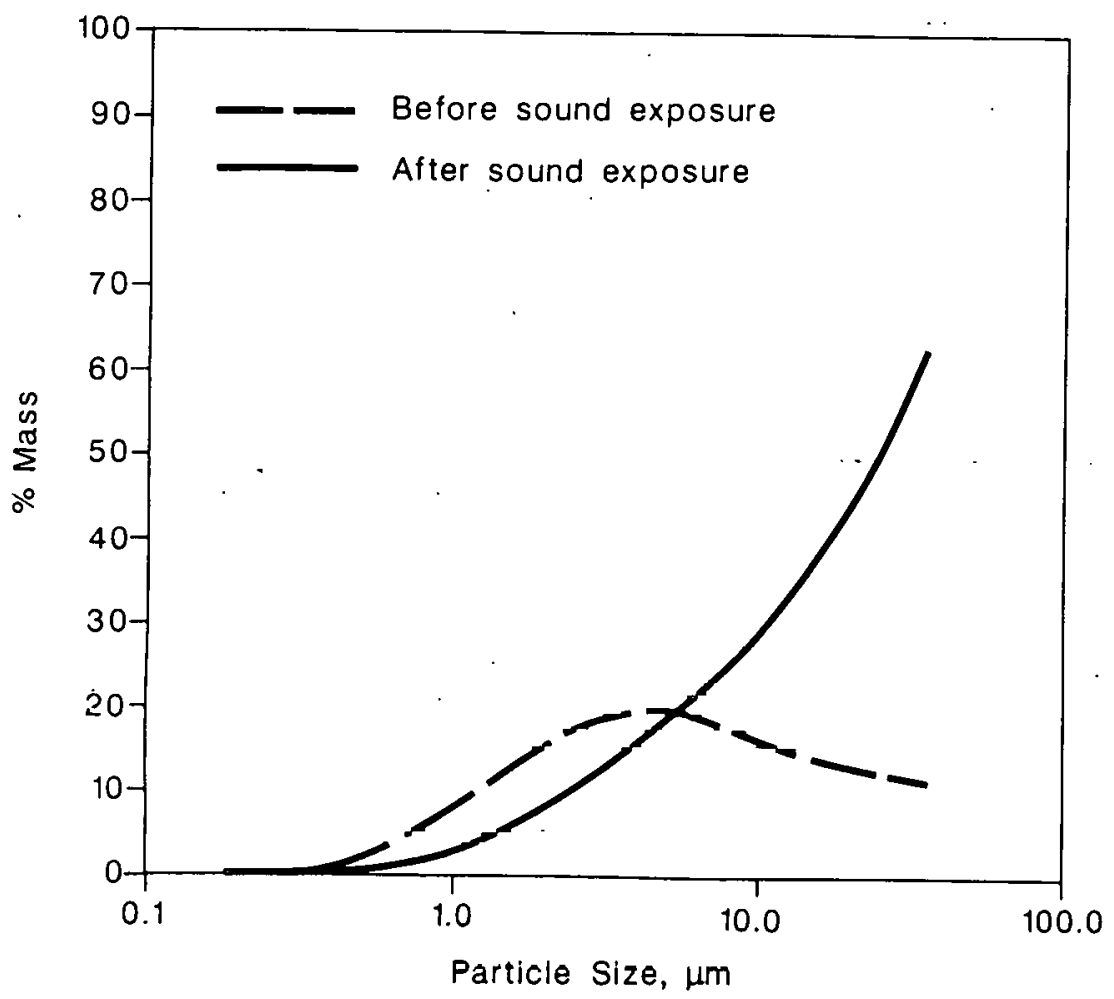

Figure 4-12. Particle size distribution before and after being conditioned with the Aerojet/PSU Acoustic Agglomerator (Ref. 8 ).

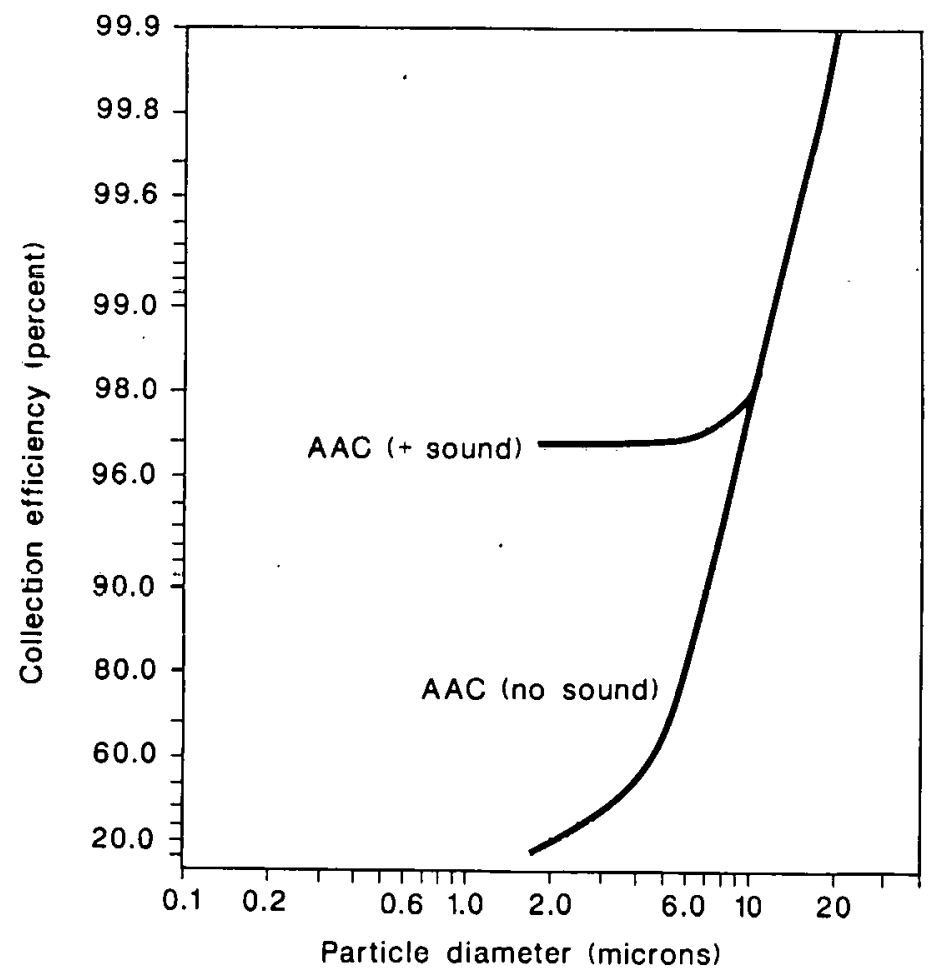

Figure 4-13. Particle collection efficiency of acoustically augmented cyclones (Ref. 8). 
The development of high efficiency acoustic wave generators has made acoustic agglomeration technology one of the leading candidates for high pressure and temperature particulate control applications. An acoustic agglomerator in conjunction with high efficiency cyclones should be able to meet NSPS for particulates, although, more research is necessary to resolve some of the unanswered questions.

\subsubsection{References}

1. Shaw, D.T. and J. Wegrzyn. The Application of Sonic Agglomeration for the Control of Particulate Emissions. Proceedings: EPA/DOE Symposium on High Temperature High Pressure Particulate Control, EPA-600/9-78-004, Washington D.C., pp. 325-353, September 1977 .

2. Wegrzyn J., D.T. Shaw, and G. Rudinger. The Use of Acoustic Agglomerators for Particulate Control. Proceedings: Symposium on the Transfer and Utilization of Particulate Control Technology, Denver, Co, Vol. 3, pp. 233-241, February 1979.

3. Cooper, D.W., R. Wang, and D.P. Anderson. Evaluation of Eight Nove1 Fine Particle Collection Devices. EPA-600/2-76-035, GCA

Corporation, Bedford, MA, February 1976.

4. Reethof, G. and O.H. MCDaniel. Acoustic Agglomeration of Power Plant Fly Ash. Pennsylvania State University Under DOE Contract, Final Report: DOE/MC/16359-1521, University Park, PA, 1983.

5. Faeser, R.J. and G. Reethof. Development of Acoustic Agglomerator. Proceedings: The Fifth Annual Contractors Meeting on Contaminant Control in Coal-Derived Gas streams, DOE/METC$85 / 6025$, U.S. DOE, Morgantown Energy Technology Center, Morgantown, WV, pp. 235-2.55, May 1985 .

6. Scott, D.S., W.M. Swift, and G.J. Vogel. Pulse-Jet Acoustic Dust Conditioning in High Temperature/Pressure Applications. Proceedings: EPA/DOE Symposium on High Temperature High Pressure Particulate Control, EPA-600/9-78-004, Washington D.C., pp. 310323, September 1977 .

7. Perry, R.H. and C.H. Chilton. Chemical Engineer's Handbook. McGraw-Hill Book Company, 5th Edition, pp. 20-118 and 119, 1973.

8. Case, G.D., K. Ushimaru, G.S. Knoke, S. Bernstein, and P.J. Bekowies. Evaluation of Particulate Collection Devices Developed for Pressurized Fluidized-Bed Combustors as Applied to Coal Gasification Processes. DOE/MC/20035-1702, U.S. DOE, Morgantown Energy Technology Center, Morgantown, WV, october 1984 . 
4.7. Summary

There are five basic types of particulate control techrologies:

1. Conventional mechanical separators, i.e. cyclones and gravitational settling chambers.

2. Wet scrubbers.

3. Fabric filters.

4. Electrostatic precipitators.

5. Granular bed filters.

If $99.99 \%$ collection efficiency for any size particle is considered a superior technology then conventional mechanical separators or wet scrubbers would not meet this criteria. There have been many novel technologies developed for these control devices but none would be able to. collect submicron particles at this level of efficiency.

ESPs are the most widely used technique for removing particulate matter, particularly in the utility industry. In most utility applications, ESPs that are currently operating are not able to meet a 99.99\% collection efficiency. However, assuming, the plant is burning a coal that produces a low resistivity ash, an ESF could be designed to meet this collection requirement. It wold require a much larger SCA than current designs, which would substantially increase both capital and operating costs. In addition, because of low $\mathrm{SO}_{2}$ emission standards, many coals that are used in puwer plants produce ashes that have high resistiviry. Thls llas cieated significant problems in ESP performance. Most ESP research has been performed to improve performance in collecting these high resistivity ashes. If very stringent fine particulate control standards were enacted, almost all currently operating ESPs probably would be out of compliance, and new units would be much more costly.

Although fabric filtration is the best available technology for removing a high percentage of particulates regardless of size, many facilities would not be able to meet a $99.99 \%$ collection efficiency 
for submicron particles. Some coals produce ashes that are not easily collected in fabric filters (or ESPs) and there is a decrease in collection efficiency for particles between 0.1 and $1.0 \mathrm{um}$. A promising technology that has the potential to obtain $99.999 \%$ particulate collection efficiency for submicron particles is flue gas conditioning with ammonia and $\mathrm{SO}_{3}$. Research has shown that ammonia and $\mathrm{SO}_{3}$ conditioning can improve collection efficiency of difficultto-collect coals by up to four orders of magnitude. In addition, flue gas conditioning may allow operation of the baghouse at higher air-to-cloth ratios, making it economically attractive as well.

Electrostatically entanced granular bed filters do have the capability to remove $99.99 \%$ of fine particulates, but to obtain this level of control, they would operate at a much higher pressure drop than would ESPs or baghouses, resulting in higher operating costs. However, for high temperature and pressure technologies, conventional particulate collection devices would require substantial modifications, making GBF a prime candidate for particulate control for these applications.

Another particulate control technology that has promise for high pressure and temperature applications is acoustic agglomeration. With the development of acoustic generation systems that can produce high intensity and frequency sound waves at relatively high efficiencies, these devices are able to agglomerate particles such that high efficiency cyclones would be able to meet the NSPS. To obtain this level of efficiency requires a sound wave source that would be uneconomical for conventional applications, due to high energy consumption. In addition, the fractional efficiency of these devices in conjunction with cyclones is not known. There has been some speculation that they may increase fine particle emissions due to an agglomeration of particles less then. $0.1 \mu \mathrm{m}$, creating particles between 0.5 and $2.5 \mu \mathrm{m}$ in diameter. These particles would be very difficult to collect in cyclones. 


\subsection{FLUE GAS CONDITIONING FOR FABRIC FILTER PERFORMANCE IMPROVEMENT}

\subsection{Collection and Penetration Mechanisms}

It is well known that filtration is an effective method of removing aerosols from a gas stream, and that the particle collection efficiency of a filter is a function of the properties of the particles, the carrying gas, and the filter itself. Particle properties which may be important include size, density, shape, charge, and composition. Gas properties which may affect the filtration process include velocity, pressure, temperature, and viscosity. The important filter properties are thickness, fiber diameter, and porosity. Penetration decreases exponentially with filter thickness, decreases with decreasing fiber diameter, and increases with increasing porosity (1). Therefore, it would appear that a good filter should be of adequate thickness, made up of very fine diameter fibers, and be of low porosity. Pressure drop, however, increases rapidly with decreasing porosity, which is why fibrous filters usually have a porosity of at least 90\%. (1). The fact that effective filtration results from the use of microfine fibers is demonstrated by the glass fiber filters which are commonly used for aerosol sampling of ambient air or from stacks. These filters are constructed of glass fibers which are about 0.5 to $2 \mu \mathrm{m}$ in diameter with an overall filter thickness of $430 \mathrm{\mu m}$. The collection efficiency of these filters is $99.99+\%$ for $0.3 \mu \mathrm{m}$ particles (2).

clearly, it is possible to construct a filter which can collect virtually 100\% of suspended aerosols from a gas. However, there are major differences between filtration with a fibrous filter, as described, and fabric filtration, as currently employed to control particulate matter from coal combustion systems or other industrial processes. Fabric filters must not only provide adequate particulate control, but also must be capable of being cleaned to control pressure drop and must be durable enough to be economical. Therefore, fabric filters have been developed to provide the lnwest. cost and pressure drop while maintaining an adequate collection 
efficiency to meet regulations. This means that, while a fabric filter may provide a collection efficiency of 99 to $99.9 \%$ to meet regulations, it is operating at an efficiencý far below the 99.99+\% which is theoretically and experimentally proven to be possible. There are differences in design of fabric filters which account for the higher penetration compared to an aerosol sampling filter. To provide the required strength, fabric filters employ much larger fibers (about $10 \mu \mathrm{m}$ ) than sampling filters. Also, fabrics may be of woven construction which results in large pore openings at the yarm junctions. Even with felled fabries, howover, pore size is large enough to result in significant perietration of dust through the fabric. The result is that efflclency in falric filtration depends highly on the formation of an adequate dust cake layer on the fabric surface to act as the primary filtration media. Because of this, collection efficiency and penetration mechanisms are likely to be highly dependent on the characteristics of the dust.

In the last 25 years, fabric filtration has been extensively modeled in an attempt to accurately predict pressure drop and collection efficiency. Results, however, show that both parametere can be predicted with only marginal accuracy. The purpose of this section is not to provide details on modeling efforts to date, but rather to show where present models fall short in predicting collection efficiency and to suggest additional dust characteristics which must be included in successful modeling efforts.

\subsubsection{Classical Collection Mechanisms}

Particle capture mechanisms which explain how particles are separated from the carrier gas include impaction, interception, diffusion, gravitational settling, electrostatic attraction, and sieving. These mechanisms have been extensively reviewed in the literature as applied to fabric filtration $(3,4,5,6)$. As a fluid approaches an object such as a fiber, elements of the fluid must accelerate and diverge to pass around the object. A particle suspended in the fluid may not be able to immediately accommodate the 
local fluid acceleration and a difference in velocity between the particle and fluid may develop. Inertia tends to maintain the forward motion of the particle while the diverging fluld tends to drag the particle aside. The motion of the particle then is the resultant of inertial and fluid drag forces. If the inertia of the particle is large enough, the particle will cross fluid streamlines and impact against the object, which is particle collection by impaction. The single fiber collection efficiency due to impaction is a function of a dimensionless parameter referred to as the stokes number or impaction parameter, which is given as:

$$
I=C \rho_{p} D_{p}^{2} V / 9 \mu D_{o}
$$

where:

$$
\begin{aligned}
& I=\text { impaction or stokes number } \\
& C=\text { cunningham correction factor } \\
& \rho_{\mathrm{p}}=\text { particle density } \\
& \mathrm{D}_{\mathrm{p}}=\text { particle diameter } \\
& \mathrm{V}=\text { upstream velocity (face velocity) } \\
& \mu=\text { gas viscosity } \\
& \mathrm{D}_{\mathrm{O}}=\text { diameter of the collecting object }
\end{aligned}
$$

Collection efficiency by impaction, therefore, is dependent on the square of the particle diameter and the face velocity, and is important only for particles larger than $0.5 \mu \mathrm{m}$ (6).

The concept of interception is different than impaction in that the particle does not deviate from the streamine. Interception takes place when a streamline carries a particle close to a collection object, and because of the finite size of both the particle and object, contact occurs and the particle is captured. collection efficiency by interception depends mainly on geometric considerations such as particle and fiber size and the pore size of the filter. For collection by a single fiber, the larger the particle in a streamiine approaching the fiber the greater the probability of collection by interception. For an entire filter, 
interception can be thought of as collection because particles are simply too large to pass through all the pores or passageways of the filter. For example, if the pore size is $10 \mu \mathrm{m}$, a $5 \mathrm{\mu m}$ particle in passing through several pores is likely to eventually be captured by the incidental meeting of the particle with a filter surface. This mechanism is important only for particles larger than $0.1 \mathrm{\mu m}(6)$.

Diffusion is an important particle capture mechanism only for particles smaller than $0.5 \mathrm{\mu m}(6)$. Additional zigzag movement is imparted to these particles because of Brownian motion. As streamlines carry paricles ncar a collection surface, the random Brownian motion will cause particles to cross streamlines and be collected as they contact a collection surface. The parameter which relates fluid motion to diffusion is the Peclet number:

$$
\mathrm{Pe}=3 \pi \mu \mathrm{D}_{\mathrm{p}} \mathrm{D}_{\mathrm{f}} \mathrm{V} / \mathrm{k} \mathrm{T} \mathrm{C}
$$

where:

$$
\begin{aligned}
& \mu=\text { gas viscosity } \\
& D_{p}=\text { particle diameter } \\
& D_{f}=\text { fiber diameter } \\
& \mathrm{V}=\text { face velocity } \\
& \mathrm{k}=\text { Boltzmann's constant } \\
& \mathrm{T}=\text { absolute temperature } \\
& \mathrm{C}=\text { Cunningham correction factor }
\end{aligned}
$$

Several equations have been proposed which relate the Peclet number to collection efficiency by diffusion (6). In each of these, efficiency is inversely proportional to the Peclet number raised to the $1 / 2$ or $2 / 3$ power, and all show that collection efficiency by diffusion increases with decreasing particle size, face velocity, and collector diameter.

sieving refers to collection when the pore size is smaller than a particle and is therefore important only for larger particles. BY definition, collection by sieving must be $100 \%$ efficient. 
Gravitational settling as a particle collection mechanism in fabric filters is usually assumed to be negligible (3), but for larger particles the gravitational settling velocity may be high enough to be significant. For example, a $20 \mathrm{\mu m}$ particle with a specific gravity of 2 will have a settling velocity in air of about $2 \mathrm{~cm} / \mathrm{s}$ compared to a face velocity of $1 \mathrm{~cm} / \mathrm{s}$ (for the common air-tocloth ratio of $2 \mathrm{ft} / \mathrm{min})$. However, for larger particles collection by impaction is expected to. dominate so gravitational settling is not usually included in efficiency models.

If either the particles or fibers are electrically charged, there is an additional coulombic force to facilitate particle collection. If the particles have been deliberately precharged or if an electric field has been added such as in ESFF it is expected that collection efficiency would increase. Charge effects, however, are not thought to have a major influence on particle collection in conventional fabric filtration (3).

A very extensive modeling effort has been completed by Dennis (5) to predict the collection efficiency of woven glass fabrics when filtering fly ash. Similarly, extensive efforts have been completed by Leith $(4,7)$ to predict penetration with felted fabric and pulse jet cleaning. By combining classical equations for predicting collection efficiency by impaction and interception. Dennis has shown that the expected removal efficiency of a completely clean (i.e. brand new) woven glass fabric for a $1 \mu \mathrm{m}$ particle is only $14 \%$ while for a $5 \mathrm{\mu m}$ particle it would be 97\%. The low initial collection efficiency for the woven fabric is caused by the large pores in the weave. It was found that theoretical predictions of initial (clean fabric) penetration were in good agreement with actual experimental measuremerits.

The clean fabric collection efficiency will apply only for a very short time from the moment filtration begins. As soon as dust begins to collect on the filter fibers, collection efficiency should increase very rapidly because pores become plugged and deposited particles become part of the collection media. At this point, the clean fabric collection efficiency is no longer signiflcant; instead 
the collection efficiency of the dust cake determines the overall filtration efficiency. Again using classical collection efficiency equations, but applied to a dust cake, Dennis (5) showed that for an unflawed dust cake only $10 \mu \mathrm{m}$ thick, collection efficiency for $0.25 \mu \mathrm{m}$ particles would be about $98 \%$, while for $1.0 \mu \mathrm{m}$ and larger particles efficiency would approach 100\%. For a cake thickness of $20 \mu \mathrm{m}$, efficiency for $0.25 \mu \mathrm{m}$ particles increases to $99.95 \%$, and for larger particles it is virtually 100\%. Leith (7) also states that a continuous unflawed dust deposit should, in theory, collect virtually all particles from the gas passing through it. It is apparent that classical theory would predict near $100 \%$ collection efficiency for a uniform but thin dust cake. Such a dust cake would be expected to provide a collection efficiency even higher than aerosol sampling filters since the dust cake porosity is less than that of a sampling filter. However, two assumptions in applying classical theory to a dust cake have been experimentally shown not to be valid $(4,5)$. The first is that the dust cake builds up in a continuous layer without any large pores or fissures. Experimental evidence, however, has shown that large pores or pinholes in the dust layer can develop which pass a large portion of the total amount of dust. The second assumption is that once a particle is captured, it will remain in the dust cake. Experimental results show that a significant amount of dust can be reentrained or seep through the dust cake so that these mechanisms become major factors in determining the overall collection efficiency (7). Attempts have been made to incorporate pinhole or large pore penetration into collection efficiency models which then predict a more reasonable collection efficiency compared to actual measurements $(5,6)$. It is difficult, however, to accurately predict collection efficiency when there is significant penetration via the mechanisms discussed in the next section. 


\subsubsection{Penetration Mechanisms}

There are just two general mechanisms of ash penetration through a fabric filter. The first is direct or straight through penetration, in which suspended particles remain in the gas streamline and pass directly through the filter along with the gas. Direct penetration implies that there must be large enough pores in the dust cake/fabric such that particles can avoid collection via the previously mentioned mechanisms. If the pores are sufficiently large (e.g. 10 times the median particle size), the particle size distribution of the penetration fraction should be approximately the same as the inlet distribution. The second type of penetration is indirect or delayed penetration, in which particles were initially collected, but are somehow reentrained and end up in the gas exiting the clean side of the fabric. Indirect penetration can occur by several submechanisms. One such possibility is when pinhole plugs break loose, which occurs when large pores are initially bridged over, but with increased pressure drop and dust cake buildup, some of them break loose (4). Indirect penetration may also occur if particles are not held rigidly in the dust cake, but gradually seep through the fabric (4). A somewhat similar mode occurs when particles are reentrained from the rear face of the dust cake, which Dennis (5) refers to as rear face slough-off. It should be recognized that indirect penetration may be induced by mechanical vibration or flexing of the fabric. The extreme case of induced penetration occurs after bag cleaning and represents still another type of indirect penetration. With pulse jet cleaning, the shock of the fabric striking the cage after a pulse will most likely cause particles to perietrate the fabric. W1th shaker or reverse gas type cleaning, this effect may also occur when the bags snap back into the inflated position after bag cleaning.

of the penetration mechanisms, it would appear that direct penetration would be the most straightforward to model. Assuming the number and size of pinholes were known, it would be possible to determine the collection efficiency. Although attempts have been 
made to include pinhole penetration in efficiency prediction modeling $(5,7)$, variables such as seepage, pinhole size, and the number of pinholes make accurate prediction difficult. Prediction of penetration by indirect seepage or slough-off is even more difficult because the extent of this type of penetration is as much a property of the dust as it is the fabric. Cooper and Hampl (8) recognize the importance of seepage in penetration prediction, but admit that the variables controlling the rate of seepage are unknown. Penetration is additionally complex because several mechanisms may be occurring at the same time. Leith (4), in experiments in which ash was tagged for identification, distinguished between straight-through, seepage, and pinhole plug penetration. He determined that straight through penetration decreased rapidly with dust cake build up, but seepage and pinhole plug penetration increased. When filtering fly ash from coal combustion, it should be possible to distinguish between direct and indirect penetration by looking at the relative amount of submicron particles present. If penetration is strictly by indirect methods, the proportion of submicron particles should be significantly less than the inlet dust, because these particles should be attached to larger particles. It is not expected that the submicron fume particle mode would be redisbursed as separate particles (5). On the other hand, with straight-through penetration the submicron fume particles would never be collected, and would therefore be present in the outlet dust in the same relative proportion as the inlet dust.

The fact that indirect penetration can dominate as the primary mechanism (at least after forming a dust cake) implies that some particle or dust cake properties must be significant in controlling this mechanism. Whatever property of the dust that describes its ability to resist seepage, reentrainment, and pore plug breaking would appear to be of major significance in any attempt to model penetration by these mechanisms. The dust properties which immediately come to mind are the cohesiveness of the dust cake and the adhesion between the particles and the fabric. In experimental study on the influence of dust properties on particle penetration, 
Donovan et.al. (9) conclude that particle adhesion and cohesion could have major influences on dust cake formation and particle penetration, but these properties were not part of their study. similarly, with high velocity filtration, Leith et.al. (10) discuss the importance of adhesion probability which is related to the kinetic energy of the particle. However, this relates only to fiberparticle adhesion and not to the bulk cohesiveness of the dust cake. Dust cake cohesiveness will be further discussed in section 5.2.

One parameter which almost all studies indicate has a profound effect on penetration is face velocity. classical theory predicts that collection efficiency by impaction will increase with increasing velocity, collection by interception should be unchanged and collection efficiency by diffusion will decrease. Diffusion is important only for particles smaller than $0.5 \mu \mathrm{m}$; therefore, for most dusts classical theory would indicate an increase in collection efficiency with increasing face velocity (assuming no pinholes and no reentrainment). However, studies which have included face velocity as a test parameter show that penetration increases significantly with increases in face velocity. This again demonstrates the significance of indirect penetration and the importance of the dust properties which control it. It follows that increasing the face velocity will increase the stress on deposited particles; subsequently, if reentrainment is a dominant mechanism, increased particle penetration is expected with increased velocity.

one further aspect of particle penetration will be discussed here, relating to the question of whether the filtration process significantly fractionates the particle size distribution compared to the inlet distribution. Theory predicts, as shown by Lee and Liu (11), that for fibrous fliters there is a definite minimum fractional collection efficiency for particle sizes between 0.1 and $1.0 \mu m$, but the exact location of the minimum is dependent on the velocity. However, this theory is for fibrous filters and would apply to fabric filtration only during initial dust deposition and only for direct penetration. If there are differences in fractional efficiency, there will be a shift in the particle size distribution toward the 
most penetrating size. The extent of fractionation, however, in fabric filtration appears to show a complex dependence on the penetration mechanism. Many studies show that penetration increases with decreasing particle size as predicted by classical theory, while others seem to indicate no significant fractionating effect (9).

\subsubsection{Inadequacy of Existing Penetration Models}

It follows from the preceding section that seepage or indirect penetration is one of the most lmpullant mechanicms of dust penetration. However, there are no known models which relate seepage to a measurable dust parameter, such as cohesiveness. Furthermore, the characteristic cohesiveness of a dust is likely to be dependent on other dust characteristics, such as chemical composition and electrostatic effects. It is very clear, then, that further modeling attempts must focus more on dust characteristics, such as cohesiveness, which are likely to be highly dependent on the specific dust. Cohesiveness will have a major effect on penetration by all of the mentioned mechanisms except for initial direct penetration with a new fabric. For example, the cohesiveness of the dust will obviously affect the ablitty of the dust to bridge over large pores and will also determine the extent of these pore or pinhole plugs breaking loose. Therefore, dust cohesiveness is a major parameter in predicting penetration via pinholes. Seepage or indirect penetration implies that particles break louse after being captured. Again, the cohesiveriess of the dust is an important measure of the ability of the dust to resist this reentrainment. Therefore, d better understanding of $f y$ ash cohesiveness characteristics would lead to a much better predictive model for penetration. Also, if one is interested in optimizing fabric filtration for improved collection efficiency of fine particulate matter, a much better understanding of the relationship between dust cohesiveness and penetration is needed.

A second major deficiency of existing penetration models is that no contribution is included for electrical effects. In Donovan's recent comprehensive review of fabric filtration (6), some of the

$$
5-10
$$


ways that electrical forces may affect the filtration process are given, but he states that this is a missing element in all general fabric filtration models. One of the methods to optimize fabric filtration would be to capitalize on electrical effects to reduce penetration. Further details on possible electrical effects which may occur in conventional fabric filtration are given in section 5.2. Electrical effects may be important both in particle capture and in the dust cake structure, but electrical characteristics are also likely to be very dependent on the specific dust. Again, this demonstrates the importance of focusing modeling efforts on dust characteristics.

\subsubsection{References}

1. Davies, C.N. Aerosol Science, Academic Press, London and New York, pp. 195-271, 1966 .

2. Fisher Scientific catalog, 1986.

3. Billings, C.E. and J. Wilder. Handbook of Fabric Eilter Technology, Volume $I$, Fabric Filter systems study. GCA Corporation, NTIS PB 200-648, December 1970 .

4. Leith, D., S.N. Rudnick, and M.W. First. High-Velocity, High Efficiency Aerosol Filtration. EPA-600/2-76-020, January 1976.

5. Dennis, R., et al. Filtration Model for Coal Fly Ash With Glass Fabrics. EPA-600/7-77-084, August 1977 .

6. Donovan, R.P. Fabric Filtration For Combustion Sources. Marcel Dekker, Inc., New York, 1985.

7. Lejth, D. and M.J. Ellenbecker. Theory for Penetration in A Pulse Jet Cleaned Fabric Filter. Journal of the Air Pollution Control Association. Vol. 30, No. 8, pp. 877-881, 1980 .

8. Cooper, D.W. and V. Hampl. Fabric Filtration Performance Model. Conference on Particulate collection Problems in Converting to Low Sulfur Coals, EPA-600/7-76-016, October 1976 .

9. Donovan, R.P., B.E. Daniel, and J.H. Turner. EPA Fabric Filtration studies: 6. Influence of Dust Properties on Particle Penetration. EPA-600/7-78-141, JulY 1978 . 
10. Leith, D., M.J. Ellenbecker, M.W. First, J.M. Price, A. Martin, and D.G.Gobson. Performance of a High Velocity Pulse Jet Eilter, II. EPA-600/7-80-042, March 1980 .

11. Lee, K.W. and B.Y.H. Liu. On the Minimum Efficiency and the Most Penetrating Particle Size for Fibrous Filters. Journal of the Air Pollution Control Association, Vol.30, No.4, 1980 . 


\subsection{Ash Characteristics Affecting Collectibility}

It is the intent of this section to review some of the basic particle or ash characteristics which affect the efficiency at which particles will be collected in a fabric filter. The focus will be on the primary particle characteristics which are thought to control ash-dependent collection and penetration mechanisms. It is further intended that this section will provide a basis for explaining the mechanisms of improvement of fine particle collection with flue gas conditioning, which is presented in section 5.5.

The important particle characteristics such as size, adhesive/cohesive nature, electrical nature, and chemical composition have already been mentioned, but will be further explored in this section. There are other characteristics, such as density, morphology, surface area, and hydrophilic nature, which are relatively less important and will not be emphasized. It is recognized that most of these characteristics are not completely independent. For example, ash cohesiveness will likely be dependent on chemical composition, particle size, and perhaps on electrical effects. Electrical resistivity is dependent on chemical composition, while the maximum charge a particle may carry depends on particle size. Particle size will depend on the degree of coagulation and agglomeration prior to collection, which is related to the cohesive nature and chemical composition of the ash. If one particle characteristic is altered by some external means, it is expected that other properties will also be affected. Therefore, caution must be used in trying to establish cause and effect relationships between collectibility and specific characteristics.

\subsubsection{Particle Size Distribution}

The effect of particle size on collection efficiency can be confusing to understand because of the non steady state conditions which are usually present during each filtration cycle. Also, as mentioned in section 5.1, there may be several penetration mechanisms 
occurring simultaneously, each with different size dependence. According to theory, there is some collection efficiency dependence on particle size, but the question is, whether or not it is significant.

There are two particle size effects which should be considered separately. The first effect is for a given dust with a given particle size distribution, where a minimum collection efficiency may exist for 0.1 to $1 \mathrm{\mu m}$ particles. As previously mentioned, this is predicted by classical theory for direct penetration through fibrous Filters, and has been shown to be true for a fill-scale baghouse (refer lu Flyure 4-9). For a full-scale baghouse, direct penetration is most important just after bag cleaning when there is the lightegt residual dust cake and the most open pores. In this case size dependent penetration can be significant. There is no classical theory which predicts size dependence for reentrained ash, but in general, reentrained ash would not display the same particle size dependence that occurs in direct penetration. On the contrary, the very smallest particles (less than $1 \mathrm{\mu m}$ ) are not expected to be separately reentrained, and therefore would show the opposite sizedependent penetration to that which occurs in direct penetration.

A secona effect of particle size on penetration is that which occurs because of different inlet particle size distributions. For example, comparing the predicted penetration of an ash with a $10 \mu \mathrm{m}$ mass median diameter (MMD) to an ash with a $5 \mu m$ MMD, where hoth ashes have the same geometric standard deviation and inlet concentration, according to classical collection theory, the finer ash will have the highest fine particlc cmisgions, welduse 1 t has more particle mass in the size range of lowest collection efficiency $(0.1$ to $1 \mathrm{~mm})$. Huwever, other dust characteristics that affect penetration may change along with particle size. Therefore, the net effect of inlet particle size distribution on penetration cannot be arrurately predicted. One dust characteristic which has been reported to increase with a decrease in particle size is the dust cohesiveness (1). If this occurs, the overall net effect could be decreased penetration rather than the increase which would be 
predicted by classical theory. Donovan $(2,3)$ also reports that the particle size dependence of penetration is complex, and is affected not only by the penetration mechanism and bag cleaning method, but also by the time into the filtration cycle.

\subsubsection{Fly Ash Chemical Composition}

At one time, fabric filter collection efficiency was thought to be largely independent of the chemical composition of the dust being collected. Therefore, the most extensive published research in fabric filtration has concentrated on baghouse related parameters such as pressure drop, fabric type, cleaning mode, cleaning cycle, and air-to-cloth ratio. Little research has been reported relating coal or ash properties to fabric filter performance. Although for many fly ashes baghouse parameters may be the most significant factors, results reported by UNDERC and SoRI have shown that ash properties can also be important $(4,5,6)$. In particular, pilot scale tests at UNDERC. showed that several Texas lignites, a North Dakota lignite and a western subbituminous coal were difficult to collect in a baghouse. In addition, ash penetration as high as 4 to $5 \%$ at the Monticello Power Plant, when burning a wilcox formation Texas lignite, has been reported ( 7 ). It is clear that not only baghouse related parameters, but also coal and ash-specific characteristics are important in fabric filtration. This raises the question, "What are the characteristics of the ash that result in poor baghouse performance?"

As discussed in the previous section, particle size distribution is one property that may affect collectibility and certainly has an effect on pressure arop. The electrical properties and the cohesiveness of the fly ash have also been shown to affect fabric filtration performance $(8,9)$. Both of these properties, as they are related to the chemical composition of the fly ash, will be discussed in more detail in sections 5.2 .3 and 5.2 .4 of this report. 
Tests at UNDERC related penetration to the sodium, magnesium and phosphorus content of the ash $(4,5)$. It was found that ashes with higher concentrations of these elements resulted in lower penetration. The strongest correlation between elemental concentration and penetration was for sodium. The other two elements did not show as strong a correlation individually but provided a synergistic relationship with sodium. The effects of sodium may be related to ash cohesiveness and particle morphology. Sodium is known to play an impnrtant role in ash fouling of pc-fired coal combustors and agglomeration in fluidized bed combustion. Although these are high temperature phenomena, sodium may also cause an increase in particle agglomeration in the flue gas stream by producing a more cohesive dust cake (5). Using a scanning electron microscope it was found that low sodium fly ash particles were smoother, more spherical and had fewer smaller particles attached to larger particles than did fly ashes that were higher in sodium (5). Smoother particles may more easily bleed or seep through the fabric, increasing penetration.

In a report by Carr and Smith (10), data correlating baghouse performance with chemical composition was presented. They looked at the thickness of the residual dust cake vs the concentration of different chemical components and reported that higher cuncentrations of sodium in the ash correlated with lighter residual dust cake. This would seem to be the opposite of what was reported by UNDERC; that increased sodium concentration correlated with higher ash cohesiveness. It would be expected that a greater sodium concentration in the ash would result in a hcavier residual dust cake. The data presented by Carr and Smith, however, were taken from different plants, with quite low sodium concentrations in the ash, with each operating at somewhat different conditions. The cleaning cycles, cleaning mode, and air-to-cloth ratios were not the same for all plants, making interpretation of the results difficult. Most of the UNDERC data resulted from testing with western coals, with tests completed using the same baghouse operating at the same conditions. 
There may also be differences between the behavior of ashes produced from eastern and western coals in a baghouse. The sulfur content of the ash (as $\mathrm{SO}_{3}$ and $\mathrm{SO}_{4}$ ) may play an important role. Smith and Carr reported that sulfur correlated directly with increased residual dust cake weight. Although UNDERC data showed no correlation of penetration with sulfur for lignites, and subbituminous coals, this could be due to western coals having a much higher alkali concentration and lower sulfur content than eastern coals.

If chemical composition is an important parameter affecting fabric filtration performance, this suggests that modification of the fly ash chemistry could result in improved performance. This was demonstrated at the Monticello power station and at UNDERC where injection of either ammonia or ammonia and $\mathrm{So}_{3}$, resulted in significant improvements in fabric filter performance $(6,11,12)$. Results of conditioning tests at UNDERC are presented in section 5.5 of this report.

Chemical composition may be a property that could be used to optimize fabric filtration performance. Those fly ashes that have chemical compositions that may result in high penetration may require special care in baghouse design. Careful selection of fabric and conservative air-to-cloth ratios $(<2 \mathrm{ft} / \mathrm{min})$ may be necessary. On the other hand, ashes which have a chemical composition that suggests they may be easy to collect could be candidates for high air-tocloth ratio ( $>3 \mathrm{ft} / \mathrm{min}$ ) operation. Chemical composition of the dust and its relationship to fabric filtration performance has not been an area of active research, but it is now clear that composition effects must be included before a basic understanding of fabric filtration performance can be obtained. 


\subsubsection{Cohesiveness}

Forces between solids are predominantly attractive in nature and cause adhesion of particles to each other and to surfaces. These forces become increasingly significant for fine particles since the particle mass varies to the third power of the particle diameter. Terminology regarding this subject is somewhat confusing. For this report cohesion is considered the result of various forces that hold one particle to another, and adhesion forces are those resulting in the attachment of a particle to a substrate, such as a plate or fiber. The terms cohesiveness and cohesivity refer to characteristics of a bulk powder. Cohesion is an important parameter affecting both particles entrained in the flue gas stream and the formation of the dust cake.

Two major forces that play a role in particle cohesion are van der Waals and electrostatic forces. Although these forces are usually referred to as long-range attractive forces, for particle sizes greater than 2 to 3 molecular diameters (which is true for all dusts important in fabric filtration), van der waals forces can be thought of as a surface phenomena. Electrostatic forces, on the other hand, produce an effect not only at the solid-solid interface, but also have significant effects outside the interface, even for larger particles.

Van der Waals forces arise from electrons in the molecules at the surface of a particle, being in constant motion and since they are not symmetrically distributed at any instant, they acquire a temporary net charge. At each moment, an attractive force exists between the induced and inducing dipoles of adjacent molecules, resulting in molecular attraction. The strength of the van der Waals force varies directly with the magnitude of the net charge and indirectly with the sixth power of the distance separating the molecules (13). Therefore, the magnitude of this force decreases rapidly as the distance between the molecules increases and is only effective within several molecular diameters. 
Electrostatic forces, unlike van der waals forces, which can only arise from the random motion of electrons in the surface molecules, result if the particles have been in contact with an ionic solid or if electrons are transferred between surfaces of particles by contact charging. When a net charge exists on the particle or substrate, attraction between opposite charges results. Electrostatic interactions, particle-particle or particle-substrate, can occur either through contact-potential or coulombic forces $(14,15)$.

The effect of interparticle electrostatic attraction on particle flow properties cannot yet be predicted from either a theoretical or an empirical standpoint, as the mechanisms of charge acquisition are not very well understood. The whole phenomenon is strongly dependent on the nature of the particle surface and previous history (15). Particle-particle attraction by electrostatic forces may greatly exceed van der Waals forces, especially in the case of particles with a high degree of surface asperities (16). Short-range attractive interactions are the result of molecular bonding due to chemical reactions as well as from intermediate bonds such as hydrogen bonds. Chemical reactions can form a solid bridge between particles thereby linking them together. Although these short-range interactions do not play a major role in the formation of a dust cake, they may occur during coal combustion when fly ash particles are first forming. At this point, two fly ash particles may well bond together through chemical reactions.

A third type of bonding that can occur between particles is the result of sintering effects, diffusive mixing, mutual dissolution and alloying at the surface interface. These bonds only result from high temperature processes such as that which occurs during coal combustion and metallurgical operations. In coal combustion, these interactions are important only during the initial stages of $f(y$ ash particle formation and may play a role in particle agglomeration. Once the particle has reached the collection device, the temperature is such that these interactions are negligible. Therefore, very little modeling has been done to explain the mechanisms and effects of these interactions on cohesion (16). 
Cohesion can be thought of as a three step process.

1. The particles come in contact with each other at one point by a contact area of atomic dimensions.

2. For non-smooth particles, long-range attractive forces between the two particles subject them to a moment of forces so that several contacts are formed at surface asperities.

3. By the interaction of forces, the contact area increases until the attractive forces and forces resisting the further deformation at the interface are in equilibrium. At this point, a cohesive area of finite size is formed between the two particles.

An important factor determining the cohesive strength is the degree of surface asperities or irregularities. The effect of surface irregularities on cohesion has not adequately been explained. Corn (17) states that surface asperities decrease the area of contact, thereby decreasing the adhesion of the particles to a substrate. This work was done using very 1 ight deformation loads. In the work by sutton (13), surface irregularities were shown to increase particle cohesion because at the point of contact tremendous pressures can be generated over very tiny areas. Cohesion then is directly related to the magnitude of the forces causing deformation. In addition, interlocking at the irregularities can take place, which increases cohesion of particles.

The magnitude of electrostatic forres is also directly related to the number of surface asperities. In particular, with insulating particles, surface asperities may result in pronourced electrostatic effects on cohesion (16). In general, the number of points of contact per unit volume increases as the radius of curvature of the particles decreases. Therefore, for insulating materials, not only will very rough particles form strong bonds, but so will very small particles.

Although substantial research has been done on various aspects of the cohesive and adhesive nature of particles, there is no current physical model relating cohesive strength to established fields of physics (16). The difficulty is the result of two major factors. 
First, the measurable cohesive and adhesive strength between two solid bodies is the result of very complex chemical and non-chemical bond formations, as well as a complex field of mechanical strains and stresses at and around the interface between the bodies. Secondiy, cohesive forces can only be measured in a destructive manner: therefore, these measurements do not represent an equilibrium situation. Thus, a kinetic model of cohesion is required. To minimize these difficulties, very simple geometric models are used, which many times do not accurately describe actual situations.

In a coal combustion system, individual fly ash particles are initially formed, but almost immediately the very small particles agglomerate. Diffusion is the primary mechanism by which these particles come in contact with each other, with cohesive forces then holding them together. The degree of agglomeration depends on the chemical and morphological characteristics of the fly ash as well as the size distribution of the coal. The greatest degree of agglomeration usually occurs for particles that are less than $0.1 \mu \mathrm{m}$ in diameter, because for these ultra fine particles van der wals forces are very strong. For almost all particulate control systems, the degree of agglomeration has a direct influence on the performance of the collection device. The particle size distribution at the inlet of the collection device, which is partially dependent on the extent of agglomeration, has a substantial effect on collection efficiency. For example, acoustic agglomerators improve particulate collection efficiency of a cyclone by increasing particle agglomeration. By generating an intense sound wave, the motion of the particles is increased, thereby increasing the number of collisions.

of primary concern in fabric filters are the dust cake characteristics. Since the energy required to pull flue gas through the dust cake is an important parameter determining the operating cost of a fabric filter, a basic understanding of dust cake formation is very important in optimizing fabric filter performance. Two parameters that have an impact on fabric filter performance and are closely related to the cohesive characteristics of the fly ash 
particles are dust cake porosity and thickness of the residual dust cake. It is known that $f l y$ ashes have a tendency to form dendrites when deposited on a filter medium (18). When these dendrites grow, they form arch-like structures that have considerable mechanical stability, and at the same time are very porous. The extent of dendritic growth depends on the cohesiveness of the ash being collected, since low cohesiveness would result in collapse of the dendritic structure. Forces due to flowing flue gas and particle deposition tend to compact the dust cake. The degree to which compaction occurs is partlally dependent on the cohesiveness of the particles. The more cohesive the parlicles, the lcoe compartinn nf. the dust cake will take place, again resulting in the formation of a more porous dust cake (1). Therefore, particle cohesiveness has a direct influence upon dust cake porosity, which in turn has a majur effect on operational pressure drop (11).

Particle cohesion is also an important parameter in determining the thickness of the residual dust cake after multiple cleaning cycles. However, the relationship is complex and is dependent not only on the cohesiveness of the particles but also on particle size, porosity, cleaning mechanism and operating mode.

To control the operational pressure drop in a fabric filter, the bags are periodically cleaned. The effectiveness of the cleaning is very dependent on the cohesion and adhesion of the particles. Initially when particles are deposited, they collect on the fabric fibers. It is important that the particles bridge over fabric pores and form a filtering matrix (19). After the initial layer has been established, particles begin to adhere to each other, the extent of which, is dependent un lie cohesion forces of the narticles and external drag forces caused by the Eluwilig flue gas.

once the pressure drop across the dust cake exceeds some desired level, the bags are cleaned. If the dust cake is very cohesive, then a more vigorous or more frequent clcaning is necessary to remove it, resulting in decreased bag life. In a study by Baker and Holcomb (9), a correlation was made between ash cohesiveness ailu pressure drop. They reported that, for several Australian coals, fly ashes 
that produced the highest pressure drop were also the most cohesive. However, a more cohesive dust cake may also be beneficial if it is also more porous, because this will result in less frequent cleaning. In addition, when cleaned, the dust cake may be released as large agglomerates helping to reduce dust reentrainment. An ideal situation would occur if the porosity of the dust cake was such that, before the pressure drop reached undesirable levels, the dust cake sheared off under its own weight. In this case, further mecharical cleaning of the bags would not be necessary.

It is obvious that cohesion of the particles forming the dust cake is an important parameter that must be measured to have a real understanding of dust cake formation and structure. The difficulty is that cohesion and adhesion forces can only be measured by determining some mechanical properties of the bulk powder that give an indication as to these forces, for example, shear and tensile properties. All of the devices that have been developed, therefore, lack a theoretical basis that links a measurable parameter to individual particle cohesion. Although some of the measured parameters of bulk powders have been given names similar to basic particle properties, for example, cohesiveness is a bulk property used to describe particle cohesion, a model that links these bulk parameters to basic particle properties has not been established (1).

Several methods for measuring cohesive behavior of bulk powders have been developed. The most important are:

1. Tensile strength measurements.

2. Measuring the minimum diameter of an opening which a powder is capable of passing through without application of external forces.

3. Dispersion of the particles on impact after a fall from a given height.

4. Dispersion by an air jet.

5. Measurement of shear strength either by rotation or by using an inclined plane. 
The most common devices used to measure bulk powder properties are shear devices. These devices have undergone some modification, but the difficulty with reproducibility remains. There is a strong dependence on the sample preparation procedure, making the operator an important factor in the system.

An example of a device used to measure tensile strength is a tensile tester developed by warren springs Laboratories and described in an article by Ashton et.al. (20). This instrument is also very dependent on sample preparation to obtain good results.

A different type nf shear device, developed by uNDERC to evaluate fly ash cohesiveness, measures the breaking strength of a fly ash pellet formed in a mold using a high pressure prese (21). A force is exerted on the center of the pellet, which is supported at its edges. The force necessary to break the pellet is then measured. The breaking force can be correlated with the cohesiveness of the ash. Although the same pressure is applied in forming each pellet, it is very important that the thickness of the pellet be the same each time. This does make the method somewhat operator dependent, but with a little practice good reproducibility can be obtained.

Recently, work has been conducted at sorI to develop a reproducible measurement of culiesivcness, ning an annular ring shear device. This method, described by Pohl (1), is not as affected by sample preparation procedures as other measurement techniques. This device was used to evaluate the cohesiveness of several different fly ashes and is capable of operating at temperatures up to $400^{\circ} \mathrm{F}$ under different gas environments. Cohesiveness of the bulk fly ash is quantified by what is refered to as the internal angle of friction. The reported range of measurements was from $30^{\circ}$ for non-cohesive materials to around $50^{\circ}$ for highly cohesive materials. Using this instrument, it was determined that there is a wide variability in cohesiveness between different fly ashes. For example, a fly ash produced from a Texas lignite was determined to be very non-cohesive which may help to explain why this ash was difficult to collect in a baghouse. Its non-cohesive nature could allow sigrificant seepage or ash bleed-through, resulting in high penetration. 
In addition, the porosity of several residual dust cakes was compared with the effective angle of internal friction. Results showed there was a direct relationship between porosity and the effective angle of internal friction. This correlation is shown in Figure 5-1.

A basic understanding of particle cohesion and adhesion is essential to the development of a dust cake formation model that accurately explains variations in performance of a baghouse for different dusts. Although a good theoretical understanding currently does not exist, cohesive forces can be described in terms of measurable bulk powder characteristics. From these measurements, empirical correlations have been made that may help to optimize baghouse design. Nevertheless, an important research need in optimizing fine particle capture with a fabric filter is to understand the relationships among ash cohesiveness, dust cake structure, and penetration mechanisms.

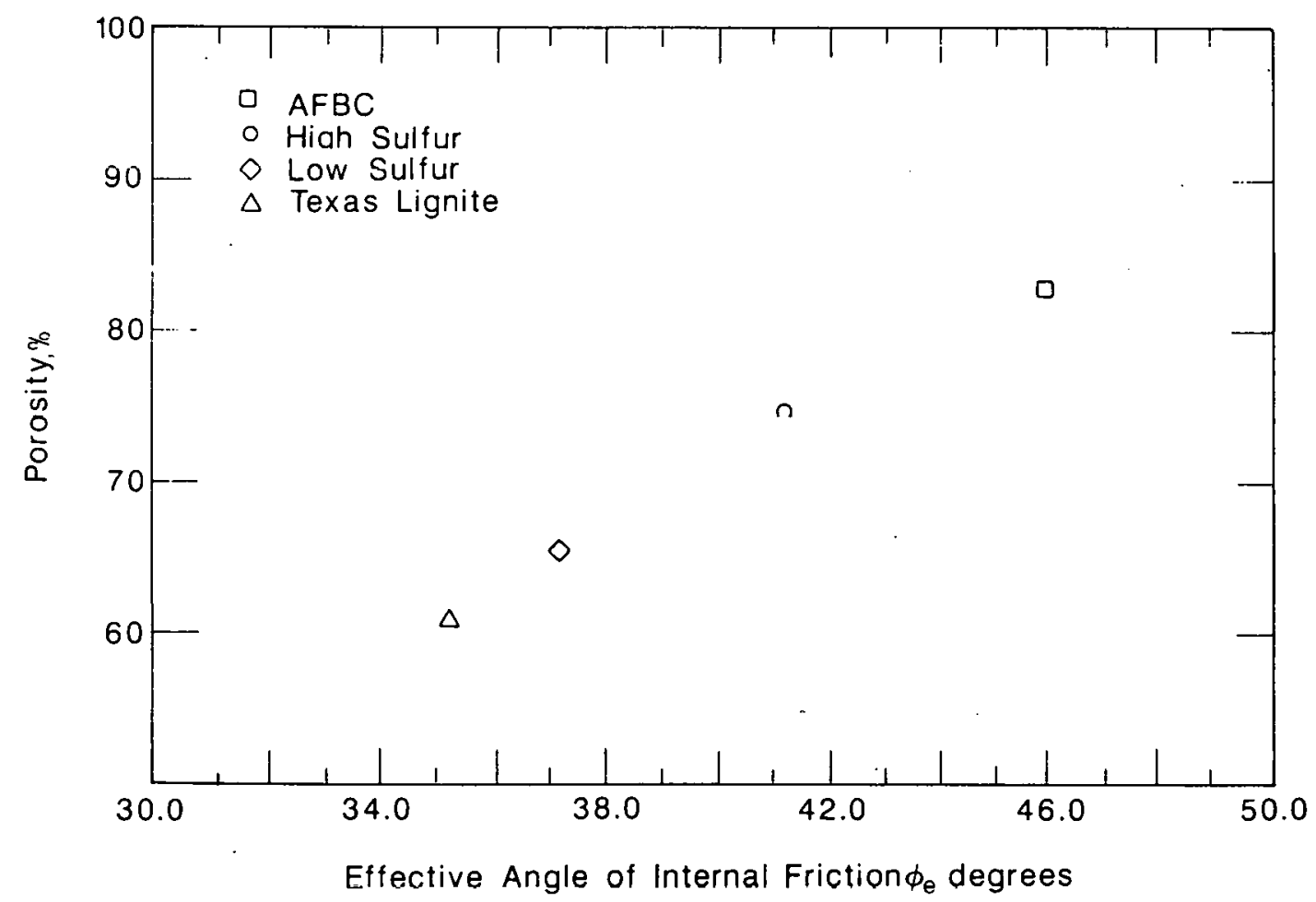

Figure 5-1. Dust cake porosity as a function of the effective angle of Internal friction (Ref. 1). 


\subsubsection{Electrical Characteristics}

It was reported as early as 1961 by Frederick (22) that electrical effects in conventional fabric filtration can have important influences on collection efficiency, pressure drop, and fabric cleanability: In a later report he also stressed the importance of electrical effects on the tendency of dusts to agglomerate and to form a porous dust cake (23). Little research has been done to further investigate the important effects that were noted by Frederisk.

It has been well documented that electrical charge on an aerosol will enhance collection efficiency with a fibrous or fabric filter $(19,24,25,26)$. With charged particles, there is an additional force which will drive particles toward a collection surface, thereby increasing collection efficiency. If both the particles and collector are charged, there is a simple coulombic force, but if only the particles or collector are charged, there is still a polarization force to improve collection efficiency. This polarization force may be the force between a charged aerosol particle and its image force in a collector (24), or it may be a result of the dielectrophoresis effect (27). This effect results in a net attractive force raused by a nonuniform electric field polarizing a neutral particle. The polarized charge on one side of the particle will be in a stronger electric field than the equal but opposite polarized charge on the other side of the particle. The net result is always a force on the neutral particle toward the region of higher field strength regardless of field direction (27).' According to Donovan (27), with parameters typical of fabric filtration, coulomb forces are most significant, followed by dielectrophoretic forces, with image forces being the least significant. However, Lundgren (24) states that image forces can be the primary mechanism responsible for removal of charged aerosols by a fibrous tilter. Although several mechanisms contribute, the net effect is enhanced collection when particles are charged. Therefore, it would appear desirable to have the particles precharged before collection. Although all natural or artificially 
generated aerosols are to some extent electrically charged (25), the charge is usually small compared to the maximum charge level the particles may carry. A method of enhancing collection, then, would be to artificially charge the particles such as with a corona precharger located upstream of the baghouse. This method has been successfully tested, as was reported in section 4 . It also has the advantage that with precharged particles, a more porous dust cake is formed, resulting in reduced pressure drop.

With conventional fabric filtration, the degree to which charge contributes to particle collection depends on the natural level of charge present. Little work has been done to measure the aerosol charge distribution as a function of particle size for coal combustion aerosols. Carr and Smith (10) reported measurement of total net particle charge per unit mass for several coal fly ashes. It was reported that ash from the Monticello station had a much higher negative net charge than other measured ashes. However, the Monticello ash has proven to be a difficult-to-collect ash which is opposite of the expected effect. This brings up the possibility that there might be other electrical effects which inhibit high collection efficiency. It cannot be disputed that, if particles are precharged, there is an additional force to facilitate particle collection, but there might also be some electrical effects within the dust cake that contribute to poor collection efficiency. It was previously stated in section 5.1 that one of the main penetration mechanisms is seepage or indirect penetration due to particle reentrainment. A possible mechanism, then, with precharged particles is for net penetration to increase because of increased seepage, even though the charged particles may have been initially collected with improved efficiency. For example, if charged particles caused a dust cake to be less cohesive, this could result in increased seepage and an overall net increase in penetration as compared to neutral particles.

There are additional electrical effects within the dust cake which may influence fabric filter performance. Frederick (23) states that electrical resistivity of the dust is important, because it determincs the rate of charge dissipation. Penney (26) gives a 
resistivity limit on the order of $10^{14} \mathrm{ohm-cm}$, above which the dust cannot carry away the charge on the arriving particles. If this occurs, there would be charge build-up in the dust cake which could have a detrimental effect on the dust cake structure and on collection efficiency. Frederick (22,23) also states that the triboelectric characteristics of both the dust and the fabric are important, and that to get optimum performance, there must be an electrostatic "balance" between the dust and fabric. He also suggests the use of the following test to determine the agglomeration tendency of a dust. A dust sample is pur 1 inlu a buttle and then rolled for a specified period of time, after which it is inspected lu determine the relative amount of agglomeration. He found, in general, that dusts which did not agglomerate in this test were more difficult to collect. The tendency to agglomerate was not correlated with any basic particle or dust parameter, but it was attributed to electrostatic effects. Frederick's experiments were conducted primarily with dusts other than fly ash. Although his tests were somewhat qualitative in nature, they show the importance of electrical effects within the dust cake and the electrical interaction between the dust cake and fabric.

Electrical characteristics of the ash, then, which appear to affect collectibility in fabric filters, include particle charge, dust resistivity, and its triboelectric nature. The most extensively researched of these parameters is particle charge. Other than the work of Frederick $(22,23)$ and Penney (26), little work appears to have heen done concerning the importance of electrical resistivity and the triboelectric nature of dusts. If one is interested in enhancing the collection efficiency of a fibrous filter, controlling particle charge with precharging is a logical option. With fabric filtration, however, enhancing collection efficiency with precharging or by applying an external electric field may not be necessary. It was stated in section 5.1 that only a very thin continuous dust cake is needed to attain near $100 \%$ collection efficiency, assuming no reentrainment. If the electrical characteristics of the dust cake could be controlled, along with other important parameters such as 
cohesiveness, it might be possible to attain just the right conditions to achieve near 100\% theoretical collection efficiency. Unfortunately, it is not well known what the ideal cohesiveness and electrical characteristics should be. For example, it is important to know if there is charge build-up in the dust cake for ashes which are most difficult to collect. The Monticello ash has a reported electrical resistivity (10) of $2 \times 10^{12} \mathrm{ohm}-\mathrm{cm}$, which is considered to be a high resistivity fly ash. However, this is lower than the $10^{14}$ value stated by Penney for which charge dissipation could be a problem. The ashes which were difficult to collect in the tests at UNDERC were also high resistivity, but it is not known if there was any charge build-up in the dust cake or if the high resistivity contributed to poor collection efficiency. There is also the possibility that high resistivity, in combination with a specific chemical composition or low cohesiveness, makes some ashes difficult to collect. A key research need is to understand how electrical effects in dusts influence collection efficiency, and to learn how to control these effects to optimize fabric filter performance.

\subsubsection{References}

1. Pohl, F.G. A Novel Ring Shear Device for the Purpose of Classification of Fine Powders. Presented at: The 17 th Annual Meeting of the Fine Particle society, San Francisco, CA, July 1986.

2. Donovan, R.P., B.E. Daniel, and J.H. Turner. EPA Fabric Filtration studies: 6. Influence of Dust properties on Particle Penetration. EPA-600/7-78-141, July 1978.

3. Donovar, R.P. Fabric Filtration For Combustion Sources. Marcel Dekker, Inc., New York, pp. 149-261, 1985.

4. Sears, D.R. and S.J. Miller. Impact of FlY Ash Composition Upon Shaker Baghouse Efficiency. Presented at: 77th Annual Meeting of the Air Pollution Control Association, Paper 84-56.6, San Francisco, CA, June 1984 . 
5. Miller, S.J. and D.R. Sears. The Influence of Coal-Specific Fly Ash Properties Upon Baghouse Performance: A Comparison of Two Extreme Examples. Proceedings: Fifth Symposium on the Transfer and Utilization of Particulate Control Technology, Kansas City, Mo, Vol. 3, pp. 22-1 to 21, February 1986.

6. Felix, L.G., R.L. Merritt and K. Durican. Improving Baghouse Performance at the Monticello Generating Station. Journal of the Air Pollution Control Association, Vol. 36, No. 9, pp. 10751085, September 1986.

7. Fabric Filter Newsletter, McIlvane Co., 91:3, May 10, 1983.

8. Ohambers, R., J.J Spivey, and D. Harmon. EsFr Pilot Plant Operation at Harrington Station. Proceedings: Fifth Symposium on the Transfer and Utilization of Particulate Control Technology, Kansas City, MO, Vol. 3, pp. 25-1 to 17, February 1986.

9. Baker, J.W. and D. Holcombe. Measurement of the Yield Strength of Fly Ash to Predict Difficulties in Cleaning Power station Fabric Filters. Proceedings: The Seventh Clean Air Congress, Sydney, Australia, pp. 245-252, August 1986.

10. Carr, R.C. and W.B.Smith. Fabric Filter Technology for Utility Coal-Fired Power Plants, Part III: Performance of Full-scale Utility Baghouses, Journal of the Air Pollution Control Association, Vol. 31, No. 3, pp. 281-293, March 1984.

11. Laudal, D.L. and S.J. Miller. Flue Gas Conditioning for Improved Baghouse Performance. Proceedings: Sixth symposium on the Transfer and Utilization of Particulate Control Technology, New Orleans, LA, Vol. 3, pp. 14-1 to 16, February 1986.

12. Miller, S.J. and D.I. Laudal. Particulate Removal Enhancement of a Fabric Filter Using Flue Gas Conditioning. Preserted at: Third EPRI Conference on Fabric Filter Technology for Coal-Fired Power Plants. Scottsdale, AZ, November 1985.

13. Sutton, H.M. Flow Properties of Powders and the Role of Surface Character. Characterization of Powder Surfaces. Edited by G.D. Parfitt and K.S.W. Sing, Academic Press, New York, NY, pp. 107$1.58,1976$.

14. Ranade, M.B. Particle Adhesion and Removal. Short Cou'se Notes, International Symposium-Workshop on Particulate and Multi-Phase Processes and 16th Annual Meeting of the Fine Particle Society. Miami Beach, FL, April 1985 .

15. Penney, G.W. Adhesive Behavior of Dust in Electrostatic Precipitation. Journal of the Air Pollution Control Association, Vol. 25, No. 2, pp. 113-117, February 1975. 
16. Krupp, H. Particle Adhesion. Advances in Colloid and Interface Science. Vol. 1, pp 111-239, 1967 .

17. Corn, M. Adhesion of Particles. Aerosol Science. Edited by C.N. Davies, Academic Press, New York, NY, pp. 359-391, 1966.

18. Ensor, D.S. and M.E. Mullins. The Fractal Nature of Dendrites Formed by the collection of particles on Fibers. Research Triangle Institute, Research Triangle Park, NC, 1986.

19. Davies, C.N. Air Filtration. Academic Press, New York, NY, 1973 .

20. Ashton, M.D., R. Farley, and F.H.H. Valentin. An Improved Apparatus for Measuring the Tensile Strength of Powders. Journal of Scientific Instruments, No. 41, p. 763,1964 .

21. Miller, S.J. Particulate Characterization. Low-Rank Coal Research Under DOE Cooperative Agreement. Quarterly Technical Progress Report, DOE/FE/60181-1682, University of North Dakota Energy Research Center, Grand Forks, ND, p. 1-1, November 1984.

22. Frederick, E.R. How Dust Filter selection Depends on Electrostatics. Chemical Engineering, June 26, 1961.

23. Frederick, E.R. Electrostatic Effects in Fabric Filtration: Volume II, Triboelectric Measurements and Bag Performance (Annotated Data). EPA-600/7-78-142b, PB 287207, July 1978 .

24. Lundgren, D.A. and K.T. Witby. Effect of Particle Electrostatic Charge of Filtration BY Fibrous Filters, I\&EC Process Design and Development. Vol. 4, No. 4, October 1965.

25. Witby, K.T. and B.Y.H. Liu. The Electrical Behavior of Aerosols. Aerosol Science. Edited by C.N. Davis, Academic Press, London and New York, pp. 59-86, 1966.

26. Penney, G.W. Electrostatic Effects in Fabric Filtration: Volume I, Fields, Fabrics, and Particles (Annotated Data), EPA-600/778-142a, PB 288576, September 1978 .

27. Donovan, R.P. Eabric Filtration for Combustion Sources, Marcel Dekker, New York, pp. 287-396, 1985. 


\subsection{Dust Cake Properties Affecting Pressure Drop}

The pressure loss across a fabric filter is the result of viscous flow through a porous medium. The magnitude of the pressure drop is dependent on gas properties such as viscosity and velocity, and on filter media properties such as filter thickness, porosity (void volume fraction), and pore size. The term permeability is a measure of the ability of gas to flow through a media: it is the inverse of resistance to flow and is dependent on more basic powder properties such as particle size, porosity, pore size, and pore shape.

\subsubsection{Permeability}

The starting equation for modeling pressure drop in fabric filtration is usually Darcy's Law, which is given as:

$$
\Delta P=\mu V L / K
$$

where:

$$
\begin{aligned}
& \mu=\text { gas } v i s c o s i t y \\
& V=\text { superficial gas velocity } \\
& L=\text { filter cake thickness } \\
& \mathrm{K}=\text { permeability }
\end{aligned}
$$

This is similar to the equation for laminar flow pressure drop in pipes :

$$
\Delta P=32 \mu \mathrm{L} V / \mathrm{D}^{2}
$$

where:

$$
\begin{aligned}
& \mathrm{L}=\text { pipe length } \\
& \mathrm{V}=\text { average velocity } \\
& \mathrm{D}=\text { pipe diameter }
\end{aligned}
$$

Darcy's law applies to rigid porous filters as long as the assumptions of incompressible flow, small pressure drop compared to ambient pressure, and steady viscous flow are valid. The assumption 
of viscous flow is valid when the calculated Reynolds number for a typical fiber or particle is less than unity, which is usually the case in fabric filtration (1).

The permeability term, $K$, depends on dust cake or particle properties which describe the geometric characteristics of the filter media, including porosity, particle size, pore size, and pore structure. Billings (1) lists seven geometric properties which describe porous media:

1. Porosity (void volume fraction).

2. Specific surface (surface area per unit volume of solids).

3. Pore size distribution.

4. Particle size.

5. Pore structure.

6. Shape factor.

7. Granule surface roughness.

However, several of these are closely related and describe essentially the same thing. This report will consider only three general parameters which determine the permeability. The particle size of the incoming dust will determine the size of particles in the cake, and has an important effect on pressure drop. The smaller the particle size, the smaller the expected passageways through the dust cake, which results in higher pressure drop. Other factors such as porosity may change along with particle size, but, in general, experimental results show that pressure drop goes up (decrease in permeability) as particle size gets smaller. Porosity is a measure of the degree of packing of the dust cake, and is therefore a very important parameter affecting permeability. The porosity determines the average velocity through the dust cake. The average local gas velocity in the dust cake equals face velocity/ (1 - porosity). In addition to particle size and porosity, a third property is needed to describe the size and shape of the pores. The pore dimensions are 
certainly dependent on particle size and porosity, but it would be possible to have two dust cakes with the same particle size distribution and same porosity, but with different permeabilities due to differences in pore size and shape. Therefore, this third parameter, which we will refer to as pore structure, is needed to describe permeability: Any attempt, then, to model pressure drop in a fabric filter will have to account for these three terms.

\subsubsection{Flow Resistance}

The permeability term in Darcy's law is not widely used in modeling equations. Instead, Darcy's law is written in a different form with two new terms. Because the dust cake thickness is difficult to measure, a different term is introduced, the areal dust cake density, $w$, which is simply the mass per unit area of the dust cake. The thickness of the dust cake is given as:

$$
L=W / \rho_{p}(1-e)
$$

where:

$$
\begin{aligned}
& \rho_{p}=\text { particle density } \\
& e=\text { dust cake porosity }
\end{aligned}
$$

Replacing I in Darcy's law we have:

$$
\Delta F=\mu \mathrm{WV} / \mathrm{K}, \rho_{\mathrm{p}}(1-\mathrm{\theta})
$$

Then $\mu / K \rho_{\mathrm{P}}(1-e)$ is replaced by a new term called the specific cake resistance, $K_{2}$, which gives:

$$
\Delta P=K_{2} W V
$$

However, $\triangle P / V$ can also be replaced by another term referred lo as the drag or resistance, denoted by $S$, which then gives:

$$
\begin{gathered}
S=K_{2} W \\
5-34
\end{gathered}
$$


Therefore, the plot of drag lor pressure drop assuming constant velocity) versus $w$, the areal cake density, will be linear if $k_{2}$ is constant. If the dust builds up on the fabric in a continuous homogeneous layer, it seems reasonable to expect a linear increase in drag. However, it is well known that during initial deposition on a new fabric, particles tend to fill the larger voids first which results in a nonlinear increase in drag (2). After bag cleaning, the residual dust cake is usually very nonuniform; therefore, when returned to service, drag also increases in a nonlinear manner. To model pressure drop in continuous operation, an additional term is included to account for the pressure drop contribution due to the residual dust cake. Thus, the basic filtration equation most often used in laboratory and field studies is (2):

where:

$$
S=s_{E}+K_{2} w_{O}
$$

$$
\begin{aligned}
& \mathrm{S}_{\mathrm{E}}=\text { residual effective drag } \\
& \mathrm{w}_{\mathrm{O}}=\text { areal dust load added only during filtration cycle }
\end{aligned}
$$

Prediction of $K_{2}$ on the basis of dust parameters has been attempted, but accurate prediction has not been attained. The best method of obtaining $\mathrm{K}_{2}$ values appears to be experimental determination in a laboratory $(2,3)$. A known $k_{2}$ value allows one to predict the rate of increase in pressure drop for a given filtration cycle, but it does not allow the prediction of the residual effective drag, $S_{E}$. Residual drag is largely dependent on the residual dust cake weight, which in turn is dependent on the cleaning method and dust cake release properties. According to Donovan (2), $s_{E}$ is one of the variables in the filtration equation which has not yet been adequately modeled and is predicted with even less certainty than $\mathrm{K}_{2}$. Carr and Smith also state that the inability to predict baghouse pressure drop for a given face velocity is one of the, most perplexing problems in fabric filtration (4). 


\section{3 .3 Porosity}

$\mathrm{K}_{2}$ can be predicted in terms of the Carman-Kozeny theory as reported by Dennis (3):

$$
\mathrm{K}_{2}=\mathrm{k} \mu \mathrm{s}_{\mathrm{o}}^{2}(1-\mathrm{e}) / \rho_{\mathrm{p}} \mathrm{e}^{3}
$$

where:

$$
\begin{aligned}
k= & \text { Carman-Kozeny constant, frequently assumed } \\
& \text { to be } 5.0 \\
11= & \text { gas } v 1 \text { scnsity } \\
\mathrm{s}_{0}= & \text { specific surface } \\
\rho_{\mathrm{p}}= & \text { particle density } \\
\mathrm{e}= & \text { porosity }
\end{aligned}
$$

The specific surface refers to the surface area exposed to the gas flow, which for perfect spheres (fly ash particles are primarily spherical) is simply the surface, area divided by the volume which is $6 / D$, where $D$ is the particle diameter. Substituting for $S_{0}$, the equation then becomes:

$$
\mathrm{K}_{2}=36 \mathrm{k \mu}(1-\mathrm{e}) / \rho_{\mathrm{p}} \mathrm{e}^{3} \mathrm{D}^{2}
$$

From this theoretical basis, it can be seen that $K_{2}$ varies inversely with the square of the particle size. For example, a decrease in particle size by a factor of 2 will increase the specific resistance by a factor of 4 . It can also be seen from the porosity term, $(1-e) / e^{3}$, that $k_{2}$ is very sensitive to porosity. For example, a drop in porosity from 0.65 to 0.55 will increase $\mathrm{K}_{2}$ by more than a factor of 2. Donovan (2) reports that for porosity values greater than 0.7, the Carman-Kozeny prediction is not valid, and that an alternative model (Rudnick and First) which has a more complex dependence on porosity can be used. Nevertheless, predicted values of $K_{2}$ typically are in error by a factor of 2 or more compared to measured values (2). This theoretical relationship, however, shows 
that an effective means of reducing pressure drop would result if a method could be found to increase porosity (other factors unchanged).

The factors which determine the porosity of a dust cake are not weII known, other than the general increase in porosity with decreasing particle size for a variety of bulk powders (1). Particles larger than $30 \mu \mathrm{m}$ tend to have porosities in the 0.4 to 0.5 range, while smaller sized particles tend to form much more porous structures, presumably due to the relationship between cohesive forces and particle mass (1). Very fine particles of about 1 micron or less will typically have porosities of 0.9 or greater. For a given particle size, there are no known models or relationships which would predict porosity in a filter cake. However, it was recently reported by Pohl (5) that there is a correlation between dust cake porosity and dust cohesiveness, the more cohesive ashes forming the more porous dust cakes.

\subsubsection{Pore structure}

The microstructure of the dust cake as particles build up in layers would be expected to depend on the particle shape and size distribution of the incoming dust. In addition, it would depend on the degree to which particles remain in position after deposition. For example, packing or cake collapse due to an increase in pressure drop will change pore structure. More cohesive ashes would be expected to be better able to resist packing due to particle shift in the dust cake. Therefore, the cohesiveness of the dust will also affect pore structure. Finally, if significant electrical forces are present, they would also be likely to affect pore structure.

Fly ash from coal combustion is usually characterized as being predominately spherical in shape. However, the larger particles usually have smaller particles attached to them, which adds surface roughness and makes pore structure more complex. Also, because of the wide range of particle sizes which are present in coal fly ash, it is expected that smaller particles will fill some nf the interstitial spaces formed by larger particles. There are two 
additional possible effects which show the importance of pore structure in determining the dust resistance. First, it is possible that some "dead" spaces might. be formed which contribute to the overall porosity but which are not available to pass gas flow. In such a case, the dust cake would act like one of lower porosity and pressure drop would be greater than expected from particle size and porosity predictions. A second possibility is the formation of an anisotropic dust cake which has distinctly different flow properties in the directions parallel and perpendicular to the face velocity. An extreme case is the forllaliuil of pinholco which are relatively large flow channels parallel to the face velocity. If an anisotropic dust cake leads to reduced resistance $1 \mathrm{n}$ lit flow direction, actual pressure drop would be less than predicted from measured porosity and particle size distribution.

Little work has been done characterizing the effect that dust cake pore structure has on resistance, and yet this is necessary to accurately predict $\mathrm{K}_{2}$. Furthermore, what is needed beyond a knowledge of dust cake characteristics is an understanding of the factors which control the way in which porosity and pure structure develop with dust cake buildup. Ensor (6) has proposed using fractal geometry as a possible means of characterizing dust cake structure, but this is only in the conceptual stage at this point. In addition, cohesiveness will likely affect both porosity and pore structure, so again the importance of this property is stressed if a better understanding of fabric filtration is to be attained.

\subsubsection{References}

1. Billings, C.E. and J. Wilder Handbook of Fabric Filter Technology, Volume I, Fabric Filter systems study. GCA Corporation, NTIS PB 200-648, December 1970 .

2. Donovan, R.P. Fabrlc Filtration For Combustion Sources. Marcel Dekker, Inc., New York, 1985.

3. Dennis, R., et al. Eiltration Model for Coal Fly Ash With Glass Eabrics. EPA-600/7-77-084, August 1977 . 
4. Carr, R.C. and W.B. Smith. Fabric Filter Technology for Coal Fired Power Plants. Journal of the Air Pollution Control Association, Vol. 31 , No. 4, pp. 399-413, 1984 .

5. Pohl, F.G. A Novel Ring Shear Device for the Purpose of Classification of Fine Powders. Presented at: The 17 th Annual Meeting of the Fine Particle Society, San Francisco, CA, July 1986 .

6. Ensor, D.S. T. Yamamoto, and A.S. Viner. Aerosol Deposition in Fabric Filters. Proceedings: Sixth Symposium on the Transfer and Utilization of Particulate Control Technology, New Orleans, LA, Vol. 3, pp. 12-1 to 19, February 1986 . 


\subsection{Fabric Effects}

An important factor influencing the overall performance of the fabric filter is the type of fabric used and its construction characteristics. There is a wide variety of fabrics that are available commercially and an extensive research program is underway to develop new fabrics. The fundamental characteristics of fabrics that affect fabric filtration performance are:

1. Fabric composition.

2. Eabric construction.

3. Pore size.

These characteristics are related to each other, but the composition and morphology of the dust, as well as operating parameters such as face velocity and temperature are also important in fabric filtration. This makes exact theoretical modeling of dust filtration through a fabric almost impossible without some geometric simplification and assumptions as to the dust behavior. In general, models assume dust drag to be determined by intrinsic properties of the dust only, yet slight variations in fabric structure can significantly alter filter performance. Therefore, simplified models do not accurately describe what is actually occurring. Empirical equations have been developed, but in many cases these are sitespecific and attempts to use them in design can result in catastrophic failures. Therefore, it is essential that a better understanding of the fundamental behavior of filtration be obtained before more accurate theoretical and more general empirical models can be developed. 


\subsubsection{Fiber Composition}

The primary effect of fiber composition is on the gross properties of the fabric such as chemical, temperature, and abrasion resistance as well as tensile strength. Although these properties are important in developing design criteria, such as bag life, chemical composition is not a major variable affecting filtration performance (1). The exception occurs when the chemical composition determines the structure of the fabric, such as the natural curly fibers of cotton or the needle-like fibers of Tefaire ${ }^{\circledR}$

\subsubsection{Fabric Construction}

A very important part of optimizing fabric filtration is understanding how fabric structure affects performance. This includes the type of weave, porosity, pore size, degree of texturization, and type of fabric finish.

Fabrics used in fabric filtration can either be woven or nonwoven. Reverse air and shake-deflate baghouses use almost exclusively woven fabrics while pulse jet baghouses can use either woven or nonwoven fabrics. Weaving is the traditional method of making textile fabrics and can be used to produce fabrics from both natural and synthetic fibers. Woven fabrics are produced in a three step process. First, the fibers are made or collected; secondly, the fibers are processed into yarns. Finally, the yarns are woven together to make a fabric. Yarns are made either by the staple fiber process or by the filament process. The staple fiber process uses short fibers which are aligned and then twisted together to form a tight yarn. The amount of twisting partly determines the strength of the yarn but if the fibers are twisted too much. kinking can occur, forming weak points. Yarns formed from staple fibers generally are not very smooth and have extensive protrusion of fibers, which tends to improve collection efficiency. 
In the filament process, extruded continuous filament fibers are made into yarns immediately after solidification. The monofilaments formed are must often twisted together as they solidify, to form multifilament yarns. These multifilament yarns then can be twisted together to produce ply yarns. Although filament yarns are usually quite smooth, many times they are cut into short lengths to form staple fibers and then processed into yarns. This allows blending of fibers, such as glass and teflon, which may provide a better collection efficiency and bag life (1). Fabric filtration performance of staple riluei fabrice and rnntinuous filanient fabrico differ, since the fabric structure is different.

Yarns can also be texturized uy air blowing the yarns to increase the apparent volume. This has been shown to improve the collection efficiency of a fabric since the number of fibers extending into the void spaces is increased. This allows the dust cake to more easily bridge over the pores in the fabric, but has the disadvantage of decreased fabric strength (2). For this reason, usually only the fill yarns of the fabric are texturized.

Weaving is accomplished by interlacing yarns at right angles to each other in an established sequence. The lengthwise yarns that form the basic structure of the fabric are cailed the warp yarus and those that are crosswise are refered to as the fill yarns. There is a wide variety of weaving patterns such as simple, twill, satin, and sateen. Each of these patterns produces a different fabric structure with different porusities, pore sizes and pore depths.

Proceeding directly from fiber to fabric is both simpler ard less costly than making yarn and then weaving it. The most common nonwoven materials used for fabric filtration are felted fabrics. originally,- felts were made simply by matting the flber using heat and pressure, which worked well for fibers that were naturally binding, such as wool. However, for other fibers, particularly synthetics, a stronger and more durable felt 1 made by attaching the fibers to a woven base called a scrim. Fabrics made by this process are called needled felts. Needled felts generally have very high collection efficiencies which are somewhat independent of the 
formation of a dust cake. The pore structure of felted fabrics is very irregular when compared to woven fabrics and has an extensive amount of fibers protruding into the void spaces. This virtually guarantees that a high percentage of the particles will be collected by the fabric.

To improve fabric durability, thereby improving bag life, a finish is applied to the fabric. Although the type of finish used may have an effect on the cake release properties of the fabric, generally they do not affect filtration performance. The exception is a Gore-Tex laminate, which was developed primarily to improve collection efficiency and reduce pressure drop. Gore-Tex ${ }^{\circledR}$ is a very thin polytetrafluroethylene (PTFE) membrane which is stretched two dimensionally across a fabric and then bonded to it. This stretching shreds the PTFE laminate into "a microporous matrix of nodules interconnected by fine fibrils", making an ideal filtration media.

\subsubsection{Pore Size}

Baghouse collection efficiency is strongly dependent on the pore structure of the fabric. The pore size of woven fabrics is often much larger than the particles that are being collected which requires that the pores be bridged over before effective collection of particles can occur. If pores are not bridged over during the initial particle deposition, pinholes may form in the dust cake. Pores which are open to straight-through flow are subject to bleeding as they increase in size; a critical pore size for bridging purposes occurs at roughly 10 diameters of the dust being filtered (1). Bleeding or seepage of dust is a function of the number of pores above the critical size, which in turn is related to the particle size distribution of the dust. Therefore, the pore size distribution in a direction normal to the flow is largely responsible for outlet particulate concentration in a fabric filter (1).

Projection of fibers within the pore spaces greatly reduces the effective characteristic pore dimension with respect to dust bridging. These fibers, while significantly improving collection 
efficiency, have little effect on the total void volume of the fabric, therefore not affecting the pressure drop. Thus, staple and texturized yarns can have the added benefit of better collection efficiency than the continuous filament yarns.

Deep, channel-like pores formed by rounded yarns leads to very high localized gas velocity, which may be an order of magnitude greater than the face velocity. These high local velocities tend to increase dust packing density and can result in the formation of pinholes. If, on the other hand, the pores are very shallow, a completely unsupported dust layer may form, resulting in collapse of the dust cake and a very high pressure drop across the bag. If the fabric has protruding fibers, it appears to support a more porous dust cake that is less subject to collapse (1).

clearly, overall collection efficiency can be improved by using a fabric with smaller pore sizes. This can be accomplished by using smaller diameter fibers, by more complete texturization, by using heavy felted fabrics, or by using a microporous membrane such as Gore-Tex ${ }^{\circledR}$. However, fabrics must also be economical, have a long bag life, and be easily cleaned to control pressure drop. The result is that most fabrics today, to meet the needs of industry, are designed for long bag life, and therefore rely on dust cake formation to provide the required collection efficiency. Expensive specialized fabrics can be used to better control difficult-to-collect dusts, but this does not preclude altering the dust characteristics as an alternative or better approach.

\subsubsection{References}

1. Draeme1, D.C. Relationship Between Fabric structure and Filtration Performance in Dust Filtration. EPA-R2-73-288, U.S. Environmental Protection Agency, Research Triangle Park, NC, July 1973.

2. Donovan, R.P. Fabric Filtration for Combustion Sources. Marcel Dekker, Inc. New York, NY, pp. 11-87, 1985. 


\subsection{Flue Gas Conditioning Results}

\subsubsection{Introduction}

Previous research at UNDERC $(1,2,3)$ has shown that fine particulate emissions from a fabric filter are highly dependent on the specific coal. Tests were conducted with a pilot combustor and baghouse (described in the next section) which resulted in a particulate penetration range from $0.1 \%$ to $24 \%$ depending on the specific coal. Since the tests were conducted with the same woven glass fabric, cleaning cycle, face velocity, and combustion conditions, it was concluded that differences in penetration originated with differences in the fuels. Additional tests with several fabrics and three bag cleaning modes (shaker, pulse jet, and reverse air) confirmed that some fly ashes can be more difficult to collect in fabric filters than others.

Penetration in the pilot-scale tests correlated strongly with fly ash composition. The strongest correlation between elemental concentration and penetration was with sodium, but there was a better correlation between baghouse particulate penetration and a linear combination of sodium, magnesium, and phosphorous, as shown in Figures 5-2 and 5-3. It needs to be reemphasized that all tests were intentionally performed with the same fabric, at the same temperature and face velocity, and with the same cleaning cycle parameters. Therefore, any significant differences in removal efficiency among the various ashes must be regarded as originating in differing fuel or ash characteristics.

Difficult-to-collect $f l y$ ashes have also been observed in full scale utility baghouses. For example, at the Monticello station, which burns a wilcox group Texas lignite, high particulate emissions have been reported $(4,5)$. At the Escalante station, high opacity spikes were seen following bag cleaning after switching from a Wyoming to a New Mexico coal (6). Similarly, in Australia, physical properties of the ash have strongly influenced haghouse particulate emissions (7). Bench-scale laboratory data also show the importance 


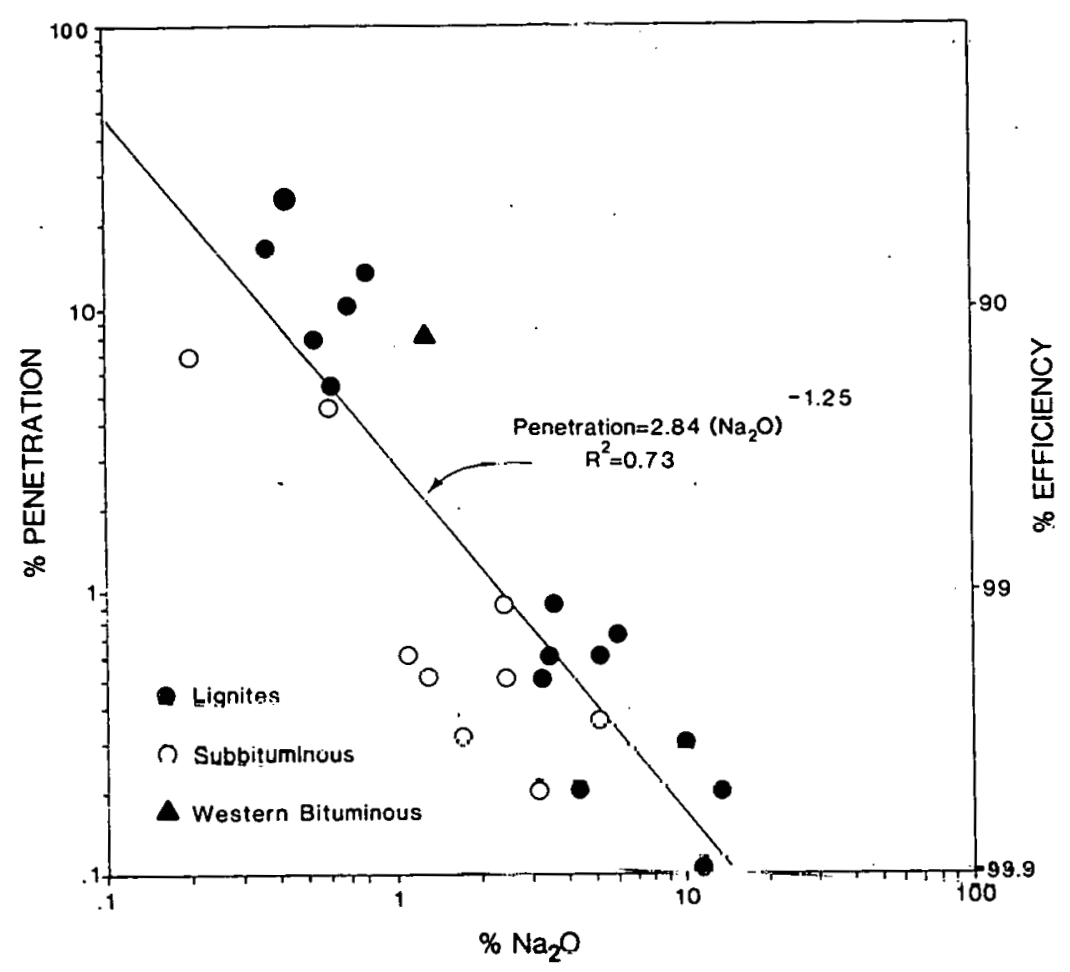

Figure 5-2. Penetration as a function of $\mathrm{Na}_{2} \mathrm{O}$ in the fly ash.

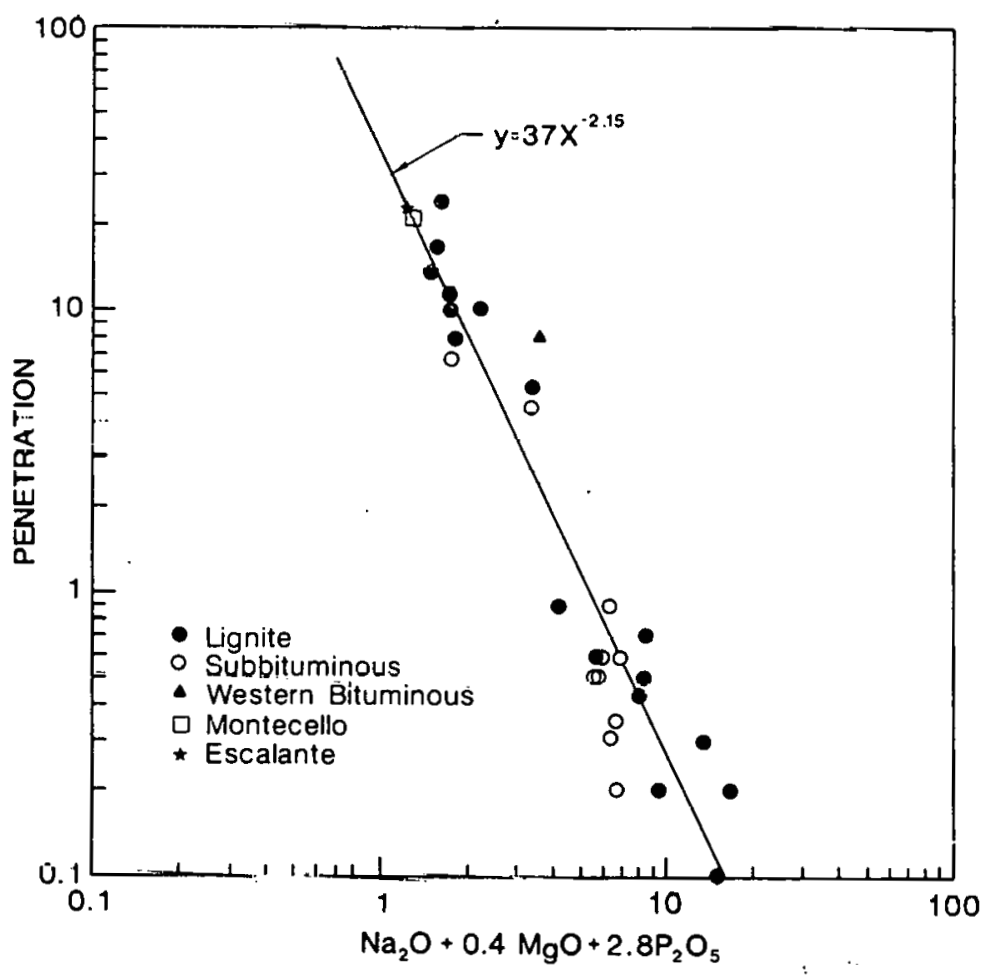

Figure 5-3. Penetration as a function of $\left(\mathrm{Na}_{2} \mathrm{O}+0.4 \mathrm{MgO}+2.8 \mathrm{P}_{2} \mathrm{O}_{5}\right)$. 
of physical. fly ash properties on fabric filter emissions (8). Pilot and full-scale data clearly indicate baghouse emissions are dependent on the coal or ash properties. However, the exact relationship between basic ash properties--particle size, cohesiveness, chemical composition, particle morphology, electrical nature--and penetration behavior has never been established.

It would appear that a change in one of these basic properties might affect fabric filter collection efficiency. Because of the correlation between ash composition and baghouse penetration, it follows that changing the ash composition with additives would affect removal efficiency. Since the high sodium ashes were more easily collected, it would seem logical that collection efficiency could be improved by adding sodium to the coal. Therefore, the first attempts to improve collection efficiency for difficult-to-collect ashes consisted of adding sodium sulfate and sodium acetate to the coal, or blending high and low sodium coals. These tests, however, did not result in improved collection efficiency (3). Apparently, the sodium was not incorporated into the coal in a way that simulated naturally occurring sodium in combustion and particle formation, or possibly sodium simply correlated with some other ash property.

Conditioning agents which have been used to improve the performance of electrostatic precipitators (ESPs) include: sulfur trioxide $\left(\mathrm{SO}_{3}\right)$ and ammonia (9). $\mathrm{SO}_{3}$ addition decreases fly ash resistivity and for some ashes increases cohesive strength, thus reducing rapping reentrainment. Ammonia appears to improve ESP performance by space charge enhancement and by increasing the fly ash cohesiveness. From the previous discussion in sections 5.1 and 5.2, an increase. in ash cohesiveness would also be desireable for improving fabric filter collection efficiency. Therefore, $\mathrm{SO}_{3}$ and ammonia were tested as conditioning agents to improve fabric filter collection efficiency for difficult-to-collect ashes. Initial tests using ammonia injection alone and $\mathrm{SO}_{3}$ alone, with a North Dakota lignite, did not result in significantly reduced fine particulate emissions. However, there was a substantial reduction in emissions 
using a combination of $\mathrm{SO}_{3}$ and ammonia. Details of the conditioning experiments and results are presented in the following sections of this report.

\subsubsection{Experimental Approach}

Flue gas conditioning tests were conducted with a total of 6 different coals. These include: three Texas lignites, one North Dakota lignite, a Montana subbituminous coal, and an Indiana bituminous coal. For each coal a minimum of a baseline test without conditioning and a test with conditioning were completed and the results compared. All the tests were performed using tho UNDERC Particulate Test Combustor (PTC) and baghouse.

\subsubsection{Particulate Test Combustor and Baghouse}

The pilot furnace, known as the Particulate Test Combustor (PTC), is a 550,000 btu/hr pulverized coal-fired unit designed specifically to generate fly ash representative of that produced in a full wscale utility boiler. The combustor is oriented vertically to minimize wall deposits. A refractory lining helps triensure adequate flame temperature for complete combustion and prevents rapid quenching of trie coalescing or condensing fly ash. The mean residence time of a particle in the combustor is approximately three seconds based on the superficial gas velocity. Combustor efficiencies of $99+\%$ based upor loss on ignition of the fly ash and the co concentration in the flue gas, are evidence that incomplete combustion is not a problem with this combustor.

The coal nozzle of the PTC fires axially upward from the bottom of the combustor and secondary air is introduced concentric to the primary air with turbulent mixing. In addition, tertiary air is supplied above the base of the combustor. Coal is introduced to the primary air stream via a screw feeder and ejector. An electric air preheater is used for precise control of the combustion air temperature. Water jacketed heat-exchargers provide flue gas 
temperature control at the baghouse inlet. The PTC instrumentation permits system temperatures, pressures, flow rates, flue gas constituent concentrations, and baghouse operating data to be monitored continuously and recorded on a data logger. Recent modifications of the PTC were designed to allow operation up to 500 hours without shutting down due to fouling at the transition points.

The UNDERC pilot-scale baghouse is equipped with both pulse jet and shaker modes. The pulse jet chamber uses three cage mounted bags and is pulsed using compressed air. The rate of pulsing can be adjusted to provide a reasonable pressure drop. During pulsing, the bags remain on-line.

The shaker chamber has three compartments of three bags each for a total of nine bags, each $71 / 2$ inches in diameter by 50 inches long. The bottom of the bags are clamp mounted on the tube sheet thimbles and the bag tops have sewn loops which are mounted on the shaker hangers. Both the shaker amplitude and frequency are adjustable. The bags are cleaned off-line.

Prior to the flue gas entering, the baghouse is preheated to $300^{\circ} \mathrm{F}$ using electric heaters. This prevents water from condensing in the baghouse during start-up. Sampling ports are located at the inlet and outlet sides of the baghouse for particulate sampling. operating parameters for the PTC and baghouse for the conditioning tests are given in Tables 5-1 and 5-2. Figure 5-4 illustrates schematically the PTC and the baghouse.

\section{TABLE 5-1}

\section{PTC OPERATING PARAMETERS}

Coal Feed Rate

Flue Gas Flow Rate

Excess Oxygen

Combustion Exit Temp.
45-75 lbs/hr $(550,000 \mathrm{btu} / \mathrm{hr})$

130 sctm

$4.5 \%$

$1825^{\circ} \mathrm{F}$ 
TABLE 5-2

BAGHOUSE OPERATING CONDITIONS

Shaker Chamber.

Air-to-cloth Ratio Fabric

Mfgr. designation

Fiber

Construction

Weight

Finish

Cleaning Interval

Baghouse Temperature
$3 \mathrm{ft} / \mathrm{min}$

Filter Media Products

$601 \mathrm{E}$

Glass

Woven $3 \times 1$ Twill

$10.3 \mathrm{oz} / \mathrm{yd}$

10\% TefION B

Varied Depending on Test

$300^{\circ} \mathrm{F}$
Pulse Jet Chamber

Carter-Day

Daytex ${ }^{(\circledR)}$

Ryton ${ }^{\circledR}-$ Gortex ${ }^{\circledR}$ scrim

Fel ted

22. $0 z / y d$

None

3 min

$300^{\circ} \mathrm{F}$

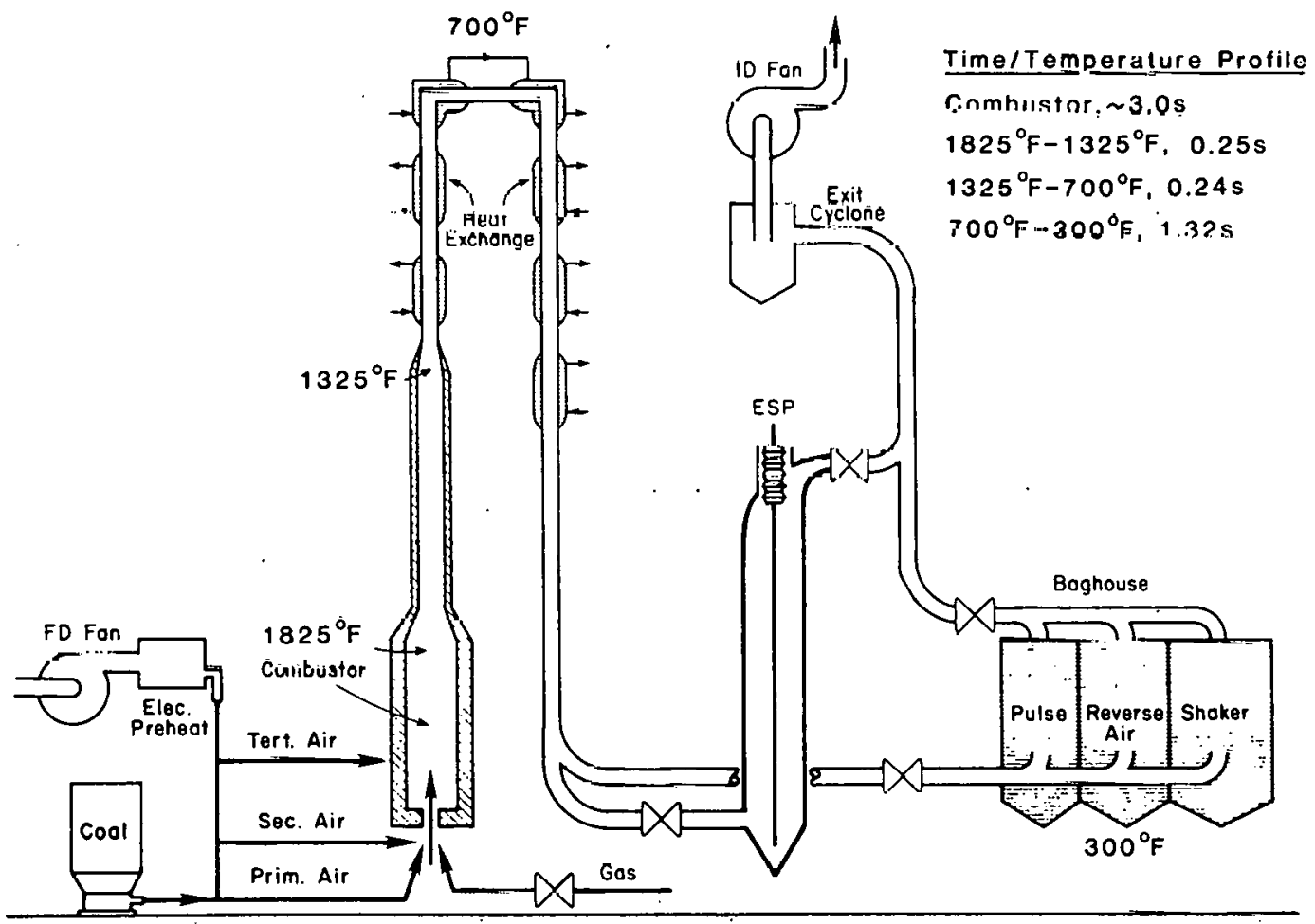

Figure 5-4. Schematic of Particulate Test Combustor and baghouse. 


\subsubsection{Particulate Sampling and Measurement}

Near real-time measurements can be made for particles ranging in size from $0.5 \mu \mathrm{m}$ to $15 \mathrm{\mu m}$ using an Aerodynamic Particle Sizer (APS 33) manufactured by TSI Inc, shown schematically in Figure 5-5. The primary advantages of this system are the high resolution and short sampling time. In the APS, particle laden air is passed through a thin-walled orifice and because of their higher inertia the particles lag behind the gas: The velocity lag is uniquely related to the aerodynamic diameter of the particles. Therefore, the aerodynamic diameter of a particle can be determined by measuring the particle velocity as it exits from the orifice. To measure the particle velocity, the APS employs a laser which is split into two beams. The light scattered by a particle passing through these beams is collected and two pulses are emitted, separated by the time taken for the particle to cross the distance between the two beams. From this time interval, which is measured electronically, the aerodynamic diameter is calculated. For most applications, the particle size distribution can be obtained within 20 seconds, giving near real-time measurements.

The APS system includes a computer for obtaining the output. The particle size distribution can be obtained as number concentration or mass concentration. Rather than looking at emissions of several particle sizes fine particle emissions can be combined by using a calculated value of respirable mass. The American council of Governmental and Industrial Hygienists (ACGIH) deflnition of respirable mass as given in Table 5-3, is used. The ACGIH definition is extrapolated and interpolated to calculate the percentage at the midpoint of each.channel for that particle size. The respirable mass from all of the channels is added to obtain the total respirable mass. This provides a convenient and effective method of plotting fine particle emissions as a function of time or baghouse pressure drop. 


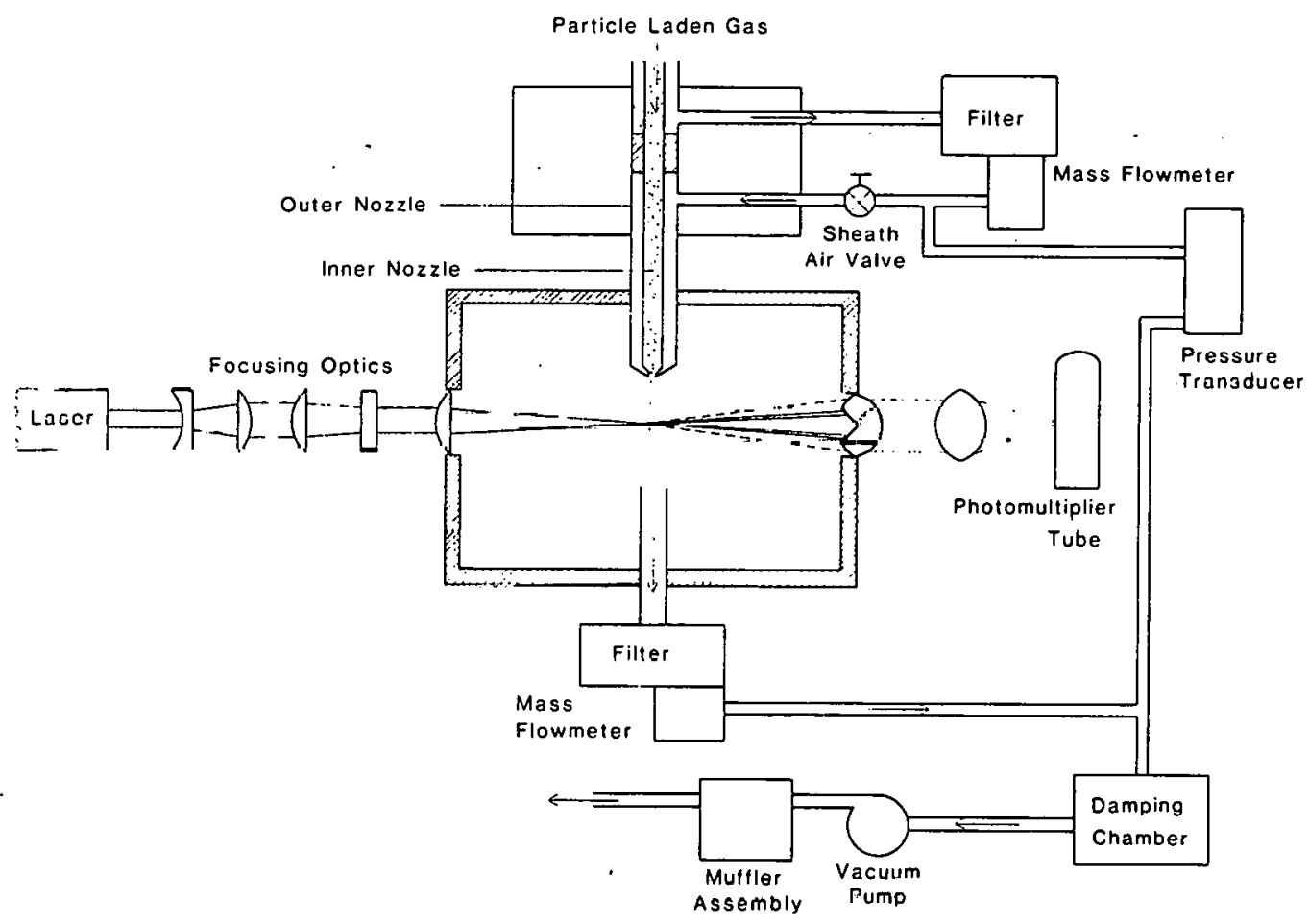

Figure 5-5. Schematic of AFS 33

Table 6 -3

ACGIH Respirable Mass Definition

Aerodynamic Diameter

(micrometers)

2.0

2.5

3.5

5.0

10.0
Respirable Mass Eraction (percent)

90

75

50

25

0 
To determine the concentration of submicron particles 10.01 to 1.0 $\mu \mathrm{m}$ ), a Differential Mobility Particle sizer (DMPS), also manufactured by TSI Inc., was used. Electrical mobility is a measure of how rapidly an electrically-charged particle responds to an electric field. This response time is related to the particle diameter and the number of charges carried by the particle. The DMPS system consists of two primary sections, an electrostatic classifier and a condensation nucleus counter (CNC). The purpose of the electrostatic classifier is to remove a predictable fraction of the particles within a narrow size range and pass these on to the CNC where the particles are counted. Aerosols are initially passed through a Krypton-85 neutralizer which exposes the particles to high levels of both positive and negative ions. The particles acquire a charge distribution that is described by the Boltzmann equilibrium charge distribution equation (10). A voltage is applied to the electrostatic classifier which maintains a center electrode at a precise negative potential which attracts the positively charged particles. Only those particles with a narrow predictable mobility range pass through a slit near the bottom of the center electrode. A small air flow (0.3 liters/min) carries these particles to the CNC.

The CNC measures particle number concentration by using the light scattering technique. Since the dry submicron particles are too small to be easily detected by light scattering, the particles pass through a vapor which condenses on the particle, forming a droplet. Each droplet is large enough to scatter a detectable amount of light when it passes through a light beam. The droplet size is nearly independent of the size of the original particle over a wide range of particle sizes, so the light scattered is a function of number concentration only, not of size distribution. This instrument was also used independently of the electrostatic classifier as a continuous real-time monitor of the number of fine particles that were present in the flue gas. An impactor, prior to the gas stream entering the $C N C$, removed the larger particles giving the number concentration of submicron particles. 
For both the APS 33 and DMPS particle analyzers, a dilution system was employed. Dilution of the flue gas is necessary to prevent moisture condensation in the sensors and to reduce particle concentration, which if too high may exceed the maximum output of the CNC and may cause coincidence error in the APS. To be effective the dilution system must provide a constant flow of aerosol through the nozzle regardless of the pressure in the stack. A schematic of the particulate sampling system with diluter is shown in Figure 5-6. The APS pump draws the sample into the diluter volume. A second pump is usen to draw off a portion of the flue gas and recycle it bark as dilution gas after it has been cleaned and the mo1slure removed. As is shown in the Iigure, woth the APS and pMPS were operated simultaneously using this dilution system. The maximun dilution that can be obtained with this system is about 10 to 1 ; if higher dilutions are needed the system is operated with the TSI 3302 diluter, as was the case at the inlet to the baghouse. With both systems operating, dilutions up to 1000 to 1 can be obtained.

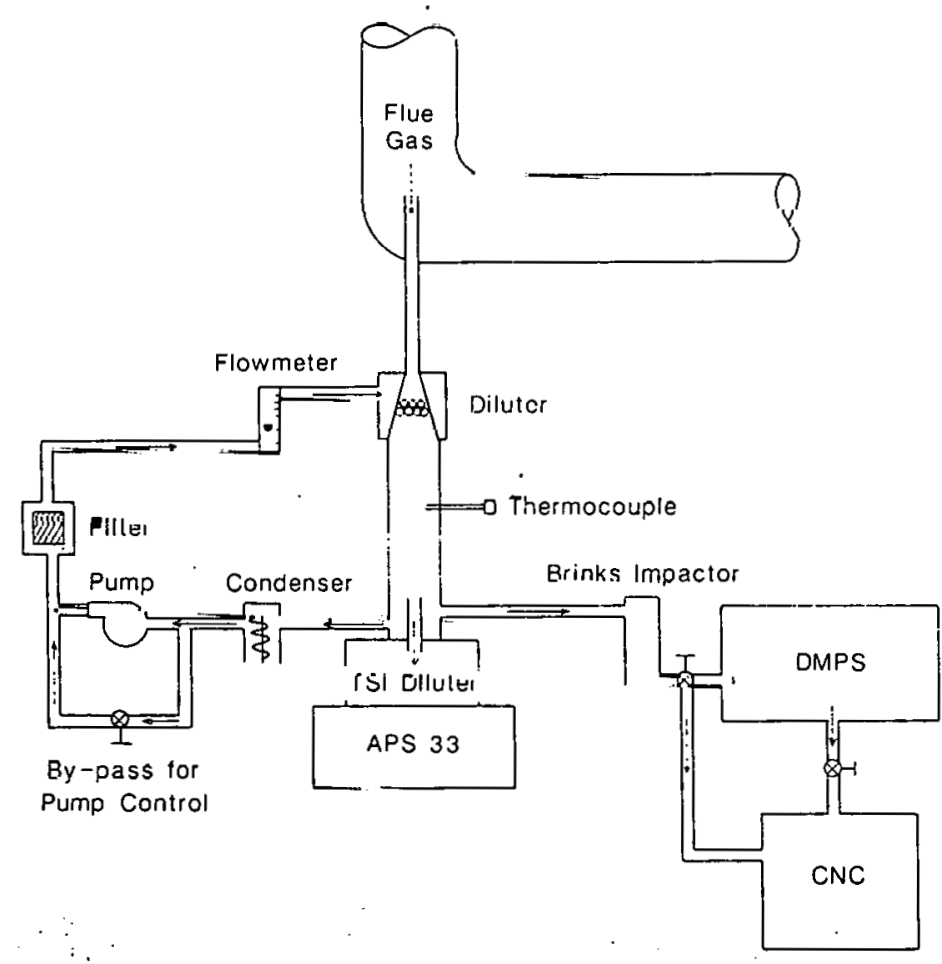

Figure 5-6. Schematic of particulate sampling system (APS 33 , DMFS and dilution system). 
In addition to the DMPS and APS, other particulate measurement techniques that were used are: a Flow Sensor 6-stage multicyclone to provide an inlet particle size distribution and to collect size fractionated samples and EPA-method 5 to provide dust loadings at the inlet and outlet of the baghouse to determining the overall baghouse collection efficiency. The particle size distribution of the bulk fly ash was determined using a coulter counter.

\subsubsection{Sulfur trioxide and Ammonia Injection}

Two methods of injecting $\mathrm{SO}_{3}$ were used for the conditioning tests. The first, shown in Figure 5-7, involved passing dry nitrogen gas over $30 \%$ fuming sulfuric acid, which is similar to a method reported by spafford (11). The acid bath was maintained at $105^{\circ} \mathrm{F}$ to ensure a steady $\mathrm{SO}_{3}$ injection rate. The concentration of added $\mathrm{SO}_{3}$ in the flue gas was measured by EPA method 8 when firing the PTC on natural gas to prevent interference due to a possible reaction of the $\mathrm{SO}_{3}$ with alkaline components in the fly ash.

This injection method had several drawbacks. Fuming sulfuric acid is a very hazardous material to handle. In addition, the quantity of $\mathrm{SO}_{3}$ obtained was depleted over time, requiring the acid be replaced. Therefore, a catalytic $\mathrm{SO}_{3}$ generator was built. As is shown in Figure 5-8, air and $\mathrm{SO}_{2}$ are passed through a vanadium pentoxide $\left(\mathrm{V}_{2} \mathrm{O}_{5}\right)$ filled reactor that is heated to $800^{\circ} \mathrm{F}$, thereby oxidizing the $\mathrm{SO}_{2}$ to. $\mathrm{SO}_{3}$. Conversion was measured using $\mathrm{SO}_{2}$ analyzers and was found to be greater than 99\%. Therefore, the quantity of $\mathrm{SO}_{3}$ injected into the system can be determined by measuring the $\mathrm{SO}_{2}$ flow rate into the generator. Ammonia is injected just upstream of the $\mathrm{SO}_{3}$ and is monitored using a calibrated flowneter. 


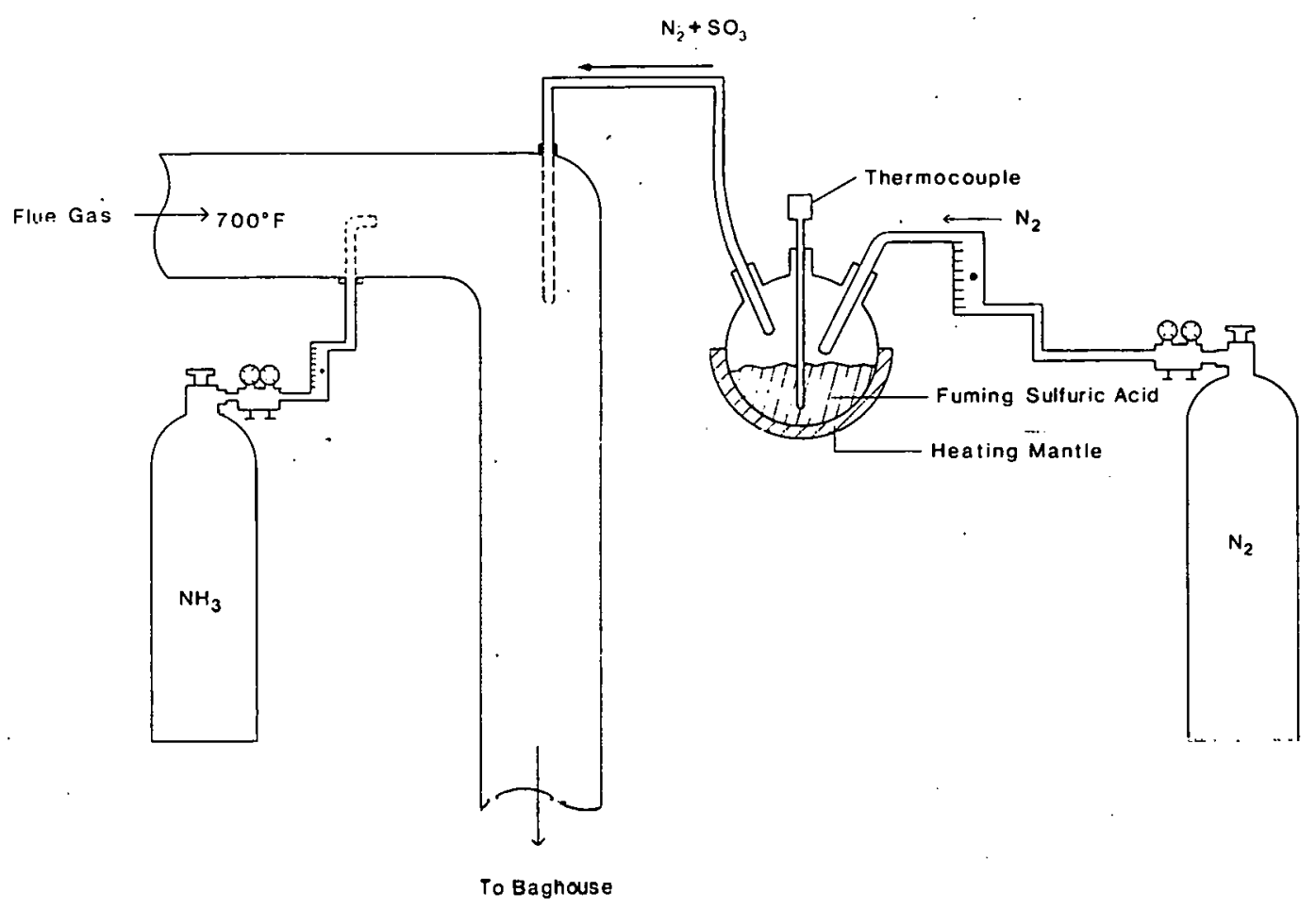

Figure 5-7. Schematic of sulfur trioxide and ammonia injection system using fuming sulfuric acid.

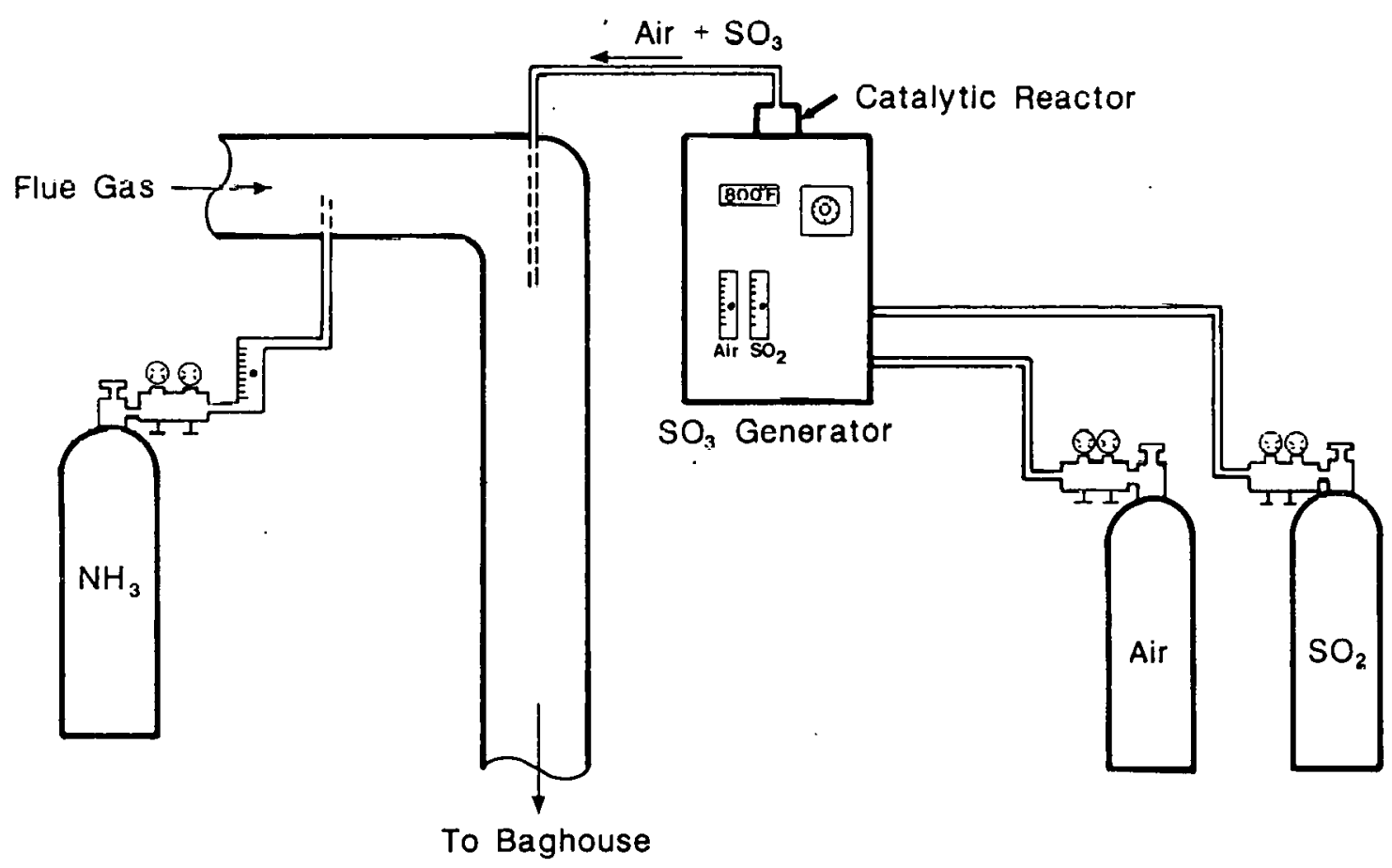

Figure 5-8. Sulfur Trioxide and ammonia injection system using $\mathrm{SO}_{3}$ generator. 


\subsubsection{Chemical Analyses}

Ammonia, which is injected into the flue gas stream, is considered an air pollutant. Therefore, it was important that the ammonia exiting the baghouse (ammonia slip) be measured. A known quantity of flue gas was extracted and drawn through impingers containing $0.1 \mathrm{~N}$ sulfuric acid which absorbed the ammonia in the extracted flue gas. The solution was diluted to a known volume and the ammonia concentration measured using a selective ion electrode. To insure that all the ammonium ions in the solution are converted to ammonia, the $\mathrm{pH}$ of the solution was increased to 11 by adding $6 \mathrm{~N}$ sodium hydroxide. The amount of ammonia at the outlet of the baghouse was then calculated. In addition, the ammonia absorbed on the fly ash was determined by leaching the fly ash with $0.1 \mathrm{~N}$ sulfuric acid and measuring the ammonia concentration in solution with a selective ion electrode.

Flue gas samples were taken at three system sample points: the furnace exit and the baghouse inlet and outlet. After passing through sample conditioners to remove the moisture, the flue gas was analyzed for $\mathrm{O}_{2}, \mathrm{CO}_{2}, \mathrm{SO}_{2}, \mathrm{NO}_{X}$, and $\mathrm{CO}$. Except for the $\mathrm{CO}_{2}$ and $\mathrm{CO}$ each constituent was analyzed at both the inlet and outlet of the baghouse simultaneously using two analyzers. The concentrations for all of the instruments were recorded continuously using circle charts. In addition, all data were recorded at set time intervals by the PTC operators. No $\mathrm{N}_{\mathrm{x}}$ was determined using two Thermo Electron Chemiluminescent $\mathrm{NO}_{\mathrm{x}}$ analyzers with molybdenum converters which convert the $\mathrm{NO}_{2}$ to $\mathrm{NO}$. The $\mathrm{O}_{2}, \mathrm{CO}$, and $\mathrm{CO}_{2}$ analyzers are made by Beckman and the $\mathrm{SO}_{2}$ analyzers are manufactured by DuPont. Each of these analyzers are regularly calibrated and maintained to provide accurate flue gas concentrations.

To provide documentation as to the type of coals used in these tests, ultimate and proximate analyses, using a Leco CHN analyzer and a Fisher sulfur analyzer, and determination of the heating value (ASTM Method D2015-77) were completed for each coal. In addition, inorganic constituents of the coal were determined using $x-r a y$ 
fluorescence analysis (XRFA) with the coal ash samples:prepared by ASTM Method D3174-82. Since fly ash composition is an important parameter in the operation of a fabric filter $(1,2)$, an analysis of the baghouse ash was completed following each test using XRFA. To determine carbon carryover, loss on ignition (ASTM Method D3174-82) was performed on the fly ash samples.

To aid in the evaluation of the chemistry of flue gas conditioning, elemental analysis of the surface of the fly ash particles was performed using Electron spectroscopy for chemical Analysis (ESCA). In addition, x-ray diffraction (XRD) was used to determine the chemical constituents of the fly ash.

\subsubsection{Physical Characterization}

Cohesiveness plays an important role in the formation of the dust cake. One measure of ash cohesiveness is to determine the breaking strength of a pellet formed using a high pressure press. This was the technique used to determine the cohesive strength of the fly ashes produced during the conditioning tests. The formed pellet ( $5 \mathrm{~mm}$ thick $\times 30 \mathrm{~mm}$ in diameter) was suspended on it edges and a load placed at the center. The breaking strength was determined by the magnitude of the load. This technique has been shown to be fairly reproducible and the results were verified with a shear cell, which measured the internal angle of friction. Scanning electron microscopy (SEM) was used to determine differences in particle morphology due to conditioning. The SEM was also used to provide a non-aerodynamic verification of particle size.

\subsubsection{Test Parameters}

The test program was divided into two phases. Phase I consisted of initial tests on 3 low-rank coals. Two of the coals, Falkirk, North Dakota lignite and Big Brown, Texas lignite were chosen because previous tests at UNDERC (1) had shown that they produced difficultto-collect fly ashes. The third coal, South Hallsville, Texas 
lignite was selected because the correlation between ash composition and baghouse penetration (2) predicted it too would produce a difficult-to-collect ash. The tests were conducted primarily to determine if $\mathrm{SO}_{3}$ and ammonia conditioning would provide an effective method for improving fine particulate collection efficiency in a baghouse and to determine what effect it would have on operating pressure drop. For each coal, a baseline test was conducted without conditioning. Ar identical test was performed with $\mathrm{SO}_{3}$ and ammonia conditioning to determine differences in emissions and pressure drop. starting with new bags, tests with these coals were completed with the baghouse shaker chamber. The first 2-3 hours of each test were performed without bag cleaning to measure both particulate emissions and pressure drop as a function time with dust cake build-up on the fabric. Bag cleaning was then initiated, and over several cleaning cycles, emissions as a function of time as well as total dust loading measurements were taken. In addition, two 50 hour tests utilizing South Hallsville lignite were completed to evaluate the longer term effects of conditioning on emissions and pressure drop.

An injection location well upstream of the baghouse was chosen for Phase I testing to provide enough residence time for adequate mixing of the $\mathrm{SO}_{3}$ and ammonia with the flue gas. At this injection point, the flue gas temperature was $700^{\circ} \mathrm{F}$. Additive concentrations

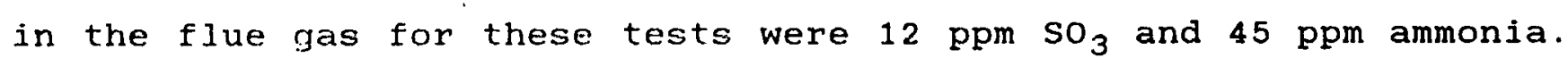
However, one short test was conducted where the concentrations were increased to $60 \mathrm{ppm} \mathrm{SO}_{3}$ and $225 \mathrm{ppm}$ ammonia to help evaluate the reaction products.

After the Phase I evaluation the following questions remained:

1. Will the process work at lower injection temperatures (temperatures equivalent to the cold side of an air preheater)?

2. Can a lower concentration of ammonia be used?

3. What is the effect of coal type (e.g. higher rank coals)?

Phase II tests were designed to help answer these questions. 
For Phase II tests, three different coals were chosen. The first coal, Monticello, Texas lignite, was selected because this coal produced an ash that was difficult to collect in a full-scale baghouse (5). The other two coals selected, Sarpy Creek, Montana subbituminous coal, and an Indiana bituminous coal were chosen to evaluate the effects of flue gas conditioning on coals other than lignites. Three runs were completed with Monticello lignite, including a baseline test, a conditioning test with high temperature injection $\left(700^{\circ} \mathrm{F}\right)$ of the additives, and a conditioning test with low temperature injection $\left(350^{\circ} \mathrm{F}\right)$. Two tests were conducted with each of the other coals: a baseline test, and a low temperature injection test. For all of the Phase II conditioning tests, the ammonia and $\mathrm{SO}_{3}$ injection rates were set at 25 and $12 \mathrm{ppm}$, respectively. To provide a better understanding of dust cake build-up and its relationship to penetration, the cleaning cycle for the Phase II tests was changed from that used during phase I. Starting with new bags, the first three hours were performed without cleaning, after which all of the bags were cleaned off-line every two hours.

Table 5-4 summarizes the operating parameters for all of the tests conducted. 
TABLE 5-4

\section{TEST PARAMETERS}

\begin{tabular}{|c|c|c|c|c|c|c|}
\hline Coal & Chamber & $\begin{array}{l}\text { Clean: } \\
\text { Initial }\end{array}$ & $\begin{array}{r}\text { ng Interval } \\
\text { cycle }\end{array}$ & $\begin{array}{c}\mathrm{NH}_{3} \\
\text { Conc. } \\
\text { (ppm) }\end{array}$ & $\begin{array}{l}\mathrm{SO}_{3} \\
\text { Conc. } \\
\text { (ppm) }\end{array}$ & $\begin{array}{c}\text { Test } \\
\text { Duration }\end{array}$ \\
\hline Falkirk & Shaker & $3 \mathrm{hrs}$ & 3 bags $/ 20 \mathrm{~min}$ & - & -- & 11 hrs \\
\hline Falkirk & Shaker & 3 hrs & 3 bags $/ 20 \mathrm{~min}$ & 130 & - & $4 \mathrm{hrs}$ \\
\hline Falkirk & Shaker & $4 \mathrm{hrs}$ & -- & - & 12 & $4 \mathrm{hrs}$ \\
\hline Falkirk & Shaker & $2 \mathrm{hrs}$ & All bags-once & 60 & 12 & 4 hrs \\
\hline Falkirk & Shaker & 3 hrs & $3 \mathrm{bags} / 20 \mathrm{~min}$ & - & 12 & 9 hrs \\
\hline Falkirk & Shaker & $3 \mathrm{hrs}$ & $3 \mathrm{bags} / 20 \mathrm{~min}$ & 45 & 12 & $8 \mathrm{hrs}$ \\
\hline Big Brown & Shaker & 2 hrs & $3 \mathrm{bags} / 20 \mathrm{~min}$ & 45 & 12 & 10 hrs \\
\hline Big Brown & Shaker & 2 hrs & 3 bags $/ 20 \mathrm{~min}$ & - & - & $4 \mathrm{hrs}$ \\
\hline South Hallsville & Shaker & $3 \mathrm{hrs}$ & $3 \mathrm{bags} / 20 \mathrm{~min}$ & -- & -- & $6 \mathrm{hrs}$ \\
\hline South Hallsville & Pulse Jet & $1 \mathrm{hr}$ & $3 \mathrm{~min}$ & - & - & $2 \mathrm{hr}$ \\
\hline South Hallsville & Pulse Jet & $2 \mathrm{hrs}$ & $3 \mathrm{~min}$ & 45 & 12 & $3 \mathrm{hrs}$ \\
\hline South Hallsville & Shaker & $2 \mathrm{hrs}$ & $3 \mathrm{bags} / 20 \mathrm{~min}$ & 45 & 12 & $4 \mathrm{hrs}$ \\
\hline South Hallsville & Shaker & $4 \mathrm{hrs}$ & 3 bags/40 $\mathrm{min}$ & - & -- & 49 hrs \\
\hline South Hallsville & Shaker & $4 \mathrm{hrs}$ & $3 \mathrm{bags} / 40 \mathrm{~min}$ & 45 & $12^{a}$ & 48 hrs \\
\hline South Hallsville & Shaker & - & 3 bags $/ 40 \mathrm{~min}$ & 230 & 100 . & 4 hrs \\
\hline Monticello & Shaker & $3 \mathrm{hrs}$ & All bags $/ 2 \mathrm{hrs}$ & 25 & 12 & 11 hrs \\
\hline Monticello $b$ & Shaker & $3 \mathrm{hrs}$ & All bags $/ 2$ hrs & 25 & 12 & 11 hrs \\
\hline Monticello & Shaker & $3 \mathrm{hrs}$ & All bags $/ 2 \mathrm{hrs}$ & -- & - & $11 \mathrm{hrs}$ \\
\hline Indiana Bit. & Shaker & $3 \mathrm{hrs}$ & All bags $/ 2 \mathrm{hrs}$ & 25 & 12 & $10 \mathrm{hrs}$ \\
\hline Indiana Bit. & Sl laker & $3 \mathrm{hrs}$ & All bags/2 hrs & - & $-\infty$ & $11 \mathrm{hrs}$ \\
\hline Sarpy Creek & Shaker & 3 hrs & All bags $/ 2$ hrs & 25 & 12 & 11 hrs \\
\hline Sarpy Creek & Shaker & $3 \mathrm{hrs}$ & All bags $/ 2$ hrs & - & - & 11 hrs \\
\hline
\end{tabular}

a First test the $\mathrm{SO}_{3}$ generator was used. All tests following used the generator as well.

b Injection temperature of $\mathrm{SO}_{3}$ and ammonia was $350^{\circ} \mathrm{F}$ for this test and all following tests. For all previous tests the injection temperature was $700^{\circ} \mathrm{F}$. 


\subsubsection{Effects of $\mathrm{SO}_{3}$ and Ammonia Conditioning on Baghouse Emissions}

Baghouse removal efficiency results determined by inlet and outlet dust loading measurements are given in Table 5-5. A significant improvement in removal efficiency is clearly seen using $\mathrm{SO}_{3}$ and ammonia conditioning. Removal efficiency for a Beulah lignite is included as reference since, prior to the flue gas conditioning work, this coal resulted in the highest removal efficiency of all coals tested (1). The results from the first series of tests (Phase I) cannot be compared directly to those from the Phase II tests, since the cleaning cycles were different. During Phase I, the outlet dust loadings included three to four 20 minute cleaning intervals while the dust loadings from phase II were completed between bag cleanings. Therefore, the Phase I dust loadings included the increased emissions that occur immediately following bag cleaning. However, for both series of tests the dust loading measurements show significant improvement in removal efficiency. The reduction in penetration ranged from a factor of 400 for Big Brown to 2.25 for Sarpy Creek.

Baghouse emissions as a function of time were meastired using the APS 33. Typical particle size distributions (0.5 to 15 jum) for the conditioned and nonconditioned tests (South Hallsville) are given ir Figure 5-9. Figures 5-10 to 5-17 present the respirable mass emissions as a function of time for all the coals tested. Flgure 510 shows respirable mass emissions from the shaker chamber with no cleaning cycle for three coals, starting with clean bags. With conditioning, respirable mass emissions quickly drop for the first 40 minutes of dust cake build-up and then appeared to remain constant. After 40 minutes respirable mass emissions are reduced wy 3 to 4 orders of magnitude when conditioned with $\mathrm{SO}_{3}$ and ammonia. The baghouse removal efficiency at this point is greater than $99.999 \%$. cleaning cycle effects are shown in Figures 5-11 to 5-16. As expected, just after bag shaking there is an increase in emissjons for the conditioning tests but there is also rapid recovery. 
PERCENT BAGHOUSE REMOVAL EFFICIENCY DETERMINED BY EPA METHOD 5 DUST LOADINGS

Coal

Nonconditioned

Conditioned

(Phase I - $20 \mathrm{~min}$. cleaning interval)

Beulah

Falkirk

Big Brown

South Hallsville,

South Hallsvilleb

(Phase II - 2 hour cleaning interval)

Monticello

Monticello

Sarpy Creek

Indiana Bituminous
99.93

94.70

80.00

91.03

99.03
Not tested

$99.64^{\mathrm{a}}$

99.95

99.90

99.76
96.57
96.57
$99.98 \mathrm{C}$
99.82
$99.97^{\mathrm{d}}$
99.41
99.92
99.99

a A leak between compartments caused some forward flow through bags while shaking. Removal efficiency would likely be higher if the leak had not occurred.

b Pulse jet results with felted fabric.

c High temperature injection of conditioning agents $\left(700^{\circ} \mathrm{F}\right)$.

d Low temperature injection of conditioning agents $\left(350^{\circ} \mathrm{F}\right)$.

Throughout several cleaning cycle intervals, there is a significant reduction in fine particle emissions for all the coals with the exception of the Sarpy creek subbituminous coal. For Sarpy Creek there was still a reduction, but it was not as significant as for the previous coals. This may be a result of differences in ash chemistry as will be discussed in section 5.5.6. Figure 5-17 shows the effects of conditioning with South Hallsville, Texas lignite when using a felted fabric in a pulse jet. Starting with a new felted fabric, emissions were about the same for both the conditioned and $5-63$ 


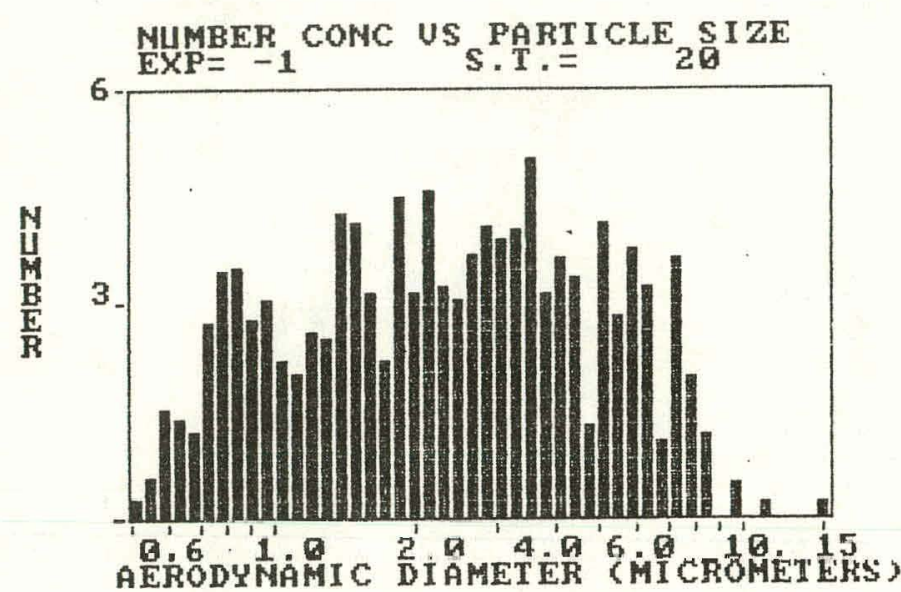

WITH CONDITIONING

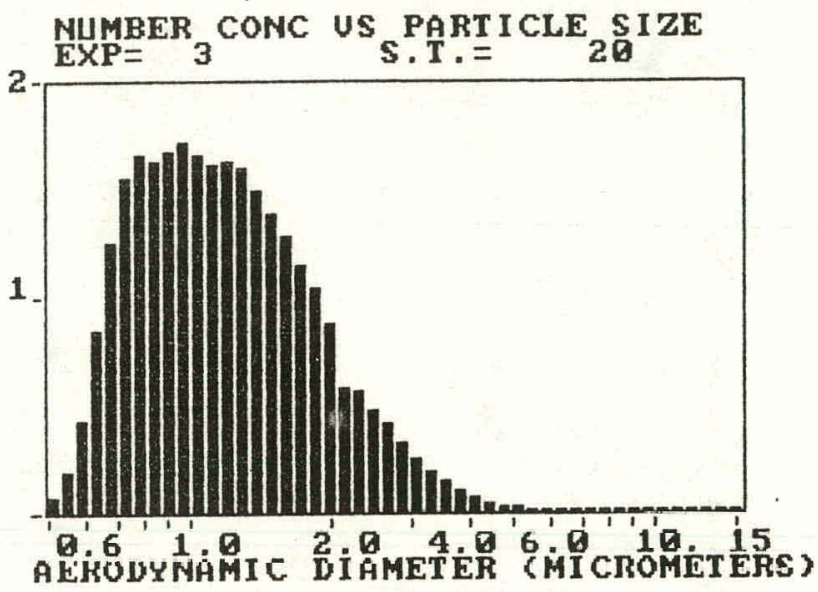

WITHOUT CONDITIONING

Figure 5-9. Particle size distributions $(0.5$ to $15 \mu \mathrm{m})$ for South Hallsville lignite as measured using the APS 33 .

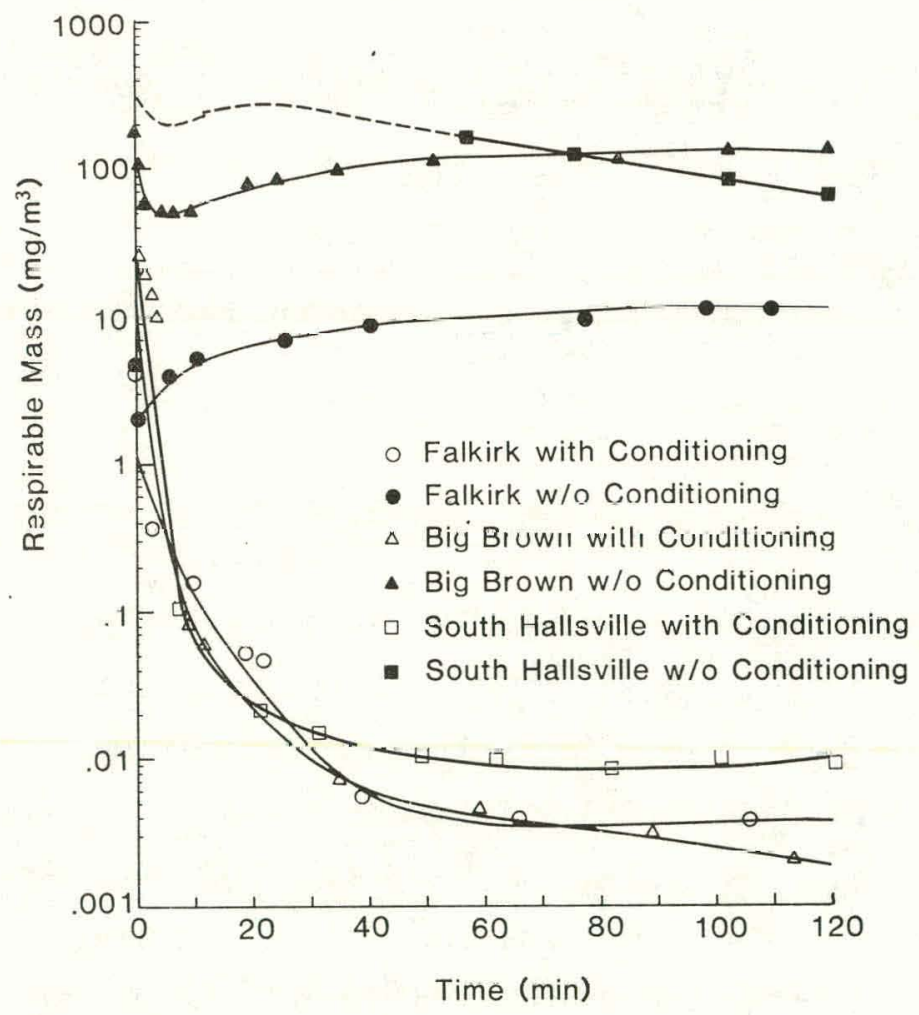

Figure 5-10. Respirable mass emissions vs time for Falkirk, Big Brown, and South Hallsville coals without bag cleaning. 


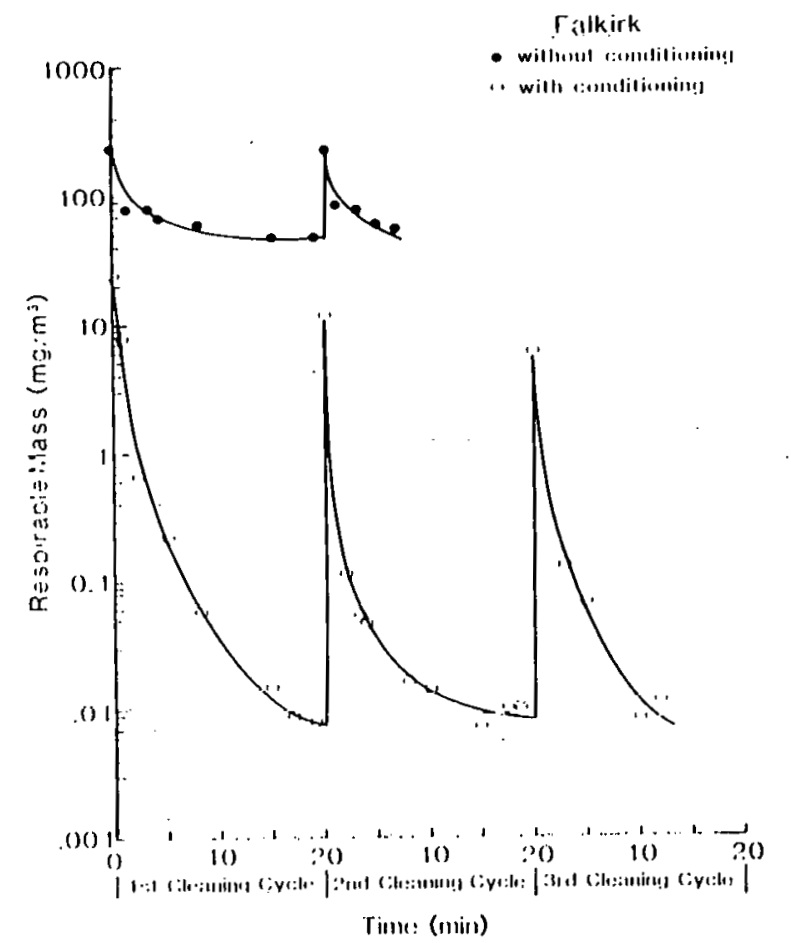

Figure 5-11. Respirable mass emissions vs time with and without conditioning for Falkirk lignite using shaker bag cleaning.

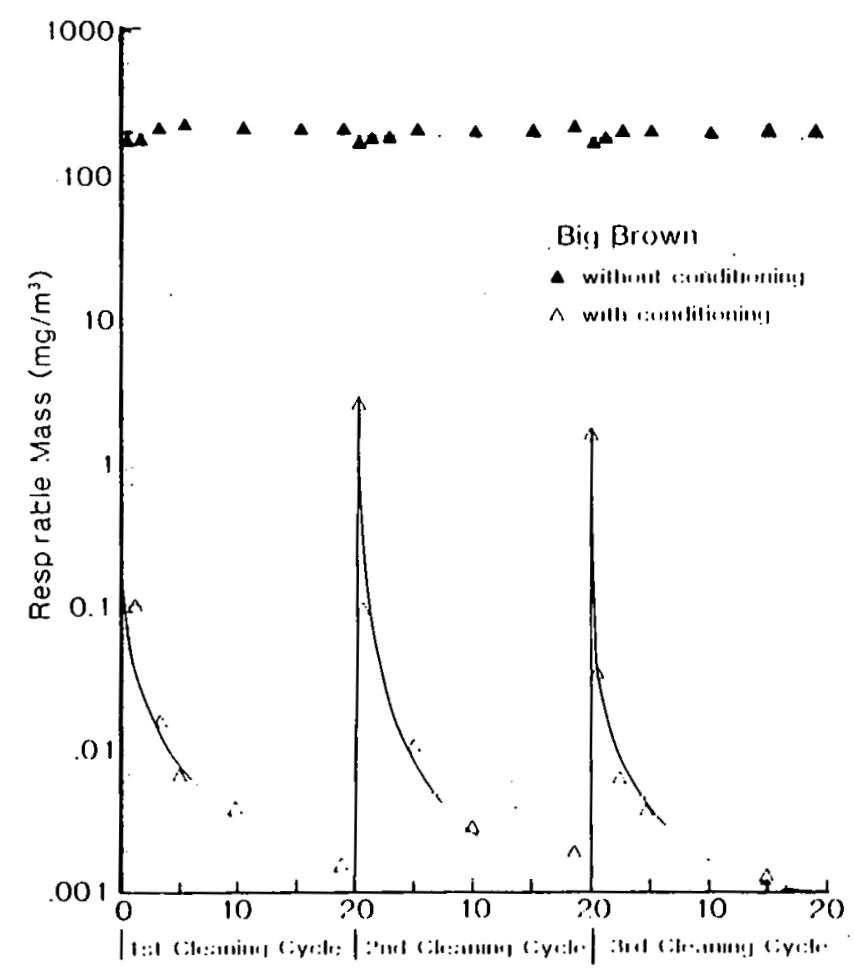

Time: (mil1)

Figure 5-12. Respirable mass emissions vs time with and without conditioning for Big Brown lignite using shaker bag cleaning. 


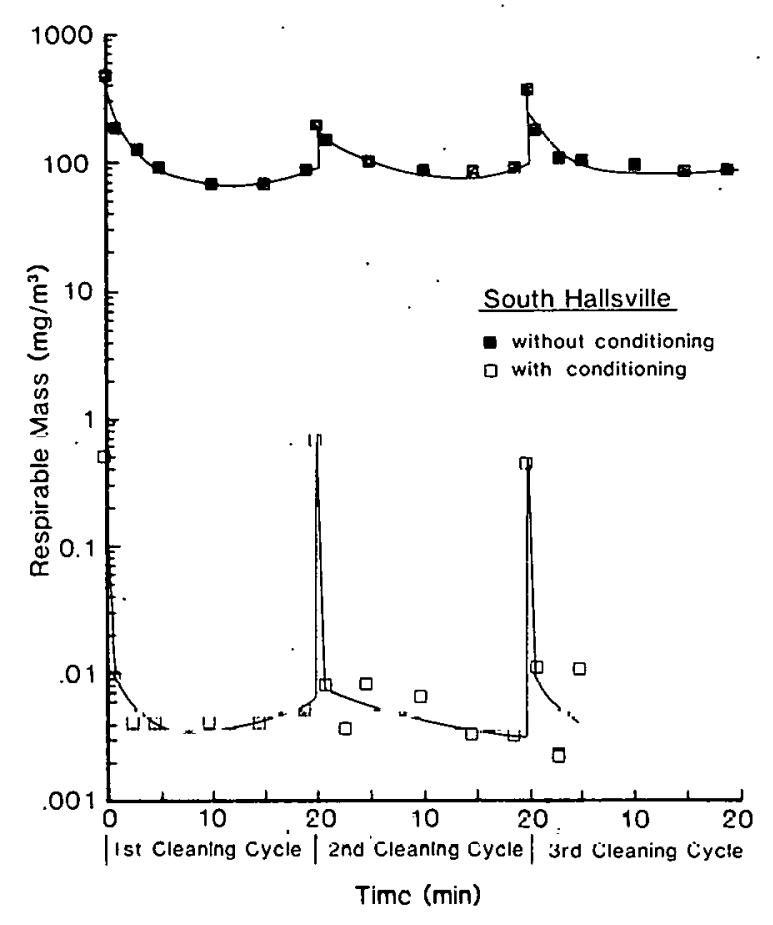

Figure 5-13. Respirable mass emissions vs time with and without conditioning for South Hallsville lignite using shaker bag cleaning.

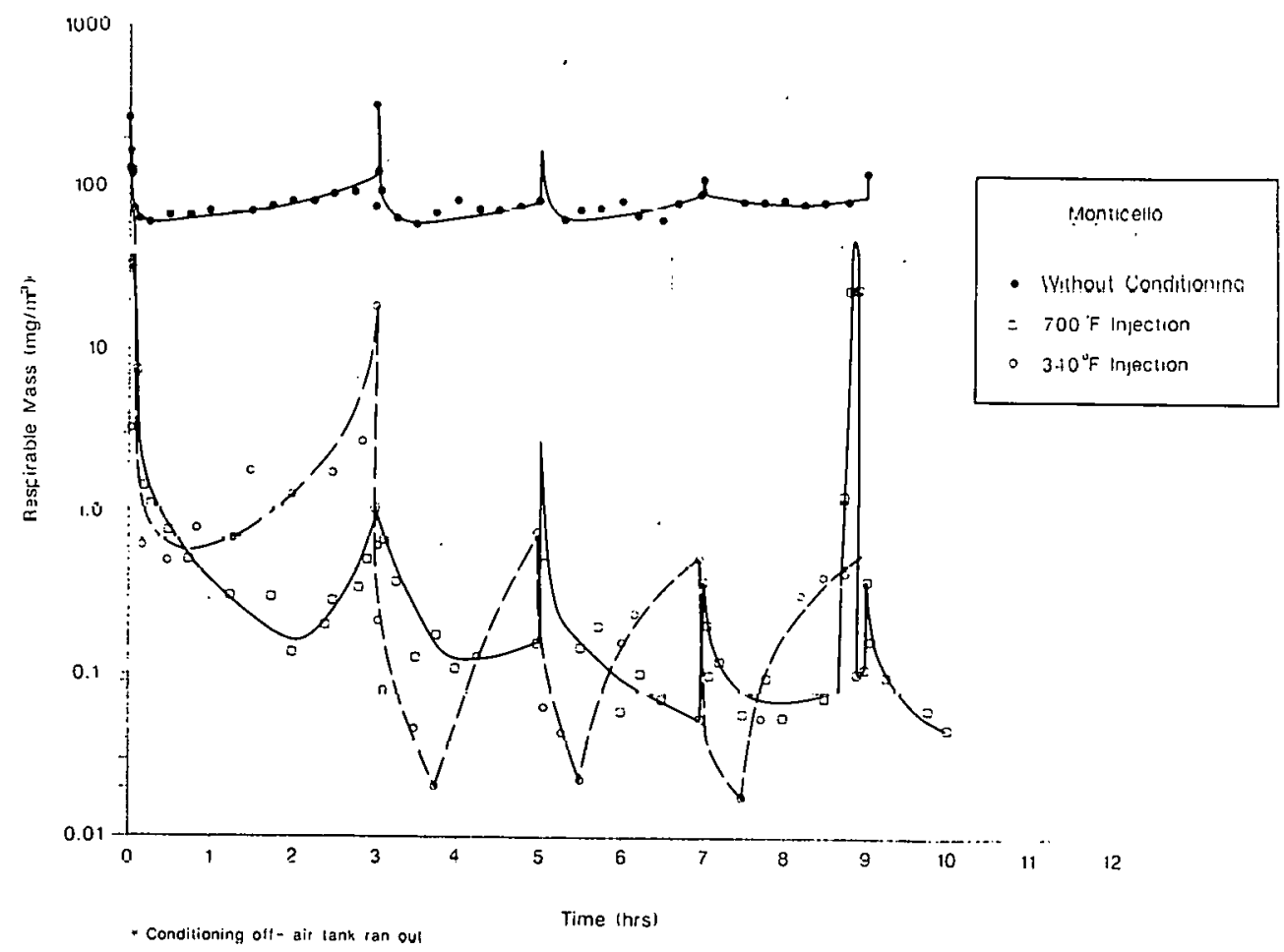

Figure 5-14. Respirable mass emissions vs time with and without conditioning for Monticello lignite using shaker bag cleaning. 


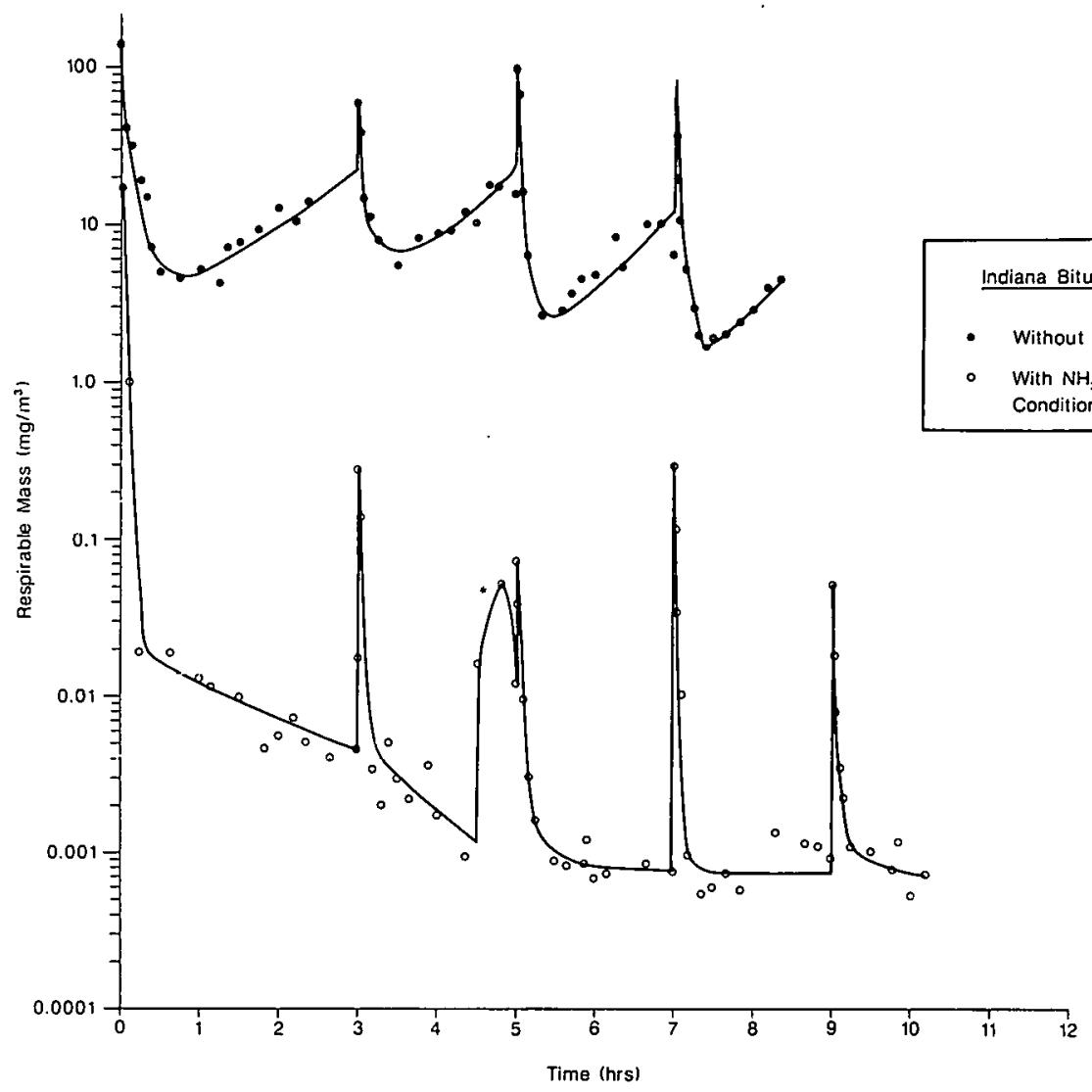

* Coal Plug

Figure 5-15. Respirable mass emissions vs time with and without conditioning for Iridiara bituminous coal using shaker bag cleaning.

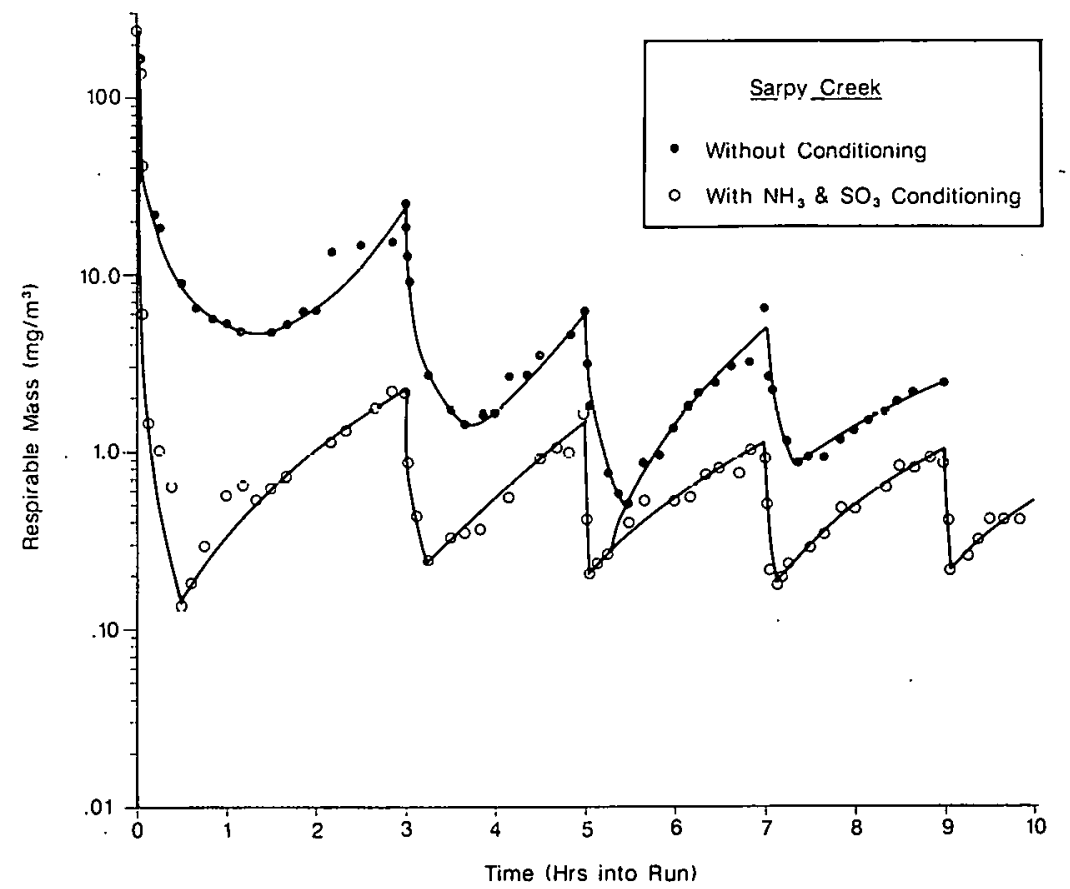

Figure 5-16. Respirable mass emissions vs time with and without conditioning for Sarpy Creek coal using shaker bag cleaning. 


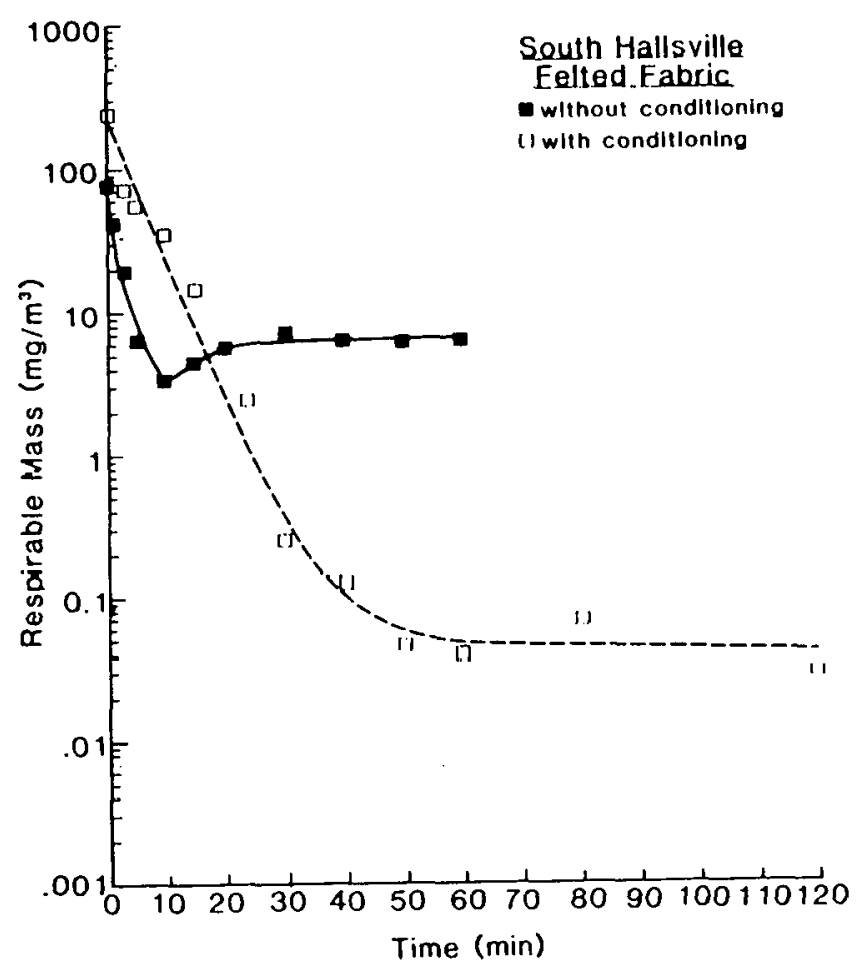

Figure 5-17. Respirable mass emissions vs time with and without corditioning for South Hallsville lignite using felted bags in pulse jet chamber (no bag cleaning).

nonconditioned tests for the first 20 minutes; at which point emissions without conditioning remained steady. However, for the test with conditioning, emissions continued dropping until they were reduced by two orders of magnitude atter which they remained constant.

The Monticello. Texas lignite was used to determine if the temperature of the injection point of $\mathrm{SO}_{3}$ and ammonia had an effect on baghouse emissions. Ihree tests were completed, a baseline test, a conditioning test at an injection temperature of $700^{\circ} \mathrm{F}$, and a conditioning test at an injection temperature of $350^{\circ} \mathrm{F}$. Figure $5-15$ illustrates that the injection temperature did not have much of an effect on respirable mass emissions. Therefore, the tests with the Sarpy creek and Indiana bituminous coals were completed at the lower injection temperature. 
The DMPS and CNC were used to measure submicron particles that penetrate the baghouse since there was a concern that conditioning could produce a large number of these particles. Results for the South Hallsville tests show that submicron particle emissions were also reduced at the baghouse outlet by over 3 orders of magnitude when comparing the conditioned to the nonconditioned test. These instruments were used more extensively for the tests with Monticello, Sarpy creek and Indiana coals and again, $\mathrm{SO}_{3}$ and ammonia conditioning resulted in a substantial reduction in submicron emissions for all coals with the exception of the Sarpy creek. However, even for this coal the submicron particulate emissions were still less for the conditioned test compared to the baseline. Figures 5-18 to 5-20 present the CNC data. Figure 5-21 gives an example (Indiana bituminous coall of the submicron particle size distribution for a conditioned and nonconditioned test using the DMPS.

Flue gas conditioning has been shown to be an effective method of reducing fine particulate emissions from a baghouse for all lignites tested. For the two higher rank coals tested, the bituminous coal showed a substantial reduction in emissions with conditioning, while the subbituminous coal tested showed a smaller level of improvement. 


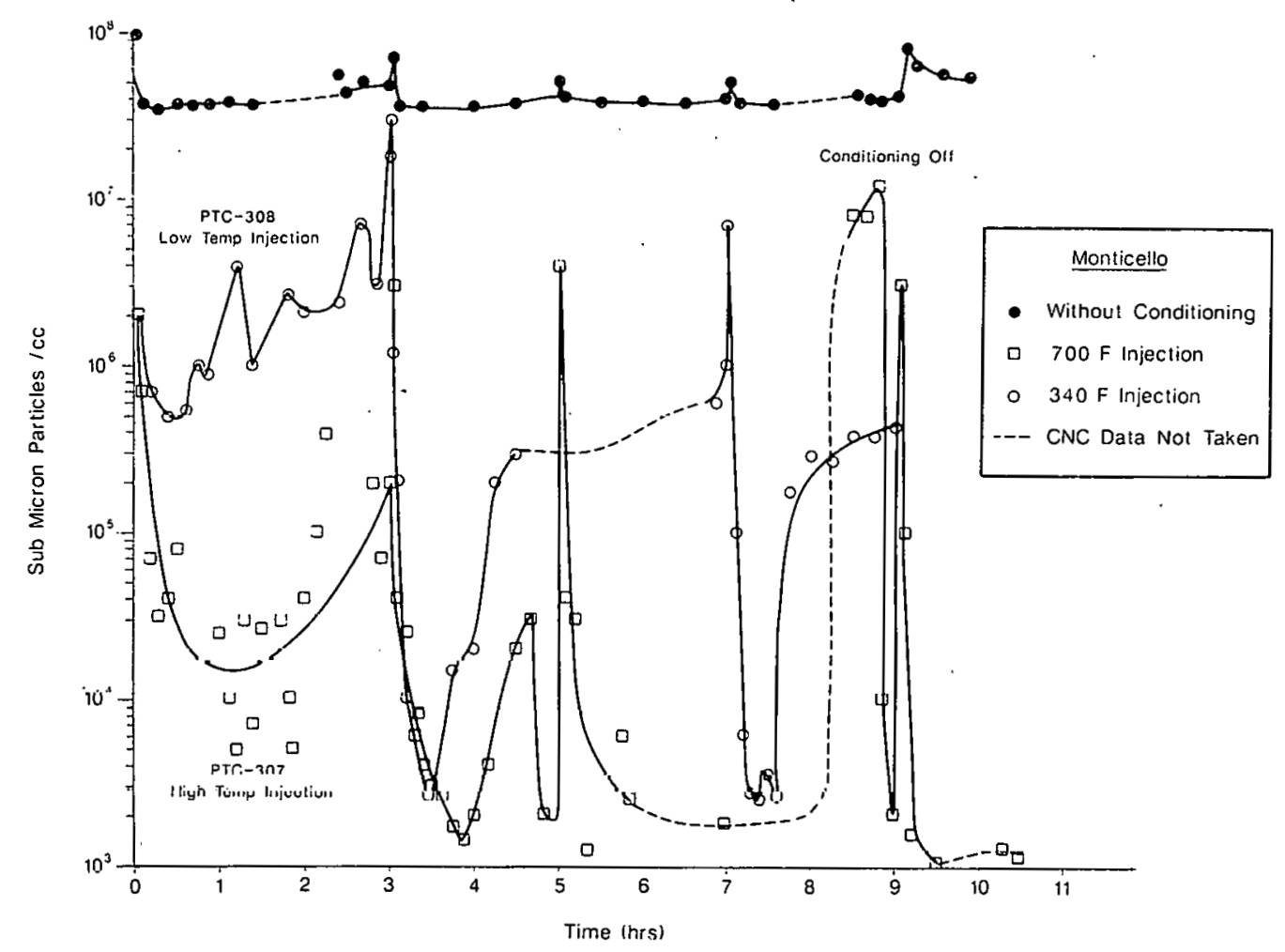

Figure 5-18. Submicron particle emissions for Monticello lignite.

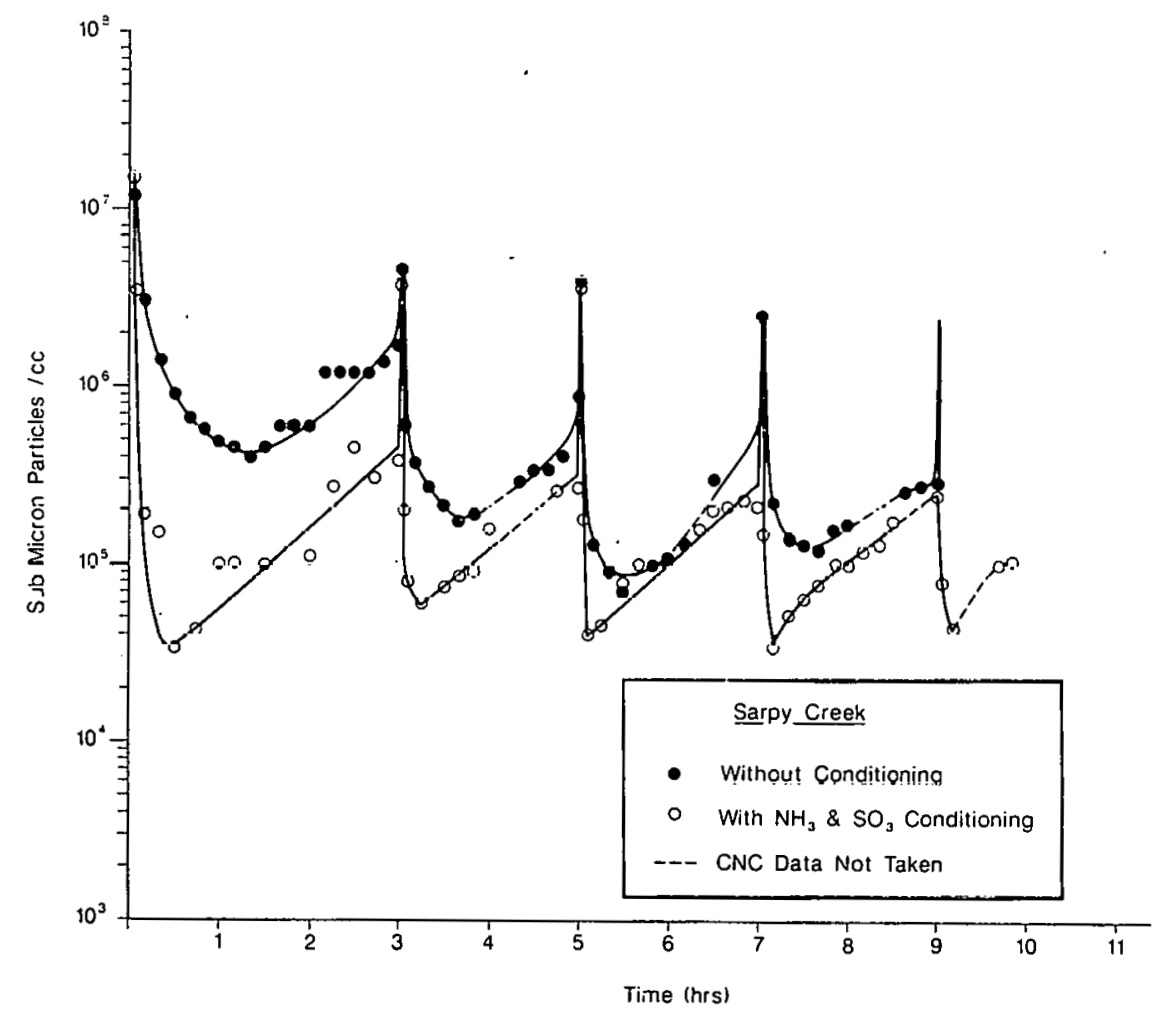

Figure 5-19. Submicron particle emissions for Sarpy creek subbituminous coal. 


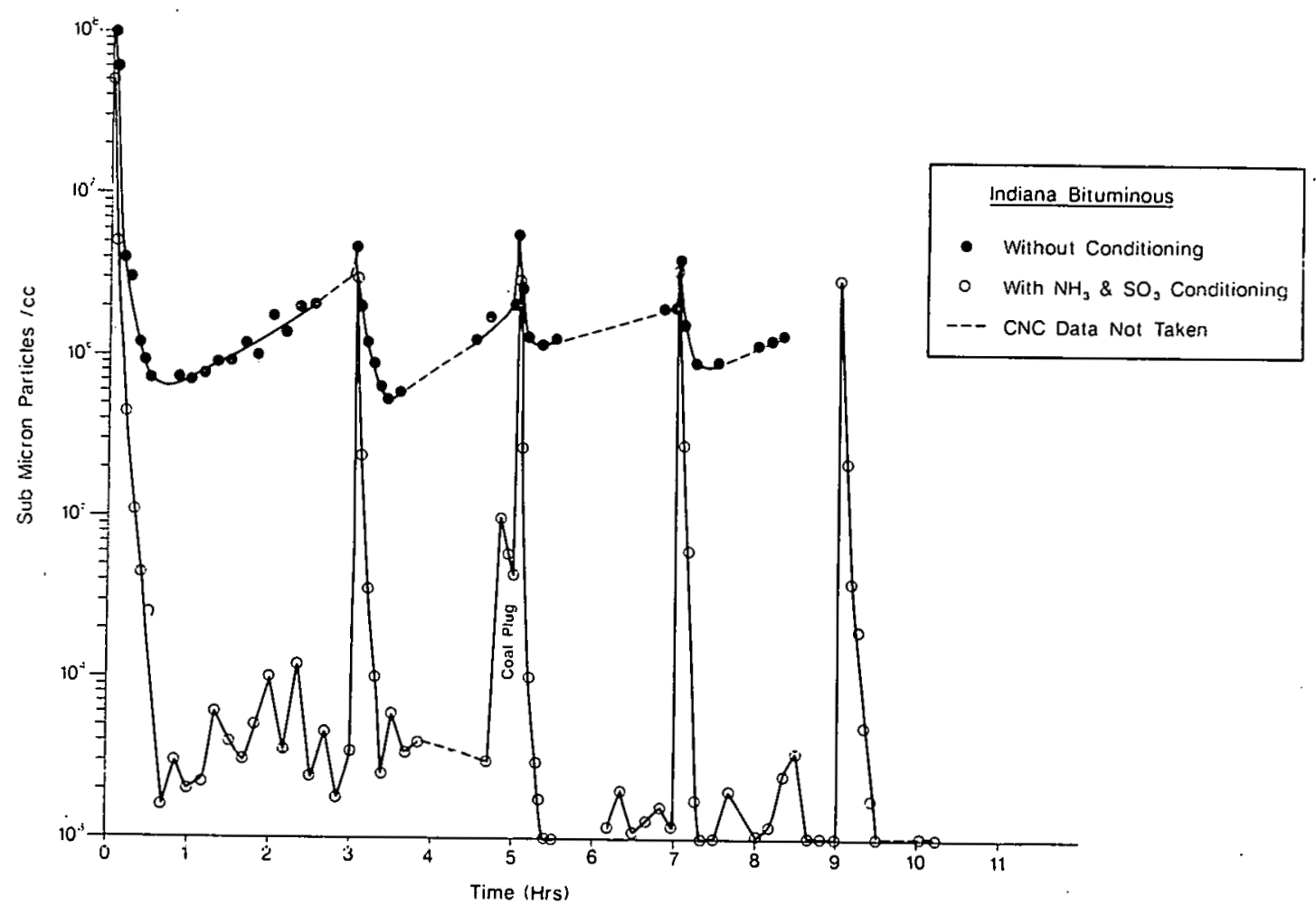

Figure 5-20. Submicron particle emissions for an Indiana bituminous coal.

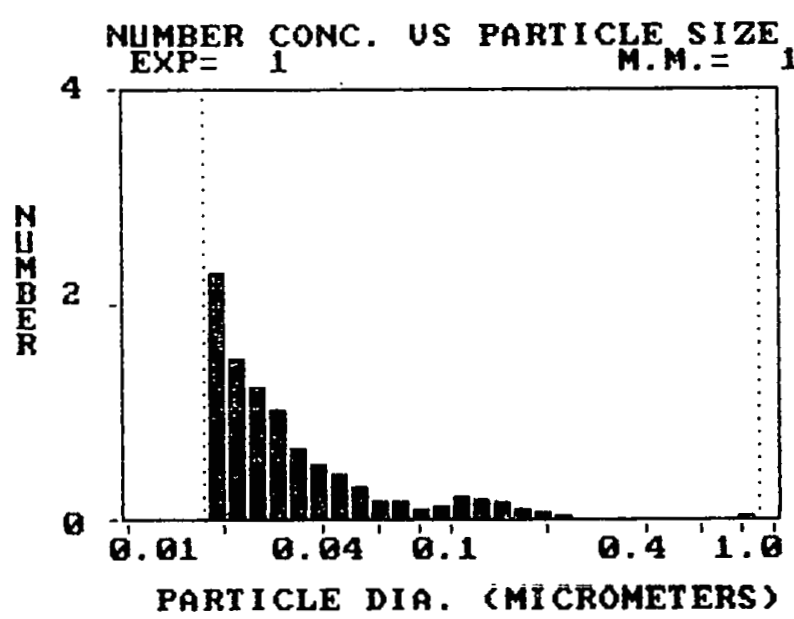

WITH CONDITIONING

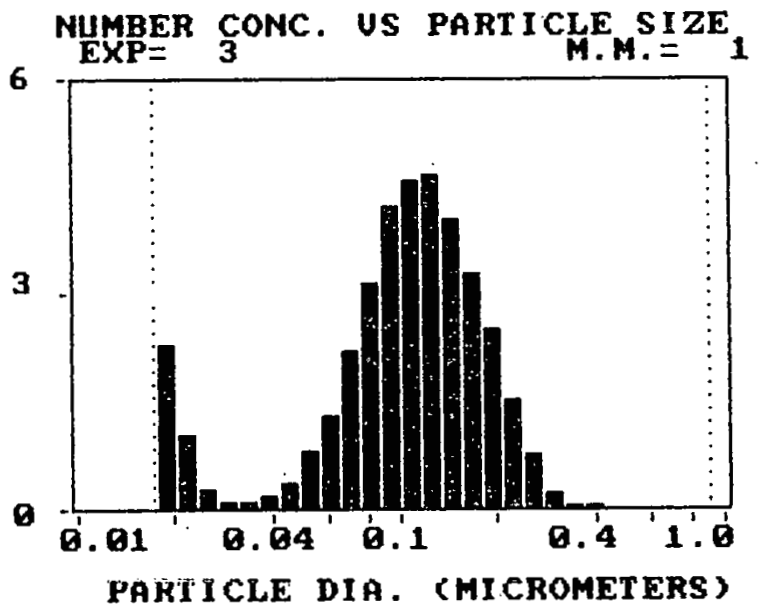

WITHOUT CONDITIONING

Figure 5-21. Submicron particle size distributions with and without conditioning for an Indiana bituminous coal as measured by the DMPS. 


\subsubsection{Effect of Conditioning on Baghouse Pressure Drop}

Baghouse pressure drop as a function of time is plotted in Eigures 5-22 to 5-29 for all of the conditioning tests. All tests were started with new fabric except for the Falkirk conditioning test for which the bags were hand vacuumed. For the shaker cleaning tests, all runs were with the same woven glass fabric. Two additional tests with south Hallsville, Texas lignite were completed using cage mounted, felted Ryton bags, and pulse jet cleaning. Looking at the data, there is clearly a reduction in pressure drop with conditioning. The level of pressure diup reduction, however, is highly dependent on the coal. During the initial filtration cycle, starting with new fabric, the slope of the pressure drop versus time plot is a measure of the specific dust cake resistance, $K_{2}$. The plots allow a direct comparison of $K_{2}$ between the conditioned and nonconditioned tests, since the dust loadings remained constant for the same coal. After starting the cleaning cycle, the pressure drop is the result of the residual dust cake resistance as well as resistance of the dust deposited during the cycle. Calculated values of $\mathrm{K}_{2}$ are given in Table 5-6. The most significant reduction in $\mathrm{K}_{2}$ occurred for the Big Brown and Indiana bituminous coals with shaker cleaning and for the Scuth Hallsville test with cage mounted bags and pulse jet cleaning. For the Monticello and Sarpy creek coals, there was not a significant difference in pressure drop during the initial filtration cycle. However, after several cleaning cycles, there was a greater difference as noted in Figures 5-27 and 5-29. For these tests, calculated $K_{2}$ values were based on the 4 th filtration cycle. The starting pressure drop at the beginning of the cycle for the conditioned and baseline tests was approximately the same, so this should be a valid comparison. Why the pressure drop reduction did not show up in the first filtration cycle is not apparent. Further discussion on the mechanism of reduced pressure drop is given in Section 5.5.7.

The effect of conditioning on residual dust cake weight is also important becaluse of the long-term effect on pressure drop. Also 
listed in Table $5-6$ is the residual dust cake weight, after normal bag cleaning, at the end of the tests. Measurements were taken only for the $50 \mathrm{hr}$. tests and the $11 \mathrm{hr}$. tests. Results show that there was a statistically significant difference (at the $99 \%$ confidence level) in residual dust cake weight for all coals except for Sarpy creek. These results indicate that conditioning facilitates bag cleaning, at least for the cleaning method employed for these tests. The shaker cleaning, however, is quite vigorous and these results may not be indicative of the effect of conditioning on residual dust cake weight with gentle reverse gas cleaning. Nevertheless, these results are encouraging and would indicate that longer-term testing with reverse gas cleaning is warranted.

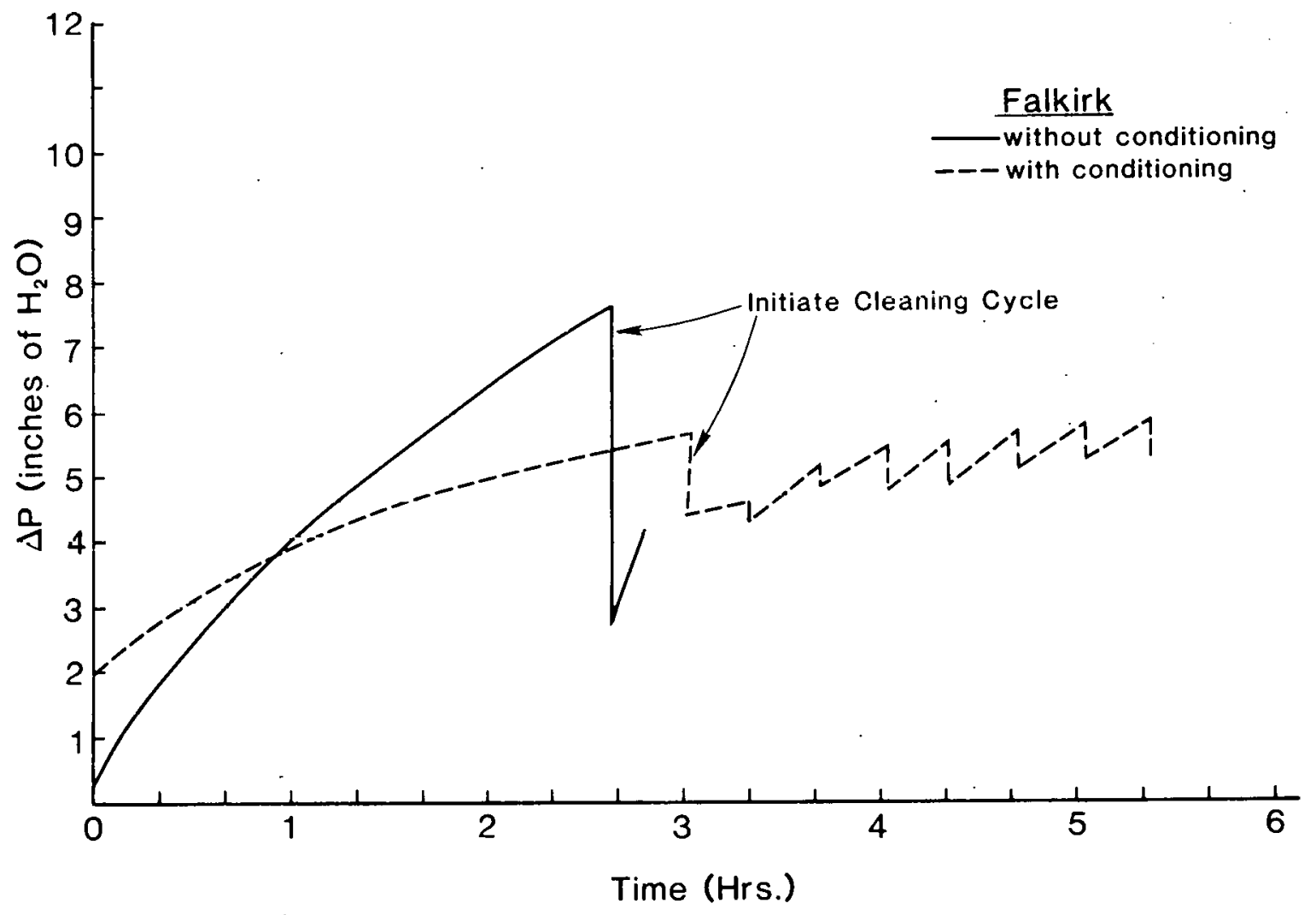

Figure 5-22. Pressure drop vs time with and without conditioning for Falkirk lignite using shaker bag cleaning. 


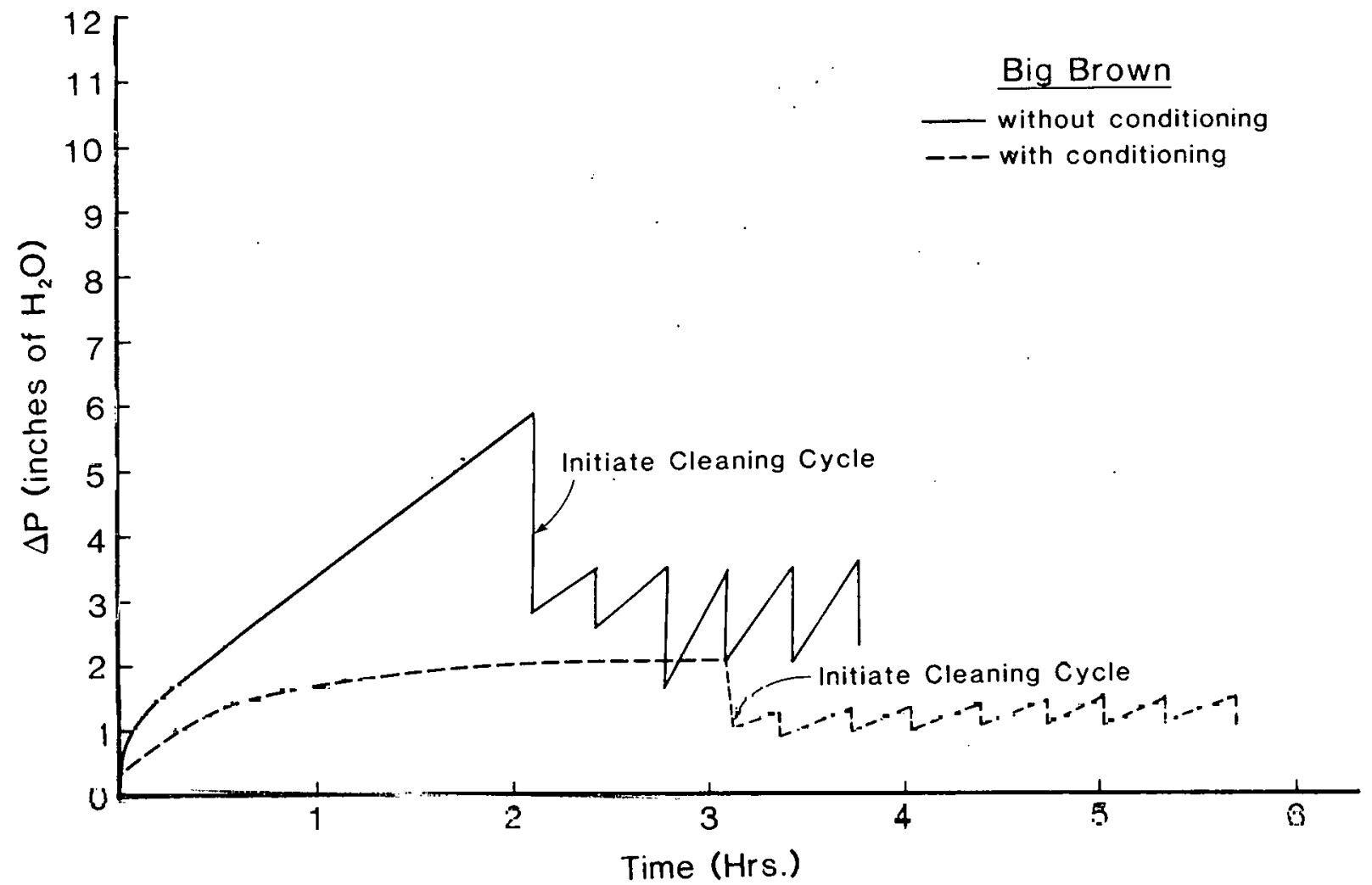

Figure 5-23. Pressure drop vs time with and without conditioning for Big Brown lignite using shaker bag cleaning.

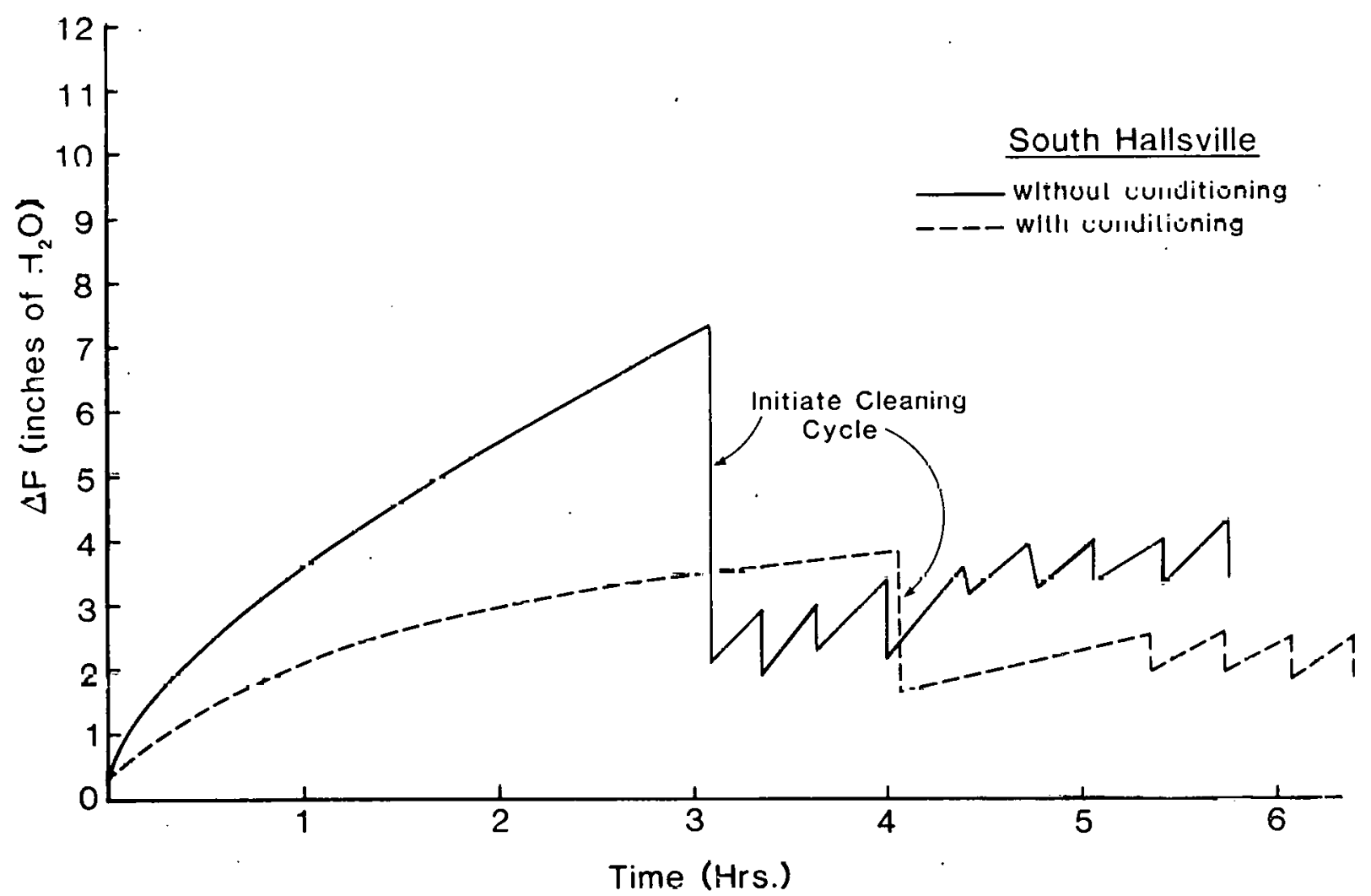

Figure 5-24. Pressure drop vs time with and without conditioning for South Hallsville lignite using shaker bag cleaning. 


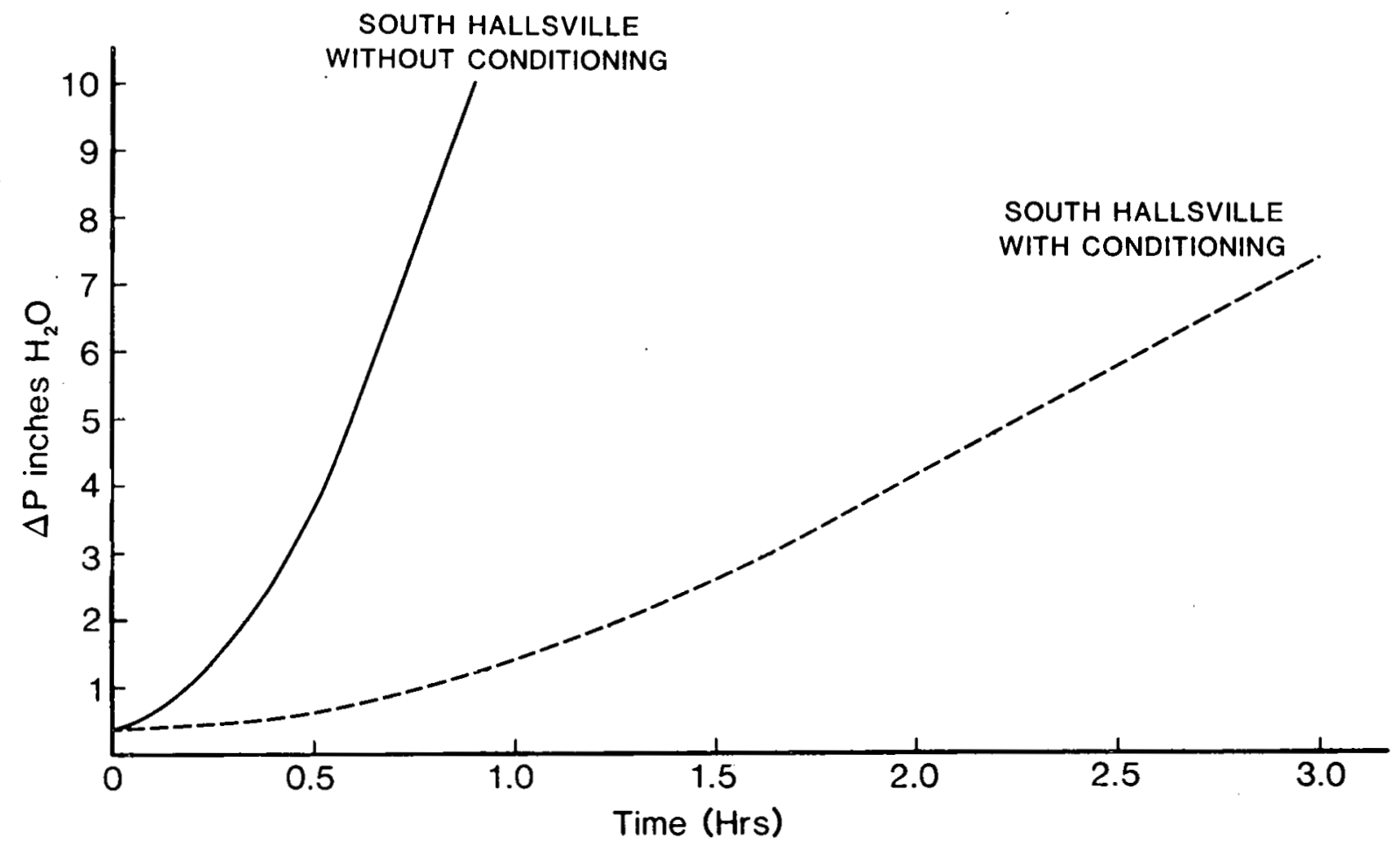

Figure 5-25. Pressure drop vs time with and without conditioning for South Hallsville lignite using felted bags in pulse jet chamber (no bag cleaning).

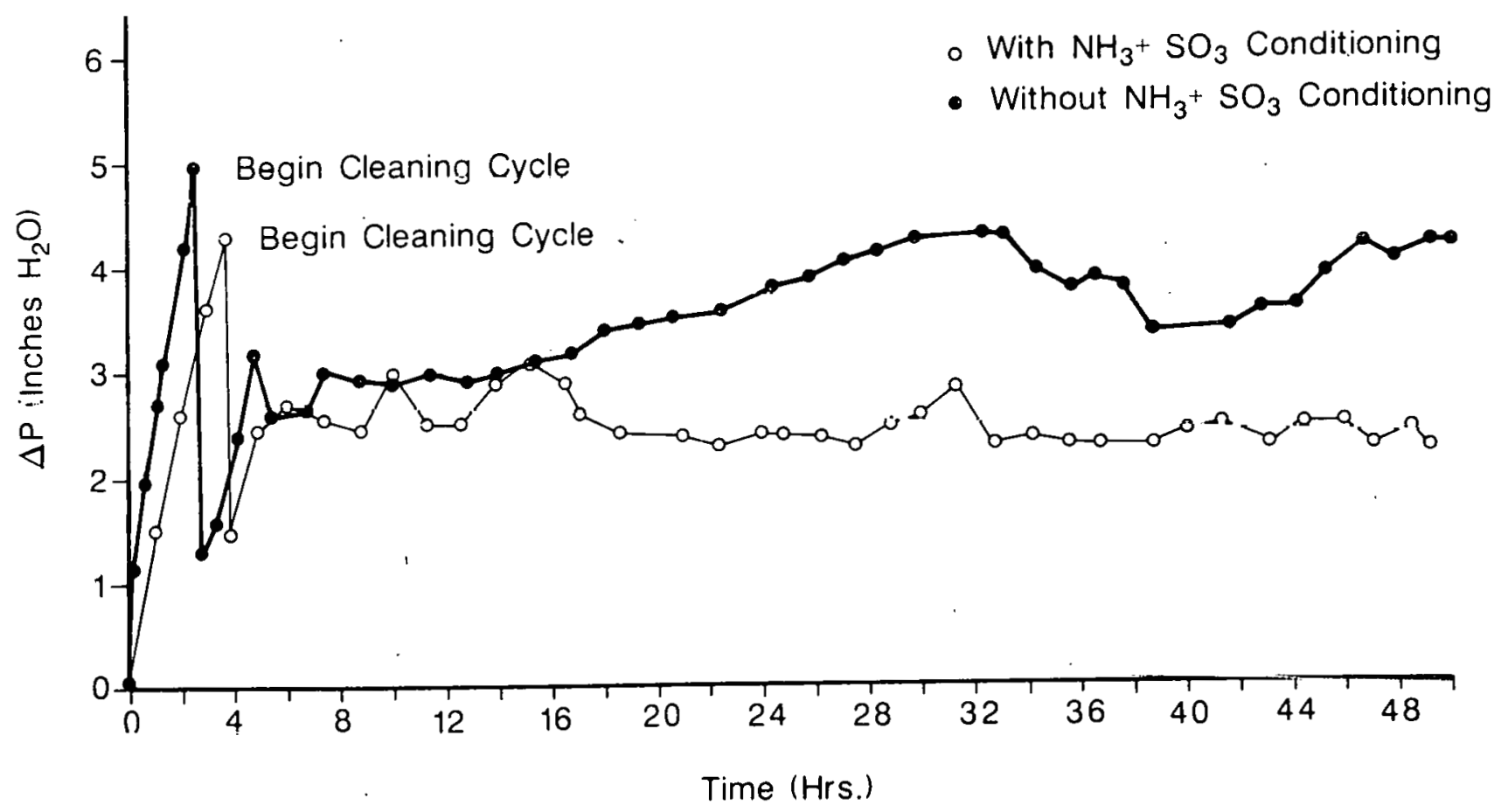

Figure 5-26. Pressure drop vs time with and without conditioning for South Hallsville lignite using shaker bag cleaning (50 hour tests). 


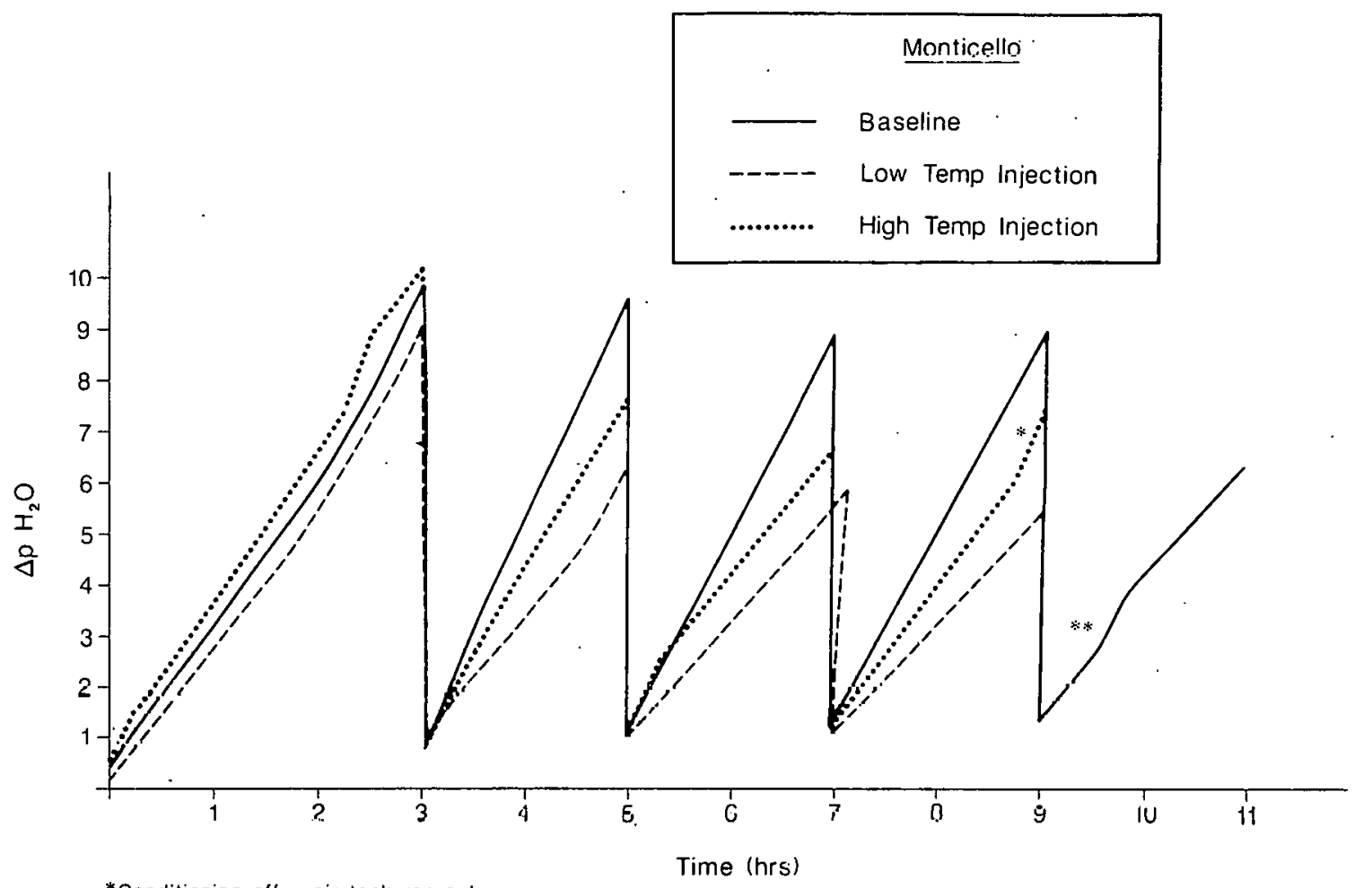

* Conditioning off - air tank ran out

$* 2$ sets of bags shook with forward gas flow

Figure 5-27, Pressure drop vs time with and without conditioning for Monticello ligrite using shaker bag clearing.

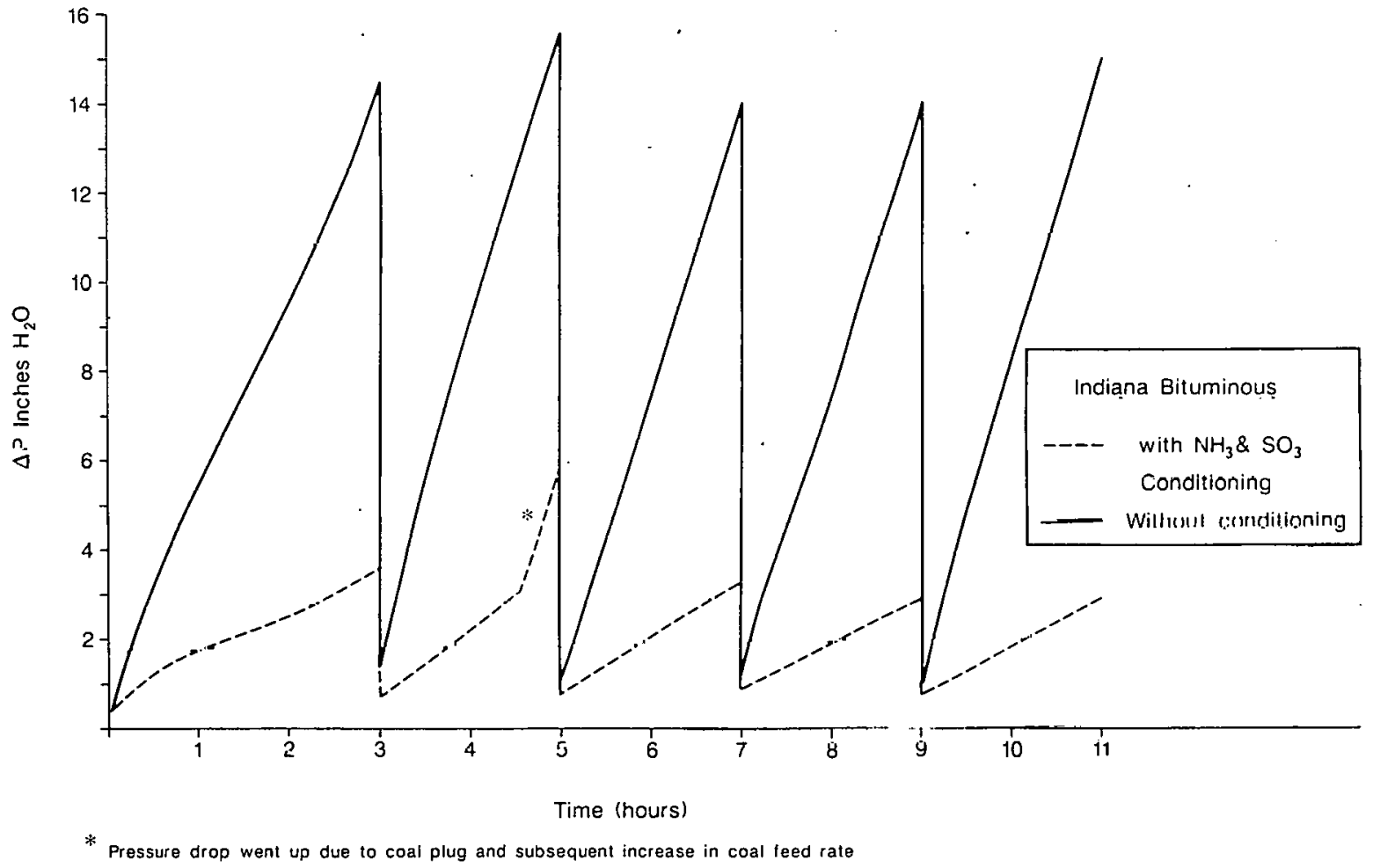

Figure 5-28. Pressure drop vs time with and without conditioning for Indiana bituminous coal using shaker bag cleaning. 


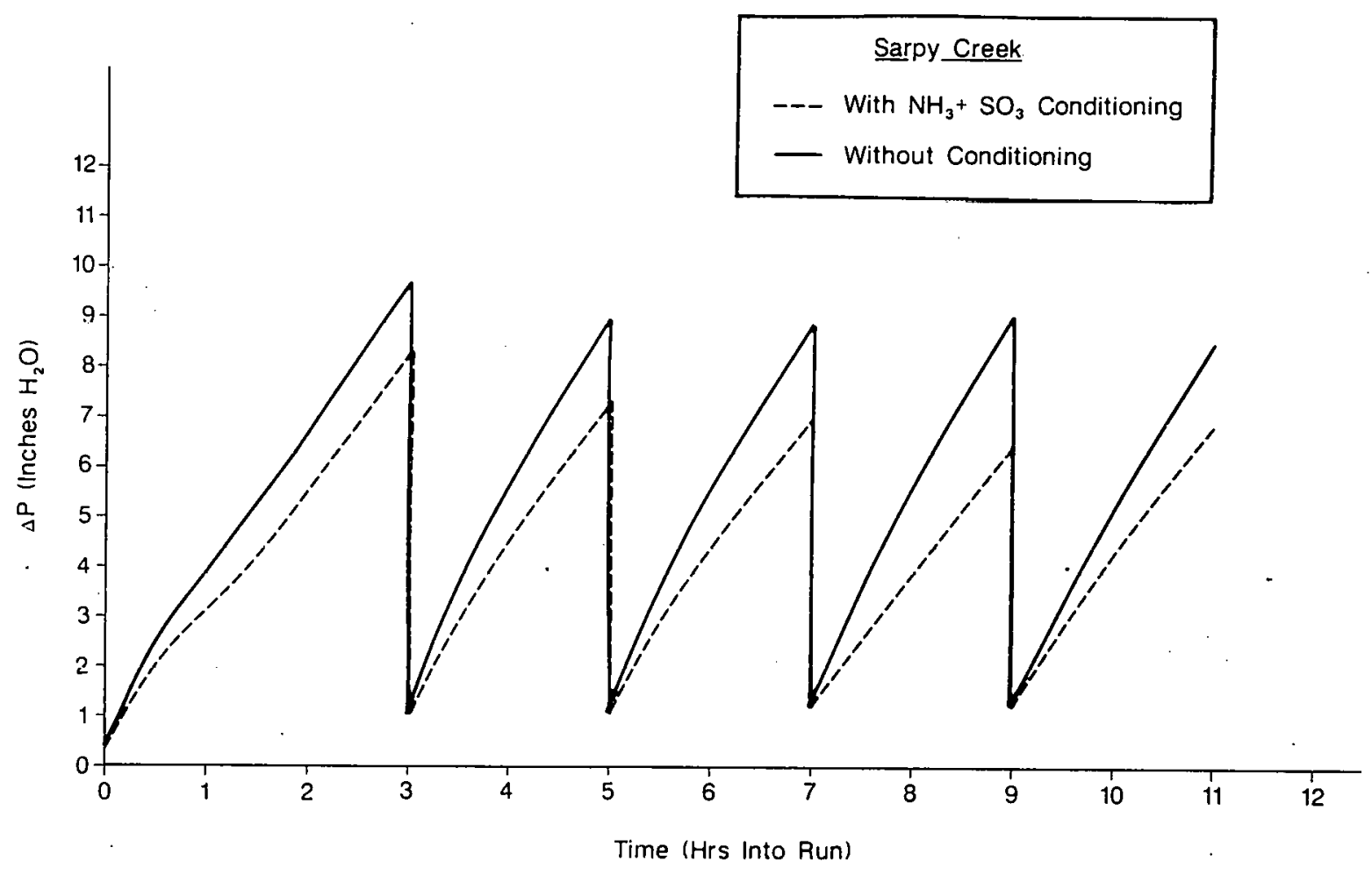

Figure 5-29. Pressure drop vs time with and without conditioning for Sarpy Creek subbituminous coal using shaker bag cleaning. 
TABLE $5-6$

SPECIFIC DUST CAKE RESISTANCE

\begin{tabular}{|c|c|c|c|c|c|c|c|}
\hline \multirow[t]{2}{*}{ COAL } & \multirow{2}{*}{$\begin{array}{l}\mathrm{A} / \mathrm{C} \\
\mathrm{ft} / \\
\mathrm{min}\end{array}$} & \multicolumn{3}{|c|}{ BASELINE } & \multicolumn{3}{|c|}{ CONDITIONED } \\
\hline & & $\begin{array}{l}\text { Dust } \\
\text { load } \\
\text { grains/ } \\
\text { scf }\end{array}$ & $\begin{array}{l}\text { Res.dust } \\
\text { cake } \\
\text { grams/ } \\
\text { bag }\end{array}$ & $\mathrm{K}_{2}^{\mathrm{a}}$ & $\begin{array}{l}\text { Dust } \\
\text { load } \\
\text { grains/ } \\
\text { scf }\end{array}$ & $\begin{array}{c}\text { Res.dust } \\
\text { cake } \\
\text { grams/ } \\
\text { bag }\end{array}$ & $\mathrm{k}_{2}^{\mathrm{a}}$ \\
\hline Falkirk & 3.3 & 3.0 & $N A^{b}$ & 7.5 & 3.0 & $\mathrm{NA} \mathrm{b}^{\mathrm{b}}$ & 3.0 \\
\hline Big Brown & 3.3 & $5.5^{c}$ & $\mathrm{NA}$ & 4.9 & $5.5^{\mathrm{C}}$ & $\mathrm{NA}$ & 1.1 \\
\hline $\begin{array}{l}\text { South Hallsville } \\
\text { ( } 6 \mathrm{hr} \text {. tests) }\end{array}$ & 3.3 & 3.2 & $\mathrm{NA}$ & 6.1 & 2.8 & NA & 2.9 \\
\hline $\begin{array}{l}\text { South Hallswille } \\
\text { (pulse jet) }\end{array}$ & 7.5 & $3.3^{c}$ & $\mathrm{NA}$ & 9.9 & $3.3^{\mathrm{C}}$ & NA & 1.9 \\
\hline $\begin{array}{l}\text { South Hallsville } \\
\text { (50 hr. tests) }\end{array}$ & 3.3 & 3.9 & 225 & 4.6 & 4.0 & 107 & 2.7 \\
\hline Monticello & 3.3 & 6.1 & 145 & $6.4^{\mathrm{d}}$ & 6.4 & 110 & $3.6^{\mathrm{d}}$ \\
\hline Indiana bituminous & 3.2 & 2.9 & 132. & 17.9 & 2.9 & 89 & 3.9 \\
\hline Sarpy creek & 3.3 & 3.2 & $170^{e}$ & $13.2^{\mathrm{d}}$ & 3.3 & $156^{\mathrm{e}}$ & $8.6^{\circ}$ \\
\hline
\end{tabular}

a Uniits for $\mathrm{K}_{2}$ are inches $\mathrm{H}_{2} \mathrm{O} /$ ( $\mathrm{lb}$ dust $/ \mathrm{ft}^{2}$ of fabric)-(ft/min)

$b$ Residual dust cake weight was not measured for the shorter tests

c Data not available for specific test; value is kased on previous runs with this coal

A Based on the 4 th filtration cycle

Baseline and conditioned values were not statistically difterent at the $95 \%$ confidence level 


\subsubsection{Effect of Conditioning on Physical Ash Properties}

Physical ash properties which conditioning might affect include the cohesiveness of the ash, the ash particle size distribution, and several electrical effects. Of these fly ash cohesiveness appears to be an the most important. A change in fly ash cohesiveness due to conditioning was observed for all the test coals except for sarpy creek, as is shown in Table 5-7. This is consistent with the baghouse emission results where sarpy creek showed the least improvement with conditioning. To help verify this data, samples of the nonconditioned and conditioned Big Brown $f l y$ ashes were sent to Southern Research Institute (SORI) to determine cohesiveness using a shear cell method. This method also indicated a substantial increase in cohesiveness due to conditioning. other nonconditioned ash samples sent to SORI showed the same relative cohesiveness as that obtained at UNDERC, confirming the validity of the UNDERC test method.

An example of the effect of conditioning on the fly ash particle size distribution is shown in Figure 5-30. This plot represents the most significant change observed for the conditioning tests. In this figure, the shaded area represents the particle size distribution range for all previous tests without conditioning for Big Brown lignite. There are two changes in particle size distribution which can be seen. First, there is an increase in mass for fine particles less than $0.5 \mu \mathrm{m}$, which can be explained by ammonium sulfate (or other ammonia- $\mathrm{SO}_{3}$ product) deposition on the comparatively large surface area of the small particles. However, the total mass percentage smaller than $0.5 \mu \mathrm{m}$ is still small at $0.2 \%$. A second change is the shift in the distribution curve in the 1 to 7 m range indicating a somewhat smaller percentage in this range with conditioning. An explanation for this shift is the possibility that flue gas conditioning promoted particle agglomeration in the duct prior to the baghouse inlet (where the particle size distribution was measured with a six-stage multicyclone). There would then be a shift 


\section{Breaking Force}

( lbs $x 10^{-2}$ )

\section{Nonconditioned}

\section{Beulah}

Falk.i.rk

Big Brown

South Hallsville

Monticello ('/00's' injection)

Monticello $\left(350^{\circ} \mathrm{F}\right.$ irjection)

Indiana bituminous

Sarpy Creek
52

4.4

5.5

12

10

10

11

15

\section{Conditioned}

Not tested

23

21

18

14

18

14

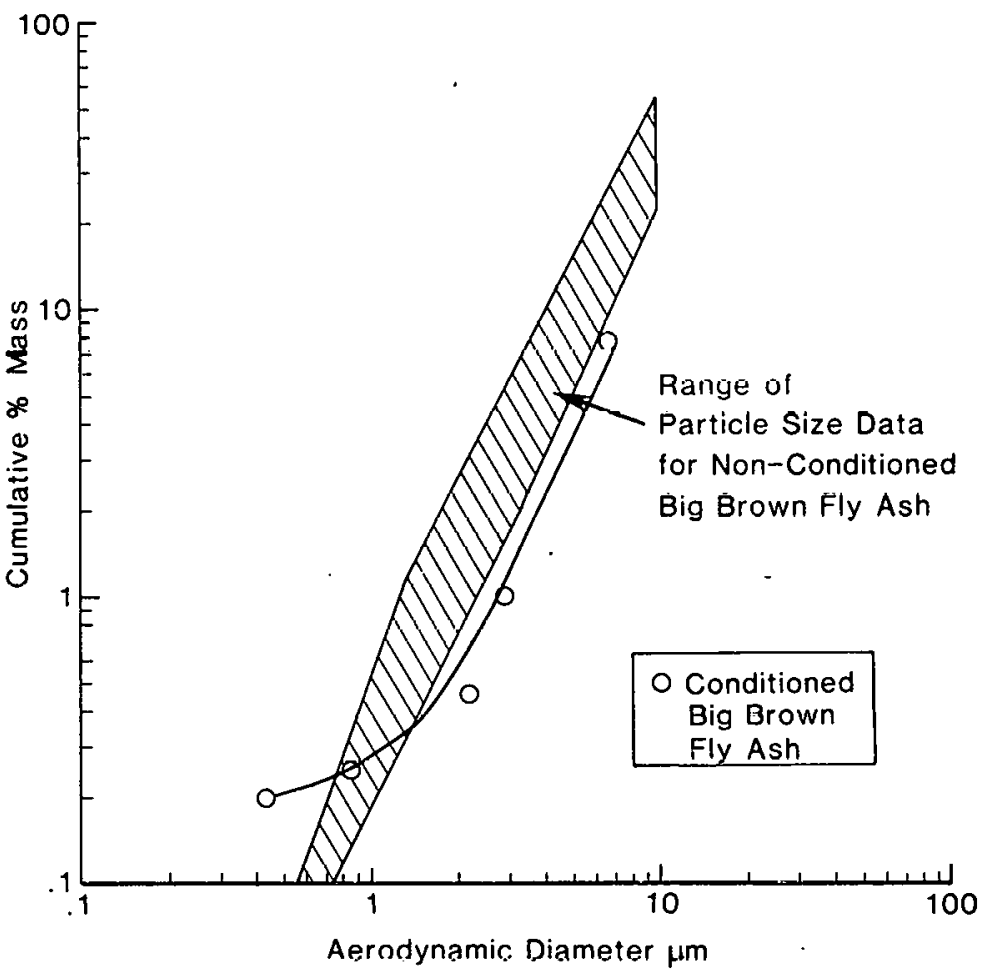

Figure 5-30. Particle size distribution for conditioned and nonconditioned Big Brown fly ash, measured with a six-stage multicyclone. 
in the distribution as shown in the graph. The relative change in particle size distribution, however, is quite small.

Possible changes in electrical characteristics due to conditioning could involve a change in the natural particle charge distribution of the fly ash in the flue gas prior to collection, or a change in the fly ash resistivity which may affect the charge dissipation rate in the dust cake. Particle charge of the aerosol prior to collection has not been measured in the conditioning tests to date, but measurement of charge effects is planned for future work. It is well known that $\mathrm{SO}_{3}$ conditioning will lower fly ash resistivity, so a change in resistivity would be expected with ammonia and $\mathrm{SO}_{3}$ conditioning. Fly ash resistivity was measured for the Big Brown and Solth Hallsville conditioning tests. At $300^{\circ} \mathrm{F}$, the noriconditioned fly ashes for Big Brown and South Hallsville had resistivities of $2.6 \times 10^{12}$ and $1.8 \times 10^{12} \mathrm{ohm}-\mathrm{cm}$, respectively. With conditioning, the Big Brown ash resistivity dropped to $4.5 \times$ $10^{10} \mathrm{ohm}-\mathrm{cm}$ while for South Hallsville it dropped to $7.0 \times 10^{10} \mathrm{ohm}-$ $\mathrm{cm}$. It is not known if this change in resistivity is important in explaining the overall mechanism of the conditioning effects.

\subsubsection{Chemistry of Conditioning Process}

Injection of $\mathrm{SO}_{3}$ and ammonia into the flue gas must have produced physical and chemical changes in the fly ash and/or dust cake to account for the observed enhanced particulate removal and lower pressure drop. Ultimate and proximate analyses for all of the coals used in the conditioning tests are given in Table 5-8. The composition of the baghouse hopper ashes determined by XRF analysis is given for both the conditioned and nonconditioned tests in Table 5-9. The important ash component to note from this table is the sodium concentration of each ash. All the coals used in the tirst series of Tests. (Phase I) were very low in sodium and all tests without $\mathrm{SO}_{3}$ and ammonia conditioning resulted in high particulate emissions. In the second series of tests (Phase II), the sodium 
TABLE 5-8

ULTIMATE AND PROXTMATE COAL ANALYSES

\begin{tabular}{|c|c|c|c|c|c|c|}
\hline $\begin{array}{l}\text { Coal Analysis } \\
\text { (moisture free) }\end{array}$ & Falkirk & $\begin{array}{l}\text { Big } \\
\text { Brown }\end{array}$ & $\begin{array}{l}\text { South } \\
\text { Hallsville }\end{array}$ & Monticello & $\begin{array}{c}\text { Indiana } \\
\text { Bit. }\end{array}$ & Sarpy Cres \\
\hline \multicolumn{7}{|l|}{ PROXIMATE } \\
\hline Ash & 11.50 & 18.81 & 13.71 & 21.98 & 11.70 & 11.31 \\
\hline Volatile Matter & 44.81 & 42.79 & 39.60 & 41.24 & 37.28 & 38.41 \\
\hline Fixed Carbon & 45.89 & 38.80 & 46.72 & 37.78 & 51.02 & 50.28 \\
\hline $\begin{array}{l}\text { Coal Moisture, \% } \\
\text { (as reccived) }\end{array}$ & 36.7 & 25.8 & $7.9^{\mathrm{a}}$ & 34.1 & 8.7 & 18.9 \\
\hline \multicolumn{7}{|l|}{ ULTIMATE } \\
\hline Carbon & 61.57 & 55.60 & 60.83 & 56.36 & 69.47 & 65.63 \\
\hline Hydrogen & 4.26 & 5.22 & 3.87 & 4.51 & 4.96 & 4.43 \\
\hline Nitrogen & 1.15 & 0.78 & 1.32 & 1.01 & 1.44 & 0.83 \\
\hline Sulfur & 1.05 & 1.14 & 1.28 & 0.75 & 2.46 & 0.73 \\
\hline Oxygen (by diff.) & 20.47 & 18.47 & 24.52 & 16.38 & 9.95 & 17.05 \\
\hline
\end{tabular}

HEATING VALUE

Btu/lb

$10,515 \quad 9,957 \quad 10,673$

$9,753 \quad 12,322$

11,093

a cuell was driead.

concentrations were low for the Monticelio and Indiana bituminous coals and these coals responded very well to conditioning. The Sarpy Creek subbituminous coal, on the other hand, was quite high in sodium, about $5 \%$ sodium as $\mathrm{Na}_{2} \mathrm{O}$. The ash from this coal, as predicted from the ash composition model discussed in section 5.5.1, would collect very well in a baghouse and this was found to be the case. The baghouse efficiency wjthout conditioning was ahout 99.8\% and increased to $99.9 \%$ with conditioning. This was not as substantial an improvement as was observed for the other coals. The high sodium concentration may have resulted in the $\mathrm{SO}_{3}$ reacting with the available sodium in the fly ash prior to reacting with ammonia. Leaching the fly ash and analyzing the leachate for ammoria showed 
TABLE 5-9

XRF ASH ANALYSIS OF BAGHOUSE HOPPER ASH

(Percent Concentration as Oxides)

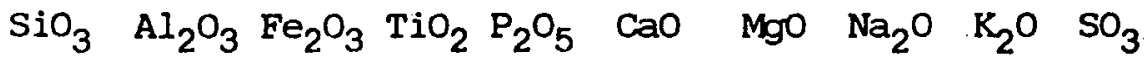

Falkirk

Nonconditioned Conditioned

Big Brown

Nonconditioned Conditioned

South Hallsville Nonconditioned Conditioned

Monticello

$\left(700^{\circ} \mathrm{F}\right.$ Inject.)

Nonconditioned Conditioned

Monticello

$\left(350^{\circ} \mathrm{F}\right.$ Inject.)

Nonconditioned Conditioned

$\begin{array}{llllllllll}42.2 & 12.1 & 12.6 & 0.9 & <0.1 & 20.8 & 7.0 & 0.6 & 1.5 & 1.8 \\ 34.7 & 12.0 & 13.2 & 0.9 & <0.1 & 24.5 & 8.2 & 0.9 & 1.3 & 4.3\end{array}$

$\begin{array}{llllllllll}51.5 & 19.3 & 8.3 & 1.7 & <0.1 & 14.4 & 2.9 & <0.5 & 1.0 & 1.2\end{array}$

$\begin{array}{llllllllll}51.9 & 19.8 & 7.6 & 1.7 & <0.1 & 13.7 & 3.0 & <0.5 & 0.8 & 1.3\end{array}$

$\begin{array}{llllllllll}39.6 & 12.5 & 24.4 & 1.7 & <0.1 & 14.5 & 2.9 & <0.5 & 0.4 & 3.2\end{array}$

$\begin{array}{lllllllllll}35.8 & 12.7 & 27.5 & 1.7 & <0.1 & 14.6 & 3.5 & <0.5 & 0.4 & 3.5\end{array}$

Indiana Bituminous Nonconditioned Conditioned

$\begin{array}{llll}56.1 & 17.2 \quad 4.1 & 1.9\end{array}$

$<0.1 \quad 16.8 \quad 2.5 \quad<0.5 \quad 0.5 \quad 1.2$

$\begin{array}{llllllllll}55.2 & 17.4 & 4.1 & 2.0 & <0.1 & 16.8 & 2.5 & <0.5 & 0.5 & 1.2\end{array}$

Sarpy Creek

Nonconditioned

Conditioned

$\begin{array}{rrrrrrrrrr}56.1 & 17.2 & 4.1 & 1.9 & <0.1 & 16.8 & 2.5 & <0.5 & 0.5 & 1.2 \\ 55.6 & 17.1 & 4.1 & 2.0 & <0.1 & 17.0 & 2.5 & <0.5 & 0.5 & 1.1 \\ & & & & & & & & & \\ 50.5 & 24.2 & 13.2 & 1.4 & 0.1 & 3.5 & 1.7 & <0.5 & 3.6 & 1.8 \\ 50.1 & 24.4 & 13.1 & 1.3 & 0.1 & 3.0 & 1.8 & <0.5 & 3.7 & 2.5 \\ & & & & & & & . & & \\ 35.0 & 20.6 & 6.4 & 1.2 & 0.3 & 25.5 & 2.4 & 5.3 & 0.7 & 2.8 \\ 34.3 & 20.9 & 6.4 & 1.2 & 0.3 & 25.0 & 2.5 & 5.0 & 0.6 & 3.2\end{array}$

that not as much of the ammonia was present on the fly ash as for the other coals. As a result, the ammonia concentration in the flue gas downstream of the baghouse was also higher for the Sarpy creek test. ESCA analyses for sulfur and nitrogen of the baghouse hopper ash samples for each of the test coals and size fractionated Big Brown fly ash are given in Tables 5-10 and 5-11. From Table 5-10, for all the coals except sarpy creek there is a large increase in surface nitrogen and sulfur with conditioning as would be expected. For Sarpy Creek the increase in surface nitrogen due to conditioning is 
TABLE $5-10$

ESCA ANALYSIS FOR NITROGEN AND SULFUR (Percent Elemental Concentration of Surface)

\begin{tabular}{|c|c|c|c|c|}
\hline \multirow[b]{2}{*}{ Baghouse Hopper Ash } & \multicolumn{2}{|c|}{ Nonconditioned } & \multicolumn{2}{|c|}{ Conditioned } \\
\hline & $\mathrm{N}$ & $S$ & $\underline{N}$ & $S$ \\
\hline Falkirk & 0.2 & 4.8 & 2.6 & 8.2 \\
\hline Big Brown & 0.6 & 5.2 & 4.6 & 7.4 \\
\hline South Hallsville & 0.4 & 6.4 & 3.7 & 7.6 \\
\hline Monticello $\left(700^{\circ} \mathrm{F}\right)$ & $<0.1$ & 3.2 & 2.6 & 5.0 \\
\hline Monticeliu $\left(350^{\circ} \mathrm{F}\right)$ & $<0.1$ & $3 . ?$ & 2.1 & 5.8 \\
\hline Indiana Bituminous & 0.8 & 3.6 & 4.3 & 5.8 \\
\hline Sarpy Creek & $<0.1$ & 4.9 & 0.4 & 6.5 \\
\hline
\end{tabular}

TABLE 5-11

ESCA ANALYSIS FOR NITROGEN AND SULFUR OF SIZE FRACTIONATED BIG BROWN ASH

(Percent Elemental Concentration of Surface)

Nonconditioried

\begin{tabular}{l}
$\mathrm{D}_{50}$ \\
$\mathrm{~m}_{\mathrm{m}}$ \\
\hline
\end{tabular}

6.31

2.73

1.94

0.79

0.43

$<0.43$

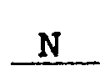

0.3

0.4

0.4

0.9

1. 3

1.2
Conditioned

$\begin{array}{r}D_{50} \\ -\mu \mathrm{m} \\ \hline\end{array}$

6.60

2.89

2. 14

0.83

0.43

$<0.43$

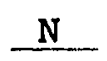

3. 3

3.1

3.5

4.1

4.7

6.9
Difference

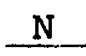

$S$

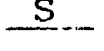

5.9

6.0

6.4

6.8

6.9

7.7

3.0

2. 1

2. 7

3. 1

2. $n$

3. 2

3.4

3. 1

2.0

5.7

1. 4

2.4

5.5

5.3

small, although there is an fairly large increase in sulfur. This, again, indicates that the $\mathrm{SO}_{3}$ is reacting with something other than the ammonia. 
For the size-fractionated samples of Big Brown (Table 5-11) the surface concentrations of sulfur and nitrogen appear to increase with decreasing particle size for both the conditioned and nonconditioned ashes. However, the difference in concentration lobtained by subtracting nonconditioning values) is quite uniform for all particle sizes except for nitrogen in the smallest size cut.

The exact ammonia-SO $\mathrm{S}_{3}$ species that is deposited on the fly ash surface is not clear. ESCA analysis reveals the measured sulfur to be present as a sulfate rather than a sulfite which is consistent with results reported by others (11). Sulfur trioxide being a strong Lewis acid will react with the ammonia that is present. At the injection temperature of $700^{\circ} \mathrm{F}$ the likely compound to be formed will

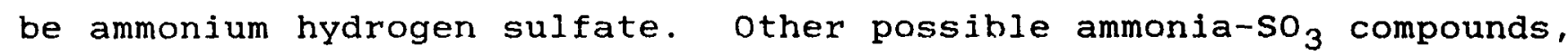
such as ammonium sulfate, which would be favored at lower temperatures, dissociate at this temperature. Ammonium hydrogen sulfate has a dissociation temperature of $770^{\circ} \mathrm{F}$ but dissociation is not complete until the temperature reaches $842^{\circ} \mathrm{F}$ (12). At $700^{\circ} \mathrm{F}$, ammonium hydrogen sulfate is above its melting point and therefore it must be in a liquid state and in equilibrium with its dissociation products (13). At an injection temperature of $350^{\circ} \mathrm{F}$, which is below the dissociation temperature of ammonium sulfate, either ammonium sulfate or ammonium hydrogen sulfate could form depending on the concentration of ammonia, $\mathrm{SO}_{3}$, and other flue gas constituents.

XRD was also completed on the size fractionated samples, but only the multicyclone backup filters revealed any crystalline ammoniasulfur species. Since XRD sensitivity is limited to concentrations of $5 \%$ or more it would be expected that these species would be detected only in the smallest particle sizes. At injected concentrations of $12 \mathrm{ppm} \mathrm{SO}_{3}$ and $45 \mathrm{ppm}$ ammonia and an injection temperature of $700^{\circ} \mathrm{F}$, XRD did not detect either ammonium hydrogen sulfate or ammonium sulfate. Therefore, if ammonium hydrogen sulfate was initially formed, further reactions must have taken place downstream as the flue gas cooled. XRD has tentatively identified triammonium hydrogen sulfate, ammonium iron (III) sulfate, and ammonium calcium sultate depending on which fly ash was tested. 
These compounds could be products of ammonia and so3 reactions at temperatures lower than $400^{\circ} \mathrm{F}$ (13). When the concentrations of ammonia and $\mathrm{SO}_{3}$ were raised to 5 times the normal level, XRD identified only ammonium sulfate. At these higher concentrations there may have been enough excess ammonia to complete the reaction of ammonium hydrogen sulfate to ammonium sulfate once the flue gas cooled below the dissociation temperature of ammonium sulfate. It is apparent that the exact chemical mechanisms occurring are complex and more laboratory study of the reactions of ammonia, $\mathrm{SO}_{3}$, and fly ash at elevated temperatures needs to be completed.

An ammonia balance was attempted for several tests and the results are presented in Table 5-12. It can be seen that up to 50\% of the ammonia is unaccounted for. It is possible that some catalytic reduction of the ammonia may have occurred. In addition. the method of absorbing the ammoria with dilute sulfuric acid may be suspect. More research is this area is planned in the future.

TABLE 5-12

AMMONIA BALANCE

(Expressed as Percent of Injected ammonia)

Coal Tested

South Hallsvilie

Monticello

Indiana Bituminous

Sarpy Creek
Fly Ash

31.1

28.0

72.0

12.0 slip.

33.3

28.0

0.0

36.0
Unaccounted For

$3 b .6$

44.0

28.0

52.0 


\subsubsection{Mechanisms of Conditioning}

The conditioned ashes have higher surface concentrations of nitrogen and sulfur indicating that the ammonia and $\mathrm{SO}_{3}$ (or ammonia$\mathrm{SO}_{3}$ product such as ammonium sulfatel are adsorbed on the $f l y$ ash surface. ESCA analysis revealed uniform concentrations of sulfur and nitrogen as a function of particle size. However, ESCA analysis of the conditioned ash also revealed silicon, aluminum, and calcium indicating that the analyzed portion included material present in the parent particles. Since ESCA may penetrate the surface to a depth of 100 Angstroms $(0.01 \mathrm{~mm})$, this would indicate that the surface layer formed by the conditioning agents is less than $0.01 \mu \mathrm{m}$ thick. SEM micrographs were taken at various magnifications of size fractionated conditioned and nonconditioned ashes. However, there were no clear differences in surface morphology between the conditioned and baseline samples at magnifications up to $30,000 x$. This also indicates that the surface layer is very thin. The theoretical thickness of the surface layer can be calculated, assuming uniform deposition over the entire fly ash surface area and all of the injected $\mathrm{SO}_{3}$ is absorbed on the $\mathrm{fly}$ ash. For a dust loading of 3 grains/scf, an $\mathrm{SO}_{3}$ flue gas concentration of $12 \mathrm{ppm}$, and a $\mathrm{fly}$ ash specific surface area of $1.5 \mathrm{~m}^{2} / \mathrm{g}$, the calculated thickness of the surface layer (assuming an ammonium sulfate product) is only 35 Angstroms. This is smaller than would be detected by SEM at $30,000 \mathrm{X}$ and thin enough to be penetrated by ESCA analysis. The evidence; therefore, shows that a very thin surface layer is formed on the fly ash surface. The presence of this layer, then, likely affects other ash properties such as cohesiveness and electrical resistivity.

From the previous discussion on penetration mechanisms in Section 5.1, it is clear that dust cohesiveness will affect penetration through pinholes and penetration by seepage or reentrainment. conditioning resulted in increased ash cohesiveness for each coal. The ash which showed the smallest increase in cohesiveness also showed the smallest improvement in particulate removal efficiency. However, the increase in ash cohesiveness for each coal was not 
directly proportional to the reduction in particulate emissions. Therefore, it is not possible to establish the exact relationship between cohesiveness and penetration behavior, based on available data. The fact that ash cohesiveness increased with conditioning, and that an increase in cohesiveness is expected to reduce emissions based on known penetration mechanisms, are strong evidence that the mechanism of emissions reduction involves an increase in ash cohesiveness. A study of the effect of concentrations of conditioning agents on emissions along with measurement of ash cohesiveness would lead to a better understanding of the relationship between conestveness and emissiuls. This is a major recearch need in further understanding and optimizing the conditioning process. From the existing data, however, we can conclude that conditioning increases fly ash cohesiveness. This reduces particulate penetration by facilitating the bridging of pinholes or large pores, and making the dust less susceptible to seepage or reentrainment.

The role of electrical effects in explaining the mechanism by which conditioning reduces particulate emissiors is not known. It does not appear that conditioning would impart a significant charge to the particles in the flue gas to increase collection efficiency. However, possible changes which inight occur in the dust cake include an increase in charge dissipation rate due to reduced resistivity. The charge dissipation rate could affect agglomeration tendency, dust cake structure, and cohesiveness. Conditioning also might affect the triboelectric nature of the dust which would result in a change in charge effects within the dust cake. A major research need in understanding and optimizing not only conditioning but also conventional fabric filtration is to model the role of electrical characteristics in the filtration process. Based on avallable data, no conclusion can be drawn regarding any possible role of electrical effects in the mechanism by which conditioning reduces particulate emissions.

The mechanism by which pressure drop is reduced may also be partially explained by increased fly ash cohesiveness. In the previous discussion on the effect of dust properties on pressure drop 
in section 5.3, it was shown that the specific dust cake resistance, $\mathrm{K}_{2}$, depends on particle size, porosity, and pore structure. The small changes in particle size distribution caused by conditioning would not have a significant effect on $\mathrm{K}_{2}$. The increase in submicron particle mass would increase $K_{2}$ rather than cause the decrease which was observed. The slight shift in particle size distribution in the 1 to $7 \mu \mathrm{m}$ range may increase the mean particle size, with conditioning, which would reduce $\mathrm{K}_{2}$. However, loose agglomerates formed in the duct would be porous so this small shift would not significantly affect $\mathrm{K}_{2}$. Therefore, a change in particle size distribution is not the explanation for reduced pressure drop. A small change in porosity, as previously stated, can significantly change the dust cake resistance. The largest change in $\mathrm{K}_{2}$ noted with conditioning was a reduction by a factor of 5 , which can be accounted for by an increase in porosity. For example, an increase in porosity from 0.47 to 0.68 would reduce $\mathrm{K}_{2}$ by a factor of 5 . It is likely that the dust cake pore structure would also be somewhat changed along with an increase in porosity, but a pore structure change alone, without an increase in porosity, could not account for the reduced $\mathrm{K}_{2}$. The most probable explanation, then, for the reduced pressure drop is an increase in dust cake porosity. Actual dust cake porosity measurements are difficult to determine (especially for thin cakes), and have not been completed for conditioning tests to date. However, future research is expected to verify the relationship between feluced pressure drop and porosity with conditioning. A more cohesive ash would be less susceptible to packing and pore collapse. It, therefore, appears that the reduced pressure drop is a direct result of increased fly ash cohesiveness.

Residual dust cake weight is also expected to be affected by the ash cohesiveness. If the ash is too "sticky", it may not be easily remuved. On the other hand, it the cohesiveness of the ash is increased while adhesion to the fabric remains unchanged, bag cleaning may be easier, since the dust would be removed in large agglomerates. The explanation for reduced residual dust cake weight, with conditioning, may be that larger fractions of the cake more 
easily shear off the bag because of increased cake cohesiveness. There may also be less packing at the fabric/dust cake interface which would mean less ash surface area in contact with the fabric fibers. The reduced force of attraction, then, between the fabric and dust cake may allow the bags to be more easily cleaned.

From the available data, surface deposition of an ammonia- $\mathrm{SO}_{3}$ product and a resulting increase in ash cohesiveness are critical steps in the conditioning process. More research, however, is definitely needed to further model the mechanisms by which contjtinning reduces particulate emissions and pressure drop.

\subsubsection{References}

1. Sears, D.R. and S.J. M1ller. Impact of Fly Ash Composition Upon Shaker Baghouse Efficiency. Presented at: 77 th Annual Meeting of the Air Pollution Control Association, Paper 84-56.6, San Francisco, CA, June 1984.

2. Miller, S.J. and D.R. Sears. The Influence of Coal-Specjfic Fly Ash Properties Upon Baghouse Performance: A Comparison of Two Extreme Examples. Proceedings: Fifth Symposium on the Transfer and Utilization of Particulate Control Technology, Kansas City. MO, Vol. 3, pp. 22-1 to 21 , February 1986.

3. Miller, S.J. and D.I. Laudal. Particulate Characterization, Final Report for the Period Ending March 31, 1986, Uriversjty of North Dakota Energy Research Center, DOE/FE/60181-2089, June 1986 .

4. Carr, R.C. and W.B. Smith. Fabric Filter Technology for CoalFired Power Plants, Part III: Performance of Full scale Utility Baghouses. Journal of the Air Pollution Control Association, 34:3, pp. 281-293, 1984.

5. Felix, I.G., R.L. Merritt, and K. Duncan. Improving Baghouse Performance at the Monticello Generating station. Journal of the Air Pollution Control Associat10n, 36:9, pp. $1075-1005,1986$.

6. Miller, R.L., D.A. Single, and W.R. Smit. Successful Baghouse operating Experience at Plains Electric Generation and Transmission Cooperative, Inc. Escalante Generating station, Unit 1. Presented at: The Third EPRI Conference on Fabric Filter Technology for Coal-Fired Power Plants, Scottsdale, AZ, November 1985. 
7. Barranger, C.B. and S. Strangert. Experience with Pulse Jet Cleaned Fabric Filter on Australian Coal-Fired Utility Boilers. Presented at: The Third EPRI Conference on Fabric Filter Technology for Coal-Fired Power Plants, Scottsdale, AZ, November 1985 .

8. Frankenburg, P.E. Laboratory studies of the Filtration Performance of Various Filter Media Under simulated Field Conditions. Proceedings: Sixth Symposium on the Transfer and Utilization of Particulate Control Technology, Vol. 3, EPRI CS4918 , pp. 9-1 to 9-16, November 1986 .

9. Dismukes, E.B. Conditioning of Fly Ash with Sulfur Trioxide and Ammonia. Environmental Protection Technology Series, EPA-600/275-015, TVA-E75 PRS-5 U.S. Environmental Protection Agency, Research Triangle Park, NC and Tennessee Valley Authority, Chattanooga, TN, August 1975.

10. Keady, P.B., F.R. Quant, and G.J. Sem. Differential Mobility Particle Sizer: A New Instrument for High Resolution Aerosol Size Distribution Measurement Below $1 \mathrm{\mu m}$. TSI Quarterly, Vol. IX, No. 2, April-June 1983 .

11. Spafford, R.B., E.G. Dismukes, and H.K. Dillon. Analysis of Thermal Decomposition Products of Flue Gas Conditioning Agents. EPA-600/7-79-1, August 1979 .

12. Kiyoura, R. and $U$. Kale. Mechanisms, Kinetics and Equilibrium of Thermal decomposition of Ammonium Sulfate. Ind. Eng. Chem. Process Des. Development, 9:4, pp. 489-494, 1970 .

13. Tu, K.W. and G.M. Kanapilly. Generation and Characterization of Submicron Ammonium Sulfate and Ammonium Hydrogen Sulfate Aerosols. Annual Report, Inhalation Toxicology Research Institute, pp. 273-279, 1977 . 


\subsection{ECONOMIC ANALYSIS OF PARTICULATE CONTROL TECHNOLOGY}

Although any consideration of a technology must be based on its technical merit, the deciding factor is usually economic. Particulate control technology is no exception. An advanced control technology must be able to meet stringent particulate control standards. In addition, it must also be able to compete economically with other technologies to be fully accepted, whether in an industrial or utility setting.

Whether a particulate control technology represents the optimum economic choice is usually very site specific. Therefore, a design engineer must prepare specifications and then determine all cost factors associated with the design, fabrication, installation, and operating costs as accurately as possible. All costs presented in this report were obtained either from the literature or vendors, and are presented as initial capital cost and annual levelized costs. Cost data obtained from the literature were updated using the Marshall and Swift cost index with all values expressed in 2nd quarter 1986 dollars.

\subsection{Inertial Separation}

The installed cost for conventional high-efficiency multiclones is $\$ 4,090,000(8.18 / \mathrm{kW})$ for a $500 \mathrm{MW}$ plant with an annual levelized uperating cost of $0.38 \mathrm{~m} 111 \mathrm{~s} / \mathrm{kWh}$. For the Electroclone the installed cost would increase to $\$ 6,790,000(\$ 13.58 / \mathrm{kW})$ to reflect the cost of the precharger. The annual levelized operating cost would also increase to $0.64 \mathrm{mills} / \mathrm{kWh}$ (1). Multicyclones are the most economic of all particulate control devices, but they cannot meet current utility particulate control standards. 


\subsection{Wet Scrubbers}

Wet scrubbers were a very economical method of removing particulates before particulate and waste disposal standards became more stringent. Several types are still in use in some utilities, with the most common being Venturi scrubbers. Table 6-1, gives the capital and annual levelized operating costs for each of these conventional scrubbing systems. Of the novel scrubbers developed in the past 10 years, only the high energy intensive systems are able to collect fine particulates at a high level of efficiency. Energy requirements for these scrubbers, as is shown in lable $6-2$, clearly make them uneconomical for most utility applications.

TABLE 6-1

\section{CAPITAL AND OPERATING COSTS FOR CONVENTIONAL WET SCRUBBERS} FOR A 500 MW PLANT (Ref. 2,3)

Srorubher

Moving Bed Scrubber

Preformed Scrubber

Venturi scrubber

$(10$ inches $W . C$. pressure drop)
Lcvelized Annual

Operating Cost

$(\mathrm{S} / \mathrm{kW})$

(Mills/kWh)

21.54

1.34

31.11

1.25

30.05

1.17 
TABLE 6-2

COLLECTION EFFICIENCY FOR PARTICLES LESS THAN $2.5 \mathrm{\mu m}$ AND OVERALL POWER CONSUMPTION FOR WET SCRUBBERS (Ref. 2,4)

Scrubber Type

Venturi scrubber

Preformed Scrubber

Moving Bed Scrubber

Flooded Fixed Bed Scrubber

Two-phase Jet Scrubber

Centripetal Vortex scrubber

Dynactor Scrubber

Steam-hydro scrubber

Mystaire Scrubber

Pentapure Scrubber

Electrostatic Droplet Scrubber

Ionized Venturi scrubber
\% Efficiency

Power Consumption $\left(\mathrm{kW} / \mathrm{acfm} \times 10^{-3}\right)$

a Fine Particle penetration is not available but overall efficiency is. $99 \%$.

\subsection{Electrostatic Precipitators}

The size of an ESP, and therefore the cost, is dependent on the amount of collection surface (SCA) that is needed to obtain the desired efficiency. For the following economic analysis of EsPs, the base case is for a $500 \mathrm{MW}$ plant requiring an SCA of 496 using conventional electrode geometry and rigid-frame design. Tables 6-3 and 6-4 present the initial capital investment and the annual levelized operating costs for the base ESP. Costs for each individual item were obtained from an economic analysis performed for EPRI by stearns catalytic, Corp. (5) and updated to 1986 costs. Assumptions for the analysis are detailed in the stearns Catalytic report. The total capital investment (TCI) is $\$ 28,178,300$ or $\$ 56.36 / \mathrm{kW}$. The annual levelized operating cost is estimated at $\$ 12,042,800 / \mathrm{Yr}$ or $3.24 \mathrm{mil} 1 \mathrm{~s} / \mathrm{kWh}$. 
TABLE $6-3$

\section{CAPITAL COST FOR A COLD-SIDE ESP FOR A 500 MW PLANT ( $1.9 \times 10^{6}$ ACFM @ $\left.496 \mathrm{SCA}\right)$ \\ UNITS - $\$ 1000$ (1986) (Ref. 5)}

\section{Cost Item}

Collector and Hoppers

Ductwork

Fly Ash Handling System

ID Fan

Misc. (Earthwork, Inst.,

Electrical, and etc.)

Purchase Equipment Cost Installation

Indirect costs (6\% PEC)

(Supervision,

Clerical \& etc.)

Total Costs

Engineering \& Fees (3\% PEC)

Contingency (10\% PEC)

Total Capital Investment

$\$ / k W$
Installed Cost

$16,152.1$

588.5

$3,343.8$

529.7

$3,066.0$

$23,680.1$

$1,420.8$

$25,100.9$

710.4

$2,368.0$

$28,178.3$

56.36 


\section{ESTIMATED OPERATING AND MAINTENANCE COSTS FOR A COLD-SIDE ESP FOR A 500 MW PLANT \\ $\left(1.9 \times 10^{6} \mathrm{ACFM} @ 496 \mathrm{SCA}\right)$ \\ UNITS - $\$ 1000$ (1986) (Ref. 5)}

$\underline{\text { Item }}$

Fixed Operating costs

Operating Labor

Maintenance Labor

Maintenance Material

Administration and Support Labor

TOTAL FIXED OPERATING COST

Variable Operating Costs

Power

Fly Ash Disposal

TOTAL VARTABLE OPERATING COSTS

Amortization (inc. financing, taxes, \& insurance $(15.3 \%$ PEC)

TOTAL ANNUAL COST

Mills/kWh
Cost

440.6

660.9

652.8

244.8

$1,999.1$

$3,488.4$

$2,244.0$

$5,732.4$

$4,311.3$

$12,042.8$

3.24

\subsubsection{Ejectrode Geometry and Construction Design}

The two major ESP construction designs are the weighted wire and the rigid frame. The rigid frame is technically superior but the weighted wire has economic benefits. The initial capital investment for the rigid frame design as was shown in Table $6-3$ is $\$ 56.36 / \mathrm{kW}$ for a 500-MW plant with an SCA of 496 , compared to $\$ 40-45 / \mathrm{kW}$ for the weighted wire design. The annual levelized cost for the rigid frame design would be $3.24 \mathrm{mills} / \mathrm{kWh}$ compared to 2.85 for the weighted wire design. This is due entirely to the higher capital cost resulting in much higher depreciation costs. The actual operation and maintenance costs excluding the cost of capital is actually less for the rigid frame (6). 
Wide spacing of the electrodes, which has been shown to provide better collection efficiency for some applications, is affected by two economic factors. First,. with widely-spaced electrodes the weight of the ESP decreases by $18 \%$ and the material cost by $23 \%$. This savings is offset by the increased cost of electrical equipment needed to generate the higher voltages necessary for widely-spaced electrodes. This may eliminate any cost savings for small and medium size ESPs. High resistivity dust also diminishes the economic advantages of wide spaced ESPs since back corona has been observed in these units as well. Therefore, to obtain good collection efficiency for these'dusts the size of lhe unit must again bc larger, resulting in no cost advantage.

\section{3 .2 Hot side ESPS}

For a hot-side ESP, costs are considerably higher because there is substantially more gas volume entering the unit at higher operating temperatures. An ESP treating $1.9 \times 10^{6}$ acfm at $300^{\circ} \mathrm{F}$ would see a volumetric flow rate of $2.90 \times 10^{6}$ acfm at $700^{\circ} \mathrm{F}$. This results in a $71 \%$ higher cost for the collector and a $87 \%$ increase in accessory equipment. The operating and mainterance costs would increase by $57 \%$. A break-even point is reached if an additional SCA of 291 must be added to a cold-side ESP to negate the decrease in collection efficiency due to high resistivity ash.

In a detailed cost comparison, performed by selzer and watson (7), which compared an enlarged ESP to a hot-side ESP when collecting a high resistivity ash, it was concluded that for almost all U.S. Iow sulfur coals, an enlarged precipitator is likely to be less costly over the life of the unit. This result, thcy concludud, will be become increasingly important as particulate and sulfur dioxide emission controls become more stringent. Subsequently, hot-side ESPS are not presently considered to be the best option for collecting high resistivity dusts. 


\section{3 .3 Flue Gas Conditioning of an ESP}

The most common method of preventing back corona problems due to $\mathrm{h}_{1}$ igh resistivity of $\mathrm{fly}$ ash is to use $\mathrm{SO}_{3}$ conditioning. Using a cost analysis by Wahlco, Inc. (8) and sterns Catalytic Corp. (5) for a 500 MW boiler burning a low sulfur coal that produces a high resistivity ash, comparisons were made as to the inost cost effective method to achieve $99.5 \%$ particulate collection efficiency. It was determined that a conventionally sized ESP with $\mathrm{SO}_{3}$ conditioning resulted in the lowest overall costs. To achieve the same collection efficiency without conditioning, the ESP would have to be over designed such that capital costs would be $85 \%$ higher and operating and overhead costs would be $72 \%$ higher. Tables $6-5$ and 6-6 itemize the costs for each alternative. The analysis assumes an SCA of 673 for the coldside ESP, 336 for the hot-side ESP, and 317 SCA for the conditioned ESP. For this case the hot-side ESP would result in an annual savings of $19.9 \%$ compared to an enlarged conventional ESP, but flue gas conditioning would incur a $72 \%$ savings annually.

\subsubsection{Pulse Energization}

Pulse energization is more economically attractive than increasing the ESP size to compensate for high resistivity. on a \$/sq ft collecting area basis, a pulse energization system would cost $\$ 5 \mathrm{to} \$ 10 / \mathrm{sq}$ ft compared to $\$ 30$ to $\$ 35 / \mathrm{sq}$ ft for additional retrofit ESP sections, or $\$ 25$ to $\$ 35 / \mathrm{sq} f t$ for a new ESP installation. For a 500 MW boiler producing a high resistivity ash there would be a 50\% power savings for a conventionally sized ESP with pulse energization compared to an ESP with enough additional SCA to provide a collection efficiency of $99 \%$ ( 8 ). For an ESP with 350 SCA the additional power requirements to add pulse energization would be $222 \mathrm{~kW}$ or 0.02 $\mathrm{mills} / \mathrm{kWh}$. 
TABLE 6-5

CAPITAL INVESTMENT FOR ESP ALTERNATIVES WHEN COLLECTING

A HIGH RESISTIVITY ASH FOR AN 500 MW Plant

UNITS - $\$ 1000(1986)$ (Ref.5,8)

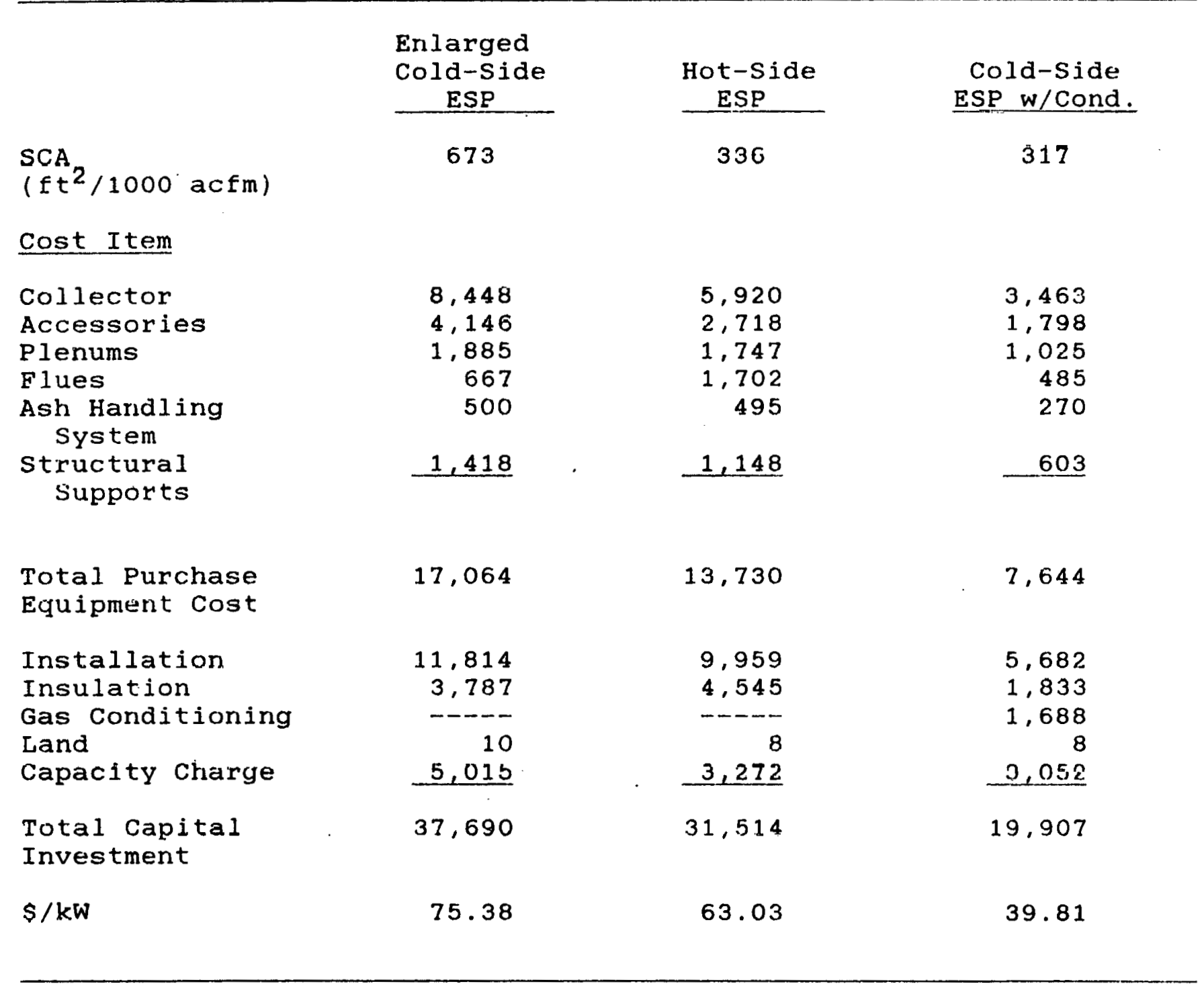


TABLE 6-6

\section{ANNUAL OPERATING AND MAINTENANCE COSTS FOR ALTERNATIVE ESP COLLECTION SYSTEMS FOR AN 500 MW PLANT UNITS - $\$ 1000$ (Ref. 5,8)}

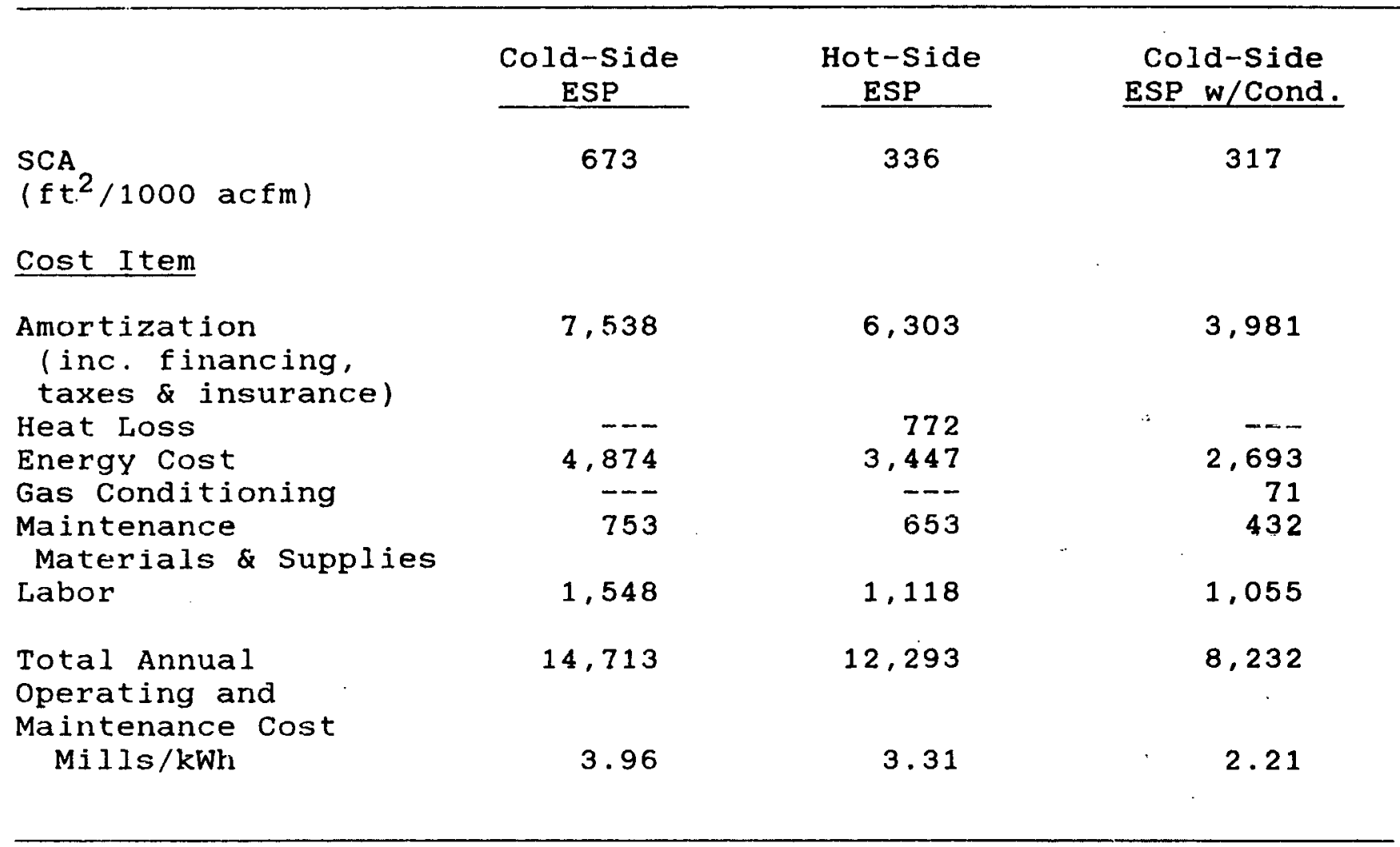

\subsubsection{Precharging}

There are two possible uses for prechargers: as a retrofit to existing ESP installations that do not comply with emission standards and for new installations. Precharging is likely to be one of the most cost-effective options to overcome performance degradation caused by back corona. In the case when no back corona is taking place its cost effectiveness tends to become so small its application would not be justified (9). Cost savings of 30-60\% would be realized for a 300,000 acfm ESP over a conventional ESP with considerably less plant space occupied. In a new installation, savings gained by the use of a precharger are expected to be on the order of $30 \%$ with no energy penalties incurred (10).

$$
6-9
$$


If ash resistivity is a problem, there are currently four retrofit alternatives. These are: enlarging the ESP by adding additional SCA, pulse energization, $\mathrm{SO}_{3}$ conditioning, and converting to a hot-side precipitator. Table 6-7 is a summary of the capital and operating costs for each of these retrofit units above the costs for a base capital cost of $\$ 36.44 / \mathrm{kW}$ and a base annual levelized cost of $2.12 \mathrm{mills} / \mathrm{kWh}$ for a conventionally sized ESP. It is assumed that, when retrofitting a hot-side ESP or adding pulse energization, much of the ducting and the shell of the ESP that is being replaced can be used. From the table it can be seen that $\mathrm{So}_{3}$ conditioning and pulse energization dre lie most cost cffcotive methods of maintaininy a high collection efficiency in an ESP. However, since conditioning is a more proven technology, this is the option most often selected by utilities.

TABLE 6-7

COSTS OF RETROFIT ESP ALTERNATIVES FOR HIGH RESISTIVITY ASH FOR A 500 MW PLANT (REf.5, 8,12)

\begin{tabular}{|c|c|c|c|}
\hline System & $\begin{array}{c}\text { Additional } \\
\text { SCA } \\
\text { Needed }\end{array}$ & $\begin{array}{c}\text { Additional } \\
\text { Capital Cost } \\
\$ \$\end{array}$ & $\begin{array}{l}\text { Additional Operating } \\
\& \text { Maintenance Cost. } \\
\text { (mills } / \mathrm{kWh})\end{array}$ \\
\hline Enlarged ESP & 356 & $\$ 33.94$ & 1.01 \\
\hline Hot-side ESP & 19 & 26.59 & 1.01 \\
\hline Pulse Energization & 0 & 10.24 & 0.45 \\
\hline $\mathrm{SO}_{3}$ Conditioning & 0 & 3.36 & 0.10 \\
\hline
\end{tabular}


At the NSPS of $0.03 \mathrm{lb} / \mathrm{million}$ Btu particulates, the economics tend to favor fabric filters for low-rank fuels (lignites and subbituminous coals) and tend to favor ESPs for high-rank coals (13). This is primarily due to the high resistivity of western coals which affects ESPs much more than fabric filters. The primary factors affecting the cost of fabric filtration systems are:

1. Desired air-to-cloth ratio.

2. Type and frequency of cleaning.

3. Type of fabric to be used.

4. Material of construction.

5. Location of the baghouse.

6. Desired collection efficiency.

7. Composition of flue gas and dust to be collected.

8. Operation temperature.

These design criteria are used to determine the size and overall cost of the baghouse. For this economic study, the following design criteria are used:

1. The plant is $500 \mathrm{MW}$ with a pc-fired boiler.

2. The plant has a capacity load factor of 0.85 .

3. Air-to-cloth ratio is $2.0 \mathrm{ft} / \mathrm{min}$.

4. The baghouse has 16 compartments with 744 bags in each.

5. Bags are woven fiberglass with a Teflon $B$ finish and have a 4 year bag 1 ife with a $25 \%$ annual replacement rate.

6. The baghouse is operated at a nominal temperature of $300^{\circ} \mathrm{F}$ and is located on the negative side of the ID fan.

7. Desired tube sheet pressure drop is 4.5 inches W.C.. 
8. The cleaning mechanism is reverse air with a 1 hour off-line cleaning cycle.

9. Inlet dust loading is 3 to $4 \mathrm{grains} / \mathrm{scf}$.

10. Desired collection efficiency is $99.9 \%$.

Tables 6-8 and 6-9 itemize the capital and operating costs for a baghouse with these design criteria. The total capital cost is $\$ 53.61 / \mathrm{kW}$ and the annual levelized cost is $3.02 \mathrm{mills} / \mathrm{kW}$.

TABLE $\quad 6-8$

CAPIIAL COST

FOR A FABRIC FILTER FOR A 500 MW PLANT

( $\left.1.9 \times 10^{6} \mathrm{ACFM}\right)$

UNITS - $\$ 1000$ (1986) (Ref. 5)

\section{Cost Item}

Collector and Hoppers

Ductwork

Fly Ash Handling System

ID Fan and Motor

Misc. (Earthwork, Inst.,

Electrical \& etc.)

Purchase Equipment Cost

\& Installation

Indirect costs (6\% PEC)

(Supervision,

Clerical \& etc.)

Total Cost

Engineering \& Fees (3\%)

Contingency (10\%)

Total Capital Investment

$\$ / k W$
Installed Cost

$15,650.9$ 363.8

$3,156.5$

941.6

$2,410.7$

$22,523.5$

$1,351.4$

$23,874.9$

675.7

$2,252.4$

$26,803.0$

53.61 
TABLE 6-9

\section{ESTIMATED ANNUAL OPERATING AND MAINTENANCE COSTS FOR A \\ FABRIC FILTER FOR A 500 MW PLANT \\ $\left(1.9 \times 10^{6}\right.$ ACFM) \\ UNITS - $\$ 1000(1986)$ (Ref. 5)}

\section{Cost Item}

Fixed Operating Cost

Operating Labor

Maintenance Labor

Maintenance Material

Replacement Filter Bags

Administration \& Support Labor

TOTAL FIXED OPERATING COST

Variable Operating Cost

\section{Power}

Fly Ash Disposal

TOTAL VARIABLE OPERATING COST

Amortization (Inc., Financing,

Taxes, \& Insurance) (15.3\% TCI)

TOTAL ANNUAL COST

Mills/kWh
Cost

$(\$ 1000 / \mathrm{yr})$

440.6

326.4

523.9

316.5

204.0

$1,810.4$

$3,060.0$

$\underline{2,244.0}$

$5,304.0$

$4,100.9$

$11,215.3$

3.02

\section{4 .1 Sonic Horns}

Sonic horns are used to reduce the operating pressure drop of a fabric filter by assisting the reverse gas cleaning mode. A fullscale baghouse requires a minimum of two horns per compartment to provide adequate cleaning. Each sonic horn has an installed cost of $\$ 2200$ using $50 \mathrm{scfm}$ of $100 \mathrm{psi}$ air to drive it. The total cost for a baghouse is site specific and depends on the energy necessary to remove the dust cake from the bags, which determines the number of horns needed in each compartment and the energy needed to drive them. 
A one inch decrease in pressure drop due to sonic horns will recover the total capital cost of the sonic horns ir less than 1 year for a 16 compartment baghouse (5). Therefore, if they are successful, sonic horns are an economical method of reducing pressure drop in a reverse air fabric filter.

\subsubsection{Electrically Stimulated Fabric Filtration}

Reducing pressure drop is the primary advantage of ESFF and, in so doing, it 15 pussible to opcrate at a higher air-to-cloth ratio while still mantalning lite plessurc drop within arceplable limito. operating at higher a air-to-cloth ratios reduces the size of the baghouse and therefore reduces the capital investment. In addition, the use of fewer bags could result in reduced operating cost because bag replacement costs may be reduced, depending on bag life. The economics of ESFF have been reported by Hovis and Viner (14). The effects of ESFF on the residual dust cake are not completely known. Therefore, in their analysis, costs were evaluated both for the case where the residual dust cake is the same as conventional baghouses and for the case where the residual drag is reduced by 50\% (worst and best case). For case 1, the air-to-cloth ratio can he increased from $2 \mathrm{ft} / \mathrm{min}$ tr $3 \mathrm{ft} / \mathrm{min}$ and still maintain the same pressure drop. For case 2 , the air-to-cloth ratio can be increased to $5 \mathrm{ft} / \mathrm{min}$.

The TCI for case 1 is $\$ 40.05 / \mathrm{kW}$ and for case 2, $\$ 29.71 / \mathrm{kW}$. For case 1 , the cost of the extra hardware needed for ESFF is $10 \%$ and Fur case 2 , it is $9.1 \%$ of the TCI. The operating and mainteralice costs, not including amortization, are higher with ESF vecause morc electricity is used and the bags would be approximately 50\% more expensive than cunventional bags. In adition, bag life wnuld probably be shorter due to higher air-to cloth ratios. However, when the cost of capital is added, the levelized annual operating cost is $4.7 \%$ less for case 1 and $16.6 \%$ less for case 2 . These results are summarized in Table 6-10. 
TABLE 6-10

COMPARISON OF COSTS FOR ESFF AND CONVENTIONAL FABRIC FILTRATION FOR A 500 MW PLANT

(1986 Dollars) (Ref. 14)

\begin{tabular}{|c|c|c|c|}
\hline & Conventional & ESFF 1 & ESFF 2 \\
\hline $\begin{array}{l}\text { Total Capital } \\
\text { Investment }(\$ / \mathrm{kW})\end{array}$ & 54.61 & 40.05 & 29.71 \\
\hline $\begin{array}{l}\text { \% Diff. Compared to } \\
\text { Conventional }\end{array}$ & ---- & $-26.7 \%$ & $-45.6 \%$ \\
\hline $\begin{array}{l}\text { Annual Levelized Operating } \\
\text { and Maintenance Cost } \\
\text { (Mills/kWh) }\end{array}$ & 3.02 & 2.89 & 2.52 \\
\hline $\begin{array}{l}\% \text { Diff. Compared to } \\
\text { Conventional }\end{array}$ & ---- & $-4.7 \%$ & $-16.6 \%$ \\
\hline
\end{tabular}

6.4.3 Flue Gas Conditioning of a Fabric Filter

The economics of conditioning flue gas with ammonia and $\mathrm{SO}_{3}$ will depend on many factors. Some of these, such as quantity of agents needed, the effects of coal type, and the effects of temperature, still need to be determined experimentally. For this economic evaluation it is assumed that $25 \mathrm{ppm}$ ammonia and $12 \mathrm{ppm} \mathrm{so}_{3}$ are to be injected. In addition, it is assumed that conditioning will not adversely affect ash handling or bag life. Capital and operating costs are determined based on air-to-cloth ratios of 2 and $3 \mathrm{ft} / \mathrm{min}$. The cost of the conditioning equipment, as well as operating costs, were obtained from wahlco Inc.. Capital costs include the cost of equipment, installation, shipping, and supervision as well as a contingency fund to provide for unforeseen events. Operating costs for conditioning includes the costs of sulfur and ammonia, additional energy needed (electrical and steam), maintenance, and labor. Costs are summarized in Tables 6-1.1 and 6-12. Turnkey cost of the fabric 
TABLE 6-11

\section{COMPARISON OF CAPITAL COSTS FOR FABRIC FILTRATION SYSTEMS WITH AND WITHOUT FLUE GAS CONDITIONING \\ FOR A 500 MW PLANT \\ UNITS $\$ 1000(1986)$}

\begin{tabular}{|c|c|c|c|}
\hline Cost Items & $\begin{array}{l}\text { Conventional } \\
A / C=2: 1\end{array}$ & $\begin{array}{l}\text { Conditioned } \\
\mathrm{A} / \mathrm{C}=2: 1\end{array}$ & $\begin{array}{l}\text { Conditioned } \\
-\mathrm{A} / \mathrm{C}=3: 1\end{array}$ \\
\hline $\begin{array}{l}\text { Turnkey cost } \\
\text { Fabric Filter }\end{array}$ & 26,803 & 26,803 & 18,878 \\
\hline $\begin{array}{l}\mathrm{SO}_{3} \text { Generator } \\
\text { plus supports }\end{array}$ & & 1,300 & 1,300 \\
\hline $\begin{array}{l}\text { Ammonia Irjection } \\
\text { Equipment plus } \\
\text { Supports }\end{array}$ & & 260 & 260 \\
\hline $\begin{array}{l}\text { Ereight } \\
\text { Installation } \\
\text { Engineering } \\
\text { Contingency }\end{array}$ & & $\begin{array}{r}8 \\
515 \\
208 \\
208 \\
\end{array}$ & $\begin{array}{r}8 \\
515 \\
208 \\
208 \\
\end{array}$ \\
\hline $\begin{array}{l}\text { Total Capital } \\
\text { Investment }\end{array}$ & 26,803 & 29,402 & 21,377 \\
\hline$S / k W$ & 53.61 & 58.80 & 42.75 \\
\hline
\end{tabular}

filter is obtained from Table 6-9 and Figure 6-1. It is assumed that the gas flow and the number of compaitments will remain the same but with a reduction in the total number of bags. If the injection of ammonia and $\mathrm{SO}_{3}$ results in reduced pressure drop, such that the baghouse can operate at an air-to-cloth ratio of $3 \mathrm{ft} / \mathrm{min}$, then the TCI will be reduced by 20.3\%. Although the annual operatirg cost is 10.8\% higher with conditioning, the lower capital investment results in an annual levelized cost that is $9.3 \%$ less. The annual leveiized cost break even point, comparing fabric filters with and without conditioning, would occur for a fabric filter with conditioning operating at an air-to-cloth ratio of $2.35 \mathrm{ft} / \mathrm{min}$. 
Table 6-12

\section{COMPARISON OF OPERATING AND MAINTENANCE COSTS POR A FABRIC FILTRATION SYSTEM WITH AND WITHOUT CONDITIONING UNITS $\$ 1000$}

\begin{tabular}{|c|c|c|c|}
\hline Cost Items & $\begin{array}{l}\text { Conventional } \\
\mathrm{A} / \mathrm{C}=2: 1\end{array}$ & $\begin{array}{l}\text { Conditioned } \\
\mathrm{A} / \mathrm{C}=2: 1\end{array}$ & $\begin{array}{l}\text { Conditioned } \\
\mathrm{A} / \mathrm{C}=3: 1\end{array}$ \\
\hline $\begin{array}{l}\text { Annual Operating \& } \\
\text { Maintenance Cost of } \\
\text { Fabric Filter }\end{array}$ & $11,215.3$ & $11,215.3$ & $9,374.1$ \\
\hline $\begin{array}{l}\text { Conditioning Equipment } \\
\text { Sulfur } \$ 175 / \text { tn del. } \\
\text { Ammonia@ } \$ 165 / \text { tn del. } \\
\text { Miscellareous } \\
\text { Labor } \\
\text { Energy Cost } \\
\text { Amortization }\end{array}$ & & $\begin{array}{r}57.4 \\
60.7 \\
5.0 \\
78.8 \\
169.3 \\
312.0 \\
\end{array}$ & $\begin{array}{r}57.4 \\
60.7 \\
5.0 \\
78.8 \\
169.3 \\
312.0 \\
\end{array}$ \\
\hline $\begin{array}{l}\text { Total Annual Operating } \& \\
\text { Maintenance Cost }\end{array}$ & $11,215.8$ & $11,898.5$ & $10,057.3$ \\
\hline Mills/kWh & 3.02 & 3.20 & 2.74 \\
\hline
\end{tabular}




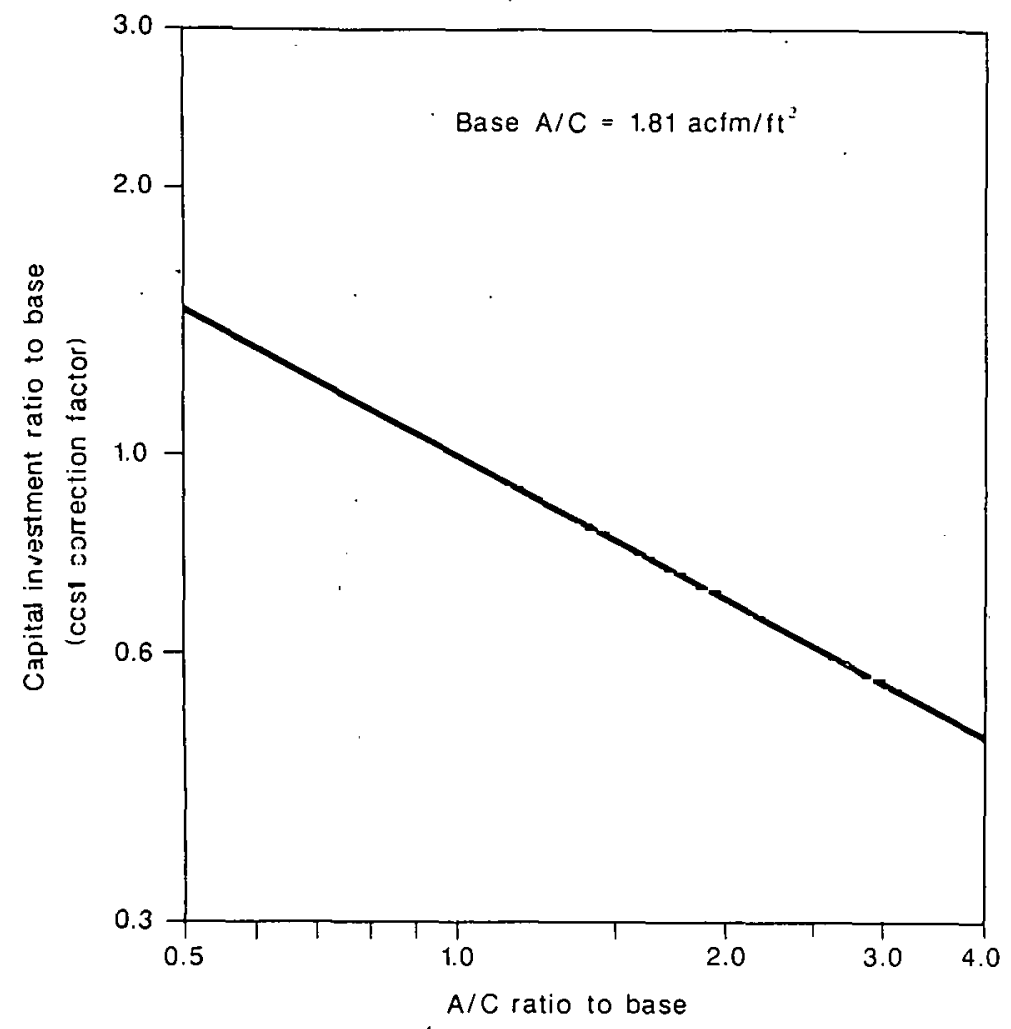

Figure 6-1. Fabric filtration capital costs as a function of airto-cloth ratio (Ref. 5).

\subsection{Granular Bed Filtration}

A cost analysis was made by Combustion power Company for a hot gas cleanup system employing a moving bed granular filter in a $500 \mathrm{MW}$ plant using pressurized fluidized bed boilers (15). The tace velocity for the $G B F$ was $40 \mathrm{ft} / \mathrm{min}$ using 18 modules giving a total of $15,876 \mathrm{ft}^{2}$ of filtration surface area. The filter media was $2 \mathrm{~mm}$ high quality silica sand and would be replaced at a rate of 110.25 tons/yr. For a $500 \mathrm{MW}$ plant burning an eastern bituminous coal with $16 \%$ ash and a heating value of 10,100 Btu/lb, a collection efficiency of $99 \%$ would be required to meet the NSF' limit for particulates of $0.03 \mathrm{lbs} / 10^{6}$. From the CPC economic analysis updated to 2nd quarter 
1986 dollars, the total installed cost of the GBF system to meet this requirement. would be $\$ 54,797,000$ or $\$ 109.59 / \mathrm{kW}$ and the annual levelized operating and maintenance cost would be $3.79 \mathrm{mills} / \mathrm{kWh}$.

GBFs designed for high pressure and temperature applications usually have higher capital costs, primarily due to higher costs for materials of construction. If a GBF system was designed for a conventional power plant, the capital cost would be comparable to a baghouse or ESP. Operating and maintenance costs, however, would be higher since a GBF would need to be operated at a higher pressure arop to provide collection efficiencies similar to a baghouse or ESP.

\section{Acoustic Agglomeration}

The primary use of acoustic agglomerators in the future will be high temperature and high pressure applications where many of the more conventional techniques cannot be used or must be modified such that they become very costly. Although it is expected that an acoustic agglomerator with high efficiency cyclones will have a capital cost that is about $20 \%$ less than an ESP modified for high pressure and temperature operation, the operational costs will be considerably higher because of the energy required to drive the acoustic agglomerator. Power requirements for the acoustic agglomerator without a collection device would, for a plant gerierating $500 \mathrm{MW}$, have an energy consumption of $15.3 \times 10^{6} \mathrm{kWh}$ annually. In addition, an acoustic agglomerator is only a conditioner for other particulate control devices such as cyclones, which have their own energy requirements. When high efficiency cyclones are added to the system, the overall energy consumption would be $71.9 \times 10^{6} \mathrm{kWh}$ per year. This is substantially more than the $19 \times 10^{6} \mathrm{kWh}$ needed for a fabric filter or the $35 \times 10^{6} \mathrm{kWh}$ for an ESP with an SCA of 350. The energy consumption of the system is a sum of the pressure drop across the collection device, power needed for the sonic generator, plus fan requirements to move the gas through the agglomerator. 
An economic study was performed using a combustion pulsor Aerojet/PSU Acoustic Agglomerator and high efficiency cyclones, as the particulate collection system for a $500 \mathrm{MW}$ PFBC plant (16). In this study the TCI was $\$ 46,871,000$ using high efficiency cyclones as the collectors. The levelized annual operating cost was 4.33 $\mathrm{mi} 11 \mathrm{~s} / \mathrm{kWh}$.

\subsection{Summary}

Table 6-13 Summarizes the economic evaluations for the various types of particulate control technoluyy. Althugh multicyclonca and Venturi scrubbers are the most economical they do not meet technical requirements. ESPs and fabric filters have very similar economics but fabric filters have much greater potential for removing fine particulates.

Enhancement technologies for ESPs such as pulse energization, hot-side ESPS and using $\mathrm{SO}_{3}$ conditioning add to the cost of a conventional ESP, but savings result when compared to enlarging an ESP to obtain a satisfactory collection efficiency when collecting a high resistivity ash. Three enhancement technologies have been developed for fabric filters, sonic horns, ESFF, and flue gas conditioning. If decreasing pressure drop is the primary goal, sonic horns are the most economical method. However, they do have limited applications. The economics for conditioning technology are comparable to those for ESFF, but flue gas conditioning has the potential to provide much higher collection efficiencies for fine particulates and is much easier to retrofit. Both can decrease fabric filter pressure drop such that operation at an $A / C$ ratio of $3: 1$ is possible, making both economically advantageous. 
TABLE 6-13

\section{SUMMARY OF THE CAPITAL COST AND LEVELIZED ANNUAL COST FOR DIFEERENT PARTICULATE CONTROL TECHNOLOGIES EVALUATED FOR A 500 MW PLANT (1986 DOLLARS)}

\section{Control Technology}

Multicyclones

Electroclone

Venturi Scrubber

(10" W.C.)

ESP ( 495 SCA)

Hot-Side ESP ( 337 SCA)

ESP w/Conditioning (SCA 317)

Pulse Energized ESP (SCA 317)

Fabric Filter $(A / C=2: 1)$

Fabric Filter $(A / C=3: 1)$ w/ESFF

Fabric Filter $(A / C=3: 1)$ w/Conditioning

Fabric Filter $(A / C=2: 1)$ w/Sonic Horns

Granular Bed Filtera

Acoustic Agglomeratora w/Multicyclones
Capital Cost

$(\mathrm{s} / \mathrm{kW})$

8.18

13.58

30.05

56.36

63.03

39.81

46.68

53.61

40.05

42.75

53.75

109.59

93.74
Annual Levelized Cost (Mills/kWh)

0.38

0.64

1.17

3. 24

3. 31

2.21

2.55

3.02

2.89

2.74

3.04

3.79

4.33

a Economic values determined for a 500 MW PFBC installation.

\subsection{References}

1. Wark, K. and C.F. Warner. AIR POLLUTION Its origin and Control. Harper and Row Publishers, New York, NY, Pp. 190, 1981.

2. Buonicore, A.J., J.P. Reynolds and L. Theodore. Control Technology for Fine-Particulate Emissions. Chemical Engineering Department, Manhattan College for Argonne National Laboratory, ANL/ECT-5, 1978 . 
3. Calvert,.S., N.C. Jhaveri and S. Yung. Fine Particle Scrubber Performance Tests. Environmental Protection Technology Series, EPA-650/2-74-093, October 1974 .

4. Burns and Roe Service Corporation and Science Applications International Corporation. Fine Particulate Control Technology Assessment. Draft Final Report, DOE Contract No.DE-AC2284PC72571 subtask.7.3. June 28, 1985.

5. Scheck, R.W., R.R. Mora, V.H. Belba, and F.A. Horney. Economics of Fabric Filtration and Electrostatic Precipitators - 1984. EPRI CS-4083, Electric: Power Research Institute, Palo Alto, CA, June 1985 .

6. Wrighl, R.A., N.D. Gravee. Rigid-frame va Weighted-wire Electrostatic Precipitators Comparison and Evaluation. Paper TIS6383, Presented at: Coal l'echnology '79. 2ud Iritemational Coal Utilization Conference, Houston, TX, November 1979.

7. Selzer, D.R. ard W.D. Watson Jr. "Hot" versus "Enlarged" Electrostatic Precipitation of Fly Ash: A Cost-Effectiveness study. Journal of the Air Pollution Control Association, Vol. 24, No. 2, pp. 115-121, Eebruary 1974 .

8. Breisch, E.W. Method and Cost Analysis of Alternative Collectors for Low Sulfur Coal Fly Ash. Proceedings: Symposium on the Transfer and Utilization of Particulate Control Technology, Denver, Co, Vol. 1, pp. 121-130, February 1979.

9. Landham, E.C., J.L. DuBard, W. Piulle, and L.E. Sparks. Precipitator Performance Enhancement with pulsed Energlzatiun. Proceedirigs: Fifth Symposium on the Transfer and Utilization of Particulate Control Technology, Kansas city, MO, Vol. 2, pp. 19 1-15, February 1986 .

10. Masuda, S. State of the Art of Precharging. Proceedings: Second International Conference oi Electrostatic Prccipitation, Senichi Masuda, Editor, Kyoto, Japan, pp. 177-193, November 1984.

11. Tassicker, 0 . and J. Schwab. High-Intensity lonizer for Improved ESP Performance. EiPkl Journal, Electric Power Research Institute, pp. 56-61 June/July 1977 .

12. Feldman, P.L. and P.J Aa. Operating Results From the First Commercial Pulse Energization System to Enhance Electrostatic Precipitator Performance. Proceedings: American Power Conference, Chicago, IL, Vol. 43, pp. 379-383, April 1381. 
13. Belba, V.H., F.A. Horney, R.C. Carr, and W. Piulle. Economics of Electrostatic Precipitators and Fabric Filters. Proceedings: Fifth Symposium on the Transfer and Utilization of Particulate Control Technology, Kansas City, Mo, Vol. 1, pp. 11 1-18, February 1986 .

14. Hovis, L.S. and A.S. Viner. Economics of Advanced Electrostatic Stimulation of Fabric Filtration. Proceedings: The Sixth Symposium on the Transfer and Utilization of Particulate Control Technology, EPA/EPRI, New Orleans, LA, Vol. 3, pp. 7-1 to. 16, February 1986.

15. Guillory, J., J. Cooper, J. Ferguson, G. Goldback, and F. Placer. Granular Bed Filter Development Program. Phase II. Final Report, DOE/ET/10373-T10, Combustion Power Company, Inc., Menlo Park, CA, May 1983 .

16. Rubow, L.N. et.al. Technical and Economic Evaluation of Ten High Pressure Particulate cleanup systems for Pressurized Fluidized Bed Combustion. DOE/MC/19196-1654, Gilbert/Commonwealth, Reading, PA, JulY 1984 . 


\subsection{CONCLUSIONS AND RECOMMENDATIONS}

Conclusions for section 3.0, Basis for Particulate Control include the following:

Fine particles from coal combustion $<2.5 \mu \mathrm{m}$ present a greater health hazard than larger particles because they are more likely to deposited in the lower respiratory system through normal breathing, have long residence times in the atmosphere, and are enriched in hazardous trace elements.

The trace elements arsenic, cadmium, lead, and selenium are highly enriched in fine coal fly ash particles, have highly toxic acute or chronic effects on humans, and are known or suspected carcinogens. Mercury is highly toxic and enriched in fine particles but is not considered to be carcinogenic. Chromium and nickel are highly toxic and known carcinogens, but show much less enrichment in fine particles. Therefore, these seven trace elemerts in coal present the most significant health hazard of fine particle emissions from coal combustion.

- Health effects studies show that fine particles ( $2.5 \mu m)$ and sulfates are among the most harmful particles to public health. However, the exact threshold level of fine particles and trace elements in the atmosphere, which presents a significant health hazard, is not known.

Visibility degradation is caused primarily by fine particles less than $2 \mu \mathrm{m}$. The primary constituents which make up the fine particle fraction of atmospheric aerosols include sulfates, elemental carbon, organic material, ammonium, nitrate, and crustal material. Coal fly ash is not the main cause of atmospheric light extinction, but the exact contribution of fine coal fly ash particles to visibility impairment is not well known. With low $\mathrm{SO}_{2}$ emissions and good background visibility, the contribution of fly ash to light extinction may be significanl on a regional basis.

Current New Source Performance (NSPS) standards for coal-fired boilers require about 99.5 to $99.8 \%$ particulate removal efficiency and $20 \%$ opacity. However, the prevention of significant deterioration and visibility protection aspects of the Clean Air Act may require higher levels of control. 
Conclusions of Section 4.0, Technical Evaluation of Conventional and Emerging Particulate Control Technology include the following:

- Conventional technologies which are widely employed to reliably meet current NSPS include only electrostatic precipitators (ESP's) and baghouses. In general, fabric filters are expected to provide better particulate removal efficiency than ESP's for fine particles less than $2.5 \mu \mathrm{m}$.

- ESP enhancement technologies such as chemical conditioning, pulse energization, and pre-charging can improve collection efficiency, but not beyond the efficiency for a well operating ESP with normal resistivity fly ash.

- No emerging particulate technology was found that is techicically superior to fabric filtration with flue gas conditioning, in terms of finc particulate remuval efficicncy and system operability (pressure drop and energy usage).

Conclusions for section 5.0, Flue Gas conditioning For Fabric Filter Performance Improvement include the following:

- Classical theory would predict near 100\% collection efficiency for fabric filters assuming a continuous unflawed dust cake and no dust reentrainment. However, dust penetration through pinholes and by seepage causes fabric filters to operate at reduced efficiency.

- The important ash characteristics which affect with a fabric filter include particle sizt cohesiveness, and electrical characteristics (resistivity, charge, and triboelectric nature). Cohesiveness is a very important ash characteristic which has not been incorporated into existing fabric filtration models.

Conditioning with small amounts of ammonia and $\mathrm{SO}_{3}$ is an effective method of reducing fine particle emissions from a fabrio filter.

Conditioning is an effective method of reducing baghouse pressure drop for the given tabric and cledulug method.

The mechanism by whlch curditioning roducos fine particle emissions and baghouse pressure drop involves surface deposition of an ammonia- $\mathrm{SO}_{3}$ product and a resulting increase in fly ash cohesiveness. 
Conclusions for Section 6.0, Economic Analysis of Particulate control technology include the following:

- The total levelized cost of a conventional reverse gas fabric filter which operates at an air-to-cloth ratio of 2.0 , is comparable to the cost of a conventional ESP with an SCA of 450 to 500. For high resistivity fly ashes, fabric filters are generally the economic choice to reliably meet current NSPS.

- Sonic horns and electrostatic enhancement have the potential to somewhat reduce fabric filter costs by reducing pressure drop.

- Flue gas conditioning would add about $9 \%$ to the cost of operating a baghouse. However, this cost could be more than recovered if pressure drop is reduced or, for a new installation, if the airto-cloth ratio can be increased from 2.0 to 2.35 . Flue gas conditioning, applied to fabric filtration, has the potential to offer a superior fine particle control method at a net cost savings compared to conventional technology.

In spite of the promising results to date, there are some remaining questions to be answered before flue gas conditioning, applied to fabric filtration, is ready for commercialization. Two important technical questions about the process remain. Optimum concentrations of ammonia and $\mathrm{SO}_{3}$ as a function of coal type are not known, and the effect of baghouse temperature on the performance improvement level is also not known. It is recommended that these questions be addressed in further research.

Regarding the mechanism by which flue gas conditioning reduces particulate emissions and pressure drop, a better understanding of the relationship between penetration behavior and ash cohesiveness is netued. In addition, possible changes in the electrical characteristics of the ash need to be documented to model and optimize the process. The effect of conditioning on dust cake properties such as porosity and cake structure needs to be measured to achieve the lowest operating pressure drop. It is recommended that these questions be addressed in bench-scale studies.

A major research need in developing this technology is to verify its effectiveness on a longer term basis and with larger scale tests. A much more severe test of this technology would be tests with more gentle reverse-gas cleaning and full-scale bags. Such research would

$$
7-3
$$


address the question of the effect of conditioning on longer term pressure drop and residual dust cake weight. It is recommended that longer-term pilot-scale tests, using reverse gas cleaning and fullscale bags, be conducted to study this effect. 
1 Programiliojecl ldentilication No.

2. Program.Froject Tille

FINE PARTICULATE EMISSIONS

Page __ of _ 4. Name and Addicss

University of North Dakota Energy Research Center

Box 8213, University Station, Grand Forks, ND 58202

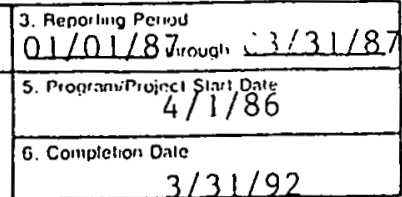
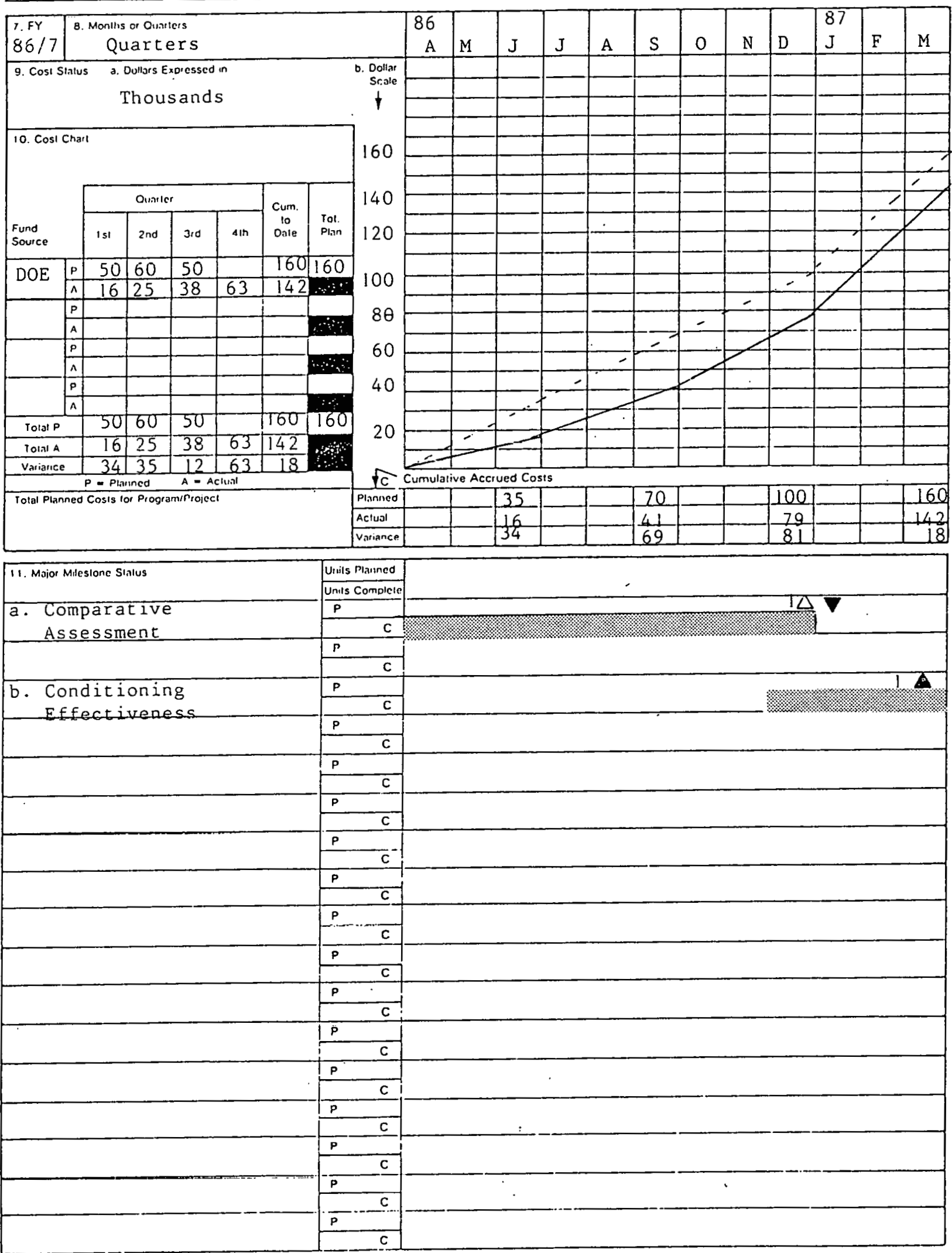
Page __ of _ _

\begin{tabular}{|c|c|}
\hline 1. ProgramiProject ldentilicalion No. & $\begin{array}{r}\text { 2. Program/Proiect rille } \\
\text { FINE PART ICULATE EMISS IONS }\end{array}$ \\
\hline $\begin{array}{c}\text { 4. Name and Addess } \\
\text { University of North Dakota Energy Research Center. } \\
\text { Box } 8213, \text { University Station, Grand Forks, ND 58202 }\end{array}$
\end{tabular}

3. Redoning Period

$01 / 01 / 8$ Fnrough $03 / 31 / 87$

5. ProgramiProject Siarl Oale

$4 / 1 / 86$

6: Completion Oate

$3 / 31 / 92^{2}$

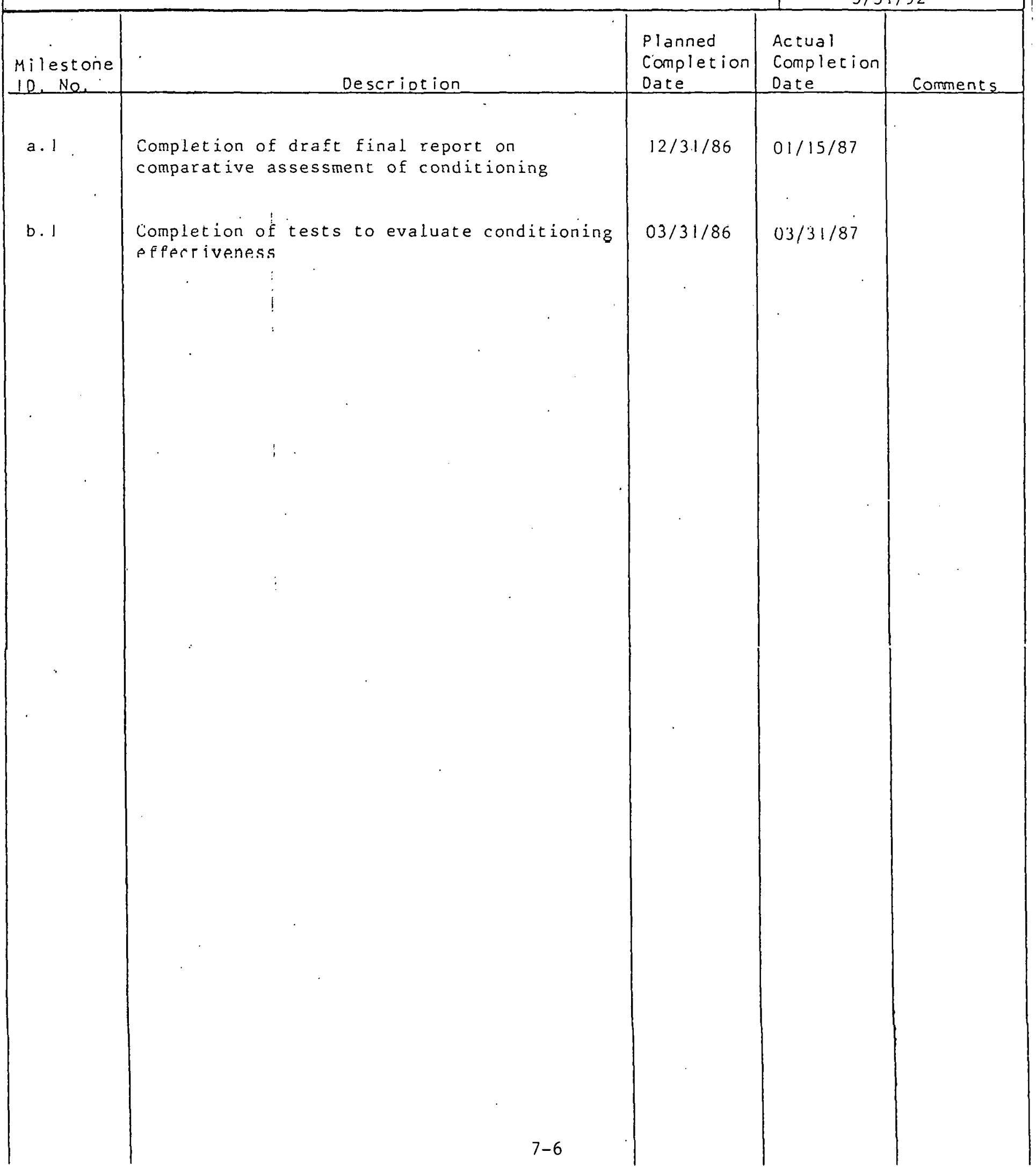


DOE/MC/10637-2414(Vol.2)
LOW-RANK COAL RESEARCH DOE 